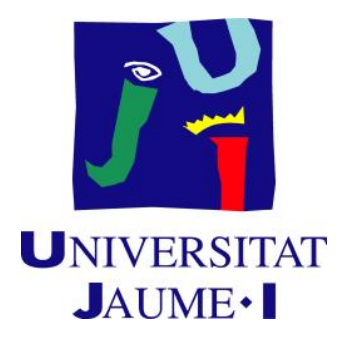

Departamento de Ingeniería de Sistemas Industriales y Diseño

\title{
Modelo basado en Elementos Característicos para la Planificación Supervisora de la Inspección
}

TESIS DOCTORAL

Presentada por:

Gracia M. Bruscas Bellido

Dirigida por:

Dr. Fernando Romero Subirón

Dr. Pedro Rosado Castellano

Castellón de la Plana, diciembre 2015 



\section{RESUMEN}

En los entornos de desarrollo integrado de nuevos productos es necesaria la aplicación de nuevos enfoques y metodologías que den respuesta a la complejidad que implica la cooperación entre todos los participantes en el ciclo de vida del producto. De entre estos, adquieren especial relevancia aquellos que permiten garantizar la integridad del producto a través del ciclo de diseño-fabricación-inspección y que se centran en la representación y tratamiento de la información geométrica del mismo. De entre las alternativas existentes para esta representación del producto, en la tesis se opta por una representación basada en Elementos Característicos (EC), porque permiten completar la información geométrica con información y conocimiento específico de un determinado dominio, en este caso el de planificación de procesos de inspección.

En las plantas industriales ahora las actividades de inspección son vistas como una actividad productiva más, potenciándose la integración de estas, tanto las realizadas en proceso como las post proceso, con las de conformado, como es el caso de las de mecanizado. Un planteamiento que ha puesto de manifiesto la necesidad de elaborar planes integrados de mecanizado e inspección. Por ello, para el desarrollo de la investigación se planteó la hipótesis de que el modelado de ensambles/mecanismos en base a EC, que se ha utilizado habitualmente en la fase de especificación del producto, también se puede utilizar en la de elaboración de los planes integrados de mecanizado e inspección. Un planteamiento que además podría facilitar la integración entre estas fases, asegurando el cumplimiento de todos los requisitos impuestos al producto y mejorando la calidad y la eficiencia del proceso global.

Partiendo de este planteamiento, en la tesis se propone un nuevo tipo de EC, el Elemento Característico de Inspección (ECI), adecuado para la planificación de los procesos de inspección a nivel supervisor y que propicia la integración en el proceso de desarrollo integrado y colaborativo de productos, procesos y recursos. El ECI desarrollado contiene toda la información necesaria para los ejercicios y razonamientos propios de la especificación del plan de inspección a nivel supervisor y está basado en un meta-modelo de EC que establece una estructura y semántica común. Se trata de una característica que permite su integración con modelos de EC específicos de otros dominios, garantizando así la coherencia y compatibilidad entre modelos. Para asegurar la consistencia entre los modelos de ensamble de inspección y de ensamble producto, el ECI propuesto es una especialización de un Elemento Característico de Especificación (ECE) genérico, que contiene información común a cualquier ejercicio de diseño y especificación que se pueda realizar sobre un ensamble, como puede ser el correspondiente al producto final o a los establecidos durante el proceso de inspección. Para ello el ECE, y por lo tanto también el ECI, contemplan la geometría con defectos, esencial en estos ejercicios.

Para hacer posible estos ejercicios, y especialmente los de análisis de tolerancias e incertidumbres, los EC desarrollados se integran en unos modelos de ensamble. Estos modelos, que como ya se ha comentado integran a los ECE y ECI, presentan algunas características reseñables, como su compatibilidad con el lenguaje Geospelling, del que adopta muchas nociones (especificación, característica, operación, condición, etc.), y con las especificaciones GD\&T tradicionales basadas en zonas de tolerancia. Estos modelos contienen información sobre las arquitecturas de los ensambles representados, permitiendo el análisis de los bucles o cadenas de requisitos, establecidos alrededor de las condiciones geométricas funcionales o de verificación. En el trabajo se detalla el modelo de ensamble de inspección correspondiente a una configuración de medida concreta y que contiene la 
información de la misma, perteneciente tanto a la geometría de la pieza a medir como a la del recurso utilizado para la medida, en ambos casos representadas en base a instancias de ECI de la biblioteca propuesta. Estos recursos se han clasificado en función del tipo de proceso de medición, permitiendo así establecer planes de procesos de inspección, entendidos como secuencias de ensambles de inspección, a partir de una reglas lógicas basadas en el análisis de los grados de libertad y las incertidumbres de los diferentes procesos de medida contemplados. La metodología establecida para determinar estos planes se basa en razonamientos que el planificador realiza sobre los modelos de ensamble correspondientes a las configuraciones contempladas. Estos modelos también permiten, en fases más avanzadas, validar la adecuación de cada una de las configuraciones para verificar con suficiente precisión las especificaciones establecidas sobre la pieza que se van a verificar en las mismas. 


\section{RESUM}

En els entorns de desenrotllament integrat de nous productes és necessària l'aplicació de nous enfocaments i metodologies que donen resposta a la complexitat que implica la cooperació entre tots els participants en el cicle de vida del producte. D'entre estos, adquirixen especial rellevància aquells que permeten garantir la integritat del producte a través del cicle de disseny-fabricació-inspecció i que se centren en la representació i tractament de la informació geomètrica del mateix. D'entre les alternatives existents per a esta representació del producte, en la tesi s'opta per una representació basada en Elements Característics (EC), perquè permeten completar la informació geomètrica amb informació i coneixement específic d'un determinat domini, en este cas el de planificació de processos d'inspecció.

En les plantes industrials ara les activitats d'inspecció són vistes com una activitat productiva més, potenciant la integració d'estes, tant les realitzades en procés com les post procés, amb les de conformat, com és el cas de les de mecanitzat. Un plantejament que ha posat de manifest la necessitat d'elaborar plans integrats de mecanitzat i inspecció. Per això, per al desenrotllament de la investigació es va plantejar la hipòtesi que el modelat d'acoblaments/mecanismes basat en EC, que s'ha utilitzat habitualment en la fase d'especificació del producte, també es pot utilitzar en la d'elaboració dels plans integrats de mecanitzat i inspecció. Un plantejament que a més podria facilitar la integració entre estes fases, assegurant el compliment de tots els requisits imposats al producte i millorant la qualitat i l'eficiència del procés global.

Partint d'este plantejament, en la tesi es proposa un nou tipus d'EC, l'Element Característic d'Inspecció (ECI), adequat per a la planificació dels processos d'inspecció a nivell supervisor i que propicia la integració en el procés de desenrotllament integrat i col-laboratiu de productes, processos i recursos. L'ECI desenrotllat conté tota la informació necessària per als exercicis i raonaments propis de l'especificació del pla d'inspecció a nivell supervisor i està basat en un meta-model d'EC que establix una estructura i semàntica comú. Es tracta d'una característica que permet la seua integració amb models d'EC específics d'altres dominis, garantint així la coherència i compatibilitat entre models. Per a assegurar la consistència entre els models d'acoblament d'inspecció i d'acoblament de producte, l'ECI proposat és una especialització d'un Element Característic d'Especificació (ECE) genèric, que conté informació comuna a qualsevol exercici de disseny i especificació que es puga fer sobre un acoblament, com pot ser el corresponent al producte final o als establits durant el procés d'inspecció. Per a això l'ECE, i per tant també l'ECI, contemplen la geometria amb defectes, essencial en aquests exercicis.

Per fer possible estos exercicis, i especialment els d'anàlisi de toleràncies i incerteses, els EC desenrotllats s'integren en uns models d'acoblament. Estos models, que com ja s'ha comentat integren els ECE i ECI, presenten algunes característiques ressenyables, com la seua compatibilitat amb el llenguatge Geospelling, del qual adopta moltes nocions (especificació, característica, operació, condició, etc.), i amb les especificacions GD\&T tradicionals basades en zones de tolerància. Estos models contenen informació sobre les arquitectures dels acoblaments representats, permetent l'anàlisi dels bucles o cadenes de requisits, establits al voltant de les condicions geomètriques funcionals o de verificació. En el treball es detalla el model d'acoblament d'inspecció corresponent a una configuració de mesura concreta i que conté la informació de la mateixa, pertanyent tant a la geometria de 
la peça a mesurar com a la del recurs utilitzat per a la mesura, en els dos casos representades en base a instàncies d'ECI de la biblioteca proposta. Estos recursos s'han classificat en funció del tipus de procés de mesura, permetent així establir plans de processos d'inspecció, entesos com a seqüències d'acoblaments d'inspecció, a partir d'unes regles lògiques basades en l'anàlisi dels graus de llibertat i les incerteses dels diferents processos de mesura contemplats. La metodologia establida per a determinar estos plans es basa en raonaments que el planificador realitza sobre els models d'acoblament corresponents a les configuracions contemplades. Estos models també permeten, en fases més avançades, validar l'adequació de cadascuna de les configuracions per a verificar amb suficient precisió les especificacions establides sobre la peça que es van a verificar en les mateixes. 


\section{AbStraCT}

In the context of new product integrated development the application of new approaches and methodologies is necessary to cope with the complexity of the required cooperation of all participants in the product lifecycle. Of special relevance are the ones that allow guaranteeing product integrity through the design-manufacturing-inspection cycle and that focus on product geometry representation and processing. Among existing alternatives for this product representation, in this doctoral thesis a Feature based one has been chosen, since it allows for completing the geometrical information with additional domain specific (inspection process planning in this case) information and knowledge.

Now, in manufacturing factories inspection activities are seen as one more productive activity, encouraging their integration, both in process and post process, with the manufacturing ones, such as machining operations. This approach has revealed the need of developing integrated machining and inspection plans. Therefore, for the development of this investigation it was assumed that the Feature based assembly/mechanism modelling, typically used in the product specification stage, can also be used in the development of integrated machining and inspection plans. Additionally, this approach could ease the integration of these stages, assuring the compliance with all product requirements and improving global process quality and efficiency.

Based on this approach, in this doctoral thesis a new Feature type is proposed: the Inspection Feature (InspF). The InspF is appropriate for the supervisory level inspection process planning and favours its integration in the collaborative and integrated development process of product, process and resource. The proposed InspF contains all the required information for the exercises and reasoning typical of the inspection plan specification at a supervisory level and is based on a Feature meta-model that establishes a common structure and semantics. In this way, the InspF can be integrated with other domain specific Feature models, assuring consistency and compatibility between different models. To ensure the compatibility between the inspection assembly and product assembly models, the proposed InspF is a specialization of a generic Specification Feature (SpecF) that contains all the information common to any design and specification exercise carried out on an assembly, such as the final product assembly or the ones established during the inspection process. For this, the SpecF, and thus also the InspF, consider the geometry with defects, essential in these exercises.

In order to make these exercises possible, and especially the tolerance and uncertainty analysis ones, the developed Features are integrated in assembly models. These models, that as previously mentioned integrate the $\mathrm{SpecF}$ and InspF, have worth mentioning characteristics, such as their compatibility with the Geospelling language, from which they take many notions (specification, characteristic, operation, condition, etc.), and with the traditional GD\&T specifications based on tolerance zone. These models contain information about the represented assembly architectures, allowing for the analysis of requirements loops or chains established around the functional or inspection geometrical conditions. In this work, the inspection assembly model of a specific measurement configuration is detailed. It contains the information related to both the geometry of the part being measured and the measurement resource being used for the measurement. Both are represented based on InspF instances of a proposed library. The inspection resources have been classified considering the type of measurement process, allowing for establishing inspection process plans, understood as a sequence of inspection assemblies, according to logical rules based on the analysis of the degrees of freedom and uncertainties 
of the different measurement processes. The developed methodology to determine these plans is based on the reasoning the planner carries out on the assembly models of the considered configurations. These models, in later stages, also allow for validating the appropriateness of each of these configurations to verify with sufficient precision the specifications established on the part. 


\section{ZUSAMMENFASSUNG}

Im Rahmen der integrierten Entwicklung neuer Produkte, sind neue Ansätze und Methoden notwendig, um der Komplexität Rechnung zu tragen, die auf Grund der vielfältigen Interaktionen der beteiligten Bereiche während des gesamten Produktlebenszyklus entstehen. Von übergeordneter Bedeutung sind diejenigen, die die Produktintegrität über den gesamten Design-Fertigung-Prüfungszyklus garantieren und die besonders auf Darstellung und Verarbeitung der Geometrie abzielen. Aus bereits bestehenden alternativen Produktdarstellungen, wurde in dieser Doktorarbeit eine auf Merkmale (Feature) basierende Darstellung gewählt, weil diese es erlaubt, den geometrischen Informationen zusätzliche bereichsspezifische (in diesem Fall die Prüfplanung) Informationen und Fachwissen beizufügen.

Heutzutage werden in Fertigungslinien die Prüfverfahren mehr denn je als gleichwertiger Bestandteil der Verarbeitung angesehen, und ihre Integration in den Fertigungsprozess wird gefördert, sowohl in den Bearbeitungs- als auch in den Nachbearbeitungsprozess, wie z.B. den Zerspanungsvorgang. Dieser Ansatz zeigt die Notwendigkeit integrierte Fertigungs- und Prüfspläne zu entwickeln. Aus diesem Grund stellt diese Dissertation die Hypothese auf, dass merkmalbasierte Montage/Mechanismus Modellierung, die typischerweise in der Produktspezifizierungsphase Anwendung findet, auch bei der Entwicklung von integrierten Zerspanungs- und Prüfspläne verwendet werden kann. Zusätzlich könnte dieser Ansatz die Integration dieser beiden Phasen vereinfachen, und dadurch die Einhaltung aller Produktanforderungen gewährleisten, sowie die generelle Prozessqualität und Effizienz verbessern.

Diesem Ansatz folgend, schlägt diese Doktorarbeit einen neuen Merkmal Typen vor: das Prüfmerkmal (PM). Das PM ist für Prüfprozessplanung auf mittlerer Ebene geeignet und begünstigt seine Integration in den gemeinschaftlichen und integrierten Produkt-, Prozess- und Betriebsmittelentwicklungsprozess. Das vorgeschlagene PM beinhaltet alle notwendigen Informationen für die Überlegungen und Gedankengänge, welche typisch für die Prüfplanspezifikation auf mittlerer Ebene sind und basiert auf einem Merkmal-MetaModel, welches eine gemeinsame Struktur und Semantik definiert. Deshalb kann das PM mit anderen bereichsspezifischen Merkmalmodellen integriert werden und die Konsistenz und Kompatibilität mit anderen Modellen gewährleisten. Um die Kompatibilität zwischen Prüfmontage- und Produktmontagemodellen sicherzustellen, ist das vorgeschlagene PM ein Spezialfall eines allgemeinen Spezifikationsmerkmals (SM), welches alle Informationen enthält, die gleich sind für jede Design- und Spezifikationsübung einer Montage, wie z.B. die finale Produktmontage oder diejenigen Montagen, die während des Prüfprozesses verwendet werden. Aus diesem Grund, berücksichtigen sowohl das SM als auch das PM die Geometrie der Bauteile mit ihren Defekten als essentiellen Bestandteil in diesen Überlegungen.

Um diese Überlegungen zu ermöglichen, insbesondere die Toleranz- und Unsicherheitsanalysen, werden die entwickelten Merkmale in ein Montagemodell integriert. Diese Modelle, welche wie erwähnt das SM und das PM integrieren, haben nennenswerte Eigenschaften, wie ihre Kompatibilität mit der Geospelling-Sprache, von der sie viele Grundelemente übernehmen (Spezifikation, Eigenschaft, Operation, Bedingung, etc.) und mit den traditionellen GD\&T Spezifikationen, welche auf Tolleranzzonen basieren. Diese Modelle enthalten Informationen über die dargestellte Montagearchitektur, welche eine Analyse von Anforderungsschleifen oder -ketten der geometrischen Funktionoder Prüfbedingungen erlaubt. 
Diese Doktorarbeit beschreibt im Detail ein Prüf-Montage-Modell von einer speziellen Messkonfiguration. Es beinhaltet Information bezüglich beidem, der Geometrie des gemessenen Werkstücks und des Prüfmittels, welches für die Messung Anwendung findet. Beide werden dargestellt basierend auf PM-Instanzen einer vorgeschlagenen Bibliothek. Die Prüfmittel werden anhand des Messprozesstyps klassifiziert, welcher die Erstellung eines Prüfplans erlaubt, welcher als Abfolge einer Sequenz von Prüfmontagen verstanden wird, den logischen Regeln folgend, welche auf den Freiheitsgraden und Unsicherheiten der unterschiedlichen Messverfahren beruhen. Die entwickelte Methodik, wie diese Pläne erstellt werden, basiert auf den Gedankengängen des Planers über die Montagemodelle für die gedachte Konfiguration. Später erlauben diese Modelle auch die Überprüfung, wie geeignet eine Konfiguration ist, für die Prüfung der Spezifikationen des Bauteils mit genügender Präzision. 


\section{Agradecimientos}

Quiero expresar mi más sincero agradecimiento a mis directores de tesis, Fernando Romero Subirón y Pedro Rosado Castellano, por su paciencia, guía, ayuda y apoyo a lo largo de estos años. Sus contribuciones a esta tesis han sido esenciales y sin ellas el desarrollo de esta investigación no hubiera sido posible. Poder trabajar bajo su supervisión me ha dado la valiosa oportunidad de aprender enormemente. 



\section{ÍNDICE}

CAPÍTULO 1 INTRODUCCIÓN...................................................................................................... 1

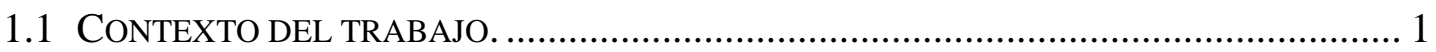

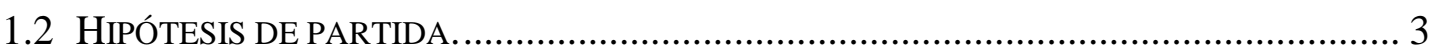

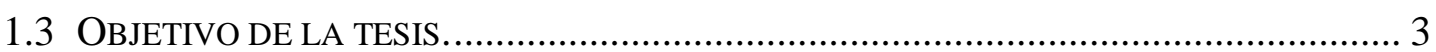

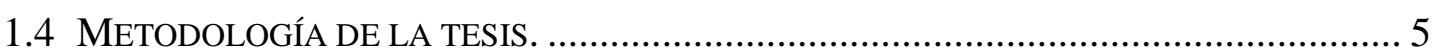

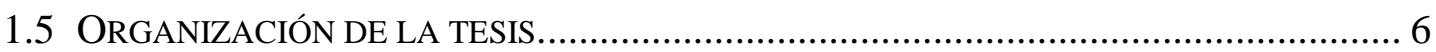

CAPítulo 2 La PlanificaCión de la InSPECCión EN ENTORNOS COLABORATIVOS...... 9

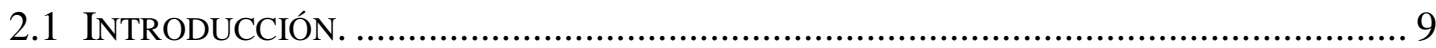

2.2 LA INSPECCIÓN Y LA PLANIFICACIÓN DE LA INSPECCIÓN....................................... 11

2.2.1 LA INSPECCIÓN Y LA VARIABILIDAD EN FABRICACIÓN........................... 11

2.2.2 LA PLANIFICACIÓN DE LA INSPECCIÓN. ................................................ 17

2.3 El DESARROLLO COLABORATIVO E INTEGRADO DE PRODUCTO-PROCESO-

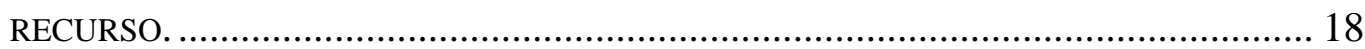

2.4 MODELO FUNCIONAL PARA LA PLANIFICACIÓN SUPERVISORA DE LA

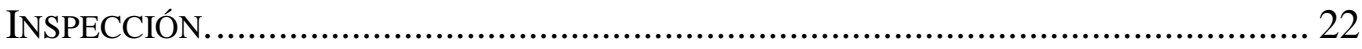

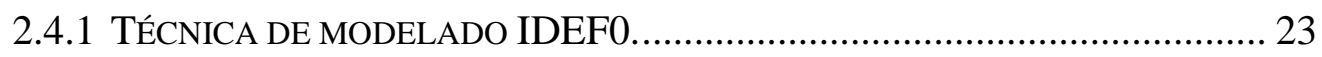

2.4.1.1 Sintaxis y semántica. ............................................................. 23

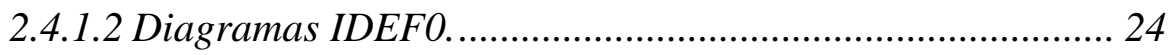

2.4.2 ESTRUCTURA DEL MODELO FUNCIONAL PROPUESTO............................ 24

2.4.3 DESCRIPCIÓN DE LAS ACTIVIDADES DEL MODELO FUNCIONAL

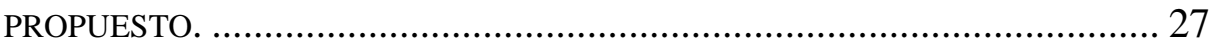

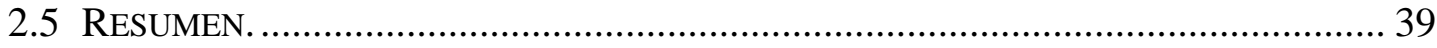

\section{CAPÍTULO 3 EL TRATAMIENTO DE LA VARIABILIDAD EN LA ESPECIFICACIÓN Y LA}

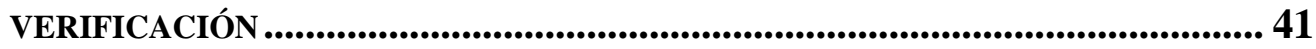

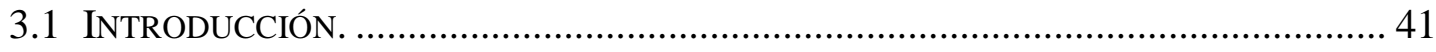

3.2 EL MODELADO GEOMÉTRICO EN LA SIMULACIÓN Y LA ESPECIFICACIÓN................ 44

3.2.1 LA REPRESENTACIÓN DEL SISTEMA REAL: LOS MODELOS DE SIMULACIÓN Y ESPECIFICACIÓN. ..................................................... 45

3.2.2 EL SISTEMA PRODUCTO: LOS COMPONENTES Y LAS INTERFACES............. 48

3.2.3 LAS PROPIEDADES Y LAS OPERACIONES GEOMÉTRICAS......................... 49

3.2.3.1 Los objetos y sus propiedades............................................. 49

3.2.3.2 Las operaciones geométricas........................................... 52

3.2.4 LAS ESPECIFICACIONES Y LAS INCERTIDUMBRES................................... 54

3.2.4.1 El lenguaje Geospelling. ...................................................... 55 
3.3 EL MODELADO ESTRUCTURAL Y FUNCIONAL DEL PRODUCTO...............................57

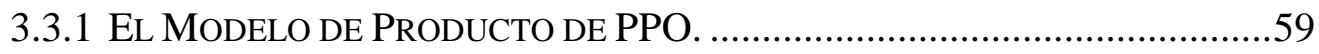

3.3.2 LOS MODELOS GEOMÉTRICOS Y BASADOS EN GRAFOS EN LAS PRIMERAS FASES DEL DISEÑO.

3.3.3 LOS MODELOS GEOMÉTRICOS EN LAS FASES AVANZADAS DEL DISEÑO. ..63

3.4 EL DISEÑO DE TOLERANCIAS EN EL DESARROLLO DEL PRODUCTO........................63

3.4.1 EL ANÁLISIS DE TOLERANCIAS EN ENSAMBLES...................................65

3.4.2 EL ANÁLISIS DE TOLERANCIAS EN FABRICACIÓN....................................66

3.5 LA ESPECIFICACIÓN DE LA GEOMETRÍA DE PIEZAS. .............................................68

3.5.1 MODELOS MATEMÁTICOS BASADOS EN GEOMETRÍAS CONTINUAS. ..........68

3.5.1.1 Modelos de grados de libertad..............................................69

3.5.1.2 Modelos de torsor de pequeño desplazamiento.....................72

3.5.2 LAS NORMAS DE ESPECIFICACIÓN DIMENSIONAL Y GEOMÉTRICA DEL

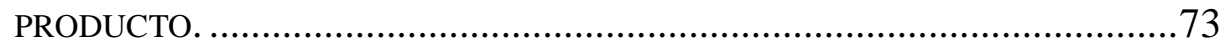

3.5.3 LAS CARACTERÍSTICAS EN EL LENGUAJE GEOSPELLING.........................75

3.6 EL MODELADO GEOMÉTRICO EN LA VERIFICACIÓN. ..............................................75

3.6.1 LA REPRESENTACIÓN DEL SISTEMA REAL: EL MODELO DE

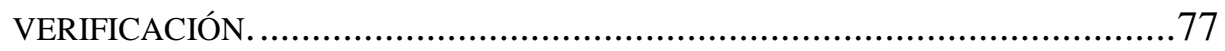

3.6.1.1 El modelo de verificación de la pieza. ..................................77

3.6.1.2 El modelo de verificación del recurso de medida.................79

3.6.2 EL SISTEMA DE MEDIDA: LOS COMPONENTES Y LAS INTERFACES. ............80

3.6.3 LAS PROPIEDADES Y LAS OPERACIONES GEOMÉTRICAS EN LA

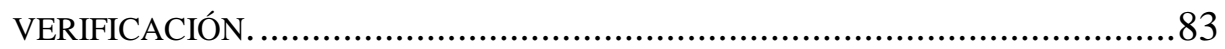

3.6.3.1 Los objetos medidos y sus propiedades. ..............................83

3.6.3.2 Las operaciones de verificación. .........................................85

3.6.4 LAS ESPECIFICACIONES Y LAS INCERTIDUMBRES EN LA MEDIDA..............87

3.6.4.1 La especificación de la medida en el lenguaje

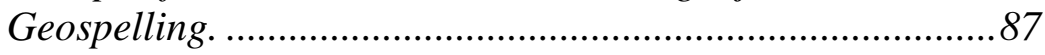

3.6.4.2 La incertidumbre de medida...........................................8

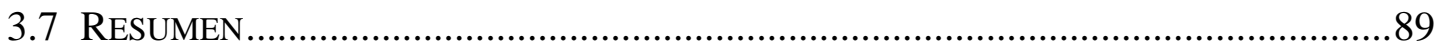

Capítulo 4 Modelo de Elemento Característico .......................................................91

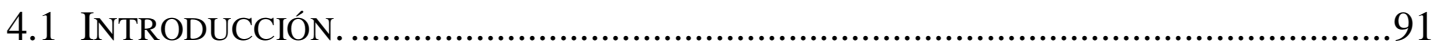

4.2 Fundamentos DEL CONCEPTO DE ELEMENTO CARACTERÍSTICO........................92

4.2.1 MODELO DE EC PARA SISTEMAS MECÁNICOS. ........................................93

4.2.2 MODELO DE EC PARA SISTEMAS SOFWARE...........................................95

4.2.3 MODELO DE EC PARA SISTEMAS EMBEBIDOS.......................................96

4.3 LOS ELEMENTOS CARACTERÍSTICOS DE APLICACIÓN PARA EL MECANIZADO Y

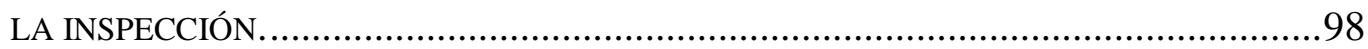


4.3.1 El Elemento CARACTERÍstico EN LA PlanifiCACión DEL

MECANIZADO.

4.3.2 El ElEMENTO CARACTERÍSTICO EN LA PlANIFICACIÓN DE LA INSPECCIÓN. 100

4.4 El Elemento CARACTERÍSTICO EN El MODELAdo DE PRODUCTO. 103

4.4.1 ESQUEMAS GENÉRICOS ADOPTADOS EN EL MODELADO DE PRODUCTO. 103

4.4.2 EL DESARROLLO COLABORATIVO DE PRODUCTOS. 107

4.5 RESUMEN. 110

\section{Capítulo 5 Los Elementos CaRACTERÍSTICos de ESPECIFICACión de PRODUCTO Y DE INSPECCIÓN}

5.1 INTRODUCCIÓN.

5.2 Meta-Modelo de Elemento Característico.

5.3 MODELO DE ELEMENTO CARACTERÍSTICO PARA LA ESPECIFICACIÓN E INSPECCIÓN DE PRODUCTOS.

5.4 Modelo de Elemento CARACTERÍstico de EsPECIFICACIÓn DE Producto. 119

5.4.1 REQUISITOS DE LA PROPUESTA.

5.4.2 MODELO DE ELEMENTO CARACTERÍSTICO DE ESPECIFICACIÓN DE PRODUCTO PROPUESTO. 120

5.5 MOdELO DE ElEMENTO CARACTERÍSTICO DE INSPECCIÓN. 122

5.5.1 REQUISITOS DE LA PROPUESTA. 122

5.5.2 MODELO DE ELEMENTO CARACTERÍSTICO DE INSPECCIÓN PROPUESTO. 123

5.5.3 BiblioteCA DE ELEMENTOS CARACTERÍSTICOS DE INSPECCIÓN. 126

\section{Capítulo 6 La EsPecificación del Producto y la Planificación de la}

INSPECCIÓN. 139

6.1 INTRODUCCIÓN.

6.2 MODELO DE CADENA DE ENSAMBLE PARA LA ESPECIFICACIÓN Y LA INSPECCIÓN DE PRODUCTO. 140

6.2.1 Modelo DE CADENA DE ENSAMBLE PARA LA ESPECIFICACIÓN. 140

6.2.2 MOdELO DE CADENA DE ENSAMBLE DE ESPECIFICACIÓN DE PRODUCTO.

6.2.2.1 Requisitos de la propuesta. 141

6.2.2.2 Modelo de Cadena de Ensamble de Especificación de Producto propuesto.

6.2.3 Modelo DE CADENA DE ENSAMBLE DE INSPECCIÓN. 143

6.2.3.1 Requisitos de la propuesta. 143

6.2.3.2 Modelo de Cadena de Ensamble de Inspección propuesto. 144

6.3 El ENSAMBLE DE INSPECCIÓN Y LOS PROCESOS DE INSPECCIÓN. 146

6.3.1 Los PROCESOS DE MEdición TIPO. 146 6.3.1.1 El recurso de medición. 146 
6.3.1.2 Los procesos de medición y la selección de equipos. ..........149

6.3.1.3 Clasificación de los Procesos de Medición Tipo................150

6.3.2 Modelo DE ENSAMBLE DE INSPECCIÓN................................................156

6.3.2.1 Requisitos de la propuesta. ...............................................156

6.3.2.2 Modelo de Ensamble de Inspección propuesto...................156

\section{CAPítulo 7 Metodología basada EN GRAFOS PARA LA INSPECCión ..........................159}

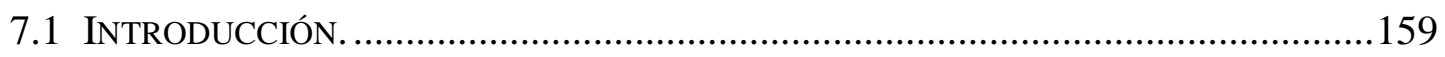

7.2 SINTAXIS Y SEMÁNTICA DE LA REPRESENTACIÓN..............................................160

7.2.1 LOS NODOS. .................................................................................161

7.2.1.1 El Elemento Característico de defectos de medición...........161

7.2.1.2 Las referencias...................................................................162

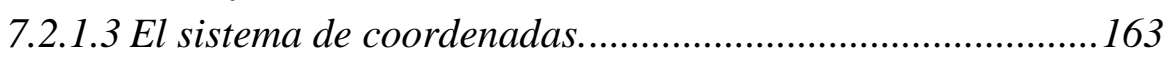

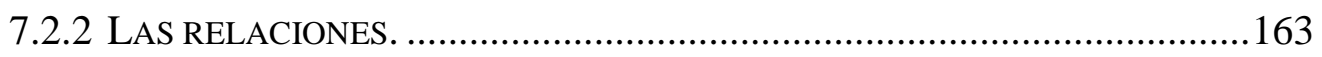

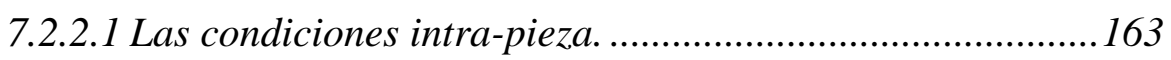

7.2.2.2 Las condiciones inter-pieza. ..........................................164

7.2.2.3 Las condiciones de contacto. .............................................165

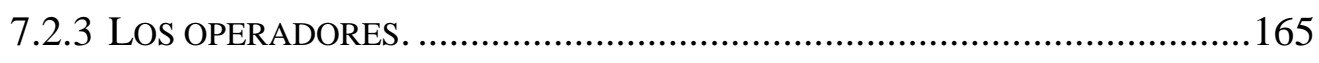

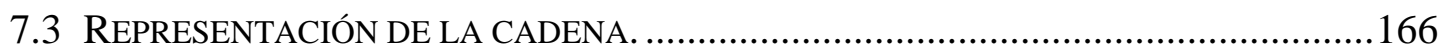

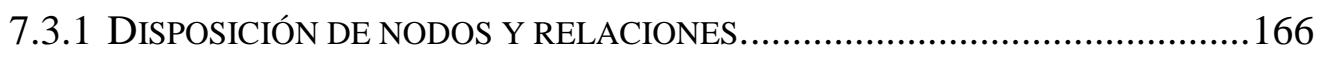

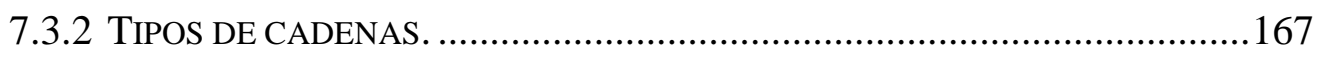

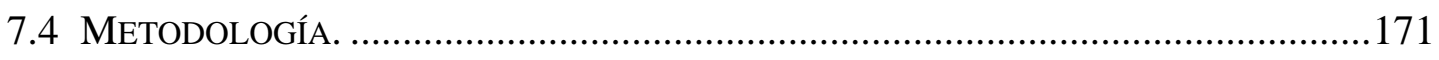

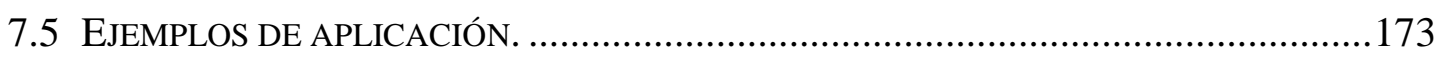

CAPÍtulo 8 Conclusiones y TRABAJOS FUTUROS .............................................................183

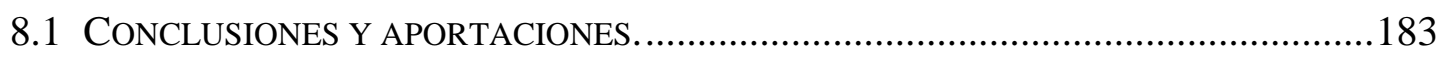

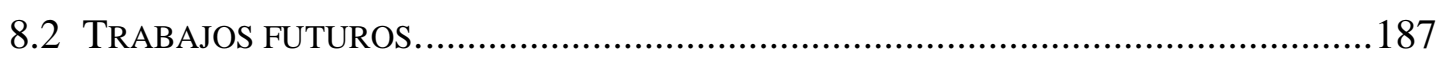

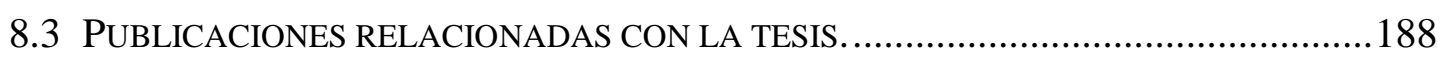

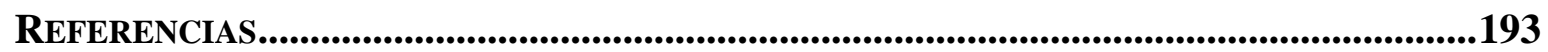




\section{LISTA DE FIGURAS}

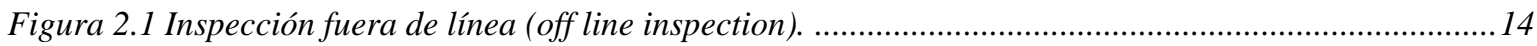

Figura 2.2 Inspección en línea y en proceso (in line and in process inspection)........................................15

Figura 2.3 Inspección en línea y post proceso (in line and post process inspection). .................................... 15

Figura 2.4 Círculo de control de la calidad de especificación, fabricación e inspección de Shewhart...........16

Figura 2.5 Ejemplo de una posible especificación estadística de las especificaciones. ................................ 16

Figura 2.6 Arquitectura funcional del proceso $C I D P^{2} R$ [Rosado et ál., 2009]. ..............................................20

Figura 2.7 Esquema general y elementos principales de los diagramas IDEFO. .....................................23

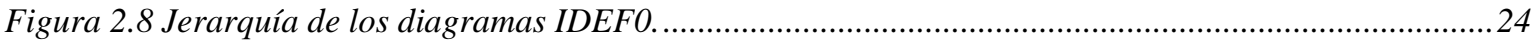

Figura 2.9 Diagrama de nodos de mayor nivel con numeración negativa. ....................................................25

Figura 2.10 Organización jerárquica de los diagramas IDEFO del modelo funcional propuesto...................26

Figura 2.11 Diagrama de contexto del modelo funcional propuesto para la planificación de la inspección geométrica de una pieza.

Figura 2.12 Descomposición de la actividad A0-Realizar la planificación supervisora de procesos de fabricación e inspección.

Figura 2.13 Descomposición de la actividad A3-Realizar la planificación supervisora de la inspección.

Figura 2.14 Descomposición de la actividad A31-Desarrollar la planificación supervisora de la inspección.

Figura 2.15 Esquema del árbol de soluciones del PPNL con señalización de una operación (rama) válida.

Figura 2.16 Descomposición de la actividad A311-Definir elementos característicos, procesos tipo y recursos de inspección.

Figura 2.17 Descomposición de la actividad A3111-Definir la pieza en base a elementos característicos de inspección.

Figura 2.18 Descomposición de la actividad A3113-Seleccionar los posibles recursos de inspección............38

Figura 3.1 Modelización del objeto volumen (ejemplos) [de Charpentier, 2014] .........................................46

Figura 3.2 Traducciones de condiciones y de especificaciones [de Costadoat, 2010]................................51

Figura 3.3 Clasificación de nueve operaciones GPS [de Charpentier, 2014] ...........................................53

Figura 3.4 Interrelación entre las definiciones de elementos característicos geométricos para el ejemplo de un cilindro [de Ma et ál., 2007 e ISO17450-1, 2011]............................................................54

Figura 3.5 Definición de especificación en el lenguaje Geospelling [de Costadoat, 2010]...........................55

Figura 3.6 Objetos y relaciones del modelo de producto del proyecto IPPOP (Integration of Product,

Process and Organisation for Performance Enhancement in Engineering) [de Ballu et ál., 2007]................59

Figura 3.7 Grafo de relaciones [de Costadoat, 2010]......................................................................62

Figura 3.8 Los seis tipos de primitivas de referencia [de Kandikjan et ál., 2001]. ....................................... 70

Figura 3.9 G.d.l. invariantes y activos para cada una de las seis primitivas de referencia [de Kandikjan et ál., 2001]....

Figura 3.10 Elementos característicos recortados más comunes que corresponden a cada primitiva o sus combinaciones [de Shen et ál., 2003].....

Figura 3.11 Relaciones entre varias incertidumbres en GPS [de Nielsen, 2006 e ISO17450-2, 2012]..........76

Figura 3.12 Principio de dualidad entre especificación y verificación [de ISO17450-1, 2011]. 
Figura 3.13 Modelos de superficie [de Ma et ál., 2007].

Figura 3.14 Esquema general de un recurso de medida.

Figura 3.15 Procesos de muestreo - Superficie cilíndrica [de Charpentier, 2014 e ISO14406, 2010] .

Figura 4.1 Modelo de capas típico de un sistema CAX paramétrico basado en elementos característicos [de Brunetti y Grimm, 2005].

Figura 4.2 Modelo de Elemento Característico Unificado [de Chen at ál., 2006 y Ma et ál., 2009]............. 94

Figura 4.3 Diagrama UML del meta modelo de EC [de Zha y Sriram, 2004] ..........................................97

Figura 4.4 Diagrama de clases UML del CPM (Core Product Model) [de Fenves et ál., 2008]. 105

Figura 4.5 Diagrama de clases UML del OAM (Open Assembly Model) del CPM [de Rachuri et ál., 2006].

Figura 4.6 Diagrama de clases UML del OESFM (Open Embedded System Feature Model) [de Zha y Sriram, 2004].

Figura 4.7 Diagrama UML del modelo PPO (Product-Process-Organization) [de Noël y Roucoules, 2008].

Figura 5.1 Diagrama de clases UML del Meta-Modelo de Elemento Característico (EC) propuesto...

Figura 5.2 Diagrama de clases UML que muestra la relación de clases del Meta-Modelo de EC con el Modelo de Producto PPO.

Figura 5.3 Diagrama de clases UML del Modelo de Elemento Característico de Especificación (ECE) propuesto.

Figura 5.4 Diagrama de clases UML del Modelo de EC de Especificación de Producto (ECEP) propuesto.

Figura 5.5 Diagrama de clases UML del Modelo de Elemento Característico de Inspección (ECI) propuesto.

Figura 6.1 Diagrama de clases UML del Modelo de Cadena de Ensamble de Especificación (CE) propuesto.

Figura 6.2 Diagrama de clases UML del Modelo de Cadena de Ensamble de Especificación de

Producto (CEP) propuesto.

Figura 6.3 Diagrama de clases UML del Modelo de Cadena de Ensamble de Inspección (CEI) propuesto.

Figura 6.4 Ejemplo de medición utilizando un montaje de tipo PMT4. ................................................... 153

Figura 6.5 Ejemplo de medición utilizando un montaje de tipo PMT4. ........................................................ 153

Figura 6.6 Ejemplo de medición utilizando un montaje de tipo PMT5. ...................................................... 154

Figura 6.7 Ejemplo de medición utilizando un montaje de tipo PMT6. .................................................. 155

Figura 6.8 Diagrama de clases UML del Modelo de Ensamble de Inspección (EI) propuesto..................... 157

Figura 7.1 Símbolos utilizados para los nodos. ....................................................................................... 161

Figura 7.2 Símbolos utilizados para las relaciones........................................................................ 163

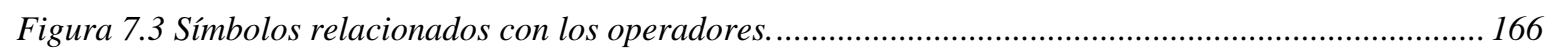

Figura 7.4 Ejemplo de nodos y relaciones de una pieza con característica intrínseca. ............................... 167

Figura 7.5 Ejemplo de nodos y relaciones de una pieza con una característica de situación con una única referencia (datum)..

Figura 7.6 Ejemplo de nodos y relaciones de una pieza con una característica de situación con referencia (datum) múltiple.

Figura 7.7 Ejemplo de nodos y relaciones de un equipo de inspección en el que no se utiliza utillaje......... 169

Figura 7.8 Ejemplo de nodos y relaciones de un equipo de inspección en el que se utiliza utillaje. 170 
Figura 7.9 Ejemplo de nodos y relaciones de un equipo de inspección en el que se utiliza utillaje medido previamente en la misma subfase.

Figura 7.10 Ejemplo 1: Pieza a inspeccionar y esquema del ensamble de inspección seleccionado. ............173

Figura 7.11 Esquema de la cadena del ensamble de inspección del Ejemplo 1. .......................................175

Figura 7.12 Ejemplo 2: Pieza a inspeccionar y esquema del ensamble de inspección seleccionado. ............176

Figura 7.13 Esquema de la cadena del ensamble de inspección del Ejemplo 2. ......................................178

Figura 7.14 Ejemplo 3: Pieza a inspeccionar y esquema del ensamble de inspección seleccionado. ........... 179

Figura 7.15 Esquema de la cadena del ensamble de inspección del Ejemplo 3. .........................................180 



\section{LISTA DE TABLAS}

Tabla 3.1 Clases invariantes [adaptada de Srinivasan, 1999 y Lu, 2011] ....................................................47

Tabla 5.1 Biblioteca de Elementos Característico de Inspección (ECI) propuesta. ……………………….... 128

Tabla 5.2 Simbología utilizada para representar las referencias mínimas................................................... 137

Tabla 6.1 Clasificación de los recursos metrológicos en Procesos de Medición Tipo (PMT) con sistema de sensor únicamente en una dirección. 



\section{Capítulo 1}

\section{INTRODUCCIÓN}

\subsection{CONTEXTO DEL TRABAJO.}

Para dar respuesta a la complejidad inherente a los entornos de desarrollo integrado y colaborativo de nuevos productos, en los que todos los participantes en el ciclo de vida del producto deben cooperar de una forma dinámica, eficaz y eficiente, es necesaria la aplicación de nuevos enfoques y metodologías. De entre estas adquieren una especial relevancia aquellos que garantizan la integridad de la función del producto a través del ciclo diseño-fabricación-inspección y que permiten el mejor uso de las capacidades de los procesos (de fabricación y de inspección), como son las contempladas por los enfoques conocidos como Ingeniería Concurrente o Ingeniería Colaborativa.

Los programas de Diseño para Seis Sigma (Design For Six Sigma, DFSS), que proponen intervenir ya en las primeras etapas del ciclo de vida del producto con el fin de garantizar su calidad y aceptación en el mercado, es otro buen ejemplo de estos nuevos enfoques. Según el DFSS las etapas iniciales del diseño son de vital importancia para lograr definir unos requisitos funcionales que, además de corresponder a una correcta interpretación de las necesidades del mercado, permitan llegar a soluciones robustas. Por ello, y en el ámbito concreto vinculado a la geometría del producto, durante el proceso de la definición de las especificaciones dimensionales y geométricas del producto es importante valorar soluciones en las que la variabilidad geométrica tenga poca influencia en la funcionalidad y que además sean favorables desde las perspectivas del ensamblaje, la fabricación y la inspección. En ese sentido, el DFSS destaca la importancia de realizar la evaluación y validación (de producto, proceso y sistema de fabricación) a todos los niveles de desarrollo (sistema, subsistema y pieza), tanto en el contexto digital como en el físico.

Pero para conseguir la integración de los diferentes procesos, metodologías y aplicaciones presentes en un sistema integrado de desarrollo colaborativo de productos es fundamental disponer de unas representaciones de los productos, procesos y recursos adecuadas. En concreto, si se centra la atención en las actividades de especificación geométrica del producto y de planificación de procesos, foco de interés en este trabajo, va a ser necesario contar con unos modelos de producto, coherentes y unívocos, que permitan un tratamiento adecuado de las desviaciones geométricas. De entre las alternativas existentes para esta representación del producto, en este trabajo se opta por las basadas en Elementos Característicos (Features), que se han manifestado en los últimas décadas como las más apropiadas para este tipo de actividades, puesto que permiten que la información 
geométrica se complete con información y conocimiento específico de un determinado dominio.

Esta representación del producto basada en Elementos Característicos es fundamental para el proceso $\mathrm{CIDP}^{2} \mathrm{R}$ (Collaborative and Integrated Development of Product, Process and Resource / Desarrollo Colaborativo e Integrado de Producto, Proceso y Recurso), un marco desarrollado en el proyecto de investigación "La planificación de procesos como elemento vertebrador de la concurrencia y la integración en redes de ingeniería y fabricación distribuida", que propugna un modelo de flujo de actividades concurrente que engloba todo un conjunto de tareas técnicas vinculadas con el Diseño Robusto y el DFA (Design For Assembly / Diseño para el Ensamblaje), DFM (Design For Manufacturing / Diseño para la Fabricación) y DFI (Design For Inspection / Diseño para la Inspección), y en el que son fundamentales las actividades de Planificación de Procesos (Mecanizado e Inspección) a los tres niveles que el modelo de proceso contempla: agregado, supervisor y operacional. El proceso $\mathrm{CIDP}^{2} \mathrm{R}$ necesita de una representación y tratamiento de las tolerancias armonizado, tanto en lo que se refiere a la especificación y análisis funcional como a la verificación de las mismas.

La verificación de tolerancias, foco central de esta investigación, implica la definición del plan de inspección con los que comprobar las tolerancias, funcionales y de fabricación, y es una tarea que debe integrarse con la especificación geométrica del producto. Además, tal y como se ha mencionado antes, es importante considerarla, en las fases tempranas del proceso de diseño.

Para la especificación y el análisis de las tolerancias funcionales de un producto en las fases tempranas se han utilizado, habitualmente, enfoques basados en modelos de ensamble (mecanismo), sobre los que se realizan ejercicios de análisis de tolerancias utilizando diferentes técnicas y herramientas disponibles. Sin embargo, los razonamientos de la verificación de tolerancias, que suponen la especificación del plan de inspección, no suelen estar basados en modelos que representen el ensamble adoptado para el proceso de inspección. Pero, aunque muchas veces no sea explícito, la especificación del plan de inspección suele implicar el establecimiento de las configuraciones de ensamble definidas para cada una de las subfases del plan y los ejercicios de análisis de incertidumbres se pueden realizar sobre ellos, de forma similar al análisis de tolerancias funcionales del producto.

La importancia de la relación entre la especificación de GD\&T (Geometric Dimensioning and Tolerancing / Dimensionado y Toleranciado Geométrico) del producto y su verificación ha sido puesta de manifiesto, desde hace muchos años, por los desarrollos normativos, en concreto con el establecimiento del principio de dualidad de la norma ISO17450, perteneciente al grupo de normas GPS (Geometrical Product Specification / Especificación Geométrica de Producto) de la ISO (International Organization for Standardization / Organización Internacional para la Estandarización), que propugna que el operador de verificación sea un espejo del de especificación para disminuir la incertidumbre.

Por otra parte, también es importante valorar la posibilidad de integrar la planificación de la inspección con la planificación de procesos de conformado. Esta necesidad se evidencia en el hecho de que ahora las actividades de inspección (en proceso y post proceso) son vistas como una actividad productiva más, impulsándose un tratamiento conjunto de estas operaciones con las de conformado. Para ello, es necesario disponer de unos modelos unificados de proceso y de producto, que ayuden a definir planes de proceso integrados, en este caso de mecanizado e inspección. 


\subsection{HiPÓTESIS DE PARTIDA.}

El trabajo de desarrollo de la tesis se ha realizado considerando que:

- Las actividades de inspección son una actividad productiva más, potenciando la inspección en línea mediante la integración de las operaciones de inspección en proceso y post proceso con las de mecanizado y, por tanto, posibilitando la elaboración de planes integrados de mecanizado e inspección. Se trata de un enfoque fundamental para muchos contextos actuales de fabricación, en los que el desarrollo del producto, proceso y recurso debe realizarse de manera concurrente y colaborativa.

- El modelado de los conjuntos mecánicos (mecanismos o ensambles) en los que participa la pieza a lo largo de su ciclo de vida es una buena base para abordar las actividades de definición y validación de las especificaciones GD\&T funcionales y de los planes integrados de mecanizado e inspección.

- La representación de las piezas en base a elementos característicos específicos de cada ámbito (elementos característicos de aplicación) resulta adecuada para abordar los razonamientos y ejercicios propios de las diferentes tareas implicadas en un entorno de desarrollo concurrente y colaborativo de producto, proceso y recurso.

- Es posible establecer una estructura y semántica unificadas para los elementos característicos que dé soporte y garantice la consistencia entre todos los elementos característicos de aplicación utilizados en los diferentes ámbitos implicados en el desarrollo concurrente y colaborativo de producto, proceso y recurso.

- Es posible definir un elemento característico para la planificación supervisora de la inspección que sea válido para entornos de desarrollo concurrente y colaborativo y que favorezca tanto la integración de la planificación de procesos de mecanizado e inspección como la dualidad entre la especificación GD\&T y la inspección del producto.

\subsection{OBJETIVO DE LA TESIS.}

En el contexto expuesto anteriormente y teniendo en cuenta las hipótesis establecidas, el objetivo principal de la tesis se concretó en: el desarrollo de un elemento característico adecuado para la planificación supervisora de la inspección en un entorno $\operatorname{CIDP}^{2} \mathrm{R}$. Una propuesta de elemento característico de inspección que debía contener toda la información necesaria para llevar a cabo los ejercicios de simulación propios de la especificación del plan de inspección a nivel supervisor, considerando asimismo la integración de dicha planificación con la del mecanizado. Adicionalmente, y con el fin de adecuar la propuesta a un entorno $\mathrm{CIDP}^{2} \mathrm{R}$, también debería integrarse en un modelo de producto, estableciéndose una semántica común que garantizara la coherencia con otros puntos de vista presentes en el desarrollo del producto y, muy en particular, con los de la etapa de especificación dimensional y geométrica del producto, clave para asegurar la integridad del diseño.

En base a este objetivo general se concretaron los siguientes objetivos específicos, que establecen el alcance del trabajo:

- Desarrollar un modelo funcional de la planificación supervisora de la inspección en un contexto $\mathrm{CIDP}^{2} \mathrm{R}$ y, en particular, un modelo que ponga especial atención en la relación e integración con la planificación supervisora del mecanizado, con el fin de unificar la planificación de la fabricación y la inspección e impulsar la integración de las actividades de inspección en línea. 
- Profundizar en el conocimiento sobre los ejercicios vinculados con el tratamiento de tolerancias realizados en las etapas de desarrollo de producto y proceso en los niveles agregado y supervisor.

- Explorar las propuestas elaboradas para la representación basada en elementos característicos en distintos ámbitos, como son los de desarrollo de sistemas mecánicos, de aplicaciones informáticas (software) y de sistemas mecatrónicos.

- Establecer un meta-modelo de elemento característico con una estructura y semánticas unificadas que garanticen la consistencia entre los diferentes puntos de vista en el desarrollo colaborativo e integrado del producto.

- Definir un elemento característico que contenga toda la información necesaria para los ejercicios realizados durante la especificación del plan de inspección del producto en la etapa de planificación de la inspección en un nivel supervisor. La definición del elemento característico de inspección debe garantizar la dualidad entre los ejercicios realizados para la especificación y validación de un plan de inspección y los que se realizan para la especificación dimensional y geométrica y validación funcional del producto. Para ello, se deberá definir un elemento característico dual al de inspección para el ámbito de la especificación del producto. Asimismo, se definirá un elemento característico apropiado para los ejercicios de especificación, que reúna los aspectos comunes y que, por tanto, garantice la dualidad entre los elementos característicos para la especificación del producto y para la especificación del proceso de inspección.

- Desarrollar una biblioteca de elementos característicos de inspección que ofrezca una cantidad y tipología de elementos característicos suficientes para interpretar una pieza con un enfoque basado en la inspección, sin olvidar la consistencia con la intención de ingeniería.

- Desarrollar modelos que, considerando el elemento característico de inspección, permitan representar el ensamble de inspección y las cadenas de inspección establecidas sobre dicho ensamble en los que basar el ejercicio de la especificación y validación del plan de inspección. Estos modelos deben garantizar la dualidad con la especificación y análisis del producto, por lo que se deberá también desarrollar un modelo de cadena de ensamble apropiado para los ejercicios de este ámbito y dual al de la cadena de inspección. Asimismo, se definirá un modelo de cadena de ensamble que permita recoger los aspectos comunes de los diferentes ejercicios que se llevan a cabo durante el desarrollo del producto y proceso con el fin de asegurar la dualidad.

- Establecer un concepto de recurso de medida y desarrollo de una clasificación de los mismos en procesos de medición tipo que sea válida para los modelos de cadena y de ensamble de inspección y permita recoger de una forma general las diferentes tipologías de instrumentos, equipos y montajes de medición que pueden ser seleccionados como recurso de inspección en un nivel supervisor. El concepto y clasificación de los recursos de medida se planteará con un nivel de generalidad suficiente que permita incluir procesos de medición que utilizan desde instrumentos metrológicos de taller más sencillos hasta máquinas universales de medida por coordenadas con mayores prestaciones, pasando por montajes y equipos de diseño específico.

- Definición de una metodología basada en una representación gráfica de las cadenas de inspección establecidas sobre un ensamble de inspección, que sirva de soporte al planificador en el proceso de elaboración del plan de inspección, tanto en la búsqueda de soluciones para el recurso de inspección como en la validación de las mismas. 


\subsection{METOdOLOGÍA DE LA TESIS.}

Para la realización del trabajo se han seguido las etapas que se exponen a continuación. Antes de pasar a describirlas, cabe aclarar que la metodología planteada inicialmente seguía un enfoque de abajo hacia arriba, ya que inicialmente el trabajo se orientó hacia la definición de modelos específicos para la planificación de la inspección adecuados para el enfoque dual que la normativa ISO establece para la especificación y verificación GD\&T, pero que posteriormente evolucionó para considerar modelos de sistemas mucho más generales con enfoques basados en el concepto de elemento característico. Por ello, en primer lugar se abordó el estudio de aspectos concretos relacionados con la especificación y la verificación de productos para, a continuación, pasar a estudiar aspectos más generales que pudieran ayudar al desarrollo de modelos genéricos.

Con las consiguientes realimentaciones, los pasos seguidos han sido:

1. Revisión de las principales aportaciones existentes en los siguientes tópicos: (1) Sistemas de co-planificación, como la propuesta del sistema Co-CAPP (Collaborative Process Planning / Planificación de Procesos Colaborativa), en el que se aborda una planificación integrada para el mecanizado y la inspección en entornos colaborativos; (2) Definición y tratamiento de los elementos característicos de aplicación para el mecanizado y para la inspección; (3) Fundamentos, conceptos y modelos contemplados en las normativas de especificación y verificación, concretamente el lenguaje Geospelling y su consideración en el desarrollo de la norma GPS de ISO; y (4) Técnicas de representación de modelos de sistemas $y$, en concreto, la técnica IDEF0 (Integrated DEFinition for function modeling / Definición Integrada para el modelado de funciones) para modelos funcionales y las técnicas EXPRESS-G y los modelos de clases de UML (Unified Modeling Language / Lenguaje de Modelado Unificado) para modelos conceptuales de información.

2. Desarrollo de un modelo funcional, representado utilizando la técnica IDEF0, de planificación integrada de procesos de fabricación (mecanizado) e inspección en un nivel supervisor, con especial énfasis en las actividades desde la vista de la planificación de la inspección.

3. Elaboración de propuestas iniciales de elemento característico de inspección, para el ejercicio de la planificación supervisora de la inspección, basadas fundamentalmente en los conceptos de grados de libertad y de tipos de procesos de medición.

4. Estudio alrededor de cuatro temáticas: (1) Modelado de las geometrías con defectos en herramientas de simulación utilizadas en las primeras etapas del proceso de diseño y aplicadas a ensambles o mecanismos; (2) El análisis y la síntesis de tolerancias y representaciones que dan soporte al tratamiento de las tolerancias a nivel de geometría; (3) Modelos geométricos obtenidos en el propio proceso de inspección y los elementos que forman parte del proceso; y (4) Tratamiento de incertidumbres para la especificación de la inspección.

5. Refinamiento de la propuesta inicial de elemento característico de inspección y elaboración de un modelo conceptual de elemento característico de inspección mediante el modelado de clases de UML.

6. Desarrollo de una propuesta de meta-modelo de elemento característico y de unas propuestas de modelos generales de producto y de elemento característico de aplicación (específicos de un ámbito) que permitan derivar los modelos de elemento característico de inspección y de especificación de los ensambles de inspección. 
7. Elaboración de una propuesta final de modelo de elemento característico de inspección y de modelo de ensamble de inspección.

8. Desarrollo de una propuesta de metodología basada en una representación gráfica de las cadenas de inspección para dar soporte a los razonamientos realizados en la planificación de la inspección.

Cabe mencionar que el orden de las etapas seguidas para el desarrollo del trabajo no coincide con el orden en el que se presentan los contenidos de la tesis. Para la redacción del documento se decidió organizar los contenidos según se describe en el siguiente apartado: se comienza con la descripción del contexto y la propuesta de modelo funcional, a continuación se agrupan las bases de las propuestas de modelos conceptuales en dos capítulos, en los tres capítulos siguientes se describen las propuestas de modelos conceptuales y se finaliza con las conclusiones.

\subsection{ORgANIZACIÓN DE LA TESIS.}

La tesis se estructura en 8 capítulos. Además del presente capítulo 1 en el que se exponen el contexto, las hipótesis, los objetivos y la metodología del trabajo, la tesis consta de otros siete capítulos adicionales, de los que a continuación se indican los títulos acompañados de una breve descripción de su contenido.

- Capítulo 2. La Planificación de la Inspección en entornos colaborativos.

Este capítulo tiene dos objetivos principales. En primer lugar, se contextualiza el trabajo desarrollado, para lo que al inicio del capítulo se repasan algunos de los principales aspectos y conceptos vinculados con la inspección y su planificación. A continuación, se explica de una forma más detallada el $\operatorname{CIDP}^{2} \mathrm{R}$ y, más concretamente, se describirá la propuesta para el desarrollo del sistema de planificación Co-CAPP. En segundo lugar, en este capítulo se desarrolla la propuesta de un modelo funcional para la planificación supervisora de la inspección, que además se presenta incorporada en un modelo integrado que contempla tanto la planificación supervisora de procesos de fabricación (mecanizado) como de inspección.

- Capítulo 3. El tratamiento de la variabilidad en la especificación y la verificación.

En el capítulo 3, y a partir de la revisión de recientes trabajos, se exponen los fundamentos de un modelo común de sistema (producto), válido para las diferentes actividades tempranas de diseño y simulación. A continuación, el foco se dirige al modelado estructural y funcional del producto y a las representaciones propias de las fases tempranas del diseño. Posteriormente, se presentan los tópicos fundamentales que cubre el toleranciado, centrándose el estudio en las técnicas de análisis de tolerancias, abordándose a continuación la especificación de tolerancias y, en concreto, las formas de expresar la geometría con defectos tanto en el ámbito normativo como en las metodologías y herramientas de análisis que se utilizan en la fase de diseño de detalle. Asimismo, en este capítulo se propone un tratamiento de la especificación desde el punto de vista de la verificación de manera unificada a la especificación y análisis funcional del producto y que se basa en el uso del lenguaje Geospelling para especificar la medida.

- Capítulo 4. Modelo de Elemento Característico.

El capítulo 4 comienza con la revisión de los fundamentos que sustentan el concepto de elemento característico y, en especial, las propuestas que utilizan una semántica unificada para definir los elementos característicos propios de diferentes etapas o puntos de vista del ciclo de vida del producto y aseguran la 
consistencia entre ellos. A continuación, se revisan las principales propuestas existentes de elementos característicos de aplicación para los ámbitos concretos del mecanizado y de la inspección. Seguidamente, se repasarán los trabajos existentes en el campo del modelado de producto, analizando como estos modelos contemplan al elemento característico y estudiando las asociaciones semánticas establecidas, con la intención de considerarlas para la propuesta.

- Capítulo 5. Los Elementos Característicos de Especificación de Producto y de Inspección.

En este capítulo, y en base a las revisiones realizadas en los capítulos anteriores 3 y 4, en primer lugar se desarrolla la propuesta de meta-modelo de elemento característico válido para entornos de desarrollo colaborativo y que incorpora los conceptos básicos propuestos en los principales trabajos de la bibliografía revisada, tal como el concepto de elemento característico de aplicación como un elemento característico asociativo que proporciona una estructura y semántica unificada. A continuación, y de acuerdo al meta-modelo de elemento característico establecido, se desarrolla la propuesta de un elemento característico de especificación, elemento que contiene toda la información relacionada con la geometría necesaria para los ejercicios de especificación que se llevan a cabo durante el desarrollo del producto. Seguidamente, se desarrollan las propuestas de elemento característico de especificación de producto y de elemento característico de inspección, de manera que resulten propuestas duales como especializaciones del elemento característico de especificación. Asimismo, y para el caso del elemento característico de inspección, en la propuesta se incluye una biblioteca que ofrezca una cantidad y tipología de los mismos suficientes para interpretar una pieza con un enfoque basado en la inspección, sin olvidar la consistencia con la intención de ingeniería.

- Capítulo 6. La Especificación del Producto y la Planificación de la Inspección.

En este capítulo se profundiza en el ejercicio de la especificación del producto y de la planificación de la inspección, integrando los elementos característicos de especificación de producto y los elementos característicos de inspección en un modelo de cadena de ensamble en el que basar los ejercicios de especificación. Para ello, se propone un modelo de cadena de ensamble para la especificación que sea común para los ámbitos de la especificación y de la inspección del producto. A continuación, y a partir del modelo común anterior, se desarrollan de forma dual los modelos de cadena de ensamble específicos para la especificación de producto y para la inspección. Por último, y dado que la planificación supervisora de la inspección es el objeto de interés principal de este trabajo, en la última parte de este capítulo se desarrolla la propuesta de un modelo para el ensamble de inspección que permite la representación de la selección de recursos y equipos de medición. Este modelo tiene en cuenta una propuesta previa de clasificación de los recursos de inspección que está basada en un concepto de recurso de inspección y en unos aspectos que afectan a la selección de dichos equipos que se exponen anteriormente a la clasificación.

- Capítulo 7. Metodología basada en grafos para la inspección.

En el capítulo 7 se propone una metodología basada en una representación gráfica de la cadena de inspección que permite dar soporte al planificador de la inspección en sus razonamientos durante la búsqueda y validación de posibles soluciones para el plan de inspección. En el capítulo se describen, en primer lugar, los elementos sintácticos utilizados para la representación de las cadenas y la 
semántica usada para expresar la relación entre ellos. A continuación, se describe la metodología para llevar a cabo la construcción de las cadenas de inspección haciendo uso de los elementos gráficos anteriores. Por último, en la última parte de este capítulo se exponen un conjunto de casos de aplicación sencillos de la construcción de la representación gráfica propuesta para las cadenas de inspección que permiten ilustrar su uso.

- Capítulo 8. Conclusiones y trabajos futuros.

El capítulo 8 recoge las conclusiones y aportaciones más significativas del trabajo realizado. Asimismo, se indican los trabajos futuros que pueden dar continuidad al trabajo realizado en esta tesis o la iniciación de nuevas líneas de investigación. 


\section{CAPítulo 2 \\ La Planificación de la INSPECCIÓN EN ENTORNOS COLABORATIVOS}

\subsection{INTRODUCCIÓN.}

La calidad de un producto se asocia normalmente a "lo bien que un producto o servicio realiza sus funciones consistentemente" [Yang y El-Haik, 2003], circunstancia que obliga a disponer de un buen diseño pero que también supone conseguir que todos los productos o servicios resulten consistentes, para que todos los clientes queden satisfechos todas las veces. En un proceso de fabricación esta exigencia obliga a medir continuamente el nivel de desempeño (performance) actual del proceso (en toda una serie de características previamente establecidas y pertenecientes a las diferentes dimensiones que contempla el concepto de calidad) y a compararlo con el nivel ideal, y establecer unas estrategias de aseguramiento y mejora de la calidad. Este seguimiento del desempeño actual es el que permite tomar decisiones en relación tanto a las salidas y el control del proceso como a su propia mejora, en lo concerniente al desempeño medio y también a su capacidad.

En particular, en el campo de la Metrología Dimensional y Geométrica este seguimiento del desempeño se realiza a través de procesos de inspección que comportan el examen o reconocimiento de la geometría resultante del proceso (pieza, ensamble), mediante las técnicas y procedimientos de medida adecuados, para obtener una información en un formato que permita comparar la geometría real fabricada con respecto a la especificada. Se trata de unos procesos que tradicionalmente se han vinculado a la función de aceptación o rechazo (y eventualmente reprocesado) del producto resultante del proceso de fabricación, como mecanismo que permite asegurar su conformidad a unas especificaciones dimensionales y geométricas, establecidas a partir de unos requisitos funcionales previamente fijados. Pero a esta función tradicional del proceso de inspección, que lo aísla del resto de procesos presentes en la etapa de la fabricación (de conformado, mecanizado, ensamble, etc.) y que no aporta valor, se le añade cada vez más otra función, más importante si cabe, como es la de proporcionar toda aquella información necesaria para evaluar (a través de los correspondientes índices de capacidad), analizar y mejorar el nivel de desempeño del proceso actual. 
Pero esta función adicional, potenciada por alguno de los enfoques que orientan la fabricación actual como el de la Fabricación Ajustada o de la Mejora de Procesos Seis Sigma, no es suficiente. La filosofía Seis Sigma [Yang y El-Haik, 2003] también propone intervenir en las etapas iniciales del ciclo de vida del producto y del proceso, a través de la metodología de Diseño para Seis Sigma (Design for Six Sigma, DFSS). Seis Sigma se diferencia de otros métodos y sistemas de calidad en que posee una estrategia para la calidad global, que extiende el alcance de la calidad del producto a la calidad de todos los aspectos operativos del negocio. Esta estrategia, que busca la excelencia global del negocio, tiene efectos en la calidad y costes de los productos pero también en el tiempo de lanzamiento del producto al mercado. Por ello el enfoque Seis Sigma también contempla, como parte fundamental de su estrategia, la mejora de la calidad de la gestión del ciclo de desarrollo de productos/servicios, proponiendo la adopción de técnicas de trabajo concurrente, de gestión de proyectos, etc. Esta misma estrategia de buscar la excelencia del negocio a través de la mejora del proceso de desarrollo del producto y del proceso de fabricación, es compartida por el Desarrollo Colaborativo de Nuevos Productos (Collaborative New Product Development), quien fundamentalmente se orienta por el objetivo de reducir el tiempo de desarrollo, como medida clave que determina la competitividad de muchas empresas de fabricación.

El Desarrollo Colaborativo de Nuevos Productos es un proceso basado en las prácticas de la Ingeniería Concurrente (Concurrent Engineering, CE), mediante la formación de grupos multidisciplinares y el uso de sistemas de Tecnologías de la Información (Information Technology, IT) para promover la comunicación, la coordinación y/o la cooperación (colaboración) entre los diferentes dominios y actividades del ciclo de desarrollo de nuevos productos. Este proceso, que es importante para la competitividad de muchas empresas, lo es de una forma muy especial para las Empresas Virtuales de Producción de Productos de Tipo Único (One of a Kind Production Virtual Enterprise) [Büyüközcan et ál., 2004]. Estas empresas se caracterizan por: su trabajo en mercados de productos personalizados, que requieren de una continua interacción con el cliente; diseño y fabricación correctos a la primera; un desarrollo de producto y de proceso con un enfoque concurrente y evolutivo; planificación y control de la producción adaptativos; departamentos de producción autónomos, etc. Es decir, tienen una gran capacidad de reconfigurarse y rápidamente adaptar su sistema al cambio.

Para permitir un proceso de Desarrollo Colaborativo de Nuevos Productos efectivo en una Empresa Virtual de Producción de Productos de Tipo Único es fundamental contar con un sistema de Planificación de Procesos Colaborativa (Collaborative Process Planning), en la que la inspección no se vea como una actividad aislada del resto de actividades de fabricación. Las actividades de inspección deben tratarse como una actividad productiva más, que añada valor al sistema, al superar la función básica de aceptación o rechazo de piezas, vinculada a una inspección fuera de línea. Para ello se debe potenciar la inspección en línea, como medio que permite disponer de la información y de los datos necesarios para poder realizar las correcciones, en base a datos del proceso, tanto en el propio proceso de fabricación como incluso en el proceso de diseño. Esto lleva, en sistemas de mecanizado, objeto de la presente investigación, a la necesidad de abordar la Planificación del Mecanizado y de la Inspección de una forma integrada y considerando las operaciones de inspección en línea.

La Planificación Integrada de Mecanizado e Inspección en entornos colaborativos debe facilitar la elaboración de unos planes completos y viables, que definan de una forma integrada todas las subfases (setups) y operaciones que se ejecutan en línea, considerando tanto las operaciones de mecanizado como las inspecciones en proceso y post proceso. Esta forma de planificar garantiza que la información necesaria esté disponible en la forma y 
momento que el buen desempeño del diseño integrado del producto-proceso-sistema de fabricación y de la propia fabricación requieren.

Pero el diseño e implantación de un sistema de planificación, que se ajuste a las necesidades identificadas anteriormente, requiere de un sistema de información que permita un intercambio dinámico, eficaz y eficiente de la información geométrica del producto desde todas las perspectivas (puntos de vista) presentes en el sistema y, de una forma muy especial, desde las perspectivas de la especificación funcional y de la inspección, objeto de interés del presente trabajo. Una exigencia que obliga a adoptar un enfoque adecuado para abordar los razonamientos propios de estas actividades (la especificación y análisis de tolerancias y la verificación de las mismas) y que debe estar sustentado por modelos apropiados e integrados en modelos genéricos de producto.

El desarrollo de estos modelos, que se describirán en los capítulos 5 y 6 , deberá atender a las necesidades impuestas por la inspección y su planificación en el contexto de desarrollo colaborativo e integrado de producto-proceso-recurso antes expuesto, y por un diseño y una fabricación a la primera. Para ello, es necesario revisar y considerar los elementos básicos que caracterizan los ejercicios de la especificación dimensional y geométrica y la inspección del producto, así como las propuestas existentes sobre modelos de producto genéricos con enfoques apropiados para entornos de desarrollo colaborativo, y que habitualmente se basan en elementos característicos, aspectos que son tratados en los capítulos 3 y 4.

Para explicar de una forma más detenida el contexto que se acaba de esbozar, en el siguiente apartado se repasarán algunos de los principales aspectos y conceptos vinculados con la inspección y su planificación, y se establecerán las bases que van a permitir realizar un tratamiento integrado y dual de la especificación de producto, la planificación de procesos de fabricación y la planificación de procesos de inspección. A continuación, en el siguiente apartado, se presentará la propuesta para el desarrollo del sistema Planificación de Procesos Colaborativa capaz de soportar el proceso de Desarrollo Colaborativo e Integrado de Producto, Proceso y Recurso (Collaborative and Integrated Development of Product, Process and Resource) en el que se enmarcará este trabajo. Posteriormente, y de acuerdo a lo establecido en los dos primeros apartados, se describirán las actividades del modelo funcional propuesto para la Planificación Supervisora de la Inspección, que se presenta incorporado en un modelo integrado que contempla la Planificación Supervisora de Procesos de Fabricación (Mecanizado) y de Inspección.

\subsection{LA INSPECCión Y LA PLANIFICACIÓN DE LA INSPECCIÓN.}

\subsubsection{LA INSPECCIÓN Y LA VARIABILIDAD EN FABRICACIÓN.}

La variabilidad es parte de todo el entorno y, por ello, duplicados exactos de cualquier cosa son imposibles. Los procesos de fabricación no están exentos de tal circunstancia y esto hace que den lugar a productos con características geométricas y dimensiones sujetas a cierta variabilidad.

La variabilidad inherente a los procesos de fabricación viene determinada por multitud de causas, las cuales se pueden agrupar fundamentalmente en dos tipos: causas comunes y causas asignables. Las primeras son de naturaleza aleatoria y, en muchos casos, de difícil y costosa eliminación. Por el contrario, las causas asignables se producen de forma esporádica, pudiéndose determinar y corregir las fuentes que las generan. 
Esta variabilidad y la necesidad de controlarla es la que motiva el establecimiento y uso de las tolerancias, que limitan el rango de variabilidad admisible de las diferentes características del producto, garantizando así su funcionalidad y otras características de calidad exigidas.

La inspección tiene aquí su primera e importante contribución: determinar si el producto fabricado (y por tanto sujeto a variabilidad) se encuentra dentro de los márgenes de tolerancia establecidos, y así decidir sobre su conformidad o eventual rechazo. Fundamentalmente en torno a este objetivo de la inspección, pueden encontrarse en la bibliografía numerosas definiciones sobre el concepto de inspección en el contexto de una empresa de fabricación. A continuación se indican algunas de ellas según diferentes autores y ordenadas cronológicamente:

Las funciones básicas de la inspección en un sistema de fabricación son eliminar o reducir los productos no conformes (defectuosos), así como proporcionar la información para el diagnóstico del defecto de fabricación y la mejora del proceso [Tang, 1992].

La inspección es un proceso de medida, examen, ensayo, calibración u otro, en el que se compara la unidad con requisitos aplicables [Suntag, 1993].

En fabricación, la inspección se refiere a la recogida de información de los resultados y salidas de un proceso, para comparar lo que se ha producido con lo que era necesario o estaba especificado [Winchell, 1996].

La inspección es cualquier operación que permite la evaluación de la calidad de un producto o servicio, mediante la comparación con sus especificaciones [Pfeifer y Torres, 1999].

La inspección es una actividad de evaluación cuyo propósito principal es comparar el producto obtenido con especificaciones y estándares aplicables y determinar si el producto es o no conforme a los requerimientos [Griffith, 2000].

La inspección es un procedimiento en el cual se examina alguna característica de una parte o producto, tal como una dimensión, para determinar si se ciñe o no a la especificación del diseño [Groover, 2007].

La intención de la inspección es asegurar que lo que se está fabricando será conforme a las especificaciones del producto [Black y Kohser, 2008].

Puede apreciarse como el concepto de inspección no ha variado substancialmente en el tiempo. Todas las definiciones son similares en cuanto que dan a entender que la inspección es una actividad de evaluación de la calidad de un producto o pieza, o incluso de un servicio en un sentido más amplio. También, en todas las definiciones aparece la necesidad de un elemento de referencia utilizado para evaluar la calidad del producto o pieza mediante la comparación. Cabe destacar, sin embargo, que, a excepción de la primera, el resto de las definiciones tienen una acepción limitada de la inspección, ya que, además de asegurar la calidad del producto, la inspección tiene otra contribución muy importante en la identificación y evaluación de las variaciones del proceso, proporcionando la realimentación necesaria para tomar acciones correctivas y mejorar los procesos. Más aún, la realimentación no debe limitarse únicamente al propio proceso de fabricación, sino que también debe realizarse al proceso de diseño con el fin de poder lograr un diseño y fabricación a la primera, lo cual es especialmente relevante en empresas del tipo Empresa Virtual de Producción de Productos de Tipo Único.

El término inspección en el contexto de la fabricación y del presente trabajo se utiliza muy a menudo junto con los términos medición o verificación. En muchas ocasiones, estos términos son utilizados como sinónimos, en otras pueden interpretarse de forma diferente. Por ello, es conveniente recordar las definiciones de estos términos con el fin de 
comprender la diferencia entre ellos. De acuerdo a la Real Academia Española [http://www.rae.es], inspeccionar, verificar y medir se definen como:

Inspeccionar. Examinar, reconocer atentamente.

Verificar. Comprobar o examinar la verdad de algo.

Medir. Comparar una cantidad con su respectiva unidad, con el fin de averiguar cuántas veces la segunda está contenida en la primera.

Considerando alguna referencia más específica del campo de la metrología, en [AENOR, 1999], verificación y medición se definen como:

Verificación. Confirmación por examen y aporte de pruebas tangibles de que las exigencias especificadas han sido satisfechas.

Medición. Conjunto de operaciones que tienen por finalidad determinar un valor de una magnitud.

Y de acuerdo a [JCGM VIM, 2008], las definiciones de los dos términos anteriores son:

Verificación. Aportación de evidencia objetiva de que un ítem dado cumple requisitos especificados.

Medición. Proceso de obtención experimental de uno o más valores de la magnitud que pueden razonablemente ser atribuidos a una magnitud.

Por lo tanto, en el presente trabajo, la inspección de una característica dimensional o geométrica de una pieza o producto es examinar o reconocer atentamente dicha característica, utilizando los procedimientos de medición adecuados, con el fin de obtener la información necesaria que permita su verificación mediante la comparación con una especificación establecida previamente. Esta inspección tiene como objetivo, no solo determinar la aceptación o rechazo de la pieza, sino también evaluar el desempeño del proceso de fabricación con el fin de realimentar tanto al propio proceso de fabricación como al proceso de diseño para tomar las decisiones y acciones correctivas necesarias para un diseño y fabricación a la primera.

Una vez establecido el concepto de inspección y sus principales objetivos, es importante prestar atención a algunos aspectos relevantes a tener en cuenta acerca del contexto concreto en el que se desarrollará dicha inspección y que influyen en gran medida en la toma de decisiones y, también, en los resultados obtenidos.

La primera consideración a tener en cuenta para el desarrollo de la inspección es la tipología del sistema de fabricación. El sistema de fabricación se entenderá en su sentido amplio, es decir, incluyendo tanto a los recursos de fabricación (conformado) como a los de inspección. De esta forma, las operaciones de inspección pueden integrarse como etapas adicionales necesarias para la obtención del producto final. La tipología del sistema de fabricación, tal y como se va a considerar, no se refiere a la naturaleza del propio proceso de fabricación, esto es, si se trata de un proceso de moldeo o de mecanizado, por ejemplo. Este aspecto, aunque también influye en la inspección por la influencia que las capacidades de los distintos procesos tienen a la hora de determinar las especificaciones de inspección y los errores que se puedan producir, no es el que va a ser considerada. Las principales características que afectan a la inspección y que se consideran son:

- Sistema de fabricación uni-etapa o multi-etapa. El primer caso, sistemas de fabricación uni-etapa, se refiere al caso de productos que se obtienen en una sola etapa de fabricación y en los que solo se considera inspección final del producto. Es decir, se integran todas las operaciones realizadas con anterioridad a la inspección como si de una sola etapa se tratara. En este caso, el problema de la localización de la inspección (cuándo realizar la inspección) se simplifica, resultando obvio que es una inspección final. El segundo caso, sistemas de fabricación multi-etapa, se refiere al caso en el que los productos se obtienen en 
más de una etapa. En este caso, la inspección y, en concreto su localización (eventualmente entre las diferentes etapas), resultan más complejas.

- Sistema de fabricación serial o no serial. En un sistema de fabricación serial, cada etapa de fabricación tiene una única etapa inmediatamente predecesora (excepto el caso de la primera etapa) y una única etapa inmediatamente sucesora (excepto el caso de la última etapa). Un ejemplo sería el caso de la fabricación de un alojamiento de motor (moldeo, taladrado, fresado y recubrimiento). En un sistema de fabricación no serial, algunas etapas de fabricación pueden suponer la unión del resultado de etapas anteriores. El ejemplo más claro son las líneas de ensamble. Este hecho puede influir a la hora de determinar la localización de la inspección.

- Sistema de fabricación con secuencia de operaciones fija o no. Plantea la situación de que la secuencia de operaciones a realizar sobre el producto (las estaciones que debe visitar) sea fija (debido a limitaciones tecnológicas o de distribución en planta) o que, por el contrario, no sea fija, permitiéndose rutas diferentes. Obviamente, el segundo caso, abre un mayor abanico de alternativas a la hora de realizar la inspección, y en concreto sobre su localización, ya que hay que tener presente las posibles diferentes rutas a seguir por el producto.

La segunda consideración a tener en cuenta para el desarrollo de la inspección es el tipo de estrategia de inspección. Se pueden identificar dos grandes tipos de estrategias de inspección: inspección en línea (in line inspection u on line inspection) e inspección fuera de línea (off line inspection).

La inspección fuera de línea (Figura 2.1) es aquella que se lleva a cabo una vez ha finalizado el proceso de fabricación, con el único fin de establecer el estado de la pieza y proceder a su rechazo, aceptación u otras consideraciones, como la posibilidad de reprocesado o venta a terceros. La principal desventaja de la inspección fuera de línea proviene del hecho de que la información se obtiene con un retraso significativo en el tiempo respecto al proceso de fabricación y cuando este ha finalizado por completo, por lo que la eventual realimentación al mismo se produciría demasiado tarde.

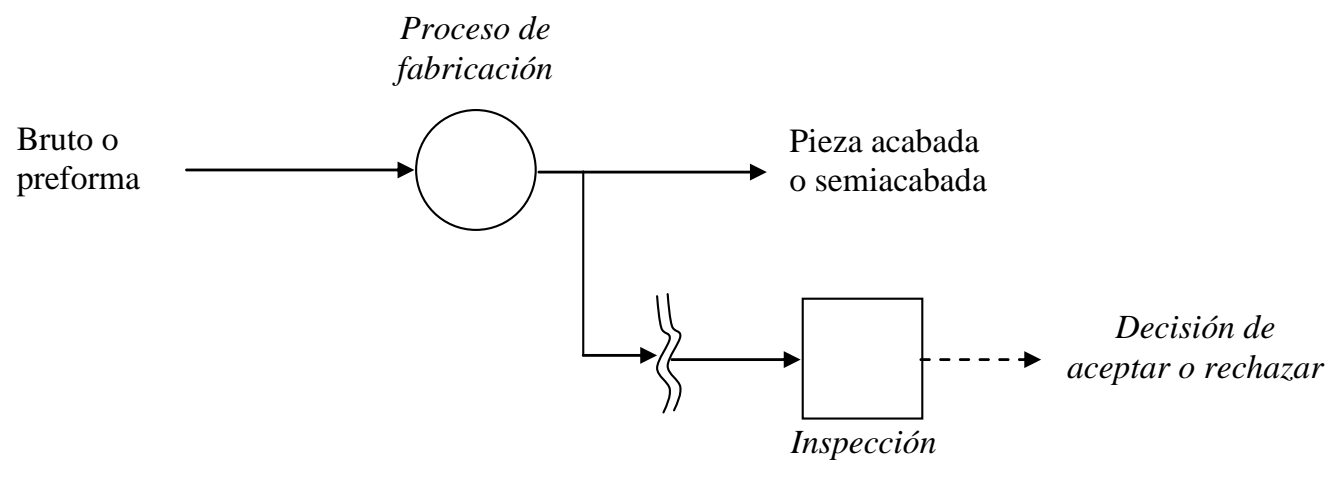

\section{INSPECCIÓN FUERA DE LÍNEA}

Figura 2.1 Inspección fuera de línea (off line inspection).

La inspección en línea, por el contrario, es aquella que se realiza durante o inmediatamente después de operaciones de fabricación, pudiendo intercalar operaciones de medición y toma de datos entre las etapas de fabricación, con el fin de obtener información tanto sobre la conformidad de la pieza, como también sobre el estado del proceso de fabricación, realimentando al mismo para poder tomar las acciones correctivas oportunas.

La inspección en línea constituye la base para obtener la información sobre el estado y resultados de los procesos de fabricación y, por tanto, para realizar el control estadístico 
del proceso. Asimismo, proporciona la información necesaria para determinar la capacidad de los procesos, de interés para el diseñador. Adicionalmente, la inspección en línea también permite monitorizar el estado de las máquinas y equipos, información que es de utilidad para llevar a cabo el mantenimiento preventivo.

Dentro de la inspección en línea, a su vez se distinguen dos estrategias a seguir: inspección en proceso (in process inspection) o inspección post proceso (post process inspection).

La inspección en proceso (Figura 2.2) es aquella que se realiza durante una subfase de fabricación (misma máquina y sujeción de pieza), intercalando operaciones de medición y toma de datos entre las operaciones de fabricación (mecanizado), de manera que la información sobre el estado de la pieza y el proceso esté disponible casi en tiempo real y las correcciones sobre él se realicen de forma inmediata.

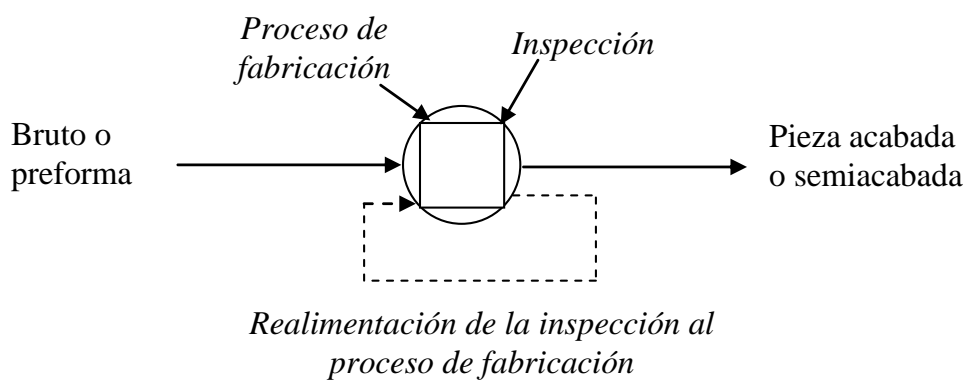

\section{INSPECCIÓN EN LÍNEA Y EN PROCESO}

Figura 2.2 Inspección en línea y en proceso (in line and in process inspection).

La inspección post proceso (Figura 2.3) es aquella que se realiza tras finalizar una fase de fabricación, acumulando todas las operaciones de medición y toma de datos al final de la fase de fabricación, de manera que la información sobre el estado de la pieza y el proceso se realimenta a la máquina u operario con un cierto retraso.

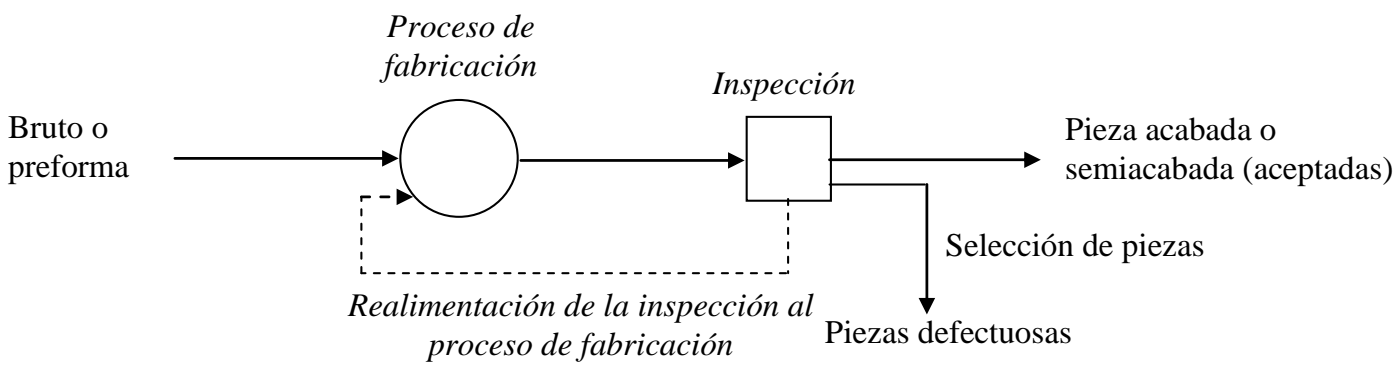

\section{INSPECCIÓN EN LÍNEA Y POST PROCESO}

Figura 2.3 Inspección en línea y post proceso (in line and post process inspection).

Adicionalmente a las estrategias de inspección descritas, cabe mencionar la inspección conocida como inspección en máquina (on machine inspection). La inspección en máquina es aquella que se realiza utilizando los propios elementos de la máquina, equipo o estación de procesado para ejecutar las operaciones de medición y toma de datos. Este método de inspección no deja de ser un tipo de inspección en línea, bien en proceso o bien post proceso. El ejemplo más extendido de este tipo de inspección con máquina es la medición llevada a cabo con sondas integradas en la máquina que se montan en el propio husillo de la misma.

La medición y toma de datos para cualquiera de las estrategias de inspección, en línea en proceso, en línea post proceso o fuera de línea, puede realizarse haciendo uso de 
diferentes tipos de instrumentos y equipos de medida, desde instrumentos de taller más sencillos, calibres pasa-no_pasa, sondas integradas en la máquina u otros métodos no convencionales.

No hay que olvidar que, al igual que la variabilidad es inherente a los procesos de fabricación, también lo es a los propios procesos de medición. Es decir, la inspección también es inherentemente variable, introduciendo siempre un cierto nivel de incertidumbre en los resultados obtenidos. Cabe recordar que esto provoca en la práctica una reducción de la zona de especificación a la hora de determinar el intervalo de aceptación [Weckenmann y Knauer, 1999].

Partiendo, por tanto, del hecho de que los procesos de fabricación son inherentemente variables y de que los de inspección también presentan un cierto nivel de variabilidad, conocida como incertidumbre, el diseñador del producto se encuentra ante el desafío de establecer límites a las especificaciones (tolerancias), teniendo en cuenta estas posibles variabilidades si se quiere realizar una asignación óptima. La determinación de las tolerancias en las especificaciones de diseño afectan en gran medida a las fases de fabricación e inspección, y a su vez estas últimas afectan también a la primera [Srinivasan, 1999]. La relación entre las especificaciones del producto, la fabricación y la inspección queda representada mediante el ciclo de control de calidad de Shewhart (Figura 2.4), que enfatiza el hecho de que la determinación de tolerancias de especificación no debería ser una actividad aislada.

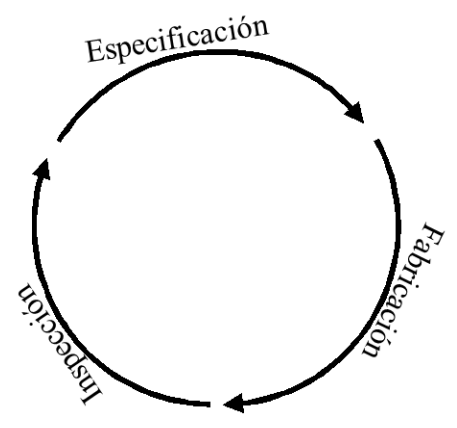

Figura 2.4 Círculo de control de la calidad de especificación, fabricación e inspección de Shewhart.

Esto ha llevado a la necesidad de tener una visión global de la variabilidad y de la asignación de tolerancias. Es imprescindible una gestión global y un enfoque sistemático para la transmisión e interpretación de la información sobre las especificaciones de producto, tomando como pilares básicos la variabilidad y la incertidumbre y utilizando como herramienta básica la estadística, que es la que permite un tratamiento adecuado de estos aspectos.

A esta visión dan respuesta muchas propuestas como las realizadas para el tratamiento estadístico de las tolerancias durante la especificación (Figura 2.5). La idea básica consiste en aplicar métodos estadísticos, que tradicionalmente se han aplicado con éxito en la fabricación y en la inspección, a las especificaciones de producto, dando lugar a especificaciones del tipo [Srinivasan, 1999]:

Estas especificaciones, en las que se incorpora la información sobre las capacidades de los procesos, facilitan el uso de la inspección en línea y en proceso con el fin de reducir o eliminar la necesidad de inspección final.

$$
\begin{array}{|l|l|l|l|lll}
\hline \oplus & \mathbf{t} & \mathrm{A}-\mathrm{B} & \mathrm{ST} & \mathrm{C}_{\mathrm{p}} \geq \mathrm{c}_{1} & \mathrm{C}_{\mathrm{pk}} \geq \mathrm{c}_{2} & \mathrm{C}_{\mathrm{c}} \geq \mathrm{c}_{3}
\end{array}
$$

Figura 2.5 Ejemplo de una posible especificación estadística de las especificaciones. 


\subsubsection{LA PLANIFICACIÓN DE LA INSPECCIÓN.}

La planificación de la inspección es la actividad responsable de asegurar que las tareas de inspección son las adecuadas, llevadas a cabo correctamente, en el momento adecuado y de forma consistente.

Es imprescindible establecer cuáles son las funciones de la planificación de la inspección, es decir, qué actividades o tareas son responsabilidad de la planificación de la inspección. En la literatura, aparecen a menudo especificadas dichas funciones. Aunque desglosadas de forma algo diferente, el conjunto de funciones propuestas por diferentes autores son muy similares. A modo de ejemplo y de forma breve, se exponen a continuación dos de ellas.

Pfeifer y Torres [Pfeifer y Torres, 1999] destacan que las tareas clásicas de la planificación de la inspección son:

Seleccionar las propiedades a controlar.

Relacionar las inspecciones a realizar con el proceso de producción.

Determinar las unidades, cantidades y frecuencias de control.

Fijar las secuencias de control de cada propiedad.

Especificar los instrumentos a emplear.

Elegir el método de control.

Determinar los instantes de control.

Especificar los documentos requeridos.

Preparar instrucciones para realizar las inspecciones.

Un enfoque algo similar es el que propone Griffith [Griffith, 2000], que destaca como elementos principales de la planificación de la inspección:

Características a inspeccionar.

Cantidad de piezas a inspeccionar.

Equipo o métodos de inspección.

Diseño del área de trabajo.

Informes de la inspección.

Coste de la inspección.

Cabe hacer notar las diferencias en los términos usados, de manera que "medir" o "control" son utilizados como sinónimos de inspección, seguramente debido a que se está pensando en una inspección de tipo geométrico.

Las referencias anteriores no son limitativas $\mathrm{y}$, por tanto, permiten considerar características o propiedades a inspeccionar no únicamente de la pieza, sino también de otros elementos participantes (utillaje, máquina, herramienta) durante la fabricación. Asimismo, la inspección puede tener cualquiera de los dos objetivos principales descritos en el apartado anterior, es decir, la evaluación de la conformidad de la pieza o la evaluación del propio proceso de fabricación para su control y mejora. Por lo tanto, se entiende que la planificación de la inspección no excluirá ninguno de los ámbitos y formas de aplicación de la inspección.

Por todo lo expuesto en el apartado anterior, la inspección en línea está, en general, ampliamente aceptada como una política de aseguramiento de la calidad más efectiva y económica. En concreto, en las empresas del tipo Empresa Virtual de Producción de Productos de Tipo Único, descritas en la introducción y en las que se enmarca el presente trabajo, la fabricación correcta a la primera es una exigencia, por lo que disponer de la información procedente de la inspección en la cantidad, calidad y formato adecuados adquiere si cabe todavía mayor importancia. Además, disponer de dicha información condiciona la eficacia y eficiencia con la que se llevan a cabo los procesos de planificación que, en un nivel supervisor y como se verá en el siguiente apartado, vinculan las 
actividades de especificación, validación y/o optimización de los procesos de mecanizado e inspección con las equivalentes pertenecientes al ámbito del producto y con las de caracterización de los recursos disponibles en la empresa desde el punto de vista de sus capacidades de precisión geométrica. Procesos estos que en el entorno de empresas del tipo Empresa Virtual de Producción de Productos de Tipo Único adquieren especial relevancia.

Estas necesidades de información han obligado a incorporar en los planes de procesos todas las operaciones de inspección (en línea, en proceso y post proceso), tanto sobre la pieza como sobre otros elementos participantes en el proceso de fabricación. Esta estrategia de potenciar la inspección en línea es la que justifica la necesidad de integrar la Planificación de los Procesos de Inspección con la Planificación de Procesos de Mecanizado (Machining and Inspection Integrated Process Planning). El desarrollo de un único plan, que contemple de forma integrada todas las operaciones de inspección y mecanizado, junto con las acciones de tratamiento de datos, toma de decisiones y, en su caso, las correctivas, es la forma de garantizar que la inspección contribuye a la calidad global de los procesos de la empresa y, por lo tanto, a la de sus productos.

\subsection{EL DESARROLLO COLABORATIVO E INTEGRADO DE PRODUCTO-PROCESO-RECURSO.}

Tal y como ya se ha mencionado en el apartado de la introducción, el Desarrollo Colaborativo de Nuevos Productos (Collaborative New Product Development, CNPD) resulta un proceso de especial relevancia para la competitividad de muchas empresas y, especialmente, en las virtuales del tipo Empresa Virtual de Producción de Productos de Tipo Único (One of a Kind Production Virtual Enterprise, OKP VE). El proceso de CNPD en OKP requiere de un elevado nivel de integración entre los diferentes subsistemas relacionados con el Diseño y Desarrollo de Productos, la Planificación de Procesos y la Programación y Control de la Producción, y la implantación de una red que permita un alto nivel de interacción entre todos los participantes para facilitar el trabajo cooperativo. Para permitir un proceso efectivo de CNPD en estos entornos, es fundamental diseñar e implantar un sistema de Planificación de Procesos Colaborativa (Collaborative Process Planning, Co-CAPP). Este sistema debe ser capaz de interaccionar con otros subsistemas del sistema de CNPD y permitir que se definan planes de proceso a través de procesos dinámicos, jerárquicos y cooperativos, inter-empresa e inter-dominio, que se establecen alrededor de la planificación de procesos. Todo un conjunto de procesos de colaboración que se integran bajo el concepto de Desarrollo Colaborativo e Integrado de Producto, Proceso y Recurso (Collaborative and Integrated Development of Product, Process and Resource, CIDP²R) [González et ál., 2009; Romero et ál., 2009].

De esta forma se pretenden alcanzar unos niveles de colaboración (cooperación) no presentes en los prototipos de sistemas de planificación de procesos colaborativos publicados en trabajos recientes, que generalmente se basan en la división y distribución de tareas y su comunicación utilizando técnicas para la gestión de proyectos colaborativos y/o flujos de trabajo centrados en documentos [Siller at ál., 2008]. En contraste, Co-CAPP impulsa la cooperación en la planificación, que es entendida como una colaboración para promover las relaciones interpersonales en el grupo de trabajo participante en el proceso CIDP $^{2}$ R. Co-CAPP hace esto utilizando la manipulación interactiva y los mecanismos de discusión y negociación sobre una representación del plan de procesos que permite alternativas (Plan de Procesos No Lineal, PPNL) y que se construye de manera incremental. Este enfoque está bastante bien desarrollado en el campo de las aplicaciones CAD (Computer Aided Design / Diseño Asistido por Ordenador), pero es incipiente en la 
planificación de la producción [Li et ál., 2006]. Los sistemas de Co-Diseño notables son los que usan elementos característicos y/o representaciones de ensambles, y por ello facilitan la integración de estos sistemas colaborativos con Co-CAPP, que también adopta este tipo de representación del producto.

Antes de continuar con la descripción del sistema Co-CAPP, es necesario hacer una breve referencia al proceso $\mathrm{CIDP}^{2} \mathrm{R}$ mencionado y a las categorías de integración que en él se consideran, con el fin de entender la necesidad del sistema Co-CAPP. El proceso $\mathrm{CIDP}^{2} \mathrm{R}$ considera, por un lado, la integración vertical dividida en tres niveles que hacen referencia al dominio: el Desarrollo de la Ingeniería, la Planificación de los Procesos y la Configuración y Asignación de los Recursos. Por otro lado, el proceso CIDP ${ }^{2} \mathrm{R}$ considera la integración horizontal dividida en tres niveles que hacen referencia al detalle alcanzado en el desarrollo en cada uno de los dominios anteriores: Agregado, Supervisor y Operacional. Asimismo, el proceso CIDP $^{2} \mathrm{R}$ está apoyado por una actividad de gestión que programa y controla las diferentes tareas y determina las necesidades de infraestructura (información/conocimiento, grupos de trabajo y roles, sistema de información). En el presente trabajo, el foco se centrará en la Planificación de Procesos, pero siempre considerando las interacciones con el resto de dominios de $\mathrm{CIDP}^{2} \mathrm{R}$.

Co-CAPP es un sistema integrado y colaborativo diseñado para ocupar un papel central en la integración jerárquica entre el Diseño y Desarrollo de Productos y la Programación y Control de la Producción, cuyo objetivo es definir PPNL representados como una red global [Rosado et ál., 2009; González et ál., 2009]. Esta red, que se establece sobre los tres niveles de agregación mencionados, se construye de forma incremental y cooperativa adoptando diferentes estrategias. De este modo los diferentes planificadores y especialistas en fabricación/inspección participantes en el equipo de trabajo llevan a cabo diferentes acciones de acuerdo con los permisos y asignaciones establecidas por el gestor del proyecto. No hay que olvidar que, tal y como también queda patente del apartado anterior, en este trabajo se plantea una planificación integrada de la fabricación y de la inspección, considerando las operaciones y recursos de ambas y con el objetivo de generar un único PPNL integrado.

El sistema Co-CAPP está constituido por tres módulos que llevan a cabo la gestión del proceso de CNPD [Rosado et ál., 2009]. En primer lugar, se encuentra el módulo del Desarrollo de la Ingeniería (para Fabricación) encargado de asegurar la fabricabilidad de la pieza, utilizando el mapa de asociación entre los elementos característicos de forma y los elementos característicos funcionales de precisión con los procesos y recursos de fabricación e inspección con las capacidades requeridas que están disponibles en el intervalo de tiempo de la fabricación de la pieza. En segundo lugar, se encuentra el módulo de la Planificación de Procesos encargado de especificar la red global de planes de proceso (producto-proceso-recurso), resultado de un procedimiento dinámico para desarrollar gradualmente los detalles del plan en diferentes fases y pasos. En tercer y último lugar, se encuentra el módulo de la Configuración y Asignación de Recursos encargado de asegurar que la asignación de recursos individuales o configuraciones de recursos se lleva a cabo teniendo en cuenta sus capacidades, disponibilidad, limitaciones logísticas y las políticas de asignación de recursos establecidas en el acuerdo de la OKP VE.

Por otra parte, las tres etapas de la Planificación de Procesos en Co-CAPP son: agregada, supervisora y operacional [Maropoulos et ál., 2006; Wang et ál., 2006]. A continuación, se describen brevemente los objetivos de cada una de estas etapas y sus interacciones con las fases equivalentes del Desarrollo de la Ingeniería (para Fabricación) y la Configuración y Asignación de Recursos (Figura 2.6).

La Planificación Agregada establece el macro-plan para la fabricación e inspección de la pieza, y representa el primer nivel de la red global de nodos y relaciones que será 
detallada en las siguientes etapas. Los nodos básicos, que representan los procesos agregados o meta-procesos (por ejemplo, fundición, mecanizado, tratamiento térmico, etc.), se asocian, por una parte, con los nodos del árbol de elementos característicos de forma $\mathrm{y}$ de especificaciones dimensionales y geométricas en el nivel de pieza correspondientes a este nivel; y, por otra parte, también se asocian con los nodos del árbol de recursos agregados para formar una red global en este primer nivel. Sobre cualquiera de las relaciones entre los nodos, se establecerán restricciones que permiten definir las posibles alternativas del PPNL en el nivel de los meta-procesos (por ejemplo, podría ser una restricción sobre la relación entre dos nodos que representan dos meta-procesos y que hace referencia a la secuencia en la cual deben ejecutarse estos meta-procesos en lo que se ha venido a denominar red o cadena de procesos [Blanch, 2011]).

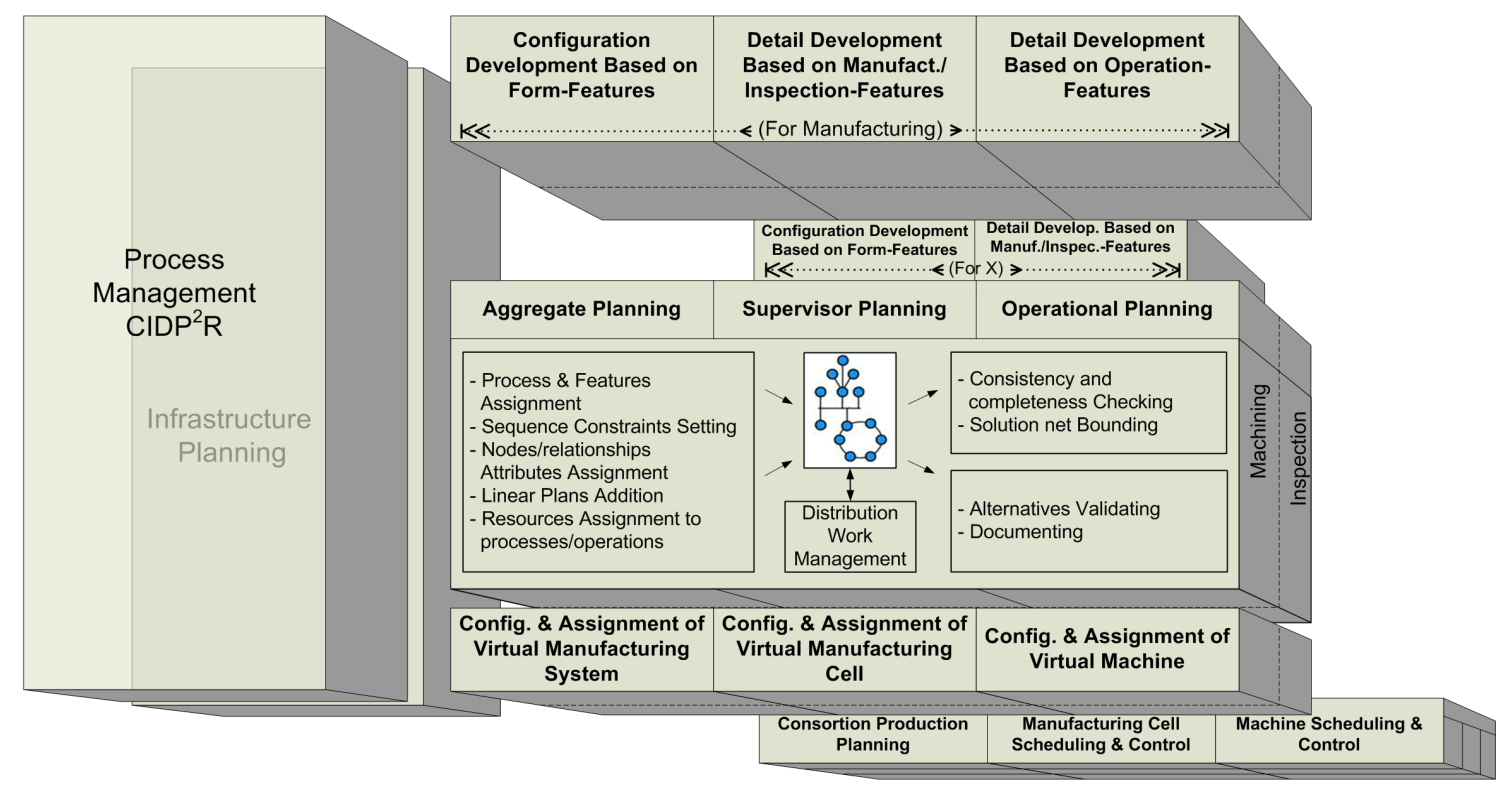

Figura 2.6 Arquitectura funcional del proceso CIDP² R [Rosado et ál., 2009].

En la actividad de Desarrollo de la Configuración es donde se establece el árbol de elementos característicos de forma y de especificaciones dimensionales y geométricas. Este árbol de elementos característicos representa el diseño preliminar del sistema, tanto a nivel de conjunto/subconjunto como de sus partes, vinculando aquellas superficies de las piezas que mantienen relaciones funcionales o de montaje. Este árbol describe la geometría de la pieza y la información asociada en un nivel agregado y para que se pueda llevar a cabo el análisis de la viabilidad de la fabricación y la inspección en este nivel de metaproceso. Del mismo modo, en la actividad de Asignación y Configuración del Sistema de Fabricación Virtual se establece un árbol de recursos agregados, que describe las configuraciones alternativas de células o grupos de máquinas virtuales que tienen las capacidades necesarias para llevar a cabo uno o más meta-procesos. Estas células o grupos virtuales, que están formados por recursos pertenecientes a diferentes empresas, se configuran con un proceso de negociación y de toma de decisiones consensuadas entre las empresas del consorcio. Esta última actividad tiene una estrecha relación con las actividades de Planificación de la Producción (materiales, recursos y órdenes) en el nivel del consorcio y, a su vez, interacciona con las partes correspondientes de cada una de las compañías participantes. La cooperación establecida alrededor de esta actividad permite diseñar las alternativas de configuraciones de recursos que pueden asignarse a los metaprocesos de manera que se adapten a las circunstancias de producción de las empresas en un periodo de tiempo determinado. 
En la Planificación Supervisora los nodos del nivel agregado de fabricación e inspección se disgregan en más nodos que representan los subprocesos (por ejemplo, planeado, medición con máquina de medida por coordenadas (MMC), etc.) de los metaprocesos y estos se asocian, de la misma forma, con los nodos de los árboles que representan los recursos (máquinas con sus tipos de utillajes y herramientas) y a la pieza (elementos característicos de mecanizado e inspección) para detallar la red global en este nivel supervisor. Asimismo, el árbol de nodos también puede ampliarse al definir la pieza bajo diferentes puntos de vista o al asignar varios procesos alternativos a un mismo elemento característico. Del mismo modo que en la etapa anterior, sobre las relaciones entre los nodos en este nivel se establecen restricciones que determinan las posibles alternativas de hojas de procesos, describiendo las secuencias de operaciones que pueden lanzarse y que tienen la información necesaria para la supervisión en un nivel de célula virtual.

En la Planificación Operacional, cada una de las operaciones (un proceso con una máquina, un utillaje y una herramienta concretas) identificadas en el nivel supervisor se asocia a uno o más pasos de trabajo (working-step) alternativos (de acuerdo al estándar STEP-NC, ISO14649). Hay que recordar que un paso de trabajo es una operación con un utillaje y una herramienta concretas asignadas. Este conjunto de pasos de trabajo correspondientes a una operación se asocian a un único elemento característico (elemento característico operacional).

Tal y como se puede ver en la parte central de la Figura 2.6, el grupo de funcionalidades proporcionadas por Co-CAPP para la Planificación de Procesos es común a las tres fases y se ha diseñado para ser utilizado en procedimientos de trabajo que implican la cooperación de personas. Esta orientación general de Co-CAPP, y específicamente de muchas de las funcionalidades del módulo de Planificación de Procesos, es compatible con el uso de funcionalidades expertas y/o de optimización incluidas en sistemas de Planificación de Procesos Asistida por Ordenador (Computer Aided Process Planning, CAPP).

En concreto, en la Figura 2.6 pueden distinguirse cuatro grupos de funcionalidades en este módulo, que serán proporcionadas a cualquier participante en el proceso de CoPlanificación de acuerdo con los permisos establecidos por el gestor del proyecto. El primer grupo de funcionalidades permiten la construcción incremental de la estructura básica de nodos (elementos característicos, procesos y recursos) de la red global o de una de sus partes (subredes), a través de acciones aditivas llevadas a cabo por funciones de asignación. La posibilidad de construir subredes independientemente para su posterior integración en la red global, es un mecanismo que facilita la ejecución de un trabajo distribuido coordinado. Sobre las relaciones existentes entre nodos individuales y/o grupos de nodos (grupos de nodos del mismo tipo y nivel) de la estructura básica pueden establecerse las restricciones de secuencia. La posibilidad de realizar agrupaciones de nodos se ha incluido para facilitar la expresión de restricciones, como por ejemplo las impuestas por ciertas especificaciones dimensionales y geométricas y que llevan al planificador a agrupar ciertos elementos característicos para mecanizarlos en la misma subfase. De la misma forma, también pueden asignarse a las relaciones y redes de nodos los atributos de coste, calidad, tiempo, etc., lo que permitirá posteriormente las comparaciones hechas entre alternativas con el objetivo de descartar las menos apropiadas de acuerdo a los criterios de optimización seleccionados. Asimismo, para permitir que planes (completos o parciales) lineales, completamente caracterizados y contrastados se puedan incorporar a la red global, el sistema también incluye la funcionalidad de adición de plan lineal. 
El segundo grupo de funcionalidades están destinadas a comprobar la consistencia y completitud de la red global de PPNL obtenida utilizando las funcionalidades descritas anteriormente. Dicha red global debe ser comprobada para determinar si cumple todas las reglas definidas para asegurar la consistencia tecnológica de las combinaciones elemento característico-proceso-recurso representadas y la existencia de al menos una solución que permita la fabricación e inspección completa de la pieza. Asimismo, en este grupo se incluye la funcionalidad que permite el descarte de algunas soluciones para obtener una red de PPNL seleccionados.

El tercer grupo de funcionalidades tienen como objetivo fundamental la validación de algunos de los planes seleccionados (alternativas) para comprobar el cumplimiento de ciertos requisitos (coste, tiempo, tolerancias, etc.), así como la generación de toda la documentación necesaria. En particular, la funcionalidad vinculada al tratamiento de la de la variabilidad (cumplimiento de tolerancias de especificación e incertidumbres de inspección) será objeto de una atención preferente, tanto en el modelo funcional de actividades del siguiente punto como en los modelos de producto desarrollados en los capítulos 5 y 6 .

Por último, se contempla un cuarto grupo de funcionalidades encargadas de la gestión, como por ejemplo: dividir el problema en partes (subredes), distribuir y planificar el trabajo requerido por estas partes, coordinar su ejecución, gestionar la estructura de PPNL, etc.

Aunque una primera lectura del marco desarrollado pueda hacer pensar que solo es válido para la planificación de procesos de fabricación (por ejemplo, mecanizado), un acercamiento en mayor profundidad permite visualizar que se trata de un enfoque genérico que considera la inspección como un proceso más. Con la adopción de este enfoque es posible abordar una planificación integrada de fabricación e inspección.

Cabe hacer notar que durante la descripción del sistema Co-CAPP se ha hecho referencia a los elementos característicos (feature), entendidos como aquellos elementos que, además de la geometría, incorporan información y conocimiento específico y útil para los razonamientos propios de un ámbito concreto. Este concepto y la adecuación de los enfoques basados en elementos característicos para entornos de desarrollo colaborativo serán objeto de estudio del capítulo 4 y constituirá una de las bases importantes para las propuestas desarrolladas en esta tesis. Asimismo, y tal y como se verá en el siguiente apartado, también se hace referencia a los elementos característicos, y más concretamente a los del ámbito de la inspección, a lo largo de la descripción de las actividades del modelo funcional propuesto en el siguiente apartado para la Planificación Supervisora de Procesos de Fabricación e Inspección.

\subsection{Modelo funcional para la Planificación SUPERVISORA DE LA INSPECCIÓN.}

A partir de los conceptos y consideraciones sobre la inspección establecidas en el apartado 2 , y una vez descrito el proceso $\mathrm{CIDP}^{2} \mathrm{R}$ y el sistema Co-CAPP en el apartado anterior, que constituyen el marco en el que se desarrolla esta propuesta, en este apartado se describirá el modelo funcional propuesto para la planificación supervisora de los procesos de inspección integrada con la planificación de procesos de mecanizado del mismo nivel. Como para la elaboración del modelo se hará uso de la técnica de modelado IDEF0, en primer lugar se incluye un breve resumen de la misma. A continuación, se expondrá la estructura general y organización jerárquica del modelo funcional propuesto, para posteriormente describir las 
principales actividades y finalizar estableciendo las necesidades principales de información y modelos que las sustentan.

\subsubsection{TÉCNICA DE MODELADO IDEF0.}

IDEF0 pertenece a una familia de técnicas de modelado llamada IDEF (Integrated DEFinition for function modeling) desarrollada con el objetivo de modelar decisiones, acciones y actividades de una organización o sistema. IDEF0 está basada en la técnica SADT (Structured Analysis and Design Technique / Técnica de Análisis y Diseño Estrucuturados) y comenzó a desarrollarse a mediados de 1970 por la Fuerza Aérea de los Estados Unidos dentro de un programa que dio lugar a la arquitectura ICAM (Integrated Computer-Aided Manufacturing / Fabricación Asistida por Ordenador Integrada, parte II, volumen IV). Además de IDEF0, cuyo objetivo es el modelado funcional, la familia IDEF posee otras técnicas: IDEF1 para el modelado de información, IDEF1X para modelos de datos tipo entidad-relación, IDEF3 para el modelado de flujos de proceso y estados de objeto, IDEF4 para modelado orientado a objeto e IDEF5 para la descripción de ontologías [http://www.idef.com/].

\subsubsection{SINTAXIS Y SEMÁNTICA.}

La sintaxis de un lenguaje define todos los componentes estructurales que se utilizan y la relación entre ellos. Los componentes básicos de la sintaxis de IDEF0 son las cajas, las flechas, las reglas y los diagramas. Las cajas representan funciones, definidas como actividades, procesos o transformaciones. Las flechas representan la información u objetos relacionados con las funciones. Las reglas definen cómo deben usarse los componentes y, finalmente, los diagramas proporcionan el formato para desarrollar verbal y gráficamente los modelos.

La semántica define el significado de cada componente, ayudando a su correcta utilización e interpretación. Las cajas representan las funciones y cada una tiene un nombre, que describe lo que hace la función, y un número, que identifica su nivel jerárquico (Figura 2.7). A esta caja hay flechas de entrada por la parte izquierda, que representan las entradas (materiales, información, etc.), que serán transformadas o consumidas y darán lugar a las flechas de salida por la parte derecha, que representan las salidas resultado de la función.

En la parte superior se muestran los controles de la función de la caja, que representan las condiciones requeridas para que la función dé lugar a las salidas correctas. En la parte inferior, las flechas de entrada representan los mecanismos necesarios para realizar la función (recursos físicos y humanos). Las flechas que salen por la parte inferior de la función representan llamadas y se utilizan cuando una función está desarrollada con más detalle en otro diagrama, permitiendo compartir detalles entre modelos o partes de un mismo modelo.

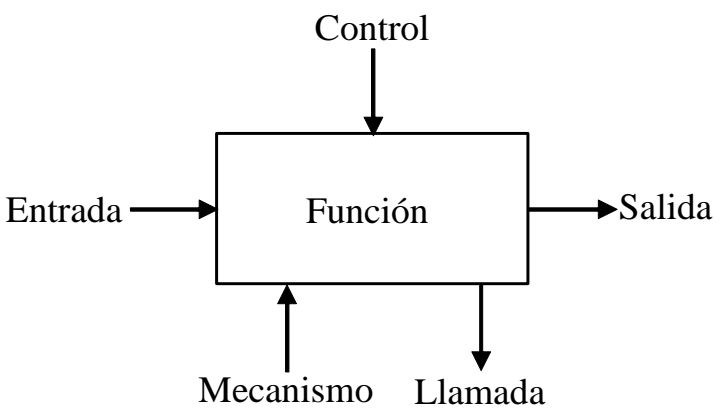

Figura 2.7 Esquema general y elementos principales de los diagramas IDEFO. 


\subsubsection{DIAGRAMAS IDEF0.}

Los modelos IDEF0 están compuestos de tres tipos de información: diagramas gráficos, texto y glosario. La técnica IDEF0 permite la descomposición de los diagramas gráficos para llegar a un mayor nivel de detalle (Figura 2.8). Partiendo del diagrama de contexto (nivel más agregado), se pueden ir desplegando los siguientes subniveles, estableciéndose así una jerarquía.

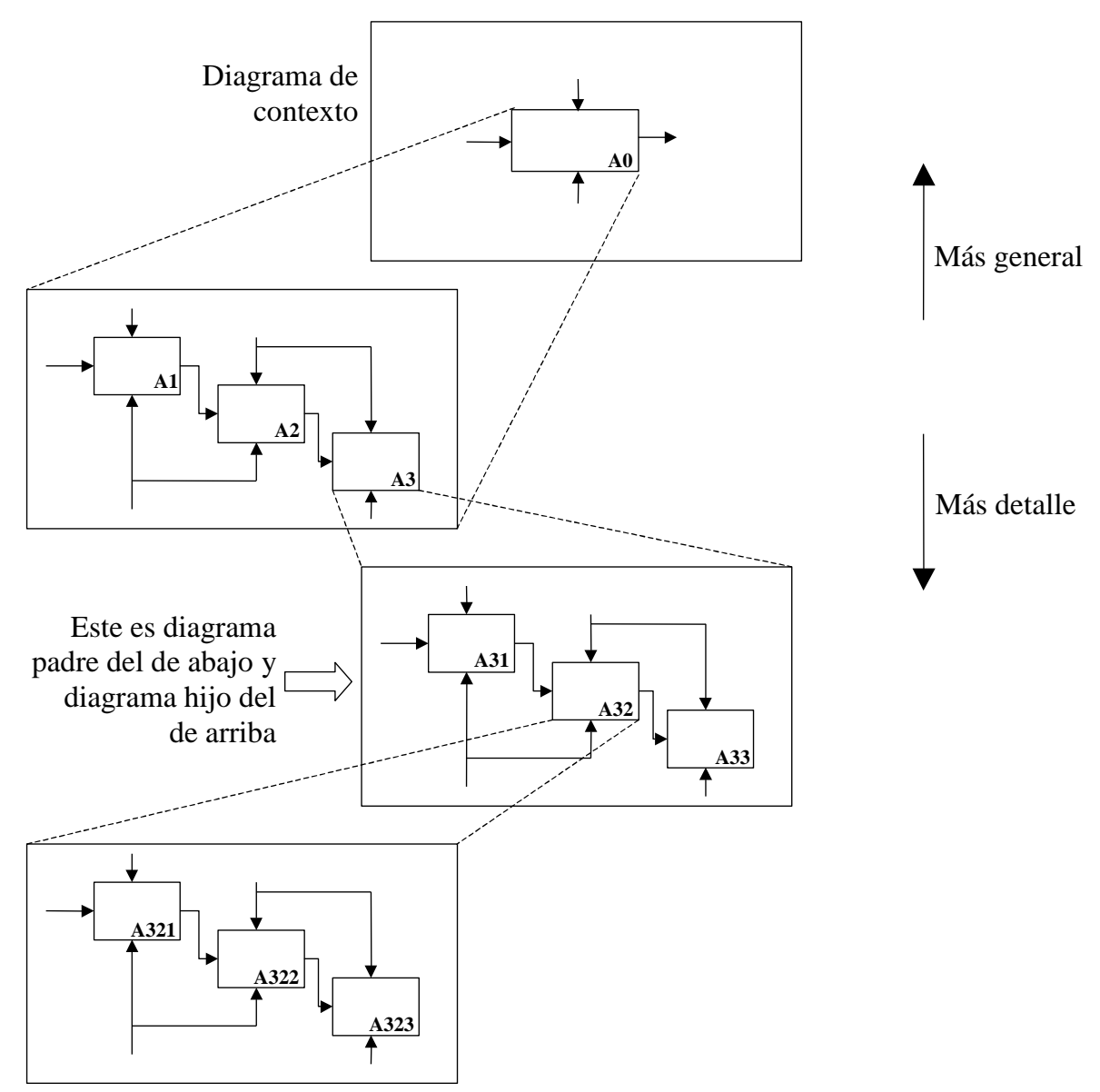

Figura 2.8 Jerarquía de los diagramas IDEFO.

Un diagrama gráfico puede tener asociado un texto, que proporciona una descripción general y concisa del diagrama. Asimismo, también se puede asociar a un diagrama gráfico un glosario, en el que se pueden definir acrónimos o palabras o frases clave utilizadas en los diagramas y que ayuden a su correcta interpretación.

El objetivo de este punto no ha sido realizar una explicación exhaustiva de la técnica IDEF0, sino únicamente llevar a cabo una breve descripción de los conceptos que se han considerado más importantes. Para mayor información sobre la técnica IDEF0 se puede consultar: http://www.idef.com/pdf/idef0.pdf.

Con estas nociones básicas sobre la técnica IDEF0, se pasa a describir el modelo funcional propuesto.

\subsubsection{ESTRUCTURA DEL MODELO FUNCIONAL PROPUESTO.}

En este subapartado se describe la estructura general del modelo funcional propuesto para realizar la planificación supervisora de procesos de inspección según el marco del proceso $\mathrm{CIDP}^{2} \mathrm{R}$ y como una vista particular de una planificación integrada de los procesos de mecanizado e inspección. 
Para ello, y en base a la técnica de modelado IDEF0, en primer lugar se presenta el diagrama de contexto para el modelo funcional, que en este caso corresponde a la actividad A0-Realizar la planificación supervisora de procesos de fabricación e inspección. Sin embargo, existen relaciones entre esta función de planificar la inspección de una pieza y otras funciones involucradas en el desarrollo integrado de producto-proceso-recurso. En previsión de ello y con el objetivo de proporcionar una exposición más completa del contexto del modelo, IDEF0 permite utilizar los denominados diagramas de contexto de alto nivel. La representación en el diagrama de nodos de estos niveles se hace utilizando una numeración del tipo A-n (donde - es un signo menos y $\mathrm{n}$ es mayor que cero). Estos diagramas de más alto nivel tienen como objetivo ayudar a la contextualización y determinación de los límites del modelo, y su utilidad es a nivel formal. La generación del diagrama de nodos es similar, con la única diferencia de tener una numeración negativa, excepto la actividad A0 que se mantiene como el origen del modelo desarrollado. Para el caso del presente trabajo, el diagrama de nodos con numeración negativa se muestra en la Figura 2.9.

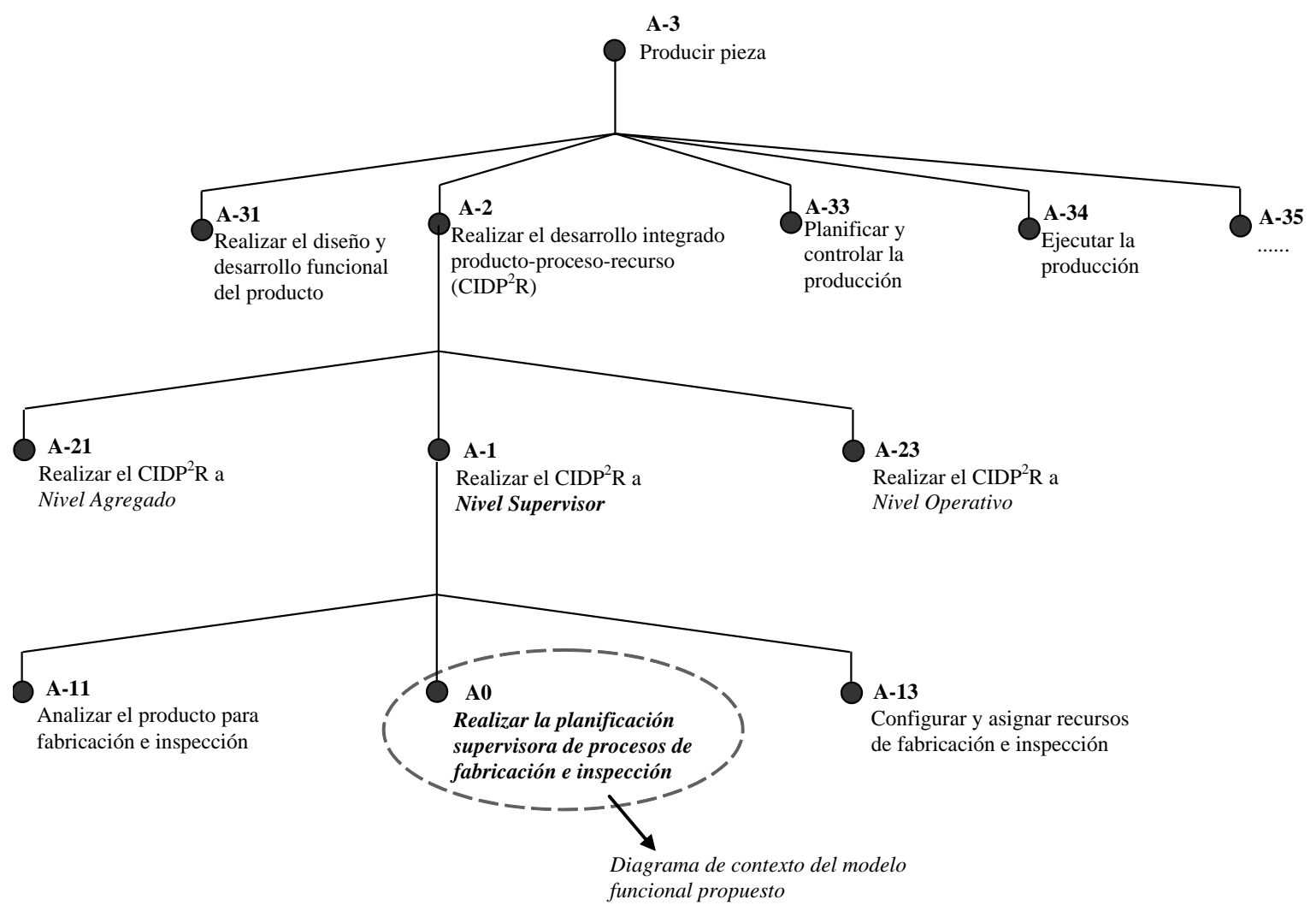

Figura 2.9 Diagrama de nodos de mayor nivel con numeración negativa.

Como puede observarse, la actividad A0 o diagrama de contexto contempla la realización de la planificación integrada de los procesos de fabricación (mecanizado) e inspección a nivel supervisor. En este punto conviene mencionar que, si bien el diagrama de contexto tiene en cuenta la planificación integrada de procesos de fabricación e inspección, las actividades que se desarrollan en mayor detalle, y tal y como se verá más adelante, son las que corresponden con aquellas vinculadas al punto de vista de la planificación supervisora de la inspección. Una vista similar, paralela, podría realizarse para la planificación supervisora del mecanizado.

Una vez establecidos el diagrama de contexto y el diagrama de nodos de mayor nivel, a continuación en la Figura 2.10 se muestra la organización jerárquica del modelo funcional propuesto identificando los niveles con sus nodos y numeración. 


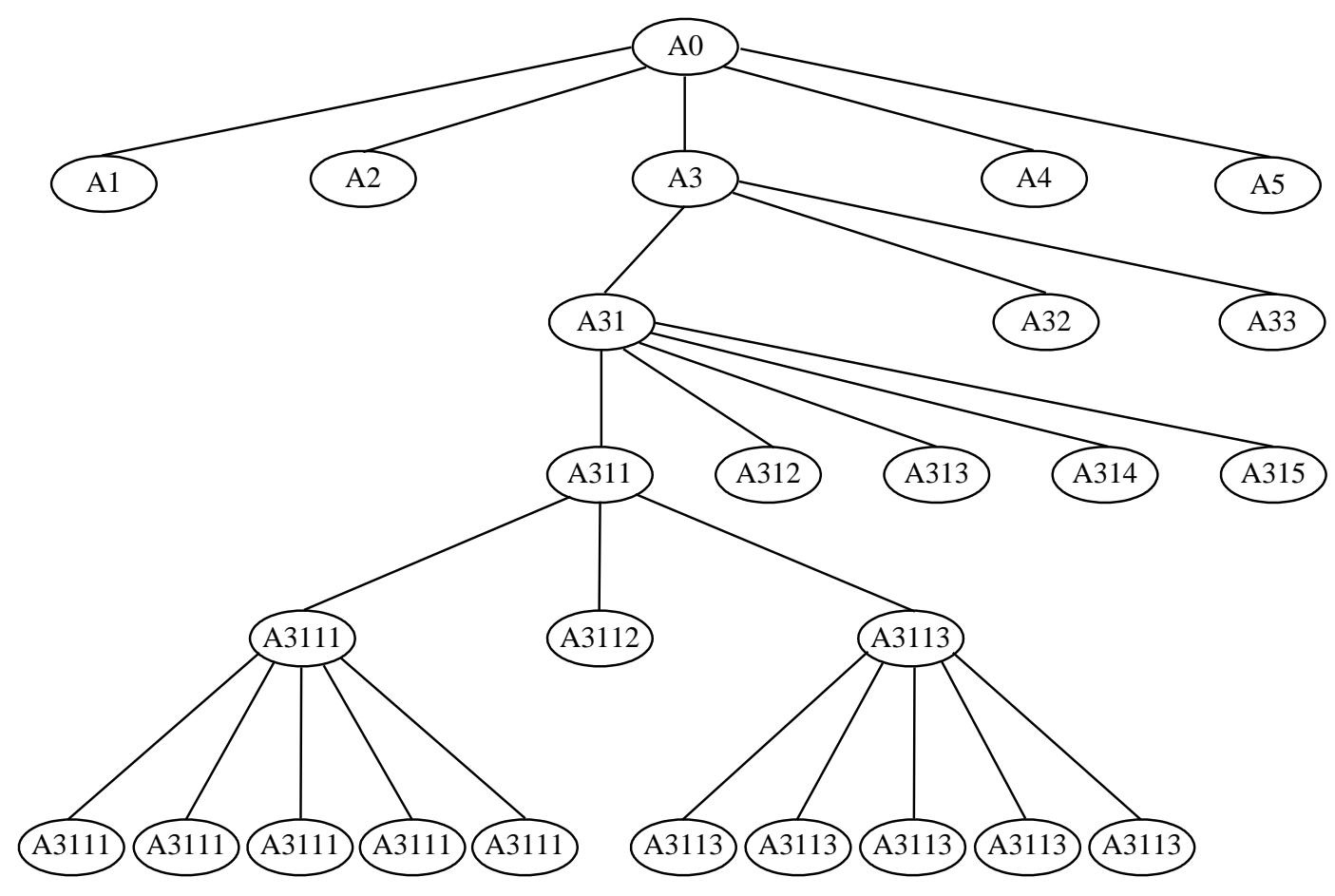

Figura 2.10 Organización jerárquica de los diagramas IDEFO del modelo funcional propuesto.

La denominación de todas las funciones del modelo funcional propuesto es la siguiente:

A0 Realizar la planificación supervisora de procesos de fabricación e inspección.

A1 Preparar la estructura del Plan de Procesos No Lineal (PPNL).

A2 Realizar la planificación supervisora del mecanizado.

A3 Realizar la planificación supervisora de la inspección.

A31 Desarrollar la planificación supervisora de la inspección.

A311 Definir elementos característicos, procesos tipo y recursos de inspección.

A3111 Definir la pieza en base a elementos característicos de inspección (ECI).

A31111 Extraer y recuperar la información geométrica.

A31112 Identificar la geometría que participa en cadenas funcionales.

A31113 Interpretar la pieza en base a ECI.

A31114 Comprobar la consistencia.

A31115 Seleccionar los ECI y crear la estructura.

A3112 Seleccionar los posibles procesos de medición tipo.

A3113 Seleccionar los posibles recursos de inspección.

A31131 Seleccionar posibles recursos de inspección por naturaleza de la medida.

A31132 Seleccionar posibles recursos de inspección por rango de la medida.

A31133 Seleccionar posibles recursos de inspección por acceso.

A31134 Seleccionar posibles recursos de inspección por incertidumbre.

A31135 Seleccionar posibles recursos de inspección y añadir a la estructura. 
A312 Asignar atributos a nodos y relaciones.

A313 Realizar agrupaciones de elementos característicos.

A314 Establecer restricciones a la secuencia.

A315 Comprobar y validar alternativas.

A32 Integrar mecanizado e inspección.

A33 Validar alternativas conjuntas de mecanizado e inspección.

A4 Comprobar y validar alternativas globales.

A5 Generar y preparar la documentación.

De este conjunto de actividades, la A3 es la actividad central. Se trata de una actividad que se realizaría, salvo en el caso de que se tratara de una inspección fuera de línea, tras y/o simultáneamente a la actividad A2, encargada de realizar la planificación supervisora del mecanizado. Los pasos a seguir en esta actividad A2 para el mecanizado serían similares a los establecidos en la actividad A3, exceptuando las actividades A32 y A33 cuyo objetivo es la integración y validación del mecanizado y la inspección.

\subsubsection{DESCRIPCIÓN DE LAS ACTIVIDADES DEL MODELO FUNCIONAL PROPUESTO.}

Una vez expuesto el esquema general del modelo funcional, a continuación se pasa a describir las actividades principales de la planificación de la inspección geométrica de una pieza.

Para el desarrollo de las actividades del modelo funcional, se han tenido en cuenta los aspectos que definen la propuesta del sistema Co-CAPP [González et ál., 2009; Romero et ál., 2009; Rosado et ál., 2009], así como otros trabajos previos [Pfeifer et ál., 2002; Bruscas et ál., 2007]. Asimismo, existen en la literatura otras propuestas realizadas para la planificación de la inspección utilizando modelos IDEF0, sin embargo muchas de ellas están centradas en el caso de la utilización de MMC [Lin y Lin, 2000; Lin y Chow, 2001; Barreiro et ál., 2003] o la medición mediante sonda en máquina [ISO10303-219, 2007] y para la inspección final. También cabe mencionar los trabajos de Zhao et ál. [Zhao et ál., 2009; Zhao et ál., 2011] en los que se incluyen propuestas de diagramas IDEF0 de definición del proceso de inspección con el fin último de lograr mayor interoperabilidad e integración entre los sistemas de metrología dimensional y los procesos de definición del producto y del proceso de fabricación.

La propuesta aquí presentada, a diferencia de las anteriores, plantea un enfoque conjunto e integrado de la planificación supervisora de procesos de mecanizado e inspección dentro del marco del proceso de CNPD. Tal y como se ha mencionado anteriormente, las actividades que se desarrollan en mayor detalle son las vinculadas al ámbito de la planificación supervisora de la inspección. Las actividades de la planificación supervisora del proceso de mecanizado, que no son objeto de desarrollo, se realizarían de forma paralela y similar a las de inspección, incluyendo así: las posibles interpretaciones de la pieza en base a elementos característicos de mecanizado; la selección de los posibles procesos tipo de mecanizado que permiten eliminar los volúmenes de material que generan las diferentes geometrías; la selección de los posibles recursos concretos de mecanizado en base a criterios de rango de trabajo, acceso de la herramienta, variabilidad del proceso, etc.; la asignación de atributos (tiempo, coste, etc.) a los nodos y relaciones entre ellos; las posibles agrupaciones de elementos característicos para generar subfases y secuencias; el establecimiento de restricciones a las secuencias; y la comprobación y validación de alternativas. Además, el modelo presentado contempla e impulsa la consideración de la inspección en línea, frente a los trabajos anteriores que están más bien centrados en una planificación de la inspección fuera de línea. También cabe mencionar que en la presente 
propuesta los recursos de inspección considerados no están limitados a las MMC o a la medición mediante sonda en máquina, incluyendo así también todo tipo de instrumentos de medición más sencillos, montajes específicos para realizar diferentes tipos de verificaciones, etc.

La Figura 2.11 muestra el primer nivel o diagrama de contexto para el modelo funcional propuesto y, por lo tanto, consta de una única función A0-Realizar la planificación supervisora de procesos de fabricación e inspección. El objetivo de esta actividad es obtener un plan de procesos no lineal (PPNL) para la fabricación e inspección geométrica de piezas esencialmente mecanizadas. La entrada básica a la función es la red (o cadena) de procesos no lineal procedente de la planificación a nivel agregado anterior. Mediante la planificación supervisora de procesos se obtendrá un plan de procesos integrado de fabricación y de inspección no lineal.

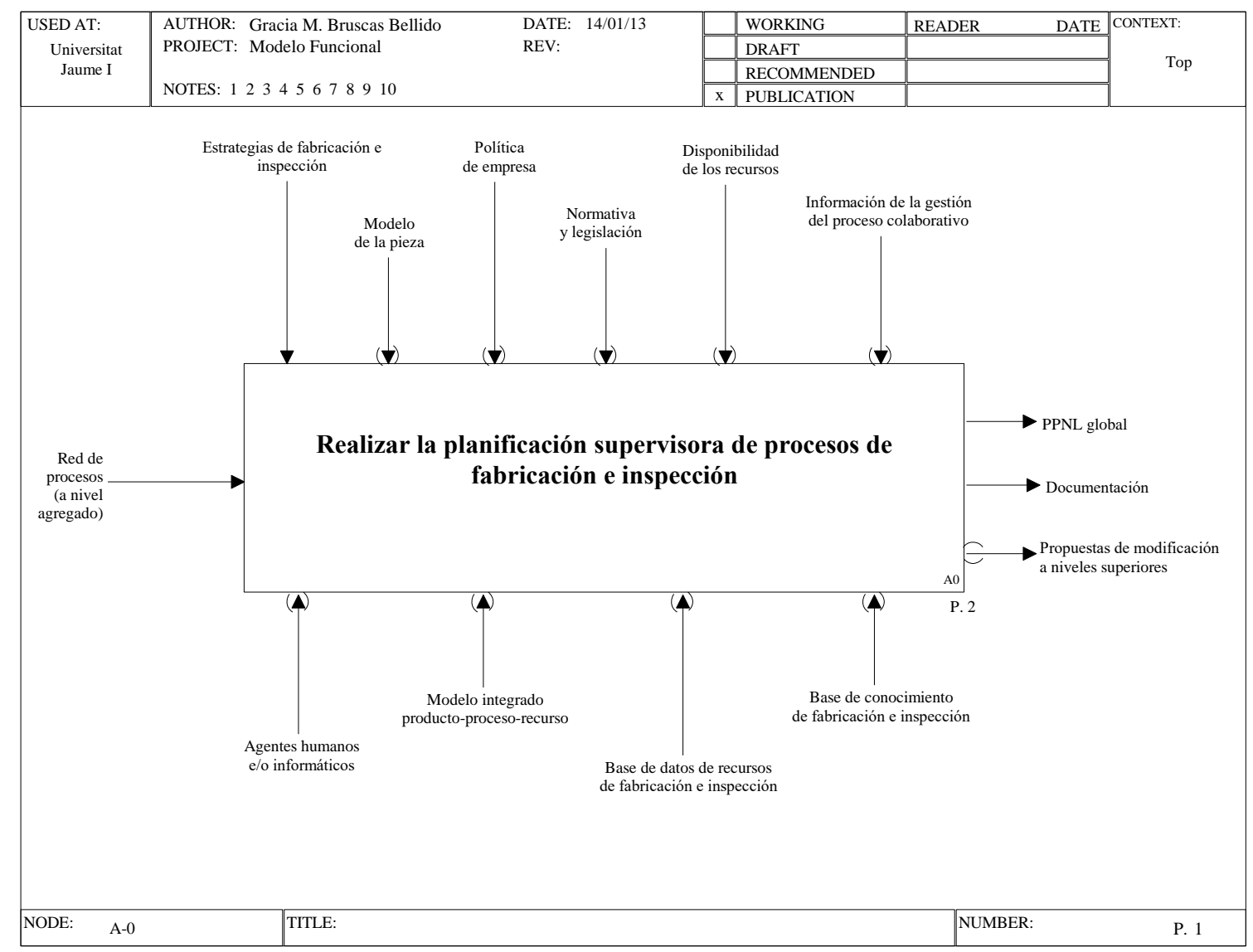

Figura 2.11 Diagrama de contexto del modelo funcional propuesto para la planificación de la inspección geométrica de una pieza.

Hay que recordar que un PPNL constituye un conjunto de alternativas válidas para la ejecución de la fabricación y de la inspección de una pieza y se representa como un árbol de nodos (elementos característicos, procesos, recursos, etc.), sobre el que se establecen unas relaciones, formando una red. Las ramas y las restricciones establecidas en las relaciones entre los nodos definen las posibles alternativas.

Adicionalmente, como resultado de la actividad A0 también se obtendrá toda la documentación necesaria que dé soporte al PPNL y un conjunto de propuestas de modificación y mejora del diseño que realimentan a otras etapas del proceso $\mathrm{CIDP}^{2} \mathrm{R}$ descrito en el apartado 2.3 de este capítulo, tanto en el sentido vertical, por ejemplo a la etapa de Desarrollo de la Ingeniería, como en sentido horizontal, a la etapa de Planificación Agregada. Cabe mencionar que, aunque en la actividad A-11-Analizar el producto para 
fabricación e inspección (Figura 2.9 del diagrama de nodos de mayor nivel con numeración negativa) ya se han podido realizar actividades destinadas a analizar la maquinabilidad e inspeccionabilidad de la pieza, cuando se realiza la planificación supervisora pueden surgir nuevas cuestiones que hagan necesaria una realimentación y/o modificación del diseño.

Los controles más importantes de esta actividad son las estrategias de fabricación e inspección establecidas como contexto para desarrollar la planificación supervisora y el modelo de la pieza, que incluye toda la información sobre la misma según diferentes formatos (planos, modelos 3D, anotaciones, etc.). Este modelo de la pieza y toda la información asociada, resultado de la actividad A-31-Realizar el diseño y desarrollo funcional del producto (Figura 2.9 del diagrama de nodos de mayor nivel con numeración negativa), puede incluir en este nivel supervisor, y tal y como se ha mencionado anteriormente, el análisis y eventuales modificaciones resultado de llevar a cabo la actividad A-11-Analizar el producto para fabricación e inspección. El resto de controles de la función incluyen aspectos tales como las políticas de la empresa y, más concretamente, las relacionadas con la calidad y la inspección, que también restringirán la función. Del mismo modo, toda la normativa y legislación existentes y de aplicación en la planificación de la inspección también deberán tenerse en cuenta. Dentro del modelo de CNPD descrito en el apartado 2.3 de este capítulo, y en el cual se enmarca la propuesta, se incluyen todo un conjunto de actividades de gestión del proceso colaborativo que condicionarán, por tanto, la forma de ejecutar estas actividades de carácter técnico. Por último, de especial importancia a la hora de realizar la planificación de la inspección es conocer la disponibilidad de los recursos, tanto de fabricación como de inspección, que es una información procedente de la actividad A-33-Planificar y controlar la producción (Figura 2.9 del diagrama de nodos de mayor nivel con numeración negativa) y que condiciona la realización de esta actividad.

En lo que respecta a los mecanismos necesarios para realizar esta actividad, se pueden destacar tanto el conocimiento, experiencia y "saber hacer" de las personas implicadas en la actividad, como las bases de conocimiento de los sistemas que eventualmente se utilicen en esta función. También es esencial disponer de bases de datos que contengan toda la información necesaria sobre los recursos de fabricación e inspección disponibles y sus capacidades tecnológicas. Finalmente, otro de los mecanismos indispensables para el mejor desarrollo de la planificación supervisora de forma integrada, es disponer de un modelo de información integrado de producto-proceso-recurso que permita soportar toda la estructura del PPNL.

El nivel de contexto de la planificación supervisora de los procesos de fabricación e inspección de una pieza se desglosa en cinco funciones principales (Figura 2.12): preparar la estructura del PPNL; realizar la planificación supervisora del mecanizado; realizar la planificación supervisora de la inspección; comprobar y validar alternativas globales; y generar y preparar la documentación.

La actividad Al-Preparar la estructura del PPNL es la encargada de realizar una primera transformación o adaptación del macroplan de procesos (red de PPNL agregado o cadena de meta-procesos) procedente del nivel anterior, para generar un primer nivel de la estructura del PPNL supervisor. De esta forma, se obtiene el PPNL inicial, que contiene los elementos característicos, los meta-procesos y los recursos a nivel agregado, a los que posteriormente, y de forma incremental, se vincularán otros elementos pertenecientes al nivel supervisor (elementos característicos, procesos y recursos de mecanizado e inspección correspondientes al nivel supervisor). Aunque algunas veces la entrada será una única cadena (plan lineal) de macro-procesos de mecanizado e inspección, extraído de 
entre las diferentes opciones que contempla la red de PPNL, se mantiene la posibilidad de que la entrada sea el conjunto total o parcial de alternativas contempladas a nivel agregado.

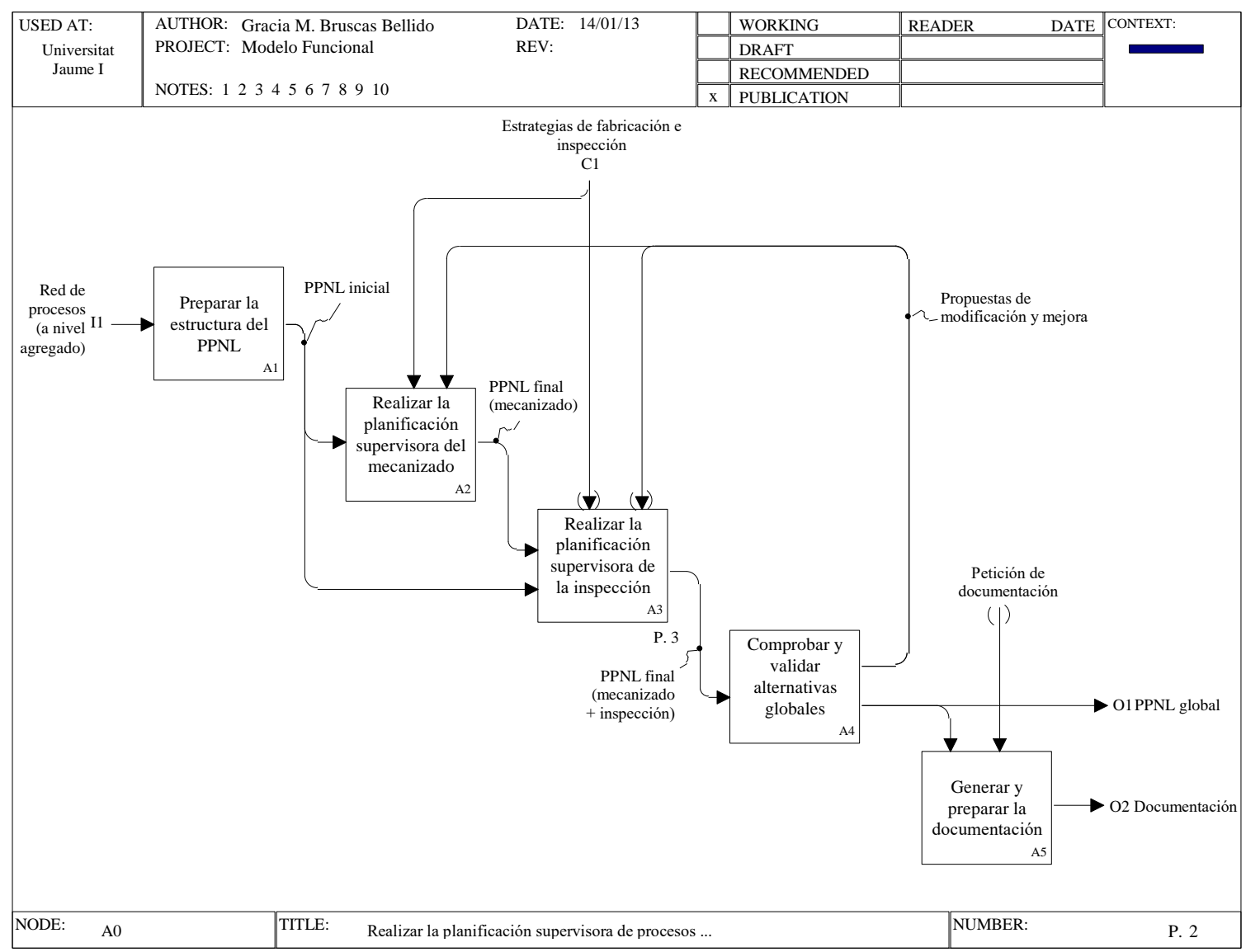

Figura 2.12 Descomposición de la actividad A0-Realizar la planificación supervisora de procesos de fabricación e inspección.

Con este PPNL inicial ya se puede comenzar la planificación supervisora propiamente dicha, tanto del mecanizado como, en su caso, de la inspección. Hay que destacar que el enfoque de la presente propuesta se basa en una planificación integrada de la fabricación y de la inspección. Por ello, actividades que tradicionalmente se plantean para ser desarrolladas de forma secuencial, pueden aquí comenzarse y llevarse a cabo en paralelo. Además, tal y como se ha explicado en el punto 2.3 , el proceso $\mathrm{CIDP}^{2} \mathrm{R}$ contempla un módulo de gestión, cuyas salidas controlan la ejecución de todas las actividades de la planificación supervisora, según lo expuesto al explicar el nivel A0. Este módulo de gestión programa y controla todas las tareas del proceso $\mathrm{CIDP}^{2} \mathrm{R}$ determinando las necesidades de información y conocimiento, gestionando los eventuales grupos de trabajo, dando los permisos correspondientes para que ciertas actividades o parte de ellas puedan comenzar, etc., y dando por tanto soporte a un desarrollo integrado y colaborativo del proceso.

La condición para la realización de la planificación supervisora de la inspección, actividad A3-Realizar la planificación supervisora de la inspección, vendrá dada por uno de los dos siguientes supuestos: a) que se esté ante una situación de inspección fuera de línea y, por lo tanto, independiente del avance y estado de la planificación de procesos de mecanizado; o b) que se vaya a abordar una planificación integrada de fabricación e inspección impulsando una inspección en línea, para lo que entonces es necesario que también comience la actividad A2-Realizar la planificación supervisora del mecanizado, en la que partiendo del PPNL inicial, se empezará a generar un PPNL de la parte de 
mecanizado. En cualquiera de los dos casos, en la actividad A3-Realizar la planificación supervisora de la inspección se obtiene el PPNL final que integra tanto el mecanizado como la inspección de la pieza.

Tras desarrollar el PPNL final a nivel supervisor, que integra mecanizado e inspección, es necesario llevar a acabo la actividad A4-Comprobar y validar alternativas globales. Se trata de una actividad que tiene como objetivo realizar todas aquellas comprobaciones que permitan garantizar la validez del PPNL final. En caso de encontrar alguna inconsistencia o falta de completitud, esta información debe realimentar a las etapas anteriores, que realizarán las modificaciones oportunas que finalmente permitan obtener un PPNL globalmente válido.

Finalmente, en la actividad A5-Generar y preparar la documentación, y ante la eventual petición de la misma, se procedería a generar todos los documentos necesarios, que en los diferentes formatos requeridos, describan la información contenida en el PPNL global.

Teniendo en cuenta que la atención preferente de la tesis es la inspección, solo se desglosará la actividad A3-Realizar la planificación supervisora de la inspección, cuya descomposición se muestra en la Figura 2.13. Esta actividad se descompone en tres actividades: desarrollar la planificación supervisora de la inspección; integrar mecanizado e inspección; y validar alternativas conjuntas de mecanizado e inspección.

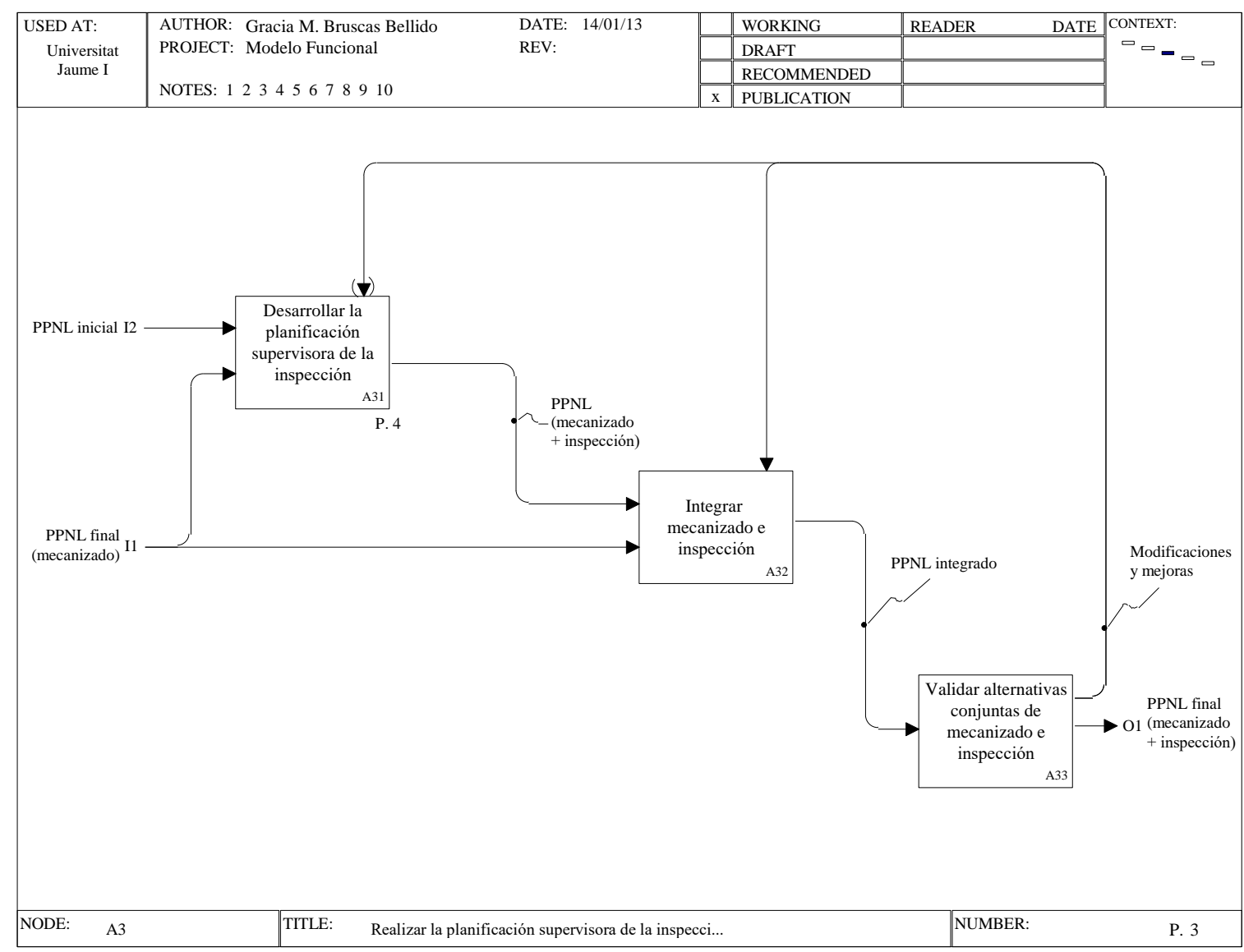

Figura 2.13 Descomposición de la actividad A3-Realizar la planificación supervisora de la inspección.

El PPNL inicial y/o el PPNL final de mecanizado son las entradas a la actividad A31Desarrollar la planificación supervisora de la inspección, el resultado de la cual es el PPNL de inspección integrado en la estructura del PPNL entrante. Para llevar a cabo esta actividad, y tal y como se ha explicado anteriormente, habrá que tener en cuenta cuál es la situación de la que se parte, es decir, si se trata de inspección fuera de línea o de inspección 
en línea. En este segundo caso, se posibilita la integración de las operaciones de inspección entre las operaciones de mecanizado con el fin de poder llevar a cabo dicha inspección en línea (post proceso o en proceso). Para la determinación de alternativas de inspección se tendrán en cuenta restricciones tales como que la inspección de una determinada geometría no puede llevarse a cabo hasta que el elemento característico de mecanizado que contiene esa geometría no esté finalizado. Asimismo, de esta manera también se puede considerar la inspección de geometrías intermedias durante la fabricación de la pieza, cuyo resultado puede incluso llevar a modificaciones en el PPNL para añadir operaciones adicionales de mecanizado, y/o de corrección y ajuste de las condiciones en las que se efectúa el mecanizado (localización pieza, trayectoria herramienta, parámetros de corte, etc.).

El PPNL de inspección y el PPNL de mecanizado son la entrada de la actividad A32Integrar mecanizado e inspección. En el supuesto en el que se trate de una inspección fuera de línea, el PPNL final de mecanizado también es una entrada, a la cual simplemente se añade el PPNL de inspección (fuera de línea). Pero en el caso de que se trate de una inspección en línea, la entrada del PPNL de inspección ya tiene integrada la parte correspondiente al mecanizado. En cualquiera de los dos casos, es necesaria esta actividad A32 en la que, además de integrar no linealmente, se extraen alternativas y se comprueba la consistencia y completitud de las mismas, además de limitar el número de ellas descartando aquellas soluciones que resulten inadecuadas según las circunstancias. El resultado de esta actividad, el PPNL integrado, es la entrada a la actividad A33-Validar alternativas conjuntas de mecanizado e inspección. Se trata de una actividad que tiene por objeto la validación tecnológica y la económica de cada una de las alternativas del PPNL. La viabilidad tecnológica de las mismas se podrá obtener a través de la realización de las correspondientes tareas de análisis de tolerancias, que permiten comparar la tolerancia natural del proceso integrado de mecanizado e inspección, que tiene en cuenta tanto las variabilidades de los procesos de mecanizado como las incertidumbres de los procesos de medición, con las especificaciones exigidas a la pieza. Por su parte, del mismo modo que se analizan y validan las capacidades tecnológicas de cada una de las alternativas, también se pueden realizar las correspondientes estimaciones de costes, teniendo en cuenta tanto los costes tradicionales (directos e indirectos) como los de la no calidad, y proceder a rechazar aquellas alternativas que superen los límites presupuestarios establecidos.

La Figura 2.14 ilustra la descomposición de la actividad A31-Desarrollar la planificación supervisora de la inspección. Como se puede observar, esta actividad se decompone en cinco funciones: definir elementos característicos, procesos tipo y recursos de inspección; asignar atributos a nodos y relaciones; realizar agrupaciones de elementos característicos; establecer restricciones a la secuencia; y comprobar y validar alternativas.

La actividad A311-Definir elementos característicos, procesos tipo y recursos de inspección tiene por finalidad crear la estructura básica de nodos y relaciones que corresponden a los elementos característicos que definen la pieza desde el punto de vista de la inspección o elementos característicos de inspección (ECI), los procesos de medición tipo (PMT) genéricos que permitirían inspeccionar dichos elementos característicos y los recursos de inspección concretos que tienen la capacidad para realizar esa operación de inspección. Conviene recordar que una operación de inspección está asociada a una terna formada por un elemento característico de inspección, un proceso de medición tipo y un recurso de inspección asignado (Figura 2.15). Por ello, el objeto de esta actividad es determinar las alternativas de operaciones válidas, que a su vez determinan las ramas del PPNL a nivel supervisor que derivan de cada uno de los meta-procesos de inspección existentes en el nivel agregado.

En la actividad A312-Asignar atributos a nodos y relaciones se incorporan atributos a los nodos de la estructura básica, formada por ECI, PMT y recursos de inspección 
posibles, y a las relaciones de asociación existentes entre ellos. Los atributos asignados pueden hacer referencia a aspectos de tiempo, coste y/o calidad, y resultan necesarios para posteriormente poder llevar a cabo la valoración, comparación, priorización y, en su caso, descarte de alternativas.

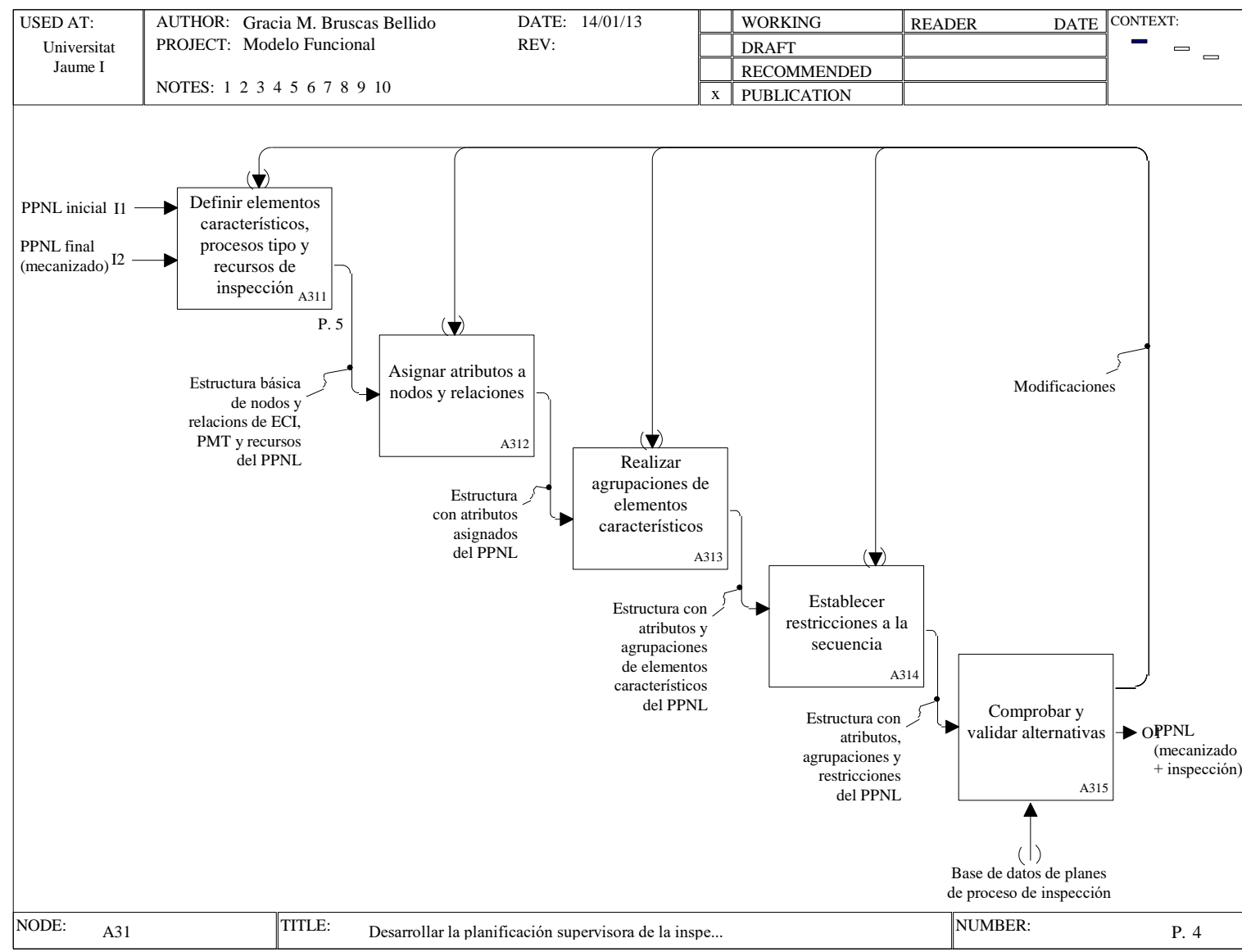

Figura 2.14 Descomposición de la actividad A31-Desarrollar la planificación supervisora de la inspección.

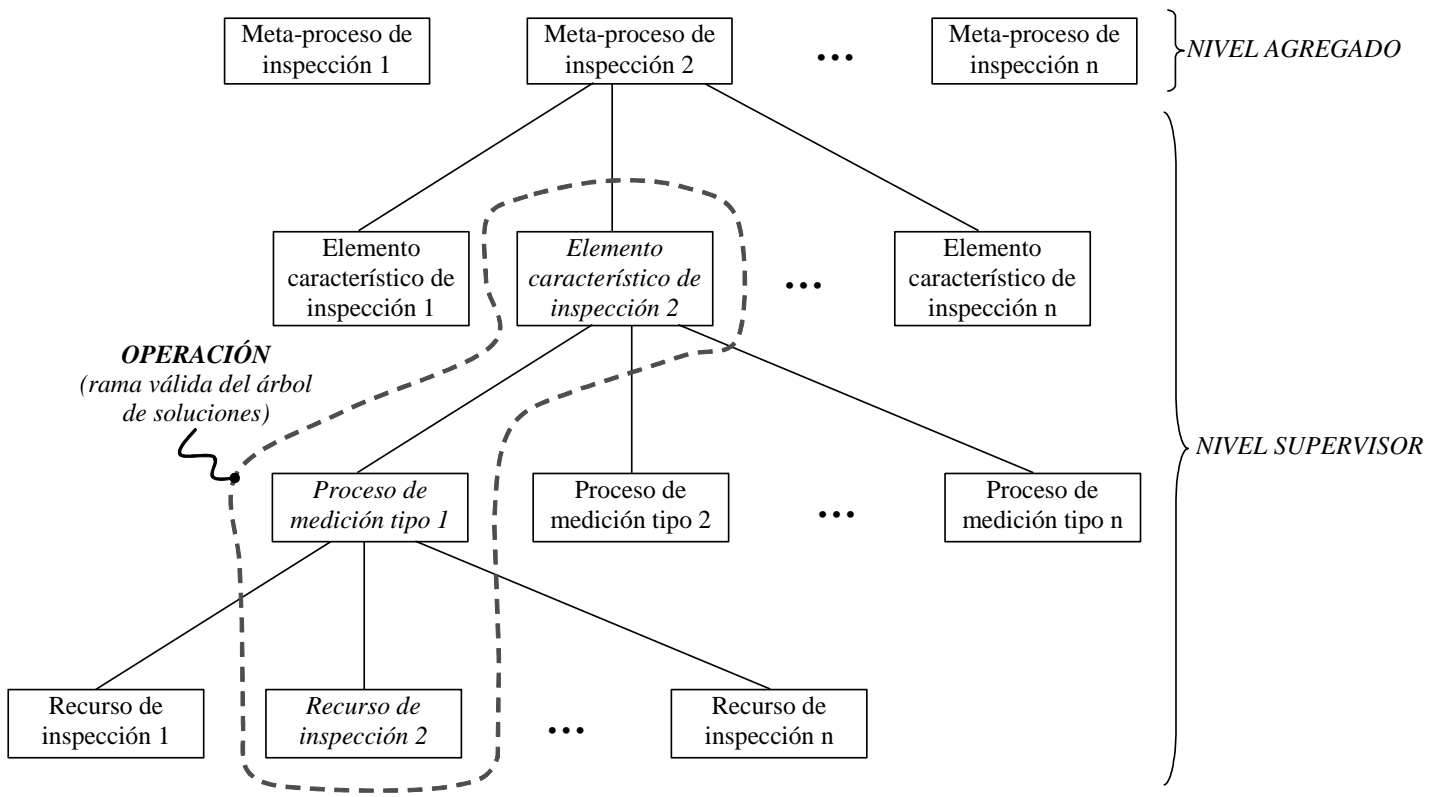

Figura 2.15 Esquema del árbol de soluciones del PPNL con señalización de una operación (rama) válida. 
A continuación, en la función A313-Realizar agrupaciones de elementos característicos, se establecen las posibles agrupaciones entre ECI que posteriormente puedan ser tratados conjuntamente a la hora de establecer posibles planes de inspección. Las agrupaciones a nivel de subfase, es decir un mismo amarre, se realizarán teniendo en cuenta las direcciones posibles de acceso para la medida por las que un ECI pueda ser inspeccionado utilizando un determinado recurso de inspección. Por lo tanto, de una misma agrupación a nivel de subfase podrán formar parte aquellos ECI que comparten un mismo tipo de PMT, recurso de inspección y dirección de acceso que son factibles para todos ellos. Cuando varias alternativas a nivel de subfase comparten, a su vez, un mismo recurso de inspección, estas pueden formar agrupaciones también a nivel de fase. En general, las mejores alternativas serán aquellas que minimizan el número de fases y de subfases, ya que supone inspeccionar todos los ECI con el mínimo número de recursos y amarres. También puede haber aspectos técnicos o productivos que aconsejen que un conjunto de ECI se ejecute en un mismo recurso de inspección, con un mismo montaje, con un mismo palpador, etc. $y$, por lo tanto, determinen fases, subfases o incluso agrupaciones de un nivel inferior a la subfase.

En la actividad A314-Establecer restricciones a la secuencia, se establecen restricciones que imponen la necesidad de respetar un determinado orden en la ejecución de los elementos característicos/operaciones y de sus posibles agrupaciones. Las restricciones pueden hacer referencia a un elemento característico individualmente o bien a un grupo de ellos, y pueden ser por imposición tecnológica o por recomendación según diferentes niveles o grados. Por ejemplo, podría establecerse que una agrupación de varios elementos característicos/operaciones debe ir necesariamente antes de una determinada operación, pero la secuencia interna entre los elementos característicos/operaciones del grupo no se impone a priori. Cabe recordar que en paralelo o previamente a todas estas actividades vinculadas a la planificación supervisora de la inspección, se han llevado a cabo las actividades equivalentes en la planificación de procesos de mecanizado. Por lo tanto, las restricciones impuestas a la secuencia de elementos característicos de mecanizado deben ser tenidas en cuenta pues influirán en la secuencia conjunta de mecanizado e inspección.

Por último, la actividad A315-Comprobar y validar alternativas se encarga de comprobar la consistencia y completitud de toda la red que representa el árbol de posibles soluciones de acuerdo a unas determinadas reglas. Una solución es completa cuando todos los ECI vinculados a las especificaciones de la pieza pueden ser inspeccionados mediante operaciones válidas. Una solución es consistente si se cumplen todas las compatibilidades entre ECI, PMT, equipos, montajes, palpadores, etc. así como entre elementos característicos de mecanizado, elementos característicos de inspección, planes, etc. Las soluciones que no sean completas o consistentes serán o bien corregidas de acuerdo a la realimentación que esta actividad haga a actividades anteriores o serán eliminadas, quedando así seleccionadas únicamente las soluciones (ramas) válidas. Además, y puesto que es posible que en la base de datos de planes de proceso de inspección exista información sobre la misma pieza o piezas similares de la familia, esta actividad también permite añadir más alternativas (ramas), que ya estarán comprobadas y validadas, al árbol de soluciones que representa el PPNL de inspección.

Como la tesis se centra en el desarrollo de modelos basados en elementos característicos válidos para la planificación de la inspección en entornos colaborativos, a continuación se detalla con mayor profundidad la actividad A311 y alguna de sus descomposiciones. En la Figura 2.16 se muestra que la actividad A321-Definir elementos característicos, procesos tipo y recursos de inspección está formada por tres funciones: 
definir la pieza en base a elementos característicos de inspección; seleccionar los posibles procesos de medición tipo; y seleccionar los posibles recursos de inspección.

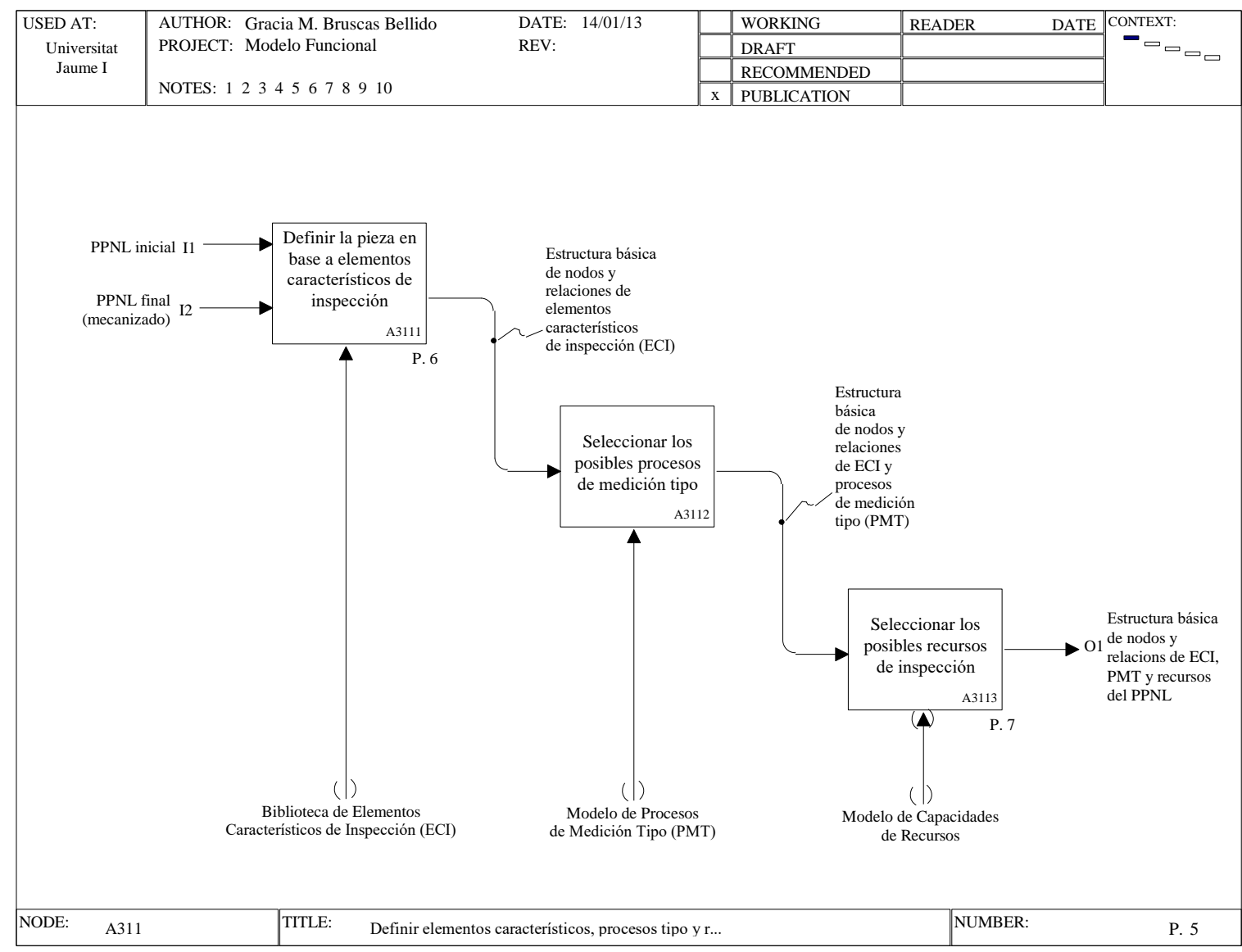

Figura 2.16 Descomposición de la actividad A311-Definir elementos característicos, procesos tipo y recursos de inspección.

La actividad A3111-Definir la pieza en base a elementos característicos de inspección genera la primera parte de la estructura básica de nodos y relaciones del nivel supervisor, definiendo la pieza en base a ECI para cada uno de los macro-procesos de inspección definidos en el nivel agregado (los macro-procesos de inspección en línea correspondientes a los diferentes macro-procesos de fabricación o a las inspecciones fuera de línea oportunas). Para llevar a cabo esta actividad, y como es habitual en los trabajos del ámbito del desarrollo integrado y colaborativo de producto-proceso-recurso, será clave la interpretación de la pieza utilizando elementos característicos que, además de la información geométrica, incluyan información útil para el razonamiento, en este caso, en el ámbito de la planificación supervisora de la inspección. Por ello, se hace necesaria la existencia de un modelo y biblioteca de ECI adecuados, que constituirán uno de los elementos fundamentales de las propuestas desarrolladas en esta tesis y que forman parte del mecanismo modelo integrado producto-proceso-recurso.

Mediante la función A3112-Seleccionar los posibles procesos de medición tipo, para cada uno de los ECI que definen la pieza se seleccionan los procesos de medición tipo factibles, vinculándolos con la estructura de nodos de elementos característicos. Para ello, será necesario establecer una taxonomía de PMT, en la que cada tipo corresponda a una familia de procesos de medición que comparten ciertas características básicas, y que será otro de los elementos importantes objeto de las propuestas elaboradas en esta tesis y que también forma parte del mecanismo modelo integrado de producto-proceso-recurso. 
Por último, la estructura básica de nodos y relaciones se completa en la actividad A3113-Seleccionar los posibles recursos de inspección, vinculando a cada PMT aquellos recursos tecnológicamente factibles para inspeccionar el ECI (teniendo en cuenta las especificaciones intrínsecas y extrínsecas que le afectan) según el modelo de Capacidades de Recursos.

Esta estructura con todos sus elementos es la que permite identificar operaciones de inspección, entendidas, tal y como se ha mencionado anteriormente (Figura 2.15), como un ECI con un PMT y un recurso de inspección factibles asignados. Un ECI puede tener varios PMT y cada par ECI-PMT varios recursos de inspección posibles, que es lo que da lugar a alternativas, constituyendo el árbol de soluciones a nivel de operaciones. Cabe recordar que el árbol de soluciones ya se ha ramificado también con las diferentes alternativas que suponen las diferentes definiciones de la propia pieza en base a ECI.

La Figura 2.17 muestra la descomposición de la actividad A3111-Definir la pieza en base a elementos característicos en cinco funciones: extraer y recuperar la información geométrica; identificar la geometría que participa en cadenas funcionales; interpretar la pieza en base a ECI; comprobar la consistencia; y seleccionar los ECI y crear la estructura.

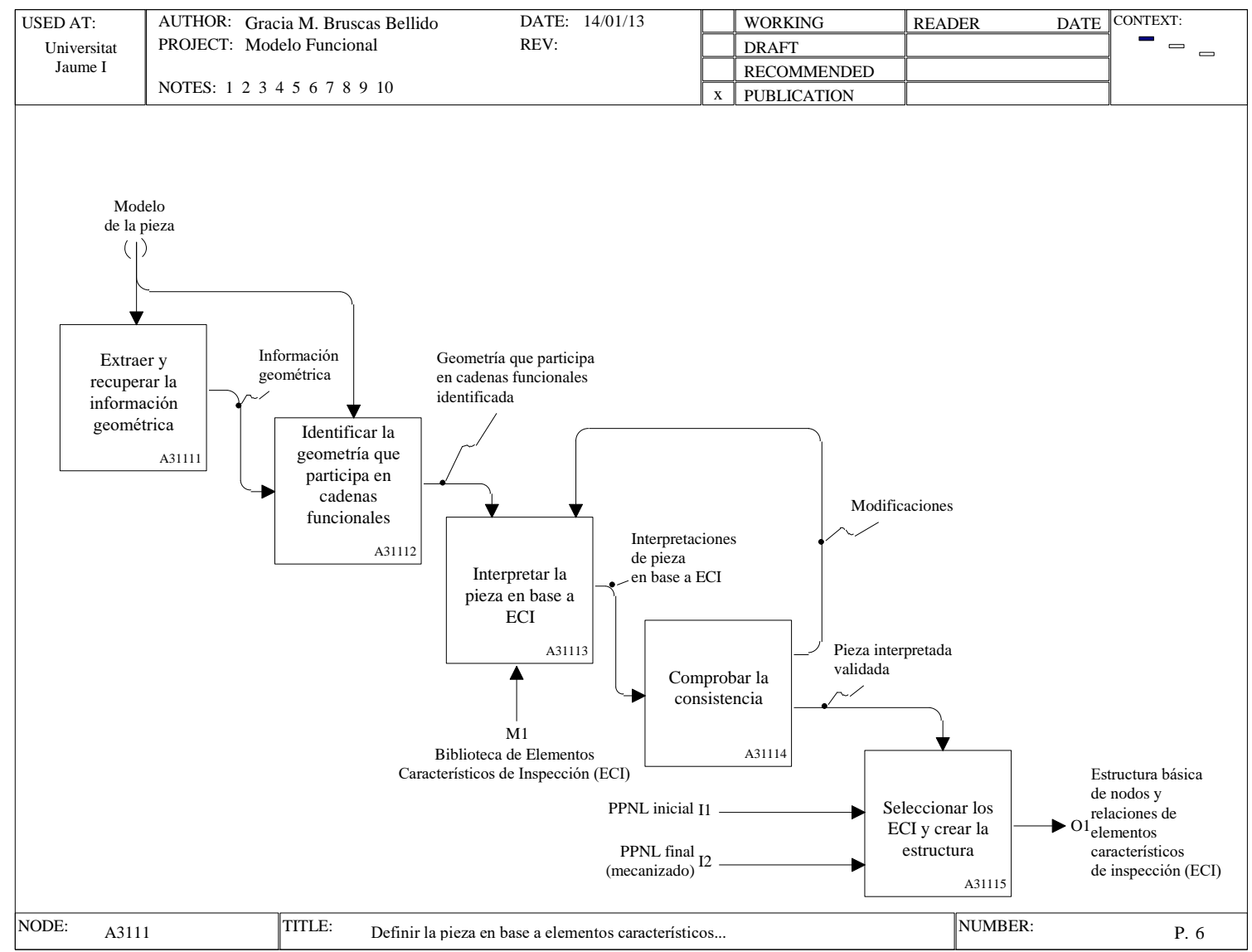

Figura 2.17 Descomposición de la actividad A3111-Definir la pieza en base a elementos característicos de inspección.

Para crear la estructura básica de nodos y relaciones de elementos característicos de inspección, es necesario llevar acabo la actividad A31111-Extraer y recuperar la información geométrica, que reconoce del modelo geométrico 3D o 2D (planos) de la pieza todos los elementos geométricos con las correspondientes anotaciones y cotas que definen la geometría de precisión de la pieza. De esta forma, se consigue representar toda la información geométrica de la pieza en el formato requerido por las actividades siguientes. 
Seguidamente, una vez recuperada la información geométrica de la pieza y a través de la actividad A31112-Identificar la geometría que participa en cadenas funcionales, se debe establecer qué elementos geométricos (ejes, planos, superficies, planos medios, etc.) de la pieza, de los extraídos anteriormente, serán objeto del plan de inspección por su importancia. Esta importancia vendrá dada por las especificaciones indicadas en los planos procedentes del diseño final, resultado del análisis funcional y del proceso de montaje del conjunto final del que forma parte la pieza. Del mismo modo, la importancia también puede venir dada por las especificaciones de los planos de fabricación resultantes de la actividad de planificar los procesos de fabricación, en la que se considerarán los montajes de la pieza durante su proceso de fabricación. Adicionalmente a las especificaciones de fabricación, también podría considerarse la necesidad de obtener información del propio proceso de fabricación con la finalidad de poder realizar un control de procesos o bien un análisis de capacidades sobre especificaciones que no vienen establecidas en los planos.

La función A31113-Interpretar la pieza en base a ECI es la encargada de obtener una representación de la pieza utilizando un conjunto de elementos característicos de inspección de una biblioteca de ECI. Tal y como ya se ha mencionado anteriormente, los ECI deben permitir asociar a la información geométrica de la pieza, información y conocimiento relevante para la planificación supervisora de la inspección. La interpretación de la pieza en base a ECI constituye una etapa fundamental para establecer los nodos básicos del plan de inspección. Para abrir lo más posible el árbol de posibles soluciones, y como ya se ha indicado, se pueden obtener diferentes interpretaciones de la pieza en base a ECI.

Una vez interpretada la pieza en base a ECI, es necesario realizar la actividad A31114-Comprobar la consistencia, en la que se revisa y verifica que el conjunto de ECI utilizados para cada una de las interpretaciones posibles de la pieza es adecuado, completo y consistente.

Teniendo como control la interpretación válida de la pieza en base a ECI se puede llevar a cabo la función A31115-Seleccionar los ECI y crear la estructura, cuyo objetivo es seleccionar qué ECI deben inspeccionarse y obtener la estructura básica de nodos y relaciones entre ellos. Para la selección de los ECI se utilizarán restricciones y limitaciones que permitan asignar un nivel de importancia o criticidad de cada elemento característico. Algunas posibles reglas o filtros aplicables para realizar la selección de qué elementos característicos de inspección se deben inspeccionar son, por ejemplo, los propuestos en los trabajos de Wong et ál. [Wong et ál., 2005; Wong et ál., 2006] que considera: las especificaciones que vienen señaladas en el plano de forma explícita; el dominio, la aplicación o ámbito específicos del producto (por ejemplo, el espesor es una característica geométrica importante en una bolsa de plástico, o el diámetro exterior es una característica geométrica importante de un pasador); el tipo de cliente o usuario al cuál va dirigido el producto; la importancia de ciertas características para la funcionalidad de la pieza; la existencia de normas y leyes de obligado cumplimiento; basándose en experiencias y resultados anteriores que señalen la necesidad de controlar alguna característica concreta; el conocimiento de la capacidad de los procesos de fabricación, que permite evitar la inspección cuando se sabe que el proceso es capaz y está bajo control o forzar la inspección en los casos en los que se conozca que el proceso puede no estar bajo control; etc.

Como puede verse en la Figura 2.18 la actividad A3113-Seleccionar los posibles recursos de inspección se descompone en cinco funciones: seleccionar posibles recursos de inspección por naturaleza de la medida; seleccionar posibles recursos de inspección por rango de la medida; seleccionar posibles recursos de inspección por acceso; seleccionar posibles recursos de inspección por incertidumbre; y seleccionar y añadir a la estructura. 
Tal y como puede observarse, las cuatro primeras funciones llevan a cabo un filtrado o preselección tecnológica de los recursos de inspección compatibles con los ECI y PMT previamente establecidos en la estructura básica de nodos y relaciones de ECI y PMT, mientras que la última función lleva a cabo la elección final que conlleva el añadirlos a la estructura básica de nodos y relaciones de ECI y PMT procedente de la etapa anterior. Los aspectos considerados para la preselección tecnológica siguen la línea de los ya considerados en otras propuestas de la literatura, como Cai et ál. [Cai et ál., 2009] y Muelaner et ál. [Muelaner et ál., 2010].

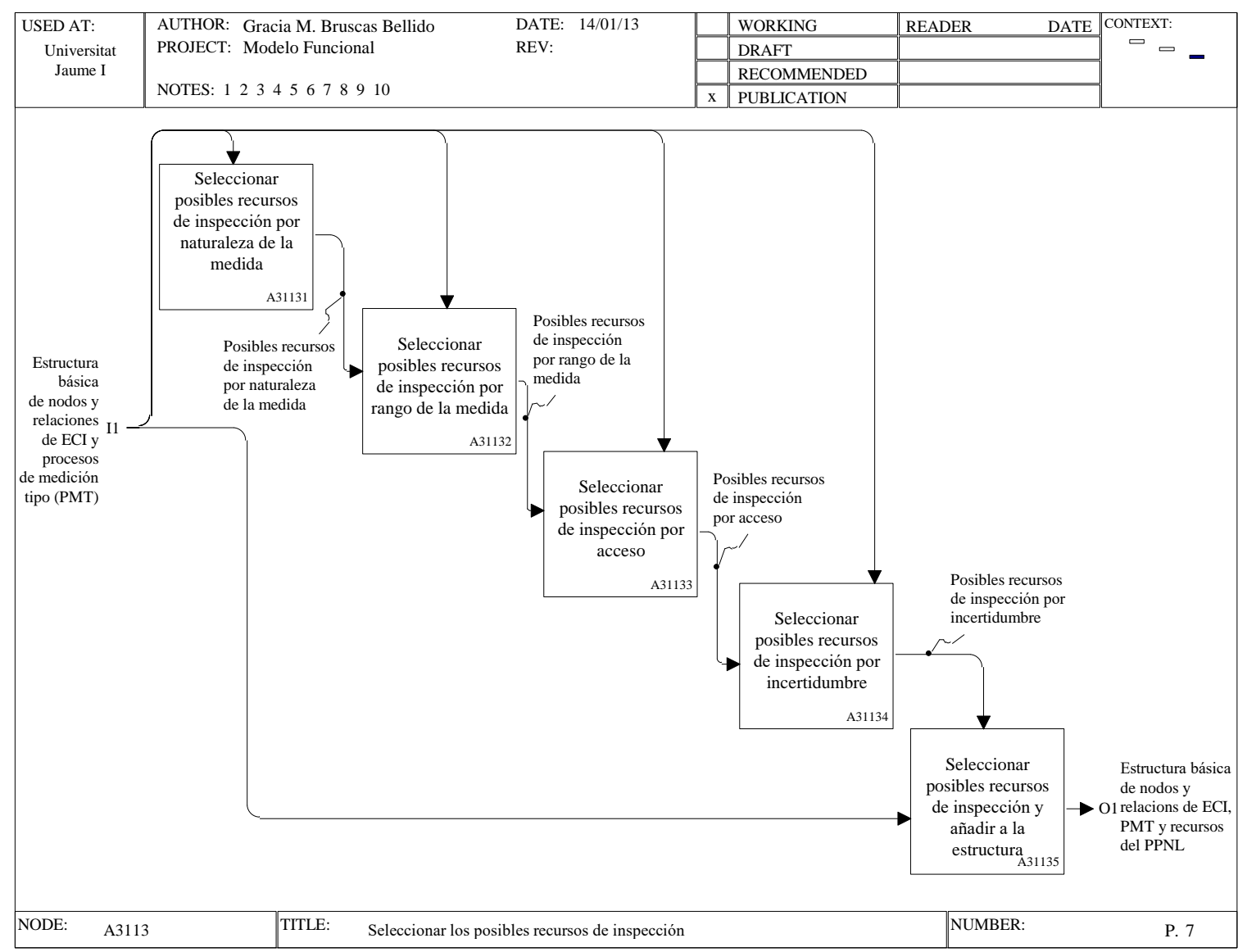

Figura 2.18 Descomposición de la actividad A3113-Seleccionar los posibles recursos de inspección.

La primera selección de posibles recursos de inspección a través de la actividad A31131-Seleccionar posibles recursos de inspección por naturaleza de la medida se basa en la capacidad de los recursos de inspección para realizar medidas de exteriores, de interiores, de profundidades u otras. A continuación, en la función A31132-Seleccionar posibles recursos de inspección por rango de medida se consideran los rangos de trabajo de los diferentes instrumentos y equipos de medida para descartar aquellos que no son válidos según los valores nominales de las especificaciones a inspeccionar y las dimensiones de la pieza. La actividad A31133-Seleccionar posibles recursos de inspección por acceso analiza las capacidades de los recursos de inspección de acuerdo a las posibles direcciones de acceso que el palpador puede utilizar para realizar la toma de datos sobre la geometría a inspeccionar. Finalmente, la última característica de los recursos de inspección considerada para esta preselección tecnológica es la incertidumbre mediante la función A31134-Seleccionar posibles recursos de inspección por incertidumbre, atendiendo a la relación con la especificación tal y como se ha explicado en el apartado 2.2.1 anterior.

Una vez completadas estas funciones, ya se tiene el conjunto de recursos de inspección tecnológicamente válidos y se pueden añadir a la estructura básica de nodos y 
relaciones de ECI y PMT, completando así la estructura básica del PPNL (actividad A31135-Seleccionar posibles recursos de inspección y añadir a la estructura).

\subsection{RESUMEN.}

En este capítulo se han revisado algunos de los principales conceptos y aspectos generales relacionados con la inspección dimensional y geométrica de producto y las tareas vinculadas a su planificación. Adicionalmente, y con el fin de establecer el marco en el que se desarrolla este trabajo, también se han presentado algunos de los fundamentos del sistema Co-CAPP, elemento esencial del proceso $\mathrm{CIDP}^{2} \mathrm{R}$, y que pone su foco en la cooperación y colaboración en las tareas de planificación de procesos, desde una perspectiva funcional.

Después de estas revisiones, se propone un modelo funcional, utilizando la técnica de modelado IDEF0, para la Planificación Supervisora conjunta de los procesos de mecanizado e inspección, con el objetivo de favorecer e impulsar la inspección en línea (en o post proceso). El resultado de la actividad "Realizar la planificación supervisora de procesos de fabricación e inspección" es un plan de procesos no lineal que contiene un conjunto de alternativas válidas para la ejecución de la fabricación y de la inspección de una pieza. El desarrollo del modelo funcional propuesto en este trabajo ha permitido corroborar que, desde una perspectiva funcional, es posible abordar una co-planificación integrada de los procesos de mecanizado y de inspección, lográndose un cierto paralelismo en ambas planificaciones de proceso.

A pesar de que el modelo funcional pone su foco de atención en la perspectiva funcional de las tareas de planificación y, por lo tanto y tal y como se ha podido apreciar, la descripción del mismo se ha centrado especialmente en las actividades con sus entradas y salidas, la elaboración del modelo funcional ha permitido poner de manifiesto la necesidad de disponer de modelos de información adecuados que den sustento a las diferentes actividades del proceso $\mathrm{CIDP}^{2} \mathrm{R}$.

Así, por ejemplo, al desglosar la actividad A311-Definir elementos característicos, procesos tipo y recursos de inspección en la que se obtiene la estructura básica del PNNL, se evidencia la necesidad de disponer de un modelo de pieza basado en elementos característicos en el que basar los razonamientos que permiten llevar a cabo la planificación de la inspección en un nivel supervisor. De la misma forma, y con el fin de poder elaborar de forma incremental el PPNL, se hace necesario disponer de un conjunto de procesos de medición tipo clasificados en familias atendiendo a algún criterio genérico que permita comenzar a ramificar el árbol de soluciones.

Por su parte, la actividad A315-Comprobar y validar alternativas, muestra la necesidad de disponer de modelos que permitan razonar sobre la idoneidad de las soluciones representadas en el PPNL. Estos modelos deberían tener en cuenta los aspectos vinculados al cumplimiento tanto de los requisitos impuestos por las necesidades de movimientos relativos que permitan la toma de datos de la pieza, como a la incertidumbre total de la opción seleccionada de acuerdo al límite impuesto por la especificación a verificar.

Pero además de estas necesidades propias del ámbito de la planificación supervisora de la inspección, no hay que olvidar que el proceso $\operatorname{CIDP}^{2} \mathrm{R}$ impone la necesidad de asegurar la consistencia entre la información utilizada en las actividades pertenecientes a los tres niveles contemplados por dicho proceso: agregado, supervisor y operacional. En concreto, en este caso son de especial importancia los requisitos impuestos por la relación entre las actividades de la Planificación de Procesos a nivel supervisor, cuyo objetivo es especificar los planes de proceso no lineales basados en elementos característicos, con las 
actividades del Desarrollo de Ingeniería a nivel agregado, cuyo objetivo es obtener un diseño preliminar del producto, visto como un ensamble de piezas, y especificar el mismo. Pero, para garantizar la consistencia entre estas actividades, las tareas realizadas en ellas deberán basarse en modelos de información que permitan una unificación entre análisis funcional y la especificación del producto y la especificación del plan de procesos de inspección, con el fin de garantizar el cumplimiento de los requisitos impuestos.

Estos modelos deberán contener información sobre todo conjunto de objetos o entidades geométricas, con propiedades que no se limiten a definir sus geometrías nominales sino también a sus defectos, y sobre las relaciones existentes entre ellos. Por ello, en el siguiente capítulo se revisarán varios aspectos vinculados con la especificación y el análisis funcional del producto, mostrando las características de los modelos de producto utilizados en las fases tempranas de diseño y las técnicas de tratamiento de las tolerancias (análisis y especificación de tolerancias). Todo ello, con el fin de valorar la posibilidad de establecer un planteamiento dual para la especificación desde el punto de vista de la verificación. 


\section{Capítulo 3}

\section{EL TRATAMIENTO DE LA}

VARIABILIDAD EN LA

\section{ESPECIFICACIÓN Y LA VERIFICACIÓN}

\subsection{INTRODUCCIÓN.}

El proceso de diseño típico [Vignat et ál., 2009] se inicia con la identificación de una necesidad, que se expresa en forma de funciones, que posteriormente se concreta en uno o varios criterios $( \pm, \leq, \geq, \ldots)$ cuantificados que se conocen como Requisitos Funcionales (RF). En ese momento es cuando ya se pueden proponer soluciones tecnológicas que cumplan con estos RF al menos en el estado nominal (óptimo). Una solución que normalmente se representa en los sistemas CAD en la forma de modelos de la geometría nominal del producto, visto como un ensamble de piezas nominales. Pero debido a las imprecisiones de los procesos de fabricación, cada pieza sufre desviaciones respecto de esta geometría nominal y ello supone una variación en el valor de cada uno de los RF, que deben ser compatibles con el margen de variación permitido por las diferentes Especificaciones Funcionales (EF) establecidas a nivel de producto (ensamble) y que posteriormente se denominarán Condiciones Funcionales. Una comprobación de la compatibilidad que normalmente se realiza a nivel de pieza, porque las EF se transfieren a cada una de las piezas y se expresan como Especificaciones de Tolerancias Funcionales (ETFU). Así, si se establecen los procesos de inspección oportunos, con unas incertidumbres de medición compatibles con las ETFU establecidas, y se asegura la conformidad de las piezas fabricadas que forman parte del ensamble con las ETFU, el cumplimiento de los RF quedará garantizado.

Pero para garantizar el cumplimiento de los RF y que el proceso de diseño sea eficiente, el diseño y los planes de procesos de fabricación e inspección asociados deben validarse. Si las posibles desviaciones de fabricación se conocen, mediante el correspondiente proceso de medición en línea, o su variabilidad se puede acotar mediante las correspondientes Especificaciones de Tolerancias de Fabricación (ETFA), es posible validar el cumplimiento de las tolerancias funcionales de las piezas (transferidas) o directamente de los propios requisitos funcionales. Además, en el primer caso también se deberá validar que con las ETFU resultantes de la transferencia cumplen los RF. Pero con 
ello no es suficiente. Si se desea que los procesos de medición no contaminen el resultado, sus desviaciones deben ser conocidas y/o acotadas mediante la correspondiente incertidumbre de medida, que como se ha indicado en el capitulo anterior debe mantener una relación con las tolerancias funcionales o de fabricación.

Como se desprende del relato de los párrafos anteriores, todas las actividades vinculadas con la gestión y el control de las desviaciones geométricas (variabilidad) en el ciclo de vida de un producto, y, en particular, las de las etapas de diseño y fabricacióninspección, deben llevarse a cabo de la forma más coherente y unívoca posible [Schleich et ál., 2014], porque de no ser así la incertidumbre del proceso se incrementa. Una forma de proceder que requiere del establecimiento de unas representaciones del producto (modelo integrado de producto-proceso-recurso) que mantengan un tratamiento coherente de las desviaciones dimensionales y geométricas y de sus efectos.

Una representación del producto que es fundamental para el desarrollo del marco del proceso $\mathrm{CIDP}^{2} \mathrm{R}$, que propugna un modelo de flujo de actividades concurrente y que potencia el uso de estrategias DFX (Design For X / Diseño para X) y que, como ya se ha apuntado en el capítulo 2, estará basada en elementos característicos. Las representaciones basadas en este enfoque tienen un impacto directo y muy positivo en el desarrollo integrado de productos y procesos, al permitir codificar y estandarizar tanto los procesos de fabricación como los métodos de medición usados por los diferentes tipos de elementos característicos, mejorando la verificación del diseño [Maropoulos y Ceglarek, 2010].

El proceso CIDP $^{2} \mathrm{R}$ parte de unas EF y de un principio de solución, definido a nivel de ensamble nominal, mediante un modelo geométrico de esqueleto y/o de sólidos basado en Elementos Característicos, y engloba todo un conjunto de actividades y técnicas vinculadas con el Diseño Robusto y el Diseño para el Ensamblaje, la Fabricación y la Inspección (Design For Assembly, DFA; Design For Manufacturing, DFM; Design For Inspection, DFI), que se integran con las actividades de Planificación de Procesos (Mecanizado e Inspección) a los tres niveles que el modelo contempla: agregado, supervisor y operacional. Se trata por tanto de un marco que, como se justifica a continuación, necesita de una armonización y unificación alrededor de una representación y un tratamiento de tolerancias, tanto en lo referente a la especificación y el análisis funcional de tolerancias como a la verificación de las mismas en todos los componentes que forman el producto. Un objetivo que se ha desarrollado parcialmente en este trabajo de tesis.

Antes de continuar, conviene recordar que la verificación de tolerancias se centra en la definición de los planes de inspección y de los procedimientos metrológicos con los que comprobar las EF, las ETFU y las ETFA [Dantan et ál., 2008], y que es importante considerarla ya en las fases tempranas del proceso de diseño, para valorar las incertidumbres desde el principio.

A la necesidad de buscar una armonización entre las tres etapas del ciclo de vida del producto, antes mencionadas, también se refirió Henzold [Henzold, 2006], que divide el dimensionado y toleranciado geométrico (Geometric Dimensioning and Tolerancing, GD\&T) en tres categorías, relacionadas con la función, con la fabricación y con la inspección. Pero Henzold también advierte de la problemática expuesta anteriormente cuando indica que si solo se realiza un GD\&T relacionado con la función (que únicamente depende del diseño) será necesario crear especificaciones adicionales, con los GD\&T relacionados con la fabricación y la inspección. Si no es así, los dibujos se deberán modificar (acotados de fabricación y de inspección), transfiriendo las tolerancias funcionales a tolerancias de fabricación y de medición, a los efectos de poder validar la capacidad de los correspondientes procesos de fabricación y medición. En otras palabras, Henzold plantea que debería realizarse un "GD\&T óptimo" [Saunders et ál., 2010] que 
recibiera entradas de todas las personas que tienen algo que decir en este proceso, incluidos los responsables de la medición. Para ilustrar esta circunstancia, en estos trabajos se exponen ejemplos de dos especificaciones (acotados) de una misma pieza en las que uno es más sensible a las necesidades del usuario y el otro a la inspección, porque presenta elementos de referencia (datums) más favorables para su posicionamiento en el sistema de medición.

Estos mismos autores, en el artículo anteriormente citado, también indican que en la literatura aparecen bastantes citas que ponen de manifiesto que existen relaciones importantes entre la medida dimensional y el diseño, directamente a través del lenguaje GD\&T e indirectamente a través del papel más integral que la metrología está teniendo últimamente en los procesos de fabricación (medición en proceso), una circunstancia que ya fue puesta de manifiesto en el capítulo anterior. Sin embargo, también indican que, más allá de las publicaciones resultantes de ciertas iniciativas de estandarización o de un pequeño número de proyectos industriales, existen pocas publicaciones que indiquen como explotar esta unión. Entre estas se encuentra la de Bruscas at ál. [Bruscas et ál., 2013].

Otro aspecto a considerar, que también debería tenerse en cuenta para el desarrollo de propuestas, es que normalmente todo el tratamiento de las tolerancias, y en concreto la especificación, análisis y verificación de tolerancias, se ha abordado cuando la geometría del producto ya estaba completamente determinada, por lo tanto el estudio de cómo se pueden integrar estas actividades en el diseño preliminar, siguiendo la dirección de las estrategias del Diseño para Verificación (Design For Verification, DFV) [Saunders et ál., 2010] y del Diseño para Ensamblaje [Socoliuc, 2010; Costadoat, 2010], debe ser objeto de estudio [Dantan et ál., 2008].

Por lo que se refiere a la especificación y la verificación de tolerancias en las fases tempranas, que en el proceso $\mathrm{CIDP}^{2} \mathrm{R}$ se sitúan a nivel agregado y supervisor respectivamente, lo importante para el desarrollo del trabajo va a ser investigar las propuestas que han aparecido en los últimos años sobre las representaciones de ensambles dirigidas a enriquecer los principios de solución en estas fases. Por ello, a lo largo del capítulo se van a estudiar las propuestas basadas en la representación geométrica de tipo esqueleto y piel o mediante grafos, instrumentos que permiten analizar las configuraciones y optimizar la montabilidad y, con ello, el cumplimiento de los requisitos geométricos funcionales.

En el campo del análisis y la síntesis de tolerancias en fabricación, al igual que el análisis y síntesis de tolerancias, es usual apoyarse en representaciones de tipo grafo y geométricas de esqueleto y/o piel (nominales y con defectos), en este segundo caso en menor medida, para plantear las ecuaciones de ensamble que caracterizan a estos ejercicios. Sin embargo, el razonamiento en base a las representaciones geométricas no es usual en la planificación de procesos de fabricación y de inspección. Unas representaciones que se denominarán, de forma genérica, como representaciones de ensambles de proceso y para el caso concreto de la inspección como representaciones de ensambles de inspección.

Las representaciones de los ensambles de inspección correspondientes a las subfases de inspección de cada una de las piezas del ensamble producto, que podrá realizarse una vez que se haya definido completamente la geometría nominal y con defectos (nivel agregado del subsistema de diseño), pueden servir para apoyar los razonamientos necesarios para elaborar los planes de inspección postproceso y validarlos. De igual forma, una vez establecidos los planes de fabricación y especificadas las correspondientes tolerancias de fabricación, las representaciones de los ensambles de fabricación servirán de base para definir los planes de inspección en proceso (por ejemplo, en máquina) y validarlos. 
Es evidente, aunque muchas veces no sea explícito, que en la Planificación Supervisora de la Inspección se trabaja sobre las cadenas (ecuaciones, esquemas) correspondientes a las configuraciones de los ensambles, que permiten realizar ejercicios de síntesis y/o análisis de incertidumbres, de forma similar a como se actúa en los ejercicios de análisis y síntesis de tolerancias, propios de la especificación funcional del producto (nivel agregado) y que se realizan sobre las configuraciones del ensamble producto. De ahí la necesidad de desarrollar modelos adecuados, que incorporen información de la geometría con defectos y permitan valorar las incertidumbres inherentes tanto a la propia medición como a las transformaciones entre modelos, propias de este proceso integrado de la especificación y la verificación (principio de dualidad). Unos modelos de producto que han de adecuarse al modelo funcional propuesto (IDEF0 de la Planificación supervisora de procesos de fabricación e inspección) y a los ejercicios y herramientas que hacen posible esta integración, que se detallarán a lo largo del capítulo.

Por otra parte, tal y como se tratará de justificar a lo largo del capítulo, la búsqueda de esta dualidad entre el ejercicio de especificación y análisis funcional del producto, realizado muchas veces a través de ejercicios de simulación, y la verificación de tolerancias de las piezas que lo conforman, basado en el modelado de los ensambles (de producto, de fabricación y de inspección), puede proporcionar un tratamiento consistente y coherente que asegure el cumplimiento de la intención del diseño. Una búsqueda que obliga a revisar toda una serie de conceptos y terminología vinculados con estos ejercicios, con las técnicas y herramientas disponibles y con las representaciones de las geometrías (de ensamble y de pieza) que pueden dar soporte a los mismos.

Para ello, en el siguiente apartado se expondrán los fundamentos de un modelo común de sistema (producto), válido para las diferentes actividades tempranas de diseño y simulación, propuesto recientemente por Charpentier [Charpentier, 2014]. A continuación, en el apartado 3, el foco de dirigirá al modelado estructural y funcional del producto y a las representaciones propias de las fases tempranas del diseño. Posteriormente, en el apartado 4, se presentaran los tópicos fundamentales que cubre el toleranciado, centrándose el estudio en las técnicas de análisis de tolerancias, abordándose a continuación, en el apartado 5, la especificación de tolerancias y, en concreto, las formas de expresar la geometría con defectos tanto en el ámbito normativo como en las metodologías y herramientas de análisis que se utilizan en la fase de diseño de detalle ${ }^{1}$. Adicionalmente, en el apartado 6, se estudiará la expresión de una especificación desde el punto de vista de la verificación, proponiéndose un enfoque basado en el lenguaje Geospelling y buscando la armonización y unificación con la especificación y el análisis funcional de las tolerancias. El capítulo finalizará con un resumen.

Cabe remarcar que la revisión de este capítulo se realizará a nivel geométrico, dejándose el análisis a nivel de elementos característicos para el siguiente capítulo.

\subsection{EL MODELADO GEOMÉTRICO EN LA SIMULACIÓN Y LA ESPECIFICACIÓN.}

Como ya se ha indicado, en los últimos años ha nacido un interés creciente por mejorar el proceso de diseño y desarrollo de nuevos productos interviniendo en las fases tempranas, que según la propuesta realizada por Pahl et ál. [Pahl et ál., 2007] son las del Diseño Conceptual y Diseño de Nivel Sistema (System-Level Design), a la que en este trabajo se designará como Diseño Preliminar (diseño realizado a nivel de sistema), y que anteceden al Diseño de Detalle. Son varias las publicaciones que indican que los resultados del diseño

\footnotetext{
${ }^{1}$ El lector que esté familiarizado con estas temáticas puede prescindir de la lectura de los apartados 4 y 5 .
} 
conceptual y preliminar son fuentes importantes para la cooperación en el campo de la ingeniería: definición de requisitos, funciones y estructuras de producto [Roy et ál., 2001; Dantan et ál., 2003].

Unas parcelas de interés que han orientado algunas de las últimas investigaciones en el campo del toleranciado [Socoliuc, 2010; Costadoat, 2010; Charpentier, 2014], que proponen metodologías concretas en el campo de la Especificación Geométrica del Producto. Unos trabajos que presentan unas características comunes: a) estudian y analizan las formas de representar la geometría con defectos e introducen nuevas propuestas (por ejemplo, el esqueleto/piel con defectos y la arquitectura con defectos de Costadoat o de Socoliuc); y b) consideran que es fundamental analizar los caminos o esquemas (cadenas) de acotación para mejorar los diseños.

Entre estos trabajos, todos ellos de gran interés para la investigación, destaca el de Charpentier [Charpentier, 2014], que indica que en el contexto del diseño, y en concreto en la fase de búsqueda de arquitecturas de soluciones, es muy importante contar con un formalismo global preciso que ayude al diseñador en su tarea. Sin este formalismo la búsqueda de soluciones de diseño resulta intuitiva y excesivamente vinculada a la experiencia del diseñador. Se trata de un formalismo que desarrolla siguiendo un esquema que se ha adoptado, parcialmente, para estructurar este apartado. Según este esquema, a continuación se van a detallar algunas de las principales aportaciones de este trabajo, que se complementarán con las de otros autores y que permitirán conocer: a) que para la representación del producto real se pueden utilizar diferentes abstracciones (modelos); b) que los objetos fundamentales del modelo de un producto son los componentes y las interfaces; c) que para responder a las necesidades del diseño es necesario describir el sistema en base a elementos estructurados (objetos) dotados de un conjunto de datos (propiedades) y de procedimientos (operaciones) que describen su manipulación; d) que el modelado de la variación de las propiedades de un producto, en concreto las geométricas (representaciones de grafos y de geometrías con defectos), son fundamentales en el proceso de diseño; e) que los procesos de modelización, realizados en base a operaciones, son determinantes a la hora de obtener las propiedades (características) de los objetos y que estos están basados en unas hipótesis; f) que la especificación de estas hipótesis se puede realizar de la misma forma que la especificación de las condiciones funcionales (especificaciones funcionales) en base al lenguaje Geospelling y que esto permite acotar la incertidumbre que comporta la construcción del modelo simulado; y g) que las representaciones con defectos son fundamentales en las etapas tempranas del proceso de diseño y especificación de producto.

\subsubsection{LA REPRESENTACIÓN DEL SISTEMA REAL: LOS MODELOS DE SIMULACIÓN Y ESPECIFICACIÓN.}

En el proceso de diseño, para evaluar la factibilidad de una solución, es fundamental verificar/validar su comportamiento físico, por simulación o experimentación. Por lo tanto, la simulación se presenta como una actividad muy interesante para el estudio (análisis) y la comprensión de los sistemas reales, sobre todo por el coste y la dificultad del proceso de construcción de prototipos y de la realización de la correspondiente experimentación.

La simulación permite predecir el comportamiento de un sistema considerando el modelo de simulación. Por lo tanto, los modelos son fundamentales para el estudio, análisis y comprensión de los sistemas (productos) reales y se basan en el postulado de que existen dos mundos: el mundo físico (real) y el mundo abstracto (modelos). Evidentemente, únicamente se puede disponer de modelos en el mundo abstracto, ya que es imposible representar el mundo físico de forma completa. Esta distinción genérica entre lo real y lo 
modelado [Charpentier, 2014], como se verá a lo largo de este apartado, también ha sido fundamental en el trabajo desarrollado en el campo de la modelización de las especificaciones geométricas con el fin de poder eliminar muchas de las ambiguiedades presentes en este dominio.

Centrando la atención en la especificación geométrica, los modelos geométricos que pueden utilizarse son numerosos (Figura 3.1), y diferirán en función del objetivo concreto o el nivel de análisis de la actividad que se está realizando. Entre ellos adquieren una especial relevancia los situados en los dos extremos: el modelo nominal y, sobre todo, el modelo de piel (skin model).

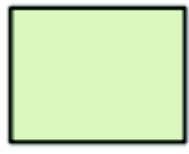

Modelo nominal

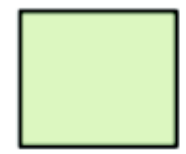

Modelo con defectos dimensionales (lineales)

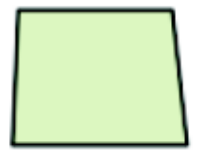

Modelo con defectos angulares

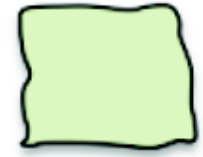

Modelo con defectos de forma

Figura 3.1 Modelización del objeto volumen (ejemplos) [de Charpentier, 2014].

El modelo de piel es un modelo de la interfaz física, o piel, de la pieza. Por lo tanto, existe una clara distinción entre la piel en el mundo físico y su modelo en el mundo abstracto. El concepto de modelo de piel, o de modelo de superficie no ideal, fue adoptado por las normas GPS (Geometrical Product Specification / Especificación Geométrica de Producto) [ISO17450-1, 2011] y últimamente fue definido por la ISO22432 [ISO22432-1, 2011] como "un modelo virtual para exprimir el operador de especificación y el operador de verificación considerando una superficie continua". La referencia a un "modelo virtual" que realiza la norma es para remarcar la naturaleza imaginaria del "modelo de piel". Por lo tanto, a nivel conceptual, el modelo de piel solo puede ser imaginado, pues puede tomar una infinidad de formas, pudiéndose representar solo una instancia particular del mismo, que no dejará de ser una de entre una infinidad de otras representaciones posibles. Además, desde un punto de vista técnico el modelo de piel es un modelo infinito, que no permite la identificación o simulación, porque se define mediante un conjunto infinito de parámetros independientes.

A esta circunstancia del modelo de piel también se refieren Schleich et ál. [Schleich et ál., 2014] que indican que para tener en cuenta realmente todas las posibles variaciones geométricas sería necesario considerar una descripción infinita. Sin embargo, para realizar las simulaciones los modelos infinitos son inadecuados (inadaptados), porque la simulación requiere de modelos finitos y manejables (adaptados), es decir que tengan un número de parámetros suficientemente grande y suficientemente fiable para limitar las incertidumbres que cualquier simplificación supone. Un análisis más profundo sobre la adaptabilidad fue realizado por Vernat et ál. [Vernat et ál., 2010], que propusieron un procedimiento para formalizar y cualificar los modelos adaptados a los requisitos del diseño.

La mayor parte de los modelos de geometría con defectos utilizados para la simulación están basados en geometría de tipo continua, en los que las desviaciones geométricas se parametrizan de alguna manera. Sin embargo, en los últimos años se han publicado trabajos que proponen representar la geometría con defectos de forma discreta [Schleich y Wartzack, 2014], con el fin último de representar mejor las variaciones geométricas que se pueden producir en una pieza fruto de diferentes fuentes de error. 
En contraposición al modelo de piel, desde la perspectiva de la ingeniería, el modelo nominal es un modelo "simple" de la pieza deseada sin tener en cuenta las inevitables desviaciones geométricas [Schleich et ál., 2014]. Al igual que el modelo de piel, el modelo nominal es un modelo imaginario (virtual) en el que la pieza tiene una geometría perfecta y que solo existe en el modelo CAD o en los planos de la pieza [ISO17450-1, 2011]. Es decir, no tiene existencia en el mundo físico (real).

Tanto si se trata del modelo de piel como del modelo nominal de la pieza, las normas GPS [ISO17450-1, 2011] definen un elemento característico geométrico (geometrical feature) como un punto, una línea, una superficie, un volumen o un conjunto de estos ítems, distinguiéndose entre elementos característicos ideales y no ideales según procedan del modelo nominal (definidos mediante una ecuación parametrizada) o del de piel de la pieza respectivamente. Los elementos característicos geométricos son importantes porque sobre ellos se especifican las características.

Los elementos característicos geométricos son considerados como cuerpos rígidos con seis grados de libertad independientes, tres traslaciones y tres rotaciones, en un espacio tridimensional. De los seis grados de libertad, hay algunos para los que un elemento característico geométrico puede permanecer idéntico en el espacio. A estos grados de libertad se les conoce como grados de libertad invariantes, frente al resto de los seis que son grados de libertad activos. A partir de estos grados de libertad inactivos y activos, se pueden definir siete clases invariantes para los elementos característicos geométricos (Tabla 3.1): esférica, cilíndrica, plana, helicoidal, de revolución, prismática y compleja.

Las características geométricas especificadas sobre los elementos geométricos pueden ser de tipo intrínseco, afectando al tamaño y/o forma del propio elemento característico, o de tipo extrínseco, cuando establecen restricciones sobre varios elementos característicos. Para este segundo caso se hace necesario el establecimiento de los elementos de situación (situation feature), elementos geométricos ideales de tipo punto, línea recta, plano o línea helicoidal, que permiten definir las situaciones (posición y/u orientación) relativas entre los elementos característicos [ISO14750-1: 2011]. En la Tabla 3.1 se muestran los elementos de situación o combinación de ellos necesarios para cada una de las clases invariantes.

\begin{tabular}{|c|c|c|c|c|}
\hline $\begin{array}{c}\text { Clase } \\
\text { invariante }\end{array}$ & $\begin{array}{c}\text { Ejemplo de } \\
\text { superficie }\end{array}$ & Elemento de situación & $\begin{array}{c}\text { Grados de libertad } \\
\text { invariantes }\end{array}$ & $\begin{array}{c}\text { Grados de libertad } \\
\text { activos }\end{array}$ \\
\hline Esférica & & Punto & $\mathrm{R}_{\mathrm{x}}, \mathrm{R}_{\mathrm{y}}, \mathrm{R}_{\mathrm{z}}$ & $T_{x}, T_{y}, T_{z}$ \\
\hline Cilíndrica & & Línea recta & $\mathrm{T}_{\mathrm{x}}, \mathrm{R}_{\mathrm{x}}$ & $\mathrm{T}_{\mathrm{y}}, \mathrm{T}_{\mathrm{z}}, \mathrm{R}_{\mathrm{y}}, \mathrm{R}_{\mathrm{z}}$ \\
\hline Plana & & Plano & $\mathrm{T}_{\mathrm{x}}, \mathrm{T}_{\mathrm{y}}, \mathrm{R}_{\mathrm{z}}$ & $\mathrm{T}_{\mathrm{z}}, \mathrm{R}_{\mathrm{x}}, \mathrm{R}_{\mathrm{y}}$ \\
\hline Helicoidal & & Línea helicoidal & $\mathrm{T}_{\mathrm{x}}, \mathrm{R}_{\mathrm{x}}$ & $T_{y}, T_{z}, R_{y}, R_{z}$ \\
\hline De revolución & & Punto y línea recta & $\mathrm{R}_{\mathrm{x}}$ & $\mathrm{T}_{\mathrm{x}}, \mathrm{T}_{\mathrm{y}}, \mathrm{T}_{\mathrm{z}}, \mathrm{R}_{\mathrm{y}}, \mathrm{R}_{\mathrm{z}}$ \\
\hline Prismática & & Línea recta y plano & $T_{x}$ & $\mathrm{~T}_{\mathrm{y}}, \mathrm{T}_{\mathrm{z}}, \mathrm{R}_{\mathrm{x}}, \mathrm{R}_{\mathrm{y}}, \mathrm{R}_{\mathrm{z}}$ \\
\hline Compleja & & Punto, línea recta y plano & -- & $T_{x}, T_{y}, T_{z}, R_{x}, R_{y}, R_{z}$ \\
\hline
\end{tabular}

Tabla 3.1 Clases invariantes [adaptada de Srinivasan, 1999 y Lu, 2011]. 
Hasta este momento, tanto en el caso de modelos de piel de geometría con defectos como en el caso de los modelos nominales de geometría sin defectos (por ejemplo, las clases invariantes), se han estado considerando fundamentalmente modelos de superficie. Sin embargo, algunos ejercicios de simulación, tal y como se verá más adelante en el apartado 3.3 e independientemente de que sean modelos de piel o modelos nominales, hacen uso de modelos geométricos de tipo esqueleto, en el que los elementos de situación (punto, línea recta, plano,...) adquieren especial relevancia, al ser estos los que se utilizan para representar la geometría.

Otro de los aspectos que cabe mencionar es que los elementos característicos geométricos, sean ideales del modelo nominal o no ideales del modelo de piel y aunque a priori de forma individual puedan definirse como infinitos, cuando se utilizan en los modelos de la pieza son finitos. Es decir, los elementos característicos geométricos son limitados o recortados, por cuanto el número de puntos, la longitud, el área o el volumen de los mismos es finito.

\subsubsection{EL SISTEMA PRODUCTO: LOS COMPONENTES Y LAS INTERFACES.}

Como ya se ha comentado, en el desarrollo de productos son fundamentales los modelos de sistemas, unos modelos que en lo básico ven al sistema como un conjunto de componentes en interacción. Un componente es una parte del sistema que tiene su propio comportamiento y puede ser el modelo de una pieza, un subensamblaje o parte de una pieza. Su modelado se puede realizar de diferentes formas, que van desde la definición completa de toda la geometría (modelos geométricos de sólidos) hasta, en el otro extremo, su definición como "caja negra" (un nodo en un modelo de grafo o un objeto en los modelos de sistema) que modela el comportamiento establecido a priori. En este contexto, la interacción es entendida [Charpentier, 2014] como una acción recíproca entre dos componentes que supone intercambio de energía y que puede ser a distancia o de contacto. El contacto se define por superficies recortadas, interfaces, por las que tienen lugar los intercambios y las interacciones mecánicas, mientras que la acción a distancia es consecuencia de un campo que actúa sobre el volumen (materia) del componente.

Centrando la atención en el concepto de interfaz, una noción fundamental para este trabajo, esta se puede definir [Charpentier, 2014] como el lugar entre dos componentes o dos medios (p.e gas-sólido) por el que se producen los intercambios o las interacciones. Una interfaz, según el autor antes citado, se modela mediante dos superficies, aunque también indica que para las interfaces sólido-líquido, sólido-gas o líquido-gas ambas superficies se confunden. Por lo tanto, si se entiende que el entorno de la pieza es el aire, la superficie y la interfaz se confunden. Esta es la perspectiva que normalmente se adopta en la normativa de especificación geométrica del producto GPS, en la que se indica que "el modelo de piel es un modelo abstracto de la interfaz física entre la pieza y su entorno" [Schleich et ál., 2014]. Una noción coincidente con la de Bourdet y Schneider [Bourdet y Schneider, 2007] que utilizan el término de interfaz para modelizar la superficie real de la pieza, pues indican que "la forma real de un objeto corresponde a la interfaz entre la materia y su entorno". Un entorno que en estos casos se supone que es el aire que envuelve el objeto (pieza). Una noción parecida es la adoptada en el modelo de producto de PPO (Product-Process-Organization / Producto-Proceso-Organización) [Dufaure, 2005; Ballu et ál., 2007; Noël y Roucoules, 2008], que posteriormente en este mismo capítulo se tratará con mayor profundidad, para el que una interfaz es "la relación entre un componente y medio exterior, pudiendo ser en el ámbito de la geometría un elemento simple de tipo superficie, línea o punto o un mallado asociado a un componente". Según Dufaure 
[Dufaure, 2005] "la interfaz es como un mango enganchado a un componente, que permite acceder a un componente con una visión específica”. Un mango que desde el punto de vista informacional proporciona el acceso a un conjunto de propiedades, no necesariamente de tipo geométrico, a través de las cuales los componentes se relacionan entre sí con el fin de proporcionar una solución técnica a una serie de especificaciones funcionales.

Por lo anteriormente indicado, el concepto de interfaz se vincula normalmente a un componente (pieza o ensamble de piezas) y a su relación con el exterior, por lo que no contemplaría la interfaz sólido-sólido de Charpentier [Charpentier, 2014], que según este autor debe modelarse mediante las porciones de las superficies de los dos componentes en contacto, limitadas a las partes que estarán realmente en contacto (superficies recortadas). Por lo tanto, tal y como indica Charpentier, la identificación de la interfaz es subjetiva, porque depende de la interpretación del modelador, de sus intenciones y de las interpretaciones de los modelos físicos y matemáticos.

\subsubsection{LAS PROPIEDADES Y LAS OPERACIONES GEOMÉTRICAS.}

Para responder a las necesidades del diseño, Charpentier [Charpentier, 2014] plantea la necesidad de contar con un módulo estructurado y limitado, formado por un conjunto de datos y comportamientos que definan su manipulación. Un módulo que denomina objeto, seguramente por su similitud al concepto de objeto en el dominio de los sistemas de información, aunque el autor no haga referencia explícita a ello y evite utilizar notación propia de este dominio. Pero como en el ámbito del modelado de software orientado a objetos, en el que el modelado de clases UML (Unified Modeling Language / Lenguaje de Modelado Unificado) es un estándar, el modelo de Charpentier contempla las nociones de clase (tipo de objetos), atributo (propiedad) y relación entre atributos (operación). Todo un conjunto de conceptos que se describen a continuación, concretándolos para el caso de la especificación geométrica.

\subsubsection{LOS OBJETOS Y SUS PROPIEDADES.}

Según Charpentier [Charpentier, 2014], las propiedades pueden ser de dos tipos: cualitativas y cuantitativas. Las segundas se expresan mediante un número (booleano, entero o real) y una referencia (para las propiedades reales), que define la unidad de la magnitud cuantificada (longitud, masa, restricción, etc.). Los valores de estas propiedades cuantitativas permiten distinguir un objeto de entre aquellos que comparten las mismas propiedades. Según Charpentier las propiedades cuantitativas son muy similares a las "características" (characteristics) de Weber [Weber, 2008], las "cantidades" (quantities) definidas por JCGM200 (Joint Committee for Guides in Metrology / Comité Conjunto para Guías en Metrología) [JCGM200, 2012 (VIM, International Vocabulary of Metrology / Vocabulario Internacional de Metrplogía)] o las "características geométricas" (geometric characteristic) definidas por la ISO25378 [ISO25378, 2011].

Por su parte, las propiedades cualitativas se utilizan generalmente para describir el comportamiento y están vinculadas a las elecciones de diseño o de modelado realizadas por diseñador (por ejemplo, la función, la seguridad o fiabilidad, el respeto medioambiental, condiciones mínimas en materia ergonómica, etc.). No pueden expresarse cuantitativamente, pero permiten definir relaciones o restricciones sobre o entre las propiedades cuantitativas. En el ámbito de la especificación geométrica, las propiedades plano, cilindro, perpendicular, etc. constituyen un conjunto de propiedades cualitativas relacionadas con el comportamiento geométrico. Por ejemplo, el que todos los puntos de la superficie estén a una misma distancia constante de un mismo eje establece relaciones concretas entre los puntos que son específicas de un cilindro. 
Para profundizar un poco más sobre las propiedades conviene detenerse en su relación con los tipos de objetos (clases). Es importante tener en cuenta que: a) los objetos de una misma clase son del mismo tipo, definido mediante las correspondientes propiedades cualitativas; b) los diferentes elementos (instancias) de una clase se diferencian por los valores de las propiedades cuantitativas; c) una subclase viene a limitar los elementos mediante restricciones a las propiedades cuantitativas y también definiendo nuevas propiedades cualitativas que son las que definen un subtipo.

Para entender el concepto de operador, Charpentier [Charpentier, 2014] primero establece una distinción entre las propiedades de base y las derivadas. Sobre las primeras indica que son las asociadas a unidades básicas (por ejemplo, en geometría la distancia entre dos puntos), mientras que las segundas lo están a unidades derivadas (en geometría, por ejemplo, un ángulo o la distancia entre una recta y un punto, que siempre se pueden expresar a partir de distancias entre puntos). A partir de ahí indica que las propiedades derivadas se obtienen de un proceso de operaciones ordenadas conocido como operador. Por lo tanto, los operadores permiten completar las propiedades de base de un objeto con nuevas propiedades, denominadas derivadas. Unas propiedades que se pueden vincular tanto a objetos ideales (modelos finitos) como a objetos imperfectos (modelos infinitos).

\section{LAS CARACTERÍSTICAS EN LA ESPECIFICACIÓN GEOMÉTRICA DE LAS PIEZAS}

El lenguaje Geospelling, un lenguaje común adoptado por la norma ISO (International Organization for Standardization / Organización Internacional para la Estandarización) para expresar las especificaciones geométricas y que Charpentier tomó de base para su trabajo, está basado en las características y las operaciones geométricas, que describen la semántica (significado) de las especificaciones. En este ámbito las características son utilizadas: a) directamente, para caracterizar el defecto especificado y b) en el criterio de una operación, para definir una restricción u objetivo.

Profundizando en el primer uso, las características son vistas como cantidades (quantities de la JCGM200 [JCGM200, 2012 (VIM)]) dimensionales definidas sobre o entre elementos geométricos (ideales, no ideales y limitados) y deben permitir que los diferentes defectos de las superficies (intrínsecos y de situación) puedan ser caracterizados separadamente. Un requisito que Costadoat [Costadoat, 2010] justificó que se cumple, estableciendo 13 restricciones de situación (de distancia, ángulo y coincidencia) que permiten establecer características de situación entre: elementos ideales (Costadoat identifica 9 tipos); un elemento limitado y un ideal; un elemento no ideal y un ideal; y entre elementos no ideales. Unos grupos de características de situación a los que hay que añadir el de características intrínsecas. Por lo tanto, las operaciones geométricas se pueden aplicar tanto a las propiedades cuantitativas (características de Geospelling) ideales, definidas por los sistemas CAD, como a las propiedades cuantitativas no ideales, que pueden representar una parte de la superficie real, el modelo de piel. La norma indica que los elementos geométricos simplificados (modelos) utilizados para la especificación se van deduciendo a partir del elemento geométrico primario, el modelo de piel, mediante operaciones.

Volviendo al ejercicio de la simulación conviene tener presente que, tal y como se verá en el apartado 3.5, en los mismos las características se expresan mediante útiles o representaciones matemáticas. Por lo tanto, si en el proceso de especificación se utilizan metodologías de simulación (ver apartado 3.5) es necesario realizar una traducción entre las características Geospelling y la representación matemática requerida por la técnica de simulación aplicada (por ejemplo, la representación mediante los torsores de pequeños desplazamientos, que será descrita en mayor detalle más adelante en el apartado 3.5). Costadoat [Costadoat, 2010] hizo referencia a esta problemática de las traducciones 
(Figura 3.2) y propuso un esquema que plantea la traducción de las especificaciones geométricas funcionales a nivel de producto (condiciones geométricas para este y otros muchos autores), expresadas bajo la forma de características Geospelling, a inecuaciones sobre las funciones de componentes de los torsores de pequeños desplazamientos.

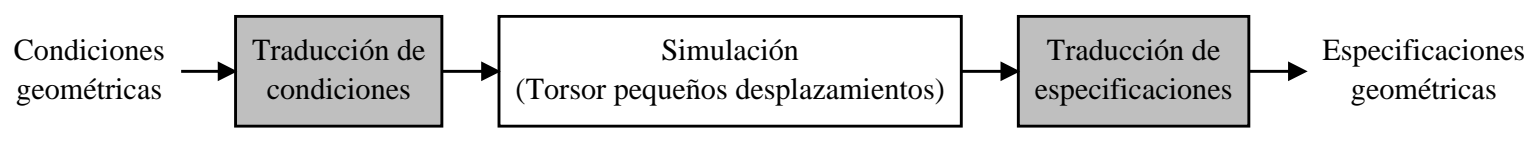

Figura 3.2 Traducciones de condiciones y de especificaciones [de Costadoat, 2010].

Se trata de una tarea muy importante, denominada traducción de condiciones, que ha sido estudiada entre otros autores por Costadoat, que indica que para la misma es importante tener en cuenta los cuantificadores [Dantan et ál., 2003], que permiten añadir las informaciones para limitar la incertidumbre de correlación (la cual será descrita en el subapartado 3.2.4), y las dependencias entre los torsores de pequeños desplazamientos. En el esquema también se aprecia que tras la simulación es necesaria la transformación de las tolerancias geométricas funcionales resultantes de la simulación, expresadas a nivel de pieza (especificaciones geométricas para este autor y otros) mediante inecuaciones sobre las funciones de los componentes de los torsores de pequeños desplazamientos, a características intrínsecas y de situación Geospelling. Se trata de una tarea que se conoce como traducción de las especificaciones y que es el problema inverso al de la traducción de condiciones, por cuanto supone el paso de torsores de pequeños desplazamientos a características Geospelling. En las traducciones en las que el modelo matemático de simulación está basado en torsores de pequeños desplazamientos, es importante considerar que estos se vinculan a elementos geométricos infinitos.

Las traducciones entre características de simulación (por ejemplo, torsores de prequeños desplazamientos) y características Geospelling suele ser directa. Sin embargo, esto no es así cuando la especificación se desea tener según la norma ISO (tolerancias dimensionales y tolerancias geométricas basadas en zona de tolerancia), porque la especificación de defectos de dimensión en las normas tiene sus reglas específicas. En cualquier caso, se trata de un problema de traducción que ha sido resuelto [Anselmetti, 2008; Costadoat, 2010], aunque aún no se disponga de aplicaciones informáticas que permitan la traducción directa de características Geospelling a ISO.

\section{LAS CARACTERÍSTICAS EN LA ESPECIFICACIÓN DE LAS CONDICIONES FUNCIONALES DE LOS ENSAMBLES}

En el punto anterior ya se indicó que la especificación de características no se limita a definir los atributos de las geometrías de las piezas. Como se verá en el siguiente subapartado, en el desarrollo último del lenguaje Geospelling ha adquirido cada vez más relevancia el estudio de su aplicación a características a nivel de producto o mecanismo (ensamble). Por ello, en este punto se va a tratar, aunque sea de forma somera, el conjunto de condiciones que se pueden imponer en un mecanismo. A partir de aquí se utilizará el término condición funcional para expresar la especificación de un requisito funcional (especificación funcional) que tiene un efecto sobre la geometría de los componentes del ensamble.

Las condiciones funcionales pueden proceder de problemáticas geométricas directamente vinculadas con las prestaciones del producto o mecanismo o con su montabilidad: las condiciones geométricas y las condiciones de montabilidad.

En la primera categoría se encuentran las condiciones geométricas más usuales en la construcción mecánica y que pertenecen a cuatro grupos [Thiébaut, 2001]: 
- Las condiciones locales de desviación, que se expresan entre elementos geométricos que pertenecen a una misma pieza.

- Las condiciones globales de desviación, que se expresan entre elementos geométricos de piezas diferentes.

- Las condiciones locales de holgura, que se expresan entre elementos pertenecientes a dos piezas diferentes que forman una junta y que se caracterizan por variaciones de situación (posición y/u orientación) relativa entre ambos elementos.

- Las condiciones globales de holgura, que se expresan entre elementos geométricos de dos piezas diferentes y que se caracterizan por variaciones de posición y de orientación.

Las condiciones del tipo desviación (diferencia) se deben diferenciar según sean de orientación o de posición. En las primeras no intervienen las dimensiones intrínsecas de los elementos geométricos, al trabajarse con elementos geométricos de situación, mientras que en las de posición sí que intervienen, cambiando la forma de la ecuación de la condición.

Por su parte, las condiciones de montabilidad se asocian con la noción de no interpenetración, que se puede producir cuando debido a una deficiente limitación de los defectos existe el riesgo de que ciertas zonas de una pieza interfieran con las de otra. Se trata de unas condiciones que se agrupan en dos clases [Costadoat, 2010]:

- De no contacto, que se establecen en algunas juntas para garantizar que estas no tendrán ninguna influencia sobre las otras juntas que forman parte del ciclo (cadena), porque no deben modificar las movilidades autorizadas de las otras juntas.

- De interfaz, una condición que permite la simplificación de los ciclos hiperestáticos.

En el apartado dedicado al modelado estructural y funcional de producto, se describirán con mayor profundidad algunos conceptos vinculados con las cadenas que se deben establecer para la simulación de los mecanismos y que son las que permiten construir las ecuaciones que resuelven este problema, que serán analizadas en el apartado dedicado al tratamiento de las tolerancias en el proceso de diseño. En el primero de los apartados que se acaban de mencionar, también se estudiarán las representaciones de las geometrías de los productos y de sus arquitecturas, unas representaciones que soportan la simulación y la especificación geométrica.

\subsubsection{LAS OPERACIONES GEOMÉTRICAS.}

Las operaciones geométricas [Charpentier, 2014] son útiles específicos que permiten generar elementos geométricos o valores de propiedades. Cuando este autor indica que los elementos geométricos se generan de otros, se está refiriendo a que las propiedades cualitativas y cuantitativas de estos derivan de las propiedades de otros elementos, incluidos los de las características especificadas (valores) y que deben ser objeto de evaluación. Esto puede verse con un ejemplo. Una de estas características puede ser, por ejemplo, la vinculada a una especificación mediante zona de tolerancia [ISO1101, 2012] como puede ser la posición de una superficie plana respecto de un plano, en el la característica (propiedad cuantitativa) es la distancia entre los puntos de la superficie y un plano restringido en posición. Se trata de una propiedad derivada que supone calcular la distancia entre dos puntos, uno perteneciente a la superficie y otro del plano, que resulta de su intersección de una recta perpendicular a él y que pasa por el punto de la superficie.

Las operaciones geométricas contempladas en la norma actualmente son diez [ISO17450-1, 2011]: partición, extracción, filtrado, asociación, colección, construcción, 
reconstrucción, reducción, evaluación y transformación. De acuerdo a la norma, las diez operaciones se definen de la siguiente forma: 1) Partición, que se utiliza para identificar una porción de un elemento característico geométrico que pertenece a la superficie real de la pieza o a la superficie del modelo de la pieza; 2) Extracción, que se utiliza para identificar puntos específicos de un elemento característico no ideal; 3) Filtrado, que se utiliza para crear un elemento característico no ideal a partir de un elemento característico no ideal o para transformar una curva de variación en otra reduciendo el nivel de información; 4) Asociación, que se utiliza para ajustar elementos característicos ideales a no ideales de acuerdo a un criterio; 5) Colección, que se utiliza para identificar más de un elemento característico geométrico que juntos juegan un papel funcional; 6) Construcción, que se utiliza para construir elementos característicos ideales a partir de otros elementos característicos ideales con restricciones; 7) Reconstrucción, que se utiliza para crear un elemento característico continuo de un elemento característico extraído; 8) Reducción, que se utiliza para establecer un elemento característico derivado mediante cálculos; 9) Evaluación, que se utiliza para identificar o bien el valor de una característica o bien su valor nominal y sus límites; 10) Transformación, que se utiliza para convertir una curva de variación en otra. Las ocho primeras operaciones son de tipo operaciones de elementos característicos, y son las necesarias para obtener elementos característicos.

De estas operaciones definidas en la norma, las nueve primeras son agrupadas en cuatro clases por Charpentier [Charpentier, 2014] (Figura 3.3). Al grupo de Restricción pertenecen la extracción, el filtrado, la reducción y la asociación, que son las que reducen el número de informaciones. Por lo tanto, estas operaciones participan en el proceso de simplificación de un modelo. La evaluación, la reconstrucción y la construcción son las que crean nuevas informaciones y forman parte del grupo de Transformación. Por último, la partición, como descompone información, se vincula al grupo denominado Descomposición y la colección, como reagrupa información, al de Lógica.

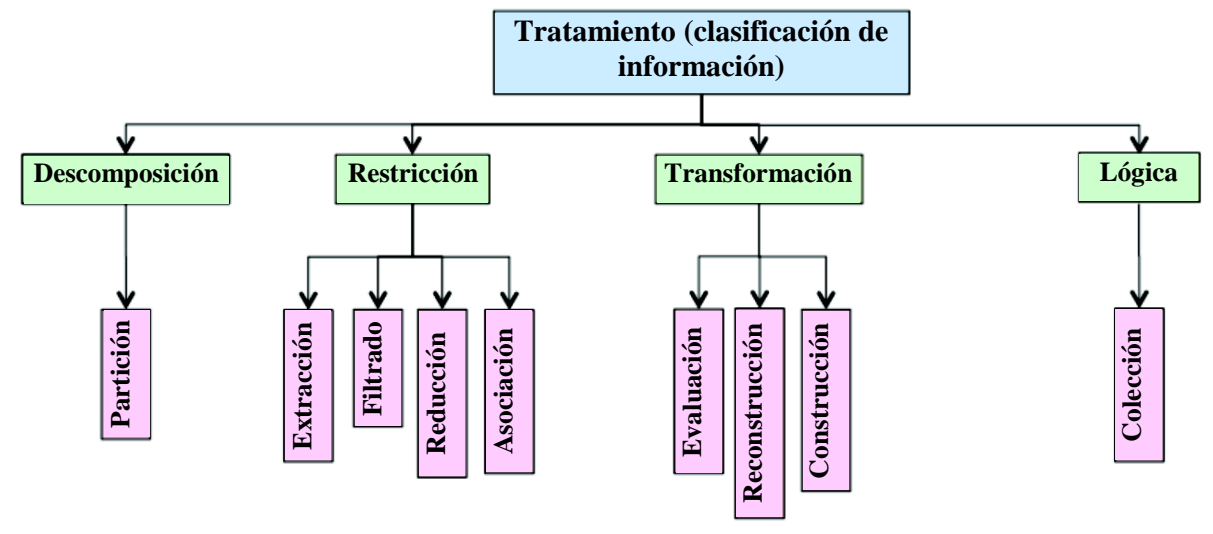

Figura 3.3 Clasificación de nueve operaciones GPS [de Charpentier, 2014].

La generación de elementos geométricos o la modificación de sus propiedades a través de diferentes operaciones permiten obtener geometrías restringidas o transformadas. En GPS [ISO17450-1, 2011], además de la geometría nominal, se pueden representar la geometría extraída, a través de elementos característicos extraídos definidos como un conjunto finito de puntos, y la asociada, mediante los elementos característicos asociados definidos a partir de modelos de superficie no ideales a través de la operación de asociación. Asimismo, las geometrías nominales, extraídas y asociadas pueden hacer referencia tanto a superficies integrales, que pertenecen al modelo de superficie, como a elementos derivados (centro, línea media, plano medio), que no existen físicamente y que se derivan de superficies integrales. 


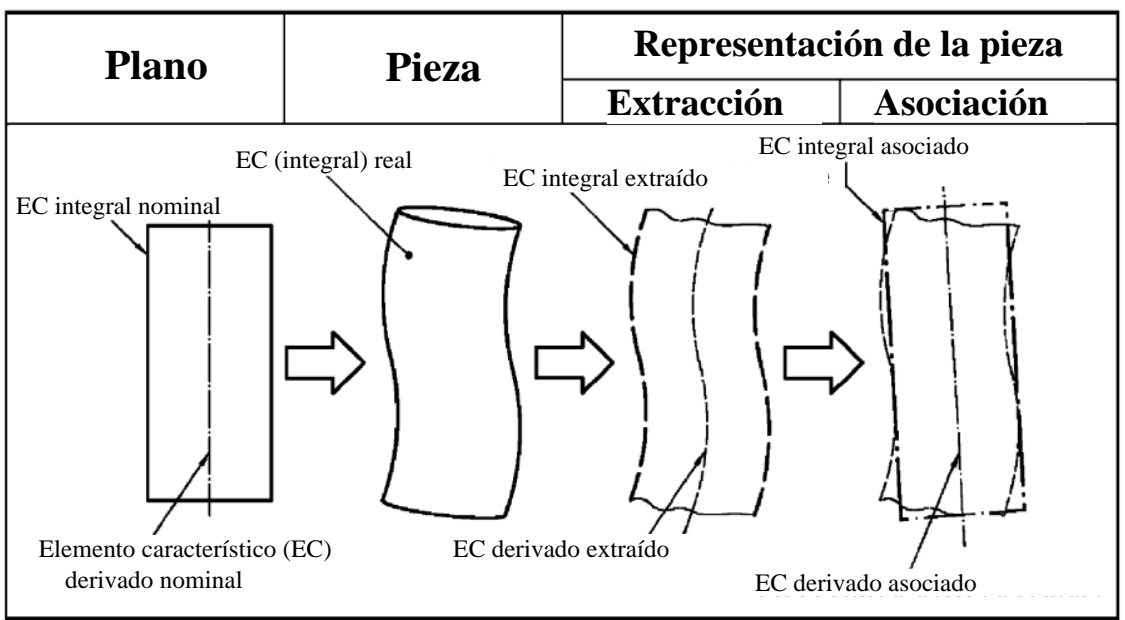

Figura 3.4 Interrelación entre las definiciones de elementos característicos geométricos para el ejemplo de un cilindro [de Ma et ál., 2007 e ISO17450-1, 2011].

Para finalizar esta síntesis sobre las operaciones, también resulta interesante acercarse a la conceptualización que Charpentier [Charpentier, 2014] realiza sobre las mismas, que pueden ser vistas como aplicaciones entre objetos entrantes y salientes que muchas veces están sujetos a un criterio, que puede ser diferente según el tipo de operación: tipo de filtro para el filtrado, restricciones y objetivos para la asociación, etc. Un concepto que presenta una gran semejanza con el concepto de función en una aplicación informática y de operación en notación UML, definida como un servicio que puede ser requerido a cualquier instancia de la clase para que muestre su comportamiento.

\subsubsection{LAS ESPECIFICACIONES Y LAS INCERTIDUMBRES.}

Una vez se han definido los elementos semánticos fundamentales para la expresión de una especificación, se va a profundizar en el propio concepto de especificación, remarcando su importancia y su evolución.

La actividad de diseñar y desarrollar artefactos mecánicos requiere usualmente del trabajo colaborativo de varias personas, que pueden estar localizadas en lugares muy diferentes, y esta colaboración debe hacerse de forma que el diseño no sufra ninguna degradación ocasionada por problemas de comunicación. Una comunicación en la que son fundamentales las especificaciones geométricas (funcionales, de tolerancias, etc.), pues son las que permiten definir el conjunto de productos diferentes al nominal que pueden responder a las necesidades establecidas y así satisfacer al cliente. Pero el proceso de especificación está sujeto a toda una serie de problemáticas [Costadoat, 2010], entre las que se encuentra la propia expresión de las especificaciones geométricas. La importancia de esto fue la que hizo que aparecieran desde prácticamente el inicio de la era industrial toda una serie de normas específicas de corporaciones industriales, nacionales $\mathrm{e}$ internacionales, que con el tiempo han desembocado en la norma GPS, auspiciada por la ISO. Pero las normas establecidas, aunque han sido muy utilizadas, no están exentas de defectos y las lagunas de sus definiciones pueden ocasionar graves confusiones y problemas de mala interpretación. Como consecuencia de ello, y para limitar estos problemas, se han ido definiendo otros medios de expresión y semánticas de símbolos, que en algunos casos se están incorporando en la normativa. Este es el caso del lenguaje Geospelling, que se tratará a continuación en una acepción amplia. La expresión de la especificación a nivel pieza se tratará en mayor profundidad en un apartado específico de este mismo capítulo. 


\subsubsection{EL LENGUAJE GEOSPELLING.}

Geospelling, que como ya se ha indicado anteriormente ha guiado el desarrollo de este apartado, define una especificación geométrica como (Figura 3.5) "una condición sobre una dimensión definida por una característica sobre unos elementos geométricos identificados por operaciones a partir de un modelo de piel". Un conjunto de operaciones ordenadas (operador de especificación) que se orientan hacia la evaluación y que permiten poner la condición y deben corresponderse con las del operador de verificación, que es el que describe las operaciones realizadas para controlar en la realidad la especificación. Una condición que define un intervalo dentro del que debe reposar o descansar el valor de la característica de los elementos geométricos. Por lo tanto, si este operador no es una simulación perfecta del de especificación origina una incertidumbre de medida, es decir, genera una duda sobre si realmente el valor medido cumplirá la condición. Las incertidumbres inherentes a los procesos de simulación y especificación se tratarán a continuación, mientras la vinculada a la medida se hará en mayor profundidad con posterioridad, en el último apartado de este capítulo.

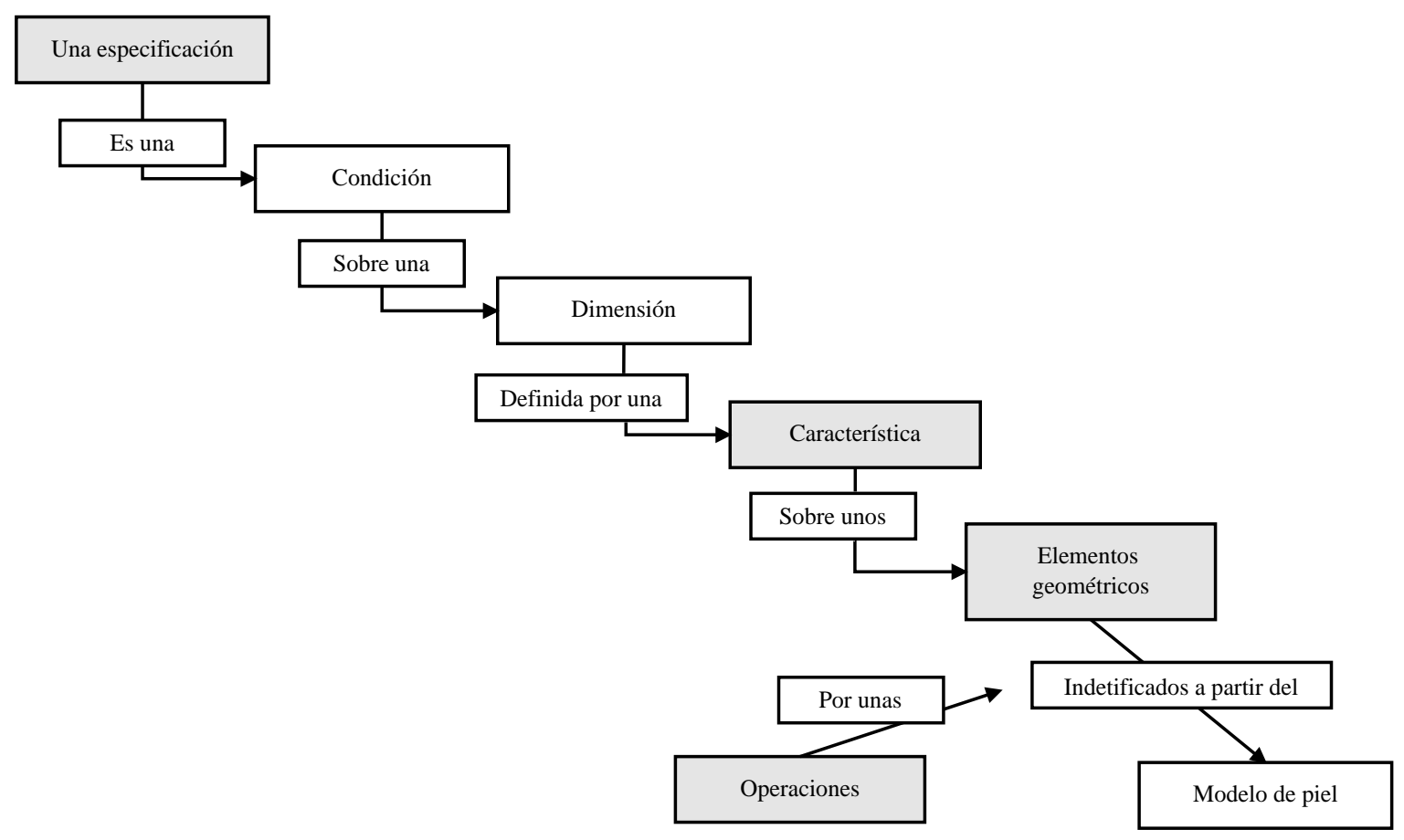

Figura 3.5 Definición de especificación en el lenguaje Geospelling [de Costadoat, 2010].

Pero las características no solo se usan para conocer las propiedades de una pieza, como pudiera suponerse de una lectura rápida, también se utilizan usualmente para identificar las propiedades funcionales, en un sentido amplio, comprendiendo las especificaciones directamente relacionadas con las funciones principales del producto y las resultantes de las funciones técnicas, de las restricciones de fabricación, etc. La especificación de esas características, y en concreto las de nivel de producto, también se pueden realizar con lenguaje Geospelling de GPS, pero las actuales normas aún no proporcionan ninguna significación (semántica) para su uso a este nivel, tal y como se requiere en algunas fases tempranas, como la del análisis funcional técnico. Por eso, en los últimos años han surgido algunas propuestas dirigidas a mejorar esta limitación, como la que propone completar la condición con un cuantificador que traslade la idea de que esta condición debe respetarse en al menos una configuración o en todas las configuraciones del mecanismo [Dantan et ál., 2008]. Según los autores, la ausencia de este cuantificador 
genera incertidumbre. Se trata de un ejemplo que indica la aceptación que está teniendo este lenguaje y los desarrollos que está teniendo para expandir su uso a otras tareas vinculadas con el toleranciado geométrico.

En esta misma dirección se pronuncia Charpentier [Charpentier, 2014], que indica que la especificación, que en Geospelling de GPS solo se aplica a los modelos primitivos (modelos de piel), también se puede aplicar a lo largo de toda la modelización (modelos intermedios y modelos de simulación), permitiendo así extender el uso de las especificaciones tanto a las especificaciones que pueden permitir limitar la falta de conocimiento sobre la influencia de las simplificaciones realizadas a lo largo del proceso de modelización (especificación del magisterio en la simplificación), como a la que indique la diferencia que se puede presentar entre dos valores simulados mediante dos modelos consecutivos (especificación de validación de las hipótesis). Una nueva especificación que se fundamenta en asumir que las hipótesis tomadas en el proceso de simplificación (como puede ser la hipótesis de que los defectos de forma de dos planos y los de orientación entre ellos son despreciables para el cálculo de un juego mínimo en el caso de un ajuste chaveta ranura) no deberían alterar en demasía los resultados de la simulación con respecto del comportamiento real.

A la extensión de Geospelling de GPS a modelos de simulación, también hace referencia Costadoat [Costadoat, 2010], que indica que el hecho de que la especificación se apoye sobre el real permite disminuir las incertidumbres de especificación con respecto a otros lenguajes. Sin embargo, como el modelo de piel es una representación que es imposible de tener en la etapas de diseño en las que se aplica la especificación, plantea la necesidad de establecer una definición para la especificación para la simulación a partir de la original: "una especificación para la simulación es una condición sobre una dimensión definida por una característica sobre los elementos geométricos ideales simulados". Por lo tanto, Costadoat parece que critica lo que muchas veces se deja entrever: que en el ejercicio de la simulación, integrado en muchos casos en el proceso de especificación, el razonamiento parta del modelo de piel. De ahí que en su investigación, y con el objetivo de validar el modelo para la especificación que propone (GeoSpecif), se haya visto en la necesidad de comparar el modelo de simulación (ideal), que llama modelo geométrico con defectos y que deriva del nominal, con el modelo de geometría de sustitución propuesto por Wirtz [Wirtz, 1991]. El modelo de sustitución es un modelo ideal que deriva del modelo de piel y que, como se verá posteriormente, está muy vinculado al modelado vectorial y a la verificación mediante MMC.

\subsubsection{LAS INCERTIDUMBRES.}

En el proceso de modelización del real, por modelos más simples, es necesario despreciar los defectos en alguna medida y, para ello, los diseñadores están forzados a imponer hipótesis, que son generadoras de incertidumbre. Por otra parte, el establecimiento de las características también está sujeto a realizar hipótesis y por lo tanto, también genera incertidumbres. Por eso, la incertidumbre de simulación/especificación depende tanto del operador que conduce al modelo final, definido como el conjunto ordenado de operaciones, como de la forma en que estas operaciones se formulan, utilizando diferentes expresiones y/o algoritmos matemáticos o geométricos (operaciones de determinación de las características). Las hipótesis que generan incertidumbre tienen que ver con despreciar un fenómeno por su poca influencia o por la falta de conocimiento de los diseñadores del fenómeno. Estos últimos son los realmente peligrosos y que deben ser objeto de atención.

De alguna manera, tal y como se intuye del párrafo anterior, se puede decir que todos los elementos presentes en la propia definición Geospelling, operaciones, características, etc., originan en principio incorrecciones o inconcreciones que son fuente de 
incertidumbre. Este esquema ya estuvo presente tanto en los trabajos de Srinivasan [Srinivasan, 2001] como en los de la norma ISO [ISO17450-2, 2012], que definieron tres tipos de incertidumbres (Figura 3.11):

- Las incertidumbres de correlación, que provienen de la diferencia entre el operador de especificación considerado y el operador funcional, que es el que establece el conjunto de operaciones que aseguran una correlación perfecta con la función prevista de la pieza o elemento geométrico.

- Las incertidumbres de especificación, inherentes a cómo el operador considerado es aplicado sobre la pieza o elemento geométrico.

- Las incertidumbres de medida, que son la suma de las incertidumbres del método, resultantes de la diferencia entre el operador de especificación y el operador de verificación considerados, y la incertidumbre de la propia realización de la medida (incertidumbre de los medios), proveniente de la divergencia entre las características metrológicas del operador de verificación considerado y las características metrológicas ideales definidas por el operador de verificación perfecto.

\subsection{EL MODELADO ESTRUCTURAL Y FUNCIONAL DEL PRODUCTO.}

A pesar de las grandes aportaciones realizadas en los últimos veinte años por diferentes investigadores e industriales, aún se están desarrollando métodos y herramientas que permitan facilitar la cooperación entre todos los actores que intervienen en el proceso de diseño, puesto que muchas veces pertenecen a culturas muy diferentes y el lenguaje que utilizan es específico del campo de especialización al que pertenecen [Dufaure, 2005]. Para resolver este problema, Grabowski et ál. [Grabowski et ál., 1999] propusieron en su momento una teoría de diseño que proporcionaba un lenguaje mínimo común para todos los participantes en el ciclo de diseño de un producto. Una teoría que describe el proceso de diseño en cuatro grandes fases que dan lugar a cuatro modelos:

- El modelo de requisitos, que lista las restricciones sobre el producto.

- El modelo funcional, que describe cómo el modelo debe responder a las restricciones del modelo de requisitos.

- El modelo geométrico de esqueleto, que permite describir la geometría del producto con la ayuda de elementos geométricos básicos (punto, recta, superficie, etc.).

- El modelo de geometría sólida del producto, derivado del de tipo esqueleto y en el que el diseñador agrega a esta geometría básica una descripción volumétrica y asigna un material.

Al proceso de diseño como un proceso de maduración o de enriquecimiento ya hicieron referencia en su día Pahl y Beitz [Pahl y Beitz, 1996], que dividieron este proceso en cuatro etapas, que dan lugar a cuatro descripciones:

- Un principio de diseño.

- Una distribución preliminar: un esqueleto.

- Un diseño completo de forma: una piel funcional.

- Un diseño detallado: un modelo geométrico final.

Se trata de dos descripciones del proceso que ponen en evidencia la necesidad de modelar las funciones y los componentes en interacción (modelado estructural). Unos modelos estructurales (de esqueleto o de piel funcional) que deben adecuarse a los 
razonamientos de las primeras fases del diseño, donde no se conoce la forma detallada de los componentes.

El modelado estructural de productos ha sido bastante estudiado en los últimos años, sobre todo en base a la utilización de diferentes tipos de grafos (grafos directos, grafos and/or, redes de Petri, etc.) usuales en el dominio de la planificación de secuencias de ensamblaje, y últimamente con modelos de producto orientados a sistemas, que explotan las posibilidades de las tecnologías de modelado semántico (por ejemplo, CPM y OAM del NIST, que serán descritos en el capítulo 4, o el modelo de producto de PPO, que será descrito más adelante en este mismo capítulo) y las ontologías. Un tipo de modelos que han adquirido una gran relevancia por su adecuación al desarrollo colaborativo de productos. Pero esta orientación también ha marcado la evolución del modelado geométrico (modelado geométrico de ensambles), que ha sufrido una rápida evolución, caracterizada por el modelado basado en elementos característicos (features) de ensamble o multi-punto de vista, que como ya se ha indicado serán tratados en el capítulo siguiente, y a otros modelos, como los de tipo esqueleto y piel, que luego se tratarán en mayor profundidad.

Toda una serie de modelos que tradicionalmente se basaban en geometrías perfectas, con superficies sin defectos de forma y/o de orientación, de manera que las herramientas de simulación de mecanismos, de cálculo de estructuras y de cadenas de cotas se integraban sin problema alguno con los sistemas CAD basados en la modelización nominal. Todo ello a pesar de que tanto los defectos geométricos, como los defectos de los materiales, tienen una influencia nada despreciable y son causa de graves disfunciones.

De ahí que en las últimas décadas se haya dado más importancia a la modelización y comunicación (especificación) de las diferentes variaciones de un producto, tanto por la importancia que tienen en la especificación del producto y la definición de los procesos de fabricación y de inspección, como en la integración de estas actividades. En este momento, y a pesar de las grandes aportaciones realizadas en las dos últimas décadas, aún se puede afirmar la necesidad de fijar un lenguaje completo y común para la descripción del producto en todas las tareas vinculadas con la especificación y la verificación geométrica de los ensambles, indispensable para permitir que los actores participantes en este proceso puedan almacenar y recuperar los datos requeridos.

La necesidad de modelos enriquecidos en este dominio ha dado lugar a muchas propuestas, basadas en representaciones geométricas y/o en grafos, que consideran información vinculada con la geometría con defectos y con las configuraciones de las juntas/contactos que conforman un mecanismo o ensamble, que serán presentadas en este subapartado. Pero antes de detallar estas propuestas se presentará el modelo de producto PPO, un modelo semántico del producto simple que presenta grandes posibilidades para la especificación y el análisis geométrico. Otras propuestas de modelado semántico de productos (CPM y OAM del NIST, etc.) que contemplan el concepto de elemento característico, y tal y como ya se ha indicado, se presentarán en el capítulo siguiente.

Pero antes de pasar a describir estos modelos, en estos párrafos se va a profundizar en la noción de configuraciones de juntas/contactos, citada en el párrafo anterior. El término de configuración de juntas (links en inglés o liasons en francés) de un ensamble se encuentra en el trabajo de Dantan et ál [Dantan et ál., 2008], que indican que las características funcionales del ensamble dependen de las configuraciones del mecanismo. Una configuración que, según Dantan et ál., se define como una posición relativa de las piezas de un ensamble que depende de las juntas que presentan juego entre piezas. Juegos que inducen desplazamientos entre piezas, cuyas posiciones relativas definen la configuración de la junta. Dantan et ál., tal y como se verá en el subapartado dedicado a las especificaciones, también indican que, normalmente, cuando se utiliza el concepto de 
especificación clásico existe ambigüedad en la expresión de los requisitos geométricos y que esto hace que la interpretación del requisito geométrico no sea univoca.

Para Costadoat [Costadoat, 2010], que utiliza el concepto de configuración de contacto, esta configuración se corresponde con un estado del mecanismo en el que los valores de los componentes de los torsores de pequeño desplazamiento, noción que se explicará en el apartado 3.5, están fijados. Según este autor, las configuraciones que aparecen en un mecanismo son importantes para modelar su comportamiento y, así, conseguir buenos diseños, eligiendo aquellos mecanismos que tengan un menor número de configuraciones y que estas sean buenas. Se trata de un concepto que el autor desarrolla, fundamentalmente, alrededor del estudio de mecanismos hiperestáticos y con el objetivo de mostrar cómo construir un sistema de ecuaciones que permita la especificación geométrica de las piezas. Para un mecanismo hiperestático, en función de la configuración elegida, la situación relativa de las piezas puede definirse por varias ecuaciones que relacionan las diferentes piezas y juntas. Unas relaciones entre piezas que normalmente se caracterizan por diferentes caminos (cadenas) en las representaciones basadas en grafos de tolerancias. En las juntas hiperestáticas un requisito geométrico se traduce en varios caminos, a diferencia del resto en el que un requisito geométrico se traduce en un solo camino entre piezas.

A esta problemática de las configuraciones y de los caminos también hace referencia Socoliuc [Socoliuc, 2010], que indica que la modificación o la optimización de los esquemas de acotado (o conjunto de cadenas que se corresponde con un sistema de ecuaciones) que respondan a las diferentes restricciones no es tan fácil y que para ello se necesita de una vista funcional del ensamble estudiado.

\subsubsection{El Modelo de Producto de PPO.}

Este modelo fue creado en el proyecto IPPOP (Integration of Product, Process and Organisation for Performance Enhancement in Engineering / Integración de Producto, Proceso y Organización para le Mejora del Desempeño en Ingeniería) y se basa solo en cuatro conceptos: componente (Component), interfaz (Interface), función (Function) y comportamiento (Behaviour). Se trata de un modelo que inicialmente estaba pensado para la etapa conceptual y que se desarrolló con el objetivo de enlazar los modelos estructurales con los modelos funcionales de producto, objetivo que se consiguió a través del concepto de interfaz, como entidad de enlace entre ambos modelos.

El modelo se describió de forma muy sencilla mediante un diagrama UML, tal y como ilustra la Figura 3.6. Un componente, que posee una o más interfaces, es la solución técnica a una función, que a su vez representa un requisito funcional impuesto sobre el producto o una condición de contacto entre interfaces.

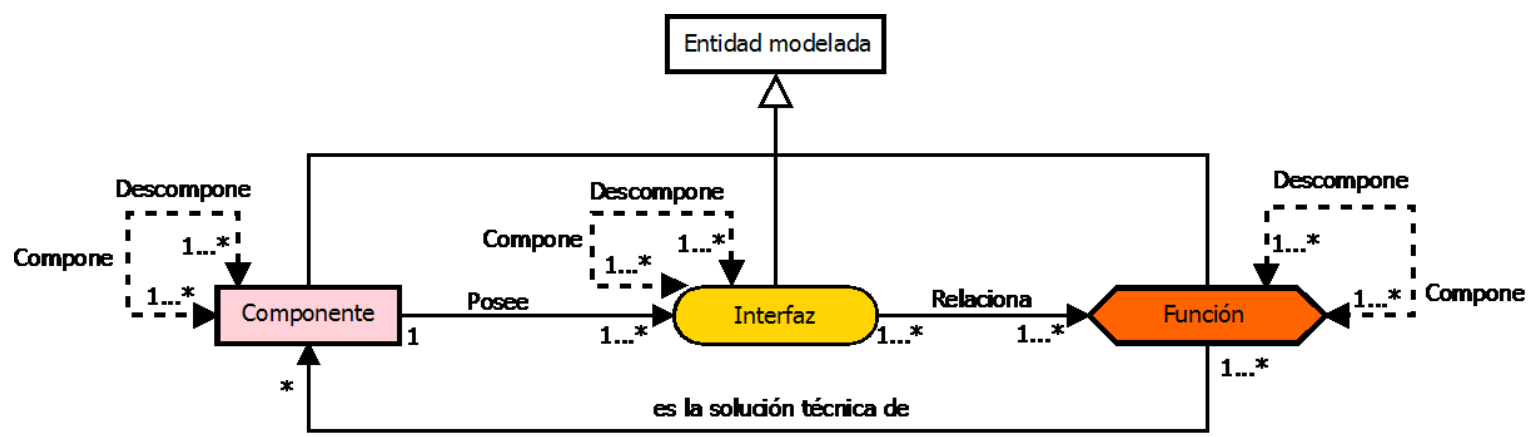

Figura 3.6 Objetos y relaciones del modelo de producto del proyecto IPPOP (Integration of Product, Process and Organisation for Performance Enhancement in Engineering) [de Ballu et ál., 2007]. 
Profundizando en el concepto de interfaces, estas pueden ser vistas [Dufaure, 2005] como "propiedades de los componentes a través de las que los componentes se relacionan entre sí con el fin de proporcionar una solución técnica a diferentes especificaciones funcionales". Aunque las interfaces de un componente pueden ser propiedades de diversos tipos, en el modelo de producto propuesto adquiere especial importancia la interfaz de tipo forma, que es una agregación de geometría y material.

Pero con el tiempo, el modelo PPO, que como se acaba de indicar se concibió para la fase de diseño conceptual, se fue utilizando en otras etapas del ciclo de desarrollo del producto o dominios de especialización diferente a la conceptual, como es el caso del dominio del tratamiento de las tolerancias en fases avanzadas [Dufaure, 2005]. Para ello, el modelo se tuvo que adaptar y reinterpretar, permitiéndose describir las especificaciones funcionales, resultantes del cuaderno de requisitos, y las especificaciones geométricas de cualquier nivel con la ayuda de una misma entidad: la función. De esta forma se consiguen ligar las funciones con las especificaciones funcionales de alto nivel, las especificaciones geométricas correspondientes, y estas con las especificaciones de las tolerancias geométricas normalizadas establecidas a nivel de pieza, utilizando para ello la operación de descomposición de la entidad función, que adicionalmente facilita el control de la trazabilidad de estas especificaciones. Una descomposición que también afecta a los componentes de la descripción estructural: componentes e interfaces. Dos nociones que ya se han descrito en el apartado anterior, donde también se ha visto que las superficies de interfaz se pueden modelar de diferentes formas, que van desde el primitivo hasta el de simulación y que las interfaces mecánicas de contacto (contactos) se deben modelar con dos superficies.

\subsubsection{LOS MODELOS GEOMÉTRICOS Y BASADOS EN GRAFOS EN LAS PRIMERAS FASES DEL DISEÑO.}

Una vez que se ha descrito el modelo semántico de producto PPO, un modelo de alto nivel que integra los dominios estructural y funcional, este apartado va a centrarse en analizar algunos modelos geométricos y basados en grafos utilizados en la especificación y análisis de los ensambles en las fases tempranas del proceso de diseño. Se trata de modelos basados en geometría ideal, porque en estas fases el diseñador no suele razonar sobre geometrías con defectos cercanas al real. Unos modelos que se tratarán en el siguiente subapartado, dedicado a los modelos en fases avanzadas.

El punto de partida para la gestión de las variaciones geométricas [Costadoat, 2010] en el proceso de diseño es, usualmente, una solución técnica, modelizada por su geometría nominal (bajo la forma de un esqueleto o una piel), una arquitectura nominal (juntas) y las condiciones geométricas (especificaciones geométricas funcionales a nivel de ensamble). Pero una vez establecida la solución técnica, como para acometer la especificación final de las tolerancias lo normal es apoyarse en métodos de simulación y estos necesitan que se añadan defectos a las representaciones nominales, son necesarias representaciones enriquecidas que contemplen información vinculada a los defectos y sus efectos en los ensambles.

Los métodos de simulación (métodos de análisis de tolerancias), tal y como se verá en el apartado siguiente, se basan en determinados modelados matemáticos que representan cómo el comportamiento geométrico del mecanismo es impactado por las variaciones geométricas. Con ellos, y en base a estas representaciones geométricas con defectos, el diseñador puede, entre otros aspectos: a) detectar las desviaciones de las superficies y juntas influyentes en los ciclos hiperestáticos, fundamental para cumplir los requisitos de ensamblabilidad; y b) determinar las contribuciones de las superficies y juntas en la 
determinación de las variaciones de los requisitos geométricos. Por lo tanto, las metodologías de simulación están directamente vinculadas con las representaciones de las geometrías y de las arquitecturas.

Entre las propuestas para el modelado geométrico con defectos para la simulación se encuentra la de Costadoat at ál. [Costadoat et ál., 2009] que, como ya hiciera Ballot [Ballot, 1995], propusieron modelar el comportamiento de la geometría de sustitución (concepto que se desarrolla en el apartado 3.5), modelándola añadiendo defectos (tamaño, posición y orientación) sobre el nominal. Como Costadoat eligió modelar el comportamiento geométrico en base a torsores de pequeño desplazamiento (ver apartado 3.5), a la geometría que resulta de aplicar los torsores de desviación sobre los elementos geométricos nominales la llamó geometría con defectos. Se trata de una geometría que permite una simulación basada en geometrías ideales y que no contempla las resultantes de las geometrías reales.

Según Costadoat, la geometría con defectos reúne dos partes: el esqueleto con defectos y la piel con defectos. El esqueleto con defectos se construye en base al nominal, que está compuesto por elementos geométricos ideales (punto, recta, plano y hélice) que constituyen los elementos de situación nominales de las juntas del mecanismo y que están relacionados con superficies (a modo de elementos de un sistema de coordenadas local que se vincula a una superficie). Estos elementos son los que permiten generar los elementos de situación con defectos, desplazándolos (en orientación y posición) de acuerdo con los valores de los componentes del torsor de desviaciones. Se trata de unos elementos que configuran el esqueleto con defectos.

Por su parte, las geometrías de piel con defectos se definen a partir de los elementos de situación con defectos descritos anteriormente y permiten representar las variaciones de las geometrías intrínsecas de tamaño, integrando otras fuentes suplementarias de defectos. Las variaciones intrínsecas de forma no se contemplan en este modelo y, como se verá posteriormente, son fuente de incertidumbre.

Pero si la representación de tipo esqueleto es fundamental en el inicio del proceso de toleranciado, la representación de la arquitectura del producto no lo es menos. Para Costadoat todas las informaciones relativas a las juntas (relaciones entre piezas) se agrupan bajo el término arquitectura del mecanismo (producto). Un término que de forma genérica se ha relacionado con la manera en que las cosas (abstractas o concretas) se organizan para formar un conjunto (un todo) y que tradicionalmente se ha representado mediante grafos.

En concreto, los grafos de toleranciado derivan de los grafos de juntas utilizados para representar la cinemática de un mecanismo y además de representar la arquitectura pueden ayudar a coleccionar información muy relevante para el análisis de tolerancias. Para que sirva como ejemplo, los grafos de tolerancias propuestos inicialmente por Ballu y Mathieu [Ballu y Mathieu, 1999], utilizados por el GRT (Groupe de Recherche en Tolérancement / Grupo de Investigación en Toleranciado) de Francia y que han ido evolucionando, contienen información sobre (Figura 3.7):

- los componentes, las superficies y los elementos de situación,

- las juntas,

- las condiciones geométricas (requisitos geométricos),

- los ciclos e influencias (cadenas),

- las especificaciones,

- y el posicionamiento o la secuencia de ensamblaje.

En estos grafos la arquitectura es la representación más básica: las juntas y los componentes, las superficies y los elementos de situación que las forman. Para Costadoat "una junta existe entre dos componentes o dos superficies si y solo si, en el funcionamiento normal del mecanismo, puede haber contacto entre ellos". Unos contactos que pueden ser 
deseables o no deseables (caso de superficies próximas que no deben entrar en contacto) y que se agrupan [Dantan, 2000] en tres clases:

- Contactos flotantes, cuando las dos superficies en contacto tienen dos tipos de desplazamientos relativos posibles: tangenciales y normales.

- Contactos deslizantes, cuando el contacto es restringido por una acción mecánica que solo permite desplazamientos tangenciales en la utilización normal del mecanismo.

- Contactos fijos, cuando el contacto está restringido por una acción mecánica que produce una adherencia que no permite ningún desplazamiento relativo entre las dos superficies en una utilización normal del mecanismo.

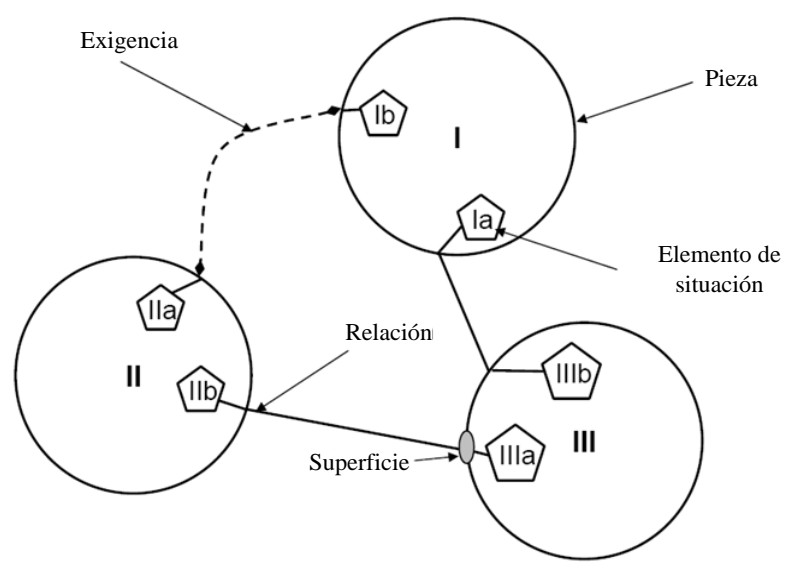

Figura 3.7 Grafo de relaciones [de Costadoat, 2010].

En el modelado de las ecuaciones de comportamiento, a los diferentes tipos de contactos les corresponden diferentes formas de torsores o formas de matrices de grados de libertad, etc., que determinan los desplazamientos autorizados o no autorizados entre los elementos de situación de los elementos geométricos con defectos. Unas formas de limitar la variabilidad de las diferentes juntas que es fundamental tener en cuenta en los modelos enriquecidos que permiten razonamientos sobre ensambles/mecanismos.

Pero los grafos de tolerancias van más allá de la pura representación de las arquitecturas, porque también permiten identificar los ciclos de desplazamientos (cadenas), fundamentales para el análisis de tolerancias de los mecanismos, y que pueden ser, según su contenido, de dos tipos:

1. Ciclos de montabilidad (componentes y juntas).

2. Ciclos de requisito (componentes, juntas y un requisito).

Los de la primera categoría se vinculan con el riesgo del hiperestatismo, que puede impedir el montaje del mismo, mientras que los de la segunda, ciclos funcionales, indican al diseñador qué juntas y piezas influyen en una condición geométrica. En general, se puede decir que la definición de los ciclos es fundamental, porque permite estudiar los conjuntos de piezas del mecanismo y analizar el impacto de los defectos geométricos sobre el comportamiento de los mecanismos. Los análisis de hiperestatismo y de sensibilidad, que se pueden realizar en las primeras fases del diseño sobre estos grafos, permiten mejorar la robustez del mecanismo y que las juntas y los parámetros arquitectónicos elegidos inicialmente puedan evolucionar, evitando la aparición de configuraciones de contactos que conducen a especificaciones demasiado costosas y reduciendo el número de configuraciones posibles.

Se trata de un proceso de refinamiento que permite simplificar el sistema de ecuaciones y que da lugar a todo un conjunto de información sobre las evoluciones en los 
contactos y las juntas, que se puede agrupar a la arquitectura nominal y que da lugar a lo que Costadoat denomina como arquitectura con defectos. Cabe recordar que para este autor el concepto de arquitectura nominal viene a indicar que las juntas son nominales (ideales), es decir, que los elementos de situación de los componentes que la forman se confunden.

\subsubsection{LOS MODELOS GEOMÉTRICOS EN LAS FASES AVANZADAS DEL DISEÑO.}

Finalmente, una vez que los materiales y procesos de fabricación ya se han seleccionado en las fases de diseño detallado, ya se pueden definir los volúmenes asociados a las superficies funcionales. Se trata de un modelo de sólidos (modelo de volumen) que permite, por ejemplo, el análisis del comportamiento mecánico y resistente.

En lo que respecta al modelado geométrico de defectos, cuando se avanza en el proceso de diseño se tiene un mayor conocimiento de las causas que provocan la variabilidad en las formas geométricas, por lo que en estos momentos es conveniente disponer de modelos de geometría con defectos basados en geometría de tipo discreto. El término discreto hace referencia a que los objetos de interés son información discreta (conjunto de puntos, mallas triangulares, mallas tetraédricas, etc.) en contraste a la geometría continua.

De entre los trabajos existentes que proponen representar la geometría con defectos de forma discreta se encuentra el de Zhang [Zhang, 2012]. Este autor, en su tesis, propone métodos para simular el modelo de piel en el marco de Geospelling de forma discreta, incluyendo desviaciones aleatorias y considerando los errores sistemáticos. Por su parte, Schleich et ál. [Schleich et ál., 2014] también realizan una contribución en la operatividad del concepto de modelo de piel de Geospelling utilizando geometría discreta. Para ello, estos autores presentan un proceso de generación de formas del modelo de piel (Skin Model Shapes), que representan al modelo de piel desde la perspectiva de la simulación, y que incluye desviaciones procedentes de la fabricación y el ensamblaje.

\subsection{EL DISEÑO DE TOLERANCIAS EN EL DESARROLLO DEL PRODUCTO.}

En los apartados anteriores se han tratado toda una serie de nociones que tienen por objeto obtener una representación de sistema común para las actividades de diseño y simulación, centrándose para ello en las propiedades de tipo geométrico y en las actividades de modelado y de transformación de la geometría con defectos. Pero una vez que se ha modelado el sistema, se pasa a la actividad de resolución (la propia simulación, entendida en un sentido amplio) y luego a la actividad de evaluación (post-tratamiento). Centrando la atención en la actividad de resolución, es importante reseñar que esta se basa en la utilización de una serie de técnicas (útiles), metodologías y herramientas software que condicionarán el uso de un determinado tipo de modelo y que en última instancia determinarán la coherencia del proceso con las hipótesis establecidas. Por ello, en este apartado se repasarán algunas nociones vinculadas con el Diseño de Tolerancias. Una exposición cuya finalidad es acercarse al dominio del toleranciado dimensional y geométrico y que complementará lo expuesto en el anterior apartado.

Como ya se ha comentado en la introducción, a pesar de los grandes avances que se producen en la precisión y exactitud de los modernos procesos de fabricación, las desviaciones geométricas, entendidas como desviaciones con respecto a la geometría ideal/nominal, son observables en todas las piezas fabricadas, consecuencia de los cambios y las fluctuaciones en los parámetros de los procesos (imprecisiones de fabricación e 
incertidumbres de medida), y tienen fuertes repercusiones en las siguientes etapas del ciclo de vida del producto, como el ensamblaje y el uso, con las connotaciones que sobre la calidad, coste y entrega del producto puede suponer la elección de una determinada gestión de las desviaciones en todo su ciclo de vida. Por eso, a lo largo del tiempo de han establecido todo un conjunto de metodologías, Diseño de Tolerancias, que tienen por objetivo predecir y cuantificar los efectos de las desviaciones sobre su comportamiento funcional y sobre la calidad del producto. Un objetivo que cada vez más se pretende llevar a cabo en las primeras fases del desarrollo del producto, para asegurar cuanto antes el cumplimiento de los requisitos funcionales.

El Diseño de Tolerancias es el primer paso en la gestión tradicional de las variaciones geométricas en el proceso de Desarrollo Integrado del Producto (Toleranciado) y según Salomons et ál. [Salomons et ál., 1996a y 1996b], que analizaron los sistemas CAT (Computer Aided Tolerancing / Toleranciado Asistido por Ordenador), reposa sobre cuatro tópicos fundamentales: la representación de tolerancias, la especificación de tolerancias, la asignación o síntesis de tolerancias y el análisis de tolerancias. Otros trabajos consideran otros tópicos de interés [Hong y Chang, 2002], pero coinciden en la importancia de los anteriormente citados.

La especificación de tolerancias, en un sentido más reducido del término que el considerado para la exposición en el apartado 3.2, consiste en especificar los tipos y valores de las tolerancias, y es uno de los ámbitos que menos atención ha recibido [Hong y Chang, 2002]. En la práctica, cuando el diseñador especifica el tipo y valor de las tolerancias se basa, muy habitualmente, en su propia experiencia o en información empírica. Las aportaciones dirigidas a construir herramientas automatizadas aún son limitadas. Según Salomons et ál. [Salomons et ál., 1996a y 1996b] consiste en la representación gráfica de los requisitos geométricos y mencionan como tema importante la necesidad de disponer de un lenguaje completo y sin ambigüedades para que pueda ser utilizado por los diferentes grupos de especialistas.

Por su parte, el método para diagnosticar el funcionamiento apropiado de un diseño recae en el análisis de tolerancias [Hong y Chang, 2002], ámbito en el que se han desarrollado muchas propuestas. Básicamente los métodos de análisis son de tipo determinista o de tipo estadístico, mientras que los modelos sobre los que se hace el análisis son 1D, 2D o 3D. Algunas de las principales propuestas para el análisis de tolerancias se revisarán más adelante, por su interés y vinculación con los modelos de representación de tolerancias. Según Salomons et ál. [Salomons et ál., 1996a y 1996b], el análisis de tolerancias es el proceso de cuantificación de la influencia del sistema (conjunto) de toleranciado definido sobre los requisitos funcionales.

La síntesis de tolerancias incluye los métodos para la asignación (reparto o distribución) de un grupo óptimo de tolerancias a los componentes individuales que intervienen de forma conjunta para satisfacer un requisito funcional o de ensamblaje relativa al conjunto [Hong y Chang, 2002]. La síntesis de tolerancias se lleva a cabo en sentido opuesto al análisis de tolerancias: de la tolerancia del requisito de interés a las tolerancias individuales. Según Salomons et ál. [Salomons et ál., 1996a y 1996b], la síntesis de tolerancias es el proceso de determinación de las tolerancias cualitativa y cuantitativamente óptimas para respetar los requisitos funcionales del ensamble.

Como se puede ver, existe alguna discrepancia sobre la extensión de la especificación de tolerancias, es decir sobre si se limita al estudio de los lenguajes de representación o incluye la selección del tipo y valor de las tolerancias, que en cualquier caso no estaría sujeto a criterios de optimización que tengan en cuenta aspectos de fabricación e inspección. En el desarrollo de esta tesis se entenderá la especificación en un sentido amplio incluyendo el proceso completo, tanto de análisis como de síntesis. Por lo 
tanto, se entiende que es función de la especificación el asegurar la coherencia entre los modelos matemáticos, necesarios para la simulación que cualquier proceso de especificación supone, y las representaciones que permiten definir y expresar cuál será la condición que hará que un producto pueda ser considerado como aceptable o no aceptable.

Por su parte, Mansuy [Mansuy, 2012] establece que en los ejercicios de toleranciado de sistemas mecánicos, sobreentendiéndose que son tanto para el proceso de análisis como para el de síntesis, se distinguen tres etapas: a) modelizar bajo la forma de objetos matemáticos las tolerancias y la geometría de las piezas con y sin defectos, obteniéndose de esta forma los modelos de desviaciones, de juegos y de requisitos geométricos; b) tener en cuenta el ensamble para establecer las relaciones que vinculan las variables de juegos, de desviaciones y de requisitos funcionales, unas relaciones que llama "ecuaciones de toleranciado"; c) traducir la condición de respeto del requisito funcional en un sistema de ecuaciones e inecuaciones, con la ayuda de las relaciones precedentes (cadenas). También indica que la resolución de estos sistemas se puede realizar mediante dos tipos de operaciones: buscando el peor caso o siguiendo un criterio estadístico. El método del peor caso tiene en cuenta las desigualdades llevándolas sobre las desviaciones de las geometrías limitadas por las tolerancias. En el estadístico, se suponen conocidas las funciones de densidad de la probabilidad y las dependencias relativas a las variables aleatorias de las desviaciones geométricas para deducir los datos estadísticos relativos a las variables que describen las condiciones funcionales.

\subsubsection{EL ANÁLISIS DE TOLERANCIAS EN ENSAMBLES.}

Sobre el análisis de tolerancias Kamali Nejad [Kamali Nejad, 2010] indica que el recrecimiento de las desviaciones (acumulación) se produce tanto en un proceso de fabricación como en uno de ensamble. Por eso, indica que el análisis de tolerancias se divide en análisis de tolerancias en fabricación y análisis de tolerancias en ensambles. El primero, también conocido como propagación de errores en procesos de mecanizado multietapa [Kamali Nejad et ál., 2009], tiene como propósito el verificar si las tolerancias funcionales de una pieza pueden obtenerse con un plan de proceso conocido y con unas desviaciones de fabricación específicas, mientras que el del segundo es comprobar el resultado de un ensamble (requisito funcional) cuando diferentes piezas con desviaciones se posicionan juntas. También indica que en ambos casos es necesario obtener la acumulación de desviaciones para comprobar cuándo las cantidades acumuladas son aceptables o no comparadas con tolerancias funcionales o requisitos funcionales.

Por su parte, respecto de los métodos de análisis, indica que estos se pueden clasificar en métodos de variaciones dimensionales y métodos de variaciones geométricas. Al primer grupo pertenecen las técnicas de cadena de tolerancias dimensionales, que representan una cadena en la que las tolerancias dimensionales $( \pm)$ se vinculan a un eslabón. Mientras que el segundo, que denomina de propagación de tolerancias 3D, cubre cadenas con tolerancias geométricas y dimensionales 3D. Este problema se resuelve, como se verá más adelante, utilizando diferentes técnicas de modelado de las zonas de variación como son los modelos de zona envolvente, los paramétricos, los de región multivariante, los de grados de libertad o los de torsores de pequeño desplazamiento.

El autor del trabajo citado anteriormente, cuando se detiene en este segundo grupo de técnicas, indica que los dos tópicos que han sido objeto de una atención preferente son la representación de la zona de tolerancia y el mecanismo de propagación (acumulación) de la tolerancia espacial. La zona de tolerancia representa para Kamali Nejad el alcance de la variación de un elemento geométrico o de sus elementos característicos (features) basado en un estándar elegido (por ejemplo, un plano o un eje de un cilindro), y un buen modelo de las zonas de variación es aquel que hace posible que converjan las semánticas completas 
de las tolerancias geométricas $\mathrm{y}$, al mismo tiempo, que posean una estructura general que pueda ayudar a analizar como las tolerancias se propagan (acumulan) en el espacio tridimensional.

En ese mismo sentido se pronuncian Khodaygan et ál. [Khodaygan et ál., 2010] cuando hacen referencia al ejercicio del análisis dimensional de ensambles, indicando, de forma similar al planteamiento expuesto por Mansuy, que este análisis se realiza en tres pasos. El primero es el modelado de las tolerancias, en el que un modelo matemático, conocido como función de ensamble (relación matemática para calcular la acumulación), es derivado para describir las variaciones dimensionales y geométricas de los componentes. Esta función es la ecuación más importante, tanto para el análisis como para la síntesis. El segundo paso es la preparación de la función de ensamble para el análisis de acumulación. Dependiendo de si son modelos linealizables o no-linealizables, los tratamientos pueden ser diferentes. Los modelos linealizables desprecian simplemente los términos de mayor orden de las series de Taylor. Cuando el análisis linealizado no es aplicable, se debe utilizar el análisis no-lineal, como puede ser la simulación de Monte Carlo. El tercer paso, análisis de acumulación, es necesario para establecer los rangos de tolerancias para todas las dimensiones que están vinculadas con la función ensamble. Los enfoques (técnicas de solución o métodos de análisis) para realizar este análisis pueden ser el peor caso (para un 100\% de índice de aceptación) o el que utiliza métodos estadísticos (para índices de aceptación menores del 100\%), como puede ser el de la suma de las raíces cuadradas. El último paso es la predicción del nivel de aceptación en producción.

\subsubsection{EL ANÁLISIS DE TOLERANCIAS EN FABRICACIÓN.}

Tal y como se ha indicado en el subapartado anterior, el análisis de tolerancias en fabricación tiene como propósito el verificar si las tolerancias funcionales de una pieza pueden obtenerse con un plan de proceso conocido que tiene unas desviaciones concretas. Este análisis también se conoce como propagación de errores en procesos de mecanizado multi-etapa, por considerar el efecto acumulativo de todas las variaciones de cada etapa individual de fabricación [Kamali Nejad et ál., 2009]. Según este autor, y a pesar de que este aspecto de acumulación de variaciones es similar en fabricación y en el análisis de ensambles tratado en el subapartado anterior, existe también una diferencia significativa entre ambos casos, provocada por el hecho de que en fabricación la propagación de los errores a través de diferentes subfases no existe en el ensamble de producto, donde habitualmente todas las piezas del conjunto se ensamblan al mismo tiempo.

Kamali Nejad [Kamali Nejad, 2010] clasifica los trabajos en torno al análisis de tolerancias en fabricación en cuatro grupos de acuerdo a los siguientes enfoques: espacio de estado, zona de tolerancia, simulación y torsor de pequeño desplazamiento.

Dentro del grupo con un enfoque de espacio de estado cabe mencionar el trabajo de Huang y Shi [Huang y Shi, 2003] para la propagación del error de la pieza en operaciones de mecanizado sucesivas. En este trabajo las desviaciones de la superficie se expresan en términos de desviación de la orientación, posición y dimensiones nominales y utilizan una versión revisada del modelo de superficie vectorial desarrollado por Martinsen [Martinsen, 1993].

Otro de los trabajos con un enfoque de espacio de estado es el de Zhou et ál., [Zhou et ál., 2003] que utilizan un modelo de estado similar al de Huang y Shi, pero en el que las desviaciones de la superficie comparada con el estado nominal se expresan utilizando vectores de movimiento diferencial.

Algo más reciente es el trabajo de Loose et ál. [Loose et ál., 2007] que también utilizaron el modelo de espacio de estado con un vector de movimiento diferencial pero aumentaron la generalidad de la propuesta al incluir más tipos de disposiciones del utillaje, 
además de la de tipo 3-2-1 ortogonal que se consideraba en los dos trabajos mencionados anteriormente. Estos autores utilizaron un vector de estado que es una acumulación de vectores de movimiento diferencial para representar la desviación de la pieza. Las desviaciones de un elemento geométrico de expresan mediante una matriz de transformación homogénea.

Por último, dentro de este grupo de enfoque de espacio de estado cabe hacer referencia al trabajo de Zhong et ál. [Zhong et ál., 2000]. Estos autores propusieron un método de evaluación general para sistemas de fabricación en el que la calidad es uno de los criterios considerados. Con el fin de comprobar la relación entra la calidad y las configuraciones del sistema, los autores desarrollaron un modelo de propagación de la variación general que predice los resultados de la ejecución de la calidad para diferentes configuraciones del sistema de mecanizado.

En el segundo grupo de trabajos con un enfoque basado en expresar la desviación de una superficie como una zona de tolerancia para el análisis de la propagación de tolerancias está el desarrollado por Lin y Zhang [Lin y Zhang, 2001]. Estos autores clasifican los errores de fabricación de acuerdo a dos tipos de errores directamente relacionados con la precisión de una pieza acabada: los errores de posicionado y los errores de mecanizado. Lin y Zhang dividen el mecanismo de propagación en dos secciones, el mecanismo de propagación del error y el análisis de tolerancias geométricas, considerando tres tipos de zonas de tolerancia, 1D, 2D y 3D.

Bajo un enfoque basado en la simulación y, más concretamente mediante el método de Monte Carlo, Huang et ál. [Huang, et ál., 2004] propusieron un método para verificar un plan de procesos en términos de la predicción de la tolerancia de fabricación. El análisis de la acumulación de tolerancias en este estudio se basa en la síntesis de errores de mecanizado reales y la propagación del error a través de procesos múltiples.

El primer acercamiento al uso de los torsores de pequeño desplazamiento (que serán descritos en el apartado 3.5) con el objetivo de analizar la propagación de errores en mecanizado es el trabajo de Villeneuve et ál. [Villeneuve et ál., 2001]. Este enfoque fue seguido por Vignat y Villeneuve [Vignat y Villeneuve, 2003] para el caso de operaciones de torneado y, más adelante, para el caso más general de procesos de mecanizado mediante el desarrollo del Modelo de Pieza Fabricada (Model of Manufacture Part, MMP) por los mismos autores [Vignat, 2005; Vignat y Villeneuve, 2005; Vignat et ál., 2009]. En este modelo, los errores generados por un proceso de fabricación se consideran como el resultado de dos fenómenos independientes: el posicionado y el mecanizado. Las desviaciones se acumulan a lo largo de subfases sucesivas y el resultado se expresa en términos de desviación de las superficies reales comparadas con las de la pieza nominal. Por su parte, el trabajo de Kamali Nejad et ál. [Kamali Nejad et ál., 2009] realiza contribuciones a las técnicas de resolución asociadas al modelo MMP de Vignat et ál., proponiendo una formulación matemática detallada para el análisis de tolerancias basado en la búsqueda del peor caso.

Siguiendo este mismo enfoque, Legoff et ál. y Tischadou et ál. [Legoff et ál, 2004; Tichadou et ál., 2005] propusieron una representación gráfica del proceso de fabricación que permite resaltar aquellos caminos o alternativas que más influencia tienen en términos de la tolerancia funcional.

En esta misma área se encuentra el trabajo de Louati et ál. [Louati et ál., 2006], seguido después por Ayadi et ál. [Ayadi et ál., 2008], que propusieron un modelo 3D de la propagación de los errores geométricos en mecanizado para optimizar el montaje de la pieza en fabricación.

Otra propuesta de representación gráfica para integrar las tolerancias funcionales con un proceso de fabricación multi-etapa es la de Serrano et ál. [Serrano et ál., 2011]. Estos 
autores proponen una herramienta de representación gráfica unificada para integrar los elementos geométricos y las relaciones que definen un ensamble (grafo de ensamble) con las fases y subfases de fabricación (grafo de fabricación). Mediante la utilización de este grafo se puede identificar el bucle que relaciona los requisitos funcionales del mecanismo con las etapas de fabricación. Además, utilizando modelado 3D de tolerancias, este bucle se puede convertir en las cadenas de tolerancias funcionales.

\subsection{LA ESPECIFICACIÓN DE LA GEOMETRÍA DE PIEZAS.}

Las especificaciones de la geometría de la pieza y de sus partes son fundamentales en todo proceso de diseño, porque además de ser clave para la comunicación entre los participantes en las diferentes etapas del ciclo de vida de esa pieza (diseño, fabricación, uso, etc.) debe adecuarse a las necesidades de las metodologías y herramientas utilizadas en las mismas. En concreto, lo deberán ser, tal y como ya se ha indicado en los apartados anteriores, a las necesidades de los procesos de simulación, especificación y verificación.

Por ello, y sin el ánimo de ser exhaustivos, en este apartado se analizarán las representaciones matemáticas basadas en geometrías continuas y las representaciones que contemplan las normas de uso industrial. Después de esta parte se presentarán algunas consideraciones sobre el lenguaje Geospelling específicas del nivel de pieza. Los modelos de geometrías discretas [Schleich et ál., 2014] utilizados en el diseño de tolerancias no se tratarán.

\subsubsection{MODELOS MATEMÁTICOS BASADOS EN GEOMETRÍAS CONTINUAS.}

En la literatura existen varios trabajos que han revisado y categorizado las principales propuestas de modelos para la representación de la geometría con defectos para utilizar en el campo del toleranciado [Hong y Chang, 2002; Wu et ál., 2003, Shen et ál., 2008; Dufaure y Teissandier, 2008; Zhao et ál., 2011; Khan, 2011; Khodaygan et ál. 2010; Hussain et ál., 2012; Schleich et ál., 2014; Dufaure y Teissandier, 2008]. Cabe mencionar que, en muchos casos, en la revisión de estos trabajos se hace referencia no únicamente a modelos basados en geometría continua considerando la pieza de forma individual, sino que también se incluyen modelos matemáticos que hacen referencia al tratamiento de las tolerancias en conjuntos. En este subapartado, se ha extraído únicamente la información que corresponde a modelos de pieza individual, identificándose los siguientes grupos: modelos de atributos, modelos de correlación/traslación o modelos de zona envolvente, modelos vectoriales, modelos variacionales y paramétricos, modelos de región multivariante, modelos de grados de libertad y modelos de torsor de pequeño desplazamiento. Los cinco primeros grupos se describen muy brevemente a continuación, mientras que los modelos de grados de libertad y los modelos de torsor de pequeño desplazamiento, por su interés y mayor relación con el trabajo desarrollado en esta tesis, se describen con algo más de detalle.

En los modelos de atributos (attribute models) las tolerancias se almacenan directamente como atributos, bien de entidades geométricas o bien de relaciones métricas, sin incorporar ningún tipo de semántica y, por lo tanto, no siendo posible utilizarlas para la validación de las especificaciones dimensionales y geométricas.

Los modelos de corrección/traslación o modelos de zona envolvente (offset models o envelope zone models) representan la tolerancia como la diferencia entre los volúmenes máximo y mínimo del objeto obtenidos mediante la traslación de dicho objeto hacia ambos lados de la línea nominal. Estos modelos no permiten ni la interrelación ni la composición 
de varias tolerancias sobre el mismo elemento característico, ya que cada tolerancia requiere su zona de tolerancia separada.

Las tolerancias de posición, orientación, forma y dimensión de una pieza se representan en los modelos vectoriales (vectorial models) mediante vectores. Además, a cada vector se le asocian dos parámetros para representar a) el estado nominal y b) la variación. Para definir una superficie real se realiza la adición vectorial de los estados nominales y de las variaciones. A este tipo de modelos también se les conoce como Modelos de Acotado Vectorial (Vectorial Dimensioning \& Tolerancing Model o VD\&T) y será descrito con algo más de detalle dentro de este mismo apartado 3.5, en el subapartado 3.5.2 correspondiente a la descripción de algunos de los conceptos más importantes relacionados con las normas de especificación.

En los modelos paramétricos (parametric models) las tolerancias se representan como variaciones más/menos $( \pm)$ de parámetros dimensionales. El modelo paramétrico consiste en un conjunto de relaciones (ecuaciones) matemáticas correlacionadas en las que las diversas casuísticas se definen variando los valores de un conjunto de coeficientes (parámetros) fijos mediante resolución iterativa. En los modelos de superficies variacionales (variational surfaces models) las tolerancias se asocian con las definiciones de superficies que incluyen las variables del modelo. Si se modifican las variables o parámetros del modelo, la superficie frontera de una pieza variacional puede variar independientemente, y las limitaciones a estas variaciones vienen impuestas por las tolerancias. Los modelos variacionales tienen muchas similitudes con los modelos paramétricos, de la misma forma que ocurre con los enfoques de diseño paramétrico y variacional. De hecho, en muchas ocasiones los términos "paramétrico" y "variacional" se han utilizado como sinónimos en contextos técnicos y especialmente comerciales. Es más, el enfoque variacional se puede considerar más general que el paramétrico, pudiendo ser este último un subtipo del primero [Zhao et ál., 2011].

En los modelos de región multivariante (multi-variate region models) las entidades geométricas (planos, líneas, círculos, cilindros, etc.) se hacen corresponder con un espacio vectorial hipotético mediante los puntos o líneas base correspondientes a las variaciones geométricas. El modelo más conocido dentro de este grupo es el denominado modelo "Mapa de tolerancias" (Tolerance Map o "T-Map"). Un T-Map es un espacio euclídeo hipotético de puntos que es una correspondencia uno a uno de las zonas de tolerancia geométricas. Una zona de tolerancia es la zona real del espacio que incluye todas las posibles variaciones para el elemento característico objetivo. El tamaño y la forma del TMap refleja todas las posibles variaciones que puede tener el elemento característico objeto de análisis.

\subsubsection{MODELOS DE GRADOS DE LIBERTAD.}

Los modelos de grados de libertad (degrees of freedom, DOF models) tratan las entidades geométricas como si fuesen cuerpos rígidos con seis grados de libertad (g.d.l.), tres rotaciones y tres traslaciones, y sus relaciones geométricas (angulares y lineales) son restricciones sobre esos g.d.l.

Todas las entidades geométricas en el espacio 3-D pueden resolverse a través de tres entidades geométricas primitivas, punto, línea y plano, y de sus combinaciones, dando lugar a los seis casos de primitivas de referencia que se muestran en la Figura 3.8 [Kandikjan et ál., 2001].

Algunos de los casos de primitivas de referencia pueden dar lugar a un sistema de coordenadas incompleto para la posición y orientación de las zonas de tolerancia, dejando algunos de los g.d.l. libres. Esto lleva a distinguir los g.d.l. invariantes, que son aquellos cuya variación no transformará la dimensión, posición u orientación de la entidad 
geométrica y que, por tanto, no es necesario controlar en el análisis de tolerancias, de los g.d.l. activos (o no invariantes) que sí será necesario controlar [Shen et ál., 2008].

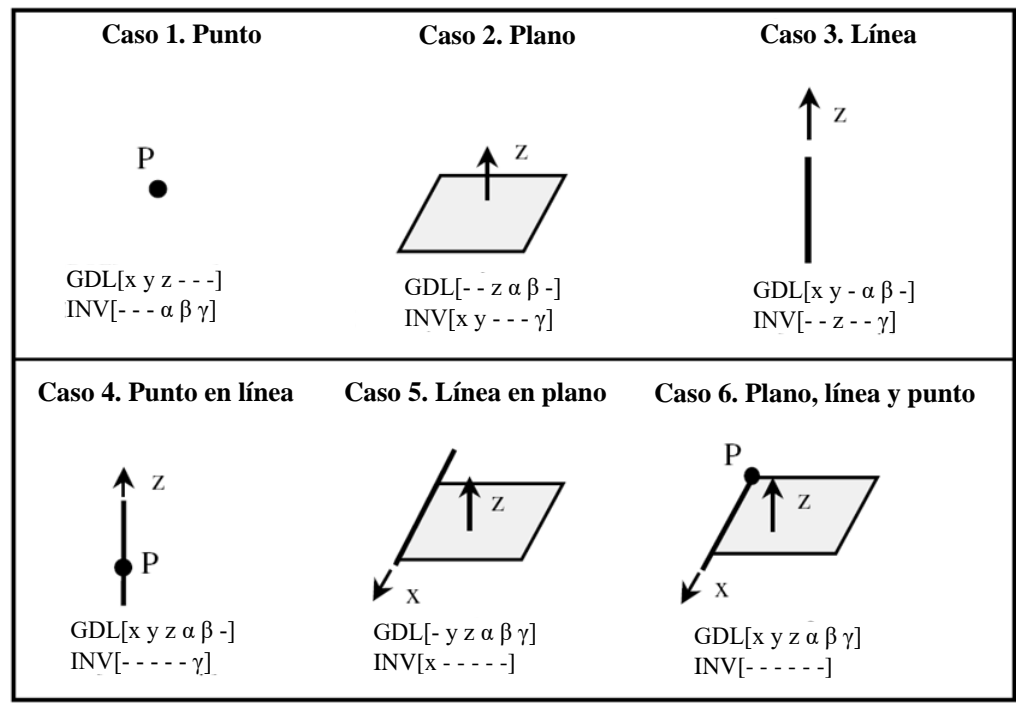

Figura 3.8 Los seis tipos de primitivas de referencia [de Kandikjan et ál., 2001].

\begin{tabular}{|c|c|c|c|c|c|}
\hline & \multirow{2}{*}{ Caso } & \multicolumn{2}{|c|}{ GDL Activos } & \multicolumn{2}{|c|}{ GDL Invariantes } \\
\hline & & GDL Tras. & GDL Rot. & GDL Tras. & GDL Rot. \\
\hline$x \longdiv { A z }$ & \#6 & 3 & 3 & 0 & 0 \\
\hline & \#5 & 2 & 3 & 1 & 0 \\
\hline $\boldsymbol{A}=$ & $\# 4$ & 3 & 2 & 0 & 1 \\
\hline Az & \#3 & 2 & 2 & 1 & 1 \\
\hline$A^{2}$ & $\# 2$ & 1 & 2 & 2 & 1 \\
\hline P & $\# 1$ & 3 & 0 & 0 & 3 \\
\hline
\end{tabular}

Figura 3.9 G.d.l. invariantes y activos para cada una de las seis primitivas de referencia [de Kandikjan et ál., 2001].

Debido a la existencia de los g.d.l. invariantes, el total de g.d.l. que se requieren para restringir completamente una entidad geométrica es inferior a seis. Por ejemplo, un punto tiene tres g.d.l. de traslación a lo largo de tres ejes perpendiculares entre sí de un sistema de coordenadas. Una línea tiene dos g.d.l. de traslación, a largo de dos direcciones ortogonales entre sí y a la dirección de la línea, y dos g.d.l. de rotación sobre las mismas direcciones que las de los dos g.d.l. de traslación. Por su parte, un plano tiene un g.d.l. de traslación a lo largo de la dirección paralela a la normal al plano y dos g.d.l. de rotación sobre dos direcciones que son ortogonales entre si y perpendiculares a la normal del plano.

Los modelos de g.d.l. utilizan matrices de transformación homogéneas para representar las variaciones en las piezas en los seis g.d.l., por lo que también se conocen como modelos de representación matricial. Por ejemplo, una superficie cilíndrica es invariante a lo largo de la rotación y traslación sobre su propio eje, lo que le deja cuatro g.d.l. activos y se puede representar mediante la siguiente matriz de transformación homogénea: 


$$
D(v, w, \beta, \gamma)=\left(\begin{array}{cccc}
\cos \gamma \cos \beta & -\operatorname{sen} \gamma & \cos \gamma \operatorname{sen} \beta & 0 \\
\operatorname{sen} \gamma \cos \beta & \cos \gamma & \operatorname{sen} \gamma \operatorname{sen} \beta & v \\
-\operatorname{sen} \gamma & 0 & \cos \beta & w \\
0 & 0 & 0 & 1
\end{array}\right)
$$

Además de las tres primitivas básicas (punto, línea, plano) y sus combinaciones indicadas, existen trabajos en los que se propone la consideración de parámetros o g.d.l. de otros tipos adicionales a los g.d.l. cinemáticos propiamente dichos. Wu et ál. [Wu et ál., 2003] proponen la consideración no únicamente de los g.d.l. cinemáticos, sino también de "g.d.l. de tamaño" (size DOF) y "g.d.l. de forma" (shape DOF) con el fin de poder fijar completamente (forma, tamaño y situación) una entidad geométrica de una pieza con respecto a todo el resto de entidades geométricas de la pieza y así poder considerar todos los tipos de relaciones GD\&T. En función del tipo de relación métrica entre dos entidades geométricas, deben controlarse una cantidad y tipo de g.d.l. Los autores distinguen cuatro tipos de relaciones métricas: tamaño, posición (distancia), orientación (angular) y forma. Algunos ejemplos son: una relación de tamaño de tipo "radio de un cilindro" controla un g.d.l. de tamaño $\mathrm{y}$ otro de forma; una relación de posición de tipo "distancia/coincidencia/simetría entre dos planos" controla un g.d.l. cinemático de traslación, dos g.d.l. cinemáticos de rotación y un g.d.l. de forma; una relación de orientación de tipo "perpendicularidad entre un plano una línea" controla dos g.d.l. cinemáticos de rotación y un g.d.1. de forma; una relación de tipo "forma de una línea" controla un g.d.l. de forma. Algunos autores [Shen et ál., 2008; Zhao et ál., 2011] consideran esta propuesta como un modelo híbrido, en el que se combina un modelo de g.d.l. con un modelo de atributos.

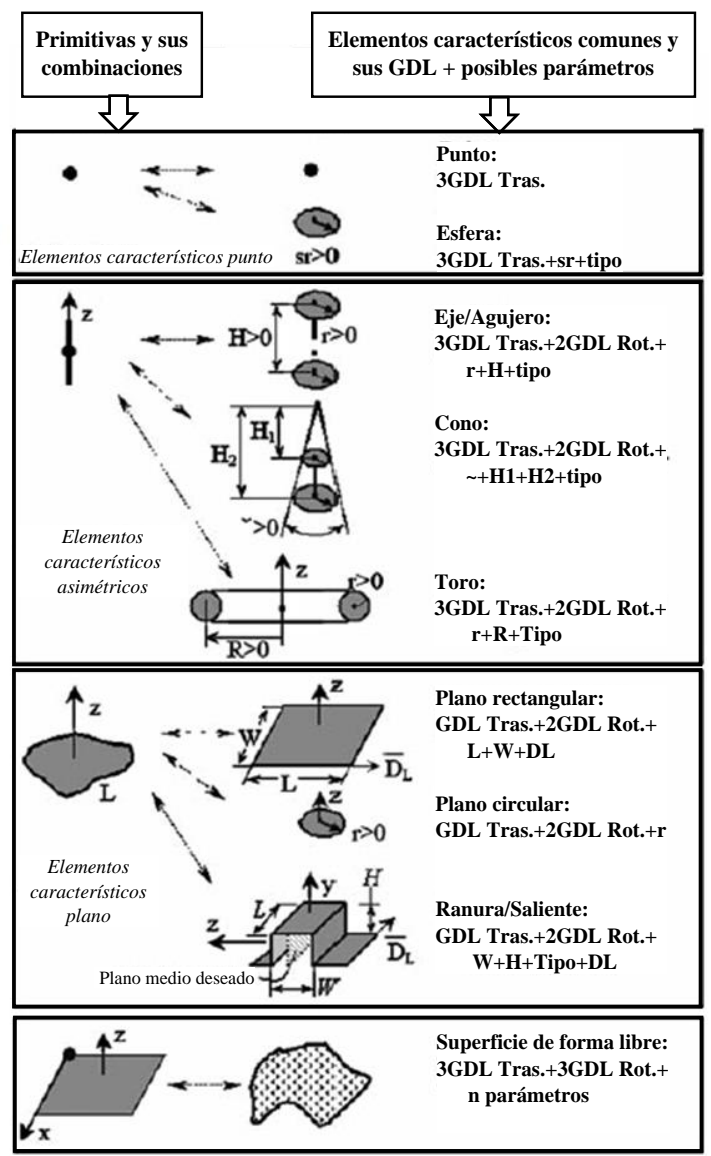

Figura 3.10 Elementos característicos recortados más comunes que corresponden a cada primitiva o sus combinaciones [de Shen et ál., 2003]. 
Posteriormente, Shen et ál. [Shen et ál., 2008] también utilizan esta idea de g.d.1. o parámetros adicionales a los g.d.l. cinemáticos, de manera que otro tipo de primitivas también pueden referirse como casos especiales del punto, línea o plano Por ejemplo, una esfera puede considerarse como un punto especial que tiene un parámetro (o g.d.l. especial) de tamaño que es el radio de la esfera. Un cilindro es una línea especial que tiene un parámetro (o g.d.l. especial) de radio y otro parámetro (o g.d.l. especial) de altura. $\mathrm{O}$ una ranura es un plano especial con tres parámetros (o g.d.l. especiales) de anchura, longitud y profundidad. Los autores de este trabajo introducen el concepto de "elemento característico recortado" (trimmed feature) para referirse a los elementos característicos aproximados o simplificados que resultan de la abstracción a partir de los elementos característicos reales. Se proponen nueve tipos más comunes de elementos característicos recortados, indicándose de qué primitiva o combinación de primita se abstraen y sus g.d.l., tanto cinemáticos como los g.d.l. o parámetros adicionales (Figura 3.10).

\subsubsection{MODELOS DE TORSOR DE PEQUEÑO DESPLAZAMIENTO.}

Existen modelos de representación y análisis de especificaciones dimensionales y geométricas basados en el concepto de torsor de pequeño desplazamiento (Small Displacement Torsor, SDT). El concepto de SDT se desarrolló inicialmente en el ámbito de la metrología para resolver el problema general de ajustar un modelo geométrico a grupos de puntos [Legoff et ál., 1999]. Un SDT es un objeto matemático que representa el desplazamiento de un cuerpo rígido en el que están implicadas tres rotaciones y tres traslaciones. La idea principal es que los desplazamientos de un cuerpo rígido se suponen pequeños. Por ello, la rotación se puede linealizar para derivar la forma final de un torsor $\mathrm{T}$ en un punto A:

$$
T=\left[\begin{array}{ll}
\alpha & u \\
\beta & v \\
\gamma & w
\end{array}\right]_{A}
$$

Cuando se aplica el concepto de SDT a superficies individuales (plano, esfera, cilindro, cono, toro, etc.) algunos componentes del SDT son indeterminados (aquellos que dejan la superficie invariante) y se denotan con $I$. Por ejemplo, para una esfera de centro $O$ :

$$
T_{\text {esfera }}=\left(\begin{array}{cc}
I_{\alpha} & u \\
I_{\beta} & v \\
I_{\gamma} & w
\end{array}\right)_{O}
$$

Y para un plano cuya normal es $Z$ y $O$ un punto del plano:

$$
T_{\text {plano }}=\left(\begin{array}{cc}
\alpha & I_{u} \\
\beta & I_{v} \\
I_{\nu} & w
\end{array}\right)_{O}
$$

En el campo de la especificación dimensional y geométrica de un mecanismo, las variaciones en la geometría se suponen suficientemente pequeñas como para poder utilizar el SDT. Aunque se definen tres tipos de SDT, únicamente uno de ellos hace referencia a la representación de las variaciones geométricas de las superficies de una pieza, mientras que los otros dos tipos de SDT representan la relación entre piezas de un conjunto. En concreto, el torsor de desviación (torseur d'écart) representa la diferencia entre la superficie nominal y el elemento ideal tangente exterior máximo que minimiza las diferencias con la superficie real. Este elemento se denomina elemento de sustitución y su 
forma depende de la geometría de la superficie o de los elementos de situación que la describen [Legoff et ál., 1999; Costadoat, 2010].

El modelo basado en SDT asume que las piezas no son deformables durante el funcionamiento del mecanismo (dilatación, esfuerzos, desgaste, etc.), por lo tanto solo debería aplicarse en los casos de mecanismos en los que estos efectos se consideren despreciables. Asimismo, en el modelo basado SDT los elementos geométricos que se manejan son elementos sustitutos o de sustitución ideales sobre los que se analizan los defectos de orientación y/o posición, sin considerar los defectos de forma [Costadoat, 2010]. Este autor indica que la superficie de sustitución es el elemento integral asociado al modelo geométrico de la pieza y se puede obtener de diferentes maneras como son: una restricción de tipo tangente exterior del material, un objetivo de tipo mínimos cuadrados o Chebyschev, etc. La elección de un criterio u otro de asociación dependerá de la aplicación. Por ejemplo, para determinar la montabilidad de piezas puede ser útil el criterio de tangente exterior de material.

También cabe destacar que en el modelo basado en SDT es siempre necesario definir una referencia (superficie, grupo de superficies, elementos sustitutos, etc.) para cada elemento geométrico respecto a la cual se sitúa el SDT. Dependiendo del elemento geométrico y de sus elementos de situación la definición de la posición de la referencia será o no completa.

\subsubsection{LAS NORMAS DE ESPECIFICACIÓN DIMENSIONAL Y GEOMÉTRICA DEL PRODUCTO.}

Antes de desarrollar algunos conceptos de especificación de la pieza según el lenguaje Geospelling, conviene hacer referencia a los esfuerzos y propuestas realizadas desde diferentes organismos de normalización y estandarización para desarrollar un conjunto uniforme de símbolos, definiciones, reglas y convenciones para llevar a cabo la especificación dimensional y geométrica de piezas que garantice la máxima homogeneidad y consistencia. Los estándares para la especificación dimensional y geométrica más destacados son los desarrollados desde la Sociedad Americana de Ingenieros Mecánicos (American Society of Mechanical Engineers, ASME) y desde ISO y, más concretamente, la norma Y14.5M de ASME y las ISO del grupo GPS [Drake, 1999].

Estos estándares proporcionan un esquema de toleranciado y en ellos se recogen las variaciones dimensionales (tamaño) y las variaciones geométricas (forma, orientación, posición y alabeo). Las tolerancias dimensionales se suelen expresar mediante una variación de tipo \pm , mientras que las tolerancias geométricas implican una zona o región permisible, la zona de tolerancia. La especificación completa de la zona de tolerancia incluye su forma, tamaño y situación (orientación y/o posición) [Henzold, 2006].

La forma de la zona de tolerancia depende del tipo de tolerancia y del elemento geométrico toleranciado. Las zonas de tolerancia son áreas (2D) o espacios (3D) limitados. Algunos ejemplos de zonas de tolerancia son: el área dentro de un círculo, el área entre dos círculos concéntricos, el área entre dos líneas equidistantes (las líneas pueden ser dos rectas paralelas), el espacio dentro de una esfera, el espacio dentro de un cilindro, el espacio entre dos cilindros coaxiales, el espacio entre dos caras equidistantes (las dos caras pueden ser dos planos paralelos) o el espacio dentro de un paralepípedo. La especificación de la forma de la zona de tolerancia se puede completar utilizando el símbolo $\varnothing$ precediendo al valor de la tolerancia, lo que indica que se trata de una zona de tolerancia circular o cilíndrica de diámetro el valor de la tolerancia. En caso contrario, la zona de tolerancia es la zona limitada entre dos líneas (rectas, círculos, perfiles envolventes) o entre dos superficies 
(planos, cilindros, superficies envolventes), la distancia entre las cuales es igual al valor de la tolerancia.

El tamaño de la zona de tolerancia hace referencia a su anchura y extensión sobre la que se aplica. La anchura de la zona de tolerancia es igual al valor de dicha tolerancia. Además, si no se indica lo contrario, la zona de tolerancia se aplica a la longitud o superficie completa del elemento característico sobre el que recae. El tamaño de la zona de tolerancia también depende de si lleva modificadores de material y/o de ciertas reglas. Algunos de los modificadores más importantes son el requisito el de condición de máximo material, el de condición de mínimo material o el requisito de envolvente. La condición de máximo y de mínimo material consideran aquel estado del elemento característico de tamaño objeto de análisis en el que el elemento característico está situado en cualquier lugar con el límite de tamaño donde el material del elemento característico es máximo o mínimo respectivamente. Por ejemplo, la condición de máximo material supone considerar el mínimo diámetro en agujeros y el máximo en ejes. La condición de mínimo material es la inversa, es decir, el máximo diámetro en agujeros y el mínimo diámetro en ejes. Por su parte, el requisito de envolvente especifica que la superficie individual de un elemento característico de tamaño (superficie cilíndrica o un elemento característico establecido por dos superficies planas paralelas opuestas) no debería violar una envolvente de forma perfecta (geométricamente ideal) con el tamaño de máximo material.

La orientación y/o posición de la zona de tolerancia queda definida por los datums. Un datum es una referencia geométrica teóricamente exacta (tal como un eje, un plano o una línea recta) respecto a la cual se relacionan los elementos característicos toleranciados. Los datums pueden estar basados en uno o más elementos característicos datum (que son elementos característicos reales con errores) de la pieza. En este segundo caso, los diferentes elementos característicos datum pueden tener la misma prioridad y, por tanto, implicar un datum común, o bien tienen prioridad diferente y la secuencia en la que aparecen indica el orden de prioridad, es decir, el orden en el que hay que utilizarlos para determinar la orientación y/o posición completa de la zona de tolerancia. En concreto, cuando los datums tienen diferente prioridad, el datum secundario se orienta perpendicularmente respecto al datum primario y el datum terciario perpendicularmente a los datums primario y secundario. Por su parte, el sistema datum se define como dos o más datums separados que se usan como referencia combinada para un elemento característico toleranciado.

En algunos de los desarrollos iniciales de la norma ISO se planteó basar dicha norma en lo que se conoce como Dimensionado y Toleranciado Vectorial (VD\&T, Vectorial Dimensioning \& Tolerancing) [Henzold, 2006], al cual ya se ha hecho referencia en el subapartado 3.5.1 al revisar los modelos de representación de la geometría con defectos basados en geometrías continuas para piezas individuales. El VD\&T es aquel dimensionado y toleranciado cuyo objetivo es el uso de elementos sustitutos definidos mediante vectores. Los elementos sustitutos (elementos característicos sustitutos) son elementos característicos imaginarios y geométricamente ideales (por ejemplo, una línea recta, un círculo, un plano, un cilindro, una esfera, un cono y un toro). Su posición, orientación y, si procede, tamaño se calculan a partir de puntos medidos sobre la superficie de la pieza. Para tomar los datos de los puntos, y de acuerdo a la norma, se utiliza un sistema de coordenadas cartesianas (rectangular) o un sistema de coordenadas cilíndrico utilizando la regla de la mano derecha. Los puntos en el espacio se definen mediante un vector de posición y un vector de orientación, que siempre está dirigido hacia fuera del material de la pieza. El VD\&T requiere de las siguientes especificaciones: un sistema datum sustituto, la posición (con su tolerancia) de un punto del elemento sustituto, la orientación (con su tolerancia) del elemento sustituto, el tamaño (con su tolerancia) del 
elemento sustituto, ángulo del cono (con su tolerancia) del cono sustituto y la tolerancia de forma impuesta sobre el elemento sustituto. De acuerdo al VD\&T, los tamaños, las distancias y las desviaciones de orientación y posición hacen referencia a los elementos sustitutos y no a los elementos característicos reales que tienen desviaciones de forma. Por lo tanto, se designan como tamaños sustitutos, distancias sustitutas y desviaciones sustitutas (sistema vectorial).

Tanto el sistema de dimensionado y toleranciado de la norma habitual, en el que los requisitos funcionales (para ensamblaje) pueden indicarse mediante tolerancias de perfil de superficie en relación a un sistema datum de la pieza, como el sistema vectorial, en el que se indicarían las tolerancias vectoriales en relación al mismo sistema datum de la pieza, tienen ventajas y desventajas, utilizándose en ambos casos la misma información nominal. Para ello, es importante tener presente que, y tal y como se ha comentado anteriormente, el sistema datum de acuerdo al sistema de norma está basado en el requisito de mínima inestabilidad (que se explicará en el siguiente apartado), mientras que en el sistema VD\&T el sistema datum está basado en elementos sustitutos. Para obtener resultados comparables existen estrategias para llevar a cabo la transformación necesaria del sistema datum sustituto. Para la especificación de requisitos funcionales tales como ajustes, el sistema de norma puede ser más ventajoso. Sin embargo, el sistema vectorial tiene más ventajas para el control del proceso de fabricación y es el que se utiliza muy a menudo en las MMC. Es posible desarrollar algoritmos que permitan transformar para algunos elementos característicos las tolerancias convencionales en tolerancias vectoriales $\mathrm{y}$, tal vez, a la inversa [Henzold, 2006].

\subsubsection{LAS CARACTERÍSTICAS EN EL LENGUAJE GEOSPELLING.}

Aunque en el segundo apartado ya se expusieron con detalle todos los elementos del lenguaje Geospelling, en este subapartado se apuntarán algunos aspectos sobre las características que son de interés para la especificación a nivel de pieza. En Geospelling, las características se utilizan dentro de la expresión de una especificación, directamente para caracterizar el objeto de la especificación o bien dentro del criterio de una operación (restricción o valor objetivo).

El lenguaje Geospelling fue considerado y adoptado en el desarrollo de la norma GPS [ISO17450-1, 2011] y según esta norma las características pueden ser de varios tipos: intrínsecas, que son características geométricas de un elemento ideal; de situación, definidas entre elementos ideales, entre elementos ideales y elementos limitados, entre elementos ideales y elementos no ideales y entre elementos no ideales. Además, sean del tipo que sean, estas se definen siempre como distancias o ángulos entre elementos geométricos de tipo punto, recta y plano. Por lo tanto la norma permite propiedades derivadas. Por su parte, la condición se expresa mediante un límite máximo y/o mínimo de la característica.

\subsection{EL MODELADO GEOMÉTRICO EN LA VERIFICACIÓN.}

Como ya se ha comentado en el segundo apartado, en el que se ha realizado desde la perspectiva de la simulación y la especificación todo un repaso a los conceptos presentes en la especificación según el lenguaje Geospelling, para que la funcionalidad final del producto sea aceptable se deben controlar las incertidumbres de correlación y de conformidad (Figura 3.11). Si al observar la figura se pone el foco en la incertidumbre de conformidad se puede apreciar que esta incertidumbre está influenciada tanto por el proceso de especificación como por el de verificación que, como ya se había indicado en la 
introducción de este capítulo, se centra en la definición de los planes de verificación y de los procedimientos metrológicos con los que comprobar los requisitos funcionales, las tolerancias funcionales y las tolerancias de fabricación. Pero si aún se afina más el enfoque y de entre los componentes de esta incertidumbre se centra la atención en la imputable al método de medida, causada por la diferencia entre el método de inspección especificado por el diseñador y el seleccionado el metrólogo, se puede ver que en la generación de esta incertidumbre concurren ambos procesos. Por ello, en este apartado se estima oportuno realizar un repaso de todos los conceptos presentes en la expresión de una especificación pero ahora desde la perspectiva de la verificación.

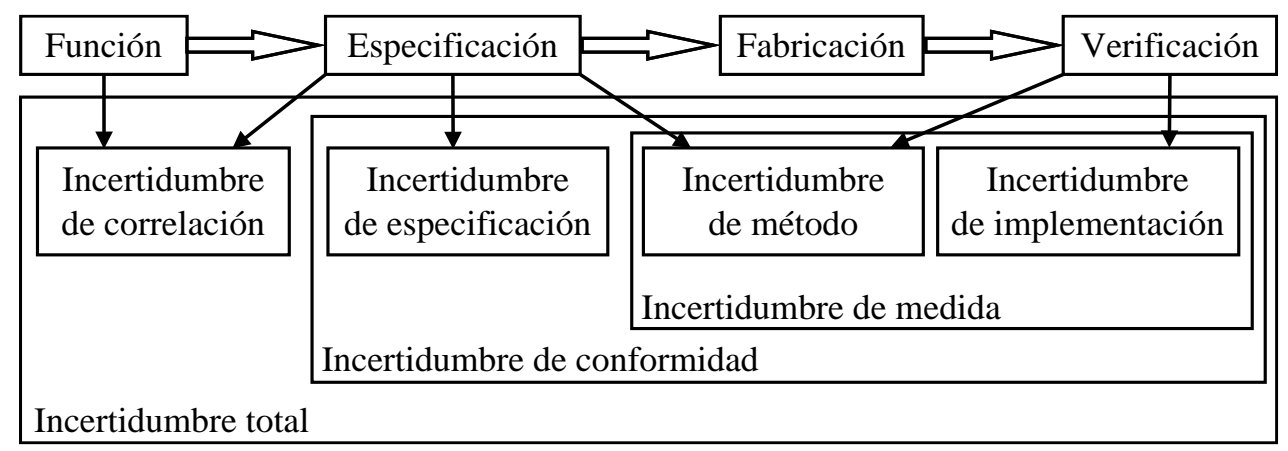

Figura 3.11 Relaciones entre varias incertidumbres en GPS [de Nielsen, 2006 e ISO17450-2, 2012].

Aunque según la normativa GPS los operadores de especificación y de verificación deben ser duales (Figura 3.12), para disminuir la incertidumbre de conformidad, especialmente la de especificación, esto no significa que el operador de verificación vaya a ser idéntico al de especificación y menos que se implante como hubiera podido imaginar el diseñador. A esta circunstancia han hecho referencia diferentes autores, como Srinavasan [Srinivisan, 1999], que indica que las operaciones establecidas en los operadores de especificación y de verificación son más familiares para los metrólogos, porque estos son los que utilizan e implantan las operaciones del operador de verificación para realizar su trabajo sobre la pieza física, mientras que un diseñador, responsable de expresar la intención de su diseño, normalmente no piensa o documenta explícitamente los detalles establecidos por el operador de la especificación. Por lo tanto, el operador de verificación es independiente en sí mismo, aunque por el principio de dualidad se propone que sea un espejo del de especificación [ISO8015, 2011]. De ahí que la GPS indique que si el operador de especificación es visto por el metrólogo como una instrucción virtual, esto ayudará a disminuir la incertidumbre del método [Srinivisan, 2001].

Por todo ello, se puede concluir que el principio de dualidad GPS no compromete el principio de independencia de la verificación. Es cierto que este principio busca estandarizar las operaciones para la especificación de manera que coincidan con las de la verificación, con el fin último de garantizar la integridad de la intención del diseño, pero el cómo se implanten las operaciones estandarizadas para la verificación sigue formando parte de las decisiones que el metrólogo debe tomar, optando por alguna de las múltiples alternativas, todavía existentes, en base a su conocimiento y experiencia [Srinivasan, 2001].

Atendiendo a la discusión anterior y a que, tal y como se tratará de justificar, se piensa que el lenguaje Geospelling también se puede utilizar para especificar la medida, en lo que queda de apartado se van a tratar todos los conceptos presentes en el lenguaje Geospelling. Para ello, se va a seguir la misma estructura del segundo apartado de este mismo capítulo, que allí se centró en la modelización en la simulación y la especificación. 

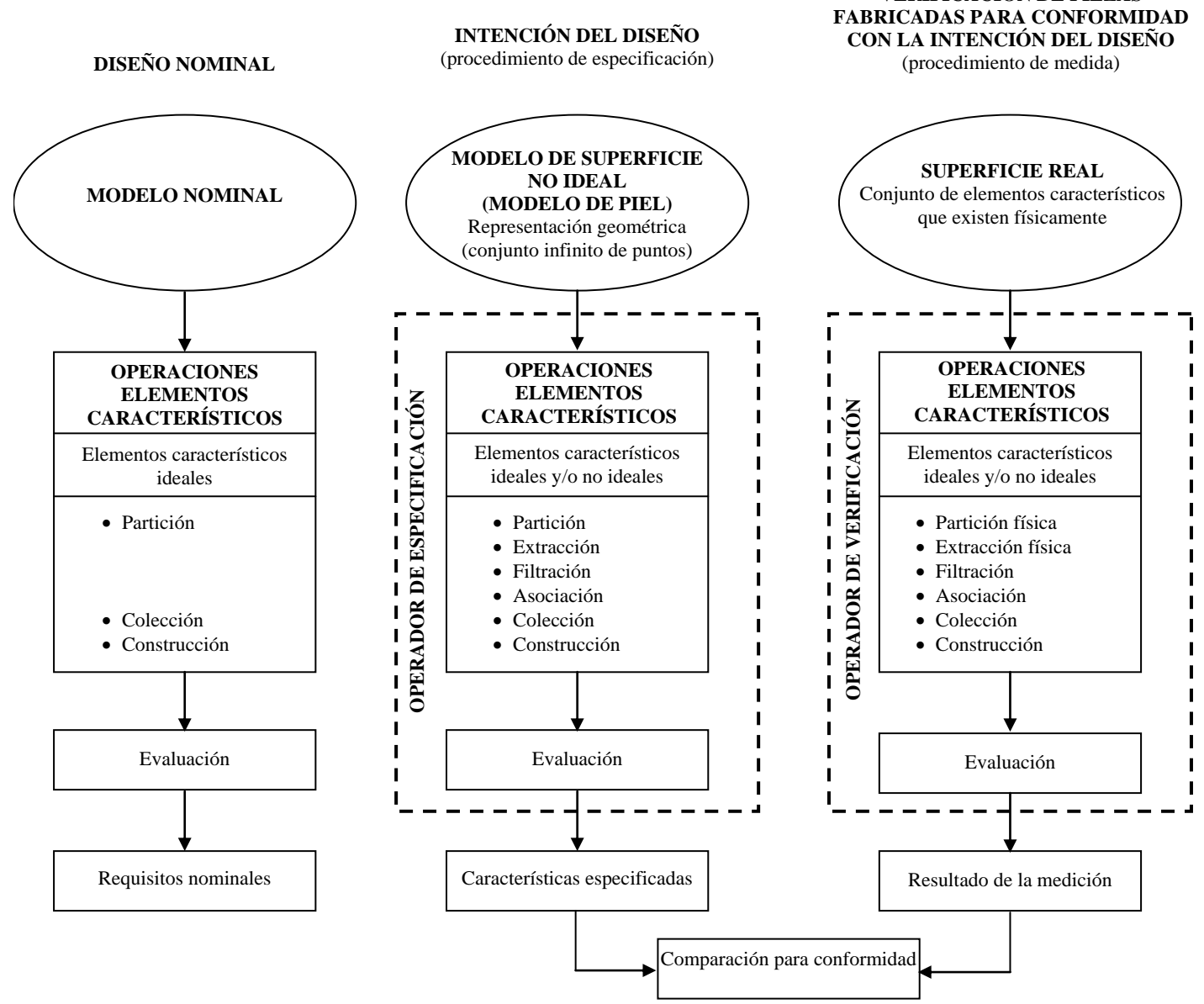

Figura 3.12 Principio de dualidad entre especificación y verificación [de ISO17450-1, 2011].

\subsubsection{LA REPRESENTACIÓN DEL SISTEMA REAL: EL MODELO DE VERIFICACIÓN.}

El trabajo del planificador de procesos de inspección comienza, normalmente, con un acercamiento a la geometría nominal de la pieza y a las especificaciones de tolerancias expresadas en los correspondientes planos, valorando los posibles defectos que puede presentar, y sigue con el análisis de los operadores establecidos para estas especificaciones y con la búsqueda de elementos de referencia sobre los que obtener las desviaciones, que permitirán conocer los valores de las características. Esta búsqueda es fundamental para la fase posterior de definición del plan de inspección, porque estos elementos de referencia están directamente vinculados con las características cinemáticas y geométricas de los equipos o instrumentos de medida, que determinan las operaciones de medida que se pueden realizar.

Por lo tanto, el planificador trabaja con dos realidades geométricas, la de la pieza a verificar y la del recurso metrológico, que se analizan a continuación.

\subsubsection{EL MODELO DE VERIFICACIÓN DE LA PIEZA.}

En el segundo apartado ya se comentó que el análisis y la comprensión de los sistemas reales se basa en el postulado de que existen dos mundos: el mundo físico (real) y el mundo abstracto (modelos). También se vio que en los procesos de simulación y especificación los modelos utilizados resultan de la simplificación del modelo primitivo (de piel), que solo representa una de las instancias imaginadas del modelo de piel, que 
debería contemplar toda una infinidad de representaciones posibles. Además, también se ha visto que la norma GPS establece que el modelo de piel está representado por una geometría continua.

Pues bien, estas nociones e hipótesis de esos dominios no coinciden con los del de la verificación, donde el modelo de piel se vincula a una instancia del real y se construye en base a la información resultante del proceso de medición. Esto es lo que también se desprende de lo establecido por la norma GPS, que indica que la geometría de una pieza existe en tres "mundos" distintos: el mundo de las especificaciones, donde el diseñador imagina diferentes representaciones de la pieza futura; el mundo de la propia pieza, el mundo físico; y el mundo de la verificación, donde se emplea una representación de la pieza dada a través del muestreo con instrumentos de medida. Como consecuencia de esta asunción, en la norma se proponen tres modelos de superficie para representar las interfaces completas de una pieza con su entorno: el nominal, el de especificación y el de verificación (Figura 3.13).
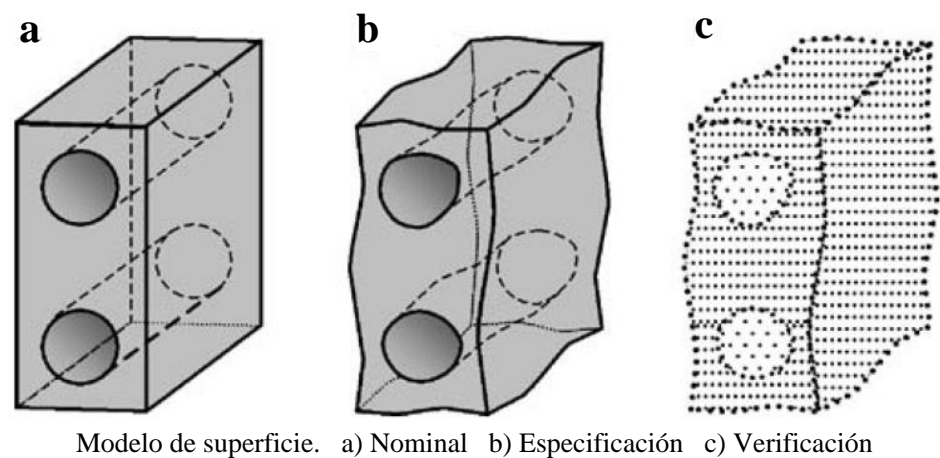

Figura 3.13 Modelos de superficie [de Ma et ál., 2007].

Además, en la literatura especializada, de igual manera que en la norma GPS, se sobreentiende que el modelo de verificación primitivo es un modelo de geometría discreta, que está constituido por un conjunto de puntos obtenidos mediante muestreo con equipos de medición. Sin embargo, esto es solo verdad cuando se utilizan sistemas metrológicos desarrollados basados, por ejemplo, en la medición por coordenadas con sondas mecánicas u ópticas. Cuando se utiliza cierta metrología básica (pie de rey, micrómetros, goniómetros, reglas de senos, etc.) el modelo primitivo resultante del proceso de verificación es un modelo mucho más simple, porque con la información obtenida solo se puede obtener un modelo con desviaciones (variaciones) dimensionales que se asemeja al nominal. Por ejemplo, cuando un elemento geométrico de tamaño se mide con un micrómetro de bocas planas, la medida que se obtiene solo permite obtener información sobre la distancia entre elementos ideales recortados (generatrices o planos del tamaño de las bocas) que se supone que se mantienen paralelos y que no tienen defectos de forma. Se trata de un proceso de verificación simple, en este caso de longitud, que puede proporcionar directamente el valor del atributo especificado pero que asume algunas hipótesis arriesgadas: a) que los defectos de orientación existentes entre los elementos geométricos sobre los que se mide y los defectos de forma de ambos elementos se presumen bajos; y b) que el valor de la dimensión obtenida no se encontrará cerca de los límites establecidos. En la buena práctica metrológica, cuando asumiéndose el principio de envolvente la medida obtenida está cerca de ese límite, se aconseja aplicar un método de medida más desarrollado, que proporcione mayor información sobre la geometría real y que por lo tanto permita obtener un modelo primitivo más desarrollado y cercano al real, eliminando la duda del cumplimiento de las hipótesis antes mencionadas. 
Por lo tanto, el modelo primitivo de la medición puede corresponder a diferentes tipos de geometrías, resultantes de la extracción:

- modelos discretos de piel con defectos (superficies integrales o derivadas), formadas por puntos o teselas, obtenidas mediante MMC o equipos de medición óptica;

- modelos discretos de líneas con defectos (perfiles de la superficie o líneas derivadas), formadas por puntos o segmentos obtenidos mediante metrología de perfiles/formas o de textura de superficies;

- modelos ideales con defectos dimensionales, unos modelos de piel que mantienen la forma del nominal y que se construyen con las medidas obtenidas mediante equipos que proporcionan una medida concreta de distancia o ángulo (directa o indirecta) o el margen de variación de estas obtenido mediante un barrido (ver apartado 3.6.3).

Pero además, en el caso de que estos modelos primitivos sean discretos el operador de verificación establece unos modelos simplificados: a) modelos de superficies/perfiles continuas, que se pueden obtener por reconstrucción (operaciones de ajuste e interpolación) de los primitivos con el objetivo de obtener puntos que coincidan con los puntos de muestreo establecidos en la especificación; b) modelos de superficies ideales con defectos dimensionales; c) modelos de superficies ideales con defectos angulares; y d) modelos de elementos ideales con defectos derivados de los anteriores.

Los de tipo b) y c) pueden considerarse equivalentes a los modelos de piel con defecto de Costadoat y los de tipo d) a los de esqueleto con defectos del mismo autor, estudiados en el subapartado 3.3.2. Los de simulación se construyen en base a geometrías ideales con defectos dimensionales y angulares, en este caso infinitos, construidos a partir de los modelos nominales mientras que los de verificación se construyen en base a elementos sustitutos y derivados resultantes de los primitivos de verificación. Como ya se comentó en el subapartado 3.3.2, Costadoat demostró en su tesis doctoral la posibilidad de hacer equivalentes los elementos ideales con defectos con los sustitutos de especificación, pero no los confundía. Esto último también es de aplicación para la especificación y la verificación porque, aunque los elementos sustitutos y derivados de la verificación tengan que ser reflejo de los de la especificación, los dos son independientes y tienen existencias diferentes, de igual forma que ocurre con los operadores de verificación y especificación.

Otra diferencia entre el proceso de simplificación seguido en la simulación y el de la especificación/verificación, es que en el caso de estos últimos no se pretende obtener un modelo final (de simulación). En la verificación, como en la especificación, la simplificación del modelo de piel pretende obtener modelos ideales (integrales o derivados) que sirvan para poder establecer los valores o resultados de la medida o las características especificadas, que se establecen en muchos casos entre modelos.

\subsubsection{EL MODELO DE VERIFICACIÓN DEL RECURSO DE MEDIDA.}

Como ya se ha comentado en la introducción de este subapartado, en la medición también participan geometrías reales pertenecientes al recurso de medida (instrumento o equipo), como por ejemplo superficies de un mármol, de unas pinzas de sujeción, etc. Se trata de unas geometrías, normalmente de elevada precisión, que se tratan como modelos primitivos ideales y que son conocidas en el dominio metrológico como geometrías de materialización (embodiments). Un adjetivo que, como se verá a continuación, también se atribuye a otras geometrías ideales que tienen la misma geometría nominal que la geometría de la pieza con las que se vinculan y que se utilizan como referencia en la medida, obteniéndose respecto a ellas las desviaciones de las geometrías de la pieza. 
Estas geometrías de referencia, que como ya se acaba de indicar se materializan en el equipo de medida, pueden ser de los siguientes tipos: a) geometrías de materialización cinemática, que son geometrías ideales generadas por los movimientos de las guías del equipo de medida; b) geometrías calculadas, que se obtienen mediante operaciones matemáticas de asociación, realizadas en base a criterios como el de mínimos cuadrados, mínimo diámetro exterior, etc.; c) geometrías de materialización de posicionamiento, pertenecientes a las pletinas, mandrinos, pinzas de precisión, utillajes de precisión, etc. utilizadas para este posicionamiento. Sobre estas últimas interesa indicar que, siempre que sea posible y no se presenten complicaciones excesivas para su materialización, lo normal es elegirlas para que tengan correspondencia con alguno de los datums establecidos en la especificación sobre las geometrías objeto de medida. Pero cuando esa condición no se da o en muchos casos por conveniencia, el planificador puede seleccionar otras aunque ello pueda implicar la necesidad de obtener más geometrías calculadas para los datums especificados no materializados. Las posibles soluciones establecidas dependerán en gran medida de los datums especificados en la pieza, la complejidad de esta y la flexibilidad de los equipos disponibles para la medida.

Estas geometrías de referencia, reales o ficticias, al actuar como el elemento básico para obtener las desviaciones, tienen una marcada influencia en la verificación. Además, cada una vendrá expresada en un sistema de coordenadas concreto, perteneciente al equipo de medición. Por otra parte, cada una de las seleccionadas tiene que poseer el número mínimo de g.d.l. activos requeridos para medir las desviaciones involucradas en las especificaciones.

En el proceso de determinación del plan de medida, la consideración de diferentes geometrías de referencia factibles para un determinado equipo y configuraciones es fundamental. De ello depende el número de subfases necesarias para verificar la pieza y la posibilidad de minimizar tanto este número como el de las alineaciones necesarias para cada una de estas sujeciones. Con las alineaciones se busca que los elementos de situación de las geometrías de materialización cinemática, de posicionamiento o calculadas, coincidan al máximo con los elementos sustitutos de las geometrías reales de la pieza. Al respecto, conviene tener presente que los equipos que permiten obtener geometrías de materialización calculadas, como las MMC, tienen mayores posibilidades para extraer información de muchas geometrías. Esta versatilidad, que permite disminuir el número de subfases, es una de las causas por las que este tipo de equipos, en sus diferentes versiones, son cada vez más utilizados.

\subsubsection{EL SISTEMA DE MEDIDA: LOS COMPONENTES Y LAS INTERFACES.}

La verificación de las piezas se realiza a partir de los valores de los atributos de modelos primitivos extraídos, construidos a partir de una serie de medidas (distancias y ángulos) derivadas de las lecturas proporcionadas por unos instrumentos o equipos de medida (recurso de medida).

Un recurso de medida está formado por varios sistemas (Figura 3.14): un sistema mecánico, un sistema sensor y, en su caso, un sistema de tratamiento de la información [Zhao et ál., 2011]. El sistema mecánico está formado por una unidad base, que incluye los ejes de desplazamiento y/o de giro básicos (estructurales y del cabezal) que permiten orientar y posicionar la sonda de acuerdo a unas estrategias de muestreo, y la sonda mecánica (mechanical probe), que puede incorporar ejes adicionales, en este caso con el simple objetivo de mantener las condiciones de funcionamiento requeridas por el sensor de la sonda. Por su parte, el sistema sensor estará formado por los sensores de la unidad base 
(escalas) y los sensores de la sonda que registran/miden la posición de sus correspondientes ejes como respuesta a un estímulo físico (por ejemplo, posición o fuerza de un contacto mecánico, nivel de un potencial eléctrico, etc.). Un registro que se realiza con respecto a un origen absoluto o relativo del equipo o instrumento. Por último, el sistema de información, que estará formado por el sistema de control y por el sistema de tratamiento de la información (ambas pueden ser de tipo manual o de tipo automático), se encarga de procesar los datos proporcionados por el sistema sensor para obtener los valores de un mesurando, vinculados a uno o varios g.d.l. y relacionados con la geometría extraída de la pieza y sus incertidumbres.

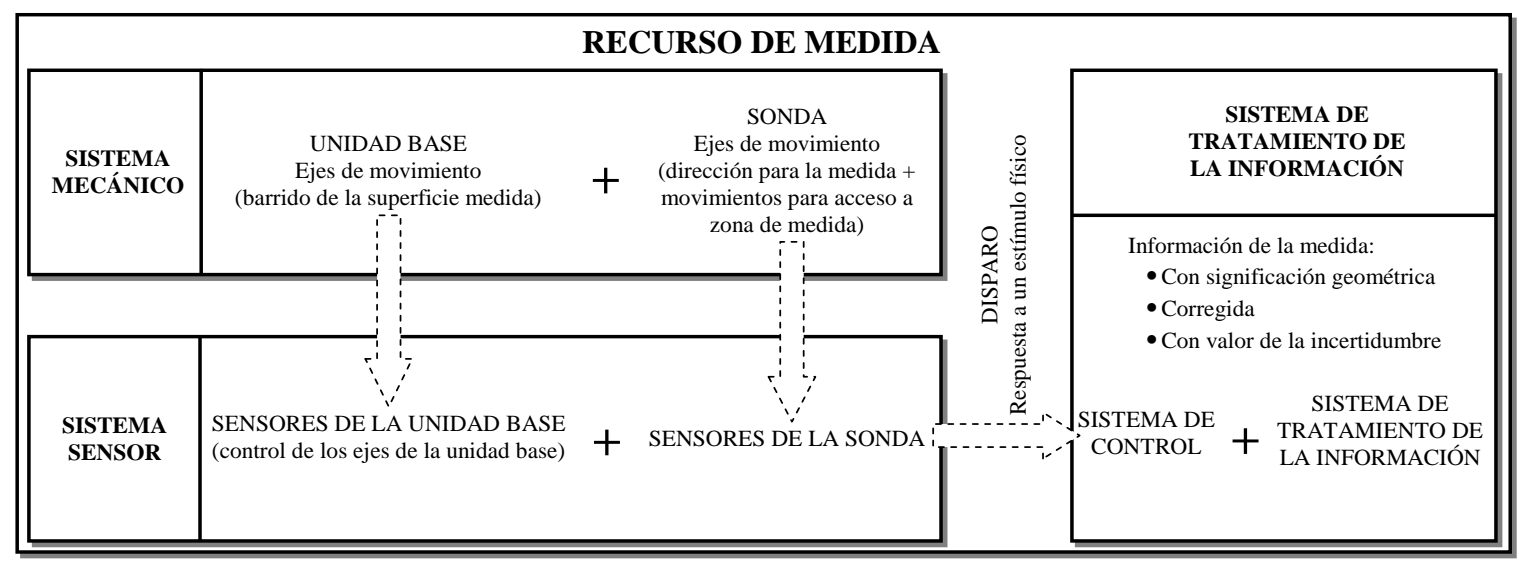

Figura 3.14 Esquema general de un recurso de medida.

Se trata de una descripción que aunque parece referirse a equipos mecatrónicos de cierta complejidad, también abarca a los instrumentos más sencillos, que pueden ser vistos como una simplificación de los anteriores, sobre todo en lo que respecta al sistema mecánico y sensor. Así, como ejemplo, un micrómetro de exteriores con un reloj comparador en la boca fija es un equipo de medida con una unidad base dotada de una traslación sensorizada y una sonda de variable dotada de una traslación coincidente, en dirección, con la de la unidad base. Por lo tanto, el mesurando se obtiene de la suma de los valores procedentes de los transductores de ambos sensores y el estímulo lo proporciona el operario cuando este considera que la posición de la boca y del palpador del reloj son los establecidos.

Una vez descrito el recurso de medida se va a centrar la atención en su uso durante el proceso de medición. Como es bien conocido, la pieza debe posicionarse (orientarse y/o posición) con respecto a ciertas geometrías del recurso de medida con una cierta precisión, para disminuir ciertos errores de medida. Para cada uno de estos posicionamientos (subfases) la pieza y el recurso forman un sistema mecánico de nivel superior (mecanismo o ensamble de inspección) que puede poseer una o varias configuraciones, que corresponden con los diferentes instantes de extracción (lecturas). Se trata de usar ensambles de inspección en los que se establecen dos interacciones importantes, que dan lugar a sendas interfaces: a) la de situación, que establece el contacto entre la pieza y el subconjunto (del propio recurso o del utillaje montado sobre él) que tiene la función de fijarla y de posicionarla/orientarla con respecto al sistema de referencia del recurso; y b) la de medida, que no tiene que ser necesariamente de contacto, y genera el estímulo para la lectura de los sensores de los ejes. El tratamiento, en su caso, de las lecturas de estos sensores es el que en última instancia proporcionará el valor (medida) de las características especificadas vinculadas a los elementos geométricos que conforman la pieza.

Como el sistema se considera que está formado por solo dos componentes, la pieza y el recurso, este último se trata como si fuera una caja negra. Por lo tanto, las interfaces 
existentes entre componentes del propio recurso no se contemplan y las incertidumbres vinculadas a las mismas se entiende que ya se han tenido en cuenta a la hora de obtener la incertidumbre global de ese recurso.

Por lo que respecta a las interfaces de contacto, cabe indicar que estas son del tipo sólido-sólido y que, como ya se indicó en el subapartado 3.2.2, están formadas por las dos geometrías en contacto, pertenecientes a la pieza y al equipo o instrumento de medida. De ahí que ciertos elementos geométricos recortados pertenecientes al recurso, como son los de, por ejemplo, las bocas de contacto del instrumento, los mármoles de apoyo, los palpadores esféricos, etc., también deban modelarse según lo establecido para cualquier geometría que forma parte de un ensamble. Sin embargo, estas geometrías no serán necesarias para las interfaces de medida sin contacto.

Otro aspecto interesante, en este caso vinculado con las interfaces de posicionamiento, es que cuando lo que se busca es una característica de orientación o posición, la geometría de la pieza de esa interfaz corresponderá normalmente con la establecida, directa (normas GD\&T clásicas) o indirectamente (caso, por ejemplo de una especificación geométrica establecida según el lenguaje Geospelling, que describe completamente el operador), en la especificación como elemento de posicionamiento (datum). Estos elementos de posicionamiento se materializan mediante unas geometrías reales del recurso (mármoles, pletinas, mandriles, etc. de gran precisión) que se conocen como datums simulados, sobre los que la pieza establece la interfaz de contacto. La geometría de contacto de la pieza se confunde con la geometría ideal (virtual) materializada por el recurso.

Por último, se va a aprovechar este subapartado para profundizar en algunos aspectos específicos de la arquitectura del ensamble de inspección y sobre las configuraciones de los contactos que estos ensambles pueden adoptar. Como en el análisis de cualquier mecanismo o ensamble, en el análisis de un ensamble de inspección también resultan útiles los grafos de tolerancias, porque sobre ellos se pueden identificar los denominados ciclos o cadenas de requisito (componentes, juntas y requisito) correspondientes a una determinada configuración, que en este caso también podrán corresponder a condiciones geométricas o condiciones de montabilidad, descritas en el punto 3.2.3.1 y que en el siguiente subapartado se analizarán en mayor profundidad desde la perspectiva de la medida. El estudio de estos ciclos permitirá, como para cualquier ensamble, primero la búsqueda de las mejores soluciones, tanto a nivel de concepto como de configuraciones, y después estudiar las desviaciones en las medidas realizadas sobre la pieza y analizar los límites impuestos a estas desviaciones motivadas: a) por el propio instrumento o equipo de medición (incertidumbre de los medios); b) las interfaces de medida; y c) las interfaces de posicionamiento, debidas entre otras causas a los defectos de alineamiento (por procedimiento físico o por operaciones de cálculo). Todas estas causas son las que hacen que la geometría de referencia pensada en la determinación del método no se corresponda con la implantada. Además, las últimas no se suelen considerar en la incertidumbre de los medios, porque cuando se realiza la calibración se hace normalmente con unos procedimientos y piezas de alta precisión.

Con respecto a las desviaciones que se pueden producir en las interfaces de posicionamiento, cabe indicar que este asunto ha merecido cierta atención en el campo de la metrología, por su efecto sobre la incertidumbre. Con este objetivo es necesario adoptar algunos requisitos para gobernar el posicionamiento relativo de las superficies de la interfaz, como son el requisito mínimo (mínimum requirement) o el requisito de mínima inestabilidad (mínimum rock requirement).

El requisito mínimo establece que la orientación y/o posición de la geometría real con respecto a la de referencia debe ser la que minimiza el tamaño de la envolvente, 
construida sobre la geometría de referencia, que contiene la geometría real. Cuando se trata de líneas o planos, la distancia entre las líneas o planos que contienen la geometría real, debe ser mínima. En el caso de circunferencias y cilindros, la diferencia radial entre las circunferencias y cilindros que contienen la geometría real es la que debe ser mínima. Por su parte, el requisito de mínima inestabilidad establece que, cuando la geometría de la pieza correspondiente al datum no sea estable con respecto a la geometría de materialización, se debe orientar de forma que el posible movimiento en cualquier dirección sea igual, es decir que se orienta en una posición media respecto de la geometría de materialización.

El requisito mínimo se suele establecer cuando se quieren verificar características intrínsecas, mientras que el de mínima inestabilidad es más apropiado cuando el objetivo son especificaciones de orientación y/o posición. Estos aspectos han sido tratados en profundidad en algunos libros de referencia sobre GD\&T [Henzold, 2006].

\subsubsection{LAS PROPIEDADES Y LAS OPERACIONES GEOMÉTRICAS EN LA VERIFICACIÓN.}

El proceso de medida de una pieza es el que en última instancia permite obtener las propiedades cuantitativas que definen a los diferentes objetos de información (modelos geométricos) sobre los que se apoya esta actividad, que son las que en última instancia permiten valorar el cumplimiento de las características especificadas. Al principio esta asignación de propiedades (características) se realiza sobre los modelos primitivos de las geometrías que han sido objeto de medidas de extracción y posteriormente sobre otros modelos simplificados, que son el resultado de aplicar diferentes operaciones Geospelling.

Aunque, como se ha indicado en el subapartado anterior, las geometrías primitivas (extraídas) pueden ser de diferentes tipos, para simplificar el desarrollo del resto del subapartado, se va a suponer que el modelo primitivo del que se parte es un modelo discreto de puntos y que los modelos corresponden a una única configuración, es decir, a la geometría extraída con un posicionamiento recurso-pieza determinado.

\subsubsection{LOS OBJETOS MEDIDOS Y SUS PROPIEDADES.}

Como se acaba de indicar, los objetos manejados durante la medida de una geometría pueden ser diversos y, por lo tanto, las propiedades geométricas también lo serán. Además, la mayoría de ellas derivarán de la propiedad de base, que en geometría es la distancia entre dos puntos.

Si se hace referencia, por ejemplo, al objeto de información correspondiente al modelo primitivo de puntos de una geometría elemental (por ejemplo, la nube de puntos de un cilindro), obtenido mediante una $\mathrm{MMC}$, este objeto será la agregación de todo un conjunto de objetos vinculados a estos puntos, que tendrán como características las coordenadas de estos puntos con respecto a un sistema de coordenadas. Se trata de unas características que derivan de la distancia entre el punto y los planos del sistema de coordenadas. Si la extracción de esta misma geometría se hubiera realizado con una máquina de medida de redondez y se accediera al objeto de información del modelo extraído, este estaría compuesto por una serie de puntos que en este caso tendrían la información en coordenadas polares de los puntos de extracción del cilindro de referencia y las distancias radiales de esos puntos con respecto a los de la geometría real, que se transforman en muchos casos en distancias radiales con respecto al eje del cilindro de referencia.

De igual forma, si se representan los objetos correspondientes a geometrías transformadas de la anterior, como por ejemplo el correspondiente a la geometría asociada 
por mínimos cuadrados, este estaría compuesto por una dimensión (radio o diámetro) y el objeto eje, que vendría definido por unas distancias y unos ángulos respecto del sistema de coordenadas. Todas ellas características derivadas (distancias punto-plano y ángulos) que proporcionan información sobre el tamaño de un cilindro recortado ideal y sobre la situación (orientación y posición) de su eje.

\section{LAS MEDIDAS DE LAS CARACTERÍSTICAS ESPECIFICADAS EN LAS PIEZAS}

Las medidas de las características especificadas son los resultados de la medición (Figura 3.12) obtenidos tras aplicar la operación de evaluación sobre las geometrías creadas en base a la geometría discreta de puntos que, como se ha indicado en el subapartado anterior, se ha obtenido con los valores de las medidas de las características de extracción tomadas con los recursos de medida (desviaciones respecto a una geometría de referencia). Por lo tanto, la medida de una característica especificada viene determinada por un operador (operador de verificación) en el que la última operación es una evaluación y que, como se ha indicado reiteradamente, debería ser espejo del operador de especificación.

Las medidas de estas características, de igual forma que sus especificaciones, se vinculan a geometrías elementales (características de forma o tamaño) o a las relaciones entre las mismas (características de posición u orientación) y en el lenguaje Geospelling se expresan con el valor de una dimensión (distancia o ángulo). Por ejemplo, en el caso en que la característica especificada fuera de forma/posición/orientación y se expresara por zona de tolerancia (normativa GD\&T clásica), la característica es la distancia (desviación) entre cualquier punto de la geometría extraída toleranciada y una geometría asociada, bien a la geometría toleranciada (target) bien a la de referencia de medida (datum).

Las características, como ya se indicó en el punto 3.2.3.1, pueden ser de 13 tipos y se pueden establecer [Costadoat, 2010]:

- entre una geometría recortada y una ideal,

- entre una geometría no ideal y una geometría ideal,

- y entre elementos no ideales.

\section{LAS CONDICIONES DE EXTRACCIÓN ESTABLECIDAS SOBRE LOS ENSAMBLES DE MEDIDA}

Las medidas que permiten construir la geometría primitiva de verificación (medidas de las características de extracción), como ya se ha comentado, son obtenidas a partir de los registros de señales provenientes del sistema sensor del recurso de medida, que se traducen en valores de dimensiones (distancias o ángulos) de unas características. Pero estas medidas corresponden a un momento o intervalo de tiempo en el que la pieza y el recurso presentan una determinada configuración (ensamble de inspección) y expresan las dimensiones de características que se establecen entre una geometría de referencia del recurso y una geometría de la pieza.

Por lo tanto, la obtención de un determinado conjunto de características de extracción (física) según unos requisitos (condiciones de extracción) es el que desencadena el proceso de búsqueda de una solución de verificación (ensamble de inspección). De igual forma a como ocurría en las condiciones funcionales del producto, vinculadas a prestaciones del producto o mecanismo, las condiciones de extracción también podrán ser de dos tipos: geométricas o de montabilidad. Las segundas, en el caso de la verificación, están vinculadas a la inspección mediante calibres y quedan fuera del alcance de este trabajo. Con respecto a las condiciones de tipo geométrico que se pueden dar en las medidas de extracción (ver punto 3.2.3.1), cabe indicar que solo pueden ser del tipo condiciones globales de desviación. Se trata de un tipo de condiciones que, como ya se indicó, pueden 
ser tanto de orientación como de posición y que se expresan entre geometrías de componentes diferentes del ensamble, en este caso una perteneciente a la pieza objeto de inspección y otra al recurso (geometría de referencia).

Aunque la exposición se ha limitado a la medida de características de extracción que permiten obtener una geometría primitiva de verificación del tipo geometría discreta de superficies (puntos o teselas) o perfiles (puntos o segmentos), ya se ha indicado en el subapartado 3.6.1 que estas geometrías también pueden ser ideales. En aquel momento, como ejemplo de una geometría primitiva de verificación ideal, se comentó el caso en que mediante un instrumento convencional de medida de longitudes, se obtenía la distancia entre dos geometrías primitivas que correspondían a dos segmentos o planos recortados paralelos. Un repaso de los instrumentos y métodos de medida [Griffith, 2002; Campbell y Roth, 2003; Henzold, 2006; Pfeifer y Schmitt, 2010] puede dar una idea de la gran variedad de características, expresadas en distancias o ángulos, que se pueden extraer. Por lo tanto, la medida de las características extraídas no se limita a distancias entre puntos y superficies de referencia que son equivalentes a las nominales, también pueden ser geometrías que resultan de procesos de partición o extracción de estas superficies nominales (segmentos, teselas u otras geometrías recortadas).

Un caso especial, que no se comentó en el subapartado 3.6.1, es aquel en el que la geometría primitiva extraída es una superficie recortada ideal equivalente a la nominal, por ejemplo un cilindro completo. Esta geometría se obtiene mediante instrumentos y procesos de medida que no registran valores en posiciones concretas sino que acumulan la variación o desviación total de un perfil de la superficie o de toda ella tras realizar un proceso de barrido. Un proceso de barrido en el que la configuración del ensamble se supone única, como si los g.d.l. que permiten ese barrido no fueran considerados. A las medidas de estas características se las denominará características proyectadas y dependiendo del número de g.d.l. no controlados utilizados para el barrido, se denominarán de proyección global, cuando el barrido para la proyección utiliza dos g.d.l., o de proyección orientada, cuando el barrido para la proyección utiliza un único g.d.l.

Una buena expresión de las características de extracción es fundamental, porque ellas determinan las cadenas de medida (ciclos de requisitos) a estudiar sobre los grafos del ensamble de inspección. En este caso, en la cadena de medida participará un requisito (la condición de extracción), las juntas correspondientes a las interfaces de posicionamiento y de medida y varios elementos geométricos con defectos pertenecientes a la pieza a verificar y al recurso de medida. La definición de estas cadenas es la que permite analizar, y en su caso validar, una configuración concreta de medida (ensamble), teniendo en cuenta los g.d.l. del mecanismo de inspección y las incertidumbres de estos g.d.l. y de las juntas de las dos interfaces pieza-recurso. Un análisis de las incertidumbres que puede realizarse con las técnicas de análisis de ensambles tratadas en el subapartado 3.4.1.

\subsubsection{LAS OPERACIONES DE VERIFICACIÓN.}

Como las operaciones que puede contemplar un operador de especificación ya se enunciaron brevemente en el punto 3.2.3.2 y estas son las mismas que puede contemplar un operador de verificación, en este punto solo se van a tratar ciertos aspectos interesantes que algunos de estos operadores presentan desde la perspectiva de la verificación, en concreto los que sirven para la construcción de la geometría primitiva. Como ya se indicó, muchos de estos aspectos son desconocidos por el diseñador y solo se consideran en el campo de la verificación.

Como se ha mencionado anteriormente, al medir una determinada característica lo que se hace es comparar la geometría real de la pieza con respecto a una geometría de referencia, obteniéndose unas medidas (desviaciones) de distancias o ángulos, que son las 
que permiten, en su caso, obtener la geometría primitiva medida. Aunque no se ha insistido en ello, en muchas ocasiones el objeto de información de esta geometría primitiva ya contiene los valores de las características especificadas, como es el caso de muchas características simples de tamaño que se obtienen por medición directa. Por lo tanto, en estos casos, al igual que en los de medida por barrido, ya no será necesaria ninguna transformación posterior de la geometría para obtener la característica especificada. Pero ello no significa que el valor de la característica resultante de la medición esté ausente de error, aunque el procedimiento de extracción se realice tal y como indique la operación de extracción.

La propia extracción está sujeta a toda una serie de operaciones físicas o de cálculo que se ejecutan bajo unos principios y/o hipótesis que no se puede asegurar que se respetan completamente en la mayoría de los casos y que son fuente de incertidumbres que no son contempladas en la típica incertidumbre de implantación de la medida obtenida mediante un proceso de calibración del recurso.

Si se supone, por ejemplo, que la geometría primitiva extraída de una pieza, obtenida en un determinado posicionado (subfase), está formada por unos conjuntos de puntos correspondientes a varias geometrías elementales y que se analiza el proceso de obtención de los mismos, como se ha indicado anteriormente, la medida de los puntos de cada una de las geometrías elementales se realiza mediante desplazamientos de la sonda con respecto a una geometría de referencia, que puede ser materializada o calculada. Pues bien, cuando la referencia es calculada, esta debe corresponder a una geometría sustituta, calculada mediante operaciones de asociación. Estas operaciones de asociación se realizan respetando un conjunto de restricciones y optimizando un determinado criterio, como puede ser minimizar el tamaño de la envolvente exterior, maximizar el tamaño de la envolvente interior, etc., que dependerán de las hipótesis/principios considerados. Sin embargo, si esta referencia es materializada, la posición y orientación de esta con respecto a la pieza es la que determina el cumplimiento de las hipótesis/principios establecidos, por lo que son necesarias en muchas ocasiones operaciones de alineación física de la pieza con respecto a la referencia materializada del equipo de medición, posicionando los datums de la pieza con las superficies y/o guías del equipo que definen esas geometrías materializadas en la forma que indica el principio adoptado. Si esta alineación no se produce en la forma determinada y con la precisión requerida, los puntos obtenidos acumularían un error debido a que las desviaciones se realizarían en direcciones diferentes de las previstas, ocasionando los conocidos errores de coseno e incertidumbre en el contacto.

Sobre los elementos de referencia establecidos se determinan, mediante una operación de extracción, los puntos en los que se medirá el valor de las desviaciones respecto del mismo. Para ello, la operación de extracción establece una estrategia de muestreo y su tamaño (número de puntos), aspectos que tienen gran relevancia a la hora de valorar si la geometría primitiva medida representa a la real. A medida que se aumenta el número de puntos, se supone que el modelo primitivo obtenido será más rico y que por lo tanto se disminuye la incertidumbre de medida pero, sin embargo, se encarece el proceso de medida. Muchos investigadores han estudiado los efectos de las diferentes estrategias de muestreo y han propuesto diferentes estrategias, que también son contempladas en las normas [Nyquist, 1928; Haralick et ál., 1989; Walter, 1992; Kim y Raman, 2000; ISO16610-40, 2015], con el objetivo de limitar el número de puntos controlando la inevitable pérdida de información del elemento.

De todo ello se deduce que tanto las operaciones, matemáticas o físicas (alineaciones), que sirven para determinar la posición y orientación y, en su caso, el tamaño de las geometrías de referencia, como las de extracción (imaginaria y física) de los puntos, influyen directamente en la incertidumbre de construcción del modelo primitivo. 


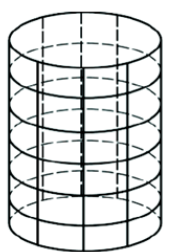

a - Jaula

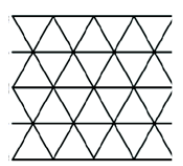

b - Especificado
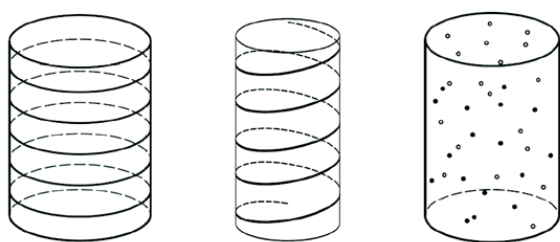

c - Estratificado d - Helicoidal e - Por puntos

Figura 3.15 Procesos de muestreo - Superficie cilindrica [de Charpentier, 2014 e ISO14406, 2010]

Esto también ocurre en los procesos de medición que proporcionan información sobre los puntos derivados a partir de los modelos primitivos discretos, como por ejemplo es el caso de la determinación del centro de un perfil circular discreto. La estrategia para el muestreo de este perfil, número y localización de los puntos, y el criterio elegido para la operación de asociación, influyen directamente en la incertidumbre de localización de punto central. Si estos puntos los hubiera proporcionado directamente el equipo de medida, estas incertidumbres no participarían.

Por último, para finalizar este acercamiento a las operaciones desde la perspectiva de la verificación, señalar que entre las operaciones del operador de verificación adquieren especial relevancia ciertos aspectos relacionados con las operaciones de evaluación, que son las que permiten obtener los valores de las características especificadas y verificar si cumplen con la condición establecida (tolerancia). Para la evaluación de las especificaciones es importante tener presente los posibles modificadores establecidos, como los de independencia, máximo material, mínimo material, etc.

\subsubsection{LAS ESPECIFICACIONES Y LAS INCERTIDUMBRES EN LA MEDIDA.}

Como ya se indicó en el subapartado equivalente dedicado a la especificación (dentro del apartado 3.2), con el lenguaje Geospelling también se pueden especificar características a nivel de producto, que se expresan sobre geometrías pertenecientes a dos componentes o piezas. Por lo tanto, esta posibilidad de expresión (especificación) también puede aplicarse a los ensambles de inspección, teniendo en cuenta que en este caso las características de este nivel son las que se han designado como características de extracción. Las características resultantes del operador de verificación, y que se comparan con las características especificadas en el diseño de la pieza que ahora es objeto de verificación, es obvio que también se pueden expresar con el lenguaje Geospelling, de forma idéntica a las especificaciones geométricas a nivel pieza. Por lo tanto, su expresión y las incertidumbres que conlleva la misma (incertidumbre de especificación) no se desarrollarán en este subapartado.

\subsubsection{LA ESPECIFICACIÓN DE LA MEDIDA EN EL LENGUAJE GEOSPELLING.}

En Geospelling "una especificación para la medida es una condición sobre la medida de una dimensión definida por una característica sobre elementos geométricos de referencia del recurso, materializados o calculados, y los elementos geométricos primitivos de la pieza". Aquí los operadores pueden ser tanto físicos (por ejemplo, barridos o desplazamientos según ejes, filtros mecánicos, etc.) como matemáticos, y las condiciones son las que limitarán las desviaciones o errores que la medida podrá sufrir a la hora de obtener esa característica.

Por lo tanto, estas condiciones geométricas de extracción se deben establecer en la forma de incertidumbres de realización de la medida y su valor se determinará en función de las condiciones impuestas a las características especificadas (tolerancias) de la pieza 
vinculadas a esa extracción. Cabe recordar que se recomienda que el cociente entre la tolerancia e incertidumbre esté entre 3 y 10 en medidas directas, por lo que cuando intervienen incertidumbres de implantación de la medida es interesante que la relación entre la tolerancia e incertidumbre de los medios este más cercana a 10 que a 3.

Aunque el desarrollo del lenguaje Geospelling para la extracción no es objeto de esta investigación, es evidente que al igual que en la especificación a nivel de producto, el establecimiento de cuantificadores que indiquen si la característica debe cumplirse en todas las configuraciones del ensamble de inspección o solo en alguna es importante. Hay que recordar, por ejemplo, que a la hora de establecer la interfaz de posicionamiento de la pieza sobre el recurso a veces interesa atender ciertos requisitos, como el de requisito mínimo o el requisito de mínima inestabilidad, que condicionan la configuración del ensamble de inspección.

\subsubsection{LA INCERTIDUMBRE DE MEDIDA.}

Como se ha indicado en el apartado 3.6 (ver Figura 3.11), la incertidumbre del proceso de verificación de una especificación depende de la incertidumbre de medida, cuyas fuentes son la incertidumbre debida al método de verificación utilizado y la incertidumbre en la propia ejecución de la medida.

La incertidumbre debida al método es aquella que proviene del operador de verificación, que establece el verificador durante la planificación de la verificación. El operador de verificación está compuesto por un conjunto de operaciones diferentes que tienen su influencia sobre la incertidumbre. Algunas de estas operaciones no introducen incertidumbre, como es el caso de las operaciones de construcción o las de evaluación, pero otras tienen un gran efecto sobre la misma, como es el caso de las operaciones de extracción y asociación. Como se ha visto en el subapartado anterior, las operaciones de extracción incluidas en el operador de verificación, al determinar el número y localización de los puntos de muestreo, implican una pérdida de información y por tanto una incertidumbre, que aumenta cuando el grado de representación de la geometría real disminuye. Por su parte, las operaciones de asociación incluidas en el operador de verificación propagan las incertidumbres correspondientes a los valores de las características medidas utilizadas como entrada. Una propagación que depende de los algoritmos matemáticos utilizados, que a su vez dependen de las restricciones y objetivos de la asociación.

En cuanto a la incertidumbre imputable a la propia ejecución de la medida, que tiene su origen en el proceso de medición, cabe destacar algunos aspectos que ya han aparecido a lo largo del capítulo y que se encuentran directamente relacionados con el ensamble de medición establecido por el verificador, en concreto con el recurso de medida seleccionado (incertidumbre de los medios) y con las interfaces establecidas entre el recurso y la pieza. La incertidumbre de los medios, que caracteriza el recurso de medida, es la que se obtiene mediante unos procedimientos de calibración, en los que se miden unos patrones de gran precisión y se comparan las medidas de las características obtenidas con los valores certificados correspondientes. Pero habitualmente estos procedimientos consideran el recurso como una caja negra y asumen la hipótesis de que la configuración del ensamble de calibración es similar a la de que se establecerá en la medida. Una hipótesis que implicaría que el patrón que sustituye a la pieza tiene una geometría equivalente a la de la pieza y que, por lo tanto, las interfaces también serán equivalentes, una circunstancia que no se producirá. Como la precisión de las características de tamaño, forma y rugosidad de las geometrías de las piezas y de los patrones nunca pueden ser equivalentes, los contactos establecidos entre esas interfaces tampoco pueden serlo. Además, la calibración se suele hacer solo para unas configuraciones de ensamble tipo, debido al elevado coste que 
supondría tener muchos patrones y realizar múltiples calibraciones a medida, por lo que la incertidumbre se incrementa, aunque se apliquen procedimientos de extrapolación de resultados.

Por lo tanto, la incertidumbre de los medios depende de las características de precisión inherentes al recurso de medida, de la equivalencia geométrica pieza-patrón y de la similitud de los alineamientos realizados en ambos procesos (medición y calibración). Por ello, para disminuir esta incertidumbre es importante que el verificador detalle para los ensambles de inspección críticos el tipo de alineación a realizar en ambos procesos y, en su caso, la necesidad de realizar una calibración con una configuración de ensamble similar a la que se utilizará en la medición de la pieza.

Finalmente, también interesa remarcar que la reducción de la incertidumbre de ejecución, que se ha vinculado a la medida de la característica de extracción, es muy importante, tanto por el peso que esta puede tener a la hora de valorar la incertidumbre de la medida de la característica especificada como por el hecho de esta se propaga a través de las diferentes operaciones de creación de geometrías y de evaluación de la característica verificada. Se trata de un efecto poco estudiado y que se suele despreciar, seguramente por desconocimiento.

\subsection{RESUMEN}

En este capítulo se ha establecido un tratamiento de la especificación desde el punto de vista de la verificación que es homogéneo con el tratamiento que habitualmente se ha dado a la especificación funcional del producto, poniéndose de manifiesto que el lenguaje Geospelling también se puede utilizar para especificar la medida. De la misma forma que en el análisis y la especificación GD\&T del producto, el análisis y la especificación del sistema de verificación también debe realizarse sobre ensambles que consideren tanto las geometrías de la pieza como las del recurso de medida utilizado el ensamble de medida.

En el modelado de este sistema se consideran dos componentes diferenciados (pieza y recurso de medida) y dos interfaces: a) la de situación, que posiciona, orienta y fija la pieza respecto al sistema de referencia del equipo; y b) la de medida, que genera el estímulo para lectura, por contacto o sin contacto. Este ensamble de inspección permite al planificador de la inspección realizar la especificación de la medida de extracción que, extendiendo el lenguaje Geospelling, se establece como "una condición sobre la medida de una dimensión definida por una característica sobre elementos geométricos de referencia del recurso, materializados o calculados, y los elementos geométricos primitivos de la pieza".

Definido un conjunto de características a extraer y establecidas las condiciones (incertidumbres de realización de las medidas), una tarea que se realiza a partir de las condiciones de las características especificadas (tolerancias) y una vez conocidos los operadores de verificación establecidos para las mismas, el planificador ya puede establecer una solución para extraer esa/s característica/s (ensamble de medida) y definir y valorar diferentes cadenas del ensamble que corresponden a las diferentes especificaciones a extraer (condiciones de las medidas de extracción). Sobre estas cadenas alternativas el planificador ya puede realizar toda una serie de razonamientos que le permitan establecer la solución final, analizando los grados de libertad y las incertidumbres que incorporan los diferentes elementos participantes, y finalmente validarla.

En estas cadenas, de igual manera que en cualquier cadena de ensamble, se consideran todo un conjunto de propiedades referentes a la geometría de la pieza y del recurso y a las juntas que aparecen en las dos interfaces existentes entre ellas. Por ello, a lo largo del capítulo se ha realizado una exposición estructurada de los diferentes tipos de 
modelos geométricos inherentes a los ensambles en general y especialmente a los de verificación, resaltando alguna de sus peculiaridades.

En los procesos de verificación de la pieza, a diferencia de los de simulación y especificación el producto, el modelo primitivo de las piezas se vincula a una instancia real de la geometría (no imaginada). Por otra parte, ese modelo primitivo de la pieza no es necesariamente de geometría discreta, como parece sobreentenderse en la mayor parte de los trabajos y desarrollos normativos en este ámbito, sino que también puede corresponder a geometrías ideales con defectos. Además, en la verificación, de igual forma que en la especificación, a partir de estos modelos primitivos el operador de verificación establece otros modelos simplificados requeridos para poder evaluar las características especificadas.

Sin embargo, las geometrías de los recursos de medida solo serán ideales en tanto que corresponden a geometrías materializadas o calculadas por asociación. Estas geometrías materializadas (materialización cinemática, materialización de posicionamiento) o calculadas, son las que se utilizan como referencia para obtener las medidas extraídas (desviaciones) de la pieza. Se trata de unas geometrías que no están presentes en el operador de verificación, establecido inicialmente como imagen del de especificación, pero que tienen una gran influencia a la hora de determinar la extracción física (medida) y, por lo tanto, para su planificación.

En resumen, en el capítulo se han presentado toda una serie de nociones, fundamentalmente en los apartados 2, 3 y 6, que sustentan los modelos conceptuales desarrollados en los Capítulos 5 y 6 y la metodología expuesta en el 7. Adicionalmente, en los apartados 4 y 5 se han revisado los tópicos más importantes que cubre el toleranciado y, en concreto, el análisis y la especificación de tolerancias y las formas de expresar la geometría con defectos tanto en el ámbito normativo como en las metodologías y herramientas de análisis que se utilizan en la fase de diseño de detalle. 


\section{Capítulo 4}

\section{MODELO DE ELEMENTO CARACTERÍSTICO}

\subsection{INTRODUCCIÓN.}

Para hacer efectiva la Planificación de Procesos de Inspección y su integración con otras funciones propias del proceso de desarrollo integrado de producto pertenecientes al nivel supervisor, como son la especificación geométrica del producto y las planificaciones de procesos de mecanizado (determinación de subfases y operaciones, posibles agrupaciones y secuencias, posibles recursos a utilizar, especificación geométrica del proceso de fabricación), no son suficientes los enfoques clásicos de modelado de producto basados fundamentalmente en compartir datos geométricos (Initial Graphics Exchange Specification (IGES) / Especificación de Intercambio Gráfico Inicial, Standard for the Exchange of Product model data - Application Protocol 203 (STEP AP203) / Estándar para el Intercambio de datos de Producto - Protocolo de Aplicación 203, etc.), siendo necesario un enfoque de ingeniería que permita incorporar y enriquecer el proceso con mayor información y conocimiento específico del ámbito de aplicación, especialmente el no geométrico. El concepto que permite una interpretación del producto, o de parte de él, desde este enfoque es lo que se conoce como Elemento Característico (Feature).

Pero para hacer posible la integración, antes mencionada, el Elemento Característico que se defina, el Elemento Característico de Inspección, deberá ser consistente con las definiciones de Elementos Característicos propios de los dominios que se quieren integrar. Esto conduce a la necesidad de establecer un Meta-Modelo de Elemento Característico que incorpore los aspectos y semánticas comunes de todos los dominios a integrar. Cabe recordar que un meta-modelo define el conjunto de conceptos del dominio a modelar (meta-clases) y las relaciones entre ellos (meta-asociaciones). En este caso, el meta-modelo define los tipos de Elementos Característicos que pueden utilizarse, sus propiedades y sus relaciones mutuas [Zha y Sriram, 2004], y es un elemento importante para dar soporte al proceso de desarrollo concurrente de un producto a lo largo de todas las etapas de su ciclo de vida [Ma y Tong, 2003].

Para asegurar el requisito anteriormente mencionado, y antes de proponer el Metamodelo de Elemento Característico que se describirá en el capítulo 5, en este capítulo en primer lugar se revisarán los fundamentos que sustentan el concepto de Elemento 
Característico y tres de las propuestas más relevantes que utilizan una semántica unificada para definir un modelo de Elemento Característico y que provienen de tres ámbitos diferentes: los sistemas mecánicos, los sistemas software y los sistemas embebidos. A continuación, en el siguiente apartado, se presenta una revisión de las principales propuestas que se han realizado para los elementos característicos de aplicación orientados a la planificación del proceso de mecanizado y del proceso de inspección. Finalmente, se revisarán las propuestas más importantes existentes en el campo del modelado de productos, analizando como estos modelos contemplan al Elemento Característico y estudiando las asociaciones semánticas establecidas, con la intención de considerarlas para la propuesta.

\subsection{FUNDAMENTOS DEL CONCEPTO DE ELEMENTO CARACTERÍSTICO.}

Algunas definiciones de Elemento Característico (EC) ampliamente aceptadas lo describen como: aquellas formas genéricas con significado en un producto a la que los ingenieros pueden asociar ciertos atributos y conocimiento útil para el razonamiento [Shah y Mäntylä, 1995]; conjunto de elementos de forma con un significado funcional en un determinado contexto de aplicación que permite la asociación entre forma y funcionalidad [De Martino et ál., 1998]; o como una representación de aspectos de forma de un producto que encajan con una forma genérica y que son funcionalmente significativos para alguna fase del ciclo de vida del producto [Bidarra y Bronsvoort, 2000]. De la mayor parte de las definiciones existentes y de las propuestas de EC presentes en la literatura, se desprende que los EC tienen dos características fundamentales [Ma et ál., 2008]: (1) los EC hacen referencia a la geometría del producto en un nivel superior al de las entidades geométricas y topológicas; (2) representan una intención de ingeniería.

A la primera característica también hacen referencia Brunetti y Grimm [Brunetti y Grimm, 2005] cuando establecen los niveles del EC de forma (Form Feature) y los de aplicación y ensamble (Application Feature, Assembly Feature) como unos niveles superiores a los de geometría, de topología y paramétrico, en su descripción del modelo de capas en el que habitualmente se organizan los sistemas de X Asistido por Ordenador (Computer Aided X, CAX). Se trata de un modelo de capas en el que cada nivel se construye en base a los inferiores (Figura 4.1).

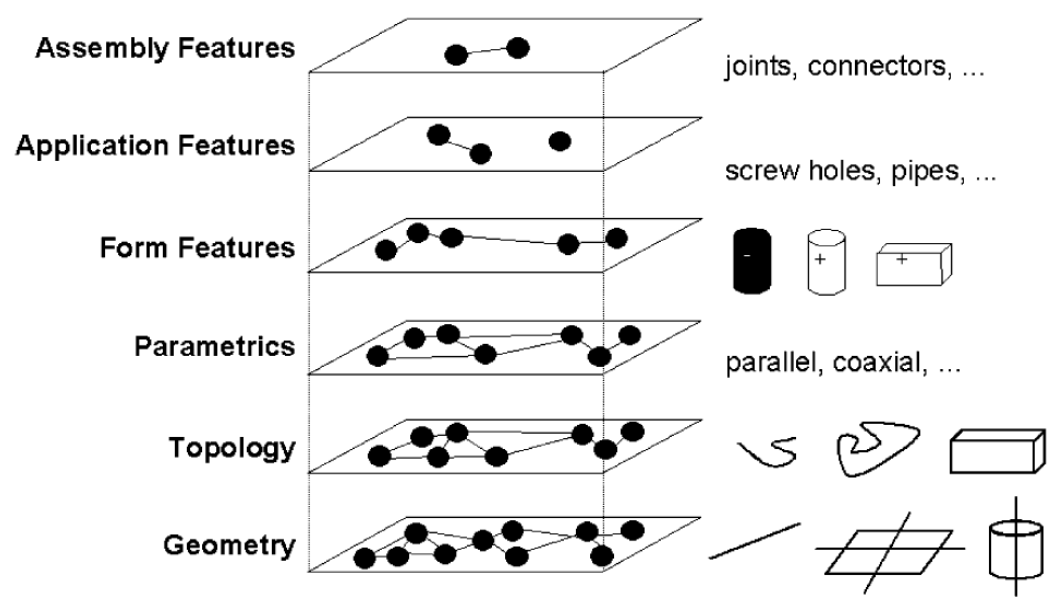

Figura 4.1 Modelo de capas típico de un sistema CAX paramétrico basado en elementos característicos [de Brunetti y Grimm, 2005]. 
Sobre esta primera característica también han insistido diferentes investigaciones, desde las aportaciones iniciales de los ya mencionados Shah y Mäntylä [Shah y Mäntylä, 1995], que indicaban que a la información sobre la forma debía asociarse información funcional, hasta otras más recientes que abordan la temática del mantenimiento de la validez de los EC. Bronsvoort et ál. [Bronsvoort et ál., 2001] señalan la importancia de comprobar las condiciones de validez del significado del propio EC, es decir su semántica, después de cada operación de modelado, embebiendo dichas condiciones de validez, basadas en restricciones geométricas y topológicas, en una clase de EC (modelado de EC semánticos). Ma et ál. [Ma et ál., 2008] van más allá, determinando la necesidad de mantener también la validez y la consistencia del EC en un modelo completo de producto propio de un campo de aplicación, embebiendo la intención de ingeniería a través de restricciones geométricas, algebraicas o semánticas entre EC.

Entre las aportaciones que dan respuesta a la necesidad que se acaba de indicar, destacan la de Ma y sus colaboradores, que se centra en el producto mecánico, la de Riebisch en el campo de los sistemas software y la de Zha y Sriram para sistemas embebidos. Unas propuestas que se describen a continuación en los tres siguientes subapartados y que han servido de base para el desarrollo de la propuesta de Meta-Modelo de Elemento Característico que se describirá en el capítulo 5.

\subsubsection{MODELO DE EC PARA SISTEMAS MECÁNICOS.}

En el desarrollo de su trabajo, Ma y sus colaboradores [Ma et ál., 2009] ponen de manifiesto que la representación y mantenimiento de forma completa de la intención de ingeniería, a la que se ha hecho referencia anteriormente al describir las características de un EC, requiere establecer relaciones no geométricas entre los EC y, sobre todo, entre los EC y otras entidades no geométricas. Estas últimas relaciones, semánticas, son fundamentales para que el modelado de EC sea consistente con la intención del diseño. Conviene recordar que muchos autores relacionan el concepto de consistencia con el establecimiento de un conjunto completo de relaciones establecidas entre EC y entidades semánticas, y que el mantenimiento de esta consistencia es un aspecto poco estudiado todavía, aunque de gran importancia para el modelado del producto, sea cual sea su orientación (basado en EC o no).

En sus primeros trabajos, para representar de forma completa la intención del diseño, Ma y Tong [Ma y Tong, 2003] establecieron el concepto de EC Asociativo Unificado, definido como un conjunto de asociaciones restringidas entre un grupo de entidades geométricas y no geométricas. Concepto que permite establecer un formato de EC genérico, válido para las diferentes etapas de desarrollo del producto, y unos mecanismos de unión entre los modelos de EC y los modelos geométricos, por una parte, y entre los modelos de EC y los modelos semánticos basados en conocimiento, por otra [Chen et ál., 2004; Chen et ál., 2006; Ma et ál., 2007]. Esta última vinculación es muy importante en los sistemas intensivos en conocimiento, como los vinculados con el desarrollo integrado y colaborativo de producto-proceso-recurso (Diseño Funcional, Especificación del Diseño, Planificación de Procesos de Fabricación, Planificación de Procesos de Inspección, etc.).

Para estos mismos investigadores los conceptos de asociación y unificación, que caracterizan al EC Unificado, son fundamentales para construir modelos de información de producto integrados basados en EC. En base a estos, proponen un esquema de modelado de producto basado en el EC Unificado [Chen et ál., 2004; Chen et ál., 2006; Ma et ál., 2009], en el que el Modelo de EC Unificado (Unified Feature Model) se concibe como una capa intermedia entre el Modelo de Conocimiento y el Modelo Geométrico (que manipula las entidades geométricas y topológicas del producto) en el que coexisten varios submodelos, pertenecientes a diferentes etapas de desarrollo o ámbitos de aplicación. Se trata, sin lugar 
a dudas, de un esquema que da respuesta a las necesidades de un desarrollo concurrente y colaborativo de producto-proceso-recurso.

Las propuestas de Ma y sus colaboradores ponen de manifiesto no solo la necesidad de disponer de un concepto general de EC Unificado, sino también la necesidad de utilizar esquemas de modelado de EC apropiados para entornos de desarrollo de producto colaborativo, haciendo uso de diagramas de clase UML.

Tal y como se puede observar en la Figura 4.2, para estos autores el modelo de EC (FeatureModel) se define como una composición de EC Unificado (UnifiedFeature), que es una clase de elemento característico que puede representar de forma genérica las propiedades comunes así como los métodos requeridos a lo largo de las etapas del ciclo de vida del producto [Ma et ál., 2009]. El EC Unificado se define como un conjunto de asociaciones restringidas (composiciones, agregaciones y dependencias UML) entre un grupo de entidades geométricas y no geométricas.

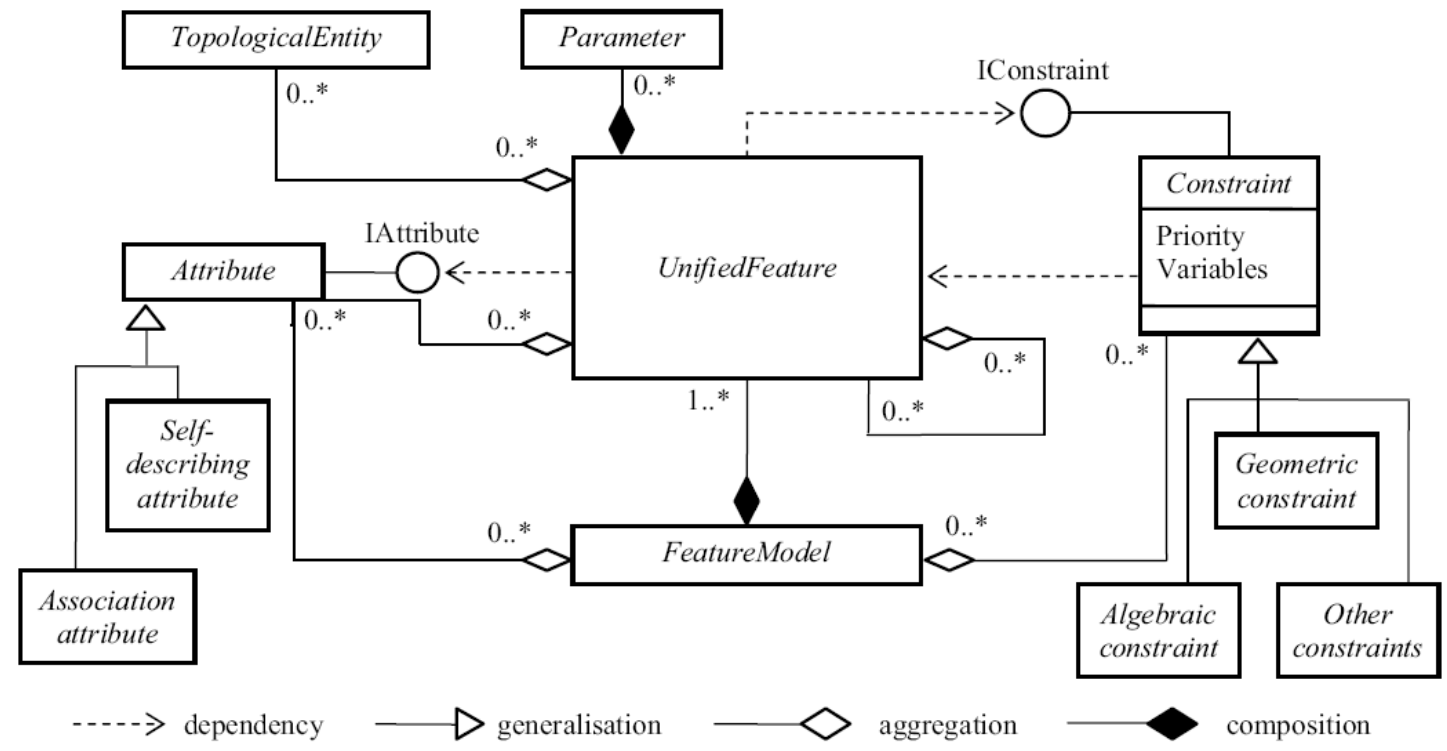

Figura 4.2 Modelo de Elemento Característico Unificado [de Chen at ál., 2006 y Ma et ál., 2009].

Tal y como se observa en la Figura 4.2, el EC Unificado tiene cuatro campos principales [Chen et ál., 2006; Ma et ál., 2009]:

- Atributos no geométricos (Attribute), que son propiedades del EC pero que no describen su geometría. Estos atributos pueden ser de tipo autodescriptivo (Selfdescribing attribute), que representan propiedades que son especiales de esa clase de EC particular y describen su naturaleza (por ejemplo tipo de material, color, acabado superficial, etc.), o de tipo asociativo (Association attribute), que son referencias o punteros a otras entidades asociadas al EC (otros EC, funciones, comportamientos, etc.). Cabe indicar que en una representación UML en un nivel conceptual no es necesario hacer explícitos todos los atributos y métodos de cada una de las clases o entidades representadas.

- Parámetros geométricos (Parameter), que describen la forma, las dimensiones, la posición y la orientación de la geometría del EC. Los parámetros geométricos se utilizan como entrada para los métodos de creación de la geometría.

- Restricciones (Constraints), que especifican las asociaciones intra-EC (restringen los valores dentro del EC), las inter-EC (especifican las relaciones entre dos o más EC) o las semánticas (especifican las relaciones entre un EC y otras entidades que no son EC). Cualquiera de estos tres tipos de restricciones pueden ser de tipo algebraico, geométrico, basadas en reglas, etc. 
- Referencias geométricas (TopologicalEntity), que son punteros a entidades topológicas en un modelo geométrico. Como el EC se utiliza para describir relaciones entre entidades topológicas, la geometría de un EC no es necesariamente volumétrica, conectada o completa y cerrada (two-manifold).

Además de estos campos principales, los autores proponen una serie de métodos para el EC Unificado que puedan garantizar la validez y consistencia del mismo: creación y edición de la geometría del EC, soporte al conocimiento embebido (interacción con la base de datos de conocimiento, notificando, actualizando y comprobando el cumplimiento de hechos y reglas) y soporte a la asociación de datos y el mantenimiento de la validez (interacción con el gestor de relaciones, responsable de las relaciones de dependencia y de las restricciones sobre el EC y sus atributos).

De acuerdo a lo expuesto, y aunque Ma y sus colaboradores indican que los diferentes tipos de EC específicos de aplicación (de diferentes etapas de desarrollo y para diferentes propósitos o puntos de vista) pueden derivarse de la clase de EC Unificado que se acaba de describir, como es el caso del EC de Diseño Conceptual, la realidad es que no se encuentra un patrón que permita determinar los tipos de elementos constituyentes, sobre todo los atributos autodescriptivos y asociativos, y los tipos de relaciones para estos EC específicos. Por ejemplo, para el caso de un EC Unificado Conceptual, en los atributos autodescriptivos Ma et ál. [Ma et ál., 2009] registran los datos relativos al comportamiento representado por el EC, mientras que sobre los atributos asociativos indican que estos podrían hacer referencia a las funciones, los comportamientos, las reglas u otros EC conceptuales. Sobre los parámetros indican que son las características de las geometrías que interaccionan y que estas pueden ser geometrías parametrizadas incompletas. Esta descripción realizada sobre un EC de Concepto, como las que se pueden encontrar para otros tipos de EC, denota la falta de consistencia motivada por la falta de unas de definiciones completas de los conceptos utilizados, que además son muy diferentes en cada tipo de EC. Como ejemplo, cuando en el EC de Concepto se habla de funciones, como atributos (no geométricos) asociados al EC, en el EC de Planificación de Procesos se señalan máquinas y operaciones.

\subsubsection{MODELO DE EC PARA SISTEMAS SOFWARE.}

El uso de diagramas UML al que se ha hecho referencia en la propuesta de Ma y sus colaboradores que se acaba de describir deriva del ámbito del software, donde los modelos de EC se aplican para describir variables y propiedades comunes de productos en una línea de productos y para validar configuraciones de sistemas software [Riebisch, 2003]. Este autor indica que es factible el uso de la simbología de los diagramas de clase UML para representar los EC y sus relaciones, aunque pueden originar ciertos problemas de entendimiento con los desarrolladores de software. Por eso propugna la necesidad de desarrollar notaciones específicas que posean una semántica y sintaxis formal capaz de expresar con concisión las restricciones y dependencias entre EC. Sin embargo, para salvar esta problemática, otros trabajos proponen anotar el modelo base utilizando extensiones del lenguaje de modelado, como por ejemplo la utilización de perfiles UML con estereotipos [Gomaa, 2006].

Otros aspectos relativos a los EC, desarrollados alrededor del análisis de dominio orientado a EC (Feature-Oriented Domain Analysis, FODA) y que son de interés para el ámbito de la Ingeniería del Producto, son las definiciones, categorías y vistas que se han dado en este campo del software. Riebisch, en el trabajo antes mencionado, hace referencia a dos definiciones de EC en el ámbito del software. La primera define un EC como un aspecto, calidad o característica prominente o distintiva y visible para el usuario de un sistema o sistemas software [Kang et ál., 1990]. La segunda, algo más general, define un 
EC como la propiedad de un concepto de un dominio que es relevante a alguno de los participantes en el dominio y que es utilizada para discriminar entre las instancias o casos concretos del concepto [Czarnecki y Eisenecker, 2000]. Además, en este contexto, el propio autor propone una definición de $\mathrm{EC}$, indicando que un EC representa un aspecto valioso para el cliente y establece cuatro categorías de EC: EC funcional (Functional Feature), EC de interfaz (Interface Feature), EC de parámetro (Parameter Feature) y EC de concepto (Concept Feature). Estas categorías se definirán en el siguiente subapartado, en el que el modelo de EC propuesto para sistemas embebidos toma como punto de partida esta clasificación.

\subsubsection{MODELO DE EC PARA SISTEMAS EMBEBIDOS.}

La clasificación de las categorías de EC desarrollada por Riebisch, a la que se ha hecho referencia en el subapartado anterior, fue el punto de partida de la propuesta de Zha y Sriram [Zha y Sriram, 2004], que refinaron la de Riebisch pensando en su aplicación en el dominio del diseño de sistemas embebidos. Los sistemas embebidos son sistemas híbridos de hardware y software, es decir, se pueden considerar ensambles de componentes hardware y componentes software. En concreto, estos autores establecieron las siguientes categorías de EC:

(a) El EC de función o de comportamiento (Functional/Behavioral Feature), que expresa el comportamiento de un sistema o el modo en el que los usuarios pueden interaccionar con el sistema, describiendo tanto aspectos estáticos como dinámicos de la funcionalidad.

(b) El EC de estructura (Structural Feature), que describe aspectos de conectividad y conformidad así como los componentes contenidos. A su vez, incluye:

(b1) El EC de forma (Form Feature), que expresa la forma/estructura general de un sistema embebido o de sus componentes hardware/software y sus relaciones.

(b2) El EC de interfaz (Interface Feature), que expresa la conformidad de un sistema o subsistema con un estándar

(c) El EC de parámetro (Parameter Feature), que expresa propiedades numerables o listables de entorno o no funcionales. Cubren todos los EC con propiedades que requieren una cuantificación por valores o por asignación de una calidad, por ejemplo el color.

(d) El EC de concepto (Concept Feature), que representa una categoría adicional que encapsula EC abstractos en una estructura jerárquica de EC. La raíz de la jerarquía siempre representa un EC de concepto. Los EC de esta categoría no tienen una implantación concreta, pero sus subEC sí proporcionan una.

La Figura 4.3 muestra el diagrama UML que representa el meta-modelo de EC que proponen estos autores. Para estos investigadores el modelado de EC es una actividad en la que se modelan los EC y sus interdependencias organizándolos en un modelo de EC en el que se muestran las entidades de interés.

Las ideas básicas que caracterizan el modelo de EC mostrado en la Figura 4.3 pueden resumirse de la siguiente manera [Zha y Sriram, 2004]. Un EC puede tener subEC, pero las conexiones entre un EC y sus subEC están arbitradas por el grupo. Un grupo reúne un conjunto de EC que son hijos de EC de otros EC. Por lo tanto, un grupo representa un conjunto de EC que son hijos del mismo EC y que obedecen ciertas restricciones en sus combinaciones posibles. Los grupos también se utilizan para reforzar las restricciones locales. Un mismo EC puede pertenecer a varios grupos. Tanto los EC como los grupos tienen cardinalidades. La cardinalidad de un EC define el número de casos concretos o instancias del EC que pueden aparecer en una aplicación. La cardinalidad de un grupo 
define el número de EC elegidos de entre los de un grupo que pueden ser instanciados en una aplicación.

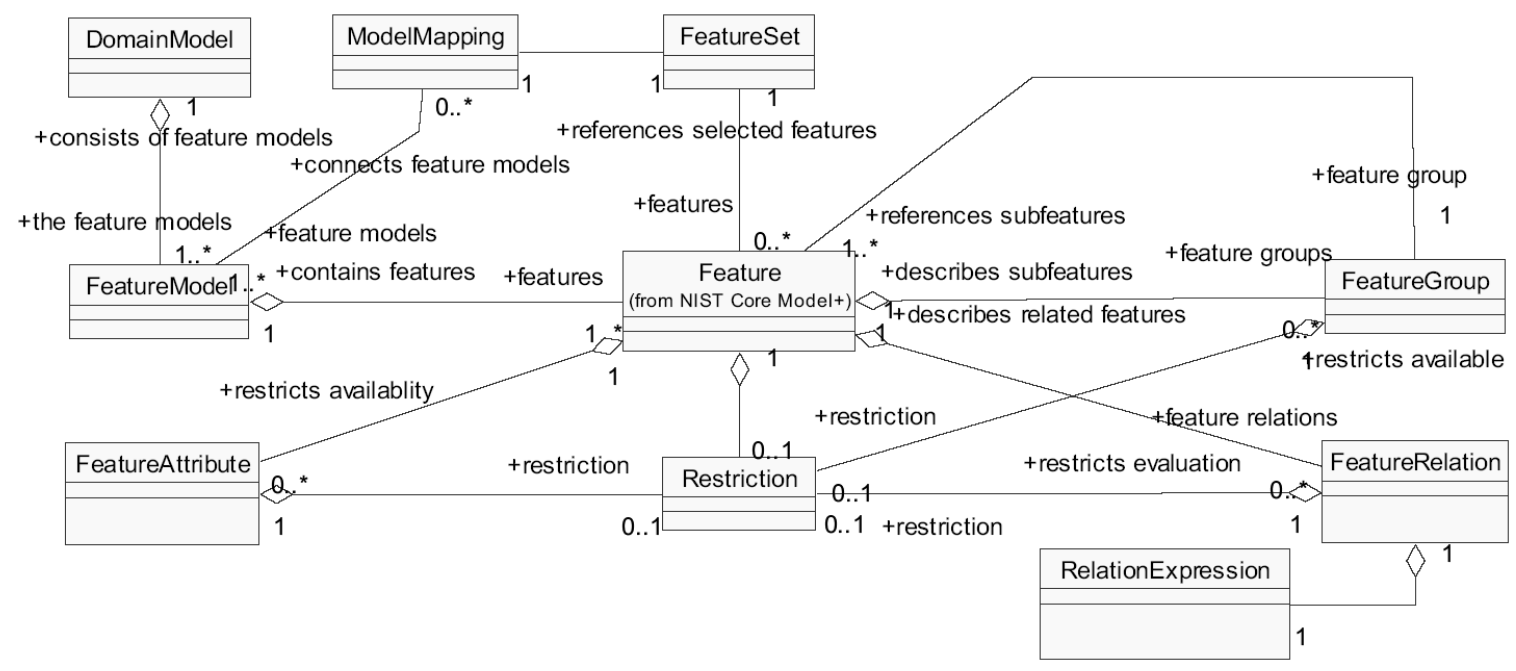

Figura 4.3 Diagrama UML del meta modelo de EC [de Zha y Sriram, 2004].

Pero además del concepto de grupo en el que los autores insisten al describir su propuesta, y a pesar de que dicha propuesta está hecha en el marco de sistemas embebidos, pueden apreciarse ciertas similitudes con la propuesta descrita anteriormente de Ma et ál., además de que en ambos casos se utilizan diagramas UML para representar los modelos. Por ejemplo, Zha y Sriram consideran la clase atributo de EC (Feature Attribute) de forma independiente y externa a la propia clase EC (Feature), de la misma forma que Ma et ál. incluían la clase atributo (Attribute). También aparece como concepto común la clase restricción (Restriction), que en el caso de Ma et ál. correspondía a la clase restricción (Constraint). Igualmente, en ambos modelos la agregación de la clase básica EC (Feature) da lugar al modelo de EC (Feature Model). Por otra parte, y a diferencia de Ma et ál., cabe destacar en la propuesta de Zha y Sriram la inclusión de las clases Modelo de dominio (Domain Model) y Transformación de modelos (Model Mapping), que vienen a reforzar la adecuación de la propuesta a entornos colaborativos en los que hay diferentes puntos de vista durante el desarrollo de un sistema o producto.

Llegados a este punto conviene apuntar que cuando se adoptan nuevos enfoques en el desarrollo integrado de nuevos productos, la integración de los modelos de EC específicos de diferentes ámbitos de aplicación (EC funcionales, EC de mecanizado, EC de ensamble, EC de medición dimensional, etc.) no se puede realizar en base a tecnologías como las de Diseño Basado en EC, Reconocimiento Automático de EC o Conversión entre EC, propios del enfoque secuencial, siendo necesario un único modelo, multipunto de vista, que mantenga la consistencia entre los diferentes modelos. En estas representaciones de producto, el modelo de un determinado ámbito de aplicación es una vista de un modelo global que está vinculada a una etapa de desarrollo y a un ámbito de especialización concreto.

Otro aspecto a señalar es que para hacer efectivo un desarrollo concurrente y colaborativo basado en EC hace falta un esquema estandarizado, flexible y común que permita la compartición y la asociación de información de alto nivel semántico. Esta opinión es compartida por Ma y sus colegas [Ma et ál., 2008], quienes a pesar de las aportaciones relevantes que han realizado en los últimos años, todavía indican que se echa en falta una definición genérica, completa y flexible de EC que sea capaz de representar los elementos comunes de los diferentes EC de aplicación, y que garantice la consistencia de las diferentes representaciones, especialmente en lo referente a la intención de ingeniería. 
Cabe recordar que un EC está formado por una representación geométrica y por otra no geométrica y que la unificación de la representación geométrica hoy está más resuelta. Los esquemas de modelado basados en la topología celular son un buen ejemplo de cómo se está abordando esta unificación.

\subsection{LOS ELEMENTOS CARACTERÍSTICOS DE APLICACIÓN PARA EL MECANIZADO Y LA INSPECCIÓN.}

En este apartado se presenta una revisión de las propuestas realizadas para EC de aplicación orientados a la Planificación del Proceso de Mecanizado y del Proceso de Inspección. En primer lugar, se recogen las propuestas relativas a los EC de Mecanizado que, aunque no son el objeto de este trabajo, han sido muy numerosas desde hace varias décadas. En segundo lugar se presentan las propuestas en el ámbito de la inspección, que han sido menos desarrolladas.

\subsubsection{El Elemento Característico en la Planificación DEL MECANiZAdo.}

El concepto de EC de aplicación, como una parte de la geometría del producto con una interpretación para un dominio concreto, encontró sus primeras aplicaciones en el dominio del mecanizado, como un elemento ligado a la planificación de estos procesos. Una de las definiciones de EC de Mecanizado más utilizadas desde sus inicios es la forma de un volumen de la pieza que puede ser eliminada mediante un proceso de arranque de material.

Desde ese punto de vista, los EC de Mecanizado siempre han estado unidos a una interpretación de las formas geométricas de una pieza para su obtención mediante procesos de mecanizado. En ese sentido, y desde las primeras propuestas que se remontan a los años 70 del siglo pasado [Zhang et ál., 2014], siempre han llevado implícitamente una gran carga semántica, que les daba un significado en el ámbito del mecanizado. Esta carga semántica es la que a juicio de todos los autores, sitúa a los EC de Mecanizado como el puente entre las aplicaciones CAD y CAPP, considerándolos un medio de comunicación entre ellas. Además, esta semántica, al capturar la información de ingeniería, permite razonar con un nivel de abstracción mayor que el correspondiente a las entidades geométricas y topológicas.

Gran parte de los trabajos realizados en el campo de los EC de Mecanizado se ha dirigido, por una parte, a establecer clasificaciones de los mismos y, por otra, a proponer metodologías para el reconocimiento de los EC a partir de los modelos geométricos (B-rep o de tipo CSG (Constructive Solid Geometry / Geometría Sólida Constructiva). Esta última línea de trabajo ha resultado de mucho interés para los investigadores, ya que todos coinciden en que la interpretación de los EC de forma, utilizados en el diseño, no necesariamente tiene que coincidir con los EC de Mecanizado. Si bien, como señalan Maropoulus y Ceglarek [Maropoulos y Ceglarek, 2010], aunque teóricamente se trata de un enfoque mucho más general, no aprovecha los beneficios que un diseño basado en EC puede aportar al diseño y a la estandarización y verificación de los procesos.

Una de las clasificaciones de los EC de Mecanizado más conocidas es la que realizó Kramer a principios de los años 90 [Kramer, 1992] en lo que denominó "Material Removal Shape Element Volume (MRSEV)". Esta clasificación está concebida como un conjunto estructurado de clases y subclases (con herencia) de entidades "tipo", que se utilizan en los planes de procesos para piezas a ser procesadas en centros de mecanizado de tres ejes que no incluyen superficies esculturales. Cada una de las clases viene definida por unos atributos propios y otros heredados, que definen exclusivamente sus propiedades 
geométricas. De esta forma, la clase principal de esta clasificación, la MRSEV, se va especializando hasta llegar a las clases más específicas como "cajera_rectangular_con_islas", "cajera_rectangular_sin_islas", "agujero", etc.

Otra de las clasificaciones de los elementos característicos de mecanizados es la que propusieron Lim et ál. [Lim et ál., 2001]. Esta clasificación, como otras, está basada no tanto en aspectos y criterios tecnológicos, sino en las características propias de las técnicas de reconocimiento basadas en pistas. Cada uno de los grupos de la clasificación viene definido por el conjunto de reglas que permite su clasificación. A su vez, dentro de cada grupo, existen otros conjuntos de reglas que permiten realizar sub-clasificaciones más detalladas.

Entre las clasificaciones de EC propuestas, es necesario referirse a la incluida en la parte 224 de la norma ISO10303-224 [ISO10303-224, 2006] que desde su publicación ha sido referencia para innumerables trabajos. La parte 224, con título "Definición mecánica de un producto para la Planificación de Procesos usando Elementos Característicos de Mecanizado" (Mechanical product definition for process planning using machining features), tiene por objeto la definición de un sistema de información para la representación del plan de procesos de una pieza, y además de la unidad funcional correspondiente a los EC de Mecanizado, incluye otras dedicadas a los datos administrativos de la pieza, documentación para la fabricación, tolerancias, etc. En esta clasificación, cada uno de los EC de Mecanizado se define en base a unas geometrías que definen el volumen eliminado como una combinación de la forma de la herramienta de corte y los movimientos que realiza.

Otra de las clasificaciones es la propuesta por Sridharan y Shah [Sridharan y Shah, 2004] que, además de criterios geométricos, incorpora otros directamente relacionados con el mecanizado, como son la selección de las herramientas, la configuración de la máquina, la accesibilidad, y el amarre o sujeción de la pieza. Se trata de criterios tecnológicos directamente relacionados con la forma de proceder de un planificador experto.

Cabe señalar, que como indican Kang et ál. [Kang et ál., 2014] no existe todavía un amplio consenso en la clasificación y denominación de los EC de Mecanizado, y que se requieren clasificaciones en las que se establezca una clara correlación entre los EC de Mecanizado y los procesos de fabricación.

También han sido numerosos los trabajos que se han dirigido al reconocimiento de los EC de Mecanizado, mediante la aplicación de diversas técnicas. Entre estas cabe señalar, la aplicación de técnicas algorítmicas, la búsqueda de patrones mediante grafos, la conversión o mapeo a partir de EC de forma, la descomposición en volúmenes, etc. Todas las propuestas que se han realizado para el reconocimiento presentan problemas en algunas situaciones, no existiendo ninguna completamente satisfactoria. En este sentido, uno de los aspectos que más problemas introducen en el reconocimiento son las relaciones entre los diferentes elementos que forman una pieza, cuando estos no son elementos aislados. Este aspecto pone de manifiesto la necesidad de disponer, como se ha indicado en los apartados anteriores, de modelos de EC entre los que se establecen asociaciones que permiten mantener la consistencia del modelo.

En el reconocimiento de los EC de Mecanizado, se han realizado propuestas que han puesto su foco de atención principal en su relación con el proceso de mecanizado, de forma que para establecer un EC, además de afectar a un volumen de mecanizado con relaciones de concavidad, es necesario que de acuerdo a unos tipos de movimientos, exista una herramienta con una geometría válida y con posibilidad de acceder al volumen a mecanizar [Gutiérrez, 2008].

En las aportaciones que se han realizado más recientemente, se ha incorporado la aplicación de modelos ontológicos, como en la propuesta de Eum et ál. [Eum et ál., 2013]. 
En esta propuesta, se establece una ontología basada en unos conceptos básicos (Proceso de Mecanizado, Plan de Proceso, Elemento Característico, Volumen Eliminado y Rango de Proceso de Mecanizado) y las relaciones entre ellos. Además se incorpora el conocimiento del dominio del mecanizado como un conjunto de reglas que posibilita los razonamientos necesarios para la generación de un plan de proceso.

Señalar por último, que no se encuentran propuestas de EC de Mecanizado, en los que estos se consideren componentes del ensamble correspondiente a la ejecución del proceso de mecanizado. Ensamble, que incluye otros componentes como son la máquina, la herramienta, etc., y que a partir de las relaciones entre sus componentes posibilita el análisis y validación del proceso de mecanizado.

\subsubsection{El Elemento Característico en la Planificación de LA INSPECCIÓN.}

Se ha realizado una revisión de algunos de los principales trabajos en los que se proponen entidades a utilizar en la Planificación Supervisora de la Inspección, si bien cabe señalar que en la mayor parte de estos trabajos se refieren a la Planificación Detallada u Operativa de la Inspección (Medición) y no a la Planificación Supervisora.

Para Zhang et ál. [Zhang et ál., 2000] el punto de partida para el proceso de planificación de la inspección son los elementos característicos de tolerancia (tolerance features), que contemplan las especificaciones dimensionales y geométricas, y que a su vez se descomponen en elementos característicos individuales de superficie (surface features). El proceso de planificación de la inspección propuesto se centra en aspectos de nivel operativo como son el análisis de la accesibilidad de las superficies, la agrupación de los elementos característicos de superficie para compartir una misma orientación de la pieza y tipo de palpador, y la selección y distribución de los puntos para la toma de datos sobre las superficies. La propuesta está desarrollada para la inspección en MMC y queda implícito que se trata de una inspección final fuera de línea.

Pfeifer et ál. [Pfeifer et ál., 2002] determinan el plan de inspección como una secuencia ordenada de características de inspección (inspection characteristics) que se corresponden con las especificaciones dimensionales y geométricas. De forma similar a Zhang et ál. [Zhang et ál., 2000], estas características, a su vez, hacen referencia a los elementos de medida (measurement element), que son elementos geométricos básicos de la pieza accesibles por los equipos de medida. La propuesta tiene en cuenta cualquier tipo de recurso metrológico y pretende integrar las operaciones de inspección en un plan de fabricación.

Por su parte, Barreiro et ál. [Barreiro et ál., 2003], centrándose en la inspección final en MMC, definen el elemento de inspección (inspection element) como un aspecto de la forma de la pieza que tiene una o más tolerancias dimensionales o geométricas asociadas y que, por tanto, debe ser medido. Presentan un modelo de información de producto para la integración de la inspección muy completo, en el que se definen operaciones de inspección que pueden ser: calibración del sensor, alineación de pieza, medida de la pieza (número de puntos, localización, secuencia), operaciones constructivas y comprobación de la tolerancia.

Hwang et ál. [Hwang et ál., 2004] establecen el plan de inspección de una pieza con MMC como la secuencia ordenada de elementos característicos de inspección (inspection features) que minimiza el tiempo de recorrido del palpador. Cada elemento característico de inspección se corresponde con un elemento geométrico básico (plano, cilindro, etc.). Los ítems de inspección (inspection items) son especificaciones dimensionales y geométricas que relacionan elementos característicos de inspección entre sí. Una vez más, 
la planificación de la inspección se trata con un alto nivel de detalle, por cuanto establece la secuencia de elementos característicos de inspección que minimizan el número de orientaciones de la pieza y del palpador, además de determinar el número de puntos sobre cada superficie y la distribución de los mismos.

Wong et ál. [Wong et ál., 2005 y 2006] proponen que un elemento característico de inspección (inspection feature) es aquella pareja de caras que deben ser palpadas. Clasifican estos elementos en función de la dirección de acceso del palpador: exteriores, interiores, profundidades y superficies libres. La propuesta está limitada a especificaciones dimensionales de longitud y considera todo tipo de recursos de inspección, incluyendo los instrumentos manuales. La planificación de la inspección se realiza en función del amarre (dirección de acceso) y del instrumento metrológico a utilizar (exterior, interior, profundidad).

Ali et ál. [Ali et ál., 2005] utilizan la entidad ítem de inspección (inspection item), directamente relacionada con las tolerancias dimensionales y geométricas y, a su vez, relacionada con los elementos característicos de fabricación (2.5D manufacturing feature). El plan de inspección está formado por actividades de inspección referidas al amarre y a operaciones de palpado. En este caso el trabajo se refiere a la inspección con sondas integradas en máquina herramienta o en MMC.

Cho y Choi et ál. [Cho, 2005; Choi et ál., 2006] proponen un sistema de planificación de la inspección para MMC en dos etapas: planificación global de la inspección y planificación local de la inspección. En la planificación global se realiza una agrupación y secuenciación de elementos característicos de fabricación (manufacturing feature) de la pieza según accesibilidad. En la planificación local, los elementos característicos de fabricación, como no se pueden utilizar directamente, se descomponen en elementos geométricos básicos (plano, cilindro, etc.), para los cuales se determinan el número, la localización y la secuencia de puntos de medida para minimizar el tiempo de recorrido del palpador. De nuevo, la propuesta sólo considera una inspección final fuera de línea en MMC.

La norma ISO10303, en su parte 219 de intercambio de la información de la inspección dimensional [ISO10303-219, 2007], utiliza la entidad elemento característico de medición dimensional (dimensional measurement feature) que contiene la información necesaria para identificar formas, que representan volúmenes de material de una pieza que serán inspeccionados mediante inspección dimensional. La norma establece una biblioteca de elementos característicos de medición dimensional y está desarrollada para la medición en MMC o en máquinas con sonda integrada.

Tras la revisión de los principales trabajos encontrados sobre el uso y tratamiento de elementos característicos en la Planificación de la Inspección, se llega a toda una serie de conclusiones sobre:

- El nivel de Planificación de la Inspección. Si bien la mayor parte de los trabajos se refieren a la Planificación de la Inspección, la mayoría se centran fundamentalmente en aspectos propios de la Planificación Operativa de la Inspección (o de la Medición), tales como la determinación del número de puntos a tomar sobre una superficie, la selección del palpador concreto a utilizar, la optimización de la secuencia a seguir para la toma de datos, etc., y no tanto de la Planificación Supervisora de la Inspección. Únicamente Pfeifer et ál. incluyen alguna consideración relativa a aspectos tales como la asignación de posibles recursos de inspección, el alcance de la inspección, la agrupación y la secuenciación.

- El tipo de recursos de inspección considerados. La mayor parte de los trabajos revisados consideran un único tipo de recurso de inspección, la MMC o alguno 
similar como la sonda integrada en máquina de fabricación. Salvo en las propuestas de Pfeifer et ál. y de Wong et ál., en el resto no se tienen en consideración otros recursos metrológicos todavía ampliamente utilizados como son los pequeños instrumentos de taller, los montajes específicos u otro tipo de equipos.

- Las especificaciones dimensionales y geométricas. Como aspecto común a todos los trabajos revisados hay que señalar el hecho de que uno de los puntos de partida en todos ellos son las especificaciones dimensionales y geométricas, referidas con diferentes denominaciones: elementos característicos de tolerancia (tolerance feature), características de inspección (inspection characteristic), ítems de inspección (inspection item) o bien directamente como especificaciones.

- Los elementos geométricos básicos. En la mayor parte de los trabajos revisados, aunque utilizando diferentes denominaciones (elementos característicos de superficie/surface feature, elemento de medición/measurement element, elemento de inspección/inspection element, elemento característico de inspección/inspection feature, elemento característico de medición dimensional/dimensional measurement element), se utilizan elementos geométricos básicos de la pieza, que corresponden directamente a superficies de la misma (plana, cilíndrica, esférica, etc.) sobre la que se puede realizar la toma de datos o a algún otro elemento geométrico perteneciente o derivado de las mismas (línea, punto, etc.). En estos elementos se echa en falta información adicional del ámbito específico de la Planificación de la Inspección que enriquezca a la información geométrica.

- La relación entre la especificación y la inspección del producto. Aunque las especificaciones dimensionales y geométricas son consideradas en todos los casos como características vinculadas al funcionamiento y ensamble del producto, todavía se aprecia la necesidad de enfatizar la relación entre la especificación del producto y su inspección. En concreto, las especificaciones dimensionales y geométricas consideradas en todos los trabajos se establecen entre geometrías de la pieza que participan en el ensamble de piezas que forman un subconjunto o el producto final. Sin embargo, en ninguno de los trabajos se plantea que en el ciclo de vida, las piezas también forman parte de otros ensambles, como pueden ser los montajes (subconjuntos) necesarios para la ejecución de la fabricación y la propia inspección de la pieza en una determinada estación de trabajo.

- La integración con la Planificación de la Fabricación y la propia Fabricación. Todos los trabajos revisados, a excepción del de Pfeifer et ál., desarrollan las propuestas para una inspección final, tras la finalización de la fabricación. Es decir, se trata de una inspección final y fuera de línea. Se echa por tanto en falta un mayor esfuerzo en la integración de la inspección en la fabricación, considerando la inspección en línea (en y post proceso).

- Obtención de la geometría extraída. Aunque en la mayor parte de trabajos se hace referencia a aspectos vinculados con la toma de datos (medición) de diferentes geometrías para realizar la verificación dimensional y geométrica, se echa en falta una referencia más explícita a las diferentes formas de obtener la geometría extraída y, por tanto, de representar la geometría real de la pieza (geometría continua o discreta, modelos de piel/superficies integrales o modelos de esqueleto/elementos derivados, etc.). 


\subsection{El Elemento Característico en EL MOdELAdo DE PRODUCTO.}

Todo lo expuesto en los apartados anteriores, especialmente en el 4.2, evidencia la necesidad de dotar al EC de una semántica unificada que permita que las definiciones específicas que se realicen sean consistentes entre sí, facilitando de esta forma los análisis de compatibilidad de las soluciones representadas en los diferentes modelos específicos de EC pertenecientes a diferentes etapas y puntos de vista, circunstancia que va más allá del análisis de consistencia de la geometría. Una semántica común que se va a buscar profundizando, aunque sea brevemente, en las asociaciones semánticas presentes en algunos modelos genéricos de producto propuestos en la literatura, tratando de encontrar una intención común.

Además, en la segunda parte de este apartado se van a revisar de forma concisa algunas de las propuestas existentes en el ámbito de las tecnologías CAX, cuyo uso es habitual en entornos de ingeniería concurrente y colaborativa con diferentes puntos de vista del desarrollo del producto, y cuyo objetivo es proporcionar una estructura tecnológica que garantice el mantenimiento de la consistencia y la integridad semántica entre los modelos de EC necesarios para los diferentes ámbitos de interés.

\subsubsection{ESQUEMAS GENÉRICOS ADOPTADOS EN EL MODELADO DE PRODUCTO.}

En un reciente trabajo de Zheng et ál. [Zheng et ál., 2014] se realiza una revisión de métodos de diseño y modelos de producto para el ámbito del desarrollo de sistemas mecatrónicos (sistemas que combinan cuatro disciplinas: mecánica, electrónica, computación y control automático) bajo los principios de la ingeniería concurrente y el diseño integrado. Como parte del trabajo, y en relación a las formas de abordar los problemas relacionados con los datos de diseño para el desarrollo de sistemas mecatrónicos, resumen las aportaciones de los principales modelos de producto existentes en la actualidad. En particular, Zheng et ál. evalúan y comparan cuatro modelos de producto: STEP, MOKA (Methodology and tools Oriented to Knowledge-based engineering Applications / Metodología y herramientas Orientadas a Aplicaciones de ingeniería basadas en Conocimiento), CPM (Core Product Model / Modelo de Producto Núcleo) y PPO.

La propuesta CPM será descrita con mayor profundidad mas adelante en este mismo subapartado, mientras que las principales características del modelo PPO ya se han tratado en el capítulo 3. Previamente a la descripción de CPM, se mencionarán brevemente las otras dos propuestas (STEP y MOKA), también muy relevantes en el campo del modelado de productos, pero que no han sido referencia directa para el presente trabajo.

STEP es una propuesta de modelo de producto que se organiza en un conjunto de normas conocidas como ISO10303, y que han sido desarrolladas por expertos de todo el mundo. La intención de STEP es proporcionar una representación de la información de producto junto con los mecanismos y definiciones necesarias para permitir el intercambio de datos de producto [ISO10303-1, 1994]. STEP ha desarrollado numerosos protocolos de aplicación (AP, Application Protocol) y partes para intentar dar respuesta no únicamente al intercambio de información puramente geométrica del producto, sino para cubrir la mayor parte de las etapas del ciclo de vida del producto y de ciertos dominios industriales. Más relacionadas con los principales aspectos del modelo genérico de producto y su estructura, cabe mencionar la parte 44 [ISO10303-44, 2014], que se centra en la configuración de la estructura de producto, incluyendo aspectos tales como: las relaciones entre componentes y 
ensambles del producto, la gestión de la estructura para la configuración de ensambles y componentes de acuerdo a su planificación para fabricación, la descomposición de un producto para dar soporte a actividades de diferentes etapas del ciclo de vida, etc. También es de interés la parte 239 [ISO10303-239, 2012] que especifica el protocolo de aplicación para dar soporte al ciclo de vida del producto, y que incluye aspectos tales como: información para definir y mantener productos complejos, la representación de estructuras, ensambles y despieces de producto (identificación y representación de piezas y sus versiones, representación de múltiples vistas de la estructura del producto, representación de interfaces entre productos, etc.), la representación de un producto a lo largo de su vida, la especificación y planificación de actividades de un producto y los recursos utilizados (representación de las tareas a realizar sobre un producto, las condiciones en las que se realizan, planificación y programación de las tareas, gestión de tareas y sus permisos, etc.), la representación del histórico del producto y sus actividades, etc. A diferencia de otras propuestas de modelo de producto que utilizan UML, STEP hace uso de un lenguaje propio para la representación de sus modelos de datos de producto que se conoce como EXPRESS y su representación gráfica como EXPRESS-G [ISO10303-11, 2004].

Por su parte, desde el proyecto MOKA se proponen el desarrollo de una metodología y de unas herramientas de apoyo al uso de aplicaciones de ingeniería basada en conocimiento (Knowledge-based Engineering, KBE) [Callot et ál., 2000]. En este contexto, también se ha propuesto un modelo de producto basado en unas pocas entidades básicas y en el que se utilizan diagramas UML para su representación. En concreto, existen cinco vistas básicas que deben utilizarse para la construcción del modelo de producto [Brimble y Sellini, 2000]: Estructura (Structure), Función (Function), Comportamiento (Behaviour), Tecnología (Technology) y Representación (Representation). Asimismo, el modelo de producto contempla la existencia de restricciones, que representan restricciones generales del diseño que deben ser satisfechas. Además del modelo de producto, MOKA también propone una metodología para el proceso de diseño, describiendo actividades y reglas de diseño.

El CPM, desarrollado por el NIST (Nacional Institute of Standards and Technology / Instituto Nacional de Estándares y Tecnología) [Fenves et ál., 2008], es un modelo de producto abstracto y genérico, centrado en el artefacto y desarrollado a un nivel conceptual. Como corresponde a una propuesta de este nivel, en él no se definen ni los atributos de las clases ni la semántica significativa de ningún dominio particular, que se embebe en el modelo de implantación y en la política de uso del mismo. El modelo conceptual permite extensiones en este mismo nivel o en niveles intermedios.

Tal y como se observa en la Figura 4.4, en el CPM el objeto artefacto (Artifact) se define como una agregación, que es un tipo de asociación en términos UML, de tres objetos fundamentales: la función (Function), la forma (Form), agregación a su vez de una geometría (Geometry) y un material (Material), y el comportamiento (Behaviour) que, según los autores, constituyen la base del modelo. Pero el CPM también contempla otras clases objeto (Commom Core Object), clases abstractas (clases sin instancias) y todo un conjunto de clases relación (Common Core Relationships), equivalentes a las clases de asociación de UML. Las cuatro clases de asociación específicas del esquema son: asociación de entidades (Entity Association), restricción (Constraint), uso (Usage) y trazabilidad (Trace).

El CPM, a pesar de no ser un modelo orientado a EC, contempla la clase EC (Feature) como subtipo de la clase entidad núcleo (Core Entity) y la describe como la agregación de una función y una forma, definiéndolo como una porción de la forma de un artefacto que tiene alguna función específica. Es decir, el concepto de EC en el modelo CPM se interpreta claramente como un EC de forma. Un artefacto contiene EC de Diseño, 
de Análisis, de Fabricación, etc., tal y como establezcan sus respectivas funciones. El EC tiene su propia jerarquía de descomposición, de forma que se pueden crear EC compuestos a partir de otros EC (pero nunca artefactos). Otro aspecto que también diferencia la clase artefacto con respecto a la de EC es que en esta última no existe una relación de asociación simple con la clase especificación (Specification), que es una agregación de requisitos (Requirement).

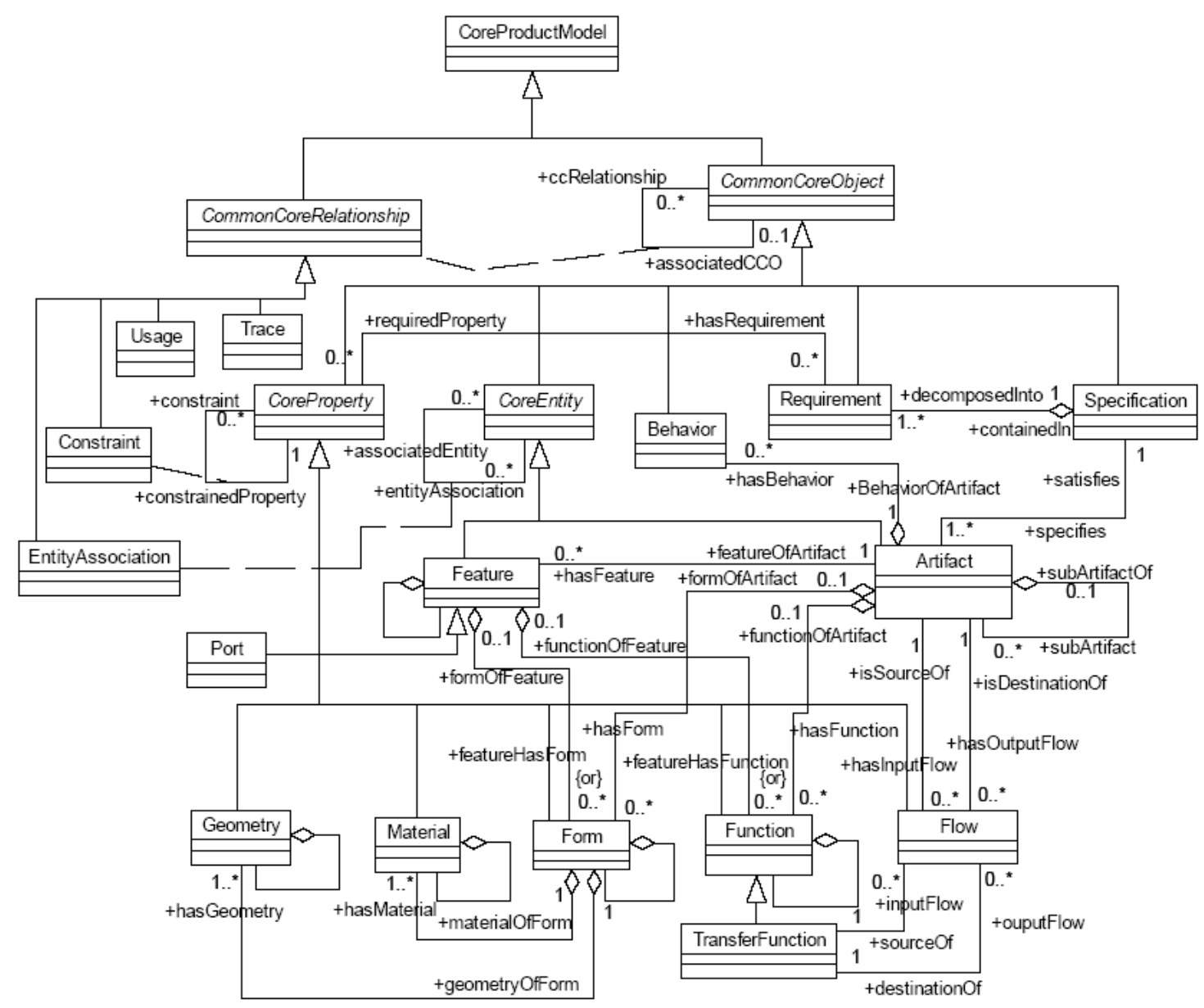

Figura 4.4 Diagrama de clases UML del CPM (Core Product Model) [de Fenves et ál., 2008].

Otro aspecto destacado de la clase EC (Feature) de CPM, como subtipo de entidad núcleo (Core Entity), es que entre EC se pueden establecer asociaciones, que se vinculan a la correspondiente clase asociativa. Una posibilidad que utiliza el OAM (Open Assembly Model / Modelo de Ensamble Abierto), una iniciativa desarrollada en el contexto de CPM para extender el modelo de producto general al ámbito del ensamble, a través de la clase asociación de EC de ensamble (Assembly Feature Association), subclase de asociación de entidades (Entity Association). Clase asociativa que, como puede verse en la Figura 4.5, se relaciona directamente con la clase EC de ensamble (Assembly Feature), subclase de EC (Feature).

A pesar de que el desarrollo del modelo de producto general se realizó con un amplio consenso de especialistas pertenecientes a muchos campos de la ingeniería de producto, Fenves et ál. [Fenves et ál., 2008] indican que en algunas extensiones del CPM conceptual se han detectado algunos conflictos, como son el hecho de que algunos EC de dominio tengan comportamiento (hay que recordar que el comportamiento se agrega al artefacto pero nunca al EC en el esquema CPM), o el hecho de que en algunos dominios la 
geometría y el material no sean las especializaciones de alto nivel más adecuadas para la forma.

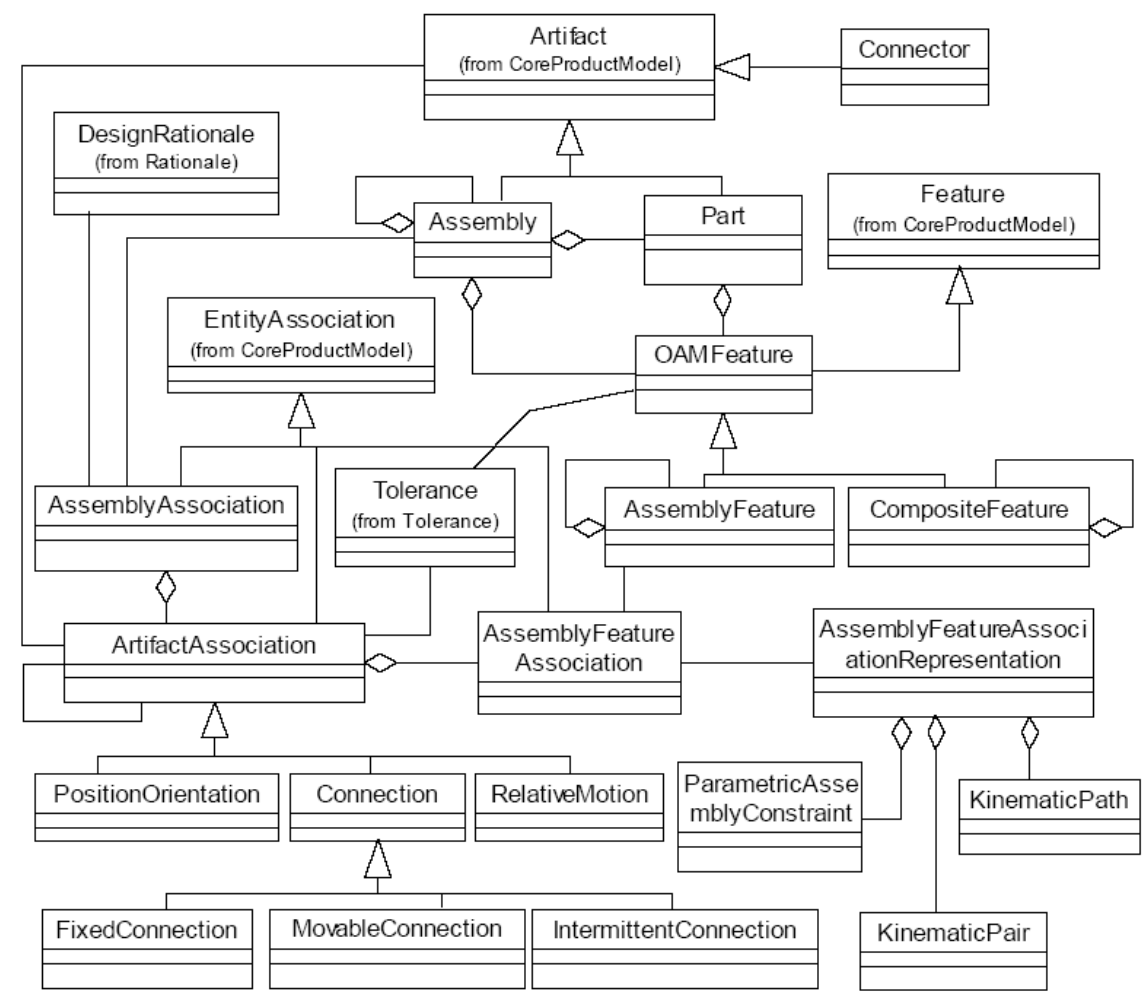

Figura 4.5 Diagrama de clases UML del OAM (Open Assembly Model) del CPM [de Rachuri et ál., 2006].

Del primer conflicto también dan cuenta Yu y sus colegas [Yu et ál., 2008], quienes reinterpretan en cierta manera lo establecido para el EC en el CPM del NIST, e indican que el EC es una clase que contiene las características de información del producto, incluida la de las funciones, formas y comportamientos, etc. La propuesta de Yu et ál. tiene una clara orientación a EC, justificada por frases como la que indica que "el artefacto es entendido como el cuerpo principal del producto que está compuesto por EC".

Por su parte, Zha y Sriram [Zha y Sriram, 2004], cuya propuesta de modelo de EC ha sido explicada en el apartado 4.2 de este capítulo, también hacen referencia a estas posibles limitaciones del modelo CPM conceptual, y más concretamente al hecho de que inicialmente CPM se centró básicamente en artefactos de tipo físico para productos y ensambles electro-mecánicos. Sin embargo, el propio NIST reconoció la necesidad de incluir ciertas modificaciones o extensiones cuando el CPM se aplica a artefactos más de tipo informacional (por ejemplo, aplicaciones informáticas, organizaciones, procesos de negocio, planes y programaciones, etc.). De hecho, estos mismos autores, y basándose en los conceptos propuestos por Riebisch [Riebisch, 2003], proponen una modificación/extensión del modelo CPM (Figura 4.6) para el modelado de sistemas embebidos que, como ya se ha indicado en el subapartado 4.2.3, son sistemas híbridos de hardware y software, es decir, se pueden considerar ensamblajes de componentes hardware y componentes software.

Como se puede observar en la Figura 4.6, el modelo incorpora información sobre las especificaciones de diseño (Design Specification), la partición (System Partitioning), la especificación del sistema embebido (System Specification), la composición de componentes (Composition Association) y las relaciones de configuración/ensamble. 


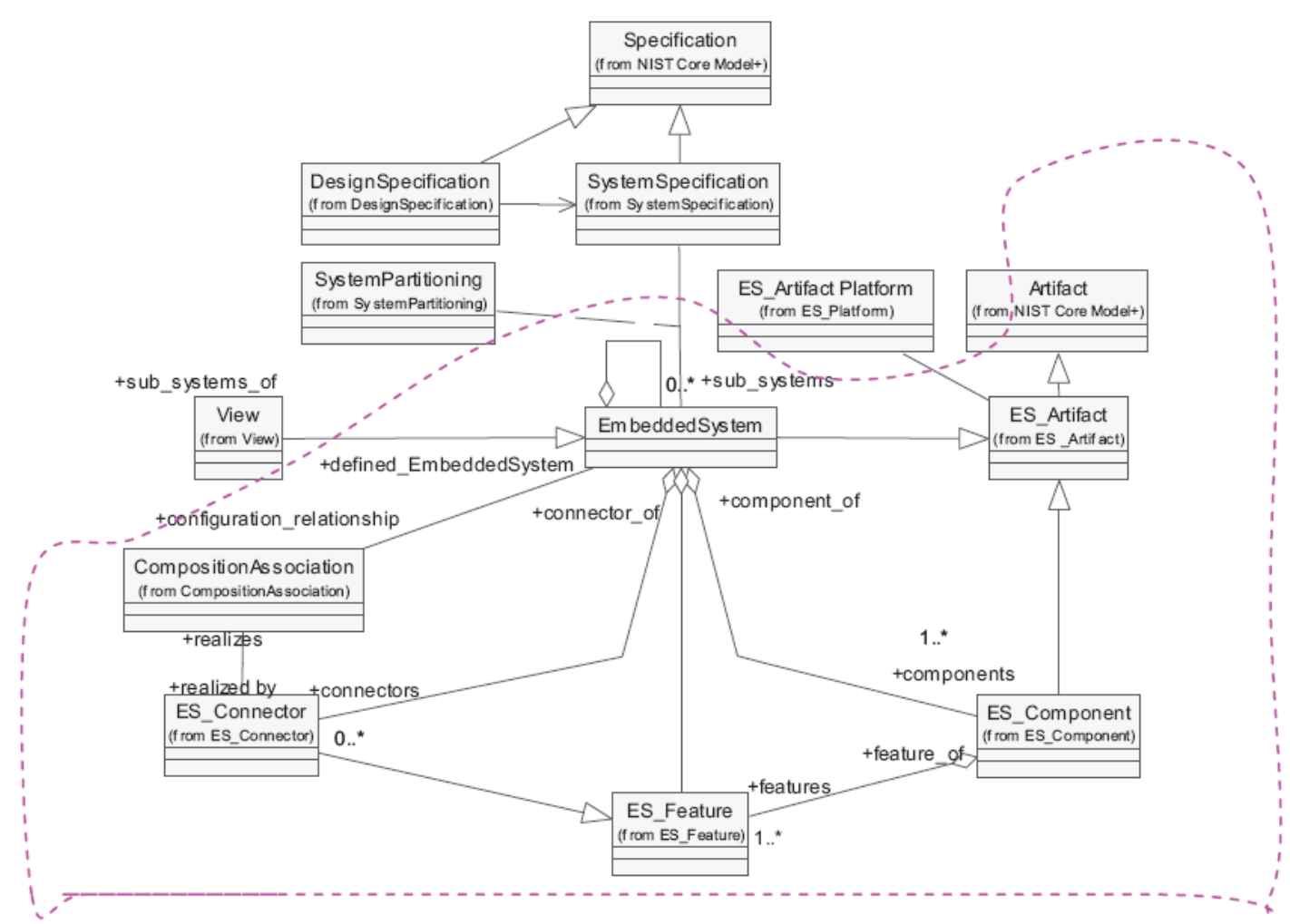

Figura 4.6 Diagrama de clases UML del OESFM (Open Embedded System Feature Model) [de Zha y Sriram, 2004].

Como resultado de la revisión anterior, incluyendo la del modelo PPO realizada en el capítulo 3 , se puede concluir que los modelos genéricos de producto y los conceptos, entidades y relaciones utilizadas en ellos, pueden ser un apoyo efectivo para encontrar la semántica o intención común que permita representar adecuadamente un modelo de EC apropiado para el desarrollo integrado de producto-proceso-recurso y que facilite la compatibilidad de modelos específicos de EC correspondientes a diferentes puntos de vista o etapas de desarrollo del producto. En concreto, se puede concluir que, de las propuestas de modelos de producto revisadas y a pesar de que algunas limitaciones todavía no han sido resueltas, PPO es la que mejor respuesta da en estos momentos a los requisitos impuestos por los entornos de desarrollo colaborativo de productos complejos que combinen varias disciplinas (mecánica, electrónica, control automático, etc.) [Zheng et ál., 2014]. A ello contribuye que PPO se extiende integrando el modelo de producto con el de proceso de diseño y el de organización, cubriendo de forma completa, y a diferencia de los otros modelos revisados en los que únicamente se hace de forma parcial, las necesidades de los aspectos organizacionales propios de los entornos de desarrollo colaborativo, en los que los diferentes participantes, cada uno con necesidades distintas, deben tomar decisiones en varios momentos del proceso.

Por ello, a continuación se explicará con algo más detalle cómo el modelo PPO de producto se integra con el de proceso y organización junto con la revisión de algunas propuestas del ámbito de las tecnologías CAX habituales en entornos de ingeniería concurrente y colaborativa.

\subsubsection{EL DESARROLLO COLABORATIVO DE PRODUCTOS.}

Una de las problemáticas que todavía queda por resolver, para hacer más efectivos y eficientes los procesos de trabajo que caracterizan la ingeniería concurrente y colaborativa, es la dificultad para mantener la integridad de unos modelos de producto comprensivos, ya 
que las tecnologías $\mathrm{CAX}$ de hoy no soportan suficientemente la transferencia y/o compartición de datos entre etapas, fundamentalmente los no geométricos [Ma et ál., 2009]. Para salvar estas deficiencias y teniendo presente que estos procesos se desarrollan normalmente en entornos distribuidos, en los últimos años se han presentado diferentes enfoques y propuestas tanto en el campo del modelado genérico de producto como en el del modelado de producto basado en EC [Ma et ál., 2009; Yu et ál., 2008; Khaled et ál., 2008; Ballu et ál., 2007].

Entre ellas destacan las que proponen la definición de modelos propedéuticos para conseguir una interoperatividad CAD/CAM (Computer Aided Manufacturing / Fabricación Asistida por Ordenador) completa, incluida la intención [Bianconi et ál., 2006]. Se trata de un enfoque que ha sido adoptado, entre otros investigadores, por Chettaoui y Noël [Chettaoui y Noël, 2010], que plantean la integración y la gestión de modelos heterogéneos en base a servicios Web y a través de un entorno extendido basado en una Arquitectura Conducida por el Modelo (MDA, Model-driven Architecture), eligiendo el meta-modelo de producto PPO como nivel intermedio para el intercambio de información sobre el producto. El modelo PPO del proyecto IPPOP [Noël et ál., 2005], tal y como se ha descrito en el capítulo 3, es un meta-modelo de producto, ligero pero evolutivo, en el que el modelo de producto se define en base a unas pocas entidades o conceptos (Componentcomponente, Interface-interfaz, Function-función y Behaviour-comportamiento) y a sus interrelaciones. Por otra parte, aunque en el modelo PPO no se contempla de forma explícita la entidad EC, si se interpretan algunas publicaciones de aplicación del modelo [Chettaoui y Noël, 2010], se sobreentiende que el concepto de EC puede corresponder tanto al concepto de componente como al de interfaz del modelo PPO, dependiendo del nivel de análisis en el que se esté trabajando. En cualquier caso, en el modelo PPO las tres clases componente, interfaz y función son necesarias y adquieren sentido consideradas todas juntas, lo que equivale al concepto de EC. En este sentido el EC podría considerarse como una clase abstracta similar al EC de concepto definido por Riebisch [Riebisch, 2003], y descrito anteriormente, que no tiene implantación concreta por sí mismo, sino a través de los subEC (componente, interfaz y función) para los que sirve de contenedor.

Otro de los aspectos que caracterizan al modelo PPO y que conviene destacar es que, tal y como se ha indicado al final del subapartado anterior, integra el modelo de producto con los modelos de proceso y organización, lo que lo hace muy adecuado para entornos de desarrollo colaborativo. La Figura 4.7 [Noël y Roucoules, 2008] muestra el diagrama UML con las clases PPO del modelo de producto anteriormente descritas y las clases básicas correspondientes a la organización (centro de decisión (Decision Center), marco de decisión (Decision Framework) y marco de diseño (Design Framework)) y al proceso (proyecto (Project), humano (Human), hardware, software e información (Information)). Los tres modelos (de producto, de organización y de proceso) se integran básicamente alrededor de la clase proyecto.

Asimismo, hay que mencionar que las entidades básicas del modelo de producto PPO Componente, Interface y Función pueden ser siempre de tres tipos [Sadeghi et ál., 2010]: Común (Common), que representa la entidad con las características comunes; Alternativa (Alternative), que permite descomponer la entidad en las posibles alternativas; y Vista (View), que permite descomponer la entidad según un punto de vista concreto. Este último tipo de descomposición permite adaptar la entidad con los atributos propios de un dominio concreto en función de la etapa de desarrollo en la que se encuentre.

Un planteamiento tecnológico similar al de Chettaoui y Noël, también basado en una MDA, es el que proponen Yu et ál. para sustentar un marco de integración semántica basado en Web y dirigido a compartir información y conocimiento en el ciclo de vida del producto [Yu et ál., 2008]. Sin embargo, a diferencia de Chettaoui y Noël, adoptan el 
modelo de producto CPM como base para las definiciones semánticas comunes, que son descritas en UML en el nivel PIM (Platform Independent Model / Modelo Independiente de Plataforma) de la MDA y en un lenguaje ontológico en el nivel PSM (Platform Specific Model / Modelo Específico de Plataforma). También conviene indicar que para la descripción de los datos de producto estos autores adoptan la norma STEP (ISO10303) como referencia.

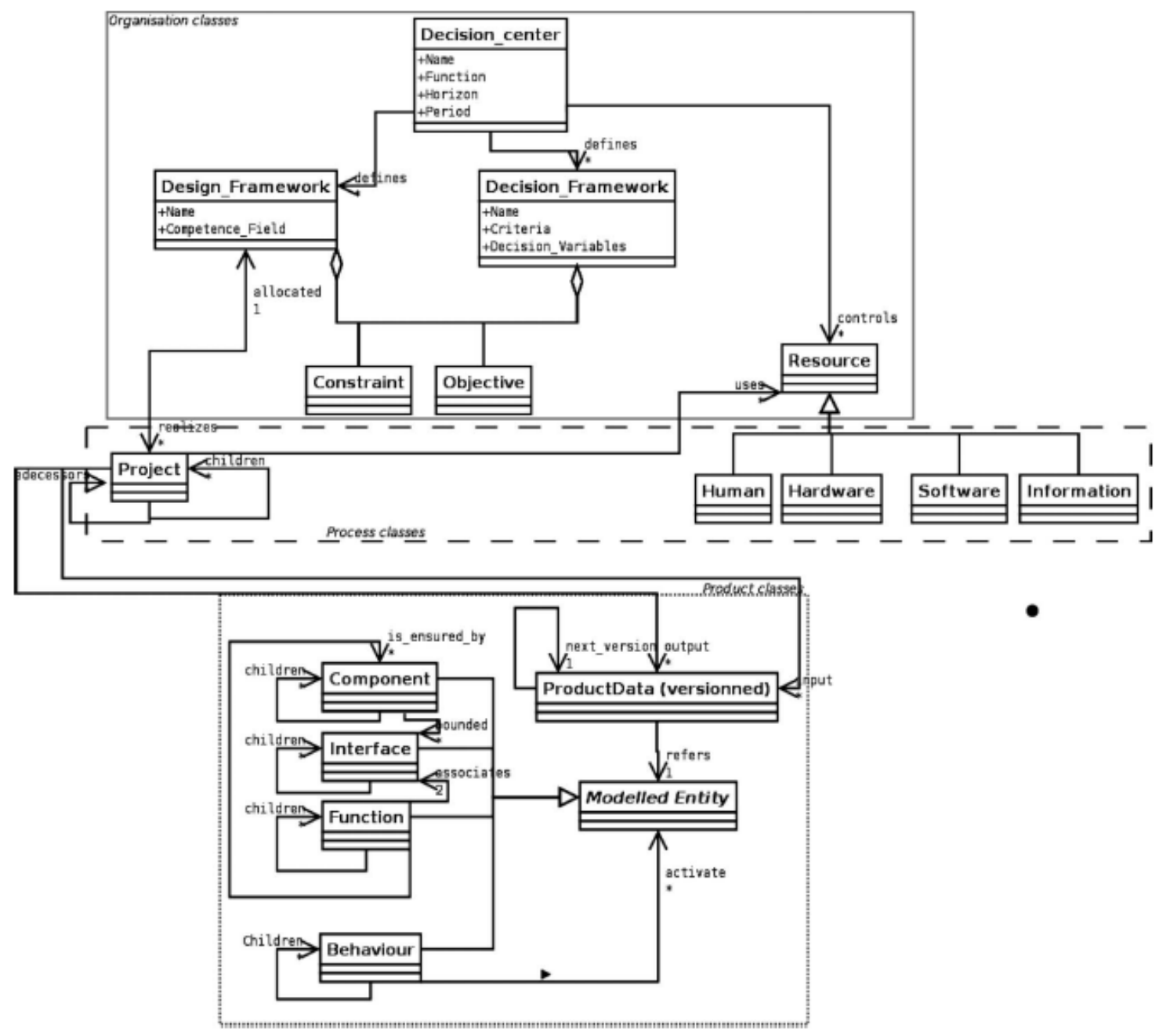

Figura 4.7 Diagrama UML del modelo PPO (Product-Process-Organization) [de Noël y Roucoules, 2008].

Otra aportación relevante en el campo de la colaboración en el ciclo de vida del producto es la de Khaled et ál. [Khaled et ál., 2008], que proponen una infraestructura para la colaboración concurrente entre aplicaciones CAX en un nivel de EC, que permite compartir información en tiempo real, preservando la semántica y la consistencia de los modelos CAX. La solución propuesta, sustentada en un Lenguaje Específico de Dominio que denominan Lenguaje de Modelado de Ciclo de vida de Producto (PLM-DSL, Product Lifecycle Management - Domain Specific Language), se basa en las siguientes nuevas tecnologías: la especificación de Servicios Web (WS-*, Web Services specification), la Arquitectura Orientada a Servicios (SOA, Service Oriented Architecture), el Lenguaje de Marcas Extensible (XML, Extensible Markup Language) y el EC Asociativo establecido por Ma y sus colaboradores, al que anteriormente se ha hecho referencia.

En estos entornos, los EC Asociativos [Ma y Bong, 2010] se utilizan como objetos de grano fino, que en el mundo del software son vistos como objetos que encapsulan a la vez información y comportamiento, en forma de entidades de bajo nivel, restricciones y 
métodos de razonamiento. Conviene recordar que últimamente en esta parcela del conocimiento se entiende que la interoperatividad entre diferentes sistemas está limitada por el tamaño del grano de información neutra accesible. Los EC Asociativos de grano fino son utilizados para modelar la intención de diseño en la forma de objetos vivos, de acuerdo con los principios de la ingeniería del software, mientras las propiedades y el comportamiento colectivo puede crearse y gestionarse dinámicamente creando objetos asociados de diferentes tamaños de grano, manteniendo sus relaciones de forma persistente, gestionando los métodos que se han aplicado y haciendo evolucionar sus estados. Se trata de un enfoque inherente al propio esquema de modelado unificado [Chen et ál., 2004; Chen et ál., 2006], que contempla relaciones entre diferentes EC Unificados (asociaciones basadas en restricciones y de compartición), genéricas o específicas de aplicación, y pertenecientes a una misma etapa o a diferentes etapas. Estas relaciones, dependiendo del tipo de entidades participantes, se establecen a tres niveles (nivel de aplicación, nivel de EC y nivel de constituyentes del EC) y son fundamentales para garantizar la validez, consistencia e integridad del modelo global. A la importancia de esta última circunstancia se refieren los autores cuando indican que un modelo de información de producto sólo podrá ser considerado como un "modelo de EC Unificado" si los diferentes modelos de EC de aplicación han sido creados utilizando el concepto de EC Unificado, y si se establecen y mantienen las relaciones de dependencia mutua (geométricas y no geométricas) a los tres niveles antes indicados.

La propuesta de Khaled et ál. [Khaled et ál., 2008] es, sin lugar a dudas, una propuesta muy interesante para resolver el problema de la colaboración cuando se utilizan aplicaciones CAX heterogéneas, pero los propios autores reconocen que todavía faltan por investigar muchos temas alrededor del PLM-DSL, en especial en las áreas de la gestión de restricciones y del modelado de la intención de ingeniería, área que tampoco parece estar bien fundamentada en el propio esquema del EC Asociativo/Unificado desarrollado en otras publicaciones de Ma y sus colaboradores.

\subsection{RESUMEN.}

En este capítulo se ha puesto de manifiesto la idoneidad de un enfoque basado en EC, entendidos como elementos que además de la información geométrica contienen la información no geométrica relevante para un ámbito de aplicación, para abordar de forma adecuada un desarrollo integrado y colaborativo del producto. Sin embargo, el uso de EC en entornos de desarrollo colaborativo hace imprescindible garantizar la consistencia entre los diversos EC utilizados desde cada punto de vista, lo que obliga a disponer de una estructura y semántica unificada con todos los aspectos comunes a los diferentes dominios a integrar, establecida mediante un Meta-modelo de EC.

El desarrollo de una propuesta de Meta-modelo de EC será uno de los objetos del siguiente capítulo, y para ello se tendrán en cuenta las revisiones realizadas y conclusiones obtenidas en este capítulo. En particular, una de las propuestas que servirá de base es el modelo de EC de Ma y sus colaboradores que se caracteriza por definir el EC como un conjunto de asociaciones restringidas entre entidades geométricas y no geométricas. Asimismo, también será fundamental la propuesta de Zha y Sriram, refinada de la de Riebisch, que además de compartir similitudes con la de Ma y sus colaboradores en cuanto al tratamiento de las restricciones y atributos del EC, establece una categorización de EC en de tipo función, estructura, forma y parámetro, además del EC de concepto, que sirve de contenedor para encapsular a los cuatro anteriores.

Para el caso concreto del ámbito de la planificación de la inspección, se han estudiando las principales propuestas existentes para revisar las entidades o elementos que 
se utilizan en la planificación, concluyéndose que no se ha encontrado una propuesta de un EC para la inspección que sea adecuado para el nivel supervisor y para entornos de desarrollo colaborativo. La mayor parte de los trabajos se centran en la planificación final fuera de línea en un nivel operativo utilizando MMC y con un enfoque muy centrado en la geometría basada en elementos ideales, sin considerar la representación de la geometría con defectos u otros aspectos no geométricos que puedan ser relevantes en el ámbito de la inspección. Además, no se han encontrado evidencias que garanticen que las entidades utilizadas para la planificación de la inspección sean consistentes con otros elementos (EC) de otros dominios con los que la inspección tiene una importante vinculación, como son la planificación del mecanizado y la especificación dimensional y geométrica del producto.

Además de las propuestas de modelos de EC mencionadas anteriormente, la búsqueda de una estructura común y una semántica unificada que también dé cabida al EC de inspección en un entorno de desarrollo colaborativo se ha hecho revisando las propuestas de algunos modelos genéricos de producto existentes en la literatura y los conceptos, entidades y relaciones utilizadas en ellos. De entre los modelos revisados, cabe destacar el modelo CPM, centrado fundamentalmente en artefactos de tipo físico para productos y ensamblajes electro-mecánicos, y en el que el EC se define como una porción de la forma de un artefacto que tiene alguna función específica, es decir, es un EC de forma. En el contexto del modelo CPM se desarrolló el OAM con la finalidad de extender el modelo de producto general al ámbito del ensamble, mediante una clase asociativa que se relaciona directamente con un EC de ensamble, subtipo de EC.

Pero, y a pesar de que algunas limitaciones todavía no han sido resueltas, el modelo PPO, que en gran parte se ha descrito en el capítulo 3, es el que mejor respuesta da en estos momentos a los requisitos impuestos por los entornos de desarrollo colaborativo de productos complejos que combinen varios dominios. Por un lado, PPO se caracteriza por ser un modelo de producto basado en pocas entidades (componente, interfaz y función) y sus relaciones. Por otro lado, y tal y como se ha descrito en este capítulo, PPO se extiende integrando el modelo de producto con el de proceso y el de organización, haciéndolo así muy adecuado para entornos colaborativos. PPO no contempla de forma explícita la entidad EC, pera está implícita como conjunto (a modo de EC de concepto de los tipos propuestos por Riebisch) de las tres entidades básicas, pudiendo ser tanto el componente, como la interfaz o la función dependiendo de la aplicación concreta y el nivel de detalle del análisis. Es por ello que algunos de los conceptos que fundamentan el modelo PPO, como la consideración de la parte estructural del producto (componente) diferenciada de la interfaz, que es la que interacciona con las interfaces de otros componentes, así como su naturaleza colaborativa servirán de base para las propuestas desarrolladas en los siguientes capítulos. 



\section{Capítulo 5}

\section{Los ELEMENTOS CARACTERÍSTICOS DE ESPECIFICACIÓN DE PRODUCTO Y DE INSPECCIÓN}

\subsection{INTRODUCCIÓN.}

En este capítulo, y en base a las revisiones realizadas en los capítulos anteriores 3 y 4, en primer lugar se desarrolla la propuesta de Meta-Modelo de Elemento Característico válido para entornos de desarrollo colaborativo y que incorpora los conceptos básicos propuestos en los principales trabajos de la bibliografía revisada, tal como el concepto de EC de aplicación como un EC asociativo que proporciona una estructura y semántica unificada.

A continuación, y de acuerdo al Meta-Modelo de Elemento Característico establecido, se desarrolla la propuesta del Elemento Característico de Especificación, elemento que contiene toda la información relacionada con la geometría necesaria para los ejercicios de especificación que se llevan a cabo durante el desarrollo del producto. En concreto, la información contenida en este modelo de Elemento Característico de Especificación permite realizar los ejercicios de especificación a través del análisis y la síntesis de tolerancias sobre las cadenas establecidas sobre un ensamble, considerando su arquitectura tanto a nivel de esqueleto como a nivel de piel (superficie). Cadenas que, cuando se establecen sobre el ensamble de producto, permiten llevar a cabo los ejercicios de especificación para los componentes de dicho producto. Por su parte, cuando estas cadenas se establecen sobre el ensamble del proceso de inspección, formado por la pieza a medir y el equipo de inspección utilizado, entonces permiten realizar los ejercicios de especificación de la inspección del producto. En los apartados 4 y 5 de este capítulo se desarrollan las propuestas de Elemento Característico de Especificación de Producto y de Elemento Característico de Inspección respectivamente, de manera que resulten propuestas duales, obtenidas como especializaciones del Elemento Característico de Especificación. Asimismo, la propuesta de Elemento Característico de Inspección se acompaña con una biblioteca que ofrece los tipos de Elementos Característicos de Inspección suficientes para interpretar una pieza desde la perspectiva de la inspección.

Para representar todos los modelos se va a hacer uso de diagramas de clases de UML. En estos diagramas las clases se representan gráficamente mediante rectángulos y 
las líneas representan gráficamente las asociaciones entre clases. Cuando en un extremo de una línea aparece un rombo, esto indica que se trata de un tipo particular de asociación, la agregación. La jerarquía que relaciona una clase con sus subclases se representa mediante un triángulo en el extremo de la línea que la une a la clase. Cuando una clase está unida mediante una línea discontinua a la relación entre otras dos clases es que se trata de una clase de tipo asociativa.

Cabe hacer notar que todos los modelos desarrollados y que se describen a continuación en este capítulo (y también en el siguiente) son modelos conceptuales y, por tanto, se centran en la estructura de clases y sus relaciones, quedando fuera del alcance de este trabajo la descripción de las multiplicidades, atributos y operaciones correspondientes a cada una de las relaciones y clases.

\subsection{Meta-Modelo de Elemento CARACTERÍSTico.}

En este apartado se describe la propuesta de un Meta-Modelo de Elemento Característico, el desarrollo de la cual se basa en los modelos de EC revisados en el capítulo 4. En particular, una de las propuestas que ha servido de base es el modelo de EC de Ma y sus colaboradores [Ma et ál., 2009] que se caracteriza por definir el EC como un conjunto de asociaciones restringidas entre entidades geométricas y no geométricas. Asimismo, también será fundamental la propuesta de Zha y Sriram [Zha y Sriram, 2004], refinada de la de Riebisch [Riebisch, 2003], que además de compartir similitudes con la de Ma y sus colaboradores en cuanto al tratamiento de las restricciones y atributos del EC, establece una categorización de EC en de tipo función, estructura, forma y parámetro, además del EC de concepto, que sirve de contenedor para encapsular a los cuatro anteriores. Además, el concepto de EC de Riebisch también integra los elementos básicos de otra de las propuestas revisadas en los capítulos 3 y 4, el modelo PPO, lo que permite incluir el EC en un modelo de producto que está integrado con modelos de proceso y organización, lo que lo hace muy adecuado para entornos de desarrollo colaborativo.

El Meta-Modelo de Elemento Característico propuesto, que se puede observar en la Figura 5.1, es un modelo que está basado en el concepto de un EC asociativo y unificado. Para ello un Modelo de EC es una agregación de EC de aplicación y de dos clases asociativas que definen las relaciones entre $\operatorname{los} E C$ de aplicación que garantizan la consistencia y coherencia del conjunto. El EC de aplicación, clase principal del modelo, define la estructura de un EC general con una semántica orientada al dominio de aplicación considerado. El EC de aplicación es de tipo EC de concepto de las categorías contempladas por Riebisch [Riebisch, 2003] y Zha y Sriram [Zha y Sriram, 2004] y, por lo tanto, se trata de un EC cuya única finalidad es contener otros EC que presentan un comportamiento conjunto en una aplicación. El EC de aplicación es una clase que resulta de la agregación de cuatro EC pertenecientes a los cuatro tipos siguientes: EC de función, $E C$ de estructura, EC de interfaz geométrica (que es una agregación de Geometrías) y EC de parámetro, que son especializaciones de la clase abstracta EC objeto. La relación de agregación entre el EC objeto y el EC de aplicación estará caracterizada por un conjunto de restricciones, no mostradas en el diagrama UML, que determinarán el tipo y número de $E C$ objeto que pueden formar parte de un EC de aplicación. De esta forma, un EC de aplicación incorpora la semántica correspondiente a su ámbito de aplicación, ya que incluye no solo la geometría del elemento sino la estructura en la que esta contenido y la funcionalidad en la que participa a través de sus interfaces geométricas.

A su vez, la agregación de varios Modelos de EC define la clase Modelo de dominio, que incluye todos los Modelos de EC correspondientes al mismo dominio o ámbito de interés. Con el fin de garantizar la compatibilidad y coherencia entre Modelos de EC de un 
mismo dominio, se define la clase asociativa Asociación de modelos, que es una agregación de Asociación de EC inter-modelo. Esta clase junto con Asociación de EC intra-modelo son especializaciones de la clase Asociación de EC de aplicación, que se define como una agregación de Restricciones inter-EC que restringen las relaciones entre EC objeto. La Asociación de EC inter-modelo se encarga de garantizar la correspondencia entre EC de aplicación de diferentes Modelos de EC, mientras que la Asociación de EC intra-modelo asegura la compatibilidad, coherencia, consistencia, etc. entre EC de aplicación dentro de un mismo Modelo de EC.

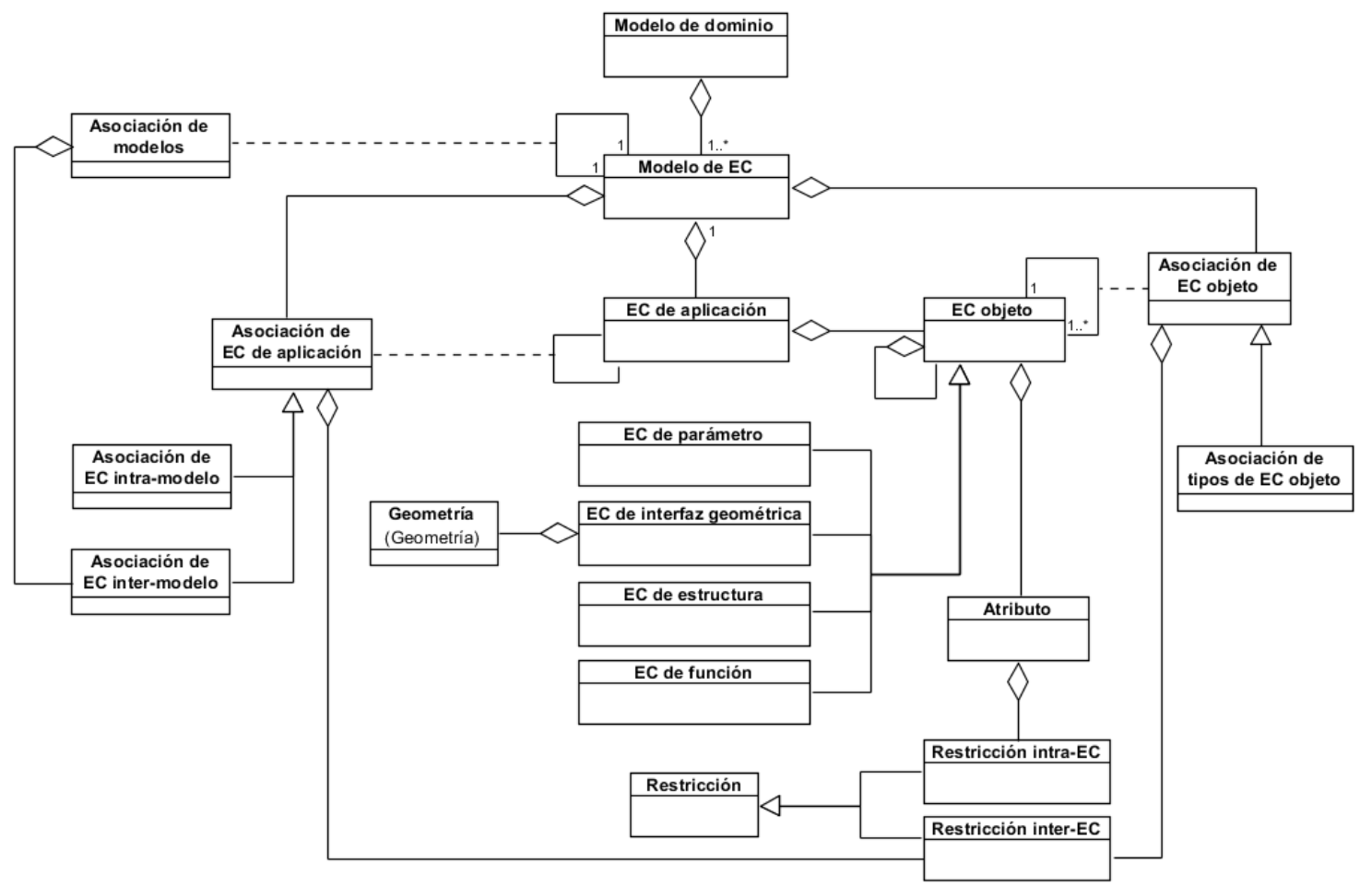

Figura 5.1 Diagrama de clases UML del Meta-Modelo de Elemento Característico (EC) propuesto.

El EC objeto, en la línea de las propuestas de Ma et ál. [Ma et ál., 2009] y Zha y Sriram [Zha y Sriram, 2004], a las que se ha hecho referencia anteriormente, se define como una agregación de instancias de la clase Atributo. Para caracterizar las relaciones entre los EC objeto se definen dos clases asociativas, compuestas por instancias del tipo Restricción inter-EC: Asociación de EC objeto, que limita las relaciones entre EC objeto del mismo tipo, y Asociación de tipos de EC objeto, que limita las relaciones entre EC objeto de diferentes tipos. El modelo también contempla la clase Restricción intra-EC, el otro subtipo de la clase Restricción, que se encarga de restringir los tipos y valores de los atributos que definen un determinado tipo de EC objeto.

El hecho de que el EC de aplicación contenga varios EC objeto con una semántica similar a las clases básicas contempladas en el modelo de producto PPO explicado en los capítulos 3 y 4, ofrece la oportunidad de relacionar el Meta-Modelo de EC que se acaba de proponer con dicho modelo PPO, lo que permite dotar a los modelos de aplicación de un cierto dominio basados en el Meta-Modelo de EC de la naturaleza colaborativa de PPO. En el modelo PPO, para cumplir una determinada función (Función PPO), se establece una solución formada por una arquitectura de componentes (Componente PPO), que poseen unas interfaces (Interfaz PPO) que participan en la función. Para ello, y tal y como puede observarse en la Figura 5.2, las especializaciones del EC objeto se han definido como subclases de las clases básicas de PPO. En concreto, El EC de parámetro y el EC de función se han definido como subtipos de la clase PPO Función, ya que el EC de 
parámetro especifica el EC de función. Por su parte, el EC de estructura y el EC de interfaz geométrica se han hecho corresponder con las clases de PPO Componente e Interfaz respectivamente. Juntas representan la solución desarrollada para una funcionalidad determinada, especificando los componentes (es decir, la estructura) que participa en dicha funcionalidad y las formas geométricas como interfaces que permiten obtenerla. Esta interfaz geométrica contendrá todas las propiedades geométricas a través de las cuales un componente puede relacionarse con la interfaz de otro componente. En el dominio de la especificación y la inspección, estas geometrías tienen en cuenta tanto la geometría nominal (EC nominal) como otras geometrías (EC con defectos, etc.), relacionadas con ellas, necesarias para los ejercicios de análisis, síntesis, simulación etc. propios de este dominio. Unos EC, que como EC de forma, incluirán propiedades pertenecientes a los niveles paramétrico, topológico y geométrico.

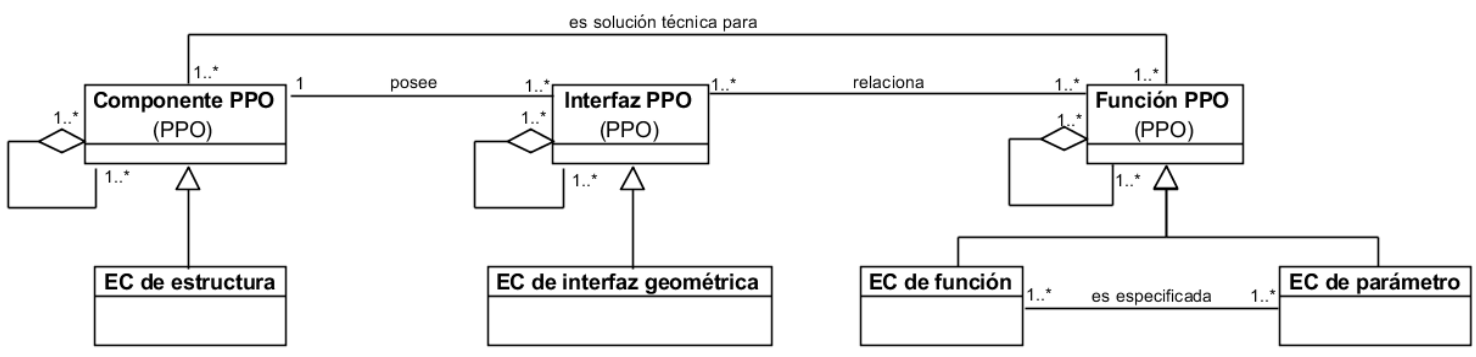

Figura 5.2 Diagrama de clases UML que muestra la relación de clases del Meta-Modelo de EC con el Modelo de Producto PPO.

Además, como consecuencia de esta vinculación, los diferentes EC objeto poseerán las propiedades que poseen las clases PPO correspondientes y las relaciones definidas en este modelo que se pueden observar en la Figura 5.2. En concreto, y tal y como se ha indicado anteriormente al describir el modelo PPO, sus clases se podrán componer o descomponer (agregación UML), permitiendo realizar los ejercicios a diferentes niveles de detalle, y especializarse en tres tipos: a) Común; b) Alternativa y c) Vista. Con las dos primeras especializaciones en el modelo se pueden representar objetos (componentes, interfaces y funciones) que tienen unas partes comunes y otras alternativas. Además, con la especialización de tipo vista, estos objetos pueden poseer atributos adicionales adecuados para diferentes ejercicios del dominio. Esto comporta que en un modelo de EC pueden existir diferentes objetos del tipo EC de aplicación (por ejemplo, un EC de especificación) que comparten ciertos atributos, y otros específicos derivados de las alternativas y vistas a las que pertenecen (por ejemplo, un EC de especificación de producto, un EC de inspección).

A modo de conclusión, cabe remarcar algunos de los aspectos de la propuesta que dan respuesta a toda una serie de insuficiencias comentadas a lo largo del capítulo 4. El Meta-Modelo de EC propuesto proporciona un modelo genérico que agrega modelos de un dominio, que a su vez se definen como la agregación de los EC de ese dominio y de las relaciones entre ellos, con el fin de garantizar la compatibilidad y coherencia. Esto permite definir los diferentes tipos de EC de un ámbito concreto como especializaciones del EC de aplicación genérico, particularizándose los atributos y aspectos específicos. Es más, la definición de los aspectos comunes es suficientemente genérica como para que sea aplicable incluso a productos complejos que combinen varias disciplinas en las que los aspectos estructurales, de interfaz y de función tienen características diferentes.

Asimismo, la propuesta resulta adecuada para el contexto del trabajo, que son los entornos de desarrollo colaborativo de producto-proceso-recurso, por la compatibilidad con el modelo de producto PPO, que permite la integración con los procesos y modelos de organización propios de estos contextos. 
Inherente a los entornos colaborativos es trabajar con diferentes puntos de vista del producto a lo largo de las etapas de su ciclo de vida, utilizando en cada caso diferentes modelos de EC. La propuesta aquí desarrollada permite garantizar la consistencia entre las diferentes representaciones del producto al considerarse los modelos de dominio y las asociaciones restringidas que regulan la relación y coherencia entre EC de diferentes modelos.

\subsection{Modelo de Elemento CARACTERístico PARA La ESPECIFICACIÓN E INSPECCIÓN DE PRODUCTOS.}

Las tareas vinculadas al establecimiento de las especificaciones se llevan a cabo en base a razonamientos realizados sobre las cadenas de un ensamble, que vienen condicionadas por la arquitectura de dicho ensamble. Estos ejercicios se pueden llevar a cabo considerando arquitecturas en diferentes vistas (niveles), como son el de esqueleto y el de piel (superficie).

Para abordar estos ejercicios para la especificación en este apartado se propone un EC, el Elemento Característico de Especificación (ECE), que contiene toda la información necesaria. Más concretamente, el ECE debe representar de forma adecuada la interfaz geométrica, incluyendo no únicamente la información sobre la geometría nominal de definición, sino también la referente a la geometría con defectos, en la que se representan todas las variaciones geométricas que pueden darse respecto a la geometría nominal.

Cuando se trata del ejercicio de la especificación del producto en la etapa de diseño, la geometría con defectos incluye las variabilidades que pueden producirse debidas al proceso de fabricación del producto $\mathrm{y}$, considerando la función del producto final, el diseñador lleva a cabo ejercicios de simulación sobre el ensamble final de producto que le llevan a establecer o especificar los variaciones máximas (tolerancias) admitidas para cada uno de los componentes del ensamble.

Por su parte, cuando se trata del ejercicio de especificación del proceso de inspección, donde la geometría con defectos de la pieza real se representa mediante las desviaciones geométricas de las piezas obtenidas respecto a la geometría nominal, el planificador lleva a cabo ejercicios de simulación sobre el ensamble de inspección que forman la pieza a medir y el equipo de inspección utilizado, para establecer o especificar el valor de las incertidumbres de las medidas de las características, tanto de las de extracción como las especificadas.

Por lo tanto, en los dos ejercicios, y tal y como se estableció en el capítulo 3, para la especificación de producto y para la especificación del proceso de inspección, se realizan razonamientos duales considerando geometrías con defectos y cadenas de ensamble, estableciéndose unas limitaciones a la variabilidad de determinadas características geométricas, dando lugar a las tolerancias en el caso de la especificación de producto y a las incertidumbres cuando se trata de la inspección.

A partir del ECE, en los siguientes apartados se desarrollan el Elemento Característico de Especificación de Producto (ECEP) y el Elemento Característico de Inspección (ECI) como especializaciones del ECE. El disponer de un ECE permite obtener los modelos de EC para la especificación de producto y para la especificación del proceso de inspección del producto de una manera dual, de forma que se garantice al máximo la coherencia e integración de ambos ámbitos y la conservación de la intención del diseño.

Tal y como se puede observar en la Figura 5.3, para el dominio de la especificación e inspección geométricas de producto, se define el Modelo de EC de especificación e 
inspección, subclase de Modelo de EC, que agrega a los EC de especificación, subtipo del EC de aplicación.

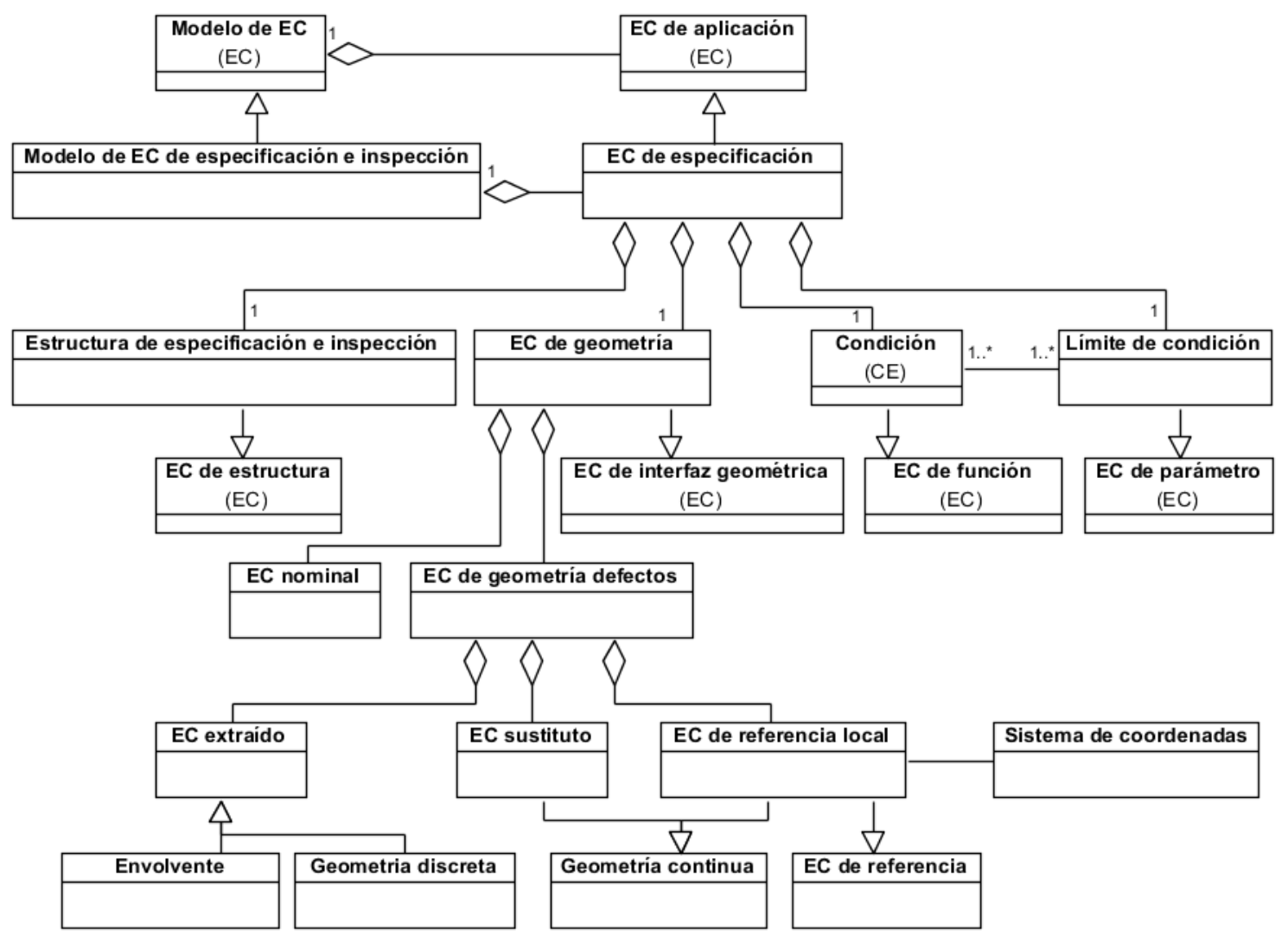

Figura 5.3 Diagrama de clases UML del Modelo de Elemento Característico de Especificación (ECE) propuesto.

El EC de especificación es una clase abstracta que contiene toda la estructura y relaciones de la información necesaria para el ejercicio tanto de la especificación como de la inspección de producto. Por ello, el EC de especificación no se instancia, sino que las instancias serán de sus subtipos, para la especificación y para la inspección de producto, que heredarán los aspectos comunes de este EC. El EC de especificación es la agregación de cuatro EC de los cuatro tipos contemplados en el Meta-Modelo de EC propuesto en el apartado anterior: un EC con la información sobre la interfaz geométrica ( $E C$ de geometría) y un EC con la información sobre los elementos estructurales (Estructura de especificación e inspección) que dan solución a una condición (Condición) y el valor que concreta a dicha condición (Límite de condición). En el ámbito de la especificación de producto se consideran los elementos estructurales del ensamble de producto y las condiciones funcionales con sus límites en términos de variaciones geométricas máximas permitidas vinculadas al mismo. En el caso de la inspección de producto, los elementos estructurales hacen referencia al ensamble de inspección y las condiciones consideradas son las vinculadas al proceso de inspección con sus límites en términos de incertidumbres.

Es importante remarcar que un EC de especificación agrega todas las condiciones (Condición) con sus límites (Limite de condición) en las que este participa a través de su interfaz geométrica ( $E C$ de geometría). En los dos ejercicios considerados, y con el objeto de establecer las condiciones, se contemplan en el imaginario una serie de posibles variaciones sobre la geometría nominal. Por ello, la interfaz geométrica del EC requiere además de la geometría nominal (EC nominal), una representación de las variaciones en esta geometría (EC de geometría con defectos). El EC de geometría con defectos agrega 
una geometría extraída ( $E C$ extraído), una geometría de sustitución ( $E C$ sustituto) y una geometría de referencia ( $E C$ de referencia local).

La geometría extraída es una geometría obtenida a partir de la geometría real con defectos (bien en el proceso de inspección, cuando se realiza la medición sobre las superficies reales de la pieza, o bien mediante un conjunto de operadores aplicados, cuando se realiza la especificación de producto imaginando los posibles defectos que genera el proceso de fabricación).

Tal y como se observa en el diagrama UML, un EC extraído puede ser de dos tipos: Geometría discreta o Envolvente. Cuando se trata de una geometría discreta está formada por un conjunto de puntos, segmentos o teselas. Cuando la geometría extraída es de tipo envolvente, está formada por un conjunto (dos) de líneas o superficies ideales recortadas que envuelven, interior o exteriormente, la geometría real con defectos. Estos tipos de geometría extraída corresponden a los diferentes tipos de modelos primitivos explicados en el capítulo 3 y que se utilizan en la especificación e inspección de producto.

La geometría de sustitución (EC sustituto) es una geometría ideal y continua, que se calcula a partir del EC extraído, utilizando para ello diferentes procedimientos de ajuste (Gauss, Chebyshev, envolventes exteriores/interiores,...) que representa la geometría con defectos. La geometría de sustitución solo puede representar los errores de orientación y posición de la geometría con defectos, pero no los defectos de forma. La referencia local (EC de referencia local) es una geometría ideal que permite situar las geometrías extraídas y de sustitución.

\subsection{Modelo de Elemento Característico de ESPECIFICACIÓN DE PROdUCTO.}

\subsubsection{REQUISITOS DE LA PROPUESTA.}

De acuerdo a todo lo expuesto en los capítulos 3 y 4 y en los apartados anteriores, la propuesta de Elemento Característico de Especificación Producto (ECEP) a desarrollar deberá contemplar los siguientes requisitos:

- El ECEP debe definirse como un subtipo del ECE, que permitirá mantener la dualidad entre los ejercicios de la especificación del producto y de la inspección. Además, por ser subtipo del EC de aplicación, de acuerdo al Meta-Modelo de EC, podrá integrarse con otros dominios y mantener la naturaleza colaborativa del modelo PPO.

- Es necesario que el ECEP contenga toda la información necesaria para el ejercicio específico de la simulación en la especificación dimensional y geométrica de producto. En particular, es de especial importancia que incluya la información sobre la geometría con defectos.

- El modelo de ECEP debe ser válido para los ejercicios de simulación realizados sobre diferentes modelos de representación de la geometría con defectos, basados en modelos de esqueleto o en modelos de superficie o piel con geometría ideal continua o con geometría discreta.

- El modelo de ECEP debe ser válido para diferentes modelos de representación y análisis de tolerancias, tales como: de corrección/traslación, de g.d.l., de SDT, etc.

- El modelo ECEP tendrá que contemplar no solo las características de situación (posición y/o orientación), sino también las características de forma y de tamaño.

- La definición del ECEP debe ser compatible con el lenguaje Geospelling y también con los principales estándares GD\&T. 
- El ECEP debe poder integrarse en un modelo de ensamble para permitir los razonamientos vinculados a la especificación geométrica de ensambles de producto.

\subsubsection{Modelo de Elemento CARACTERÍSTICO DE ESPECIFICACIÓN DE PRODUCTO PROPUESTO.}

El ECEP (Figura 5.4) es una especialización del ECE y en un modelo de ensamble de producto, como el que se presentará en el siguiente capítulo, es el componente esencial al contener toda la información requerida para los ejercicios involucrados en el proceso de especificación geométrica del producto. Estos ejercicios, que tienen por objetivo establecer los valores límite para los parámetros ( $E C$ de parámetro), se realizan sobre unas geometrías con defectos, sobre las que se establecen características Geospelling o zonas de tolerancias que restringen las desviaciones de las propias geometrías y de las relaciones que entre ellas se establezcan. Para facilitar su integración en el modelo de ensamble y facilitar la manipulación de los datos, cada ECEP contiene tanto la información geométrica (EC de geometría de producto) como la estructural (Estructura de especificación) que dan solución a la condición funcional (Condición de especificación) que se concreta en un valor (Límite de especificación). Esto significa que diferentes instancias de la clase ECEP pueden compartir instancias de los EC agregados a esta clase.

Dependiendo de cómo se realice el ejercicio de simulación, la definición de interfaz geométrica con defectos (EC de geometría defectos producto), que como se ha indicado es un elemento básico del ECEP, se realizará utilizando diferentes tipos de modelos con defectos: a) modelos de superficie (piel) ideales o b) modelos de esqueleto, cuando trabajan con geometrías derivadas. En el primer caso, se trata de una geometría continua ideal que contempla los defectos de posición, orientación y de tamaño. Sin embargo, en el segundo caso, como las geometrías correspondientes a EC de tamaño (Features of Size) se modelan a través de sus geometrías derivadas (ideales), no se pueden contemplar defectos ni de forma ni de tamaño.

El EC de geometría defectos producto incluye al EC extraído producto, que representa las geometrías con defectos imaginadas por el diseñador y que pretenden representar los posibles defectos que generen los procesos de fabricación utilizados para obtener la pieza. A partir del EC extraído producto, y mediante los operadores adecuados (Operador sustitución producto), se obtienen las geometrías de sustitución (EC sustituto producto) ideales sobre las que realizar el ejercicio de la especificación.

Como es obvio, cada metodología de simulación utilizada en el proceso de especificación de producto requerirá de unos modelos para la representación de las geometrías y la representación de tolerancia, que establece las desviaciones admisibles en ellas. Aunque en la literatura se han propuesto modelos para representar las geometrías con defectos de forma discreta [Schleich et ál., 2014], la mayoría de metodologías y herramientas de análisis trabajan con geometrías continuas y modelos de toleranciado geométrico basados en geometrías variacionales (DOF, SDT, etc.).

En el diagrama se ve que la geometría con defectos, sea ideal continua o discreta, estará vinculada con tres tipos de características que controlan los ejercicios de simulación: forma, tamaño y situación. Estas características están representadas por las clases Característica forma simulación, Característica tamaño simulación y Característica situación simulación, que son subtipos de la clase Característica simulación. Cada Característica de simulación, que establece las posibles desviaciones de la geometría con defectos en la forma propia del sistema de simulación, se puede expresar (transformar) como una característica Geospelling (Característica Geospelling), que se establecen como 
distancias y ángulos entre elementos. Por lo tanto, la propuesta es válida para los ejercicios de simulación basados en diferentes tipos de modelos geométricos con defectos (de tipo esqueleto o de tipo superficie continua o discreta) y basados en diferentes modelos de tolerancia. A cada ejercicio, en función de los tipos de modelos geométricos y de tolerancias que utiliza, le corresponderá una vista de las contempladas en el Meta-Modelo de EC propuesto, tal y como se ha comentado anteriormente.

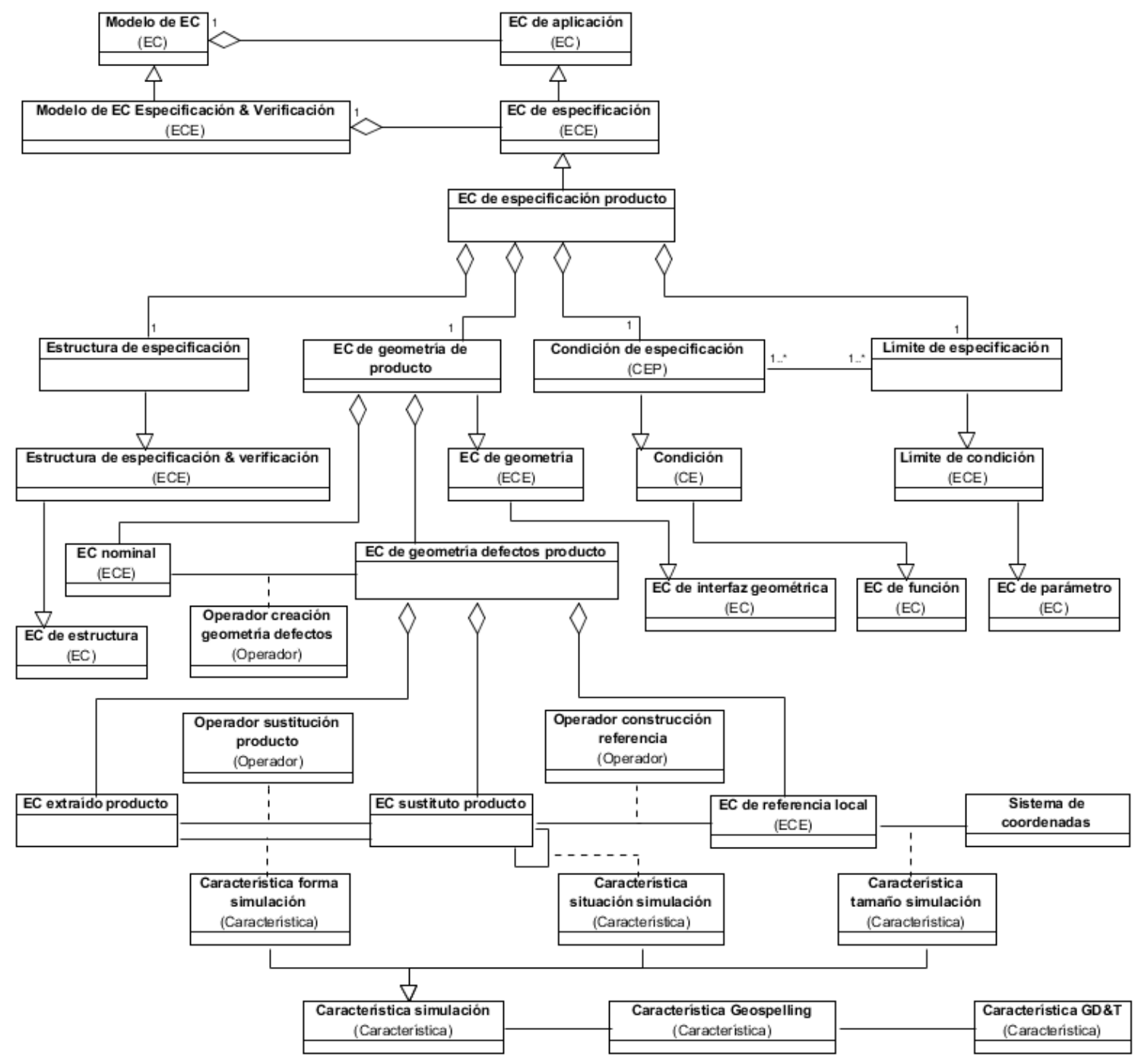

Figura 5.4 Diagrama de clases UML del Modelo de EC de Especificación de Producto (ECEP) propuesto.

Si bien la propuesta, como se acaba de indicar, se ha pensado para que sea capaz de soportar diferentes modelos de simulación, incluidas las propuestas que están siendo objeto de investigación [Schleich et ál., 2014], el modelo considera especialmente los basados en modelos geométricos de esqueleto o de superficie continua y características de simulación expresadas en SDT. Atendiendo a los requisitos que estos últimos imponen, cada $E C$ de geometría defectos producto incluye un EC de referencia local, que determina su situación y establece los valores de los g.d.l. variantes e invariantes, recopilados en el SDT. Las características de posición y orientación se establecen entre dos elementos sustitutos a través de la clase asociativa Característica situación simulación, la cual contiene los valores de los SDT (torseur de lien o torsor de desplazamiento [Legoff et ál., 1999; Costadoat, 2010]), correspondiente a la relación entre las dos geometrías sustitutas. Por su parte, la clase asociativa Característica tamaño simulación se utiliza para caracterizar, si 
procede, la relación entre el sistema de referencia local y el sistema de coordenadas (Sistema de coordenadas), y la clase asociativa Característica forma simulación determina la relación entre el EC extraído producto y el correspondiente EC sustituto producto. Los SDT correspondientes a las características de forma y, si procede, de tamaño de cada una de las geometrías sustitutas (torseur d'écart o torsor de desviación) se unen al SDT de relación entre ambas geometrías sustitutas para caracterizar la unión completa (torseur de liaison o torsor de la junta) [Legoff et ál., 1999; Costadoat, 2010].

Aunque no se ha querido mostrar en este diagrama, las Condiciones de especificación, que como se ha dicho anteriormente tienen un Límite de especificación que concreta su valor, se expresan como Características de simulación sobre las geometrías con defectos del ECEP. Esta relación se mostrará en el diagrama del Modelo de Cadena de Ensamble de Especificación de Producto que se describe en el siguiente capítulo.

Finalmente, y tal y como se puede apreciar en el diagrama, cada característica expresada en lenguaje Geospelling puede hacerse corresponder con una característica expresada utilizando las zonas de tolerancia normalizadas (Característica GD\&T) que considera los límites de tolerancia como una geometría formada por dos envolventes que presentan una distancia mínima entre ellas.

Por lo tanto, y a modo de conclusión, cabe remarcar algunos de los aspectos de la propuesta que dan respuesta a los requisitos anteriormente comentados. El modelo propuesto define el ECEP como subtipo del EC de aplicación y de EC de especificación, siendo adecuado para entornos de desarrollo colaborativo y, en particular, para entornos en los que la especificación del producto se integre con la planificación de la inspección de sus piezas.

Como ya se ha indicado, además de heredar los aspectos comunes al EC de aplicación y al EC de especificación, el ECEP es el elemento central del modelo de cadena de ensamble, sobre el que se realizan los ejercicios de simulación y los razonamientos que conducen a la especificación de producto, tal y como se verá en el capítulo siguiente. Para ello, el modelo también contempla los tres tipos de características (situación, forma y tamaño) definidas en lenguaje Geospelling, pudiéndose también expresar utilizando los estándares GD\&T.

\subsection{MOdElo de ElEMENTo CARACTERÍSTICO DE INSPECCIÓN.}

\subsubsection{REQUISITOS DE LA PROPUESTA.}

De acuerdo a todo lo expuesto en los capítulos 3 y 4 y en los apartados anteriores, la propuesta de Elemento Característico de Inspección (ECI) a desarrollar deberá contemplar los siguientes requisitos:

- El ECI debe definirse como un subtipo del ECE, que permitirá mantener la dualidad entre los ejercicios de la especificación del producto y de la inspección. Además por ser subtipo del EC de Aplicación, y de acuerdo al Meta-Modelo de EC, podrá integrarse con otros dominios y mantener la naturaleza colaborativa del modelo PPO.

- Es necesario que el ECI contenga toda la información necesaria para el ejercicio en la inspección de producto, incluyendo la representación de la geometría con defectos que permita la verificación de las especificaciones dimensionales y geométricas de la forma más dual a la realizada por el diseñador. 
- El ECI, y con el fin de no limitar la propuesta, debe permitir la consideración de cualquier tipo de recurso de inspección, incluyendo desde instrumentos metrológicos sencillos, pasando por equipos y montajes específicos, y hasta máquinas de medición o sondas integradas en máquina. Para ello, deberán considerarse diferentes tipos de geometría extraída y sustituta que representen la información de medición con mayor o menor nivel de calidad.

- La definición del ECI debe ser compatible con el lenguaje Geospelling y con los principales estándares GD\&T.

- El ECI debe poder integrarse en un modelo de ensamble de inspección para permitir los razonamientos vinculados a la especificación geométrica de ensambles de inspección.

\subsubsection{MODELO DE ELEMENTO CARACTERÍSTICO DE INSPECCIÓN PROPUESTO.}

Tal y como se ha indicado en el capítulo 1 al explicar la metodología seguida para el desarrollo de la tesis, se elaboraron unas propuestas iniciales de elemento característico de inspección, para el ejercicio de la planificación supervisora de la inspección, basadas fundamentalmente en los conceptos de grados de libertad y de tipos de procesos de medición [Gutiérrez et ál., 2009; Bruscas et ál., 2010]. A continuación, se llevó a cabo el estudio expuesto en el capítulo 3 alrededor de las temáticas sobre modelado de las geometrías con defectos en ensambles y el análisis y la síntesis de tolerancias, a partir del cual se estableció un tratamiento de la especificación desde el punto de vista de la verificación homogéneo con el tratamiento que habitualmente se ha dado a la especificación funcional del producto. Esto permitió refinar las propuestas iniciales hasta obtener la propuesta de un modelo conceptual de elemento característico de inspección que aquí se presenta.

Tal y como se puede observar en la Figura 5.5, el EC de Inspección (ECI) es una especialización del EC de especificación y en un modelo de ensamble, como el considerado en este caso también para el ámbito de la inspección, será un componente esencial al contener toda la información requerida para las actividades propias de la Planificación Supervisora de la Inspección. Para ello, el ECI debe incluir la información sobre la representación de la geometría real de la pieza, que es una geometría con defectos, obtenida durante el proceso de medición, incluyendo tanto la representación de la geometría extraída (modelos primitivos) como la representación de dicha geometría de manera adecuada para llevar a cabo la verificación de las especificaciones funcionales de la pieza. Por otro lado, también cabe destacar que, tal y como se ha mencionado anteriormente, los razonamientos para la Planificación Supervisora de la Inspección se realizan sobre la arquitectura del ensamble del proceso de inspección. Esto implica que para poder cumplir unas determinadas condiciones de inspección (Condición de inspección) establecidas sobre una o varias características geométricas de la pieza, se habrá establecido una solución técnica, determinada por un conjunto de componentes (Estructura de inspección) que poseen una geometría de inspección (EC de geometría de inspección) que participa en el proceso de inspección. La condición de inspección se establece en términos de los valores de las incertidumbres del proceso de inspección seleccionado especificadas a través de límites (Límite de inspección).

En función de cómo se lleve a cabo el proceso de obtención de la información geométrica de la pieza durante el proceso de medición, la geometría con defectos ( $E C$ de defectos medición) extraída (EC extraído de medición), que es una representación de la geometría real, se podrá realizar de acuerdo a tres tipos de modelos primitivos, tal y como 
se ha indicado en el capítulo 3: a) modelos discretos de piel con defectos, formados por puntos o teselas; b) modelos discretos de líneas con defectos, formados por puntos o segmentos; y c) modelos ideales con defectos dimensionales. Los modelos primitivos de los tipos a) y b) son los contemplados en la clase del diagrama EC de geometría extraída discreta, mientras que los modelos primitivos del tipo c) se corresponden a la clase $E C$ de geometría extraída envolvente. Estas geometrías extraídas de tipo envolvente, que son geometrías ideales, pueden ser, por ejemplo, aquellas que se obtienen con instrumentos convencionales de medida de longitudes, en los que se obtiene la distancia entre segmentos o planos recortados supuestos paralelos. También pertenecen a este tipo de modelos primitivos aquellas geometrías ideales recortadas que se obtienen mediante equipos o procesos de medida en los la información de las variaciones o desviaciones de alguno de los parámetros vinculados a los g.d.l. invariantes se acumulan tras realizar un proceso de barrido, y que en este trabajo se denominarán de proyección. La proyección será global, cuando el barrido utiliza dos g.d.l. para la proyección, u orientada, cuando el barrido para la proyección utiliza un único g.d.l.

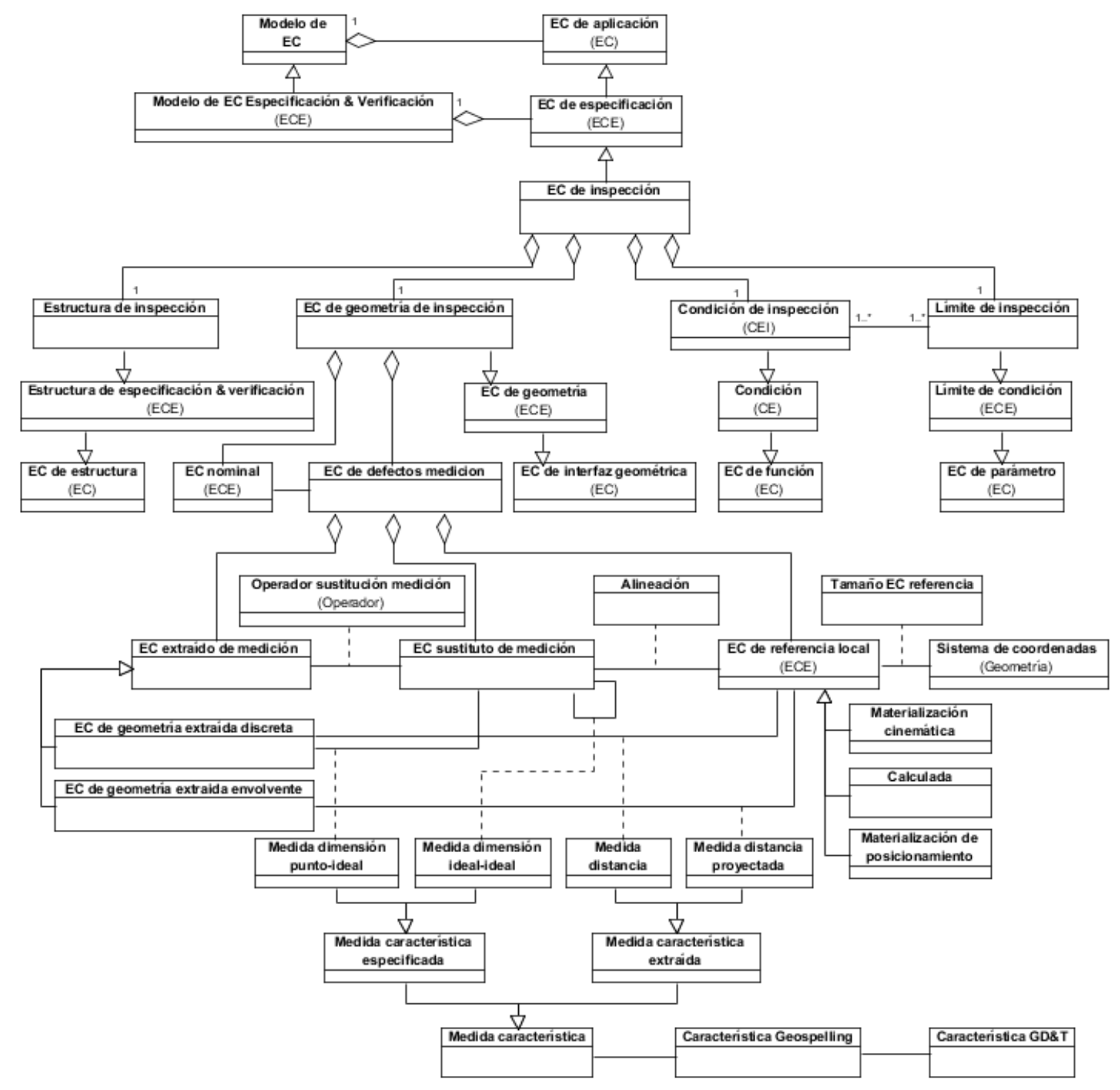

Figura 5.5 Diagrama de clases UML del Modelo de Elemento Característico de Inspección (ECI) propuesto.

Tanto en el caso de que la información geométrica extraída sea de tipo discreto como de tipo envolvente, en ambos casos la extracción se realizará respecto a una referencia 
local (EC de referencia local), que es un elemento geométrico ideal que se utiliza como referencia para medir las desviaciones y determina las direcciones/sentidos en los que se deben realizar estas mediciones. La geometría de referencia, tal y como ya se indicó en el capítulo 3, siempre se materializa en el equipo de medida y puede ser de tres tipos diferentes: a) geometrías de materialización cinemática, que son geometrías ideales generadas por los movimientos de las guías del equipo (Materialización cinemática); b) geometrías calculadas, que se obtienen mediante operaciones matemáticas de asociación, realizadas mediante criterios como el de mínimos cuadrados, mínimo diámetro exterior, etc. (Calculada); y c) geometrías de materialización de posicionamiento, pertenecientes a las pletinas, mandrinos, pinzas de precisión, utillajes de precisión, etc. (Materialización de posicionamiento). Los EC de referencia local pueden ser de cualquiera de las geometrías ideales invariantes: esférico, cilíndrico, de revolución, plano, prismático, helicoidal, complejo [Costadoat, 2010]. En los casos que proceda, esta referencia local, a su vez, estará vinculada a un sistema de coordenadas (Sistema de coordenadas) del equipo o montaje de inspección en una relación caracterizada por el tamaño (Tamaño EC referencia).

A partir del EC extraído de medición se obtiene el EC sustituto de medición que, de acuerdo al concepto de elemento sustituto utilizado en el contexto de la verificación [Henzold, 2006], es un elemento característico geométrico ideal imaginario cuya posición, orientación y, si procede, tamaño se calculan de los puntos extraídos sobre las superficies de la pieza inspeccionada. La obtención del elemento sustituto se puede llevar a cabo utilizando diferentes procedimientos de ajuste (Operador sustitución medición): Gauss, Chebyschev o envolventes exteriores/interiores. Por lo tanto, a partir del EC extraído de medición se pueden obtener diferentes EC sustituto de medición dependiendo del procedimiento de ajuste empleado, que suelen diferir del $E C$ de referencia local utilizado para obtener el EC extraído de medición del que derivan. La diferencia entre el EC sustituto de medición y el EC de referencia local puede ser en tamaño, posición y/u orientación y condiciona la calidad de la geometría extraída y, por lo tanto, las incertidumbres que afectan a la misma. Las diferencias entre el EC sustituto de medición y el EC de referencia local se pueden disminuir mediante operaciones de pre-ajuste, que corrigen posición, orientación y/o tamaño (Alineación).

Cuando la geometría extraída es de tipo discreto, las relaciones con la referencia local con respecto a la cual se obtiene la geometría primitiva están caracterizadas por medidas de distancias (Medida distancia). La información sobre la pieza real en este caso proporciona un mayor conocimiento y nivel de detalle sobre dicha geometría real, por lo que implica un menor grado de incertidumbre. Por su parte, cuando la geometría extraída es de tipo envolvente, la relación con la referencia local es una medida de distancia de manera proyectada o acumulada (Medida distancia proyectada), que se corresponderá con dos líneas isoparamétricas ideales o dos superficies ideales que se pueden construir a partir de las desviaciones máximas registradas en los sentidos de la medición. Estas líneas o superficies son las dos envolventes (interior-exterior) de la geometría real con defectos y, tal y como se ha mencionado antes, suponen obtener la información de manera proyectada. En ambos casos, las medidas corresponden a tipos de Medida de característica de extracción que, y según se ha descrito en el capítulo 3, son tomadas por los recursos de medida y constituyen valores de desviaciones respecto a la geometría de referencia.

La relación entre dos EC sustituto de medición de dos ECI diferentes establece la situación (posición y/u orientación) entre ambos y resulta ser la medida de una dimensión entre dos elementos ideales (Medida dimensión ideal-ideal). Esta relación es un tipo de Medida de característica especificada, que según lo explicado en el capítulo 3 es el resultado de la medición obtenido al aplicar la operación de evaluación sobre las 
geometrías muchas veces creadas a partir de la geometría discreta. Otro tipo de Medida de característica especificada es la Medida dimensión punto-ideal, que en este caso establece la relación entre la geometría discreta (un punto) y un elemento ideal sustituto que puede pertenecer al mismo ECI (por ejemplo, para una especificación de forma) o a otro ECI diferente.

Tanto las medidas correspondientes a características de extracción como a características de especificación son subtipos de la clase Medida característica. Estas medidas de características, tal y como se explicó en el capítulo 3, corresponden a características expresadas según el leguaje Geospelling (Característica Geospelling), siendo entonces el modelo compatible con este lenguaje. Además, las características expresadas según el lenguaje Geospelling tienen su correspondiente expresión según las especificaciones GD\&T estándar (Característica GD\&T).

Por lo tanto, y a modo de conclusión, cabe señalar algunos de los aspectos de la propuesta que se acaba de describir y que dan respuesta a los requisitos anteriormente comentados. El modelo propuesto, y del mismo modo a como ocurre con el ECEP, define el ECI como subtipo del EC de aplicación y de EC de Especificación, siendo así adecuado para un entorno de desarrollo colaborativo y, en particular, adecuado para la integración con el ámbito de la inspección de producto.

De forma análoga al ECEP, hereda los aspectos comunes del EC de aplicación y del EC de Especificación, dando además soporte a los aspectos específicos necesarios para los ejercicios en el ámbito de la especificación geométrica de la inspección del producto. El ECI permite representar la información sobre la geometría extraída del proceso de medición utilizando modelos primitivos de diferentes tipos: superficies/perfiles continuas, superficies ideales con defectos dimensionales, superficies ideales con defectos angulares y elementos ideales con defectos derivados de los anteriores. El hecho de que en el modelo se puedan representar varios tipos de geometrías, proporciona la posibilidad de realizar razonamientos sobre geometrías con defectos, tanto de piel (superficie) como de esqueleto a la hora de establecer los ensambles de inspección. Además, la extensión de las tipologías de estos modelos primitivos permite contemplar de una forma unificada tanto los procesos de medida (extracción física) basados en MMC como los no basados en MMC. Asimismo, la propuesta permite expresar tanto las medidas de las características extraídas como las medidas de las características especificadas en lenguaje Geospelling y, adicionalmente, en las del segundo tipo, según los estándares GD\&T.

El ECI, además, es integrable en un modelo de cadena de ensamble para llevar a cabo los razonamientos propios de la especificación del proceso de inspección del producto, tal y como se verá en el capítulo siguiente.

\subsubsection{BiblioteCA DE ElEMENTOS CARACTERÍSTICOS DE INSPECCIÓN.}

A partir de la propuesta anterior de ECI, en este punto se desarrolla un conjunto de ECI, una biblioteca, que permitan interpretar una pieza con un enfoque basado en la inspección. La biblioteca pretende ofrecer un número y tipología de ECI suficientes de manera que sus instanciaciones representen de forma adecuada no solo los aspectos geométricos de la pieza, sino también la intención de ingeniería útil para la Planificación Supervisora de la Inspección.

La tipología de ECI es un aspecto relevante, por cuanto aporta una parte importante de la semántica del mismo necesaria para una planificación supervisora de los procesos de inspección intensiva en conocimiento. El tipo de ECI, de los presentes en la biblioteca, determina y concreta, por un lado, de qué formas la geometría del ECI interacciona con los 
procesos y montajes de medición. Por otro lado, el tipo de ECI también determina los tipos de datos e información, referentes a la geometría con defectos, que son necesarios y relevantes para la comprobación de las especificaciones dimensionales y geométricas. Asimismo, la existencia y valores admisibles de otros aspectos que afectan al ECI dependen del tipo de que se trate: tipo de especificaciones geométricas que pueden afectar a la geometría del ECI; tipo de procesos de medición tipo que se pueden utilizar para llevar a cabo la verificación; tipos de cálculos, operaciones y construcciones necesarias para llevar a cabo la transformación de la representación de la geometría medida en la representación de la geometría especificada.

La Tabla 5.1 muestra los tipos de ECI contemplados en la biblioteca propuesta. Después de la Tabla 5.1, que se muestra en seis partes (una por página) utilizando numeración romana, se explican en detalle el contenido de la misma y el significado de la nomenclatura utilizada. Para ello, se hace referencia a las diferentes columnas de la Tabla 5.1, por lo que conviene describir brevemente cómo se estructura la información. La Tabla 5.1 se divide, en primer lugar, en tres bloques sombreados más oscuro. El primer bloque se denomina "Denominación ECI" y contiene las dos primeras columnas (la 1 y la 2). La primera de ellas es la numeración del ECI y la segunda la denominación propiamente dicha. El segundo bloque es "Aspecto medición" y, a su vez, se subdivide en dos subbloques coloreados en un gris algo menos intenso que el de los bloques. El primer subbloque se denomina "Geometría extraída" y contiene las cuatro siguientes columnas (de la 3 a la 6): "Representación de la información", "Tipo de geometría", "Información mínima requerida" y "Referencia mínima". El segundo subbloque del bloque "Aspecto medición" se denomina "Geometría sustituta" y contiene dos columnas (la 7 y la 8): "Información de la geometría sustituta que se puede obtener a partir de la extraída" y "Geometrías sustitutas construidas". Por último, el tercer bloque se denomina "Aspecto funcional" y contiene únicamente la última columna (la 9). 


\begin{tabular}{|c|c|c|c|c|c|c|c|c|}
\hline \multirow{3}{*}{\multicolumn{2}{|c|}{ Denominación ECI }} & \multicolumn{6}{|c|}{ ASPECTO MEDICIÓN (Cantidad y calidad de la información) } & \multirow{3}{*}{$\begin{array}{c}\text { ASPECTO } \\
\text { FUNCIONAL } \\
\text { Elemento característico } \\
\text { funcional elemental }\end{array}$} \\
\hline & & \multicolumn{4}{|c|}{ Geometría extraída } & \multicolumn{2}{|c|}{ Geometría sustituta } & \\
\hline & & $\begin{array}{l}\text { Representación } \\
\text { de la la } \\
\text { información }\end{array}$ & $\begin{array}{c}\text { Tipo de } \\
\text { geometría }\end{array}$ & $\begin{array}{c}\text { Información } \\
\text { mínima requerida }\end{array}$ & $\begin{array}{c}\text { Referencia } \\
\text { minima }\end{array}$ & $\begin{array}{c}\text { Información de la geometría } \\
\text { sustituta que se puede obtener a } \\
\text { partir de la extraída }\end{array}$ & Geometrías sustitutas construidas & \\
\hline 1 & Esfera-diámetro & Tamaño & \multirow{5}{*}{ Integral } & $\{\mathrm{u} / \mathrm{v} / \mathrm{w}\}$ & & $\begin{array}{l}\mathrm{Gdll}_{1}: \mathrm{r}_{\mathrm{eI}} \\
\mathrm{Gdla}_{\mathrm{a}}: \varnothing\end{array}$ & Ninguna & \multirow{8}{*}{$\begin{array}{l}\text { Esfera } \\
\operatorname{Gdl}_{2}: T_{x}, T_{y}, T_{z} \\
G_{1} l_{1}: R_{x}, R_{y}, R_{z}\end{array}$} \\
\hline 2 & Esfera-proyectada & $\begin{array}{c}\text { Proyección } \\
\text { global }\end{array}$ & & $\begin{array}{l}\mathrm{r}_{e_{-} \text {maxx. }} .\left[\alpha_{e}, \beta_{e}\right] \\
\mathrm{r}_{e_{e} \text { min. }}\left[\alpha_{e}, \beta_{e}\right]\end{array}$ & - & $\begin{array}{l}\mathrm{Gdl}_{1}: \Delta \mathrm{rr}_{\mathrm{e}, \mathrm{I}} \text { (difer._radios) } \\
\mathrm{Gdl}_{\mathrm{a}}: \mathrm{X}, \mathrm{Y}, \mathrm{Z} \equiv 0\end{array}$ & $\begin{array}{l}\text { Esferas envolventes concéntricas al } \\
\text { centro de referencia de medición }\end{array}$ & \\
\hline 3 & Esfera-proyección_axial & \multirow{2}{*}{$\begin{array}{l}\text { Proyección } \\
\text { orientada }\end{array}$} & & $\begin{array}{l}\left\{\mathrm{r}_{\mathrm{r}_{\text {_maxx }}}\left[\gamma_{\mathrm{c}}\right]\left(\mathrm{z}_{\mathrm{c}}\right)\right\} \\
\left\{\mathrm{r}_{\mathrm{c} \_ \text {_nin. }} . \gamma_{\mathrm{c}}\right] \\
\left.\left(\mathrm{z}_{\mathrm{c}}\right)\right\}\end{array}$ & d & $\begin{array}{l}\mathrm{Gdl}_{\mathrm{i}}: \Delta \mathrm{r}_{\mathrm{c}, \mathrm{I}}\left(\mathrm{z}_{\mathrm{c}}\right) \text { (difer._radios) } \\
\mathrm{Gdl}_{\mathrm{a}} \mathrm{X}, \mathrm{Y}, \mathrm{Z} \equiv 0\end{array}$ & $\begin{array}{l}\text { Circunferencias envolventes } \\
\text { concéntricas al eje de referencia de } \\
\text { medición }\end{array}$ & \\
\hline 4 & Esfera-proyección_angular & & & $\begin{array}{l}\left\{\mathrm{r}_{\mathrm{c} \text { maxx }}\left[\mathrm{z}_{\mathrm{c}}\right]\left(\gamma_{\mathrm{c}}\right)\right\} \\
\left\{\mathrm{r}_{\mathrm{c} \text { min }} .\left[\mathrm{Z}_{\mathrm{c}}\right]\left(\gamma_{\mathrm{c}}\right)\right\}\end{array}$ & $\theta$ & $\begin{array}{l}\mathrm{Gdl}_{\mathrm{i}}: \Delta \mathrm{r}_{\mathrm{c}, \mathrm{I}}\left(\gamma_{\mathrm{c}}\right)(\text { difer._radios) } \\
\mathrm{Gdl}_{\mathrm{a}} \mathrm{X}, \mathrm{Y}, \mathrm{Z} \equiv 0\end{array}$ & $\begin{array}{l}\text { Perfiles circulares envolventes } \\
\text { contenidos en el plano de referencia de } \\
\text { medición }\end{array}$ & \\
\hline 5 & Esfera & Coordenadas & & $\left\{\mathrm{r}_{\mathrm{c}} / \mathrm{r}_{\mathrm{c}}\left(\alpha_{\mathrm{e}}, \beta_{\mathrm{e}}\right)\right\}$ & $\square$ & $\begin{array}{l}\mathrm{Gdl}_{\mathrm{i}}: \mathrm{r}_{\mathrm{e}_{-I}} \\
\Delta \mathrm{r}_{\mathrm{e}-\mathrm{I}}(\text { difer._radios }) \\
\mathrm{r}_{\mathrm{e}-\mathrm{D}}(\text { (radio) } \\
\mathrm{Gdl}_{\mathrm{a}}: \mathrm{X}, \mathrm{Y}, \mathrm{Z}\end{array}$ & $\begin{array}{l}\text { - Esfera asociada, } \\
\text { - esferas envolventes de la esfera } \\
\text { integral, } \\
\text { - esfera envolvente del centro derivado, } \\
\text { con su situación respecto al sistema de } \\
\text { referencia de medición }\end{array}$ & \\
\hline 6 & Centro-esfera-proyectado & $\begin{array}{l}\text { Proyección } \\
\text { global }\end{array}$ & \multirow{3}{*}{ Derivada } & $\mathrm{r}_{\mathrm{e}}\left[\alpha_{\mathrm{e}}, \beta_{\mathrm{e}}\right]$ & - & $\begin{array}{l}\mathrm{Gdl}_{1}: \mathrm{r}_{\mathrm{eD}}(\text { radio) } \\
\mathrm{Gdl}_{\mathrm{a}}: \mathrm{X}, \mathrm{Y}, \mathrm{Z} \equiv 0\end{array}$ & $\begin{array}{l}\text { Esfera envolvente concéntrica al centro } \\
\text { de referencia de medición }\end{array}$ & \\
\hline 7 & Centro-esfera-proyección_angular & $\begin{array}{c}\text { Proyección } \\
\text { orientada }\end{array}$ & & $\left\{\mathrm{r}_{\mathrm{e}}\left[\alpha_{e} / \beta_{\mathrm{e}}\right]\left(\alpha_{\mathrm{e}} / \beta_{\mathrm{e}}\right)\right\}$ & 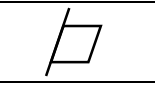 & $\begin{array}{l}\operatorname{Gdl}_{1:} \mathrm{r}_{\mathrm{r}_{\mathrm{D}}}\left(\alpha_{d} / \beta_{\mathrm{e}}\right)(\text { radio) } \\
\mathrm{Gdl}_{\mathrm{a}} \mathrm{X}, \mathrm{X}, \mathrm{Z} \equiv 0\end{array}$ & $\begin{array}{l}\text { Circunferencia envolvente contenida en } \\
\text { el plano de referencia de medición }\end{array}$ & \\
\hline 8 & Centro-esfera & Coordenadas & & $\left\{\mathrm{r}_{\mathrm{e}}\left(\alpha_{\mathrm{e}}, \beta_{\mathrm{e}}\right)\right\}$ & $\emptyset$ & $\begin{array}{l}\mathrm{Gdl}_{1:} \mathrm{I}_{\mathrm{e}-\mathrm{D}} \text { (radio) } \\
\mathrm{Gdl}_{\mathrm{A}}: \mathrm{X}, \mathrm{Y}, \mathrm{Z}\end{array}$ & $\begin{array}{l}\text { Esfera envolvente del centro derivado, } \\
\text { con su situación respecto al sistema de } \\
\text { referencia de medición }\end{array}$ & \\
\hline
\end{tabular}

Tabla 5.1 - I Biblioteca de Elementos Característico de Inspección (ECI) propuesta. 


\begin{tabular}{|c|c|c|c|c|c|c|c|c|}
\hline \multirow{3}{*}{\multicolumn{2}{|c|}{ Denominación ECI }} & \multicolumn{6}{|c|}{ ASPECTO MEDICIÓN (Cantidad y calidad de la información) } & \multirow{3}{*}{$\begin{array}{c}\text { ASPECTO } \\
\text { FUNCIONAL } \\
\text { Elemento característico } \\
\text { funcional } \text { elemental }\end{array}$} \\
\hline & & \multicolumn{4}{|c|}{ Geometría extraída } & \multicolumn{2}{|c|}{ Geometría sustituta } & \\
\hline & & $\begin{array}{l}\text { Representación } \\
\text { de la } \\
\text { información }\end{array}$ & $\begin{array}{l}\text { Tipo de } \\
\text { geometría }\end{array}$ & $\begin{array}{l}\text { Información } \\
\text { mínima requerida }\end{array}$ & $\begin{array}{l}\text { Referencia } \\
\text { mínima }\end{array}$ & $\begin{array}{c}\text { Información de la geometría } \\
\text { sustituta que se puede obtener a } \\
\text { partir de la extraída }\end{array}$ & Geometrías sustitutas construidas & \\
\hline 9 & Cilindro-diámetro & Tamaño & \multirow{5}{*}{ Integral } & $\{\mathrm{u} / \mathrm{v} / \mathrm{w}\}$ & \multirow{2}{*}{$/$} & $\begin{array}{l}\operatorname{Gdl}_{\mathrm{i}}: \mathrm{r}_{\mathrm{c} \_\mathrm{I}} \\
\mathrm{Gdl}_{\mathrm{a}}: \varnothing\end{array}$ & Ninguna & \multirow{5}{*}{$\begin{array}{l}\text { Cilindro } \\
\text { Gdl }_{\mathrm{a}}: \mathrm{T}_{\mathrm{y}}, \mathrm{T}_{\mathrm{z}}, \mathrm{R}_{\mathrm{y}}, \mathrm{R}_{\mathrm{z}} \\
\mathrm{Gdl}_{\mathrm{i}}: \mathrm{T}_{\mathrm{x}}, \mathrm{R}_{\mathrm{x}}\end{array}$} \\
\hline 10 & Cilindro-proyectado & $\begin{array}{l}\text { Proyección } \\
\text { global }\end{array}$ & & $\begin{array}{l}\mathrm{r}_{\mathrm{c} \_ \text {máx. }}\left[\gamma_{\mathrm{c}}, \mathrm{z}_{\mathrm{c}}\right] \\
\mathrm{r}_{\mathrm{c} \_ \text {min. }}\left[\gamma_{\mathrm{c}}, \mathrm{z}_{\mathrm{c}}\right]\end{array}$ & & $\begin{array}{l}\mathrm{Gdl}_{\mathrm{i}}: \Delta \mathrm{r}_{\mathrm{c} I \mathrm{I}} \text { (difer._radios) } \\
\mathrm{Gdl}_{\mathrm{a}}: \mathrm{X}, \mathrm{Y}, \alpha, \beta \equiv 0\end{array}$ & $\begin{array}{l}\text { Cilindros envolventes coaxiales al eje de } \\
\text { referencia de medición }\end{array}$ & \\
\hline 11 & Cilindro-proyección_axial & \multirow{2}{*}{$\begin{array}{l}\text { Proyección } \\
\text { orientada }\end{array}$} & & $\begin{array}{l}\left\{\mathrm{r}_{\mathrm{c} \text { máx. }}\left[\gamma_{\mathrm{c}}\right]\left(\mathrm{z}_{\mathrm{c}}\right)\right\} \\
\left\{\mathrm{r}_{\mathrm{c} \_ \text {minn. }}\left[\gamma_{\mathrm{c}}\right]\left(\mathrm{z}_{\mathrm{c}}\right)\right\}\end{array}$ & & $\begin{array}{l}\mathrm{Gdl}_{\mathrm{i}}: \Delta \mathrm{r}_{\mathrm{c} \_\mathrm{I}} \text { (difer._radios) } \\
\mathrm{Gdl}_{\mathrm{a}}: \mathrm{X}, \mathrm{Y}, \alpha, \beta \equiv 0\end{array}$ & $\begin{array}{l}\text { Circunferencias envolventes } \\
\text { concéntricas al eje de referencia de } \\
\text { medición }\end{array}$ & \\
\hline 12 & Cilindro-proyección_angular & & & $\begin{array}{l}\left\{\mathrm{r}_{\mathrm{c} \_ \text {maxx. }}\left[\mathrm{z}_{\mathrm{c}}\right]\left(\gamma_{\mathrm{c}}\right)\right. \\
\left\{\mathrm{r}_{\mathrm{c} \_ \text {min. }}\left[\mathrm{z}_{\mathrm{c}}\right]\left(\gamma_{\mathrm{c})}\right\}\right.\end{array}$ & & $\begin{array}{l}\mathrm{Gdl}_{\mathrm{i}}: \Delta \mathrm{r}_{\mathrm{c} I \mathrm{I}} \text { (difer._radios) } \\
\mathrm{Gdl}_{\mathrm{a}}: \mathrm{X}, \mathrm{Y}, \alpha, \beta \equiv 0\end{array}$ & $\begin{array}{l}\text { Rectas envolventes contenidas en el } \\
\text { plano de referencia de medición }\end{array}$ & \\
\hline 13 & Cilindro & Coordenadas & & $\left\{r_{c}\left(\gamma_{c}, z_{c}\right)\right\}$ & & $\begin{array}{l}\mathrm{Gdl}_{\mathrm{i}}: \mathrm{r}_{\mathrm{c} \_\mathrm{I}} \\
\Delta \mathrm{r}_{\mathrm{c} \_\mathrm{I}} \text { (difer._radios) } \\
\mathrm{r}_{\mathrm{c} \_\mathrm{D}} \text { (radio) } \\
\mathrm{Gdl}_{\mathrm{a}}: \mathrm{X}, \mathrm{Y}, \alpha, \beta\end{array}$ & $\begin{array}{l}\text { - Cilindro asociado, } \\
\text { - cilindros envolventes del cilindro } \\
\text { integral, } \\
\text { - cilindro envolvente del eje derivado, } \\
\text { con su situación respecto al sistema de } \\
\text { referencia de medición }\end{array}$ & \\
\hline 14 & Eje-cilindro-proyectado & $\begin{array}{l}\text { Proyección } \\
\text { global }\end{array}$ & & $r_{c}\left[\gamma_{c}, z_{c}\right]$ & & $\begin{array}{l}\operatorname{Gdl}_{1}: r_{c-D}(\operatorname{radio}) \\
\operatorname{Gdl}_{a}: X, Y, \alpha, \beta \equiv 0\end{array}$ & $\begin{array}{l}\text { Cilindro envolvente coaxial al eje de } \\
\text { referencia de medición }\end{array}$ & \\
\hline 15 & Eje-cilindro-proyección_axial & Proyección & & $\left\{\mathrm{r}_{\mathrm{c}}\left[\gamma_{\mathrm{c}}\right]\left(\mathrm{z}_{\mathrm{c}}\right)\right\}$ & & $\begin{array}{l}\operatorname{Gdl}_{1}: \mathrm{r}_{\mathrm{cD}}(\operatorname{radio}) \\
\operatorname{Gdl}_{\mathrm{a}}: \mathrm{X}, \mathrm{Y}, \alpha, \beta \equiv 0\end{array}$ & $\begin{array}{l}\text { Circunferencia envolvente concéntrica al } \\
\text { eje de referencia de medición }\end{array}$ & Cilindro \\
\hline 16 & Eje-cilindro-proyección_angular & orientada & Derivada & $\left\{\mathrm{r}_{\mathrm{c}}\left[\mathrm{z}_{\mathrm{c}}\right]\left(\gamma_{\mathrm{c})}\right\}\right.$ & & $\begin{array}{l}\operatorname{Gdl}_{\mathrm{i}}: \mathrm{r}_{\mathrm{c}-\mathrm{D}}(\mathrm{radio}) \\
\mathrm{Gdl}_{\mathrm{a}}: \mathrm{X}, \mathrm{Y}, \alpha, \beta \equiv 0\end{array}$ & $\begin{array}{l}\text { Recta envolvente contenida en el plano } \\
\text { de referencia de medición }\end{array}$ & $\begin{array}{l}\mathrm{Gdl}_{\mathrm{a}}: \mathrm{T}_{\mathrm{y}}, \mathrm{T}_{\mathrm{z}}, \mathrm{R}_{\mathrm{y}}, \mathrm{R}_{\mathrm{z}} \\
\mathrm{Gdl}_{\mathrm{i}}: \mathrm{T}_{\mathrm{x}}, \mathrm{R}_{\mathrm{x}}\end{array}$ \\
\hline 17 & Eje-cilindro & Coordenadas & & $\left\{\mathrm{r}_{\mathrm{c}}\left(\gamma_{\mathrm{c}}, \mathrm{z}_{\mathrm{c}}\right)\right\}$ & 2 & $\begin{array}{l}\mathrm{Gdl}_{\mathrm{i}}: \mathrm{r}_{\mathrm{C}_{\_} \mathrm{D}}(\mathrm{radio}) \\
\mathrm{Gdl}_{\mathrm{a}}: \mathrm{X}, \mathrm{Y}, \alpha, \beta\end{array}$ & $\begin{array}{l}\text { Cilindro envolvente del eje derivado, con } \\
\text { su situación respecto al sistema de } \\
\text { referencia de medición }\end{array}$ & \\
\hline
\end{tabular}

Tabla 5.1 - II Biblioteca de Elementos Característico de Inspección (ECI) propuesta. 


\begin{tabular}{|c|c|c|c|c|c|c|c|c|}
\hline \multirow{3}{*}{\multicolumn{2}{|c|}{ Denominación ECI }} & \multicolumn{6}{|c|}{ ASPECTO MEDICIÓN (Cantidad y calidad de la información) } & \multirow{3}{*}{$\begin{array}{c}\text { ASPECTO } \\
\text { FUNCIONAL } \\
\text { Elemento característico } \\
\text { funcional elemental }\end{array}$} \\
\hline & & \multicolumn{4}{|c|}{ Geometría extraída } & \multicolumn{2}{|c|}{ Geometría sustituta } & \\
\hline & & $\begin{array}{l}\text { Representación } \\
\text { de la } \\
\text { información }\end{array}$ & $\begin{array}{c}\text { Tipo de } \\
\text { geometría }\end{array}$ & $\begin{array}{c}\text { Información } \\
\text { mínima requerida }\end{array}$ & $\begin{array}{c}\text { Referencia } \\
\text { mínima }\end{array}$ & $\begin{array}{c}\text { Información de la geometría } \\
\text { sustituta que se puede obtener a } \\
\text { partir de la extraída }\end{array}$ & Geometrías sustitutas construidas & \\
\hline 18 & Cono-ángulo & Tamaño & \multirow{5}{*}{ Integral } & $\left\{\Delta \mathrm{r}_{\mathrm{c}}: \Delta \mathrm{z}_{\mathrm{c}}\right\}$ & / & $\begin{array}{l}\operatorname{Gdl}_{1}: \theta_{\mathrm{l}}=\mathrm{f}\left(\Delta \mathrm{r}_{\mathrm{c}}: \Delta \mathrm{z}_{\mathrm{c}}\right) \\
\mathrm{Gdl}_{\mathrm{a}}: \varnothing\end{array}$ & Ninguna & \multirow{9}{*}{$\begin{array}{l}\text { Revolución } \\
\operatorname{Gdl}_{a}: T_{x}, T_{y}, T_{z}, R_{y}, R_{z} \\
\operatorname{Gdl}_{1}: R_{x}\end{array}$} \\
\hline 19 & Cono-proyectado & $\begin{array}{c}\text { Proyección } \\
\text { global }\end{array}$ & & $\begin{array}{l}\mathrm{r}_{\mathrm{con \_} \text { maxx }}\left[\gamma_{\mathrm{c}}, \mathrm{z}_{\mathrm{c}}\right] \\
\mathrm{r}_{\mathrm{con} \text { _min. }}\left[\gamma_{\mathrm{c}}, \mathrm{z}_{\mathrm{c}}\right] \\
\end{array}$ & \multirow[b]{2}{*}{ l } & $\begin{array}{l}\mathrm{Gdl}_{1}: \Delta \mathrm{\Delta r}_{\text {con_I I }} \text { (dist._conos) } \\
\mathrm{Gdl}_{a}: \mathrm{X}, \mathrm{Y}, \mathrm{Z}, \alpha, \beta \equiv 0\end{array}$ & $\begin{array}{l}\text { Conos envolventes coaxiales al eje de } \\
\text { referencia de medición }\end{array}$ & \\
\hline 20 & Cono-proyección_axial & \multirow{2}{*}{$\begin{array}{l}\text { Proyección } \\
\text { orientada }\end{array}$} & & $\begin{array}{l}\left\{\mathrm{r}_{\text {con_máx }}\left[\gamma_{\mathrm{cc}}\left(\mathrm{z}_{\mathrm{c}}\right)\right\}\right. \\
\left\{\mathrm{r}_{\text {con_min. }}\left[\gamma_{\mathrm{c}}\right]\left(\mathrm{z}_{\mathrm{c}}\right)\right\}\end{array}$ & & $\begin{array}{l}\mathrm{Gdd}_{\mathrm{l}}: \Delta \mathrm{\Delta r}_{\text {con_I I }} \text { (dist._conos) } \\
\mathrm{Gdd}_{\mathrm{a}}: \mathrm{X}, \mathrm{Y}, \mathrm{Z}, \alpha, \beta \equiv 0\end{array}$ & $\begin{array}{l}\begin{array}{l}\text { Circunferencias envolventes } \\
\text { concéntricas al eje de referencia de } \\
\text { medición }\end{array} \\
\end{array}$ & \\
\hline 21 & Cono-proyección_angular & & & $\begin{array}{l}\left\{\mathrm{r}_{\text {con_maxx. }}\left[\mathrm{z}_{\mathrm{c}}\right]\left(\gamma_{\mathrm{c}}\right\}\right. \\
\left\{\mathrm{r}_{\text {con_min. }}\left[\mathrm{Z}_{\mathrm{c}}\right]\left(\gamma_{\mathrm{c}}\right)\right\}\end{array}$ & $\theta$ & $\begin{array}{l}\mathrm{Gdll}_{\mathrm{i}}: \Delta \mathrm{rr}_{\text {conII }}\left(\gamma_{\mathrm{c}}\right) \text { (difer._radios) } \\
\mathrm{Gda}_{\mathrm{a}}: \mathrm{X}, \mathrm{Y}, \mathrm{Z}, \alpha, \beta \equiv 0\end{array}$ & $\begin{array}{l}\text { Rectas envolventes contenidas en el } \\
\text { plano de referencia de medición }\end{array}$ & \\
\hline 22 & Cono & Coordenadas & & $\left\{r_{c}\left(\gamma_{c}, z_{c}\right)\right\}$ & 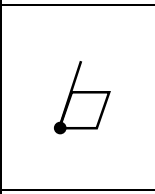 & $\begin{array}{l}\mathrm{Gdl}_{\mathrm{i}}: \theta_{\mathrm{I}} \\
\Delta \mathrm{r}_{\text {con_II }}(\text { difer._radios }) \\
\mathrm{r}_{\mathrm{c} \_\mathrm{D}}(\text { radio) } \\
\mathrm{Gdl}_{\mathrm{a}}: \mathrm{X}, \mathrm{Y}, \mathrm{Z}, \alpha, \beta\end{array}$ & $\begin{array}{l}\text { - Cono asociado, } \\
\text { - conos envolventes del cono integral, } \\
\text { - cilindro envolvente del eje derivado, } \\
\text { con su situación respecto al sistema de } \\
\text { referencia de medición }\end{array}$ & \\
\hline 23 & Eje-cono-proyectado & $\begin{array}{c}\text { Proyección } \\
\text { global }\end{array}$ & & $\mathrm{r}_{\mathrm{c}}\left[\gamma_{\mathrm{c}}, \mathrm{z}_{\mathrm{c}}\right]$ & 1 & $\begin{array}{l}\operatorname{Gdd}_{1:}: \mathrm{r}_{\mathrm{c} D} \text { (radio) } \\
\mathrm{Gdl}_{2}: \mathrm{X}, \mathrm{Y}, \alpha, \beta \equiv 0\end{array}$ & $\begin{array}{l}\text { Cilindro envolvente coaxial al eje de } \\
\text { referencia de medición }\end{array}$ & \\
\hline 24 & Eje-cono-proyección_axial & Proyección & & $\left\{\mathrm{r}_{\mathrm{c}}\left[\gamma_{\mathrm{c}}\right]\left(\mathrm{z}_{\mathrm{c}}\right)\right\}$ & 1 & $\begin{array}{l}\mathrm{Gdl}_{\mathrm{i}}: \mathrm{r}_{\mathrm{C} \mathrm{D}}\left(\mathrm{z}_{\mathrm{c}}\right)(\text { (radio) } \\
\mathrm{Gdl}_{\mathrm{a}}: \mathrm{X}, \mathrm{Y}, \alpha, \beta \equiv 0\end{array}$ & $\begin{array}{l}\text { Circunferencia envolvente concéntrica al } \\
\text { eje de referencia de medición }\end{array}$ & \\
\hline 25 & Eje-cono-proyección_angular & orientada & Derivada & $\left\{\mathrm{r}_{\mathrm{c}}\left[\mathrm{z}_{\mathrm{c}}\right]\left(\gamma_{\mathrm{c}}\right\}\right.$ & $\square$ & $\begin{array}{l}\mathrm{Gdl}_{\mathrm{l}}: \mathrm{r}_{\mathrm{c} \_\mathrm{D}}\left(\gamma_{\mathrm{c}}\right)(\text { (radio) } \\
\mathrm{Gdl}_{\mathrm{a}}: \mathrm{X}, \mathrm{Y}, \alpha, \beta \equiv 0\end{array}$ & $\begin{array}{l}\text { Recta envolvente contenida en el plano } \\
\text { de referencia de medición }\end{array}$ & \\
\hline 26 & Eje-cono & Coordenadas & & $\left\{r_{c}\left(\gamma_{c}, z_{c}\right)\right\}$ & $\square$ & $\begin{array}{l}\mathrm{Gdll}_{i}: \mathrm{r}_{\mathrm{c} D \mathrm{D}}(\mathrm{radio}) \\
\mathrm{Gdd}_{a}: \mathrm{X}, \mathrm{Y}, \alpha, \beta\end{array}$ & $\begin{array}{l}\text { Cilindro envolvente del eje derivado, con } \\
\text { su situación respecto al sistema de } \\
\text { referencia de medición }\end{array}$ & \\
\hline
\end{tabular}

Tabla 5.1 - III Biblioteca de Elementos Característico de Inspección (ECI) propuesta. 
Capítulo 5. Los Elementos Característicos de Especificación de Producto y de Inspección.

\begin{tabular}{|c|c|c|c|c|c|c|c|c|}
\hline \multirow{3}{*}{\multicolumn{2}{|c|}{ Denominación ECI }} & \multicolumn{6}{|c|}{ ASPECTO MEDICIÓN (Cantidad y calidad de la información) } & \multirow{3}{*}{$\begin{array}{c}\text { ASPECTO } \\
\text { FUNCIONAL } \\
\text { Elemento característico } \\
\text { funcional elemental }\end{array}$} \\
\hline & & \multicolumn{4}{|c|}{ Geometría extraída } & \multicolumn{2}{|c|}{ Geometría sustituta } & \\
\hline & & $\begin{array}{l}\text { Representación } \\
\text { de la } \\
\text { información }\end{array}$ & $\begin{array}{c}\text { Tipo de } \\
\text { geometría }\end{array}$ & $\begin{array}{l}\text { Información } \\
\text { mínima requerida }\end{array}$ & $\begin{array}{l}\text { Referencia } \\
\text { mínima }\end{array}$ & $\begin{array}{c}\text { Información de la geometría } \\
\text { sustituta que se puede obtener a } \\
\text { partir de la extraída }\end{array}$ & Geometrías sustitutas construidas & \\
\hline 27 & Revolución-proyección_axial & \multirow{2}{*}{$\begin{array}{l}\text { Proyección } \\
\text { orientada }\end{array}$} & \multirow{3}{*}{ Integral } & $\begin{array}{l}\left\{\mathrm{r}_{\mathrm{c} \_ \text {máx. }}\left[\gamma_{\mathrm{c}}\right]\left(\mathrm{z}_{\mathrm{c}}\right)\right\} \\
\left\{\mathrm{r}_{\mathrm{c} \_ \text {mín. }}\left[\gamma_{\mathrm{c}}\right]\left(\mathrm{z}_{\mathrm{c}}\right)\right\} \\
\end{array}$ & & $\begin{array}{l}\mathrm{Gdl}_{\mathrm{i}}: \Delta \mathrm{r}_{\mathrm{c}, \mathrm{I}}\left(\mathrm{z}_{\mathrm{c}}\right) \text { (difer._radios) } \\
\mathrm{Gdl}_{\mathrm{a}}: \mathrm{X}, \mathrm{Y}, \mathrm{Z}, \alpha, \beta \equiv 0\end{array}$ & $\begin{array}{l}\text { Circunferencias envolventes } \\
\text { concéntricas al eje de referencia de } \\
\text { medición }\end{array}$ & \multirow{11}{*}{$\begin{array}{l}\text { Revolución } \\
\mathrm{Gdl}_{\mathrm{a}}: \mathrm{T}_{\mathrm{x}}, \mathrm{T}_{\mathrm{y}}, \mathrm{T}_{\mathrm{z}}, \mathrm{R}_{\mathrm{y}}, \mathrm{R}_{\mathrm{z}} \\
\mathrm{Gdl}_{\mathrm{i}}: \mathrm{R}_{\mathrm{x}}\end{array}$} \\
\hline 28 & Revolución-proyección_angular & & & $\begin{array}{l}\left\{\mathrm{r}_{\mathrm{c} \_ \text {máx. }}\left[\mathrm{z}_{\mathrm{c}}\right]\left(\gamma_{\mathrm{c}}\right)\right\} \\
\left\{\mathrm{r}_{\mathrm{c} \_ \text {mín. }}\left[\mathrm{z}_{\mathrm{c}}\right]\left(\gamma_{\mathrm{c}}\right)\right\}\end{array}$ & & $\begin{array}{l}\mathrm{Gdl}_{\mathrm{i}}: \Delta \mathrm{r}_{\mathrm{c} \_\mathrm{I}}\left(\gamma_{\mathrm{c}}\right) \text { (dist._perfiles) } \\
\mathrm{Gdl}_{\mathrm{a}}: \mathrm{X}, \mathrm{Y}, \mathrm{Z}, \alpha, \beta \equiv 0\end{array}$ & $\begin{array}{l}\text { Perfiles envolventes del patrón } \\
\text { contenidos en el plano de referencia de } \\
\text { medición }\end{array}$ & \\
\hline 29 & Revolución & Coordenadas & & $\left\{r_{c}\left(\gamma_{c}, z_{c}\right)\right\}$ & & $\begin{array}{l}\mathrm{Gdl}_{\mathrm{i}} \text { : (Parámetros intrínsicos de la } \\
\text { superficie de revolución) } \\
\Delta \mathrm{r}_{\mathrm{c} \_\mathrm{I}} \text { (dist._superf._rev.) } \\
\mathrm{r}_{\mathrm{c} \_\mathrm{D}}(\text { radio }) \\
\mathrm{Gdl}_{\mathrm{a}}: \mathrm{X}, \mathrm{Y}, \mathrm{Z}, \alpha, \beta\end{array}$ & $\begin{array}{l}\text { - Superficie de revolución asociada, } \\
\text { - superficies envolventes de la superficie } \\
\text { de revolución integral, } \\
\text { - cilindro envolvente del eje derivado, } \\
\text { con su situación respecto al sistema de } \\
\text { referencia de medición }\end{array}$ & \\
\hline 30 & Eje-revolución-proyectado & $\begin{array}{c}\text { Proyección } \\
\text { global }\end{array}$ & \multirow{4}{*}{ Derivada } & $r_{c}\left[\gamma_{c}, z_{c}\right]$ & & $\begin{array}{l}\mathrm{Gdl}_{\mathrm{i}}: \mathrm{r}_{\mathrm{c} D \mathrm{D}}(\text { radio }) \\
\mathrm{Gdl}_{\mathrm{a}}: \mathrm{X}, \mathrm{Y}, \alpha, \beta \equiv 0 \\
\end{array}$ & $\begin{array}{l}\text { Cilindro envolvente coaxial al eje de } \\
\text { referencia de medición }\end{array}$ & \\
\hline 31 & Eje-revolución-proyección_axial & \multirow{2}{*}{$\begin{array}{l}\text { Proyección } \\
\text { orientada }\end{array}$} & & $\left\{\mathrm{r}_{\mathrm{c}}\left[\gamma_{\mathrm{c}}\right]\left(\mathrm{z}_{\mathrm{c}}\right)\right\}$ & & $\begin{array}{l}\operatorname{Gdl}_{\mathrm{i}}: \mathrm{r}_{\mathrm{C}_{\mathrm{D}}}\left(\mathrm{z}_{\mathrm{c}}\right)(\text { (radio) } \\
\mathrm{Gdl}_{\mathrm{a}}: \mathrm{X}, \mathrm{Y}, \alpha, \beta \equiv 0\end{array}$ & $\begin{array}{l}\text { Circunferencia envolvente concéntrica al } \\
\text { eje de referencia de medición }\end{array}$ & \\
\hline 32 & Eje-revolución-proyección_angular & & & $\left\{\mathrm{r}_{\mathrm{c}}\left[\mathrm{z}_{\mathrm{c}}\right]\left(\gamma_{\mathrm{c}}\right)\right\}$ & & $\begin{array}{l}\operatorname{Gdl}_{\mathrm{i}}: \mathrm{r}_{\mathrm{c}_{-} \mathrm{D}}\left(\gamma_{\mathrm{c}}\right)(\operatorname{radio}) \\
\operatorname{Gdl}_{\mathrm{a}}: \mathrm{X}, \mathrm{Y}, \alpha, \beta \equiv 0\end{array}$ & $\begin{array}{l}\text { Recta envolvente contenida en el plano } \\
\text { de referencia de medición }\end{array}$ & \\
\hline 33 & Eje-revolución & Coordenadas & & $\left\{\mathrm{r}_{\mathrm{c}}\left(\gamma_{\mathrm{c}}, \mathrm{z}_{\mathrm{c}}\right)\right\}$ & & $\begin{array}{l}\operatorname{Gdl}_{\mathrm{i}}: \mathrm{r}_{\mathrm{C} D \mathrm{D}}(\operatorname{radio}) \\
\operatorname{Gdl}_{\mathrm{a}}: \mathrm{X}, \mathrm{Y}, \alpha, \beta\end{array}$ & $\begin{array}{l}\text { Cilindro envolvente del eje derivado, con } \\
\text { su situación respecto al sistema de } \\
\text { referencia de medición }\end{array}$ & \\
\hline 34 & Barrido_cilindrico-proyección_angular & $\begin{array}{c}\text { Proyección } \\
\text { orientada }\end{array}$ & \multirow[b]{2}{*}{ Integral } & $\begin{array}{l}\left\{\mathrm{r}_{\mathrm{c}_{\_} \max }\left[\mathrm{z}_{\mathrm{c}}\right]\left(\gamma_{\mathrm{c}}\right)\right\} \\
\left\{\mathrm{r}_{\mathrm{c} \_ \text {min }}\left[\mathrm{z}_{\mathrm{c}}\right]\left(\gamma_{\mathrm{c}}\right)\right\}\end{array}$ & & $\begin{array}{l}\operatorname{Gdl}_{1}: \Delta \mathrm{r}_{\mathrm{c} \_\mathrm{I}}\left(\gamma_{\mathrm{c}}\right) \text { (dist._perfiles) } \\
\mathrm{Gdl}_{\mathrm{a}}: \mathrm{X}, \mathrm{Y}, \mathrm{Z}, \alpha, \beta\end{array}$ & $\begin{array}{l}\text { Perfiles envolventes del patrón } \\
\text { contenidos en el plano de referencia de } \\
\text { medición }\end{array}$ & \\
\hline 35 & Barrido_cilíndrico & Coordenadas & & $\left\{\mathrm{r}_{\mathrm{c}}\left(\gamma_{\mathrm{c}}, \mathrm{z}_{\mathrm{c}}\right)\right\}$ & & $\begin{array}{l}\mathrm{Gdl}_{\mathrm{i}} \text { : (Parámetros intrínsicos de la } \\
\text { superficie de revolución) } \\
\Delta \mathrm{r}_{\mathrm{c} \_\mathrm{I}} \text { (dist._superf._rev.) } \\
\Delta \mathrm{r}_{\mathrm{c} \mathrm{D}} \text { (difer._radios) } \\
\mathrm{Gdl}_{\mathrm{a}}: \mathrm{X}, \mathrm{Y}, \mathrm{Z}, \alpha, \beta\end{array}$ & $\begin{array}{l}\text { - Superficie de revolución asociada, } \\
\text { - superficies envolventes de la superficie } \\
\text { de revolución integral, } \\
\text { - cilindros envolventes del cilindro } \\
\text { derivado, } \\
\text { con su situación respecto al sistema de } \\
\text { referencia de medición }\end{array}$ & \\
\hline 36 & Cilindro-barrido_cilíndrico-proyección_angular & $\begin{array}{c}\text { Proyección } \\
\text { orientada }\end{array}$ & \multirow[b]{2}{*}{ Derivada } & $\left\{\mathrm{r}_{\mathrm{c}}\left[\mathrm{z}_{\mathrm{c}}\right]\left(\gamma_{\mathrm{c}}\right)\right\}$ & & $\begin{array}{l}\operatorname{Gdl}_{\mathrm{i}}: \Delta \mathrm{r}_{\mathrm{c}} \mathrm{D}\left(\gamma_{\mathrm{c}}\right) \text { (difer._radios) } \\
\operatorname{Gdl}_{\mathrm{a}}: \mathrm{X}, \mathrm{Y}, \alpha, \beta \equiv 0\end{array}$ & $\begin{array}{l}\text { Rectas envolventes contenidas en el } \\
\text { plano de referencia de medición }\end{array}$ & \\
\hline 37 & Cilindro-barrido_cilíndrico & Coordenadas & & $\left\{\mathrm{r}_{\mathrm{c}}\left(\gamma_{\mathrm{c}}, \mathrm{z}_{\mathrm{c}}\right)\right\}$ & H & $\begin{array}{l}\mathrm{Gdl}_{\mathrm{i}}: \Delta \mathrm{r}_{\mathrm{c}, \mathrm{D}} \text { (difer._radios) } \\
\mathrm{Gdl}_{\mathrm{a}}: \mathrm{X}, \mathrm{Y}, \alpha, \beta\end{array}$ & \begin{tabular}{|l|} 
Cilindros envolventes del cilindro \\
derivado, con su situación respecto al \\
sistema de referencia de medición \\
\end{tabular} & \\
\hline
\end{tabular}

Tabla 5.1 - IV Biblioteca de Elementos Característico de Inspección (ECI) propuesta. 


\begin{tabular}{|c|c|c|c|c|c|c|c|c|}
\hline \multirow{3}{*}{\multicolumn{2}{|c|}{ Denominación ECI }} & \multicolumn{6}{|c|}{ ASPECTO MEDICIÓN (Cantidad y calidad de la información) } & \multirow{3}{*}{$\begin{array}{c}\text { ASPECTO } \\
\text { FUNCIONAL } \\
\text { Elemento característico } \\
\text { funcional elemental }\end{array}$} \\
\hline & & \multicolumn{4}{|c|}{ Geometría extraída } & \multicolumn{2}{|c|}{ Geometría sustituta } & \\
\hline & & $\begin{array}{l}\text { Representación } \\
\quad \text { de la } \\
\text { información }\end{array}$ & $\begin{array}{c}\text { Tipo de } \\
\text { geometría }\end{array}$ & $\begin{array}{c}\text { Información } \\
\text { mínima requerida }\end{array}$ & $\begin{array}{l}\text { Referencia } \\
\text { mínima }\end{array}$ & $\begin{array}{l}\text { Información de la geometría } \\
\text { sustituta que se puede obtener a } \\
\text { partir de la extraída }\end{array}$ & Geometrías sustitutas construidas & \\
\hline 38 & Plano-proyectado & $\begin{array}{l}\text { Proyección } \\
\text { global }\end{array}$ & \multirow{3}{*}{ Integral } & $\begin{array}{l}\mathrm{w}_{\text {maxx }}[[u, v] \\
\mathrm{w}_{\text {min. }}[\mathrm{u}, \mathrm{v}] \\
\end{array}$ & $\square$ & $\begin{array}{l}\mathrm{Gdl}_{1}: \Delta \mathrm{w}_{\mathrm{I}}(\text { dist._planos) } \\
\mathrm{Gdl}_{\mathrm{a}}: \mathrm{Z}, \alpha, \beta \equiv 0\end{array}$ & $\begin{array}{l}\text { Planos envolventes del plano integral } \\
\text { paralelos al plano de referencia de } \\
\text { medición }\end{array}$ & \multirow{3}{*}{$\begin{array}{l}\text { Plano } \\
\operatorname{Gdl}_{a}: T_{z}, R_{x}, R_{y} \\
\operatorname{Gdl}_{1}: T_{x}, T_{y}, R_{z}\end{array}$} \\
\hline 39 & Plano-proyección_axial & $\begin{array}{c}\text { Proyección } \\
\text { orientada }\end{array}$ & & $\begin{array}{l}\left\{\mathrm{w}_{\text {maxx }}[\mathrm{u} / \mathrm{v}](\mathrm{u} / \mathrm{v})\right\} \\
\left\{\mathrm{w}_{\text {min. }}[\mathrm{u} / \mathrm{v}](\mathrm{u} / \mathrm{v})\right\}\end{array}$ & l & $\begin{array}{l}\mathrm{Gdl}_{\mathrm{i}}: \Delta \mathrm{w}_{\mathrm{I}}(\mathrm{u} / \mathrm{v} \text { ) (dist._planos) } \\
\mathrm{Gdl}_{\mathrm{a}}: Z, \alpha, \beta \equiv 0\end{array}$ & $\begin{array}{l}\text { Rectas envolventes paralelas al eje de } \\
\text { referencia de medición }\end{array}$ & \\
\hline 40 & Plano & Coordenadas & & $\{\mathrm{w}(\mathrm{u}, \mathrm{v})\}$ & $\square$ & $\begin{array}{l}\mathrm{Gdll}_{1}: \Delta \mathrm{w}_{\mathrm{I}} \text { (dist._planos) } \\
\mathrm{Gdl}_{a}: \mathrm{Z}, \alpha, \beta\end{array}$ & $\begin{array}{l}\text { Planos envolventes del plano integral, } \\
\text { con su posición respecto al sistema de } \\
\text { referencia de medición }\end{array}$ & \\
\hline 41 & Barrido_prismático-proyección_axial & $\begin{array}{c}\text { Proyección } \\
\text { orientada }\end{array}$ & \multirow[b]{2}{*}{ Integral } & $\begin{array}{l}\left\{\mathrm{w}_{\text {maxx }}[\mathrm{u}](\mathrm{v})\right\} \\
\left\{\mathrm{w}_{\text {min. }}[\mathrm{u}](\mathrm{v})\right\}\end{array}$ & ! & $\begin{array}{l}\operatorname{Gdl}_{1}: \Delta \mathrm{w}_{\mathrm{I}} \text { (dist._perfiles) } \\
\mathrm{Gdl}_{a}: \mathrm{Z}, \alpha, \beta\end{array}$ & $\begin{array}{l}\text { Perfiles envolventes del patrón } \\
\text { contenidos en planos perpendiculares al } \\
\text { eje de referencia de medición }\end{array}$ & \multirow{4}{*}{$\begin{array}{l}\text { Prismático } \\
\text { Gdla: } T_{y}, T_{z}, R_{x}, R_{y}, R_{z} \\
\operatorname{Gddl}_{1}: T_{x}\end{array}$} \\
\hline 42 & Barrido_prismático & Coordenadas & & $\{\mathrm{w}(\mathrm{u}, \mathrm{v})\}$ & $\square$ & $\begin{array}{l}\text { Gdli: (Parámetros intrínsecos de la } \\
\text { superficie de barrido) } \\
\Delta \mathrm{w}_{\mathrm{I}} \text { (dist._superf._barrido) } \\
\Delta \mathrm{w}_{\mathrm{D}} \text { (dist._planos) } \\
\mathrm{Gdl}_{\mathrm{a}}: \mathrm{Y}, \mathrm{Z}, \alpha, \beta, \gamma\end{array}$ & $\begin{array}{l}\text { - Superficie de barrido asociada, } \\
\text { - superficies envolventes de la superficie } \\
\text { de barrido integral, } \\
\text { - planos envolventes del plano medio } \\
\text { derivado, } \\
\text { con su situación respecto al sistema de } \\
\text { referencia de medición }\end{array}$ & \\
\hline 43 & Plano_medio-barrido_prismático-proyección_axial & $\begin{array}{c}\text { Proyección } \\
\text { orientada }\end{array}$ & \multirow[b]{2}{*}{ Derivada } & $\{w[u](v)\}$ & l & $\begin{array}{l}\mathrm{Gdl}_{\mathrm{i}}: \Delta \mathrm{w}_{\mathrm{D}} \text { (v) (dist._planos) } \\
\mathrm{Gdl}_{\mathrm{a}}: \mathrm{Y}, \mathrm{Z}, \alpha, \beta, \gamma\end{array}$ & $\begin{array}{l}\text { Rectas envolventes paralelas al eje de } \\
\text { referencia de medición }\end{array}$ & \\
\hline 44 & Plano_medio-barrido_prismático & \multirow{3}{*}{ Coordenadas } & & $\mathrm{w}(\mathrm{u}, \mathrm{v})$ & \multirow{3}{*}{$\emptyset$} & $\begin{array}{l}\operatorname{Gdl}_{1}: \Delta \mathrm{w}_{\mathrm{D}} \text { (dist._planos) } \\
\operatorname{Gd}_{a}: \mathrm{Y}, \mathrm{Z}, \alpha, \beta, \gamma\end{array}$ & $\begin{array}{l}\text { Planos envolventes del plano medio } \\
\text { derivado, con su posicionado respecto al } \\
\text { sistema de referencia de medición }\end{array}$ & \\
\hline 45 & Barrido_helicoidal & & Integral & \multirow[t]{2}{*}{$\mathrm{r}_{\mathrm{c}}\left(\gamma_{\mathrm{c}}, \mathrm{z}_{\mathrm{c}}\right)$} & & $\begin{array}{l}\text { Gdli: (Parámetros intrínsecos de la } \\
\text { superficie helicoidal })_{\mathrm{I}} \\
\text { (Paso, radio y desfase de hélice) } \\
\Delta \mathrm{h}_{\mathrm{I}} \text { (dist._superf._helicoidal) } \\
\Delta \mathrm{h}_{\mathrm{D}}(\text { dist._superf._helicoidal) } \\
\mathrm{Gdl}_{\mathrm{a}}: \mathrm{Y}, \mathrm{Z}, \alpha, \beta, \gamma\end{array}$ & $\begin{array}{l}\text { - Superficie helicoidal asociada, } \\
\text { - superficies envolventes de la superficie } \\
\text { helicoidal integral, } \\
\text { - superficies envolventes del helicoide } \\
\text { medio derivado, } \\
\text { con su posicionado respecto al sistema } \\
\text { de referencia de medición }\end{array}$ & \multirow[t]{2}{*}{$\begin{array}{l}\text { Helicoidal } \\
\mathrm{Gdl}_{\mathrm{a}}: \mathrm{T}_{\mathrm{y}}, \mathrm{T}_{\mathrm{z}}, \mathrm{R}_{\mathrm{y}}, \mathrm{R}_{\mathrm{z}} \\
\mathrm{Gdd}_{\mathrm{i}}: \mathrm{T}_{\mathrm{x}}, \mathrm{R}_{\mathrm{x}}\end{array}$} \\
\hline 46 & Helicoide-barrido_helicoidal & & Derivada & & & $\begin{array}{l}\mathrm{Gdl}_{1}: \Delta \mathrm{h}_{\mathrm{D}} \text { (dist._superf._helicoidal) } \\
\mathrm{Gdl}_{\mathrm{a}}: \mathrm{Y}, \mathrm{Z}, \alpha, \beta, \gamma\end{array}$ & $\begin{array}{l}\text { Superficies envolventes del helicoide } \\
\text { patrón, con su situación respecto al } \\
\text { sistema de referencia de medición }\end{array}$ & \\
\hline
\end{tabular}

Tabla 5.1 - V Biblioteca de Elementos Característico de Inspección (ECI) propuesta. 


\begin{tabular}{|c|c|c|c|c|c|c|c|c|}
\hline \multirow{3}{*}{\multicolumn{2}{|c|}{ Denominación ECI }} & \multicolumn{6}{|c|}{ ASPECTO MEDICIÓN (Cantidad y calidad de la información) } & \multirow{3}{*}{$\begin{array}{c}\text { ASPECTO } \\
\text { FUNCIONAL } \\
\text { Elemento característico } \\
\text { funcional elemental }\end{array}$} \\
\hline & & \multicolumn{4}{|c|}{ Geometría extraída } & \multicolumn{2}{|c|}{ Geometría sustituta } & \\
\hline & & $\begin{array}{l}\text { Representación } \\
\text { de la } \\
\text { información }\end{array}$ & $\begin{array}{c}\text { Tipo de } \\
\text { geometría }\end{array}$ & $\begin{array}{l}\text { Información } \\
\text { mínima requerida }\end{array}$ & $\begin{array}{l}\text { Referencia } \\
\text { mínima }\end{array}$ & $\begin{array}{c}\text { Información de la geometría } \\
\text { sustituta que se puede obtener a } \\
\text { partir de la extraída }\end{array}$ & Geometrías sustitutas construidas & \\
\hline 47 & Barrido_curvo & \multirow{3}{*}{ Coordenadas } & Integral & \multirow{3}{*}{$\mathrm{w}(\mathrm{u}, \mathrm{v})$} & \multirow{3}{*}{$\square$} & $\begin{array}{l}\mathrm{Gdl}_{\mathrm{i}}: \text { (Parámetros intrínsicos de la } \\
\text { superficie de barrido) } \\
\Delta \mathrm{w}_{\mathrm{I}} \text { (dist._superf._barrido) } \\
\Delta \mathrm{w}_{\mathrm{D}} \text { (dist._superf._barrido) } \\
\mathrm{Gdl}_{\mathrm{a}}: \mathrm{X}, \mathrm{Y}, \mathrm{Z}, \alpha, \beta, \gamma\end{array}$ & $\begin{array}{l}\text { - Superficie de barrido curvo asociada, } \\
\text { - superficies envolventes de la superficie } \\
\text { de barrido curvo integral, } \\
\text { - superficies envolventes de la superficie } \\
\text { media derivada, } \\
\text { con su situación respecto al sistema de } \\
\text { referencia de medición }\end{array}$ & \multirow{3}{*}{$\begin{array}{l}\text { Complejo } \\
\mathrm{Gdl}_{\mathrm{a}}: \mathrm{T}_{\mathrm{x}}, \mathrm{T}_{\mathrm{y}}, \mathrm{T}_{\mathrm{z}}, \mathrm{R}_{\mathrm{x}}, \mathrm{R}_{\mathrm{y}}, \mathrm{R}_{\mathrm{z}} \\
\mathrm{Gdl}_{\mathrm{i}}:--\end{array}$} \\
\hline 48 & Superficie_media-barrido_curvo & & Derivada & & & $\begin{array}{l}\mathrm{Gdl}_{\mathrm{i}}: \Delta \mathrm{w}_{\mathrm{D}} \text { (dist._superf._barrido) } \\
\mathrm{Gdl}_{\mathrm{a}}: \mathrm{X}, \mathrm{Y}, \mathrm{Z}, \alpha, \beta, \gamma\end{array}$ & $\begin{array}{l}\text { Superficies envolventes del patrón curvo, } \\
\text { con su situación respecto al sistema de } \\
\text { referencia de medición }\end{array}$ & \\
\hline 49 & Forma_libre & & Integral & & & $\begin{array}{l}\mathrm{Gdl}_{\mathrm{i}}: \text { (Parámetros intrínsicos de la } \\
\text { superficie de forma libre) } \\
\Delta \mathrm{w}_{\mathrm{I}} \text { (dist._superf._libres) } \\
\mathrm{Gdl}_{\mathrm{a}}: \mathrm{X}, \mathrm{Y}, \mathrm{Z}, \alpha, \beta, \gamma\end{array}$ & $\begin{array}{l}\text { - Superficie de forma libre asociada, } \\
\text { - superficies envolventes de la superficie } \\
\text { de forma libre integral, } \\
\text { con su situación respecto al sistema de } \\
\text { referencia de medición }\end{array}$ & \\
\hline
\end{tabular}

Tabla 5.1 - VI Biblioteca de Elementos Característico de Inspección (ECI) propuesta. 
La "Denominación ECI", representada en el primer bloque de dos columnas (número y denominación del ECI) de la Tabla 5.1, trata de proporcionar al lector una síntesis de sus características y puede constar de tres partes. La parte básica, que en una denominación que contenga las tres partes ocuparía la parte central y que describe el tipo de geometría, puede ir antecedida por un término que indica si la información extraída se refiere a la geometría derivada (centro, eje, cilindro, plano_medio, helicoide o superficie_media) y seguida de otro que proporciona una indicación de la calidad de la información extraída (diámetro/ángulo, proyectado/a, proyección_axial, proyección_angular). Cuando no aparezca ningún antecedente la información extraída estará vinculada a la geometría integral. De igual manera, cuando no aparezca la parte vinculada a la calidad de la información, se entenderá que esta es la máxima, circunstancia que se da cuando se proporciona información (por ejemplo, coordenadas de puntos) que permite la reconstrucción de la geometría real y aplicar, por lo tanto, las operaciones GPS de asociación y derivación.

Los tipos básicos contemplados son: esfera, cilindro, cono, revolución, barrido_cilindrico, plano, barrido_prismático, barrido_helicoidal, barrido_curvo y forma_libre. Estos tipos se han establecido en base a dos consideraciones: la funcional y la de medición/extracción. La funcional considera aspectos vinculados con la función del elemento característico en el conjunto mecánico y vienen marcadas por sus g.d.l. Tal y como ya se ha mencionado en el capítulo 3, y en base a los g.d.l. invariantes y activos, se pueden establecer siete clases invariantes y que se han considerado en esta propuesta [Desrochers y Rivière, 1997; Wu et ál., 2003; Shen et ál.; 2008; Zhao et ál., 2011; Zhang, 2012]: esférica, cilíndrica, de revolución, plana, prismática, helicoidal y compleja. Esto se muestra en la última columna "Aspecto funcional" (columna 9), que indica el tipo de clase invariante a la que se asocia el tipo de ECI y los g.d.l. activos e invariantes correspondientes. La consideración de aspectos vinculados con la medición de estos siete elementos característicos elementales ha llevado a la especialización de alguno de ellos en otros adicionales. Este es el caso del elemento característico elemental de revolución, que ha dado lugar a un tipo de ECI básico de cono y otro de barrido_cilíndrico, además del de revolución propiamente dicho, y el del elemento característico elemental complejo, que ha dado lugar a un tipo de ECI básico de barrido_curvo, además del de forma libre (complejo) propiamente dicho.

Los tipos básicos correspondientes a los barridos (cilíndrico, prismático, helicoidal y curvo) siempre son de perfiles planos, que pueden tener una recta media derivada de la sección. No se han considerado los casos de perfiles con líneas curvas medias derivadas por corresponder a diseños inusuales y por la dificultad de materializar sistemas y/o montajes específicos de medición. El que en los anteriores barridos considerados en la propuesta sí que se vislumbren sistemas y/o montajes específicos de medición no significa que necesariamente ya tengan existencia en la actualidad.

La consideración de subtipos de un ECI que hacen referencia a si se trata de información extraída sobre la geometría integral o derivada del mismo, tal y como se ha mencionado antes, hace que en la denominación del ECI pueda no aparecer ningún antecedente, lo cual significa que se hace referencia a la geometría integral, o que sí aparezca, indicándose así que se hace referencia a la geometría derivada. Todos los ECI básicos a excepción del plano y del de forma libre tienen al menos un subtipo vinculado a la geometría derivada representativa. Las geometrías derivadas consideradas en la propuesta, que eventualmente aparecen como antecedentes en la denominación básica del ECI y que dependen del tipo de geometría básica, son: centro (para la esfera), eje (para cilindro, cono, revolución), cilindro (para barrido_cilíndrico), plano_medio (para 
barrido_prismático), helicoide (para barrido_helicoidal) y superficie_media (para barrido_curvo).

Por otra parte, los subtipos que hacen referencia a calidad de la información extraída y que, tal y como se ha indicado anteriormente, hacen que eventualmente aparezca un término siguiendo a la parte central de la denominación del ECI, son los siguientes: diámetro/ángulo, proyectado/a, proyección_axial, proyección_angular. Estos subtipos expresan diferentes niveles de detalle/agregación de la información geométrica extraída, circunstancia que permite realizar análisis y verificaciones con un mayor o menor grado de incertidumbre. Por ejemplo, la información de un ECI "1-Esfera-diámetro" es de menor calidad que la de "4-Esfera-proyección_angular", porque en el primero la información (diámetros) no está referenciada e imposibilita totalmente cualquier representación, por simple que sea, de la geometría. Por el contrario, el segundo proporciona unas envolventes que permiten acercarse al conocimiento de la superficie real y, por lo tanto, de los defectos de la misma.

Cabe indicar que, para cada tipo básico de ECI (esfera, cilindro, cono, revolución, barrido_cilindrico, plano, barrido_prismático, barrido_helicoidal, barrido_curvo y forma_libre) en primer lugar aparecen los subtipos correspondientes a los que hacen referencia a la superficie integral ordenados de menor a mayor nivel de detalle de la información geométrica extraída y, a continuación, los subtipos que hacen referencia a la geometría derivada ordenados de la misma forma que los anteriores. Por ejemplo, para el caso de la esfera, en primer lugar aparecen cinco ECI vinculados a la geometría integral: "1-Esfera-diámetro" (tamaño), "2-Esfera-proyectada" (proyección global), "3-Esferaproyección_axial", "4-Esfera-proyección_angular" (estos últimos de tipo proyección orientada) y "5-Esfera" (coordenadas). En segundo lugar aparecen tres ECI vinculados a la geometría derivada de la esfera (centro): "6-Centro-esfera-proyectado" (proyección global), "7-Centro-esfera-proyección_angular" (proyección orientada)" y "8-Centroesfera" (coordenadas).

Entre las primeras columnas de "Denominación ECI" y la última de "Aspecto funcional", y tal y como se ha explicado anteriormente, aparecen en la Tabla 5.1 un grupo de seis columnas que hacen referencia al "Aspecto medición" del ECI. Estas seis columnas están agrupadas en dos subbloques: un primer subbloque (columnas de la 3 a la 6) que hace referencia a la geometría extraída y un segundo bloque (columnas 7 y 8) relativo a la geometría sustituta. De esta forma, y de acuerdo a la definición del ECI, en el primer subbloque de columnas sobre geometría extraída se incluyen aquellos aspectos importantes para los razonamientos en el dominio de la medición y, especialmente, para la selección de los procesos de medición tipo más adecuados. En el segundo subbloque de columnas, por su parte, aparecen aspectos importantes para la verificación de las especificaciones funcionales utilizando geometrías sutitutas y que están vinculados con el modelado de especificaciones dimensionales y geométricas (GD\&T).

La tercera columna de la Tabla 5.1 (y primera del subbloque "Geometría extraída") "Representación de la información" indica el nivel de agregación o detalle de la información extraída, aspecto al cual también se hace referencia en la propia denominación del ECI (parte que sigue a la parte central), tal y como se ha explicado anteriormente. La representación de la información, en orden de menor a mayor nivel de detalle, puede ser: un tamaño/ángulo, una proyección global, una proyección orientada o de tipo coordenadas. Una información extraída de tipo "tamaño/ángulo" es la que menor nivel de detalle proporciona, ya que la información obtenida de la medición del diámetro o ángulo no tiene referencia y no permite hacer ninguna aproximación a la representación de la geometría a verificar. Con la "proyección global" (según dos g.d.1.) o "proyección orientada" (según un g.d.l.) se aumenta el nivel de detalle de la información extraída, pudiéndose construir 
geometrías envolventes que aumentan las posibilidades de representación de la geometría. Finalmente, la representación de la información de tipo "coordenadas" (lo que en la denominación del ECI supone que no aparezca ningún término seguido a la parte central) es la que mayor conocimiento proporciona sobre la geometría real y, por tanto, la que permitiría representar dicha geometría real con un mayor nivel de detalle, pudiéndose así realizar análisis y verificaciones con un menor grado de incertidumbre.

El "Tipo de geometría", mostrado en la cuarta columna de la Tabla 5.1 (y segunda del subbloque "Geometría extraída"), indica si la información obtenida en la medición (extracción) hace referencia a la geometría integral o a la geometría derivada representativa del ECI. Este aspecto ya se ha mencionado anteriormente, puesto que también forma parte de la denominación del ECI, más concretamente del eventual término antecedente a la parte central. Cabe destacar que en los casos en los que se hace referencia a la geometría derivada se entiende que se tratará de procedimientos de medición (extracción) que directamente proporcionen la información sobre la geometría derivada.

La columna sobre la "Información mínima requerida" (quinta de la Tabla 5.1 y tercera del subbloque "Geometría extraída") indica los tipos de parámetros geométricos que deben ser capturados en los procesos de extracción, como mínimo, para poder caracterizar ese tipo de ECI. Con el "como mínimo" se desea hacer referencia a que se podrían utilizar equipos de extracción que proporcionen parámetros de mayor calidad siempre que mediante cálculo geométrico se puedan obtener los parámetros aquí indicados. Estos parámetros, que proporcionan el nivel de calidad exigido a la extracción, dependen del tipo de ECI y del tipo de sistema de coordenadas elegido para el mismo: esférico (subíndice "e"), cilíndrico (subíndice "c"), cónico (subíndice "con") o cartesiano (letras "u", "v" y "w" sin subíndice). Los parámetros extraídos pueden ser de tres tipos, $\Phi, \Phi(\Psi)$, $\Phi[\Psi]$, donde $\Phi$ y $\Psi$ representan las lecturas de los sensores que controlan los g.d.l. de los equipos de medición según la nomenclatura indicada en la Tabla 5.1. Los parámetros de tipo $\Phi$ tienen valores que se corresponden con las lecturas del g.d.l. Los de tipo $\Phi[\Psi]$ pueden tener un único valor que corresponde a la desviación máxima en la lectura según el g.d.l. $\Psi$ o dos valores que corresponden a las desviaciones máxima (subíndice "máx.") y mínima (subíndice "mín.) en la lectura según el g.d.l. $\Psi$. Finalmente, los de tipo $\Phi(\Psi)$ contienen múltiples valores que se corresponden con las lecturas del g.d.l. $\Phi$ obtenidas para diferentes valores del g.d.l. $\Psi$. Cuando se quiere indicar que se trata de un conjunto de valores se representará entre llaves, $\{\Phi(\Psi)\}$. Además, cuando aparecen varios parámetros separados por una barra ( / ) se debe tener en cuenta que se trata de parámetros alternativos. Por ejemplo, para el ECI "9-Cilindro-diámetro" se obtienen diferentes valores del diámetro en un g.d.l. cartesiano que puede ser indistintamente "u", "v" o "w": " $\{u / v / w\} "$. En el ECI "10-Cilindro-proyectado" se obtienen dos valores, desviación máxima y mínima, del parámetro según dos g.d.l. (giro angular respecto a un eje y desplazamiento en dicho eje) en un sistema de coordenadas cilíndrico, y sin controlar ninguno de estos g.d.l.: " $r_{c_{-} \text {máx. }}\left[\gamma_{\mathrm{c}}\right.$,

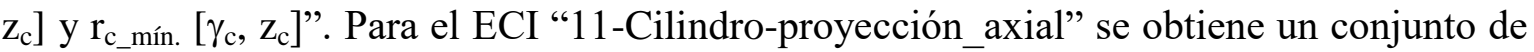
valores, de desviación máxima y de mínima, del parámetro según un g.d.l. (giro angular respecto a un eje) leídos en diferentes puntos del otro g.d.l. (desplazamiento en el mismo eje) en un sistema de coordenadas cilíndrico, y controlando este último g.d.l.: " $\left\{r_{c_{\_} \text {máx. }}\left[\gamma_{c}\right]\right.$ $\left.\left(\mathrm{z}_{\mathrm{c}}\right)\right\}$ y $\left\{\mathrm{r}_{\mathrm{c} \_ \text {mín. }}\left[\gamma_{\mathrm{c}}\right]\left(\mathrm{z}_{\mathrm{c}}\right)\right\}$ ". Cabe hacer notar que en este caso se trata de parejas de valores de desviación máxima y mínima para un mismo " $z_{\mathrm{c}}$ ". Y como último ejemplo, en el ECI "13-Cilindro" se obtiene un conjunto de valores del parámetro leídos en diferentes puntos de dos g.d.l. (giro angular respecto a un eje y desplazamiento en el mismo eje) en un sistema de coordenadas cilíndrico, y controlando los dos g.d.1.: " $\left\{\mathrm{r}_{\mathrm{c}}\left(\gamma_{\mathrm{c}}, \mathrm{z}_{\mathrm{c}}\right)\right\}$ ". 
En algunos casos, los sistemas de referencia elegidos para la extracción, independientemente de su tipo (esférico, cilíndrico, cónico o cartesiano), no requieren del control de todos los g.d.l., circunstancia a la que se hace referencia con el concepto "Referencia mínima" (sexta columna de la Tabla 5.1 y cuarta del subbloque "Geometría extraída"). El sistema de referencia mínimo será completo cuando contempla todos los g.d.l. e incompleto en caso contrario. Por ejemplo, para un ECI del tipo "11-Cilindroproyección_axial", el sistema de referencia local de extracción (cilíndrico) no requiere de dos de los g.d.l. (un desplazamiento, $\mathrm{Z}$, y una rotación, $\gamma$ ). Por el contrario, si el ECI es del tipo "13-Cilindro", que proporciona información de la superficie integral como un conjunto de puntos, se requeriría de un sistema de referencia cilíndrico completo. Esta información se muestra en la columna correspondiente de la Tabla 5.1 utilizando una simbología que representa los g.d.l. de la referencia mínima. En la siguiente Tabla 5.2 se explica la simbología utilizada:

\begin{tabular}{|c|c|c|c|c|}
\hline Referencia mínima & Símbolo & Gdl controlados & Completo/Incompleto & Referencia externa \\
\hline Plano, línea y punto & $\square$ & $\begin{array}{l}\mathrm{Gdl}_{\mathrm{a}}[\mathrm{x}, \mathrm{y}, \mathrm{z}, \alpha, \beta, \gamma] \\
\mathrm{Gdl}_{\mathrm{i}}[-,-,-,-,-,-]\end{array}$ & Completo & \multirow{3}{*}{$\begin{array}{l}\text { Con referencia } \\
\text { externa }\end{array}$} \\
\hline Línea sobre plano & $\nabla$ & $\begin{array}{l}\operatorname{Gdl}_{\mathrm{a}}[-, \mathrm{y}, \mathrm{z}, \alpha, \beta, \gamma] \\
\mathrm{Gdl}_{\mathrm{i}}[\mathrm{x},-,-,-,-,-]\end{array}$ & \multirow{5}{*}{ Incompleto } & \\
\hline Punto sobre línea & 1 & $\begin{array}{l}\operatorname{Gdl}_{\mathrm{a}}[\mathrm{x}, \mathrm{y}, \mathrm{z}, \alpha, \beta,-] \\
\operatorname{Gdl}_{\mathrm{i}}[-,-,-,-,-, \gamma]\end{array}$ & & \\
\hline Plano & $\square$ & $\begin{array}{l}\operatorname{Gdl}_{\mathrm{a}}[-,-, \mathrm{z}, \alpha, \beta,-] \\
\operatorname{Gdl}_{\mathrm{i}}[\mathrm{x}, \mathrm{y},-,-,-, \gamma]\end{array}$ & & \multirow{3}{*}{ Autoreferenciado } \\
\hline Línea & 1 & $\begin{array}{l}\operatorname{Gdl}_{\mathrm{a}}[\mathrm{x}, \mathrm{y},-, \alpha, \beta,-] \\
\operatorname{Gdl}_{\mathrm{i}}[-,-, \mathrm{z},-,-, \gamma]\end{array}$ & & \\
\hline Punto & • & $\begin{array}{l}\operatorname{Gdl}_{\mathrm{a}}[\mathrm{x}, \mathrm{y}, \mathrm{z},-,-,-] \\
\operatorname{Gdl}_{\mathrm{i}}[-,-,-, \alpha, \beta, \gamma]\end{array}$ & & \\
\hline
\end{tabular}

Tabla 5.2 Simbología utilizada para representar las referencias mínimas.

La séptima columna de la Tabla 5.1 (y primera del subbloque "Geometría sustituta") hace referencia al tipo de "Información de la geometría sustituta que se puede obtener a partir de la extraída". Por una parte, se indican cuáles son los g.d.1. activos ("Gdla”) que será necesario controlar para poder establecer la referencia, y que dependen de la geometría del ECI. Cuando aparece el símbolo de conjunto vacío (Ø) se quiere indicar que el sistema de referencia es desconocido, como por ejemplo cuando se obtiene información de los ECI "1-Esfera-diámetro", "9-Cilindro-diámetro" o "18-Cono-ángulo", lo cual determina el tipo de información que se tiene disponible en ese caso para la verificación. En el resto de ECI, los g.d.l. activos a controlar para establecer la referencia se indican mediante "X", "Y" y " $Z$ " para las traslaciones, y " $\alpha$ ", " $\beta$ ” y " $\gamma$ " para las rotaciones. En los casos en los que aparece " $\equiv 0$ " se desea indicar que se trata de un sistema de referencia que se hace coincidir con el del montaje, y ocurre siempre que la referencia mínima necesaria para la extracción sea incompleta. Por otra parte, y en la misma columna, también se indica el valor u operación a realizar de los diferentes parámetros en los g.d.l. invariantes ("Gdli"). Además del tipo de sistema de coordenadas utilizado (subíndices "e" para esférico, "c" para cilíndrico, "con" para cónico y letras "u, v, w" sin subíndice para cartesiano), también se representa si el valor u operación hace referencia a la geometría integral (subíndice "I") o derivada ("D"). Asimismo, entre paréntesis se incluye una indicación del tipo de cálculo para realizar la verificación de la especificación. 
Por último, en la octava columna de la Tabla 5.1 (y segunda del subbloque "Geometría sustituta") "Geometrías sustitutas construidas" se indica una breve descripción del tipo de geometrías que habitualmente se pueden construir a partir de la información extraída, como paso previo a la verificación de la geometría de especificación. Por ejemplo, para el ECI "9-Cilindro-diámetro", y de acuerdo al tipo de información extraída, no es posible realizar ninguna construcción geométrica que aproxime a la geometría real. Únicamente se obtendrá un valor del diámetro del cilindro integral (diámetro medio) a partir de los valores leídos: "Gdl ${ }_{\mathrm{i}}: \mathrm{r}_{\mathrm{c}_{-} \mathrm{I}}$ " (sexta columna de la Tabla 5.1). En el ECI "11Cilindro-proyección_axial”, las construcciones geométricas realizadas a partir de los datos extraídos son dos circunferencias envolventes (para desviación máxima y mínima) en diferentes puntos conocidos del eje de referencia de medida y que son concéntricas a dicho eje. A partir de estas geometrías construidas, el cálculo necesario para la verificación de la especificación será una diferencia de radios entre el valor máximo y el mínimo: " $\mathrm{Gdl}_{\mathrm{i}}$ : $\Delta \mathrm{r}_{\mathrm{c}_{-} \mathrm{I}}$ (difer._radios)" (sexta columna de la Tabla 5.1). Por su parte, en el ECI "13-Cilindro", que es en el que con mayor nivel de detalle se puede representar la geometría real a partir de los datos extraídos, las construcciones geométricas que se realizan incluyen: el cilindro asociado a la superficie integral obtenido por el método de asociación que se considere óptimo en cada caso (" $r_{c_{-} I}$ "); dos cilindros envolventes (para desviación máxima y mínima) del cilindro integral (" $\Delta \mathbf{r}_{\mathrm{c}_{-} I}$ (difer._radios)"); y un cilindro envolvente del eje derivado del cilindro (" $r_{c_{\_} D}($ radio)"). Además, todas estas geometrías extraídas están posicionadas respecto al sistema de referencia de medición: "Gdl $\mathrm{i}_{\mathrm{i}} \mathrm{r}_{\mathrm{C}_{-} \mathrm{I}}, \Delta \mathrm{r}_{\mathrm{c}_{-} \mathrm{I}}$ (difer._radios) y $\mathrm{r}_{\mathrm{c}_{-} \mathrm{D}}$ (radio)" (sexta columna de la Tabla 5.1).

Por lo tanto, y a modo de conclusión, cabe remarcar algunos de los aspectos de la propuesta de biblioteca de ECI que se acaba de describir. La biblioteca está compuesta por un número y tipología de ECI suficientes para poder interpretar una pieza con un enfoque basado en elementos característicos útil para la planificación supervisora de los procesos de inspección.

Más concretamente, la biblioteca considera diez tipos básicos de ECI: esfera, cilindro, cono, revolución, barrido_cilindrico, plano, barrido_prismático, barrido_helicoidal, barrido_curvo y forma_libre. Las formas en las que la geometría del ECI interacciona con los procesos y montajes de medición, que corresponde a la información que aparece en las columnas de la 3 a la 6, permite considerar los siguientes aspectos que llevan a desglosar los tipos básicos de ECI en más subtipos hasta llegar al total de 49: el nivel de calidad de la información obtenida en el proceso de medición (tamaño, proyección global u orientada, o coordenadas); si se obtiene información de las superficies integrales o de los elementos derivados del ECI; los tipos de parámetros geométricos que deben ser capturados en los procesos de extracción, como mínimo, para poder caracterizar ese tipo de ECI; y la referencia mínima necesaria (completa o incompleta).

Por otro lado, el tipo de ECI también determina los tipos de datos e información, referentes a la geometría con defectos, que son necesarios y relevantes para la comprobación de las especificaciones dimensionales y geométricas. Esta información se recoge en las columnas 7 y 8 , en las que se consideran los aspectos vinculados a la geometría sustituta y a las construcciones geométricas que se pueden realizar para llevar a cabo la verificación. 


\section{Capítulo 6}

\section{La EsPeCificación del Producto Y LA PLANIFICACIÓN DE LA INSPECCIÓN}

\subsection{INTRODUCCIÓN.}

Tal y como se ha visto en los anteriores capítulos, los ejercicios de simulación son esenciales para establecer las especificaciones geométricas a través del establecimiento de condiciones sobre las cadenas que se constituyen entorno al ensamble mecánico. Estas cadenas vienen determinadas por las diferentes configuraciones del ensamble, que están determinadas por el conjunto de uniones/juntas entre las interfaces geométricas de cada uno de los componentes. Por tanto, para la especificación es necesario disponer de un modelo que recoja tanto la arquitectura del ensamble, como las cadenas que se establecen y las condiciones funcionales para cada una de ellas. Los eslabones de estas cadenas establecen las relaciones entre las interfaces geométricas de los elementos participantes, interfaces que van a venir representadas por las correspondientes geometrías de defectos. Estas geometrías de defectos son las que se encuentran en los ECE. Como ya se ha expuesto en el capítulo 5, cada ECE posee, además de esta geometría de defectos, las condiciones funcionales en las que participa, que constituyen los eslabones de la cadena de especificación.

Por lo tanto, se podría decir que los ECEP y ECI pertenecen al nivel de EC de ensamble, de acuerdo al modelo de capas de Brunetti y Grimm [Brunetti y Grimm, 2005] al que se ha hecho referencia en el capítulo 4. Esto significa considerar las piezas o elementos que forman un ensamble (de producto o de inspección) como la suma de la semántica relevante en un ámbito de interés además de la información geométrica, y de los conectores, que son los que caracterizan las uniones o interacciones entre las piezas o elementos del ensamble.

En este capítulo se va profundizar en el ejercicio de la especificación del producto y de la planificación de la inspección, integrado los ECEP y ECI en un modelo de cadena de ensamble en el que basar los ejercicios de especificación. Para ello, en el siguiente apartado se propondrá un modelo de cadena de ensamble para la especificación que sea común para los ámbitos de la especificación y de la inspección del producto. A 
continuación, en el mismo apartado y a partir del modelo común anterior, se desarrollan de forma dual los modelos de cadena de ensamble específicos para la especificación de producto y para la inspección. Por último, y dado que la Planificación Supervisora de la Inspección es uno de los objetivos principales de este trabajo, en el último apartado de este capítulo se desarrolla la propuesta de un modelo para el ensamble de inspección que permite la selección de recursos y equipos de medición. Este modelo tiene en cuenta una propuesta previa de clasificación de los recursos de inspección que está basada en el concepto de recurso de medición, ya introducido en el capítulo 3, y en unos aspectos que afectan a la selección de dichos equipos que se exponen anteriormente a la clasificación.

\subsection{MODELO DE CADENA DE ENSAMBLE PARA LA ESPECIFICACIÓN Y LA INSPECCIÓN de ProduCto.}

\subsubsection{MOdelo DE CADENA DE ENSAMble PARA LA ESPECIFICACIÓN.}

La Figura 6.1 muestra el diagrama de clases UML del modelo de Cadena de Ensamble de Especificación (CE) propuesto. Tal y como se puede observar, el modelo se basa en una representación del ensamble utilizando el ECE definido en el capítulo anterior y establece las relaciones entre la geometría con defectos de dicho ECE y otros conceptos que participan en los ejercicios de simulación, como la arquitectura y las cadenas de especificación.

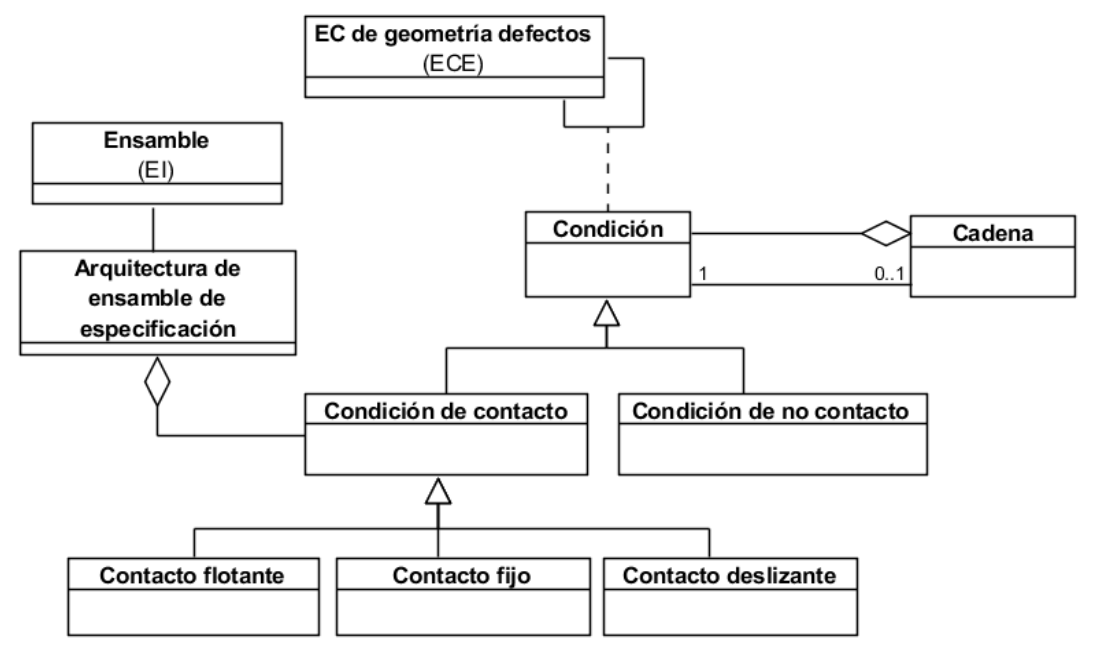

Figura 6.1 Diagrama de clases UML del Modelo de Cadena de Ensamble de Especificación (CE) propuesto.

En concreto, un Ensamble lleva asociada una arquitectura (Arquitectura de ensamble de especificación), definida como agregación de todas las condiciones de contacto (Condición de contacto) entre todos los elementos geométricos con defectos (EC de geometría defectos) que participan en la condición, sea este el ensamble de producto o el ensamble para la inspección. Además de las Condiciones de contacto, que son las que definen la arquitectura de un ensamble, el otro tipo de condiciones de tipo geométrico que se consideran son las Condiciones de no contacto, que establecen condiciones que o bien afectan únicamente a una misma pieza o elemento del conjunto o bien a dos piezas del conjunto pero con una condición de separación. 2010]:

Los tipos de contactos entre elementos del ensamble considerados son [Costadoat, 
- Contacto flotante. Un contacto se considera flotante cuando ambas superficies de contacto tienen los posibles desplazamientos relativos (normales y tangenciales).

- Contacto fijo. Un contacto se considera fijo cuando el mismo queda limitado por una acción mecánica y la adhesión entre las dos superficies, producida por esta acción, no permite el movimiento relativo entre las dos superficies durante el uso normal del mecanismo.

- Contacto deslizante. Un contacto se considera deslizante cuando el mismo queda limitado por una acción mecánica y esta acción permite solo los desplazamientos tangenciales durante el uso normal del mecanismo.

Por su parte, la Cadena agrega todas las asociaciones establecidas entre EC de geometría con defectos necesarias para cerrar el bucle correspondiente a una condición. De todas las condiciones incluidas en la cadena, únicamente una de ellas estará asociada con la condición a cumplir, sea la funcional del producto o la de inspección, y el resto estarán asociadas a otras condiciones que se establecen para crear la cadena.

\subsubsection{Modelo de CADENA DE ENSAMBLE DE ESPECIFICACión DE PROduCTO.}

\subsubsection{REQUISITOS DE LA PROPUESTA.}

La propuesta de modelo de Cadena de Ensamble de Especificación de Producto (CEP) deberá contemplar los siguientes requisitos:

- El modelo de CEP debe vincular el ejercicio de la especificación dimensional y geométrica del producto a un ensamble.

- El modelo de CEP debe ser un subtipo de CE, según lo expuesto en el subapartado anterior, para buscar la dualidad entre la especificación de producto y la inspección.

- El modelo de CEP debe considerar un enfoque basado en EC y, más concretamente, utilizar el ECEP definido en al capítulo 5, a través de su geometría sustituta, para representar el ejercicio de la especificación.

- Es necesario que el modelo de CEP permita representar los contactos entre todos los elementos o piezas que forman parte del ensamble, para lo que deberá incluirse la arquitectura del ensamble.

- El modelo de CEP también debe representar el bucle funcional, que puede estar basado en un modelo de esqueleto o en un modelo de superficie o piel, para lo que es necesario considerar la cadena funcional.

- El modelo de CEP debe utilizar las características de situación, forma y tamaño para expresar el bucle funcional.

- Es necesario que el modelo de CEP sea compatible con el lenguaje Geospelling y también con los principales estándares GD\&T.

\subsubsection{Modelo de Cadena de Ensamble de EsPeCificaCión de PRODUCTO PROPUESTO.}

En el capítulo anterior se ha propuesto una especialización del EC de aplicación, el ECEP, que reúne toda la información requerida en el ejercicio de la especificación de un ensamble de producto. A diferencia de otras propuestas de la literatura, el ECEP no solo contempla la geometría nominal y la estructura de componentes del ensamble de producto, sino que incorpora los atributos de las geometrías con defectos sobre las que se apoya el toleranciado. Un aspecto que no está presente en ninguna de las propuestas elaboradas en 
iniciativas normalizadoras (ISO10303-Parte 44 de STEP, OAM del NIST, etc.), que se centran en la información estructural del artefacto o ensamble resultante de la fase de desarrollo preliminar y solo establecen una vinculación simple de los elementos estructurales y de geometrías de interfaz (nominales) con las tolerancias normalizadas especificadas en los planos o modelos $3 \mathrm{D}$, sin considerar los múltiples requisitos que imponen los diferentes ejercicios de análisis y síntesis de tolerancias. Unos requisitos que sí que se contemplan en la propuesta de modelo de CEP que aquí se presenta, mostrada en la Figura 6.2, y que se fundamenta principalmente en: una representación del ensamble en base al ECEP descrito en el capítulo anterior, y la descripción de las especificaciones mediante el lenguaje Geospelling.

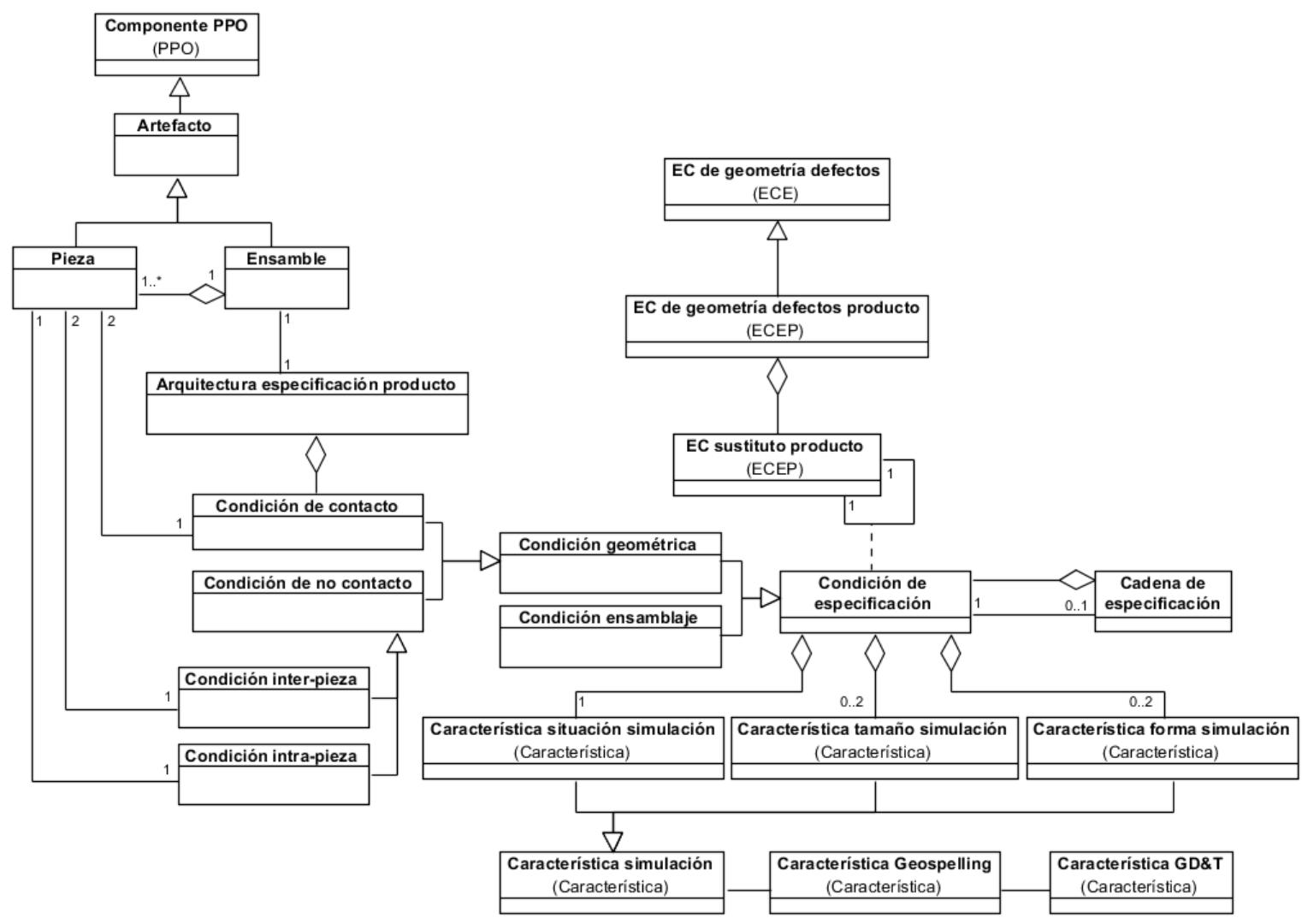

Figura 6.2 Diagrama de clases UML del Modelo de Cadena de Ensamble de Especificación de Producto (CEP) propuesto.

El modelo establece las relaciones entre el EC sustituto de producto y otros conceptos que participan en los ejercicios de simulación, como son la arquitectura y las cadenas de especificación del ensamble de producto. Mientras que la arquitectura de especificación de producto (Arquitectura especificación producto) agrega todos los objetos de tipo Condición de contacto que relacionan los EC sustituto producto que participan en una función, la Cadena de especificación es la agregación de todas las condiciones de especificación (Condición de especificación), que incluyen tanto las condiciones de contacto como las de no contacto (Condición de no contacto), inter-pieza (Condición interpieza) e intra-pieza (Condición intra-pieza), que participan en el bucle cerrado funcional. Es decir, la Cadena de especificación agrega todas las asociaciones necesarias para cerrar el bucle correspondiente a una condición funcional representada por la Condición de especificación. Por lo tanto, de todas las condiciones de especificación incluidas en la cadena, únicamente una de ellas estará asociada con la condición funcional y el resto 
estarán asociadas a otras condiciones de especificación que se establecen para crear la cadena.

Además de las condiciones de contacto y las de no contacto, que constituyen los tipos de condiciones de tipo geométrico (Condición geométrica), también son condiciones de especificación, y por tanto condiciones que pueden formar parte de las cadenas, las vinculadas al montaje del conjunto (Condición ensamblaje).

Por otra parte, cada una de estas asociaciones (Condición de especificación), independientemente del tipo de condición con que se relaciona (funcional o no funcional), agregará unas Características Geospelling que limitarán las desviaciones permitidas y que pueden afectar a: a) la forma y tamaño de los dos posibles EC sustitutos de producto (Característica forma simulación y Característica tamaño simulación); y b) la situación entre los dos posibles EC sustitutos de producto (Característica situación simulación). Unas características de especificación que, y tal y como se ha indicado en el capítulo anterior al presentar el Modelo de ECEP, se podrán transformar a las tolerancias normalizadas basadas en zonas de tolerancia.

Como se puede observar en el modelo, el ejercicio de la especificación está vinculado a un ensamble de producto (Ensamble), visto como una agregación de piezas (Pieza), de forma similar a como se considera en los modelos de producto genéricos más importantes y que se han revisado en el capítulo 4 . Un ensamble que es un tipo de artefacto (Artefacto) entendido como un tipo de Componente PPO.

Por lo tanto, y a modo de conclusión, se pueden destacar algunos de los aspectos de más importantes de la propuesta. El modelo propuesto se deriva del modelo de $\mathrm{CE}$ explicado en el subapartado anterior siendo así adecuado para alcanzar la integración de la especificación del producto con el ámbito de la planificación de inspección de las piezas de ese producto.

El CEP integra el ECEP, a través de su geometría sustituta, con otros conceptos necesarios para los razonamientos del ejercicio de la especificación de producto basada en EC y en torno al ensamble de producto: la arquitectura de especificación de producto, que determina los conctactos entre las piezas que forman el producto, y la cadena de especificación, que representa los bucles funcionales como agregación de condiciones de especificación.

Además, las condiciones de especificación se definen como agregaciones de características de forma, situación y tamaño según el lenguaje Geospelling, siendo por tanto el modelo compatible con este lenguaje así como con los estándares GD\&T, en base a los cuales se pueden expresar también dichas características.

\subsubsection{MOdelo de CADENA DE EnSAMble de InSPECCIÓN.}

\subsubsection{REQUISITOS DE LA PROPUESTA.}

El modelo de Cadena de Ensamble de Inspección (CEI), de forma similar al modelo de CEP, deberá contemplar los siguientes requisitos:

- El modelo de CEI debe vincular el ejercicio de la especificación de la inspección a un ensamble que corresponde al montaje utilizado para realizar la medición de la pieza utilizando un determinado recurso de inspección.

- El modelo de CEI debe ser un subtipo de Cadena de ensamble de especificación, según lo expuesto en el punto 6.2.1, para buscar la dualidad entre la especificación de producto y la inspección.

- Es necesario que el modelo de CEI permita representar los contactos entre todos los elementos o piezas que forman parte del ensamble de inspección (pieza y 
recurso de inspección), para lo que deberá considerarse la arquitectura del ensamble de inspección, que incluirá al recurso de inspección.

- El modelo de CEI también debe representar el bucle funcional, de igual modo a la especificación de producto, donde ahora la función será la inspección de una característica.

- Es necesario que el modelo de CEI considere tanto la cadena vinculada a los g.d.1. como la cadena que representa las incertidumbres del proceso de inspección, ya que ambas caracterizan la especificación completa del plan de inspección.

\subsubsection{Modelo de CADENA DE ENSAMble de InSPECCIÓN PROPUESTO.}

En la Figura 6.3, que muestra el modelo de CEI propuesto, puede verse la relación del $E C$ de defectos medición, descrito en el capítulo anterior, y otros conceptos que participan en el ejercicio de la especificación de la inspección, como son la arquitectura del ensamble de inspección y las cadenas de inspección. La Arquitectura de especificación de inspección, que es una especialización de la clase común para la especificación y verificación de producto Arquitectura de ensamble de especificación, representa la arquitectura del ensamble de inspección y se define como una agregación de todos los tipos de objeto de Condición de inspección que participan en la especificación de la inspección que implican una Condición de contacto. La agregación de todas las Condiciones de inspección vinculadas a la asociación de EC de defectos medición, establece una Cadena de inspección, especialización de la clase Cadena. De todas las Condiciones de inspección agregadas por la Cadena de inspección únicamente una de ellas representa la condición de especificación de la inspección (EC de función).

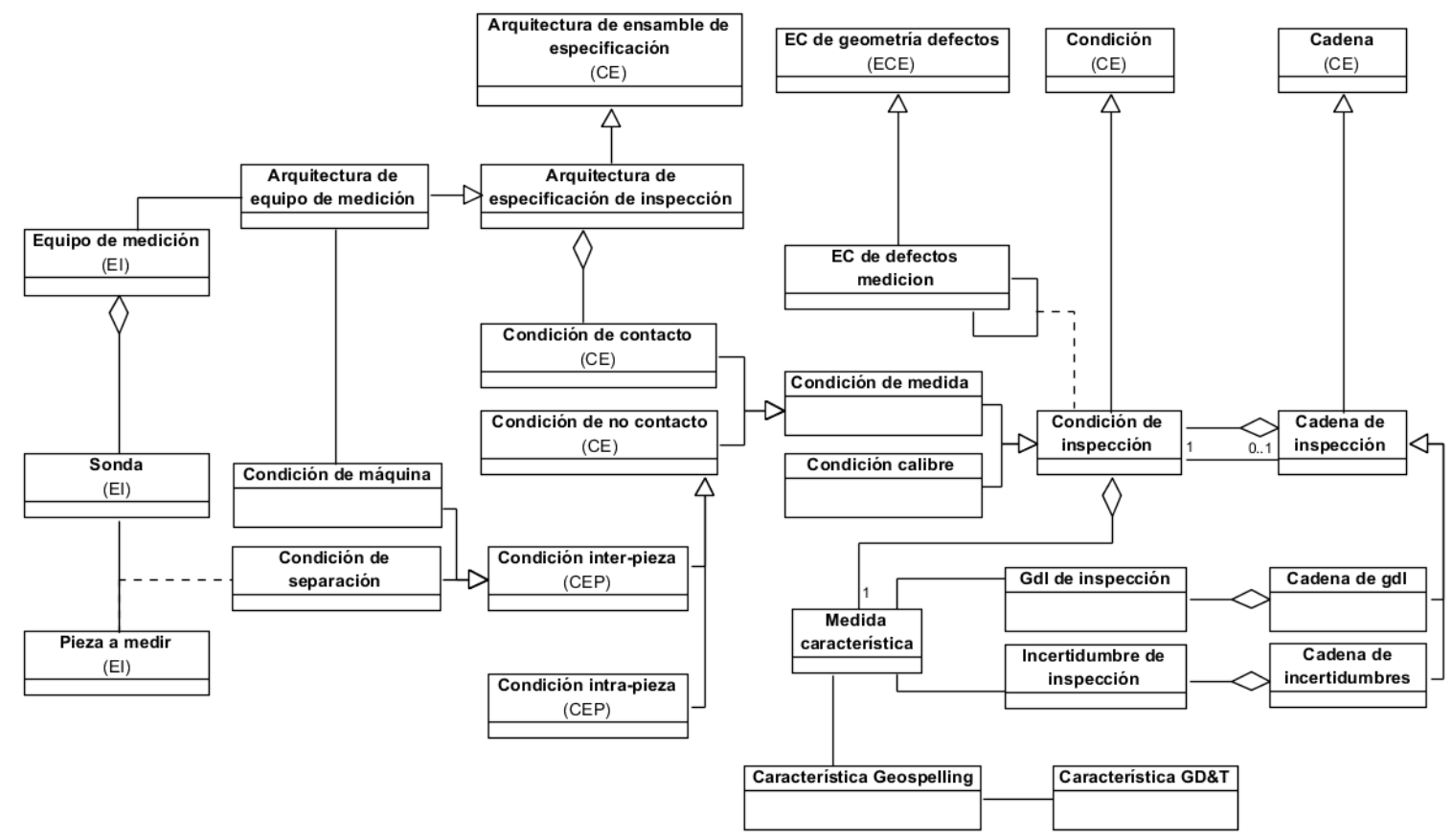

Figura 6.3 Diagrama de clases UML del Modelo de Cadena de Ensamble de Inspección (CEI) propuesto.

De entre las Arquitecturas de especificación de la inspección hay una que caracteriza al ensamble que representa al Equipo de medición y que en el diagrama corresponde a la clase Arquitectura de equipo de medición. Un Equipo de medición es una agregación de Sondas que permiten tomar los datos sobre las superficies reales de las piezas que están siendo objeto de inspección (Pieza a medir). La relación entre la Sonda y la Pieza a medir está representada en el diagrama por la clase asociativa Condición de separación, en la que 
el valor de la separación será cero para los casos de sondas de contacto. La Condición de separación es junto con la Condición de máquina los dos subtipos de condición que se establecen entre piezas diferentes (Condición inter-pieza) que formen parte del ensamble de inspección de acuerdo a la arquitectura que lo caracteriza. La Condición de máquina va vinculada a la Arquitectura del equipo de medición y establece las características propias del equipo o recurso de inspección, como es la relación de las sondas con el sistema de referencia del equipo.

Además de las condiciones entre piezas diferentes, la clase Condición de no contacto también incluye las condiciones que se establecen entre elementos geométricos pertenecientes a un mismo componente (Condición intra-pieza) del ensamble de inspección, y establece la desviación en posición y/u orientación entre dichos elementos geométricos.

Tanto las condiciones de inspección de contacto como las de no contacto corresponden a los tipos de condición que se producen cuando la inspección se realiza mediante la medida de valores de desviación individuales tomados en uno o varios puntos (Condición de medida). Este tipo de condiciones se ha distinguido del de aquellas condiciones que representan métodos de inspección basados en la utilización de galgas funcionales (Condición calibre).

Las cadenas de inspección que agregan las diferentes condiciones de inspección pueden considerarse desde dos puntos de vista, representados en el diagrama por las dos subclases de Cadena de inspección: Cadena de g.d.l. y Cadena de incertidumbres. La Cadena de g.d.l. es la agregación de los g.d.l. que caracterizan la condición de inspección (G.d.l. de inspección) y, por tanto, determinan en gran medida la selección de los posibles recursos o montajes de inspección que puedan dar respuesta a las necesidades de registro de los parámetros correspondientes a los g.d.l. invariantes. Por su parte, la Cadena de incertidumbres es la agregación de los valores de las incertidumbres correspondientes a todas las desviaciones medidas o calculadas (Incertidumbres de inspección) correspondientes a las condiciones de inspección que conforman la cadena. Esta cadena es el otro aspecto que influye en la selección de los posibles recursos de inspección, pues permite establecer el valor de la incertidumbre global que caracteriza a la condición de inspección y que no podrá ser superior al límite establecido.

Por otra parte, cada Condición de inspección incluirá una medida de una característica (Medida Característica), que será de extracción o especificada en función del tipo de condición. Cada medida de una característica requiere de la utilización de unos g.d.l. ( $G d l$ de inspección) y estará caracterizada por unos valores de incertidumbre (Incertidumbre de inspección) que incluirá las incertidumbres correspondientes (de método, de implantación,...) según el tipo de condición.

Las medidas de las características, sean de extracción o especificadas y tal y como se estableció en el capítulo 3, corresponden a características expresadas según el lenguaje Geospelling (Característica Geospelling) que, a su vez, tienen su correspondencia con las Características $G D \& T$.

Por lo tanto, y a modo de conclusión, se destacan algunos de los aspectos más importantes de la propuesta. El modelo de CEI propuesto, y del mismo modo a como ocurre con el CEP, deriva del modelo de CE, siendo así adecuado para la integración con el ámbito de la inspección de producto.

De forma análoga al CEP, el CEI integra el ECI, a través de su geometría con defectos, con otros conceptos necesarios para los razonamientos del ejercicio de la inspección de producto (especificación del plan de inspección) basada en EC y en torno al ensamble de inspección: la arquitectura de especificación de inspección, que determina los conctactos entre los elementos (pieza y recurso de inspección) que forman el ensamble de 
inspección, y la cadena de inspección, que representa los bucles funcionales vinculados a la inspección de una característica como agregación de condiciones de inspección.

Además, el modelo de CEI permite considerar tanto la cadena vinculada a los g.d.l. que caracterizan el ensamble de inspección como la cadena vinculada a las incertidumbres, de manera que los razonamientos en torno al ensamble de inspección puedan llevarse a cabo para poder definir el plan de inspección.

\subsection{EL ENSAMBLE DE INSPECCIÓN Y LOS PROCESOS DE INSPECCIÓN.}

\subsubsection{Los Procesos de Medición TiPo.}

Durante la Planificación Supervisora de la Inspección hay que tomar decisiones sobre el conjunto de instrumentos o equipos de medición (recursos de medición) que pueden utilizarse para la medición de los diferentes ECI. Entendiéndose por recurso de medición a cualquier dispositivo que permita obtener información sobre la geometría de una pieza en la cantidad y calidad requerida para verificar las especificaciones dimensionales y geométricas que recaen en un ECI. Para esta decisión se suelen contemplar procesos de medición que utilizan desde instrumentos metrológicos de taller sencillos (reglas, micrómetros, calibres pasa-no_pasa, etc.) hasta máquinas universales de medida por coordenadas con grandes prestaciones, pasando por montajes y equipos de diseño específico. Dada la gran cantidad de instrumentos o recursos de medida existentes, es necesario establecer unos grupos de procesos, llamados Procesos de Medición de Tipo $(P M T)$, que ayuden a realizar esta selección a nivel supervisor. Posteriormente, en el nivel operativo, el PMT se concretará con la elección de un recurso de inspección específico, incluyendo la sonda y el utillaje concretos.

\subsubsection{EL RECURSO DE MEDICIÓN.}

La relación de PMT se basa en el concepto de recurso de medición que se va utilizar en este trabajo y que ya se introdujo de forma breve en el capítulo 3. Según lo allí indicado, un recurso de medición estará formado por tres elementos: un sistema mecánico, un sistema sensor y, en su caso, un sistema de tratamiento de la información. Aunque la descripción básica de estos tres elementos ya se realizó en el mencionado capítulo 3, en este capítulo se va a profundizar en el concepto de recurso de medición y los sistemas que lo forman de acuerdo al uso particular que se va hacer del mismo en esta tesis y, en concreto, en el establecimiento de los PMT y en el modelo de ensamble de inspección.

Los tres sistemas que forman el recurso de medición (mecánico, sensor y, en su caso, tratamiento de la información) están estrechamente relacionados entre sí y, por lo tanto, imponen toda una serie de dependencias entre ellos. En este caso son de especial relevancia las dependencias que se establecen entre el sistema de ejes, el sistema sensor y el sistema de información en todo lo referente al control de los g.d.l. Así, el hecho de que se requiera que el mesurando contemple un determinado número y tipo de coordenadas (cartesianas, cilíndricas, polares, etc.) condicionará el número mínimo y tipo de los ejes de la estructura cinemática y cuáles de ellos estarán controlados por el sistema sensor. Evidentemente, si se eligiera un recurso con un número de ejes de la estructura cinématica superior al exigido, se dispondrá de una mayor accesibilidad y flexibilidad. Es decir, pueden existir ejes sensorizados de los que luego no se tenga en cuenta el valor a los efectos de obtener el mesurando. 
En aras a clarificar la funcionalidad de las sondas y la posibilidad de que estas posean ejes adicionales, conviene tener presente que la función básica del sistema sensor de cualquier sonda es establecer un estímulo físico (contacto/touch) que provoca el registro de las señales de los sensores, tanto de la sonda como de la unidad base. Un estímulo que dependerá del tipo de señal que se registre y que según Tönshoff e Inasaki [Tönshoff e Inasaki, 2001] puede ser de seis tipos: radiante, mecánico, térmico, eléctrico, magnético y químico. El estímulo puede establecerse de forma automática o puede ser inducido externamente, normalmente por el operador. En el primer caso este podrá ser instantáneo, caso de medidas discretas, o continuo en el caso de medidas continuas propias de procesos de escaneo y requerirá de un sensor dedicado a esta funcionalidad básica. Esta sensorización básica, no necesaria cuando el disparo es externo, puede ir acompañada de otra dedicada a registrar los desplazamientos y giros de los ejes de la propia sonda. Esta sensorización de los ejes, que no es necesaria en algunas ocasiones (sonda de contacto intermitente/Touch-sensitive probe), se suele incorporar en sondas como pueden ser las mecánicas de contacto continuo, en las que por diseño es necesario mantener un contacto mecánico versátil y con una fuerza controlada del palpador.

En este trabajo, limitado a procesos de medición con recursos dotados de sondas con captura mecánica de la señal, el estímulo viene dado por un cambio en el contacto de un palpador o boca de un instrumento, que indica que la fuerza es la requerida para poder registrar una medida (lectura). Estas sondas se identificarán como sondas de atributo, mientras que aquellas que tienen sensores de ejes adicionales se denominarán sondas de variable. Cuando un equipo o instrumento está dotado de una sonda de atributo el mesurando se obtiene a partir de las señales de los sensores de la unidad base, que se registran en el momento del disparo. Contrariamente, cuando el equipo dispone de una sonda de variable, para obtener el mesurando también se considerarán las señales de los sensores de los ejes de la propia sonda.

Tal y como se ha indicado, el sistema de tratamiento de la información se encarga de proporcionar la información sobre la geometría discreta extraída de los ECI. Esta contemplará el mesurando, junto con datos procedentes de los procesos de calibración (incertidumbres) y, en su caso, información adicional sobre las direcciones en las que se han capturado las señales, formas de los palpadores, etc. Este tratamiento de la información podrá ser realizado por el propio operario o podrá disponerse de un ordenador que asista en dicha tarea.

Para ilustrar el concepto de equipo o instrumento de medida y ver la generalidad del mismo, a continuación se describen algunos posibles ejemplos:

a) En el caso de un pie de rey mecánico con bocas biseladas se trataría de un equipo de medida en el que la unidad base tiene un único eje de traslación sensorizado y la sonda (bocas del pie de rey) es de atributo. El disparo del estímulo y el tratamiento de la información lo lleva a cabo el operario, que determina el momento en el que el contacto se produce, estímulo requerido para realizar la lectura, y registra los valores observados en las escalas (sensores) de la unidad base.

b) Un calibre pasa-no_pasa es un recurso de medida sin ejes en la unidad base y con una sonda de atributo (bocas del calibre). En este caso, tanto el estímulo (on-off) como la lectura (pasa-no_pasa) son de tipo atributo.

c) Un micrómetro de exteriores con un reloj comparador en la boca fija es un equipo de medida con una unidad base dotada de una traslación sensorizada y una sonda de variable dotada de una traslación que coincide, en dirección, con la de la unidad base. En este caso el mesurando se obtiene de la suma de los valores procedentes de los transductores de ambos sensores y el estímulo lo proporciona 
el operario cuando este considera que la posición de la boca y del palpador del reloj son los establecidos.

d) Un montaje formado por un mármol, con un reloj comparador montado sobre un soporte regulable en altura y móvil sobre dos rectas no graduadas perpendiculares entre sí y contenidas en un plano paralelo al mármol, es un recurso de medida con una unidad base dotada de dos ejes de movimiento rectilíneo y perpendiculares entre sí no sensorizadas (rectas no graduadas), y una sonda de tipo variable dotada de una traslación que no coincide con las direcciones de desplazamiento de la unidad base (es perpendicular al plano formado por las dos direcciones de desplazamiento). El mesurando se obtiene de los valores procedentes de la sonda, estando el estímulo de esta proporcionado por el operario cuando considera que la posición del palpador es la establecida.

e) Un banco de centraje con un reloj comparador montado en un soporte que se desplaza sobre un eje de traslación que está dotado con una escala, es un recurso de medida en el que la unidad base tiene dos ejes, el de desplazamiento sensorizado y el de giro sin sensorizar, y la sonda de variable, con desplazamiento perpendicular a los desplazamientos y el giro de la unidad base. En este caso, si el elemento a medir es, por ejemplo, una superficie cilíndrica el desplazamiento del sensor es perpendicular a la superficie. Al igual que en el caso anterior, el mesurando se obtiene de los valores procedentes de la sonda desde un estímulo proporcionado por el operario.

f) Una MMC con sonda de contacto intermitente, dotada de un palpador de bola (y de forma muy similar para una brazo portable de medida en tres coordenadas o una sonda integrada en máquina) es un recurso de medida con una unidad base con tres desplazamientos sensorizados y una sonda de atributo. En estos casos, contrariamente a los anteriores, el estímulo lo proporciona automáticamente el sistema de control cuando detecta un cambio en la posición de equilibrio del palpador de la sonda, determinando el momento en el que se registran los valores de los sensores de la unidad base, que serán tratados por el sistema informático para proporcionar el mesurando.

g) Un sistema de visión dotado de cámara es un recurso de inspección sin ejes en la unidad base y una sonda con sensores que proporcionan información de la medida en tres direcciones. En este caso, el estímulo también se proporciona automáticamente y los valores registrados serán tratados por el sistema informático para proporcionar el mesurando.

El recurso de medición debe proporcionar una geometría discreta del ECI en la forma que el ECI requiere para cumplir con su funcionalidad. El recurso de medición proporcionará un mesurando, asociado a puntos, segmentos o teselas de la pieza con respecto a un origen del propio recurso. Si estos están asociados a puntos se definirán por tres parámetros, si lo están a un segmento por cuatro y si lo están a una tesela por seis. Como se sabe, muchos mesurandos proporcionados por equipos/instrumentos de medición no ofrecen esa cantidad de parámetros.

Por ello, uno de los criterios que debe tenerse en cuenta a la hora de establecer la clasificación de procesos de medición es el número de parámetros independientes que es capaz de proporcionar como resultado de la medición. Si únicamente se tienen en cuenta los mesurandos de tipo punto (coordenadas o distancias/ángulos con respecto a un sistema de referencia del recurso de medición) el número máximo de parámetros necesarios serían tres.

Como es obvio, para que el recurso pueda proporcionar un cierto número de parámetros este debe disponer de un sistema cinemático que esté dotado con este número 
de ejes sensorizados como mínimo. Como ya se ha indicado anteriormente, la unidad base del recurso puede disponer de otros ejes adicionales que no están sensorizados y que se orientan según direcciones de barrido determinadas por las estrategias de extracción (por ejemplo, generatrices y/o circunferencias de un cilindro o cono, etc.). Estos ejes adicionales, se denominarán ejes de barrido y permitirán obtener, siempre que la sonda permita registrar el desplazamiento perpendicular a la dirección de barrido, las desviaciones máximas con respecto a las formas de referencia (líneas y circunferencias, cilindros y planos) que determinan los movimientos de estos ejes. A los mesurandos que proporcionan estas desviaciones máximas con respecto a estos ejes de barrido, se les llamará mesurandos proyectados, porque ofrecen una información que representa la de muchos puntos proyectados según la dirección de barrido. En estos casos, si se quiere que los mesurandos proyectados hagan referencia a elementos geométricos de la pieza (ejes, generatrices, etc.) y que estos se obtengan con un nivel de precisión elevado, es necesario alinear los elementos de referencia de la pieza con respecto a los ejes de barrido del equipo de una forma cuidadosa. Estas operaciones de ajuste/alineamiento también afectan a la dirección del eje sensorizado de la sonda, para que no se cometan los típicos errores de coseno.

El número y tipo de g.d.l. del equipo de medida, determinados tanto por los ejes sensorizados como por los de barrido, establece la cantidad y tipo de parámetros geométricos que es capaz de proporcionar (mesurando). Esta información es la que permite determinar su adecuación para la medición de un determinado tipo de ECI.

\subsubsection{LOS PROCESOS DE MEDICIÓN Y LA SELECCIÓN DE EQUIPOS.}

En base a lo expuesto y al concepto de recurso de medición explicado, a continuación se proponen unas agrupaciones de recursos vinculadas a unos tipos de procesos de medición. Estas agrupaciones son fundamentales para facilitar la selección del recurso de medición en el nivel supervisor de la planificación de la inspección dado el elevado número de instrumentos y montajes de medición existentes.

Para la selección se deben tener en cuenta los siguientes aspectos vinculados con la medición:

- La capacidad de ofrecer unos mesurandos para determinadas geometrías. Una característica que, como se acaba de indicar, está relacionada con los g.d.l. del sistema mecánico, la sensorización contemplada para estos g.d.l. y las capacidades del sistema de tratamiento de información. Esta es la característica fundamental a la hora de determinar qué recursos son los válidos para medir un determinado tipo de ECI y es la que se tendrá en cuenta a la hora de establecer los PMT.

- La posibilidad de que el mesurando se refiera a una geometría integral o una geometría derivada (eje derivado, plano medio derivado, etc.).

- La accesibilidad y flexibilidad en la medida. Una característica que es importante a la hora de realizar la elección de un recurso de medición porque, como es obvio, un recurso que posea un número de ejes superior al mínimo necesario para obtener unos mesurandos, tendrá un mayor número de direcciones de acceso y con ello se podrán disminuir el número de recursos y de montajes (subfases) contemplados en el plan de inspección.

- La posibilidad de ofrecer los mesurandos con respecto a diferentes sistemas de referencia. Aunque los equipos e instrumentos de medición siempre poseen una referencia absoluta (cero equipo), el mesurando se puede ofrecer con respecto a otras referencias del equipo (por ejemplo, superficies de utillajes utilizados en las MMC o de las bocas en $\mathrm{V}$ de micrómetros, etc.). Esta posibilidad, que depende del tipo de utillajes o bocas que se pueden utilizar en un determinado recurso, 
requiere de un proceso de calibración adicional, que proporcione las matrices de transformación y las incertidumbres adicionales asociadas a estas transformaciones. Esto es básico para vincular las geometrías de la pieza (referencias (datums) virtuales de la pieza) con las referencias del recurso, que es la base para establecer las cadenas de inspección, fundamentales para establecer la validez de un determinado proceso de medición (equipo).

- La incertidumbre asociada a los mesurandos. Estas incertidumbres se obtienen a través de una composición de incertidumbres en la que pueden participar las propias del sistema sensor, con respecto a sus referencias absolutas, y las de transformación de referencias, citadas en el subapartado anterior. Evidentemente estos valores dependen de los procesos de calibración que, en su caso, pueden comportar acciones de corrección.

Como en la selección del recurso de medición a nivel supervisor no se considera la elección de la herramienta, el tipo y dimensiones de boca o palpador de la sonda no son características que se deban tener en cuenta.

\subsubsection{Clasificación de los Procesos de Medición TiPo.}

Antes de proponer la clasificación de los procesos de medición, se van a mostrar las formas en la que los procesos de medición (equipos) ofrecen los resultados.

Cuando la geometría discreta se construye a partir de mesurandos asociados a puntos y con respecto a un único sistema de referencia completo del recurso, la información es de gran calidad, en tanto que se dispone de las tres coordenadas (parámetros independientes) de cada uno de los puntos. Cuando las bases de los sistemas de referencia son ortogonales, estas coordenadas podrán ser cartesianas, cilíndricas o esféricas. En estos casos se obtendría una geometría medida 3D (discreta), a partir de la cual, utilizando las correspondientes operaciones GPS, se puede obtener una geometría 3D de sustitución.

Cuando los mesurandos asociados a puntos de una misma geometría (cilindro, plano, etc.) no se dan con respecto a un mismo sistema de referencia, caso de las medidas realizadas con un micrómetro con una boca esférica en la sonda, la obtención de la geometría para la verificación de la especificación estará condicionada por las hipótesis que se establezcan a la hora de valorar la variabilidad en posición y/o orientación de los sistemas de referencia de cada una de las medidas. Normalmente, este tipo de medidas se dan con recursos de medición (micrómetros, pies de rey, proyectores de perfiles, etc.) dotados de menos de tres g.d.l. y que, por lo tanto, tienen unos sistemas de referencia incompletos (por ejemplo, un punto y una dirección o un punto y dos direcciones ortogonales). Las operaciones GPS que realizarán la transformación entre la geometría medida y la de verificación de la especificación dependerán de las hipótesis establecidas.

Sin embargo, la información sobre geometría se puede obtener a través de mesurandos proyectados y con respecto a un único sistema de referencia incompleto. En estos casos el mesurando representa la desviación máxima según el o los g.d.l. considerados en el sistema de referencia incompleto y se obtiene realizando el barrido según los otros g.d.l. Estas desviaciones máximas proporcionan una información sobre la separación entre líneas o superficies envolventes ideales (externa e interna), medidas según las direcciones del sistema de referencia incompleto (por ejemplo, un punto y un eje cartesiano). En estos casos, a diferencia de los anteriores, la geometría medida vendrá representada por las geometrías ideales envolventes. Como estas geometrías de medida son continuas e ideales, entre las operaciones GPS utilizables para obtener la geometría de sustitución no se encontrarán las de filtrado, asociación y derivación.

Evidentemente, la calidad de la geometría medida será diferente según el número y tipo de mesurandos (ver párrafos anteriores) obtenidos. Por ejemplo cuando los 
mesurandos se asocian a puntos, el número de puntos medidos y una distribución uniforme de los mismos es importante a la hora de establecer la incertidumbre del proceso de medición, pero también lo es el hecho de que todos los mesurandos de esa geometría estén vinculados a un mismo sistema de referencia, porque de no ser así, la incertidumbre se incrementará. Además, en este último caso, esta incertidumbre dependerá de las hipótesis que se establezcan a la hora de asociar las referencias de cada medida a una referencia de pieza única. La existencia de estas referencias múltiples, se debe a que en estos procesos de medición para realizar las diferentes medidas es necesario realizar un desplazamiento relativo entre la pieza y el instrumento, a los efectos de que las medidas alcancen toda la geometría del ECI. Por otra parte, para el caso de mesurandos proyectados, la incertidumbre dependerá tanto del número de barridos y la uniformidad de su distribución como del alineamiento conseguido entre la referencia asociada a la geometría de la pieza (real) y los ejes de barrido del recurso de medición.

Como se ha comentado en el apartado anterior, uno de los aspectos fundamentales para la selección de un equipo es su capacidad para ofrecer unos mesurandos que se adecuen a las necesidades de verificación de las geometrías de los ECI contemplados en la biblioteca. Además, los mesurandos (básicos o proyectados) resultantes de la medición de un determinado ECI, estarán vinculados a referencias de la pieza, completas o incompletas, dependiendo del tipo de proceso de medición utilizado. Esto lleva a considerar la importancia del número y tipo de parámetros independientes de los mesurandos que puede ofrecer un determinado recurso de medición y a la relación que estos tienen con el número y tipo de g.d.l. de los equipos. Un aspecto que será fundamental a la hora de realizar una clasificación de los procesos de medición.

Para realizar la clasificación, sin que ello suponga pérdida de generalidad, se han establecido las siguientes consideraciones:

- Sólo se van a estudiar procesos de medición con captura mecánica de la señal y con sondas de atributo o de variable. Además, las sondas de variable sólo podrán disponer de un único eje sensorizado, que evidentemente dispondrá de un g.d.l. que será independiente de los ejes de la unidad base.

- El tratamiento de mesurandos asociados a segmentos (cuatro g.d.1.) o teselas (seis g.d.l.) queda fuera del alcance de la clasificación.

- La clasificación se realiza en base a los ejes mínimos necesarios para obtener un mesurando. Por lo tanto, no se consideran recursos de medición que posean ejes redundantes, destinados a mejorar la flexibilidad y accesibilidad de estos recursos.

Atendiendo a estas restricciones y teniendo presente lo ya comentado anteriormente, se propone una clasificación de PMT, basada en los tres criterios siguientes (Tabla 6.1):

- El número de ejes utilizados por el equipo en la medición. Según las restricciones indicadas anteriormente, el número mínimo de parámetros de los mesurandos oscilará entre uno y tres y, por tanto, el número de ejes utilizados en la medición también oscilará entre uno y tres.

- Los ejes con sensor de variable (V). Este criterio incluye tanto el número de ejes sensorizados con movimiento, que será como máximo el número de ejes utilizados en la medición, como el tipo de movimiento de estos ejes, que puede ser de desplazamiento rectilíneo (R) o giro (C). Como se observa en la tabla, los PMT1 son los únicos procesos de medición en los que no se realiza movimiento alguno según el eje sensorizado, porque es el único tipo que no puede disponer de un sensor de variable, sino que es de tipo atributo (A).

- Los ejes de barrido del recurso de medición. En este criterio se incluye tanto el número, diferencia entre los ejes utilizados en la medición y el número de ejes con 
sensor de variable dotados de movimiento, como el tipo de movimiento de estos ejes (R o C).

Es importante destacar que a la hora de establecer las combinaciones de tipos de movimiento, tanto en los ejes sensorizados como en los de barrido, solo se han contemplado aquellas a las que se les pueden asignar instrumentos, equipos o montajes que son usuales en la metrología dimensional.

\begin{tabular}{|c|c|c|c|c|c|c|}
\hline \multirow[b]{2}{*}{ PMT } & \multirow{2}{*}{$\begin{array}{c}N^{\circ} \text { de ejes } \\
\text { utilizados } \\
\text { en la } \\
\text { medición }\end{array}$} & \multicolumn{3}{|c|}{ Ejes con sensor de variable } & \multicolumn{2}{|c|}{ Ejes de barrido } \\
\hline & & $\begin{array}{c}\mathrm{N}^{\circ} \text { de ejes } \\
\text { con } \\
\text { movimiento }\end{array}$ & $\begin{array}{c}\text { Tipo de } \\
\text { movimiento }\end{array}$ & $\begin{array}{c}\text { Tipo } \\
\text { de } \\
\text { sonda }\end{array}$ & $\begin{array}{c}\mathrm{N}^{\circ} \text { de ejes } \\
\text { con } \\
\text { movimiento }\end{array}$ & $\begin{array}{c}\text { Tipo de } \\
\text { movimiento }\end{array}$ \\
\hline PMT1. Calibre & \multirow{3}{*}{1} & 0 & No procede & A & 1 & Cualquiera \\
\hline PMT2. Medición de distancia & & \multirow{2}{*}{1} & $\mathrm{R}$ & \multirow{8}{*}{ A o V } & 0 & No neco \\
\hline PMT3. Medición de ángulo & & & $\mathrm{C}$ & & & \\
\hline PMT4. Medición sobre recta & \multirow{2}{*}{2} & 1 & $\mathrm{R}$ & & 1 & $\mathrm{R}$ \\
\hline PMT5. Medición sobre regla & & 2 & R y R & & 0 & No procede \\
\hline PMT6. Medición sobre plano & \multirow{4}{*}{3} & & & & & \\
\hline PMT7. Medición respecto a centro & & $t$ & r & & 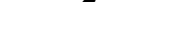 & 20 \\
\hline PMT8. Medición respecto a eje & & 2 & R y R & & 1 & $\mathrm{C}$ \\
\hline PMT9. Medición en tres coordenadas & & 3 & Cualquiera & & 0 & No procede \\
\hline
\end{tabular}

Tabla 6.1 Clasificación de los recursos metrológicos en Procesos de Medición Tipo (PMT) con sistema de sensor únicamente en una dirección.

De acuerdo a estas hipótesis y criterios y considerando las posibles combinaciones, los tipos de PMT establecidos son:

- PMT1.- Calibre. Únicamente se utiliza un g.d.l. para la extracción obteniéndose un único parámetro de tipo booleano debido a que el sensor de la sonda es de tipo atributo.

Realiza una comparación entre la superficie real y un patrón dimensional específico para ella.

Ejemplo: calibre pasa_no-pasa para ejes.

- PMT2.- Medición de distancia. Al igual que en el PMT1, únicamente se utiliza un g.d.l. para la extracción que coincide con el único eje sensorizado que es de tipo rectilíneo.

Mide la distancia entre el elemento de apoyo (punto: PT, línea recta: SL, plano: PL) y un punto.

Ejemplo: pie de rey.

- PMT3.- Medición de ángulo. Es similar al PMT2 pero ahora el g.d.l. sensorizado es de tipo circular.

Mide el ángulo entre un elemento de apoyo (PT, SL, PL) y un punto.

Ejemplo: goniómetro.

- PMT4.- Medición sobre recta. A diferencia de los casos anteriores, ahora los g.d.1 utilizados para la extracción son dos. Solo tiene un eje sensorizado, que es de tipo rectilíneo, por lo que únicamente se obtiene un parámetro. El otro g.d.l. es de barrido y también rectilíneo.

Mide la altura o la variación en altura (distancia entre la máxima y la mínima) de puntos de una línea contenida en una superficie respecto a una referencia constituida por una línea recta que coincide con el eje rectilíneo de barrido. Las 
alturas o variaciones en altura se obtienen en el plano que contiene a la línea sobre la superficie y a la recta seguida en el desplazamiento.

Ejemplo: recta y comparador.
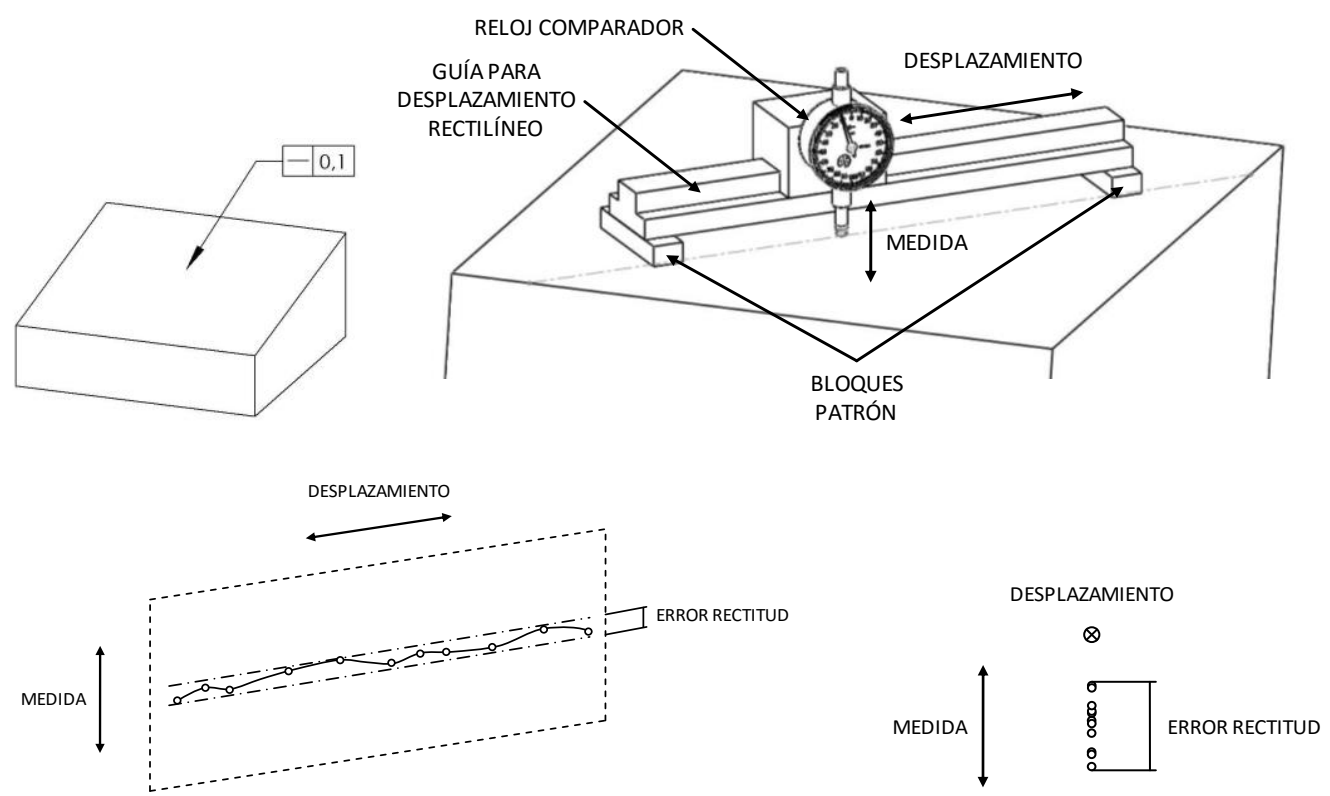

Figura 6.4 Ejemplo de medición utilizando un montaje de tipo PMT4.
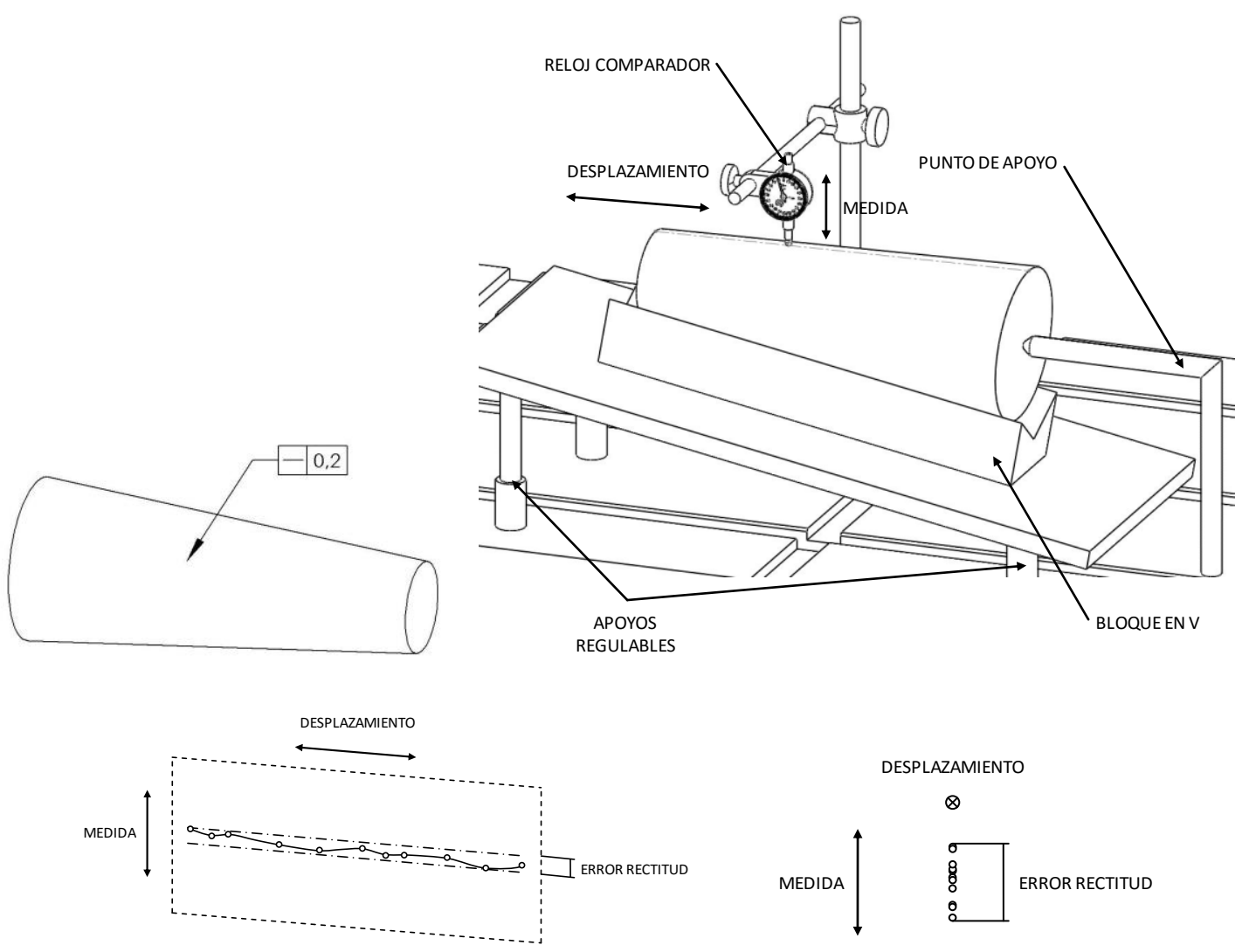

Figura 6.5 Ejemplo de medición utilizando un montaje de tipo PMT4.

- PMT5.- Medición sobre regla. Al igual que el PMT4, se utilizan dos g.d.l. para la extracción, pero en este caso ambos son ejes sensorizados de tipo rectilíneo. 
Mide la altura o variación en altura de puntos a lo largo de una línea contenida en una superficie respecto a una referencia constituida por uno de los ejes. A diferencia del PMT4, el hecho de disponer de una geometría discreta de la que se obtienen dos parámetros permite operaciones de reconstrucción del perfil extraído.

Ejemplo: regla graduada y comparador.
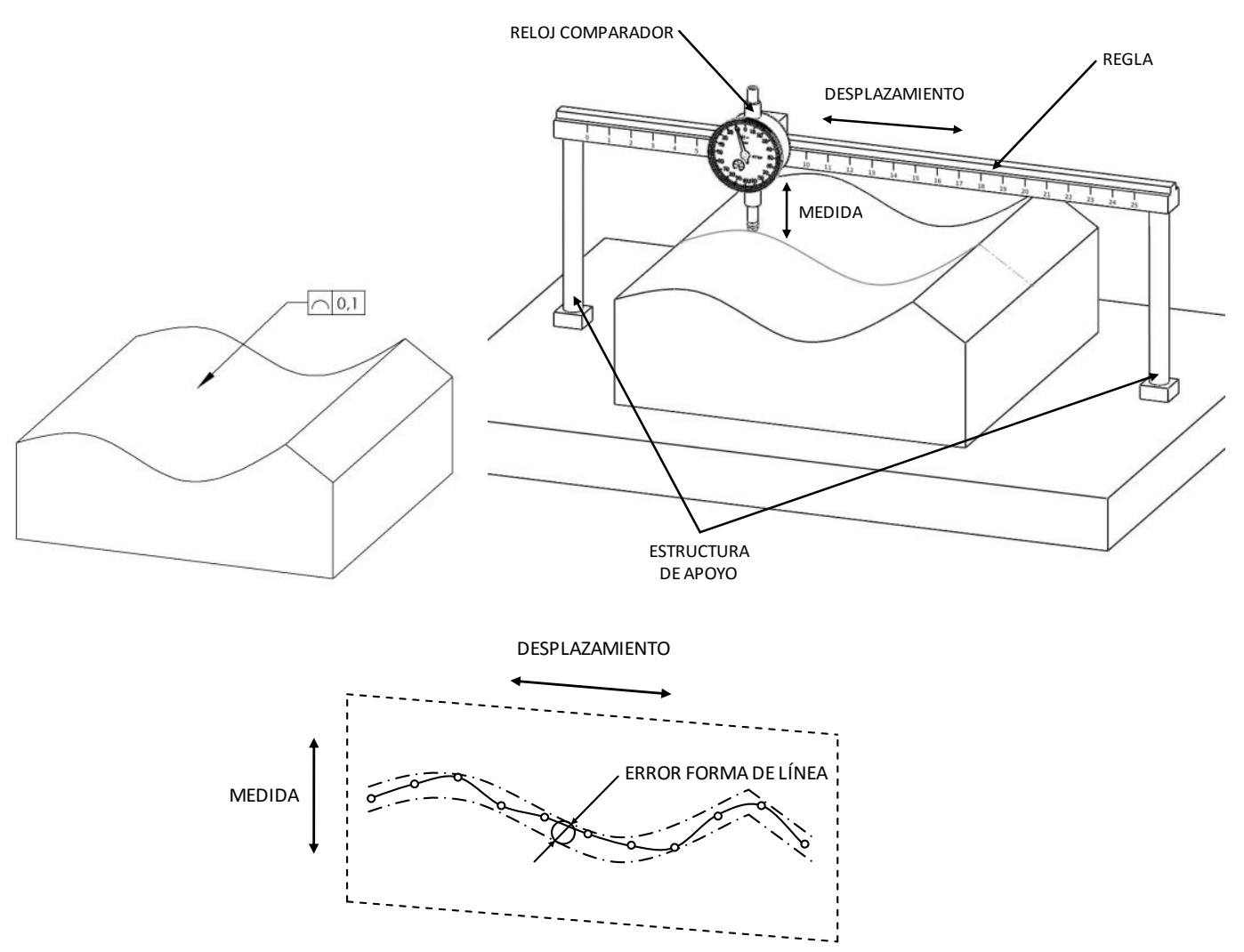

Figura 6.6 Ejemplo de medición utilizando un montaje de tipo PMT5.

- PMT6.- Medición sobre plano. Los g.d.l. utilizados para la extracción son tres, aunque la información obtenida hace referencia solo a uno de ellos. Dos de los g.d.l. corresponden al sistema de desplazamiento o barrido y son de tipo rectilíneo no controlados (es decir, no proporcionan información). El otro g.d.l. corresponde al sistema sensor, y debe ser de tipo variable. Las direcciones de los g.d.l. del sistema de desplazamiento y del sistema de sensor no coinciden.

Mide la variación en altura entre puntos contenidos en un plano y un plano construido paralelo al anterior. Sobre el plano construido se realiza el desplazamiento, según dos g.d.l. Esta variación es medida en la dirección normal al plano construido.

Ejemplo: mesa, gramil y comparador. 

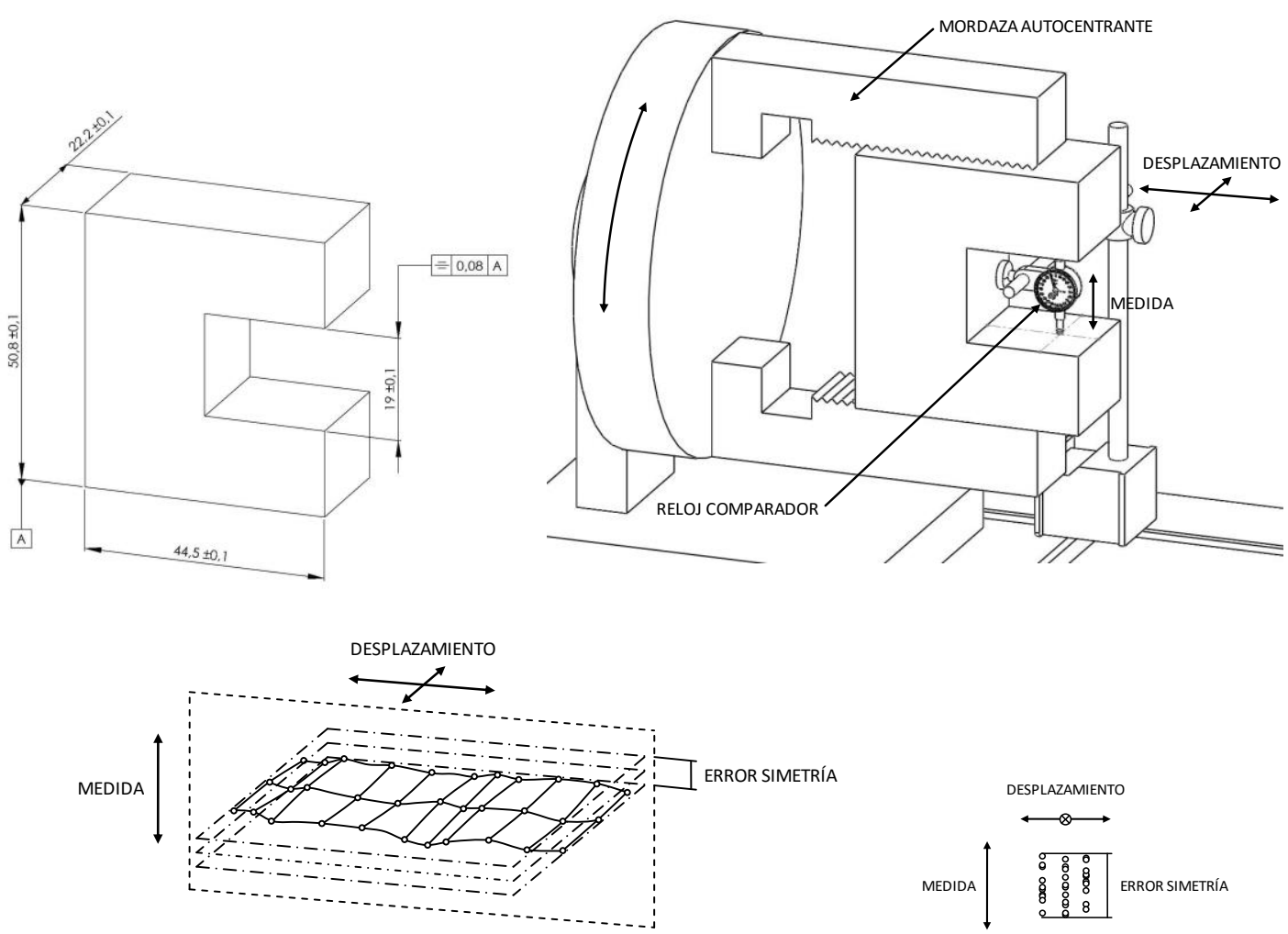

Figura 6.7 Ejemplo de medición utilizando un montaje de tipo PMT6.

- PMT7.- Medición respecto a centro. Al igual que el PMT6, se utilizan tres g.d.1 para la extracción, haciendo referencia la información obtenida solo a uno de ellos. Dos de los g.d.l. también corresponden al sistema de desplazamiento o barrido y no son controlados, y el otro corresponde al sistema sensor y debe ser de tipo variable. La diferencia es que de los dos g.d.l. de barrido, uno es de tipo rectilíneo y el otro de tipo circular. Las direcciones de los g.d.l. del sistema de desplazamiento y del sistema sensor no coinciden.

Mide la variación, en la dirección radial, entre puntos contenidos en una circunferencia y un centro construido. El centro construido depende del centro del giro realizado sobre la superficie en la que se obtienen los puntos.

Ejemplo: bloque en $\mathrm{V}$ y comparador.

- PMT8.- Medición respecto a eje. Al igual que el PMT6 y el PMT7, los g.d.l. utilizados para la extracción son tres. Sin embargo, en este caso la información obtenida hace referencia a dos g.d.1. Dos de los g.d.1. corresponden al sistema de desplazamiento o barrido y el otro al sistema sensor, que debe ser de tipo variable. De la misma forma que el PMT7, de los dos g.d.l. de barrido, uno es de tipo rectilíneo y el otro de tipo circular, estando además en este caso el de tipo rectilíneo controlado. Las direcciones de los g.d.l. del sistema de desplazamiento y del sistema sensor no coinciden.

Mide la variación, en la dirección radial, entre puntos contenidos en varias circunferencias y un eje construido. Las distancias relativas entre los planos que contienen a las circunferencias, según el eje construido perpendicular a los mismos, son de valor conocido. El eje construido depende del eje del giro realizado sobre la superficie en la que se obtienen los puntos. A diferencia del PMT7, el hecho de disponer de las distancias relativas entre las circunferencias permite construir el eje de revolución.

Ejemplo: banco de centraje y comparador sobre regla graduada. 
- PMT9.- Medición en tres coordenadas. Al igual que los PMT anteriores, se utilizan tres g.d.l. para la extracción, pero ahora la información obtenida hace referencia a esos tres g.d.l. El sistema de desplazamiento tiene tres g.d.l. controlados, de manera que la dirección del sistema sensor coincide con uno de ellos.

Mide la distancia de puntos respecto a tres planos perpendiculares entre sí. Ejemplo: MMC.

\subsubsection{MODELO DE ENSAMBLE DE INSPECCIÓN.}

\subsubsection{REQUiSITOS DE LA PROPUESTA.}

El modelo de Ensamble de Inspección (EI) deberá contemplar los siguientes requisitos::

- El modelo de EI debe utilizar el concepto de recurso de inspección según lo expuesto en el subapartado anterior, que hace especial referencia a la relación entre los movimientos de los ejes utilizados para la medición, en términos de g.d.l., y la sensorización de los mismos para el registro de una determinada información sobre el ECI medido.

- El modelo de EI debe tener en cuenta la clasificación de PMT explicada en el subapartado anterior, que pretende considerar una tipología de recursos y montajes de inspección más allá de la MMC o sonda integrada en máquina.

- Es necesario que el modelo de EI sea consistente con las principales propuestas de modelos genéricos de producto, y más concretamente con PPO, considerando el ensamble de inspección y la pieza a medir como tipos de artefactos en el sentido de componente PPO.

\subsubsection{MODELO DE ENSAMBLE DE INSPECCIÓN PROPUESTO.}

En la Figura 6.8, que muestra el diagrama de clases UML del modelo de EI propuesto, un Ensamble de inspección, en torno al cual se realiza el ejercicio de la especificación de la inspección, es la agregación de la pieza que es objeto de la inspección (Pieza a medir) y del Recurso de inspección utilizado para la medición.

El Ensamble de inspección y la Pieza a medir son tipos de Ensamble y de Pieza respectivamente que, como ya se ha indicado en el punto anterior para el modelo de CEP, son tipos de Artefacto entendido como un tipo de Componente PPO. En este modelo de EI, además, se ha considerado la distinción entre artefactos de tipo puramente mecánico (Artefacto mecánico) y artefactos que combinan las disciplinas mecánica, electrónica, de computación y de control automático (Artefacto mecatrónico) con el fin de poder representar adecuadamente los aspectos de sensorización vinculados a los recursos de inspección y que son de importancia para determinar el tipo de PMT y, por tanto, la adecuación del mismo para realizar la inspección de una determinada característica.

El recurso de inspección, y según la definición explicada en el subapartado 6.3.1 de este mismo capítulo, está compuesto por un sistema mecánico y un sistema sensor, además del sistema de tratamiento de la información que no se muestra en el diagrama UML. Por ello, el Recurso de inspección se muestra en el diagrama como la agregación del Sistema sensor de medición, que es un tipo de Sistema sensor, y el Equipo de medición, que incluye el sistema mecánico compuesto por la Unidad Base, la Sonda y el eventual Utillaje utilizado para completar el posicionado y sujeción la pieza a medir en la unidad base del equipo. El Sistema sensor de medición se define como la agregación de sensores utilizados en la medición (Sensor de medición) y que incluyen: el necesario sensor correspondiente al eje de la sonda para registrar o medir la posición de la misma según un estímulo (Eje de 
medición); y los eventuales sensores correspondientes a la unidad base (Eje de barrido), cuyos movimientos no necesariamente están sensorizados y, por tanto, quedan registrados.

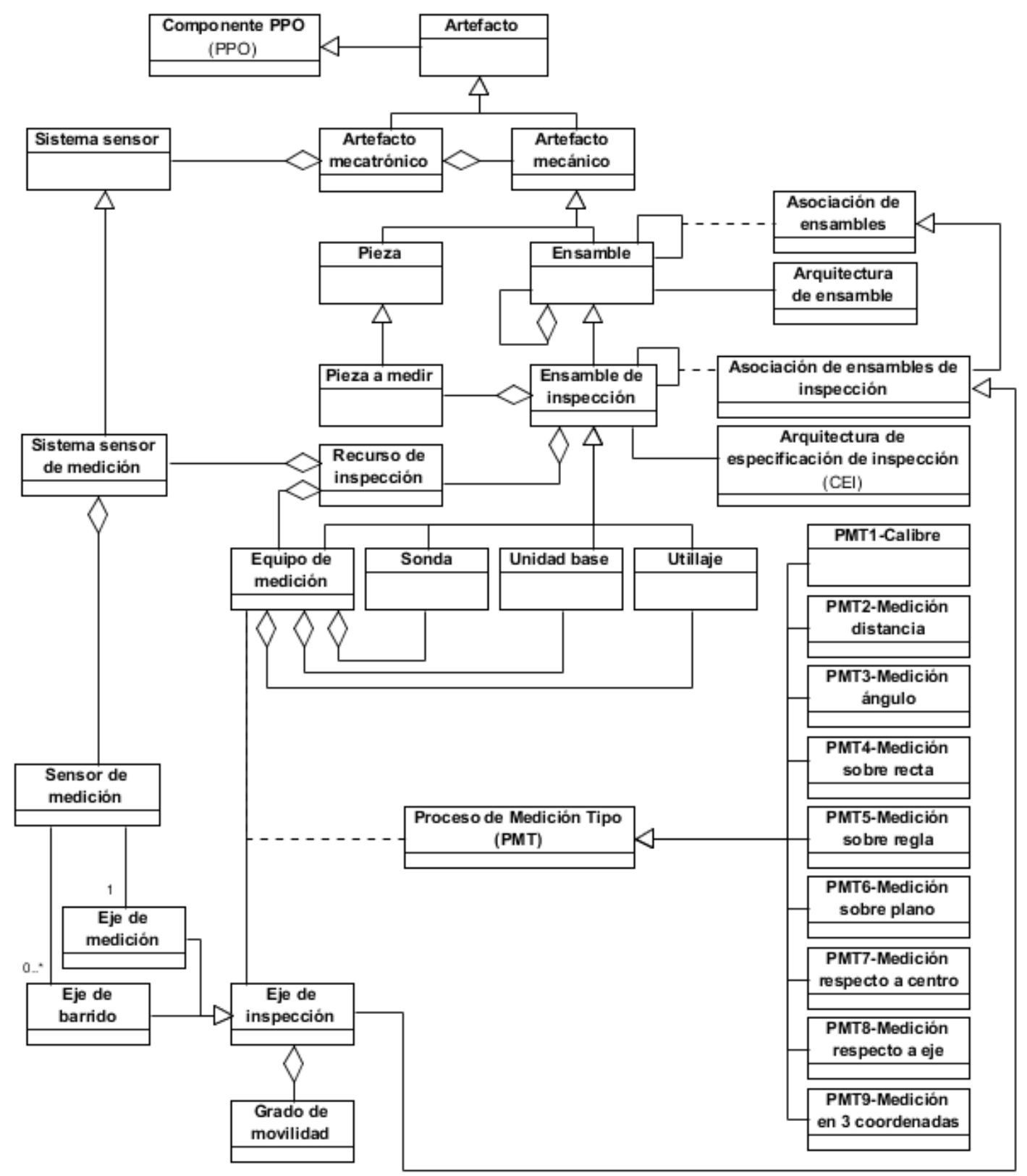

Figura 6.8 Diagrama de clases UML del Modelo de Ensamble de Inspección (EI) propuesto.

La relación entre el sistema de ejes, sean de medición o de barrido, sensorizados utilizados en la inspección (Eje de inspección), y que determinan lo referente a los g.d.l. (Grado movilidad), y el equipo de medición, viene caracterizada precisamente por el Proceso de Medición Tipo (PMT). El PMT seleccionado deberá dar respuesta a las necesidades impuestas por el elemento a medir en términos del número y tipo de parámetros independientes que puede ofrecer un determinado recurso de medición y a la relación que estos tienen con el número y tipo de g.d.l. y cómo están sensorizados. Los tipos de PMT considerados son, evidentemente, los establecidos en el punto 6.3.1.1 de este capítulo: PMT1 - Calibre, PMT2 - Medición distancia, PMT3 - Medición ángulo, PMT4 Medición sobre recta, PMT5 - Medición sobre regla, PMT6-Medición sobre plano, 
PMT7 - Medición respecto a centro, PMT8 - Medición respecto a eje y PMT9 - Medición en 3 coordenadas.

Asimismo, el Eje de inspección como agregación de grados de movilidad vinculados a un equipo de medición, caracteriza la relación entre los elementos que forman el ensamble de inspección, pudiéndose definir, por tanto, como un subtipo de la clase Asociación de ensambles de inspección, que a su vez es subtipo de Asociación de ensambles.

Tal y como ya prevé el modelo de ECE descrito en el capítulo 5, un Ensamble lleva asociada una Arquitectura de ensamble, que se definía como agregación de todas las condiciones de contacto entre todos los elementos sustitutos que participan en la condición, sea este el ensamble de producto o el ensamble para la inspección. Del mismo modo, y tal y como se ha visto en el modelo de CEI descrito en el punto anterior, el Ensamble de inspección tendrá su correspondiente Arquitectura de especificación de inspección.

Por lo tanto, y a modo de conclusión, cabe remarcar brevemente algunos de los aspectos de la propuesta que dan respuesta a los requisitos anteriormente comentados. El modelo de EI propuesto define el ensamble de inspección considerando la pieza a medir y el recurso de inspección según la definición introducida en el subapartado anterior, y en la que es de especial relevancia la relación entre los movimientos de los ejes utilizados durante el proceso de toma de datos (medición), en términos de g.d.l., y la eventual sensorización de los mismos para el registro de una determinada información sobre el la geometría del ECI a inspeccionar.

El modelo de EI propuesto hace uso de la clasificación en nueve grupos de recursos de inspección (PMT) establecida en el subapartado anterior, basada en los ejes mínimos necesarios para obtener un mesurando y considerando procesos de medición con captura mecánica de la señal y con sondas, de atributo o de variable, que disponen de un único eje sensorizado independiente de los ejes de la unidad base. 


\section{Capítulo 7}

\section{METODOLOGÍA BASADA EN GRAFOS PARA LA INSPECCIÓN}

\subsection{INTRODUCCIÓN.}

Tal y como se ha descrito en el capítulo 5 (Figura 5.5), un ECI contiene toda la información requerida para las actividades propias de la Planificación Supervisora de la Inspección, como son la selección de los recursos de inspección apropiados, la determinación de subfases, la agrupación y secuenciación de las subfases, etc. En concreto, el ECI se ha definido como la agregación de cuatro elementos característicos: Estructura de inspección, EC de geometría de inspección, Condición de inspección y Límite de inspección. De ellos, el EC de geometría de inspección y, más concretamente, uno de sus componentes, el EC de defectos medición (ECDM), es un elemento esencial por cuanto incluye la representación de la geometría real de la pieza con defectos resultante del proceso de medición realizado sobre la geometría del elemento objeto de análisis. Este resultado del proceso de medición es una agregación de geometría extraída (EC extraído de medición), geometría sustituta (EC sustituto de medición) y referencia local (EC referencia local). Hay que recordar que el EC extraído de medición es alguno de los tipos de modelo primitivo de medición establecidos en el capítulo 3: de tipo discreto (modelo discreto de piel o de líneas con defectos), que en la Figura 5.5 corresponde al EC de geometría extraída discreta, o de tipo ideal con defectos dimensionales, que corresponde al EC de geometría extraída envolvente de la misma figura. Por su parte, el EC sustituto de medición es un modelo ideal que corresponde a alguno de los modelos simplificados establecidos también en el capítulo 3: superficies/perfiles continuos obtenidos por reconstrucción, superficies ideales con defectos dimensionales o angulares (modelos de piel) o elementos ideales con defectos derivados de los anteriores (modelos de esqueleto).

Las soluciones propuestas por el planificador de la inspección deben permitir obtener los valores de las medidas que corresponden a las características de extracción. Cada tipo de medida, correspondiente a cada característica de extracción, establece unos g.d.1., que deben dar respuesta a las necesidades de registro de los parámetros correspondientes a los g.d.l. invariantes, y unos valores de incertidumbre de medida, que deben estar dentro de los límites establecidos por la condición impuesta a la característica especificada. 
Estas soluciones representan ensambles del proceso de inspección, definidos por la Estructura de inspección. Los ensambles de inspección (Figura 6.8), que están compuestos por la pieza a medir y el recurso de inspección seleccionado para realizar la medición, vienen caracterizados por una arquitectura que especifica los contactos entre ellos. Los razonamientos que lleva a cabo el planificador en un nivel supervisor se realizan considerando unas cadenas que se establecen en dicho ensamble de inspección. En estas cadenas (Cadena de inspección) intervienen unos nodos, los ECDM, y unas relaciones entre ellos, que vienen representadas por las condiciones (Figura 6.3). Cada Cadena de inspección incluye una condición (requisito) que el planificador debe especificar y que corresponde a la característica especificada a inspeccionar. Para ello, el planificador debe considerar el resto de condiciones que participan en la cadena y que serán tanto condiciones de contacto, que definen la arquitectura del ensamble, como condiciones de no contacto, inter-pieza e intra-pieza, correspondientes a los elementos que forman parte del ensamble. Conviene recordar que los ECDM del recurso de inspección ya son conocidos en el momento de la inspección de las características, porque se han obtenido en los procesos de medición previos, pertenecientes a procesos de preparación, ajuste y calibración del sistema de medida establecido.

Pero para facilitar la tarea del planificador sería interesante contar con una metodología de apoyo, basada en una representación de tipo grafo, como los utilizados en los ejercicios de análisis y síntesis de tolerancias en ensambles y en procesos de mecanizado.

Para ello, en este capítulo se propone una representación basada en grafos que contiene los elementos de la cadena necesarios para que el planificador realice todos sus razonamientos. Unos elementos que pertenecen tanto a la pieza a medir como al equipo de medida. Estos elementos podrían ser, por ejemplo, las geometrías de la sonda, del utillaje y/o de la unidad base, si el análisis se quiere realizar con gran detalle. Este grado de detalle posibilita, por ejemplo, la consideración de los diferentes tipos de bocas (geometría de boca) en instrumentos, los diferentes tipos de superficies de los utillajes, el equipo concreto para llevar la medición y su calidad en la medición, el tipo de sonda, etc.

En el siguiente apartado se explican los elementos sintácticos de la representación gráfica propuesta, incluyendo su simbología y significado, para posteriormente, en el tercer apartado, describir la forma de disponer en el grafo dichos elementos para la construcción gráfica de las cadenas de inspección. En el apartado 4 se describe la metodología para los razonamientos asociados a la construcción gráfica de la cadena del ensamble de inspección, constituyendo una parte del ejercicio de la especificación del plan de inspección que realiza el planificador. Finalmente, en el último apartado de este capítulo, se exponen unos casos sencillos de aplicación que permiten ilustrar el uso de la notación gráfica y la metodología propuestas.

\subsection{SINTAXIS Y SEMÁNTICA DE LA REPRESENTACIÓN.}

En este apartado se describe la simbología utilizada en la representación gráfica de la cadena de inspección propuesta, explicando tanto la sintaxis como la semántica de la misma. La sintaxis define todos los elementos estructurales que se utilizan y la relación entre los mismos, mientras que la semántica establece el significado de cada uno de ellos, para permitir su correcta utilización e interpretación.

En primer lugar se describen los nodos (elementos estructurales) propuestos, a continuación las relaciones entre ellos y, por último, los operadores. En los tres casos se indican los símbolos utilizados y el significado asociado a cada uno de ellos. 


\subsubsection{LOS NODOS.}

La representación gráfica propuesta utiliza tres tipos de nodos: el ECDM, la referencia y el sistema de coordenadas (Figura 7.1).

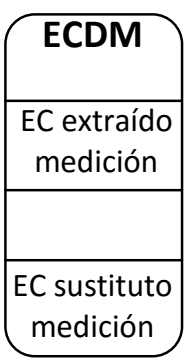

a) ECDM

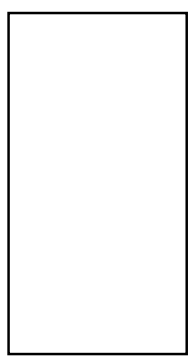

b)

Referencia

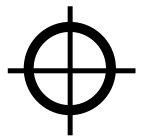

c)

Sistema de coordenadas

Figura 7.1 Símbolos utilizados para los nodos.

\subsubsection{El Elemento CaRaCterístico de defectos de MEdición.}

El ECDM se representa utilizando el primer símbolo (a) que aparece en la Figura 7.1, que contiene la información sobre la geometría con defectos de la interfaz geométrica del ECI, que resulta de interés para los razonamientos de la planificación de la inspección.

Tal y como se puede observar, dentro del símbolo utilizado para el ECDM se diferencia la información correspondiente a las geometrías extraída y sustituta. Como ya se ha mencionado anteriormente, el EC extraído de medición, de acuerdo a lo explicado en los capítulos 3 y 5 , es una representación de la geometría real de la pieza utilizando un modelo primitivo que puede ser de tres tipos diferentes: a) un modelo discreto de piel con defectos, formado por puntos o teselas; b) un modelo discreto de líneas con defectos, formado por puntos o segmentos; y c) un modelo ideal de piel con defectos dimensionales. El primer tipo de modelo primitivo de geometría extraída se obtiene cuando se utilizan recursos de medida en los que se conocen los parámetros de todos los puntos tomados vinculados a los g.d.l. invariantes, mientras que el segundo tipo resulta del uso de metrología de perfiles/formas o texturas de superficies. El tercer tipo de modelo primitivo (ideal) se obtiene cuando se hace uso de recursos de medida que acumulan la variación o desviación total de un perfil o de la superficie completa, no proporcionando la información sobre alguno de los g.d.l. invariantes y que en este trabajo se han denominado como de manera proyectada (global u orientada).

El EC sustituto de medición es un modelo simplificado obtenido a partir de los modelos primitivos discretos, que son necesarios para llevar a cabo la verificación de ciertas características especificadas.

En la representación de los nodos de la cadena, no únicamente aparecen los ECDM que constituyen la interfaz geométrica de la pieza objeto de medición, sino que también se mostrarán los nodos correspondientes a los ECDM que forman parte del equipo de medición, de acuerdo al modelo de verificación para la representación del sistema real del ensamble de inspección descrito en el capítulo 3. En concreto, la sonda y el utillaje utilizados en el equipo de medición también se interpretan en base a ECI, los cuales tendrán sus correspondientes ECDM, que son las interfaces geométricas del equipo que interaccionan con los ECDM de la pieza a medir. La interacción entre la pieza y la sonda es a través de una interfaz de medida y la de la pieza con el utillaje (o directamente superficies del equipo de medida si no se utiliza utillaje) a través de una interfaz de 
situación, según los tipos de interfaces establecidos en el capítulo 3 para el sistema de verificación.

\subsubsection{LAS REFERENCIAS.}

El segundo tipo de nodo del que se hace uso en la representación de la cadena de inspección es la referencia, que se representa utilizando el segundo símbolo (b) que aparece en la Figura 7.1. Una referencia es un elemento geométrico continuo utilizado como base para establecer o medir una característica. Estas referencias pueden ser de dos tipos: referencia local materializada, pertenecientes al recurso y vinculadas con las características de extracción, y referencia local de especificación, pertenecientes a la pieza y vinculadas con las características especificadas.

La referencia local de especificación se representará con el símbolo indicado incluyendo la denominación "de especificación". Estas referencias tendrán una representación cuando no coincidan con un nodo del tipo ECDM. Situación que se presentará siempre que se trate de una referencia que resulta de operaciones realizadas con unas geometrías continuas procedentes de las geometrías sustitutas de nodos ECDM o de otra referencia de especificación.

De acuerdo a la definición de ECI propuesta y explicada en el capítulo 5 (Figura 5.5), la referencia local es un elemento geométrico ideal que se utiliza como referencia para medir las desviaciones y determina las direcciones/sentidos en los que se deben realizar estas medidas. Cuando la característica a medir es de extracción, de acuerdo a lo establecido en el capítulo 3, la geometría de referencia siempre se materializa en el equipo de medida y puede ser de tres tipos: a) materializada cinemáticamente mediante los movimientos de las guías del recurso de medida; b) calculada mediante operaciones matemáticas de asociación según un determinado criterio; y c) materializada de posicionamiento mediante contactos físicos con superficies reales de elementos del equipo de medida.

Las referencias de materialización cinemática y de posicionamiento pertenecen a la unidad base del equipo de medición. En el caso de las de materialización de posicionamiento, se trata de aquellas superficies de la propia unidad base del equipo o del eventual utillaje utilizado para la orientación y/o fijación de la pieza durante la medición. Por ejemplo, en el caso de una medida con instrumento sencillo tipo micrómetro, la referencia local materializada de posicionamiento será la boca fija. En el caso de un montaje con un mármol y un gramil de alturas, la referencia local materializada de posicionamiento será la superficie del mármol sobre la que contacte la pieza a medir.

En el caso de las referencias materializadas cinemáticamente, estas se corresponden con las geometrías continuas generadas por los desplazamientos y/o giros de las guías del equipo de medición, con respecto a las cuales se alinea la pieza durante el proceso de medición. Por ejemplo, en el caso de la medida con una máquina de redondez, la referencia materializada cinemáticamente es el eje de giro del plato sobre el que se alinea y fija la pieza durante la medición.

Finalmente, las referencias calculadas se obtienen a partir de una medición previa que permite construir una geometría continua, orientada y posicionada respecto del sistema de coordenadas del equipo de medición, a partir de la que se medirán las desviaciones. Por ejemplo, en el caso de la medición de un plano con una MMC, a partir de una medición inicial de puntos, se establece un plano asociado que permite situar las posiciones de los puntos para el muestreo, y medir en esos puntos de muestreo las desviaciones del plano real de la pieza. 
Para realizar la distinción entre estos tres tipos de geometría de referencia, en el símbolo de referencia local materializada se incluirá la denominación concreta del tipo (cinemática, de posicionamiento o calculada).

\subsubsection{EL SISTEMA DE COORDENADAS.}

Por último, el tercer nodo mostrado en la representación de la cadena de inspección es el sistema de coordenadas, para el que se utiliza el tercer símbolo (c) de la Figura 7.1. El sistema de coordenadas siempre pertenece al equipo de medición y viene representado en el espacio por tres vectores perpendiculares entre sí que se intersectan en un punto (origen de coordenadas). Respecto a él están expresados los datos (coordenadas, desviaciones) obtenidos durante el proceso de medición. Todas las referencias locales materializadas están relacionadas con un sistema de coordenadas correspondiente al equipo de medición.

\subsubsection{LAS RELACIONES.}

Además de los nodos explicados en el subapartado anterior, también se representan las relaciones entre ellos. En concreto, el conjunto de relaciones utilizadas corresponden a las contempladas en el modelo de cadena de ensamble de inspección expuesto en el capítulo 6 (Figura 6.3). Todas las relaciones representan eslabones de la cadena (bucle) y hacen referencia a todas las condiciones de inspección: las de contacto entre elementos que forman parte del ensamble de inspección, las intra-pieza de la pieza a verificar o de elementos que forman parte del utillaje utilizado para la medición y las inter-pieza entre la pieza a verificar y el equipo de medición. Las relaciones representan una desviación que lleva asociada su incertidumbre correspondiente.

Los símbolos utilizados para las relaciones se muestran en la Figura 7.2.

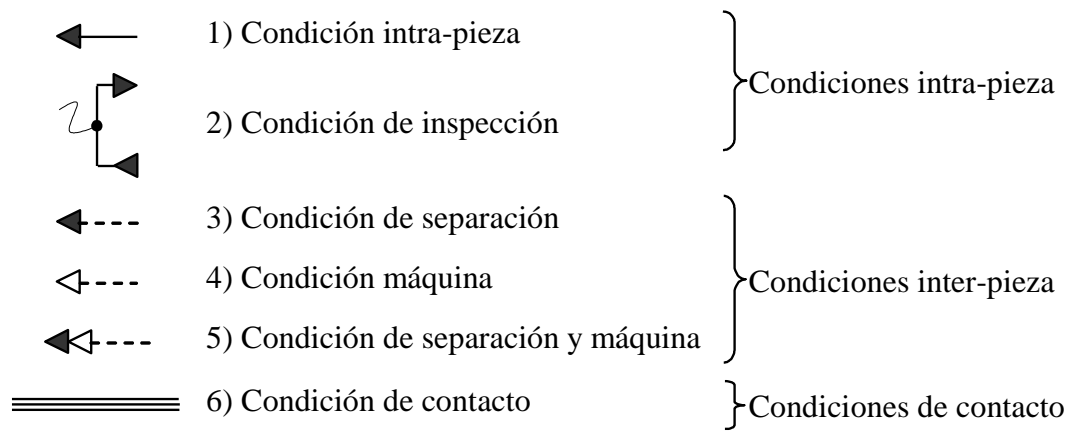

Figura 7.2 Símbolos utilizados para las relaciones.

\subsubsection{LAS CONDICIONES INTRA-PIEZA.}

Tal y como se ha explicado en el capítulo 6 (Figura 6.3), las condiciones intra-pieza, que son uno de los tipos de condiciones de no contacto contempladas, se establecen entre elementos geométricos pertenecientes a un mismo elemento del ensamble de inspección y representan la medida de forma, posición y/u orientación entre dichos elementos geométricos.

El símbolo general utilizado para representar las condiciones intra-pieza es el primero (1) que aparece en la Figura 7.2. Se trata de una línea continua con un extremo en forma de flecha, indicándose así el sentido en cual se establece la desviación.

Sin embargo, dentro de las condiciones intra-pieza, durante el proceso de medición hay una que adquiere especial importancia y es aquella que representa la condición de inspección que hace referencia a la característica dimensional y geométrica especificada que se pretende verificar. Para distinguir esta condición del resto de relaciones intra-pieza 
(como las que puedan existir para el utillaje) se ha seleccionado un símbolo que incluye más información. Es el segundo símbolo (2) que aparece en la Figura 7.2 y está constituido por una línea continua con una punta en forma de flecha en un extremo, un triángulo relleno en el extremo opuesto y una etiqueta. La punta de la flecha y el triángulo relleno permiten distinguir el elemento geométrico objeto de la especificación (target) y el elemento geométrico de la pieza que es referencia (datum) respectivamente. La etiqueta describirá la característica especificada. Cada una de estas condiciones intra-pieza hace referencia a una característica especificada, que puede ser expresada bien en términos de una característica Geospelling o bien en términos GD\&T. Teniendo en cuenta además que la geometría extraída puede corresponder a un modelo primitivo de tipo discreto o de tipo ideal, las relaciones correspondientes a estas condiciones intra-pieza pueden establecerse entre cualquier combinación de geometrías extraídas y sustitutas.

El resto de condiciones intra-pieza que no representan una característica especificada, se representan con el símbolo (1) de la Figura 7.2. Todas ellas corresponden a las relaciones que representan aquellas características que son conocidas mediante procesos de medición/calibración previos. Es el caso, por ejemplo, de las especificaciones para los utillajes utilizados para la situación y fijación de la pieza sobre el equipo de medida. Estas relaciones intra-pieza siempre se representarán entre las geometrías sustitutas de los ECDM.

\subsubsection{LAS CONDICIONES INTER-PIEZA.}

Además de las condiciones intra-pieza que se acaban de describir, y una vez más de acuerdo al modelo de cadena de ensamble de inspección presentado en el capítulo 6 (Figura 6.3), el otro tipo de condiciones de no contacto contempladas son las condiciones inter-pieza, que representan relaciones entre piezas diferentes pertenecientes al ensamble de inspección. Para representar estas condiciones, y diferenciarlas de las intra-pieza, se utilizará una línea discontinua. Esta línea discontinua tendrá en un extremo una punta de flecha que, del mismo modo que en el caso de las relaciones intra-pieza, permite indicar el sentido en el que se produce/mide la desviación.

Dentro de las condiciones inter-pieza se distinguirán tres tipos, que siguiendo una denominación similar a la utilizada en el capítulo 6 (Figura 6.3) serán: la condición de separación, la condición máquina y la condición de separación y máquina.

La condición de separación es la que se establece entre la pieza a medir y la sonda del equipo de inspección encargada de tomar los datos (interfaz de medida). Aunque existen muchos tipos de sonda como se ha indicado en la definición de recurso de inspección realizada en el capítulo 6, para este trabajo se tendrán en cuenta únicamente las sondas de contacto y, por lo tanto, el valor de la separación será cero. Para esta condición de separación se utiliza el tercer símbolo (3) de la Figura 7.2, que es una línea discontinua (por ser condición inter-pieza) con la punta de flecha rellena.

Por su parte, la condición máquina representa una de las características propias del equipo de medida, que es la relación de medida entre la sonda y la referencia local materializada utilizada para su medición. Es decir, representa la configuración de los ejes que forman la unidad base y permite relacionar la sonda con dicha configuración, lo que también establece los g.d.l. controlados por el equipo. El símbolo que representa esta condición es el cuarto (4) de la Figura 7.2 y se trata de una línea discontinua con la punta de flecha vacía. En este caso, estas relaciones inter-pieza siempre se establecerán entre una referencia local y la geometría sustituta de un ECDM.

Por último, en la representación de la cadena de inspección también se contempla una tercera relación, que se denominará condición de separación y máquina. Esta relación no forma parte del modelo de cadena de inspección expuesto en el capítulo 6 (Figura 6.3). 
Se trata de una agregación de las condiciones de separación y máquina que, durante el razonamiento realizado sobre la cadena, permite considerar de forma unitaria el conjunto de unidad base y sonda, cuando la información correspondiente al equipo de medida de la que se dispone es directamente la global desde la referencia local materializada del equipo a la pieza (sin conocer las desviaciones desagregadas que introduce la sonda). Para esta relación, cuyo símbolo es el quinto (5) de la Figura 7.2, también se utiliza una línea discontinua en este caso con una punta de doble flecha, una rellena y otra vacía, que representan la suma de las condiciones de separación y máquina.

\subsubsection{LAS CONDICIONES DE CONTACTO.}

Las condiciones de contacto son aquellas que representan los contactos físicos permanentes entre las piezas o elementos que forman el ensamble de inspección y la agregación de todas ellas define la arquitectura que caracteriza al ensamble de inspección, según lo explicado en el capítulo 6 (Figura 6.3).

De forma habitual, en las cadenas de inspección las condiciones de contacto que aparecerán serán las correspondientes al contacto de la pieza bien con geometrías del recurso de medición o bien con geometrías de los eventuales utillajes intermedios utilizados, que sitúan la pieza para realizar la medición (interfaz de situación).

Las condiciones de contacto se representarán con el último símbolo (6) que aparece en la Figura 7.2. Se trata de una línea triple continua y sin sentido, ya que en una condición de contacto la relación física entre las superficies se considera simétrica. Estas relaciones de contacto siempre se representarán entre geometrías sustitutas.

Cabe recordar, como ya se indicó en el capítulo 3, que estas relaciones de contacto deben ser especificadas por el planificador, pues van a introducir una incertidumbre cuyas contribuciones no están incluidas en el operador de verificación. Se trata de condiciones de contacto que, por ejemplo, determinan la alineación de la pieza sobre el equipo de medición.

\subsubsection{LOS OPERADORES.}

En la representación gráfica propuesta se pueden indicar las operaciones Geospelling necesarias que en su conjunto dan lugar al operador de verificación. Estas operaciones Geospelling se representarán siempre como unas etiquetas unidas a los nodos o a las relaciones entre los nodos del grafo. Etiquetas que incluirán la designación del tipo de operación dentro de un marco circular.

Al conjunto de operaciones incluidas en la relación entre el EC de geometría extraída y el EC de geometría sustituta de un ECDM, se le denominará operador de sustitución. Su representación gráfica se realiza mediante una flecha de doble trazo que relaciona la geometría extraída con la geometría sustituida, que se acompaña con las etiquetas correspondientes a las operaciones. Este operador permite, a partir de la geometría extraída obtenida durante el proceso de medición, obtener el elemento característico geométrico ideal imaginario o elemento sustituto que constituye una representación de la geometría extraída adecuada para llevar a cabo la verificación. La obtención del elemento sustituto se puede llevar a cabo utilizando diferentes procedimientos de ajuste, siendo los más habituales el de Gauss, el de Chebyschev o el de envolventes exteriores/interiores, tal y como se ha expuesto en el capítulo 5 (Figura 5.5).

Cuando las operaciones Geospelling involucradas en las relaciones permiten la creación de una referencia de especificación a partir de varios elementos sustitutos ideales pertenecientes a diferentes ECDM, se incluye un símbolo de agregación (diamante). Este símbolo, situado junto a la referencia de especificación, reúne las relaciones con cada una 
de los elementos sustitutos ideales que participan. Cada una de las relaciones reunidas, incluye las etiquetas correspondientes a las operaciones Geospelling implicadas. Esta situación se presenta siempre que una característica especificada utiliza una referencia (datum) múltiple, construida a partir de elementos sustitutos pertenecientes a diferentes ECDM (operador de creación de referencia de especificación).

La simbología relacionada con los operadores se muestra en la Figura 7.3.

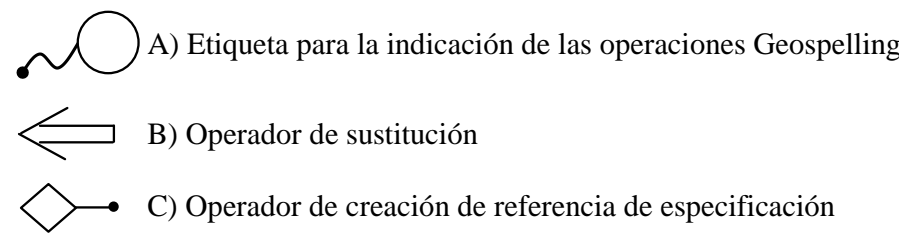

Figura 7.3 Símbolos relacionados con los operadores.

\subsection{REPRESENTACIÓN DE LA CADENA.}

Tal y como se ha indicado en la introducción, la propuesta de representación gráfica aquí descrita permite mostrar la cadena del ensamble de inspección con la finalidad de servir de ayuda al planificador durante los razonamientos que realiza en la Planificación Supervisora de la Inspección sobre dicha cadena. Antes de describir las etapas de la metodología para los razonamientos asociados a la construcción gráfica de la cadena del ensamble inspección y que constituye una parte del ejercicio de la especificación del plan de inspección, en el primer subapartado se va a explicar la estructura de la representación gráfica de una cadena, que implica la disposición de los elementos estructurales (nodos) y sus relaciones. A continuación, en el segundo subpapartado, se describirán diferentes tipos de cadenas, en función de unas combinaciones de nodos y relaciones, que agrupan a casos de ensambles de inspección que tienen algunas características en común.

\subsubsection{DISPOSICIÓN DE NODOS Y RELACIONES.}

La cadena del ensamble de inspección se representará utilizando relaciones (eslabones) que unen nodos hasta cerrar un bucle.

Los nodos a utilizar son los presentados en el subapartado 7.2.1 y se dispondrán organizados en dos columnas. La primera columna, a la izquierda, incluirá los nodos de la pieza a medir (ECDM, referencia de especificación) que están implicados en una característica especificada situados en disposición vertical. En la segunda columna, a la derecha, se dispondrán los nodos del equipo de medida (ECDM, referencia local materializada y sistema de coordenadas). Estos, a su vez, se agruparán en dos subcolumnas. Una primera subcolumna en la que se situarán los nodos correspondientes a la sonda y eventual utillaje (ECDM), y una segunda subcolumna con los nodos de la unidad base del equipo de medida vinculados a la referencia local materializada y al sistema de coordenadas. Esta subdivisión del equipo de medida en sonda, utillaje y unidad base coincide con la explicada en el modelo de ensamble de inspección propuesto en el capítulo 6 (Figura 6.8).

Los nodos se unirán entre ellos para cerrar el bucle utilizando los tipos de relaciones correspondientes de entre las explicadas en el subapartado 7.2.2. Cuando se trate de relaciones intra-pieza correspondientes a la condición de inspección asociada a la característica especificada, las líneas que representan las relaciones estarán situadas en la parte izquierda y tendrán una dirección principalmente vertical. Hay que recordar que estas 
relaciones intra-pieza se pueden establecer entre cualquier combinación de geometría extraída o sustituta de los ECDM.

Asociados a los nodos o a las relaciones entre ellos de esta parte izquierda de la cadena (primera columna), también formarán parte de la representación alguno de los símbolos relacionados con los operadores explicados en el subapartado 7.2.3. En concreto, el símbolo relacionado con la creación geométrica vinculada a los datum múltiples siempre aparecerá como elemento intermedio en las líneas que representan las relaciones entre los ECDM de los datums y el ECDM objeto de la especificación.

El resto de relaciones, tanto otro tipo de relaciones intra-pieza como las inter-pieza y las de contacto, unirán nodos que o bien pertenecen a elementos diferentes del ensamble de inspección (un nodo de la pieza con un nodo del equipo de medida, sea la sonda, el utillaje o la referencia local materializada) o bien pertenecen a partes diferentes del equipo de medida (por ejemplo, un nodo de la sonda con un nodo de la referencia local materializada). La dirección de las líneas que representan estas relaciones será principalmente horizontal.

\subsubsection{TIPOS DE CADENAS.}

Es posible identificar diferentes tipos de cadenas que agrupan a ensambles de inspección que comparten algunas características $\mathrm{y}$, por lo tanto, hacen uso de combinaciones similares de nodos y relaciones.

En primer lugar, considerando la parte izquierda de la cadena que representa la pieza a medir y la condición de inspección vinculada a la característica especificada, se pueden identificar tipos de cadenas en función del tipo de característica especificada y los modelos primitivos utilizados. La Figura 7.4, Figura 7.5 y Figura 7.6 ilustran tres ejemplos de representación de los nodos (ECDM) y relaciones intra-pieza (parte izquierda de la cadena) en los que hay una característica intrínseca, una característica de situación con datum único y una característica de situación con un datum múltiple respectivamente.
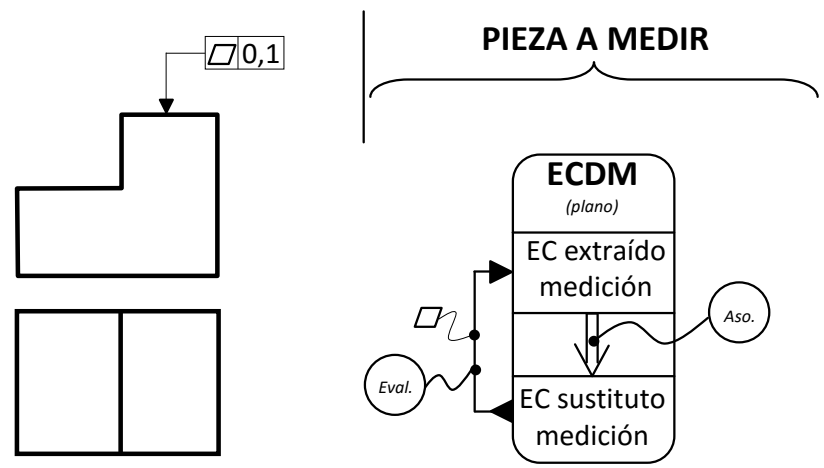

Figura 7.4 Ejemplo de nodos y relaciones de una pieza con característica intrínseca.

Aunque no es el objeto de este subapartado, se van a aprovechar estos ejemplos para recordar que, tal y como se ha mencionado anteriormente al describir las relaciones intrapieza vinculadas a las características especificadas, estas se pueden establecer entre cualquier combinación de geometrías extraídas y sustitutas. Así por ejemplo, y tal y como se puede observar, en el caso de la Figura 7.5 la relación intra-pieza correspondiente a la condición de inspección vinculada con la característica especificada se establece entre dos geometrías extraídas. Esto implica que el proceso de medición utilizado deberá dar la posibilidad de obtener modelos primitivos de tipo ideal que permitan esta verificación. En el ejemplo de la Figura 7.6, sin embargo, las relaciones intra-pieza se establecen entre geometrías sustitutas, lo que implica que el planificador ha partido de modelos primitivos 
de tipo discreto obtenidos en el proceso de medición a partir de los cuales ha obtenido unos modelos simplificados ideales que le permitan llevar a cabo la verificación.

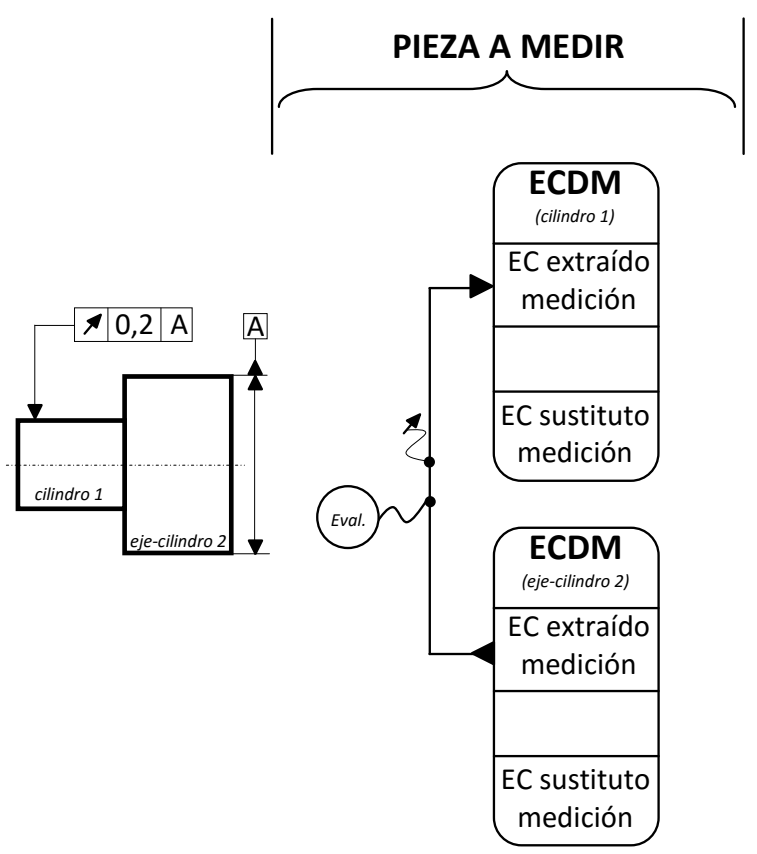

Figura 7.5 Ejemplo de nodos y relaciones de una pieza con una característica de situación con una única referencia (datum).

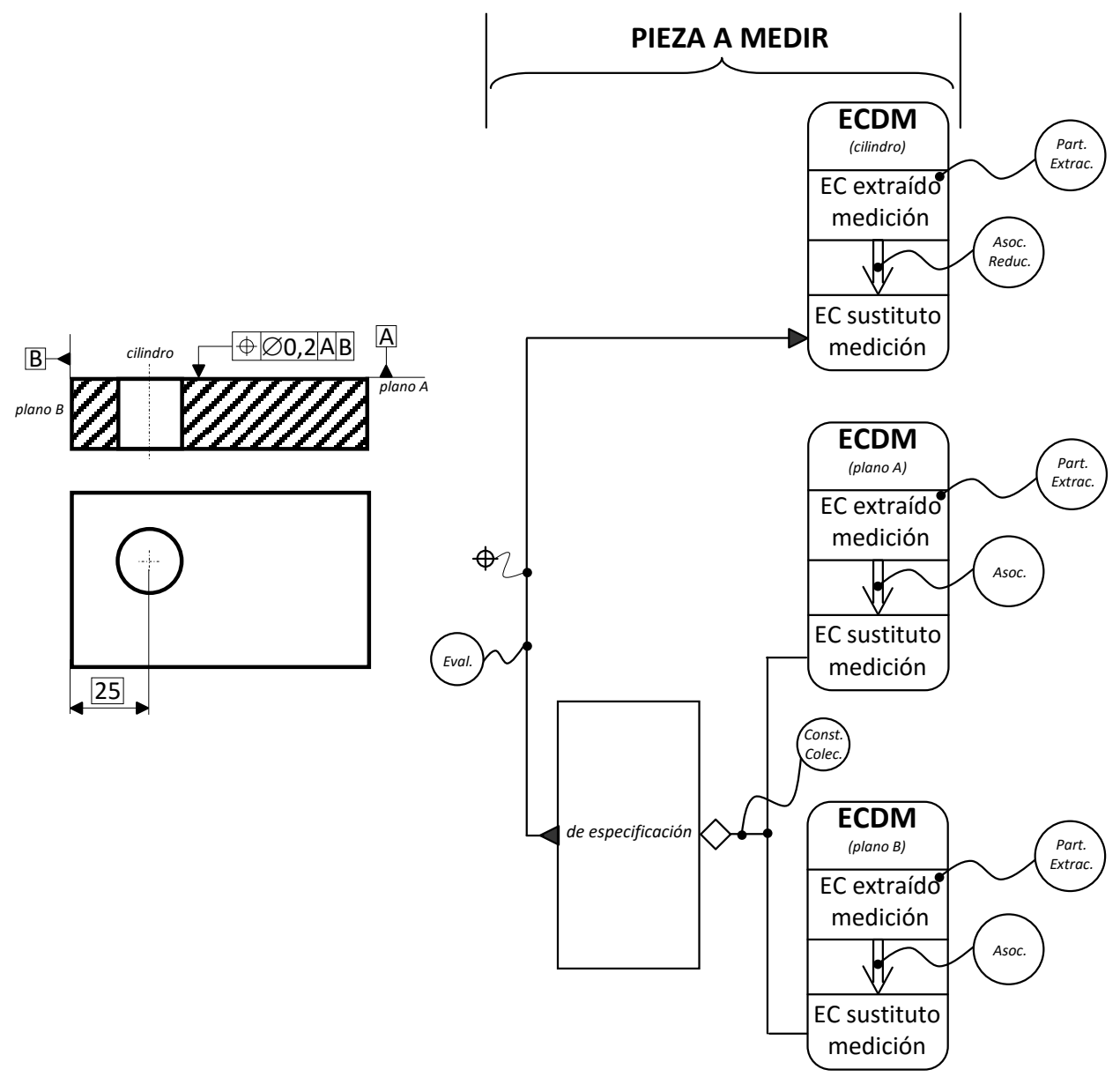

Figura 7.6 Ejemplo de nodos y relaciones de una pieza con una característica de situación con referencia (datum) múltiple. 
Si ahora se centra la atención en la parte derecha de la cadena, que incluye los nodos que representan el recurso de medida y sus relaciones con la pieza para cerrar el bucle, también se pueden identificar diferentes tipos de cadenas, de las que a continuación se presentan algunas de las más representativas y habituales.

La Figura 7.7 ilustra un ejemplo de representación de una cadena del ensamble de inspección que se cierra a través de dos relaciones de la sonda con los ECDM de la pieza a verificar. Tal y como se puede observar en la figura, la sonda se relaciona, mediante dos condiciones del tipo condición máquina, con dos referencias materializadas del tipo calculado, correspondientes a cada uno de los ECDM implicados en la cadena. Por su parte, las relaciones de la sonda con la pieza a medir son dos condiciones de tipo separación, en las que dado que se trata de sondas de contacto, el valor de la separación será cero.

También cabe hacer notar que, tal y como se aprecia en la Figura 7.7, la sonda al ser considerada un elemento diferenciado del resto del recurso de medición puede ser intercambiable. En el caso mostrado, se utilizan dos sondas, "sonda 1" y "sonda 2", representadas por sus correspondientes ECDM. Cada sonda tendrá unas características, de manera que el planificador puede representar varias alternativas y seleccionar aquella que, siendo válida, resulte más apropiada para cada condición de inspección.

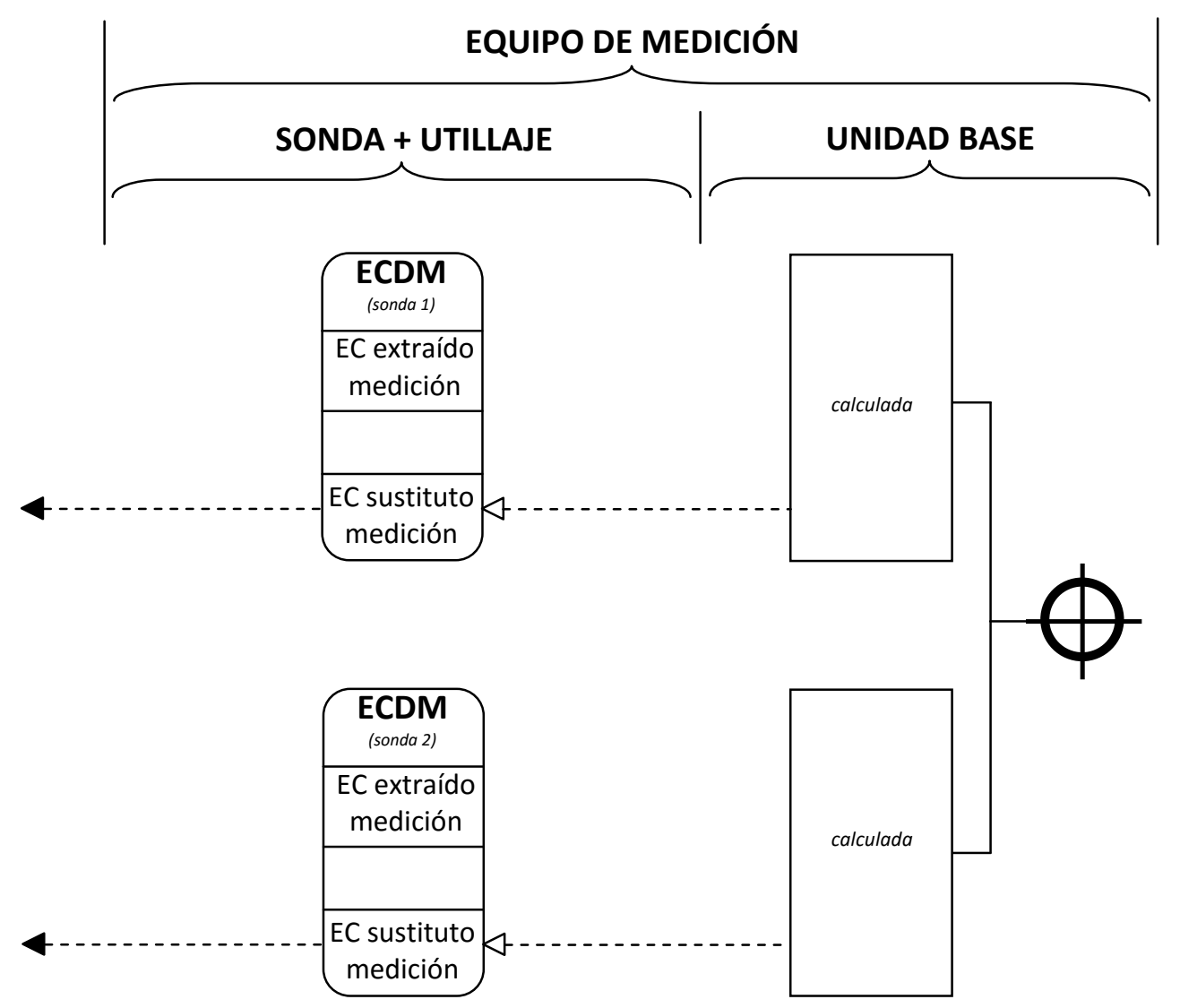

Figura 7.7 Ejemplo de nodos y relaciones de un equipo de inspección en el que no se utiliza utillaje.

En la Figura 7.8 se muestra un ejemplo de representación de una cadena del ensamble de inspección que se cierra con una relación de la sonda con un ECDM de la pieza y una condición de contacto entre un ECDM de la pieza y un utillaje de medición que a su vez se localiza sobre la referencia materializada de posicionamiento de la unidad base del equipo.

En este caso, y tal y como queda reflejado en la Figura 7.8, la relación de la sonda con la referencia materializada (cinemática en este caso) es, al igual que el caso anterior, 
una condición inter-pieza de tipo condición máquina. Y también, de la misma forma que en el caso anterior, la relación de la sonda con la pieza a medir es una condición de separación de valor cero. Pero, a diferencia del caso anterior, ahora interviene un utillaje con una relación de contacto con la referencia materializada (en este caso de posicionamiento) del equipo de medida y con una relación también de contacto con la pieza a medir.

Además, en el caso del utillaje utilizado se representa una relación de tipo condición intra-pieza entre dos superficies pertenecientes al mismo utillaje. Esta relación corresponde a una característica propia del utillaje que proporciona información sobre su nivel de precisión y cuyo valor se ha establecido mediante procesos de calibración previos.

Al igual que en el caso de la sonda, en la mayor parte de los equipos de medición el utillaje suele ser un elemento diferenciado e intercambiable. En función de las exigencias impuestas por la condición de inspección, el planificador puede seleccionar entre diferentes alternativas de posibles utillajes, que tendrán características diferentes, de entre los que se dispongan para el equipo de medición. Los utillajes, al igual que las sondas, introducen una incertidumbre (incertidumbre de los medios) que influye en la incertidumbre de la desviación medida.

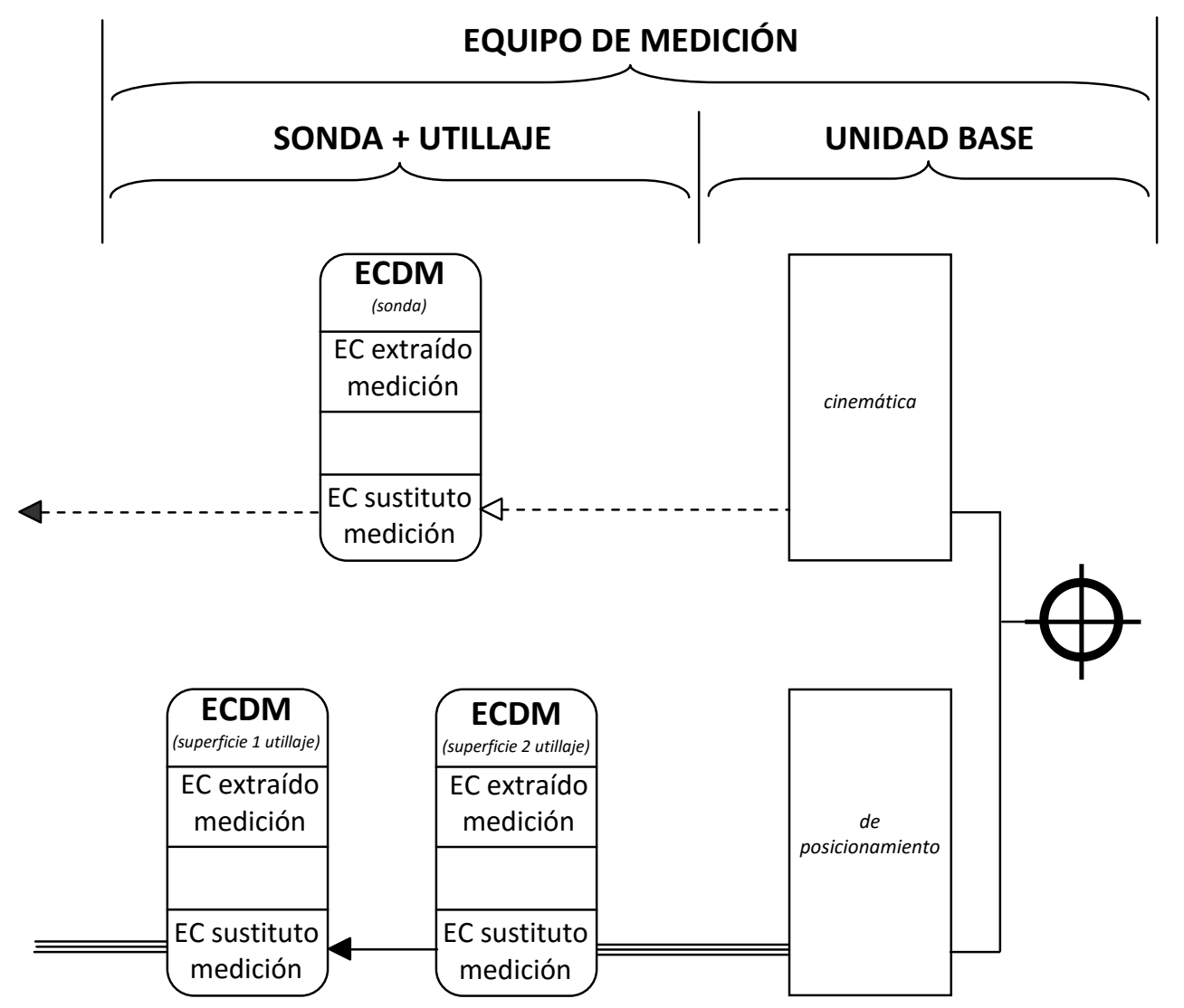

Figura 7.8 Ejemplo de nodos y relaciones de un equipo de inspección en el que se utiliza utillaje.

Por último, en la Figura 7.9 se muestra otro ejemplo habitual de representación de la cadena de inspección que se cierra a través de dos relaciones de la sonda, una con un ECDM de la pieza y otro con un ECDM del utillaje sobre el que se posiciona la pieza. Esta representación corresponde a las situaciones en las que se realiza una medición previa del utillaje de medición sobre el que se posiciona la pieza. En el caso mostrado en la figura, las dos relaciones de la sonda con los ECDM de la pieza y del utillaje se establecen con dos referencias calculadas. 


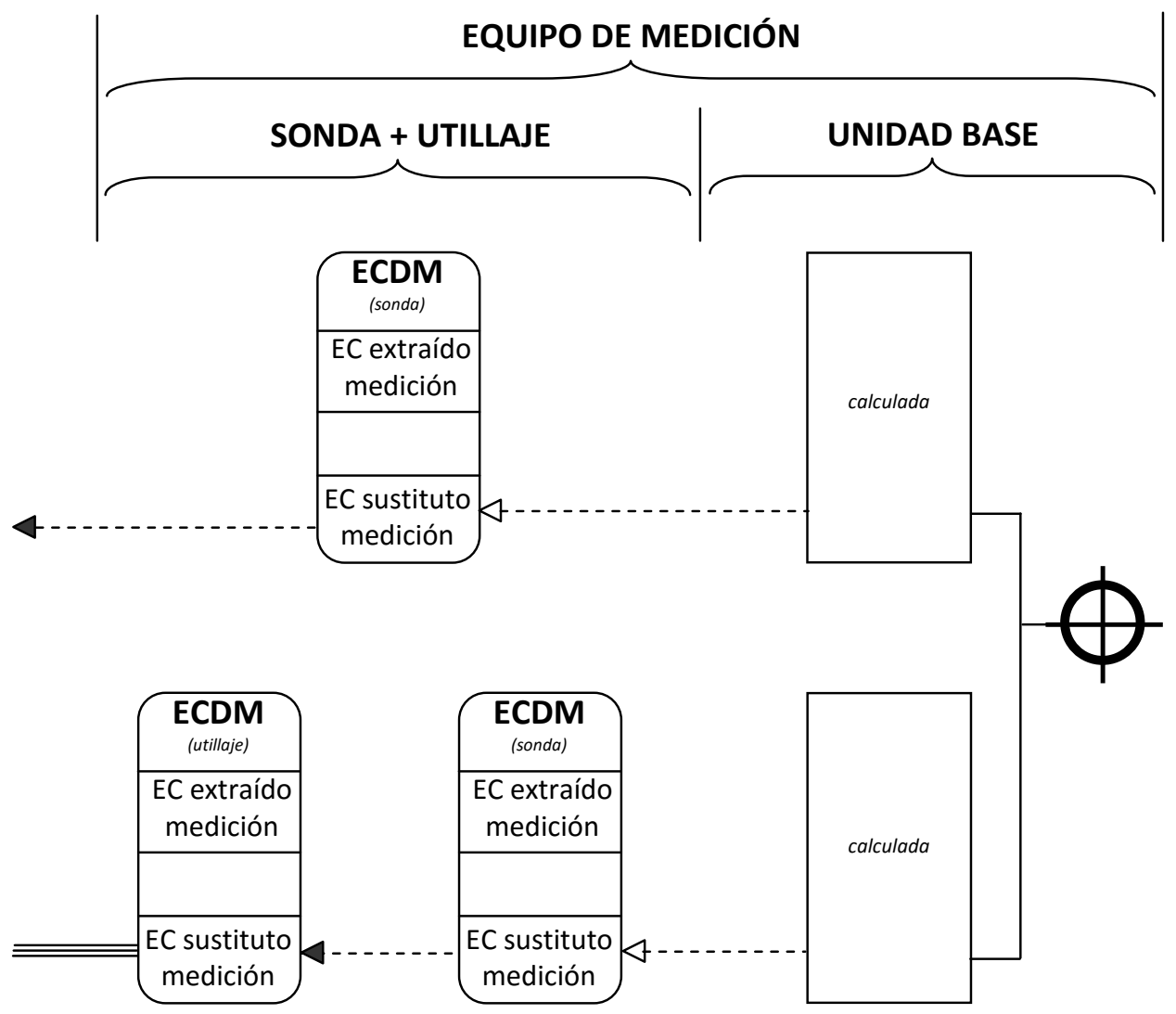

Figura 7.9 Ejemplo de nodos y relaciones de un equipo de inspección en el que se utiliza utillaje medido previamente en la misma subfase.

\subsection{METOdología.}

Tal y como se ha indicado al inicio del capítulo, y una vez descrita la sintaxis y semántica de la representación gráfica propuesta, en este apartado se va a describir una metodología para los razonamientos asociados a la construcción gráfica de la cadena de inspección y que constituye una parte del ejercicio de la especificación del plan de inspección.

La metodología consiste en cuatro etapas principales:

- Primera etapa: interpretar la pieza en base a ECI y representar los nodos y relaciones de la pieza correspondientes a una característica especificada.

Esto se plasma en a la parte izquierda del grafo, en la que se representa la pieza a medir. Será el resultado de la selección e instanciación por parte del planificador de unos ECI de la biblioteca que proporcionen unos modelos primitivos de medición válidos para las características especificadas a verificar. En general, el planificador dispondrá de varias alternativas posibles a la hora de seleccionar los ECI de entre todos los disponibles en la biblioteca que se ha expuesto en el capítulo 5. A la hora de seleccionar unas instancias concretas de ECI entre todas las posibles, el planificador considerará los elementos característicos utilizados en la especificación y, con el fin de reducir la incertidumbre, buscará aquellos que presenten la máxima dualidad posible. Los ECDM correspondientes a las instancias de ECI seleccionados se representan en la parte izquierda junto con las relaciones intra-pieza que representan las condiciones de inspección correspondientes a las características especificadas, con su información completa. Cabe recordar que estas relaciones podrán ser internas a un ECDM o entre ECDM 
diferentes y con cualquier tipo de combinación entre geometrías extraídas y sustitutas, tal y como ya se ha explicado en los apartados anteriores.

- Segunda etapa: seleccionar un tipo de proceso de medición tipo (PMT).

Una vez seleccionados y representados los ECDM de la pieza, se pasa a elaborar la parte derecha del grafo, que representa los elementos y relaciones del equipo de medición seleccionado. Para ello, primero hay que seleccionar un tipo de PMT de entre los posibles según las restricciones impuestas por los tipos de ECI seleccionados para interpretar la pieza a medir. Los tipos de PMT son los explicados en el capítulo 6 y cabe recordar que su clasificación está basada fundamentalmente en los g.d.l. que caracterizan los ejes del recurso de inspección, tanto para la toma de datos como para el barrido de la geometría a inspeccionar. Por ello, la primera restricción que el planificador considera a la hora de definir la parte derecha de la cadena hace referencia a la cadena de g.d.l., es decir, las necesidades de registro de parámetros. Cada tipo de ECI impone unas exigencias mínimas que restringe los tipos de PMT que pueden ser utilizados para la obtención de la geometría extraída.

- Tercera etapa: seleccionar el equipo de medida y representar los nodos y relaciones correspondientes a la sonda, eventual utillaje y unidad base.

Una vez seleccionado el tipo de PMT, ya se podrá iniciar la construcción de la parte derecha de la cadena con la selección del equipo de medición concreto que formará parte del ensamble de inspección. En general, existen varios posibles equipos de medición para un mismo tipo de PMT. Todos ellos cumplirán los requisitos correspondientes a la cadena de g.d.l., pero tendrán características diferentes, de entre las cuales son de especial importancia las referentes a las incertidumbres (incertidumbre de los medios). La distinción entre la sonda y el utillaje de la unidad base del recurso de medición permite considerar el hecho de que un equipo de medición tiene una única unidad base, pero puede disponer de varias sondas intercambiables y la pieza se puede posicionar sobre la unidad base utilizando diferentes tipos de utillajes. Las diferentes sondas y utillajes tendrán distintas características, ofreciendo diversas alternativas para el planificador. De entre todos los posibles equipos de medición, evidentemente la selección final del planificador deberá poder cerrar el bucle de manera que la restricción de incertidumbre máxima impuesta por la condición de inspección se cumpla.

- Cuarta etapa: validar la cadena.

Una vez representado el bucle cerrado de las cadenas del ensamble de inspección seleccionado por el planificador para verificar una condición de inspección vinculada a una característica especificada, ya se dispone de la cadena de verificación, que permitirá la validación de la solución en términos de incertidumbres. Los diferentes eslabones de la cadena introducen incertidumbres de diferente tipo: incertidumbre del contacto físico, incertidumbre de los medios y las debidas a las alineaciones, incertidumbre intrínseca al propio utillaje según la calidad del mismo, etc. Obviamente, si la solución buscada no cumple con las restricciones establecidas, el planificador debería contemplar otras soluciones, realizando los cambios oportunos. Estos cambios pueden afectar tanto al tipo de ECI seleccionado para la interpretación de la pieza como al recurso de medida completo o únicamente a alguno de sus elementos (sonda y/o utillaje). En el caso de que el planificador haya encontrado varias soluciones posibles, la selección final del equipo de medición se basará en criterios tales como el número de equipos diferentes a utilizar, el coste, el tiempo, las orientaciones diferentes de la pieza necesarias, etc. 
Cabe señalar que la metodología basada en grafos que se acaba de describir considera ensambles para la inspección tanto fuera de línea como en línea, post y en proceso. En este último caso, el ensamble sería el mismo para el proceso de mecanizado y el proceso de inspección (que compartirían una misma situación y fijación de la pieza), pudiéndose analizar de forma conjunta las cadenas vinculadas a las capacidades del proceso de fabricación y las vinculadas a las incertidumbres del proceso de inspección. El análisis conjunto del proceso de mecanizado y del proceso de inspección permitiría validar el plan de mecanizado o mejorarlo, si fuera necesario, mediante la incorporación de operaciones de inspección de la pieza o de los utillajes y herramientas para el mecanizado.

\subsection{EJEMPLOS DE APLICACIÓN.}

Con el fin de ilustrar la aplicación de la metodología basada en la representación de grafos propuesta y descrita en el apartado anterior, en este apartado se desarrollarán unos ejemplos de construcción y representación de cadenas de diferentes ensambles de inspección con el fin de ilustrar su uso.

\section{EJEMPLO 1}

Este Ejemplo 1 (Figura 7.10) corresponde a una pieza en la que se debe verificar una especificación de paralelismo entre dos superficies planas.

Para la inspección de esta pieza, y dentro de las alternativas posibles, el planificador decide utilizar, de los ECI contemplados en la biblioteca, dos ECI de tipo 38 Planoproyectado, uno para la superficie objeto de la especificación de paralelismo y otro para la superficie A, referencia (datum) de la especificación. Este tipo de ECI es compatible con los g.d.l. activos que se deben controlar y la información mínima requerida para la especificación de paralelismo. La información sobre la geometría extraída requerida por este tipo de ECI, y de acuerdo a la especificación que recae en él en este caso, se puede expresar mediante un modelo primitivo de los de tipo ideal con defectos dimensionales (tipo c) de los establecidos en el capítulo 3). Como las geometrías extraídas vienen representadas por modelos primitivos ideales, las geometrías sustitutas en este caso coinciden con ellas, correspondiendo por tanto la medida de la característica extraída con la medida de la característica especificada.
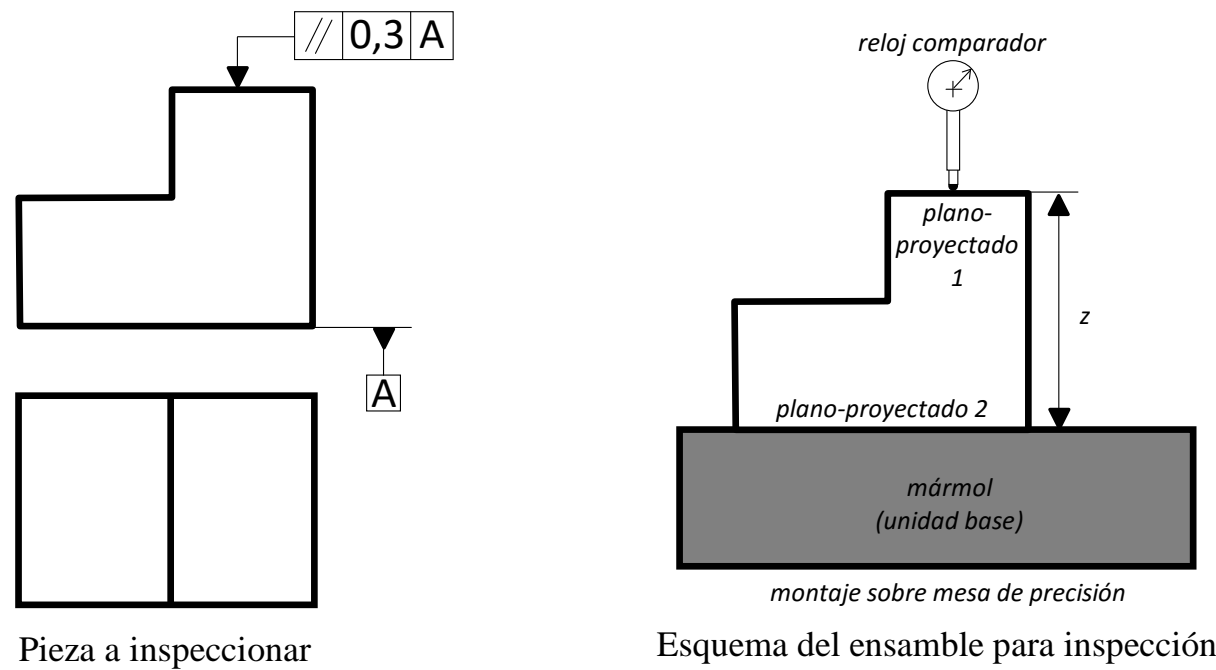

Esquema del ensamble para inspección

Figura 7.10 Ejemplo 1: Pieza a inspeccionar y esquema del ensamble de inspección seleccionado. 
De acuerdo a los tipos de ECI seleccionados, los tipos de PMT compatibles con los mismos son del tipo 6 (medición sobre plano) y 9 (medición en tres coordenadas). De ellos, en este caso el planificador selecciona el PMT de tipo 6. Para este tipo de PMT, y tal y como se ha explicado en el capítulo 6, los g.d.l. utilizados para la extracción son tres, aunque la información obtenida hace referencia solo a uno de ellos, que es el que proporcionará la información que corresponde a la medida de la característica de extracción y permite construir el modelo primitivo. Dos de los g.d.l. corresponden al sistema de desplazamiento o barrido y son dos guías rectilíneas no controladas perpendiculares entre sí (es decir, no proporcionan información). El otro g.d.l. corresponde al sistema sensor y debe ser de tipo variable. Las direcciones de los g.d.l. del sistema de desplazamiento y del sistema sensor no coinciden, debiendo ser la dirección de este último perpendicular a las de los primeros.

Una vez seleccionado el tipo de PMT, el planificador determina el equipo de medición concreto, que en este caso es un montaje sobre mesa de precisión y es el que se ilustra de forma esquemática en la parte derecha de la Figura 7.10.

La pieza se posiciona directamente sobre la unidad base del equipo de medida ( $\sin$ utilizar utillaje intermedio), que en este caso es una mesa de planitud, por ejemplo un mármol. El contacto físico entre la superficie A y la unidad base del equipo permite materializar la referencia local para el ECDM del ECI Plano-proyectado 2 mediante posicionamiento. Dado que no se presentan complicaciones, el planificador ha hecho corresponder la geometría de materialización de posicionamiento con la geometría de referencia (datum) utilizada en la especificación. Además, y con el fin de reducir las variaciones que se puedan producir en esta interfaz, el planificador ha debido adoptar algún requisito, como el de mínima inestabilidad, para realizar el posicionamiento. Mediante este contacto físico entre la pieza y la unidad base se genera el datum simulado, en este caso un plano ideal, que corresponde con la geometría sustituta del ECDM ECI Plano-proyectado 2 y que constituye la referencia para la medida de la característica especificada.

Para tomar la información sobre la superficie plana del ECDM del ECI Planoproyectado 1 se utilizará un reloj comparador con punta esférica. El reloj irá montado sobre un sistema de ejes que permitirá su movimiento según tres g.d.l. Dos de los g.d.1., según lo indicado anteriormente, corresponderán al barrido, serán rectilíneos, perpendiculares entre sí, paralelos a la superficie del mármol de la unidad base y no proporcionarán información (proyección global). El otro g.d.l. corresponderá al sistema sensor, será de tipo variable, perpendicular a los dos anteriores y proporcionará la información sobre la medida de la característica de extracción.

Situada la punta del reloj sobre un punto de la superficie objeto de la especificación de paralelismo, este se pondrá a cero. De esta manera la geometría de referencia para la medida quedará establecida como un plano ideal que pasa por ese punto, es paralelo a la superficie plana del mármol de la unidad base, está situado a una distancia $\mathrm{z}$ de la misma y se ha materializado cinemáticamente mediante los movimientos de los ejes de barrido.

La medida de la característica de extracción (que coincide con la característica especificada) en este caso será la distancia entre los puntos correspondientes a las desviaciones máximas positiva y negativa obtenidas por el reloj. Se trata, por lo tanto, de una medida de característica de extracción proyectada, al acumular la información obtenida sobre la variación total de la superficie respecto a una referencia mínima de tipo plano. El modelo primitivo que representa la geometría extraída en este caso es un conjunto de dos planos ideales paralelos al plano de referencia de medida, uno que pasa por el punto de máxima desviación positiva y otro que pasa por el punto de máxima desviación negativa.

El operador de verificación en este caso incluye una única operación, la de evaluación, que va asociada a la relación entre la geometría primitiva del ECDM del ECI 
Plano-proyectado 1 (puesto que el modelo primitivo utilizado es de tipo ideal) y la geometría sustituta del ECDM del ECI Plano-proyectado 1 obtenida mediante el contacto entre la pieza y la unidad base del equipo.

La Figura 7.11 ilustra el grafo de la cadena que representa el ensamble de inspección para la característica especificada de paralelismo que se acaba de describir. Según se puede observar, la sonda se relaciona mediante una condición de separación de valor cero (sonda de contacto) con el EC extraído del ECDM del ECI Plano-proyectado 1, y mediante una relación de tipo condición máquina con la referencia local materializada cinemáticamente de la unidad base del equipo. Por su parte, el EC sustituto del ECDM del ECI Planoproyectado 2 de la pieza tiene una relación de tipo condición de contacto con la referencia materializada de posicionamiento de la unidad base.

La condición de inspección vinculada a la característica especificada de paralelismo es la que permite cerrar la cadena en este caso. De acuerdo al tipo de ECI seleccionado y a los modelos primitivos utilizados, en este caso la relación se establece entre la geometría extraída y la sustituta de los dos ECDM implicados.

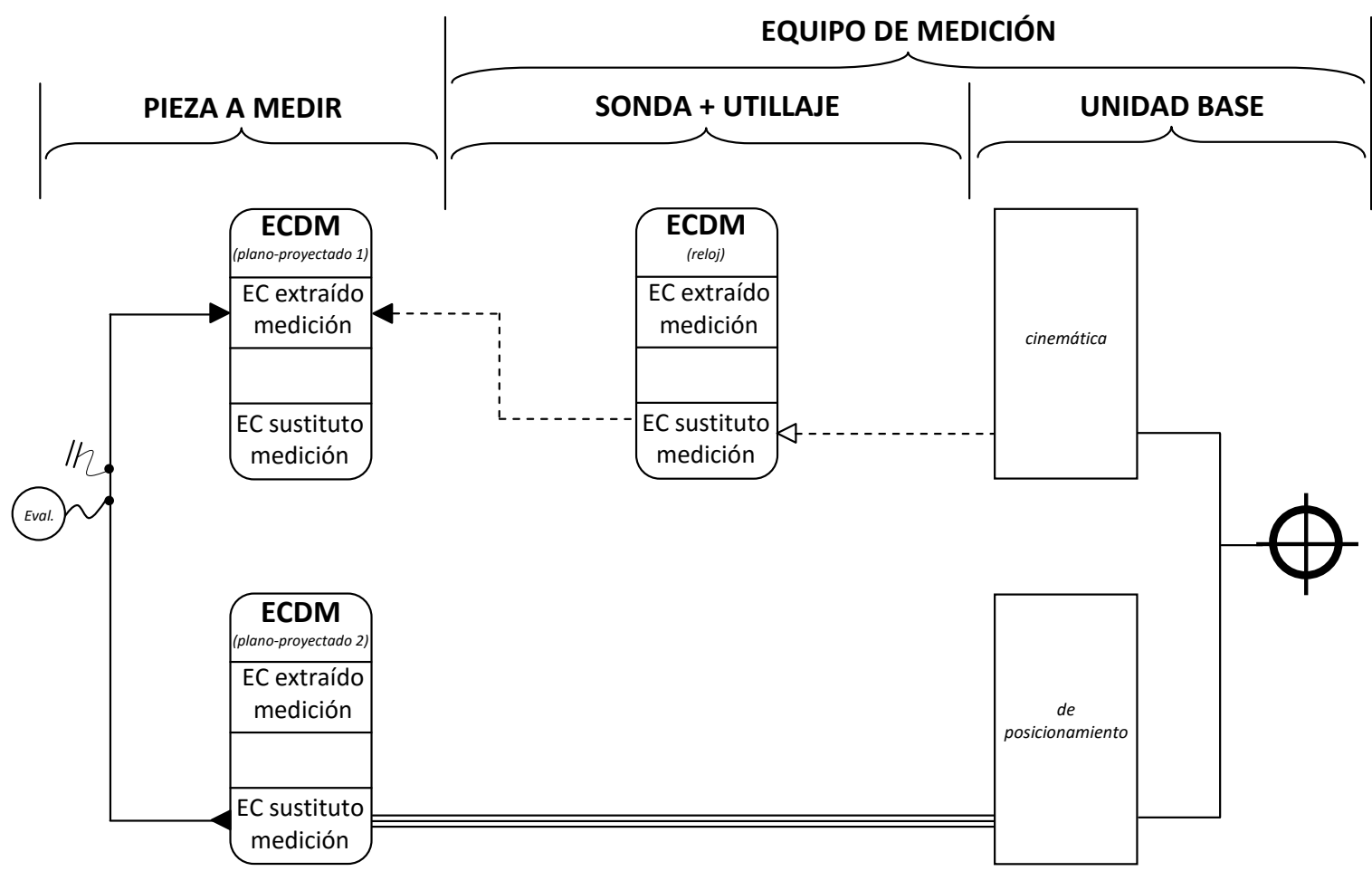

Figura 7.11 Esquema de la cadena del ensamble de inspección del Ejemplo 1.

En el grafo también se indican las operaciones Geospelling del operador de verificación, que en este caso es únicamente la de evaluación unida a la condición de inspección de la característica especificada.

Sobre la cadena, el planificador puede llevar a cabo la validación acumulando (en el sentido que marcan las flechas) las incertidumbres que se producen en cada eslabón y comprobando que el límite impuesto por la condición de inspección vinculada a la característica especificada no es superado. En caso de que la solución no se valide, el planificador deberá realizar cambios, pudiendo representar otras soluciones alternativas para su validación y comparación. Por ejemplo, el planificador podría representar otras alternativas encaminadas a reducir la incertidumbre como podrían ser la interpretación de la pieza utilizando un ECI de tipo 40 Plano, que proporciona la información completa de los planos implicados en la condición de inspección (reduciendo así la incertidumbre de método). 


\section{EJEMPLO 2}

La Figura 7.12 ilustra una pieza de la que hay que verificar una especificación de alabeo circular radial.

La forma de razonar y construir la cadena de inspección es similar al caso anterior. Los aspectos diferentes que se introducen en este ejemplo son el tipo de característica especificada, los modelos primitivos utilizados y el uso de utillaje para el posicionado de la pieza en la unidad base.

De entre las interpretaciones posibles de la pieza, el planificador decide hacerlo con un ECI de tipo 11 Cilindro-proyección_axial para la superficie cilíndrica objeto de la especificación de alabeo y un ECI de tipo 14 Eje-cilindro-proyectado para el eje A, referencia (datum) de la especificación. En ambos casos de trata de ECI en los que la geometría extraída corresponde a modelos primitivos de tipo ideal que permiten directamente la medida de la característica especificada al coincidir esta con la de extracción.

De acuerdo a los tipos de ECI seleccionados, los tipos de PMT compatibles con los mismos son del tipo 8 (medición respecto a eje) y 9 (medición en tres coordenadas), escogiendo en este caso el planificador el de tipo 8. Según lo explicado en el capítulo 6, este tipo de PMT hace uso de tres g.d.l. para la extracción. Dos de los g.d.l. corresponden al sistema de desplazamiento o barrido, siendo uno rectilíneo y el otro circular, y el otro al sistema sensor, que debe ser de tipo variable. Además de la información proporcionada por el g.d.l. del sistema sensor, el g.d.l. correspondiente al desplazamiento lineal también está controlado. El movimiento del sistema sensor es perpendicular al eje de giro del movimiento circular.

Tras la selección del PMT, el planificador puede proceder a elegir el equipo de medición concreto para realizar la inspección de la característica especificada, que en este caso corresponde a un montaje de eje de giro de precisión. Este ensamble es el que se representa de forma simplificada en la parte derecha de la Figura 7.12.

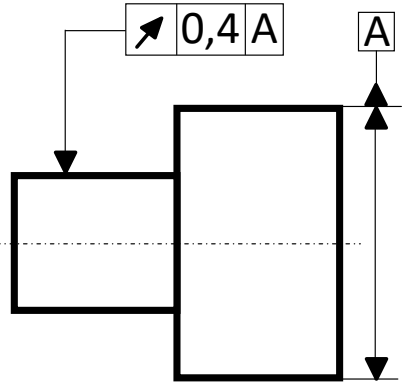

Pieza a inspeccionar

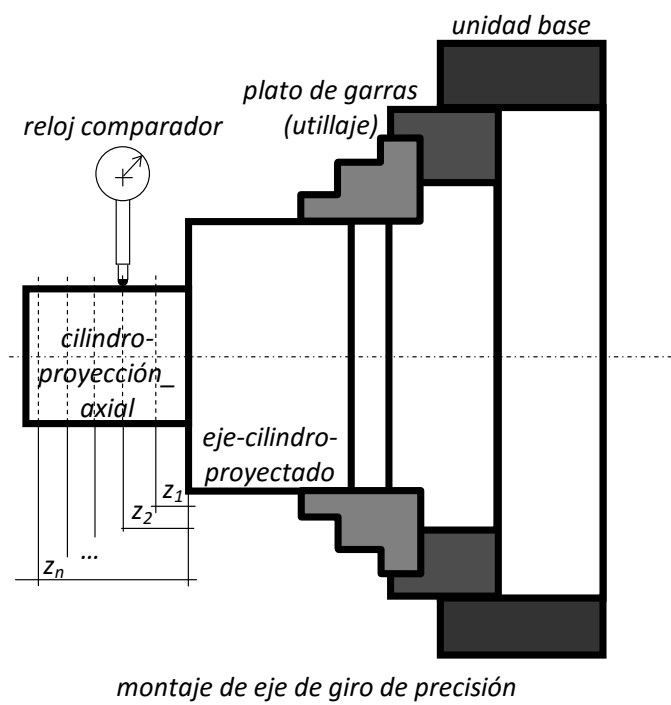

Esquema del ensamble para inspección

Figura 7.12 Ejemplo 2: Pieza a inspeccionar y esquema del ensamble de inspección seleccionado.

A diferencia del Ejemplo 1, en este caso se hace uso de un utillaje para situar y fijar la pieza sobre la unidad base del montaje de eje de giro de precisión. En particular, el planificador decide utilizar un plato de garras autocentrante montado sobre el husillo giratorio de la unidad base del equipo. El contacto físico de las garras con la superficie 
cilíndrica del ECDM del ECI Eje-cilindro-proyectado materializa la referencia local mediante posicionamiento y establecen el eje de referencia para la medición. Por lo tanto, la geometría sustituta del ECI Eje-cilindro-proyectado es un eje ideal que coincide con el eje del plato de garras (datum simulado). Al igual que en el Ejemplo 1 el planificador hace coincidir la geometría de referencia materializada de posicionamiento con la referencia (datum) de la característica especificada. En el establecimiento de esta referencia de posicionamiento será de especial importancia el proceso de alineación, con el fín de intentar hacer coincidir al máximo las geometrías reales de la pieza con los elementos de situación de las geometrías de la materialización de posicionamiento, y a los efectos de cumplir con el principio de requisito de mínima inestabilidad.

Sobre la superficie cilíndrica del ECDM del ECI Cilindro-proyección_axial se tomarán datos utilizando un reloj comparador de punta esférica. En este caso, el reloj irá montado en un soporte que permita su posicionamiento en distintos puntos de la superficie de la pieza y de los cuales se conoce su posición axial $\left(\mathrm{z}_{n}\right)$. El reloj dispondrá de un movimiento en la dirección radial perpendicular al eje de giro y que corresponde al g.d.l. del sistema sensor. El g.d.l. vinculado al giro alrededor del eje para llevar a cabo el barrido circular de la superficie cilíndrica lo realizará la pieza montada en el plato de garras. Sobre este g.d.1., y dado que se trata de un ECI Cilindro-proyección_axial y un PMT8, no se proporciona información.

Puesto que se trata de una característica de alabeo circular radial, el reloj tomará datos en secciones transversales al eje de giro del equipo de medición. La cantidad y posición a lo largo del eje de barrido rectilíneo de las secciones en las que se tomarán datos será establecido en el operador de verificación por el planificador, quedando reflejado mediante las operaciones de partición y extracción. Utilizando el contacto con un bloque de precisión de dimensión x, el reloj se pondrá a cero. A continuación, el reloj se situará en cada una de las secciones seleccionadas para la toma de datos y la pieza se hará girar según el eje de barrido circular, midiéndose las desviaciones máximas en la dirección radial positiva y negativa observadas.

En este caso, la referencia local se materializa cinemáticamente y corresponde a una circunferencia ideal contenida en un plano perpendicular al eje de giro del equipo, cuyo centro está sobre dicho eje de giro y con un diámetro x. La geometría extraída se representa mediante un modelo primitivo ideal que en este caso es un conjunto de dos circunferencias concéntricas correspondientes a las circunferencias de la sección analizada que ha dado como resultado las desviaciones máximas positiva y negativa. La diferencia de radio entre estas dos circunferencias es la medida de la característica de extracción, que en este caso también coincide con la característica especificada.

El grafo de la cadena del ensamble de inspección para la característica especificada es este ejemplo se muestra en la Figura 7.13.

Además de relaciones similares a las ya mostradas en el Ejemplo 1, en este ejemplo también aparece una relación de tipo condición intra-pieza correspondiente a la desviación que existe entre el ECDM de las garras y el del acoplamiento del plato a la unidad base. Esta relación lleva una incertidumbre asociada que caracteriza la calidad del propio utillaje y que influye en la incertidumbre de implementación. Asimismo, también aparece una incertidumbre asociada al error de alineación del plato de garras con la unidad base y que resultará en una inclinación (desviación angular) del eje de las garras con respecto al eje de giro de precisión de la unidad base.

Como ya se ha mencionado anteriormente, entre las operaciones Geospelling utilizadas en el operador de verificación en este caso, además de la de evaluación, conviene señalar que aparecen las operaciones de partición y extracción que establecen la forma en 
la que se toman los datos sobre la superficie cilíndrica del ECDM del ECI Cilindroproyectado_axial.

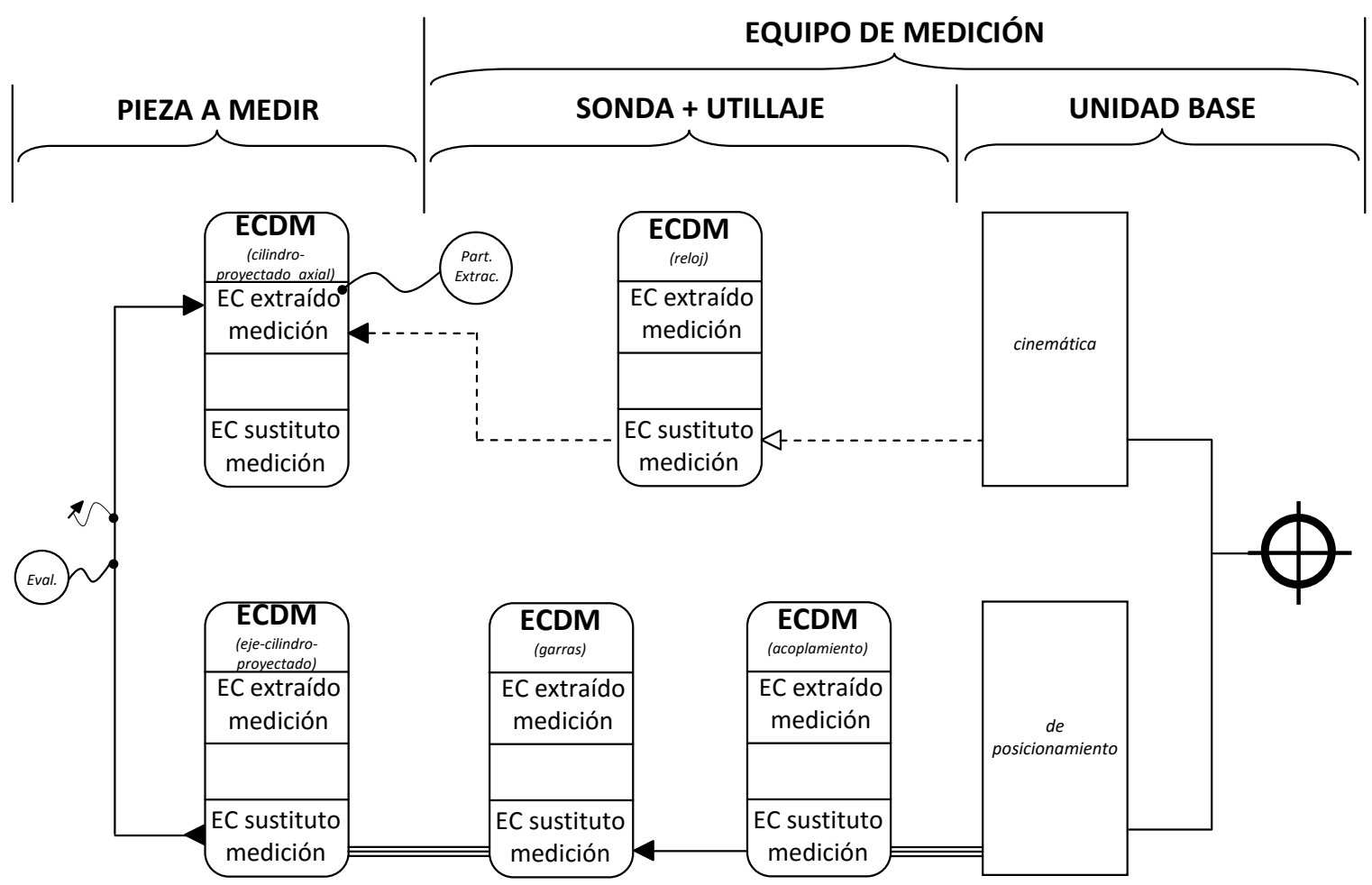

Figura 7.13 Esquema de la cadena del ensamble de inspección del Ejemplo 2.

$\mathrm{Al}$ igual que en el ejemplo anterior, sobre el grafo el planificador puede llevar a cabo la validación considerando todas las incertidumbres implicadas y comprobando que no se supera el límite impuesto por la condición de inspección vinculada a la característica especificada. En caso de que la solución propuesta no se valide, el planificador debe introducir cambios, encaminados a reducir la incertidumbre del método, la de implementación o ambas, y plantear alternativas.

\section{EJEMPLO 3}

La Figura 7.14 ilustra el último ejemplo, correspondiente a una pieza de la que hay que verificar una especificación de posición de un eje respecto a dos planos, además de las planitudes de los dos planos implicados en la especificación anterior.

Los razonamientos y consideraciones para la construcción de la cadena de inspección en este ejemplo son similares a los ejemplos anteriores. Las diferencias que se incorporan en este caso, además del tipo de característica especificada, son el uso de referencia local calculada y la representación de la geometría extraída mediante modelos primitivos de tipo discreto.

Para la inspección de esta pieza el planificador decide utilizar un ECI de tipo 13 Cilindro para el eje objeto de la especificación de posición y dos ECI de tipo 40 Plano para las superficies planas A y B, referencias (datum) de la especificación. En este caso, estos tipos de ECI representan la geometría extraída utilizando modelos discretos de piel (superficie) con defectos formados por puntos.

Para este tipo de ECI, el único PMT compatible es el de tipo 9 de medición en tres coordenadas. Este PMT utiliza tres g.d.l. controlados perpendiculares entre sí, obteniéndose la información de los tres para la extracción. 
El equipo de medición concreto elegido en este caso por el planificador es una MMC con sonda de contacto. La sonda va montada sobre los ejes de la máquina que tienen tres desplazamientos ortogonales entre sí y proporcionan la información en forma de tres coordenadas $(\mathrm{x}, \mathrm{y}, \mathrm{z})$ respecto a tres planos perpendiculares entre sí. La sonda realiza un desplazamiento de aproximación hasta que se detecta el contacto, momento en el que se toma el valor de las coordenadas.

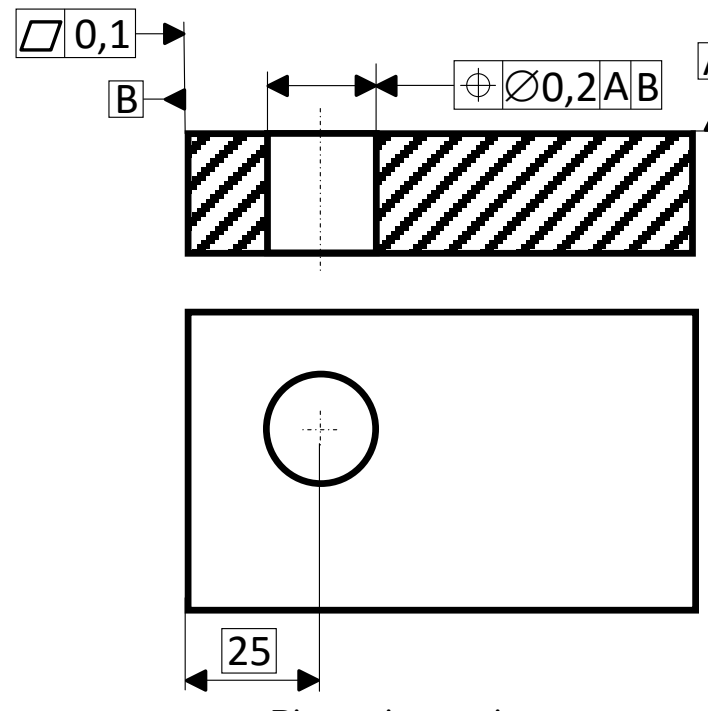

Pieza a inspeccionar
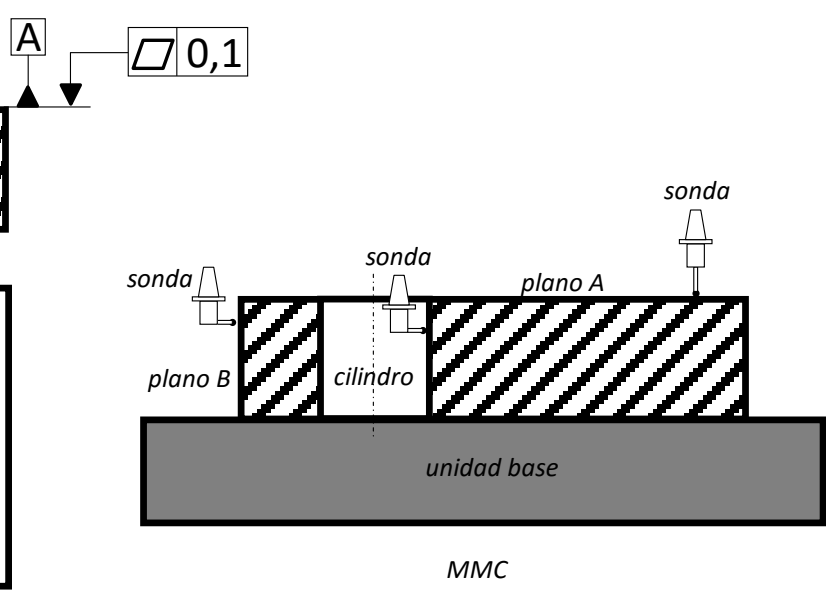

Esquema del montaje para inspección

Figura 7.14 Ejemplo 3: Pieza a inspeccionar y esquema del ensamble de inspección seleccionado.

En la parte derecha de la Figura 7.14 se muestra de forma simplificada el ensamble para la inspección de las características especificadas en este ejemplo.

La pieza se sitúa directamente sobre la unidad base de la MMC utilizando una superficie que no coincide con ninguna de las superficies correspondientes a la referencia (datum) de la característica especificada.

En este caso, la referencia local materializada en la MMC para realizar la extracción de los tres ECDM es de tipo calculada. Estas referencias calculadas se obtienen realizando una medición previa sobre las superficies de la pieza correspondientes a los ECI implicados en la especificación y determinan la dirección de aproximación de la sonda para la toma de datos durante el posterior proceso de extracción. Para el caso de ECI Cilindro la referencia local calculada es un cilindro ideal y para los ECI Plano A y B un plano ideal, resultado en los tres casos de una asociación mediante un método de ajuste a puntos tomados sobre las superficies de la pieza.

Utilizando la referencia calculada obtenida en la medición previa, la sonda tomará datos de puntos distribuidos sobre el plano A. El conjunto de dichos puntos constituye un modelo primitivo de tipo discreto que representa la geometría extraída y proporciona la información sobre la característica de extracción. El operador de verificación debe establecer las operaciones de partición y extracción que determinarán los límites de la geometría a extraer y dónde y cuántos puntos se tomarán. De forma similar ocurre con el plano B.

Como la geometría extraída para ambas superficies planas está representada mediante un modelo primitivo discreto, el planificador debe utilizar un modelo simplificado que represente a la geometría sustituta que le permita medir la característica especificada. La obtención de la geometría sustituta, dos planos ideales, se realiza a través del operador de sustitución, que en este caso incluye una operación de asociación 
siguiendo algún criterio de ajuste. Con esta información ya se puede realizar la verificación de la característica de planitud para cada uno de los dos planos.

La misma sonda se utilizará para tomar los puntos sobre la superficie cilíndrica del ECDM del ECI Cilindro. El modelo primitivo en este caso es también de tipo discreto, por lo que de nuevo se deberá utilizar el operador de sustitución para obtener la geometría sustituta. Además de la operación de asociación que proporcione las circunferencias ideales que mejor se ajusten a los puntos obtenidos según un criterio, también habrá que realizar una operación de reducción para obtener el eje derivado, que es sobre el que se encuentra especificada la característica de posición.

Dado que la característica especificada utiliza una referencia (datum) múltiple, en este caso también será necesario utilizar las operaciones de colección y construcción para la creación de la referencia de especificación que permita la medida de la característica especificada de posición.

La Figura 7.15 muestra el grafo para el ensamble de inspección de este ejemplo. Un grafo tiene como objetivo representar las cadenas establecidas sobre el ensamble de inspección utilizado para la verificación de unas características especificadas. Cada grafo representa, por tanto, una subfase, en la que con una misma situación y fijación de la pieza (mismo ensamble de inspección) se lleva a cabo la inspección de un conjunto de características especificadas. En este ejemplo, el mismo ensamble de inspección se utiliza para la verificación de una característica de posición y dos de planitud, mostrando el grafo de la Figura 7.15 los nodos, relaciones y operaciones de las tres cadenas correspondientes a dichas características.

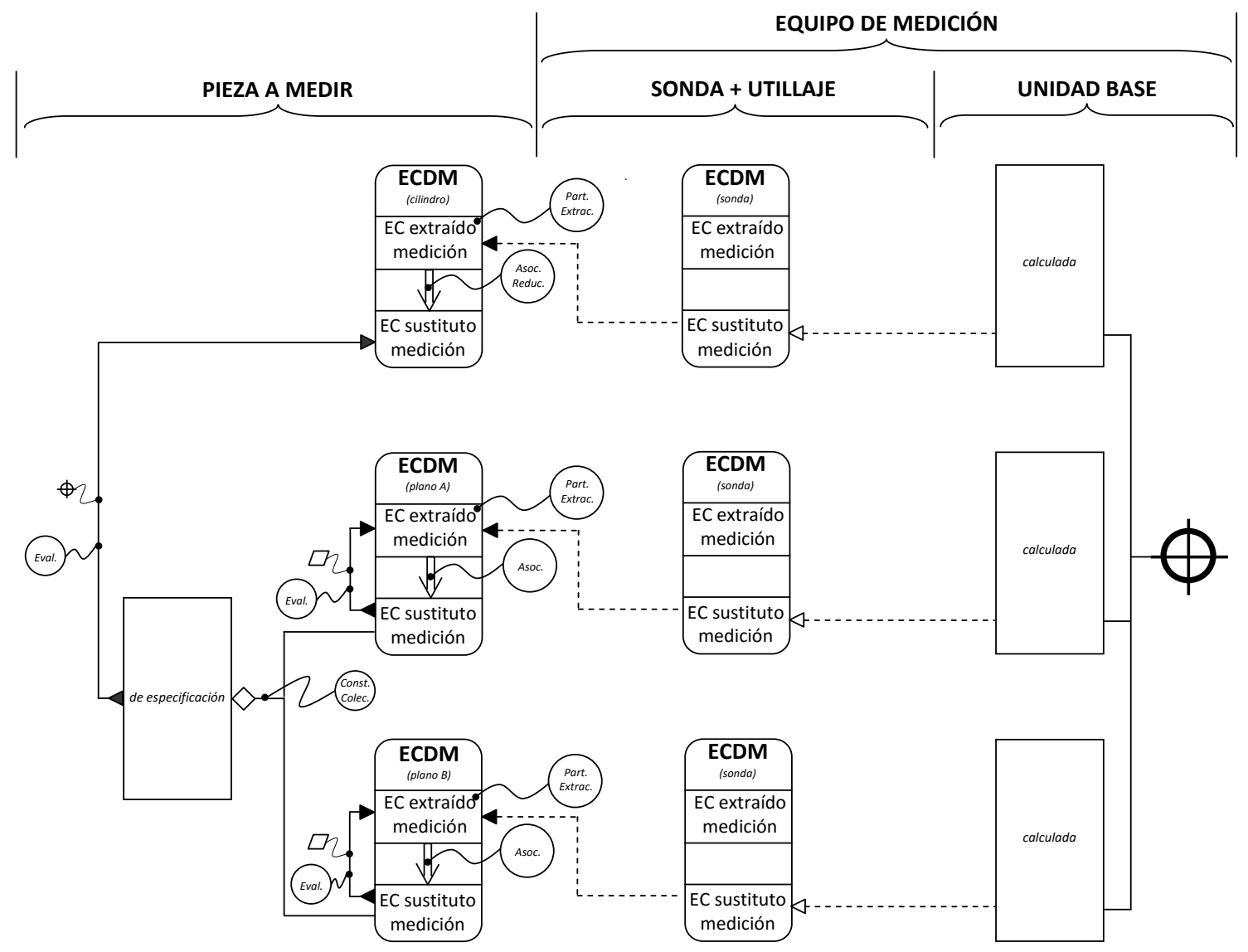

Figura 7.15 Esquema de la cadena del ensamble de inspección del Ejemplo 3.

Sobre el grafo el planificador puede llevar a cabo la última etapa de validación, de forma similar a lo indicado para los anteriores ejemplos, considerando todas las 
incertidumbres implicadas y comprobando que no se supera el límite impuesto. Si es necesario, el planificador planteará soluciones alternativas que permitan cumplir los requisitos. 



\section{Capítulo 8 \\ CONCLUSIONES Y TRABAJOS FUTUROS}

\subsection{CONCLUSIONES Y APORTACIONES.}

Aunque el alcance inicial de la tesis se limitaba a proponer un modelo de elemento característico para la planificación de la inspección en un nivel supervisor, como uno de los objetivos fundamentales de la investigación era que el mismo se adecuara a los requisitos impuestos por el proceso $\mathrm{CIDP}^{2} \mathrm{R}$ (Collaborative and Integrated Development of Product, Process and Resource / Desarrollo Colaborativo e Integrado de Producto, Proceso y Recurso), en el decurso del trabajo se planteó la necesidad de explorar tres direcciones de trabajo, con el objetivo de asegurar que: a) el proceso de planificación de la inspección y el de planificación del mecanizado se pueden realizar en base a un modelo funcional común; b) los modelos geométricos de ensamble utilizados en las especificación del producto también pueden servir para soportar los razonamientos de de la verificación, permitiendo expresar los requisitos de las medidas (especificación de la verificación); c) el desarrollo de un modelo de producto basado en elementos característicos (EC) de inspección y el propio modelo de EC de inspección pueden derivar de sendos modelos genéricos. Para ello, en los capítulos 2, 3 y 4 se revisaron los antecedentes de toda una serie de conceptos, metodologías y técnicas relacionadas con estas disciplinas, estableciendo las bases de las propuestas detalladas en los capítulos 5, 6 y 7.

El resultado del trabajo realizado se puede resumir en toda una serie de aportaciones organizadas en tres grupos. En el primer grupo se encuentran aquellas que justifican y/o sustentan los modelos conceptuales propuestos, mientras que los grupos segundo y tercero reúnen las vinculadas con los propios modelos conceptuales, genéricos y específicos, propuestos. A su vez, las aportaciones relativas a los modelos específicos se dividirán en dos subgrupos correspondientes, por un lado, a aquellos modelos específicos del ámbito de la inspección y de la especificación del plan de inspección (EC de inspección y ensamble de inspección) y, por otro lado, a los modelos específicos derivados de buscar la dualidad de estas propuestas con la especificación funcional del producto (EC de especificación y ensamble de producto).

En los capítulos 2 y 3, como resultado del estudio del marco general establecido para el proceso $\mathrm{CIDP}^{2} \mathrm{R}$ en el proyecto "La planificación de procesos como elemento 
vertebrador de la concurrencia y la integración en redes de ingeniería y fabricación distribuida", en particular de todo aquello referente al sistema Co-CAPP (Collaborative Process Planning / Planificación de Procesos Colaborativa), y de la revisión de algunos de los principales aspectos de la especificación y análisis funcional del producto, en particular lo relacionado con los modelos de representación de la geometría del ensamble producto y las técnicas y herramientas de toleranciado, se presentan unos modelos y esquemas conceptuales que pueden considerarse como aportaciones concretas, y que van más allá de lo que es un estudio del arte. Entre estas se pueden mencionar:

- La definición de un modelo funcional, utilizando la técnica IDEF0 (Integrated DEFinition for function modeling / Definición Integrada para modelado de funciones), de la planificación supervisora de procesos de fabricación e inspección en el contexto del proceso $\mathrm{CIDP}^{2} \mathrm{R}$. Un modelo que permite justificar que es posible abordar una co-planificación del mecanizado y de la inspección en la que, y fomentado el uso de la inspección en línea (en y post proceso), las actividades de ambos ámbitos se llevan a cabo de una manera dual e integrada. Este modelo, además, permite identificar algunas de las principales necesidades de información del producto requeridas para dar sustento a las diferentes actividades del proceso $\mathrm{CIDP}^{2} \mathrm{R}$ y, en concreto, a la información vinculada a las tareas de especificación de los planes de proceso en la etapa de Planificación de los Procesos a nivel supervisor y su relación con las de especificación funcional del producto en la etapa de Desarrollo de la Ingeniería a nivel agregado.

- El establecimiento de un planteamiento para el tratamiento de la especificación desde el punto de vista de la verificación de manera unificada a la especificación y análisis funcional del producto que contribuye a garantizar el cumplimiento de la intención de diseño. Un planteamiento que permite justificar que el modelado basado en ensambles, las representaciones de la geometría primitiva con defectos y las técnicas y herramientas de toleranciado que habitualmente se utilizan para dar soporte a los ejercicios de la especificación y análisis funcional del producto, son aplicables a los ejercicios de la verificación en los que se especifica el plan de inspección basado en razonamientos realizados sobre un ensamble de inspección.

En lo que respecta al capítulo 4, cabe mencionar que el estudio de los antecedentes sobre modelado semántico basado en EC de sistemas, productos mecánicos (ensambles), sistemas embebidos y sistemas software, ha permitido corroborar la idoneidad de este tipo de modelado para soportar la actividad de planificación de la inspección. Asimismo, y con el fin de garantizar la consistencia entre los diversos EC utilizados desde cada punto de vista, se concluye que es necesario el desarrollo de un meta-modelo de EC que proporcione una estructura y semántica unificada, y que considere algunas de las principales propuestas existentes en diferentes ámbitos, como son la de Ma y sus colaboradores para sistemas mecánicos, la de Riebisch para sistemas software y la de Zha y Sriram para sistemas embebidos. Además, la revisión de las propuestas de algunos modelos genéricos de producto existentes en la literatura y de los conceptos, entidades y relaciones utilizadas en ellos permiten concluir que es oportuno integrar el meta-modelo de EC en un modelo de producto genérico y que el modelo de producto de PPO (Product-Process-Organization / Producto-Proceso-Organización) es el adecuado, por ser un modelo sencillo que da respuesta a las necesidades impuestas por los entornos colaborativos.

Teniendo en cuenta los antecedentes y aportaciones mostradas en estos capítulos iniciales, en los capítulos 5 y 6 se han propuesto varios modelos conceptuales relativos al producto, visto como un ensamble de componentes representados mediante EC. Se trata de unos modelos semánticos conceptuales descritos con notación UML (Unified Modeling Language / Lenguaje de Modelado Unificado), en concreto con el lenguaje de modelado 
estructural estático de UML (Diagramas de Clases UML). Una notación que, utilizada en los niveles superiores (modelado conceptual), solo expresa las entidades participantes (clases) y sus relaciones estructurales y semánticas. En concreto, los modelos genéricos propuestos son:

- Un Meta-Modelo de Elemento Característico que proporciona una estructura y semántica unificada para definir EC de aplicación, propios de un determinado dominio, garantizando la consistencia entre ellos. Las principales características del meta-modelo son: a) se dota al EC de aplicación de semántica al definirlo a través de asociaciones restringidas y como un elemento de tipo contenedor de otros EC (estructura, interfaz, condición y parámetro); b) se garantiza la consistencia entre EC al considerar las asociaciones restringidas entre EC de diferentes modelos de dominio; c) los tipos de EC que contiene un EC de aplicación coinciden con las entidades básicas del modelo PPO, componente (información estructural sobre el ensamble en el que participa la pieza), interfaz (información sobre la geometría de la pieza que interacciona con las interfaces de otros elementos) y función (que incluye tanto las funciones como las condiciones o requisitos geométricos que la concretan). Esto proporciona al meta-modelo la naturaleza colaborativa de PPO, en el que el modelo de producto se integra con el de proceso y de organización, y donde las entidades se descomponen según un punto de vista concreto con los atributos propios del dominio de la etapa de desarrollo en la que se encuentre.

- Un modelo de Elemento Característico de Especificación (ECE) que permite garantizar la dualidad y consistencia entre los ejercicios de especificación llevados a cabo sobre cualquier ensamble, bien de producto o de proceso. Con el fin de contribuir a mantener la integridad de la función del producto en la especificación, el modelo propuesto representa y trata la información geométrica del producto de manera armonizada y unificada. Además, el modelo de ECE incorpora la representación de la geometría con defectos, imprescindible para los ejercicios de simulación propios de los procesos del ámbito de aplicación de la especificación.

- Un modelo de Cadena de Ensamble (CE) válido tanto para el ejercicio de la especificación geométrica del ensamble de producto, visto como el que debe respetar los requisitos impuestos por los procesos de ensamblaje y los requisitos de uso, como para la especificación de los diferentes ensambles de proceso (mecanizado, inspección, montaje, etc.), de los que también formará parte la pieza en la etapa de fabricación de su ciclo de vida. Este modelo se caracteriza por: considerar la arquitectura del ensamble (de producto o de proceso), definida como el conjunto de las relaciones de contacto entre los elementos que forman parte de dicho ensamble; definir las cadenas como el conjunto de todas las condiciones que permiten establecer los sistemas de ecuaciones para realizar los ejercicios de análisis y especificación geométrica (de producto o del plan de proceso).

Entre las propuestas vinculadas a la especificación de la inspección, se pueden citar las siguientes:

- Un modelo de Elemento Característico de Inspección (ECI) que permite representar la información sobre la geometría extraída del proceso de medición utilizando modelos primitivos de diferentes tipos: superficies/perfiles continuas, superficies ideales con defectos dimensionales, superficies ideales con defectos angulares y elementos ideales con defectos derivados de los anteriores. El hecho de que en el modelo se puedan representar varios tipos de geometrías, proporciona la posibilidad de realizar razonamientos sobre geometrías con defectos, tanto de piel (superficie) como de esqueleto. Además, la extensión de las tipologías de 
estos modelos primitivos permite contemplar de una forma unificada tanto los procesos de medida (extracción física) basados en MMC (Máquina de Medida por Coordenadas) como los no basados en MMC. Asimismo, la propuesta permite expresar tanto las medidas de las características extraídas como las medidas de las características especificadas en lenguaje Geospelling y, adicionalmente, en las del segundo tipo, según los estándares GD\&T (Geometric Dimensioning and Tolerancing / Dimensionado y Toleranciado Geométrico).

- Una biblioteca de ECI que amplia el desarrollo de la propuesta del modelo de ECI y que contiene 49 tipos diferentes. Las tipologías establecidas permiten considerar aspectos relevantes para los razonamientos de la planificación supervisora de la inspección: las formas en las que la geometría del ECI interacciona con los procesos de medida; el nivel de calidad de la información obtenida en la medición (tamaño, proyección global u orientada, o coordenadas); si se obtiene información de las superficies integrales o de los elementos derivados; los tipos de parámetros geométricos que deben ser capturados en los procesos de extracción, como mínimo, para poder caracterizar el tipo de ECI; y la referencia mínima necesaria (completa o incompleta). Por otro lado, el tipo de ECI también determina los tipos de datos e información, referentes a la geometría con defectos, que son necesarios y relevantes para la verificación de las especificaciones dimensionales y geométricas, considerándose los aspectos vinculados a la geometría sustituta y a las construcciones geométricas que se pueden realizar para realizar la verificación.

- Un modelo de Cadena de Ensamble de Inspección (CEI) que integra el ECI con otros conceptos necesarios para los razonamientos del ejercicio de la especificación del plan de inspección: la arquitectura de especificación de inspección, que determina los contactos entre los elementos (pieza y equipo de medida) que forman el ensamble de inspección; la cadena de inspección, que representa los bucles funcionales vinculados a la inspección de una característica como agregación de condiciones de inspección, incluidas las de no contacto vinculadas a las relaciones de la pieza a medir con la sonda o a las características del equipo. Además, el modelo de CEI contempla tanto la cadena referente a los grados de libertad que caracterizan el ensamble de inspección como la vinculada a las incertidumbres. El modelo de CEI se complementa con un modelo de Ensamble de Inspección (EI), que concreta la definición del ensamble de inspección considerando la pieza a medir y el recurso de inspección utilizado.

- La definición de un conjunto de Procesos de Medición Tipo (PMT) que permite recoger de una forma general las diferentes tipologías de instrumentos, equipos y montajes de medición que pueden ser seleccionados como recurso en el proceso de medida. La clasificación de PMT, compuesta por nueve grupos, se basa en tres criterios: el número de ejes utilizado por el equipo de medición, los ejes con sensor de tipo variable y los ejes de barrido. Esta clasificación de los recursos de medida permite incluir cualquier proceso de medida, desde los instrumentos metrológicos de taller más sencillos hasta máquinas universales de medida por coordenadas con mayores prestaciones, pasando por montajes y equipos de diseño específico.

- Una metodología, basada en una representación gráfica de las cadenas de inspección, que da soporte a los razonamientos realizados en la planificación de la inspección, tanto en la búsqueda de soluciones para el recurso de medida como en la validación de las mismas. La notación gráfica propuesta utiliza, por un lado, nodos que representan: la interfaz geométrica de la pieza y la de la sonda y el utillaje del equipo de medida; la referencia materializada y el sistema de 
coordenadas de la unidad base del equipo de medida. Por otro lado, también se representan las relaciones de contacto y de no contacto que permiten cerrar la condición de medida (bucle de la cadena). Las etapas de la metodología para la construcción de la cadena contempla los siguientes aspectos: interpretar la pieza en base a ECI de la biblioteca; establecer la condición de inspección, la especificación a verificar; valorar la cadena de grados de libertad que lleva a la selección de un PMT de entre los posibles; valorar la cadena de incertidumbres que lleva a la selección de un equipo de medida concreto de entre los posibles; validar la solución y, si es necesario, plantear y valorar alternativas.

Finalmente, con el objetivo corroborar la hipótesis de que en base al modelo de producto basado en ECE (modelo CE) y el propio modelo de ECE se podrían construir modelos específicos para la especificación del ensamble producto, duales a los de ECI y de CEI, se han propuesto:

- Un modelo de Elemento Característico de Especificación de Producto (ECEP) para el ejercicio de la simulación en el ámbito de la especificación funcional de producto. La propuesta es válida para diferentes geometrías con defectos, tanto de piel (superficie) como de esqueleto. Asimismo, el modelo de ECEP contempla los tres tipos de características que se pueden definir en lenguaje Geospelling, situación, forma y tamaño, pudiéndose también expresar las mismas utilizando los estándares GD\&T.

- Un modelo de Cadena de Ensamble de Especificación de Producto (CEP), que de forma similar el modelo de CEI, integra el ECEP con la arquitectura de especificación de producto, que determina los contactos entre las piezas que forman el producto, y la cadena de especificación, que representa los bucles funcionales como agregación de condiciones de especificación de producto. Asimismo, las condiciones de especificación se definen como agregaciones de características de forma, situación y tamaño según el lenguaje Geospelling, siendo por tanto el modelo compatible con este lenguaje así como con los estándares GD\&T.

\subsection{TRABAJOS FUTUROS.}

Una vez resumidas las principales conclusiones y aportaciones realizadas en este trabajo, a continuación se indican algunos aspectos que podrían ser objeto o bien de futuros trabajos que completarán los resultados de esta tesis o bien de nuevos proyectos o líneas de investigación:

- Establecer los modelos lógicos UML (métodos, restricciones, etc.) correspondientes a los modelos conceptuales UML desarrollados para el dominio de la inspección. Con estos modelos se facilitaría el desarrollo de aplicaciones para la planificación colaborativa de procesos de inspección, que implementaran algunos de los métodos y razonamientos expresados a lo largo de la tesis.

- Aumentar la clasificación de los Procesos de Medición Tipo para considerar mayor variedad de equipos de medida, como por ejemplo: equipos con sondas donde el estímulo físico para el registro sea de tipo radiante, térmico, eléctrico, magnético, químico u otro; equipos que recojan información sobre elementos medidos de tipo segmento (4 grados de libertad) o tesela (6 grados de libertad); o equipos que posean ejes redundantes, destinados a mejorar la flexibilidad y accesibilidad de estos recursos.

- Desarrollar un modelo conceptual UML del grafo genérico que daría soporte a los modelos de cadenas de ensamble para la especificación (de producto y de 
proceso), definiendo las clases que representen los diferentes elementos participantes así como los tipos de relaciones entre ellos. Modelos que se concretarían para el ámbito de la especificación del plan de inspección representando cadenas de ensamble de inspección en la forma propuesta en el Capítulo 7.

- Desarrollar el Modelo de Cadena de Ensamble de Inspección para las condiciones de montabilidad. Esto permitiría corroborar la utilidad de los modelos para soportar el diseño de calibres funcionales o virtuales.

- Adecuar las propuestas desarrolladas en este trabajo para al ámbito del mecanizado, estableciendo un modelo de elemento característico de mecanizado, como subtipo del elemento característico de especificación, y un modelo de cadena de ensamble de mecanizado, como subtipo de cadena de ensamble de especificación, que permitan realizar los ejercicios y razonamientos propios que llevan a la especificación del plan de mecanizado en un nivel supervisor de forma dual a los de la especificación de producto y de la inspección.

- Detallar los modelos conceptuales de cadena de ensamble de especificación de producto y de elemento característico de especificación de producto elaboradas en este trabajo, de forma similar a como se ha hecho para el ámbito de la inspección, profundizando en el ensamble de producto y los elementos y relaciones que lo caracterizan, y definiendo la biblioteca de elementos característicos correspondiente.

- Generar modelos ontológicos que, a partir de los modelos conceptuales desarrollados en este trabajo, permitan incrementar la riqueza semántica y capturar y explicitar el conocimiento sobre el producto en el dominio de interés. Además, sería importante integrar estos modelos ontológicos, que hacen referencia al producto, con modelos ontológicos de procesos y de capacidades de recursos para hacer realidad el proceso $\operatorname{CIDP}^{2} \mathrm{R}$, apoyado mediante una plataforma de desarrollo colaborativo basada en SOA (Service-Oriented Architecture / Arquitecturas Orientadas a Servicio).

\subsection{PUBLICACIONES RELACIONADAS CON LA TESIS.}

Durante el desarrollo de la tesis se han ido elaborando varias comunicaciones y artículos relacionados con el trabajo, en los que se han mostrado ciertos resultados parciales, que en algunas ocasiones correspondían a primeras aproximaciones. Una circunstancia motivada por la metodología de investigación seguida.

Según esta metodología, explicada en el capítulo 1, uno de los primeros pasos tenía por objetivo el desarrollo del modelo funcional de planificación integrada de procesos de fabricación (mecanizado) e inspección en un nivel supervisor utilizando la técnica de modelado IDEF0. Las publicaciones relacionadas con esta etapa son:

Título: $\quad$ Propuesta de modelo funcional de la planificación de la inspección integrada en la cadena de desarrollo producto-proceso

Autores: $\quad$ Bruscas-Bellido, G.M., Romero-Subirón, F., Serrano-Mira, J.

Año: $\quad 2007$

Publicación: $2^{\text {nd }}$ Manufacturing Engineering Society International Conference (Madrid, España), Proceedings of the $2^{\text {nd }}$ Manufacturing Engineering Society International Conference (ISBN: 978-84-611-8001-1). 
Título: $\quad$ Modelado de actividades para el desarrollo integrado de planes de mecanizado e inspección en entornos distribuidos y colaborativos

Autores: González-Contreras, F., Romero-Subirón, F., Bruscas-Bellido, G.M., Gutiérrez-Rubert, S.C.

Año: 2009

Publicación: $3^{\text {rd }}$ Manufacturing Engineering Society International Conference (Alcoy, España), Proceedings of the $3^{\text {rd }}$ Manufacturing Engineering Society International Conference (ISBN: 978-84-613-3166-6), pp. 264-271.

En el primer trabajo se presentó un modelo funcional utilizando la técnica IDEF0 para la planificación de la inspección geométrica de una pieza. La propuesta pretendía lograr una cierta integración con la planificación de procesos de fabricación, para lo que se identificaba el primer y el último momento posible para la inspección y así poder incorporar actividades de inspección dentro del plan de mecanizado. Sin embargo, el trabajo se centraba fundamentalmente en las actividades propias de la planificación de la inspección y la integración con fabricación no se abordaba en torno a la elaboración, desde un inicio, de un plan conjunto que considerara varias alternativas. En la segunda publicación se presentó un modelo de actividades para el desarrollo integrado de producto, procesos y recursos de fabricación en la que el elemento central era una planificación de procesos distribuida y colaborativa entorno a un plan con alternativas sobre el que los participantes podrían interactuar. El modelo, para la representación del cual no se utilizó ninguna técnica de modelado concreta, se centraba en el desarrollo de planes de proceso de mecanizado considerando la integración de las operaciones de inspección necesarias. Sin embargo, la propuesta se limitaba a un primer nivel de desglose de las principales actividades a realizar sin llegar a desarrollar el detalle de las mismas.

Por su parte, los resultados iniciales vinculados con la definición de un elemento característico de inspección para la planificación supervisora de la inspección, tercera etapa de la metodología, se presentaron en las siguientes publicaciones:

Título: $\quad$ An integrated inspection planning system for autonomous production

Autores: $\quad$ Pfeifer, T., Bruscas-Bellido, G.M., Glombitza, M.

Año: 2002

Publicación: $3^{\text {rd }}$ CIRP International Seminar on Intelligent Computation in Manufacturing Engineering (Ischia, Italia), Proceedings of the $3^{\text {rd }}$ CIRP International Seminar on Intelligent Computation in Manufacturing Engineering (ISBN: 88-87030-44-8), pp. 361-366.

Título: $\quad$ Modelo de producto para la planificación integrada de procesos de mecanizado e inspección

Autores: Gutiérrez-Rubert, S.C., Bruscas-Bellido, G.M., Rosado-Castellano, P., Romero-Subirón, F.

Año: 2009

Publicación: $3^{\text {rd }}$ Manufacturing Engineering Society International Conference (Alcoy, España), Proceedings of the $3^{\text {rd }}$ Manufacturing Engineering Society International Conference (ISBN: 978-84-613-3166-6), pp. 279-286.

Título: Product Model for Integrated Machining and Inspection Process Planning

Autores: Gutiérrez-Rubert, S.C., Bruscas-Bellido, G.M., Rosado-Castellano, P., Romero-Subirón, F.

Año: 2009

Publicación: AIP Conference Proceedings (ISSN: 0094-243X / ISBN: 978-0-73540722-0), volumen 1181, número 1, pp. 266-277. 
Título: $\quad$ Inspection feature for inspection process planning

Autores: Bruscas-Bellido, G.M., Gutiérrez-Rubert, S.C., Romero-Subirón, F., Rosado-Castellano, P.

Año: $\quad 2010$

Publicación: $21^{\text {st }}$ International DAAAM Symposium (Zadar, Croacia), Proceedings of the $21^{\text {st }}$ International DAAAM Symposium (ISSN: 1726-9679 / /ISBN: 978-3-901509-73-5), volumen 21, número 1, pp.1133-1134.

En el primer trabajo se presentaban las bases de un sistema de planificación de la inspección para mejorar la producción basada en Células Autónomas, proponiendo un modelo de información del plan de inspección representado mediante EXPRESS-G. En el modelo de información, que también incluía información referente a los recursos de inspección, el plan de procesos se definía como una agregación de "características de inspección" (inspection characteristics) que correspondían a los aspectos a inspeccionar y que suponen un primer acercamiento a la definición de un elemento característico de inspección. Estas características de inspección se definían prácticamente de forma idéntica a especificaciones dimensionales y geométricas establecidas sobre elementos geométricos básicos de la pieza, por lo que el elemento característico no se veía como una geometría de la pieza que tiene una o más tolerancias dimensionales o geométricas asociadas. Por ello y por la dificultad de incorporar información relevante y específica del dominio de la planificación de la inspección, se decidió descartar este enfoque.

A diferencia de la propuesta anterior, los dos trabajos siguientes presentan una primera propuesta de un Elemento Característico de Inspección en la que la geometría de una parte de la pieza es la parte fundamental, por cuanto sustenta toda una serie de propiedades intrínsecas y relacionales vinculadas con las especificaciones GD\&T funcionales y con aspectos relevantes en el ámbito de la inspección. Una definición que contempla al elemento característico de inspección como un objeto que participa en un ensamble de inspección. La propuesta también incluía una biblioteca de elementos característicos que estaba basada fundamentalmente en los conceptos de grados de libertad y de tipos de procesos de medición, proponiéndose una primera clasificación de instrumentos tipo. Sin embargo, la misma todavía no incluía la información sobre la geometría con defectos y su representación, ni se establecía de forma clara la dualidad con el ejercicio de especificación del producto. Tomando como base el trabajo anterior, en la cuarta publicación de este grupo se presentó una propuesta de Elemento Característico de Inspección cuyas bases son similares a la propuesta anterior (grados de libertad y de tipos de procesos de medición), si bien la definición y la librería se refinaron incluyendo aspectos relativos a la geometría extraída y a las construcciones geométricas necesarias para la verificación.

Por último, los resultados relacionados con la propuesta del Meta-Modelo de Elemento Característico y la propuesta de modelo de Elemento Característico de Especificación de Producto, explicadas en el capítulo 5, y la propuesta de modelo de Cadena de Ensamble de Especificación de Producto, explicada en el capítulo 6, y elaboradas en la sexta etapa de la metodología, se presentaron en el siguiente trabajo:

Título: $\quad$ Application Feature Model for geometrical specification of assemblies

Autores: $\quad$ Romero-Subirón, F., Rosado-Castellano, P., Bruscas-Bellido, G.M.

Año: $\quad 2015$

Publicación: $6^{\text {th }}$ Manufacturing Engineering Society International Conference

(Barcelona, España), Proceedings of the $6^{\text {th }}$ Manufacturing Engineering

Society International Conference (ISBN: 978-84-1568863-1).

Los modelos presentados en este trabajo (Meta-Modelo de Elemento Característico, modelo de Elemento Característico de Especificación de Producto y modelo de Cadena de 
Ensamble de Especificación de Producto) coinciden con los expuestos en esta tesis en los capítulos 5 y 6 . El resto de modelos conceptuales propuestos en la tesis (modelo de Elemento Característico de Especificación, modelo de Elemento Característico de Inspección, modelo de Cadena de Ensamble, modelo de Cadena de Ensamble de Inspección), incluyendo la biblioteca de Elementos Característicos de Inspección y la clasificación de Procesos de Medición Tipo, que se sustentan sobre las propuestas de esta última comunicación, aún están pendientes de publicación. 



\section{REFERENCIAS}

AENOR (1999): Metrología. Práctica de la Medida en la Industria, AENOR, Madrid, ISBN: 848143-123-0.

Ali, L.; Newman, S.T. y Petzing, J. (2005): Development of a STEP-compliant inspection framework for discrete components, Journal of Engineering Manufacture, Volumen 219, pp. 557-563.

Anselmetti, B. (2008): Manuel de tolérancement-volume 2: Bases de la cotation fonctionnelle, Hermes Science Publications, ISBN: 978-2746215962.

Ayadi, B.; Anselmetti, B.; Bouaziz, Z. y Zghal, A. (2008): Three-dimensional modelling of manufacturing tolerancing using the ascendant approach, The International Journal of Advanced Manufacturing Technology, Volumen 39, Números 3-4, pp. 279-290.

Ballot, E. (1995): Lois de comportement géométrique des mécanismes pour le tolérancement, Tesis Doctoral, Ecole Normale Supérieure de Cachan (Francia).

Ballu, A. y Mathieu, L. (1999): Choice of functional specifications using graphs within the framework of education, en Global Consistency of Tolerances, pp. 197-206, Springer Netherlands, ISBN: 978-90-481-5198-1.

Ballu, A.; Dufaure, J. y Teissandier, D. (2007): An adaptive tolerance model for collaborative design, Digital Enterprise Technology. Perspectives and Future Challenges, Editores: Cunha, P.F. y Maropoulos, P.G., ISBN: 978-0-387-49864-5.

Barreiro, J.; Labarga, J.E.; Vizán, A. y Ríos, J. (2003): Functional model for the development of an inspection integration framework, International Journal of Machine Tools and Manufacture, Volumen 43, pp. 1621-1632.

Barreiro, J.; Labarga, J.E.; Vizán, A. y Ríos, J. (2003): Information model for the integration of inspection activity in a concurrent engineering framework, International Journal of Machine Tools \& Manufacture, Volumen 43, pp. 797-809.

Bianconi, F.; Conti, P. y Di Angelo, L. (2006): Interoperability among CAD/CAM/CAE systems: a review of current research trends, Proceedings of the International Conference on Geometric Modeling and Imaging - New Trends (GMAI'06), pp. 82-89, Londres (Reino Unido).

Bidarra, R. y Bronsvoort, W.F. (2000): Semantic feature modelling, Computer-Aided Design, Volumen 32, Número 3, pp. 201-225.

Black, J.T. y Kohser, R.A. (2008): DeGarmo's Materials and Processes in Manufacturing, John Wiley \& Sons, Estados Unidos, ISBN: 978-0470-05512-0.

Blanch Font, R. (2011): Contribución a la selección de cadenas de procesos de fabricación, Tesis Doctoral, Universitat de Girona.

Bourdet, P. y Schneider, F. (2007): Spécification géométrique des produits. Cotation et tolérancement ISO, Dunod/Industries et Technologies, ISBN: 9782100069194.

Brimble, R. y Sellini, F. (2000): The MOKA Modelling Language. Knowledge Engineering and Knowledge Management Methods, Models, and Tools. Lecture Notes in Computer Science, Volumen 1937, pp 49-56.

Bronsvoort, W.F.; Van den Berg, E.; Bizarra, R. y Noort, A. (2001): Essential developments in feature modelling, Proceedings CAD/Graphics'2001, The Seventh International Conference on Computer Aided Design and Computer Graphics, Kunming (China). 
Brunetti, G. y Grimm, S. (2005): Feature ontologies for the explicit representation of shape semantics, International Journal of Computer Applications in Technology, Volumen 23, Números 2-4, pp. 192-202.

Bruscas Bellido, G.M.; Gutiérrez Rubert, S.; Romero Subirón, F. y Rosado Castellano, P. (2010): Inspection feature for inspection process planning, Annals for DAAAM 2010 \& Proceedings of the $21^{\text {st }}$ International DAAAM Symposium, October 2010, pp. 1133-1134, Zadar (Croacia).

Bruscas Bellido, G.M.; Romero Subirón, F. y Serrano Mira, J. (2007): Propuesta de Modelo Funcional de la Planificación de la Inspección Integrada en la Cadena de Desarrollo de Producto-Proceso, Proceedings of the $2^{\text {nd }}$ Manufacturing Engineering Society International Conference, Madrid (España).

Bruscas, G.M.; Romero, F.; Rosado, P. y Serrano, J. (2013): Fostering in-process inspection during process planning using tolerance charting, Procedia Engineering, The Manufacturing Engineering Society International Conference, MESIC 2013, Volumen 63, pp. 200 - 207.

Büyüközkan, G.; Dereli, T. y Baykasoğlu, A. (2004): A survey on the methods and tools of concurrent new product development and agile manufacturing, Journal of Intelligent Manufacturing, Volumen 15, Número 6, pp. 731-751.

Cai, B.; Dai, W.; Muelaner, J.E. y Maropoulus, P.G. (2009): Measurability Chraracteristics Mapping for Large Volume Metrology Instruments Selection, Proceedings of the $7^{\text {th }}$ International Conference on Manufacturing Research (ICMR09), Warwick (Reino Unido).

Callot, M.; Oldham, K.; Stokes, M.; Godwin, N.; Brimble, R.; Klein, R.; Selllini, F.; Merceron, F. y Danino, D. (2000): Methodology and tools Oriented to Knowledge based engineering Applications, Public report no 2, Project number: EP25418, Project Acronym: MOKA.

Campbell, R.G. y Roth, E.S. (2003): Integrated Product Design and Manufacturing Using Geometric Dimensioning and Tolerancing, CRC Press, ISBN: 978-0824788902.

Charpentier, F. (2014): Maîtrise du processus de modélisation géométrique et physique en conception mécanique, Tesis Doctoral, L'Université de Bordeaux, École Doctorale des Sciences Physiques et de l'Ingenieur (Francia).

Chen, G.; Ma, Y.S.; Thimm, G. y Tang, S.H. (2004): Unified feature modelling scheme for the integration of CAD and CAx, Computer-Aided Design \& Applications, Volumen 1, Números 14, pp. 595-602.

Chen, G.; Ma, Y.S.; Thimm, G. y Tang, S.H. (2006): Associations in a unified feature modelling scheme, Journal of Computing and Information Science in Engineering, Volumen 6, pp. 114126.

Chettaoui, H. y Noël, F. (2010): Synchronisation of heterogeneous design models of manufactured products by the formulation of business knowledge, International Journal of Computer Applications in Technology, Volumen 37, Números 3-4, pp. 230-242.

Cho, M.W.; Lee, H.; Yoon, G.S. y Choi, J. (2005): A feature-based inspection planning system for coordinate measuring machines, International Journal of Advanced Manufacturing Technology, Volumen 26, pp. 1078-1087.

Choi, J.H.; Jeon, B.C.; Kim, G.H.; Shin, B.C.; Lee, H.; Cho, M.W.; Seong, E.J. y Park, D.S. (2006): A Web-based on-machine mould matching and measurement system based on $C A D / C A M / C A I$ integration, Journal of Zhejiang University SCIENCE A, Volumen 7, Número 9, pp. 1474-1481.

Costadoat, R. (2010): Contribution à la recherche de spécifications pour la gestion des variations au plus tôt dans le cycle de conception, Tesis Doctoral, Université de Paris Sud 11, École Normale Supérieure de Cachan (Francia). 
Costadoat, R.; Mathieu, L.; Falgarone, H. y Fricero, B. (2009): Integrated design method based on geometric variations to generate specification since the beginning of the product life-cycle, CIRP CAT, Annecy (Francia).

Czarnecki, K. y Eisenecker, U.W. (2000): Generative Programming. Addison Wesley, ISBN: 9780201309775.

Dantan J.Y.; Anwer, N. y Mathieu, L. (2003): Integrated tolerancing process for conceptual design, Annals of the CIRP 2003, Volumen 52, Número 1, pp. 135-8.

Dantan, J.Y. (2000): Synthèse des spéecifications géométriques: modélisation par Calibre à Mobilités Internes, Tesis Doctoral, L’Université Bordeaux 1, École Doctorale des Sciences Physiques et de l'Ingenieur (Francia).

Dantan, J.Y.; Ballu, A. y Mathieu, L. (2008): Geometrical product specifications - model for product life cycle, Computer-Aided Design, Volumen 40, pp. 493-501.

Dantan, J.Y.; Mathieu, L. y Ballu, A. (2003): Geometrical product requirement: Uncertainty and expression, en $8^{\text {th }}$ CIRP International Seminar on Computer-aided Tolerancing, pp. 199-208.

De Martino, T.; Falcidieno, B. y Haßinger, S. (1998): Design and engineering process integration through a multiple view intermediate modeller in a distributed object-oriented system environment, Computer-Aided Design, Volumen 30, Número 6, pp. 437-452.

Desrochers, A. y Rivière, A. (1997): A Matrix Approach to the Representation of Tolerance Zones and Clearances, International Journal of Advanced Manufacturing Technologies, 13, pp. 630636.

Drake, P. (1999): Dimensioning and Tolerancing Handbook, McGraw-Hill, ISBN: 978-0-07018131-1.

Dufaure, J. (2005): Integration et tracabilite du transfert de specifications geometriques dans le cycle de conception d'un produit, Tesis Doctoral, L'Université Bordeaux 1, École Doctorale des Sciences Physiques et de l'Ingenieur (Francia).

Dufaure, J. y Teissandier, D. (2008): A tolerancing framework to support geometric specifications traceability, The International Journal of Advanced Manufacturing Technology, Volumen 36, Número 9, pp. 894-907.

Eum, K.; Kang, M.; Kim, G.; Park, M.W. y Kim, J.K. (2013): Ontology-based modeling of process selection knowledge for machining feature, International Journal of Precision Engineering and Manufacturing, Volumen 14, Número 10, pp. 1719-1726.

Fenves, S.J.; Foufou, S.; Bock, C. y Sriram, R.D. (2008): CPM: A core model for product data, Journal of Computing and Information Science in Engineering, Volumen 8.

Gomaa, H. (2006): Designing Software Product Lines with UML 2.0: From Use Cases to PatternBased Software Architectures, Reuse of Off-the-Shelf Components, Lecture Notes in Computer Science, Editor: Morisio, M., Volumen 4039, pp. 440, Springer Berlin-Heidelberg, ISBN: 978 3-540-34606-7.

González Contreras, F.; Romero Subirón, F.; Bruscas Bellido, G.M. y Gutiérrez Rubert, S.C. (2009): Modelado de actividades para el desarrollo integrado de planes de mecanizado e inspección en entornos distribuidos y colaborativos, Proceedings of the $3^{\text {rd }}$ Manufacturing Engineering Society International Conference, Alcoy (España).

Grabowski, H.; Lossack, R.S. y El-Mejbri, E.F. (1999) : Towards a universal design theory, en $6^{\text {th }}$ CIRP Seminar on Computer Aided Tolerancing, Integration of process knowledge into design support systems, Springer Netherlands, pp. 47-56.

Griffith, G.K. (2000): The Quality Technician's Handbook, Prentice-Hall, New Jersey (Estados Unidos), ISBN: 0-13-674250-5. 
Griffith, G.K. (2002): Geometric Dimensioning and Tolerancing. Applications and Inspection, Prentice Hall, ISBN: 978-0130604637.

Groover, M.P. (2007): Fundamentals of Modern Manufacturing, John Wiley \& Sons, Estados Unidos, ISBN: 978-0-471-74485-6.

Gutiérrez Rubert, S.; Bruscas Bellido, G.M.; Rosado Castellano, P. y Romero Subirón, F. (2009): Modelo de producto para la planificación integrada de procesos de mecanizado e inspección, Proceedings of the $3^{\text {rd }}$ Manufacturing Engineering Society Internacional Conference, junio 2009, pp. 279-286, Alcoy (España).

Gutiérrez Rubert, S.C. (2008): Análisis y procesado tecnológico del modelo sólido de una pieza para determinar sus elementos característicos de mecanizado, Tesis Doctoral, Univesidad Politécnica de Valencia.

Haralick, R.M.; Zhuang, X.; Lin, C. y Lee, J.S. (1989): The digital morphological sampling theorem. IEEE Transactions on Acoustics, Speech and Signal Processing, Volumen 37, Número 12, pp. 2067-2090.

Henzold, G. (2006): Geometrical Dimensioning and Tolerancing for Design, Manufacturing and Inspection, Elsevier, ISBN: 978-0-7506-6738-8.

Hong, Y.S. y Chang, T.C. (2002): A comprehensive review of tolerancing research, International Journal of Production Research, Volumen 40, Número 11, pp. 2425-2459.

Huang, Q. y Shi, J.J. (2003). Part dimensional error and its propagation modeling in multioperational machining processes, Journal of Manufacturing Science and EngineeringTransactions of the ASME, Volumen 125, pp. 255-62.

Huang, S.H.; Liu, Q. y Musa, R. (2004): Tolerance-based process plan evaluation using Monte Carlo simulation, International Journal of Production Research, Volumen 42, Número 23, pp. 4871-91.

Hussain, T.; Ali, Z. y Larik, J. (2012): A Study On Tolerance Representation, Variation Propagation Analysis And Control In Mechanical Assemblies, Sindh University Research Journal (Science Series), Volumen 44, Número 3, pp. 427-432.

Hwang, C.Y.; Tsai, C.Y. y Chang, C.A. (2004): Efficient inspection planning for coordinate measuring machines, International Journal of Advanced Manufacturing Technology, Volumen 23, pp. 732-742.

Integrated DEFinition Methods (IDEF): http://www.idef.com/.

ISO 10303-219 (2007): Industrial automation systems and integration - Product data representation and exchange - Part 219: Application protocol: Dimensional inspection information exchange.

ISO10303-1 (1994): Industrial automation systems and integration -- Product data representation and exchange -- Part 1: Overview and fundamental principles.

ISO10303-11 (2004): Industrial automation systems and integration -- Product data representation and exchange -- Part 11: Description methods: The EXPRESS language reference manual.

ISO10303-224 (2006): Industrial automation systems and integration -- Product data representation and exchange -- Part 224: Application protocol: Mechanical product definition for process planning using machining features.

ISO10303-239 (2012): Industrial automation systems and integration -- Product data representation and exchange -- Part 239: Application protocol: Product life cycle support.

ISO10303-44 (2014): Industrial automation systems and integration -- Product data representation and exchange -- Part 44: Integrated generic resource: Product structure configuration.

ISO1101 (2012): Geometrical product specifications (GPS) - Geometrical tolerancing Tolerances of form, orientation, location and run-out. 
ISO14406 (2010): Geometrical product specifications (GPS) -- Extraction.

ISO16610-40 (2015): Geometrical product specifications (GPS) -- Filtration -- Part 40: Morphological profile filters: Basic concepts.

ISO17450-1 (2011): Geometrical product specifications (GPS) -- General concepts -- Part 1: Model for geometrical specification and verification.

ISO17450-2 (2012): Geometrical product specifications (GPS) -- General concepts -- Part 2: Basic tenets, specifications, operators, uncertainties and ambiguities.

ISO22432-1 (2011): Geometrical product specifications (GPS) -- Features utilized in specification and verification.

ISO25378 (2011): Geometrical product specifications (GPS) -- Characteristics and conditions -Definitions.

ISO8015 (2011): Geometrical product specifications (GPS) -- Fundamentals -- Concepts, principles and rules.

JCGM (2008): Vocabulario Internacional de Metrología (VIM) - Conceptos fundamentales y generales, y términos asociados. Proyecto de norma ISO/IEC Guide 99:2007 (traducción al español).

JCGM (2012): International vocabulary of metrology - Basic and general concepts and associated terms (VIM).

Kamali Nejad, M. (2010): Propositions of numerical solution techniques for the tolerance analysis problem in manufacturing: 3D approach, Tesis Doctoral, Université Joseph-Fourier - Grenoble I (Francia).

Kamali Nejad, M.; Vignat, F. y Villeneuve, F. (2009): Simulation of the geometrical defects of manufacturing, The International Journal of Advanced Manufacturing Technology, Volumen 45, Número 7-8, pp.631-648.

Kandikjan, T.; Shah, J.J. y Davidson, J.K. (2001): A mechanism for validating dimensioning and tolerancing schemes in CAD systems, Computer-Aided Design, 33, pp. 721-737.

Kang, K.; Cohen, S.; Hess, J.; Novak, W. y Peterson, A. (1990). Feature-Oriented Domain Analysis (FODA) Feasibility Study, Technical Report CMU/SEI-90-TR-021, Software Engineering Institute, Carnegie Mellon University, Pittsburgh (Estados Unidos).

Kang, M.; Kim, G.; Eum, K.; Park, M.W. y Kim, J.K. (2014): A classification of multi-axis features based on manufacturing process, International Journal of Precision Engineering and Manufacturing, Volumen 15, Número 6, pp. 1255-1263.

Khaled, A.; Ma, Y. y Miller, J. (2008): A service oriented architecture for CAX concurrent collaboration, $4^{\text {th }}$ IEEE Conference on Automation Science and Engineering, pp. 650-655, Washington (Estados Unidos).

Khan, N.S. (2011): Generalized Statistical Tolerance Analysis and Three Dimensional Model for Manufacturing Tolerance Transfer in Manufacturing Process Planning, Dissertation, Arizona State University (Estados Unidos).

Khodaygan, S.; Movahhedy, M.R. y Saadat Fomani, M. (2010): Tolerance analysis of mechanical assemblies based on modal interval and small degrees of freedom (MI-SDOF) concepts, International Journal of Advanced Manufacturing Technology, Volumen 50, pp. 1041-1061.

Kim, W.S. y Raman, S. (2000): On the selection of flatness measurement points in coordinate measuring machine inspection, International Journal of Machine Tools and Manufacture, Volumen 40, Número 3, pp. 427-443.

Kramer, T.R. (1992): A Library of Material Removal Shape Element Volumes (MRSEVs), National Institute of Standards and Technology, NISTIR 4809, Gaithersburg, MD, Volumen 20899. 
Legoff, O.; Tichadou, S. y Ascote, J.Y. (2004): Manufacturing errors modelling: Two threedimensional approaches, Proceedings of the Institution of Mechanical Engineers, Volumen 218, Número 12, pp. 1869-1873.

Legoff, O.; Villeneuve, F y Bourdet, P. (1999): Geometrical tolerancing in process planning: a tridimensional approach, Proceedings of the Institution of Mechanical Engineers, Part B: Journal of Engineering Manufacture, Volumen 213, Número 6, pp. 635-640.

Li, V.D.; Ong, S.K. y Nee, A.Y.C. (2006): Integrated and Collaborative Product Development Environment, World Scientific Publishing, Singapore, ISBN: 981-256-680-5.

Lim, T.; Corney, J.; Ritchie, J.M. y Clark, D.E.R. (2001): Optimizing tool selection, International Journal of Production Research, Volumen 39, Número 6, pp.1239-1256.

Lin, E.E. y Zhang, H.C. (2001): Theoretical tolerance stackup analysis based on tolerance zone analysis, International Journal of Advanced Manufacturing Technology, Volumen 17, Número 4, pp. 257-62.

Lin, Z.C. y Chow, J.J. (2001): Integration Planning Model of IDEFO and STEP Product Data Representation Methods in a CMM Measurement System, International Journal of Advanced Manufacturing Technology, Volumen 17, pp. 39-53.

Lin, Z.C. y Lin, C.Z. (2000): IDEFO Model of the Measurement Planning for a Workpiece Machined by a Machining Centre, International Journal of Advanced Manufacturing Technology, Volumen 16, pp. 656-667.

Loose, J.P.; Zhou, S.Y. y Ceglarek, D. (2007): Kinematic analysis of dimensional variation propagation for multistage machining processes with general fixture layouts, IEEE Transactions on Automation Science and Engineering, Volumen 4, Número 2, pp. 141-52.

Louati, J.; Ayadi, B.; Bouaziz, Z. y Haddar, M. (2006): Three-dimensional modelling of geometric defaults to optimize a manufactured part setting, The International Journal of Advanced Manufacturing Technology, Volumen 29, Números 3-4, pp. 342-348.

Lu, W. (2011): Modelling the Integration between the Design and Inspection Process of Geometrical Specifications for Digital Manufacturing, Tesis Doctoral, University of Huddersfield (Reino Unido).

Ma, L.; Jiang, X.; Wang, J.; Xu, Z. y Li, Z. (2007): Study on the expression specifications of geometrical products for function, design, manufacture and verification based on the improved GPS language, International Journal of Advanced Manufacturing Technology, Volumen 32, pp. 990-998.

Ma, Y.S. y Bong, C.H. (2010): Fine grain associative feature reasoning in collaborative engineering, International Journal of Computer Applications in Technology, Volumen 37, Números 3-4, pp. 210-217.

Ma, Y.S. y Tong, T. (2003): Associative feature modelling for concurrent engineering integration, Computers in Industry, Volumen 51, Número 1, pp. 51-71.

Ma, Y.S.; Britton, G.A.; Tor, S.B. y Lin, L.Y. (2007): Associative assembly design features: concept, implementation and application, International Journal of Advanced Manufacturing Technology, Volumen 32, pp. 434-444.

Ma, Y.S.; Chen, G. y Thimm, G. (2008): Paradigm shift: unified and associative feature-based concurrent and collaborative engineering, Journal of Intelligent Manufacturing, Volumen 19, Número 6, pp. 625-641.

Ma, Y.S.; Chen, G. y Thimm, G. (2009): Fine grain feature associations in collaborative design and manufacturing - A unified approach, Collaborative Design and Planning for Digital Manufacturing, Editores: Wang, L. y Nee, A.Y.C., Springer-Verlag, ISBN: 978-1-84882-287$0 \_3$. 
Mansuy, M. (2012): Aide au tolérancement tridimensionnel: Modèle des domaines, Tesis Doctoral, Université de Grenoble (Francia).

Maropoulos, P.G. y Ceglarek, D. (2010): Design verification and validation in product lifecycle, CIRP Annals-Manufacturing Technology, Volumen 59, Número 2, pp. 740-759.

Maropoulos, P.G.; Kotsialos, A. y Bramall, D.G. (2006): A Theoretical Framework for the Integration of Resource Aware Planning with Logistics for the Dynamic Validation of Aggregate Plans within a Production Network, CIRP Annals - Manufacturing Technolgy, Volumen 55, Número 1, pp. 483-488.

Martinsen, K. (1993): Vectorial tolerancing for all types of surfaces, ASME Advances in Design Automation, Volumen 65, pp. 187-198.

Muelaner, J.E.; Cai, B. y Maropoulus, P.G. (2010): Large Volumen Metrology Instrument Selection and Measurability Analysis, Proceedings of the Institution of Mechanical Engineers, Part B: Journal of Engineering Manufacture, Volumen 224, Número 6, pp. 853-868.

Nielsen, H.S. (2006): New concepts in specifications, operators and uncertainties and their impact on measurement and instrumentation, Measurement Science and Technology, Volumen 17, Número 3, pp. 541-544.

Noël, F. y Roucoules, L. (2008): The PPO design model with respect to digital enterprise technologies among product life cycle, International Journal of Computer Integrated Manufacturing, Volumen 21, Número 2, pp. 139-145.

Noël, F.; Roucoules, L. y Teissandier, D. (2005): Specification of product modelling concepts dedicated to information sharing in a collaborative design context, Advances in Integrated Design and Manufacturing in Mechanical Engineering, Editores: Bramley, A; Brissaud, D.; Coutellier, D. y McMahon, C., Springer Dordrecht, ISBN: 978-1-4020-3481-7.

Nyquist, H. (1928): Certain topics in telegraph transmission theory, Transactions of the American Institute of Electrical Engineers, Volumen 47, Número 2, pp. 617-644.

Pahl, G. y Beitz, W. (1996) : Engineering design: a systematic approach, Editor: K. Wallace, Springer-Verlag, ISBN : 978-1-84628-319-2.

Pahl, G.; Beitz, W.; Feldhusen, J. y Grote, K.H. (2007): Product development process, en Engineering Design, Springer London, pp. 125-143, ISBN: 978-1-84628-318-5.

Pfeifer, T. y Schmitt, R. (2010): Fertigungsmesstechnik, Oldenbourg Wissenschaftsverlag, ISBN: 978-3486592023.

Pfeifer, T. y Torres, F. (1999): Manual de Gestión e Ingeniería de la Calidad, Mira Editores, Zaragoza (España), ISBN: 84-89859-43-4.

Pfeifer, T.; Bruscas Bellido, G.M. y Glombitza, M. (2002): An integrated inspection planning system for autonomous production, Proceedings of the $3^{\text {rd }}$ CIRP International Seminar on Intelligent Computation in Manufacturing Engineering, Ischia (Italia).

Rachuri, S.; Han, S. Foufou, Y.H.; Feng, S.C.; Roy, U.; Wang, F.; Sriram, R.D. y Lyons, K.W. (2006): A Model for Capturing Product Assembly Information, Journal of Computer and Information Science in Engineering, Volumen 6, Número 1, pp. 11-21.

Real Academia Española: http://www.rae.es/.

Riebisch, M. (2003): Towards a more precise definition of feature models, en Modelling Variability for Object-Oriented Product Lines, Editors: Riebisch, M.; James, D.S. y Coplien, O., Norderstadt (Alemania), pp. 64-76.

Romero Subirón, F.; Estruch Ivars, A. y Rosado Castellano, P. (2009): A framework for the development of an IT platform for collaborative and integrated development of product, process and resources, Proceedings of the 13th International Research/Expert Conference "Trends in the Development of Machinery and Associated Technology”, Hammamet (Túnez). 
Rosado Castellano, P.; Romero Subirón, F. y Vila Pastor, C. (2009): A model for collaborative process planning in a engineering and production network, Proceedings of the 13th International Research/Expert Conference "Trends in the Development of Machinery and Associated Technology", Hammamet (Túnez).

Roy, U.; Pramanik, N.; Sudarsan, R.; Sriram, R.D. y Lyons, K.W. (2001): Function to form mapping: Model, representation and application in design synthesis. Computer-Aided Design, Volumen 33, pp. 699-719.

Sadeghi, M.; Hadj-Hamou, K. y Noël, F. (2010): The PPO design model with respect to digital enterprise technologies among product life cycle, International Journal of Computer Integrated Manufacturing, Volumen 23, Número 3, pp. 270-282.

Salomons, O.W., Poerink, H.J J.; Haalboom, F.J.; van Slooten, F.; van Houten, F.J.A.M. y Kals, H.J.J. (1996a): A computer aided tolerancing tool I: tolerance specification, Computers in Industry, Volumen 31, pp. 161-174.

Salomons, O.W., Poerink, H.J J.; Haalboom, F.J.; van Slooten, F.; van Houten, F.J.A.M. y Kals, H.J.J. (1996b): A computer aided tolerancing tool II: tolerance specification, Computers in Industry, Volumen 31, pp. 175-186.

Saunders, P.C.H.; Orchard, N.B.; Maropoulos, P.G. y Graves, A.P. (2010): Integrated design and dimensional measurement: a review of the state of the art, Proceedings of the $8^{\text {th }}$ International Conference on Manufacturing Research ICMR, Durham (Reino Unido).

Schleich, B. y Wartzack, S. (2014): A discrete geometry approach for tolerance analysis of mechanism, Mechanism and Machine Theory, Volumen 77, pp. 148-163.

Schleich, B.; Anwerb, N.; Mathieu,L. y Wartzack, S. (2014): Skin Model Shapes: A new paradigm shift for geometric variations modelling in mechanical engineering, Computer-Aided Design, Volumen 50, Número 6, pp. 1-15.

Serrano, J., Abellan-Nebot, J.V. y Romero F. (2011): From Function to Manufacturing: A Graphical Representation for Functional Tolerancing in Multi-Stage Machining Processes, Proceedings of IDME - Virtual Concept 2010, Bordeaux (Francia).

Shah, J.J. y Mäntylä, M. (1995): Parametric and Feature-based CAD/CAM, John Wiley \& Sons, Canadá, ISBN: 0-471-00214-3.

Shen, Z., Shah, J.J y Davidson J.K. (2008): Analysis neutral data structure for GD\&T, Journal of Intelligent Manufacturing, Volumen 19, Número 4, pp. 455-472.

Siller, H.R.; Estruch, A.; Abellán, J.V.; Vila, C. y Romero, F. (2008): Modeling workflow activities for collaborative process planning with product lifecycle management tools, Journal of Intelligent Manufacturing, Volumen 19, Número 6, pp. 689-700.

Socoliuc, M. (2010): Introduction et analyse des schémas de cotation en avance de phase, Tesis Doctoral, École Centrale des Arts et Manufactures "École Centrale Paris" (Francia).

Sridharan, N. y Shah, J.J. (2004): Recognition of multi axis milling features: Part I - Topological and geometric characteristics, Journal of Computing and Information Science in Engineering, Volumen 4, Número 3, pp. 242-250.

Srinivasan, V. (1999): A geometrical product specification language based on a classification of symmetry groups, Computer-Aided Design, Volumen 31, pp. 659-668.

Srinivasan, V. (1999): Role of Statistics in Achieving Global Consistency in Tolerances (de Global Consistency of Tolerances, Proceedings of the $6^{\text {th }}$ CIRP International Seminar on Computer Aided Tolerancing), Editores: van Houten, F. y Kals, H., Kluwer Academic Publishers, Países Bajos, ISBN: 0-7923-5654-3. 
Srinivasan, V. (2001): An integrated view of geometrical product specification and verification, en $7^{\text {th }}$ CIRP Seminar on Computer-Aided Tolerancing, Geometric Product Specification and Verification: Integration of Functionality, Springer Netherlands, pp. 1-11.

Suntag, C. (1993): Inspection and Inspection Management, ASQC Quality Press, Milwaukee (Estados Unidos), ISBN: 0-87389-174-0.

Tang, K. (1992): Inspection Systems (Capítulo 23 de Intelligent Design and Manufacturing), Editor: Kusiak, A., John Wiley \& Sons, Inc., New York (Estados Unidos), ISBN: 0-471-534730 .

Thiébaut, F. (2001): Contribution à la définiton d'un moyen unifié de gestion de la géométrie réaliste basé sur le calcul des lois de comportement des mécanismes, Tesis Doctoral, Ecole Normale Supérieure de Cachan (Francia).

Tichadou, S.; Legoff, O. y Hascoët, J.Y. (2005): 3D Geometrical simulation of manufacturing. Compared approaches between integrated CAD/CAM system and small displacement torsor model, Advances in integrated Design and Manufacturing in Mechanical Engineering, pp. 446456.

Tönshoff, H.K. e Inasaki, I. (2001): Sensors Applications, Volume 1, Sensors in Manufacturing. Sensors Applications, Volume 1, Sensors in Manufacturing, Editores: Tönshoff, H.K. e Inasaki, I., Wiley-VCH, ISBN: 3-527-29558-5.

Vernat, Y.; Nadeau, J.P. y Sébastian, P. (2010): Formalization and qualification of models adapted to preliminary design, International Journal on Interactive Design and Manufacturing, Volumen 4, Número 1, pp. 11-24.

Vignat F. y Villeneuve F. (2003): 3D Transfer of Tolerances Using a SDT Approach: Application to Turning Process, Journal of Computing and Information Science in Engineering, Volumen 3, Número 1, pp. 45-53.

Vignat, F. (2005): Contribution à l'élaboration d'un modéle $3 D$ de simulation de fabrication pour l'analyse et la synthése des tolérances, le modéle MMP, Tesis Doctoral, Institut National Polythechnique de Grenoble (Francia).

Vignat, F. y Villeneuve, F. (2005): Simulation of the manufacturing process (2): Analysis of its consequences on a functional tolerance, $9^{\text {th }}$ CIRP Computer Aided Tolerancing Seminar, CAT2005, Arizona (Estados Unidos).

Vignat, F; Villeneuve, F. y Kamali Nejad, M. (2009): From the nominal model to a model of manufactured parts in a CAD context, CIRP Design Conference Netherlands (Países Bajos).

Villeneuve, F.; Legoff, O. y Landon, Y. (2001): Tolerancing for manufacturing: a threedimensional model, International Journal of Production Research, Volumen 39, Número 8, pp. 1625-1648.

Walter, G.G. (1992): A sampling theorem for wavelet subspaces, IEEE Transactions on Information Theory, Volumen 38, Número 2, pp. 881-884.

Wang, L.; Jin, W. y Feng, H.Y. (2006): Embedding machining features in function blocks for distributed process planning, International Journal of Computer Integrated Manufacturing, Volumen 19, Número 5, pp. 443-452.

Weber, C. (2008): How to derive application-specific design methodologies, en DS 48: Proceedings DESIGN 2008, the $10^{\text {th }}$ International Design Conference, Dubrovnik (Croacia).

Weckenemann, A. y Knauer, M. (1999): Causes and consequences of measurement uncertainty in production metrology, Elektrotechnik und Informationstechnik, Volumen 116, Número 4, pp. 234-239. 
Winchell, W. (1996): Inspection and Measurement in Manufacturing. Keys to process planning and improvement, Society of Manufacturing Engineers, Dearborn (Estados Unidos), ISBN: 087263-474-4.

Wirtz, A. (1991): Vectorial tolerancing for production quality control and functional analysis in design. Annals of CIRP, Pennstate (Estados Unidos).

Wong, F.S.Y.; Chuah, KB. y Venuvinod, P.K. (2005): Automated extraction of dimensional inspection features from part computer-aided design models, International Journal of Production Research, Volumen 43, Número 12, pp. 2377-2396.

Wong, F.S.Y.; Chuah, KB. y Venuvinod, P.K. (2006): Automated inspection process planning: Algorithmic inspection feature recognition, and inspection case representation for CBR, Robotics and Computer-Integrated Manufacturing, Volumen 22, pp. 56-58.

Wu, Y.; Sha, J.J. y Davidson, J.K. (2003): Computer Modeling of Geometric Variations in Mechanical Parts and Assemblies, Journal of Computing and Information Science in Engineering, Transactions of the ASME, Volumen 3, pp. 54-63.

Yang, K. y El-Haik, B. (2003): Design for Six Sigma. A Roadmap for Product Development, McGraw-Hill, Estados Unidos, ISBN: 978-0-07-154767-3.

Yu, Y.; Yan, J.; Liu, M. y Yun, B. (2008): A semantic paradigm to integrate customer demands and product designs based on model-driven architecture, 2008 International Conference on Computer Science and Software Engineering, Volumen 1, pp. 602- 605, Wuhan, Hubei (China).

Zha, X.F. y Sriram, R.D. (2004): Feature-based component model for design of embedded systems, Proc. SPIE 5605, Intelligent Systems in Design and Manufacturing V, Volumen 226.

Zhang, M. (2012): Discrete Shape Modeling for Geometrical Product Specifications: Contributions and Applications to Skin Model Simulation, Tesis Doctoral, École Normale Supérieure de Cachan (Francia).

Zhang, S.G.; Ajmal, A.; Wootton, J. y Chisholmm, A. (2000): A feature-based inspection process planning system for co-ordinate measuring machine (CMM), Journal of Materials Processing Technology, Volumen 107, pp. 111-118.

Zhang, X.; Nassehi, A. y Newman, S.T. (2014): Feature recognition from CNC part programs for milling operations, The International Journal of Advanced Manufacturing Technology, Volumen 70, Números 1-4, pp. 397-412.

Zhao, Y.F.; Habeeb, S. y Xu, X. (2009): Research into integrated design and manufacturing based on STEP, International Journal of Advanced Manufacturing Technology, Volumen 44, pp. 606624.

Zhao, Y.F.; Xu, X; Kramer, T; Proctor, F. y Horst, J. (2011): Dimensional metrology interoperability and standarization in manufacturing systems, Computer Standards \& Interfaces, Volumen 33, pp. 541-555.

Zhao, Y.Z., Brown, R.J., Kramer, T.R. and Xu, X. (2011): Information Modeling for Interoperable Dimensional Metrology, Springer, ISBN: 978-1-4471-2166-4.

Zhao, Y.Z., Brown, R.J., Kramer, T.R. and Xu, X. (2011): Information Modeling for Interoperable Dimensional Metrology, Springer London, ISBN: 978-1-4471-2166-4.

Zheng, C.; Bricogne, M.; Le Duigoi, J. y Eynard, B. (2014): Survey on mechatronic engineering: A focus on design methods and product models, Advanced Engineering Informatics, Volumen 28, pp. 241-257.

Zhong, W.; Maier-Speredelozzi, V.; Bratzel, A.; Yang, S.; Chick, S.E. y Hu, S.J. (2000): Performance analysis of machining systems with different configurations, Proceedings of the 2000 Japan-USA Flexible Automation Conference, Ann Arbor, Michigan (Estados Unidos), pp. 783-790. 
Zhou, S.Y.; Huang, Q. y Shi, J.J. (2003): State space modeling of dimensional variation propagation in multistage machining process using differential motion vectors, IEEE Transactions on Robotics and Automation, Volumen 19, Número 2, pp. 296-309. 